$\infty$

\title{
Hanford Facility Annual Dangerous Waste Report
}

Calendar Year 1999

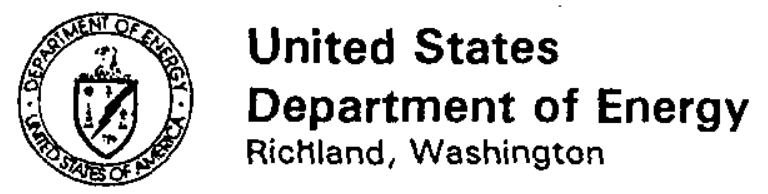


TRADEMARK DISCLAIMER

Reference herein to any specific commercial product, process, or service by trade name, trademark,

manufacturer, or otherwise, does not necessarily constitute

or imply its endorsernent, recommendation, or favoring by

the United States Government or any agency thereof or its contractors or subcontractors.

This report has been reproduced from the best available copy.

Printed in the United States of America

DISCLM-4.CHP (1-91) 


\section{Hanford Facility Annual Dangerous Waste Report}

Calendar Year 1999

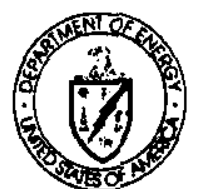

United States

Department of Energy

Richland, Washington 


\section{RELEASE AUTHORIZATION}

Document DOE/RL-2000-14, Revision 0

Number:

Document Title: $\quad$ Hanford Facility Annual Dangerous Waste Report - Calendar Year 1999

This document, reviewed in accordance with DOE Order 241.1, "Scientific and Technical Information Management," and DOE G 241.1-1, "Guide to the Management of Scientific and Technical Information," does not contain classified or sensitive unclassified information and is:

\section{APPROVED FOR PUBLIC RELEASE}

Chistiniv Srollenigham

Christine Willingham

Lockheed Martin Services, Inc.

Document Control/nformation Clearance

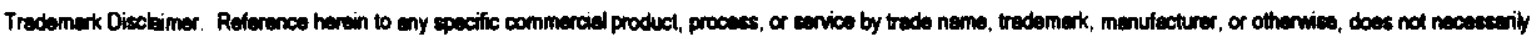
constitute or imply its endorsement, recommendetion, or favoring by the United Stues Government or eny agency thereof or its contrectors or abcontrictot. The views end

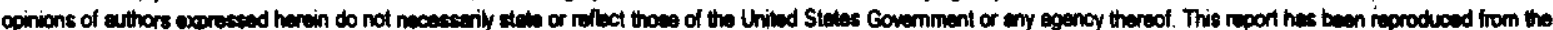
best avitable copy.

Printed in the United Steves of Amorice.

Aveilabl to the U.S. Depertment of Energy end its contretors from the U.S. Depertment of Energy Office of Scientific and Technical information, P.O. Box 62, Osk Ridge, TN 37831; Telophone: 423/576-8401.

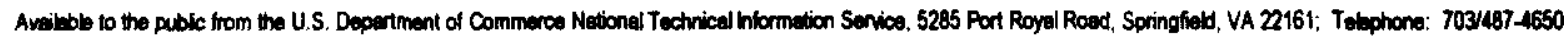




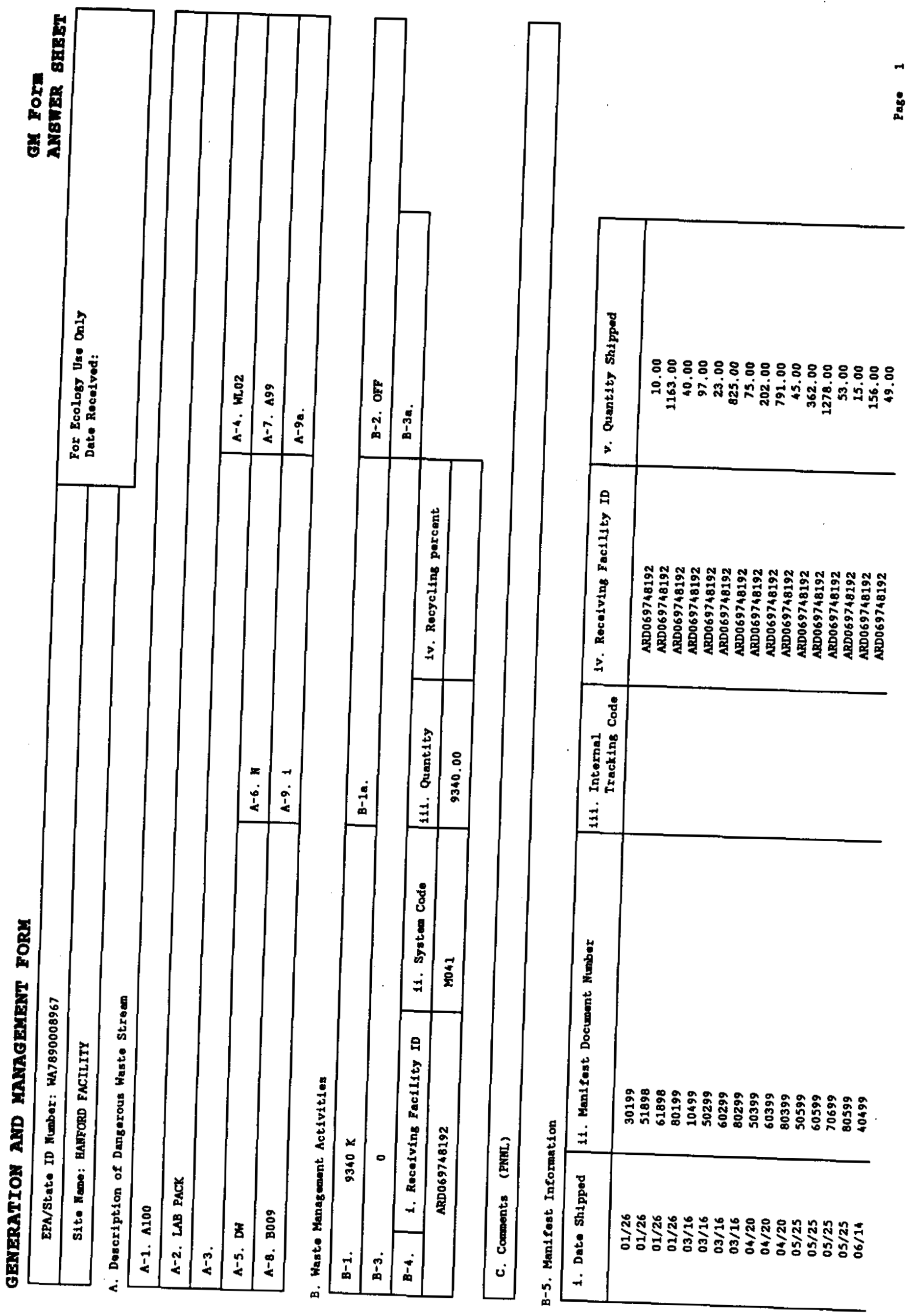




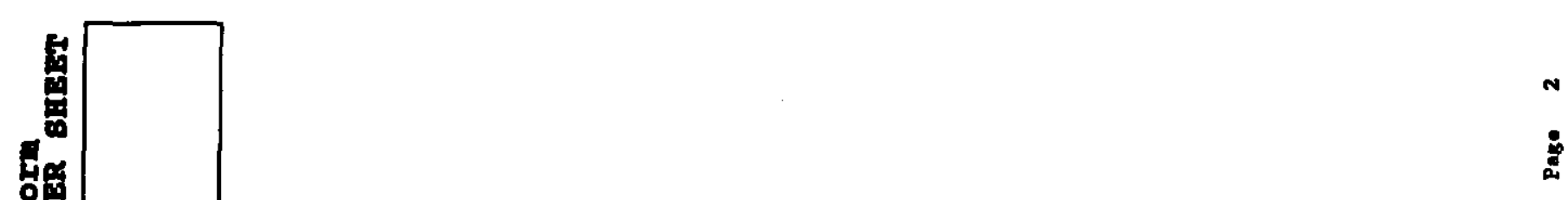

8:8:8:

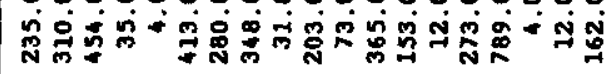

N

कृ

a o.

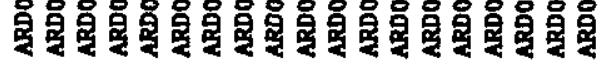

$\dot{3}$

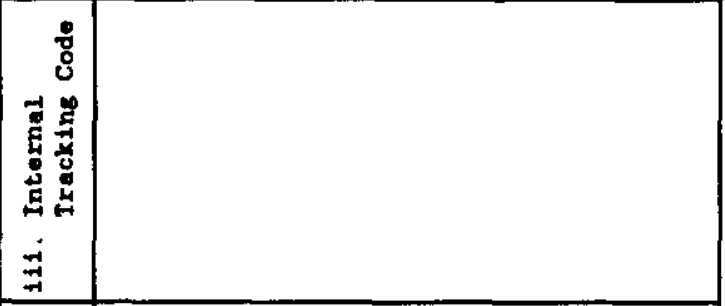

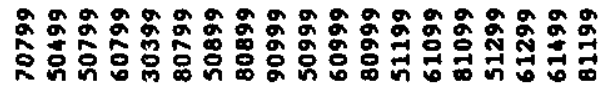

i

是

要

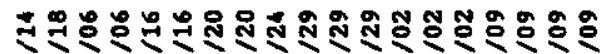

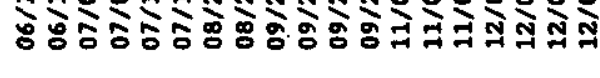




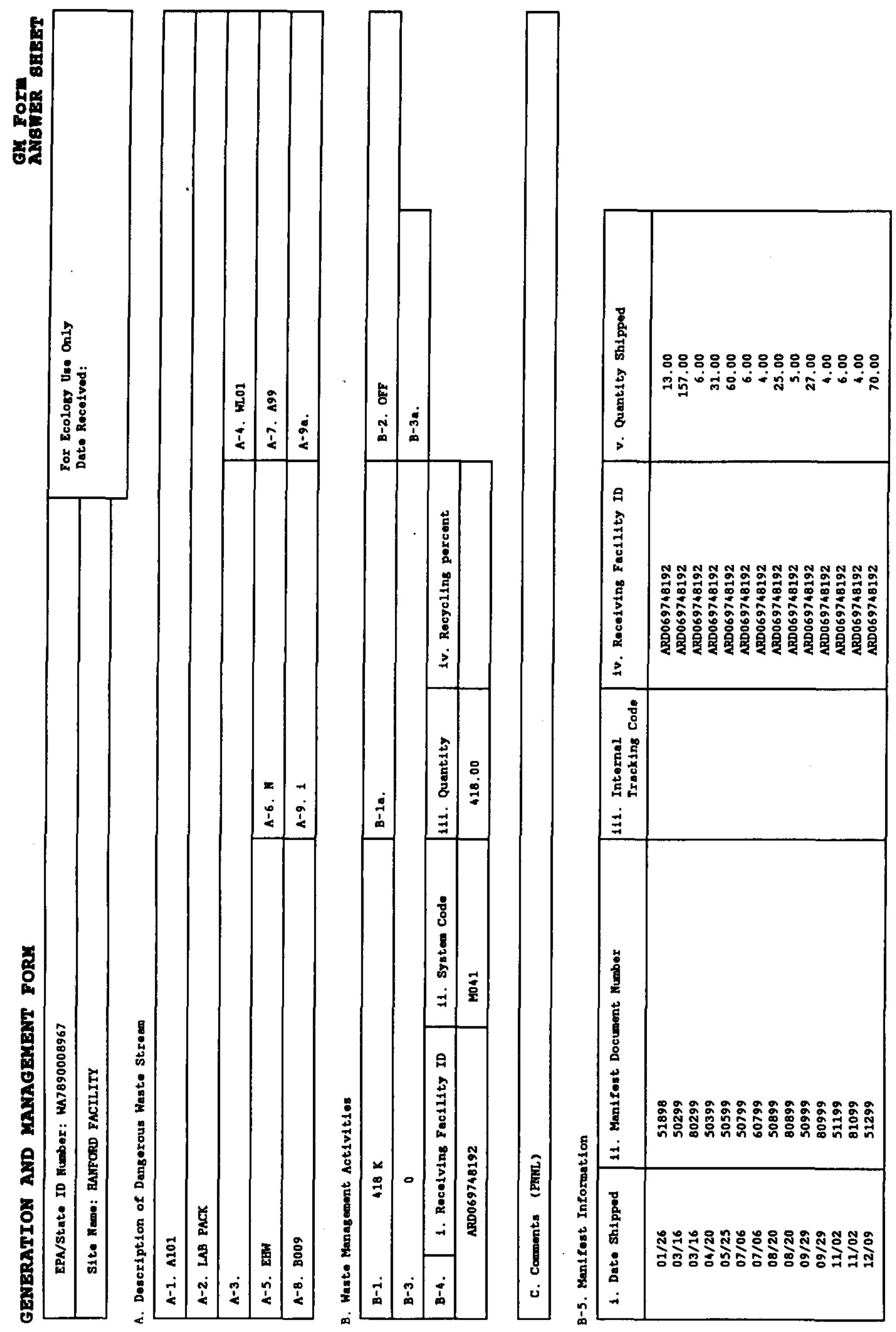




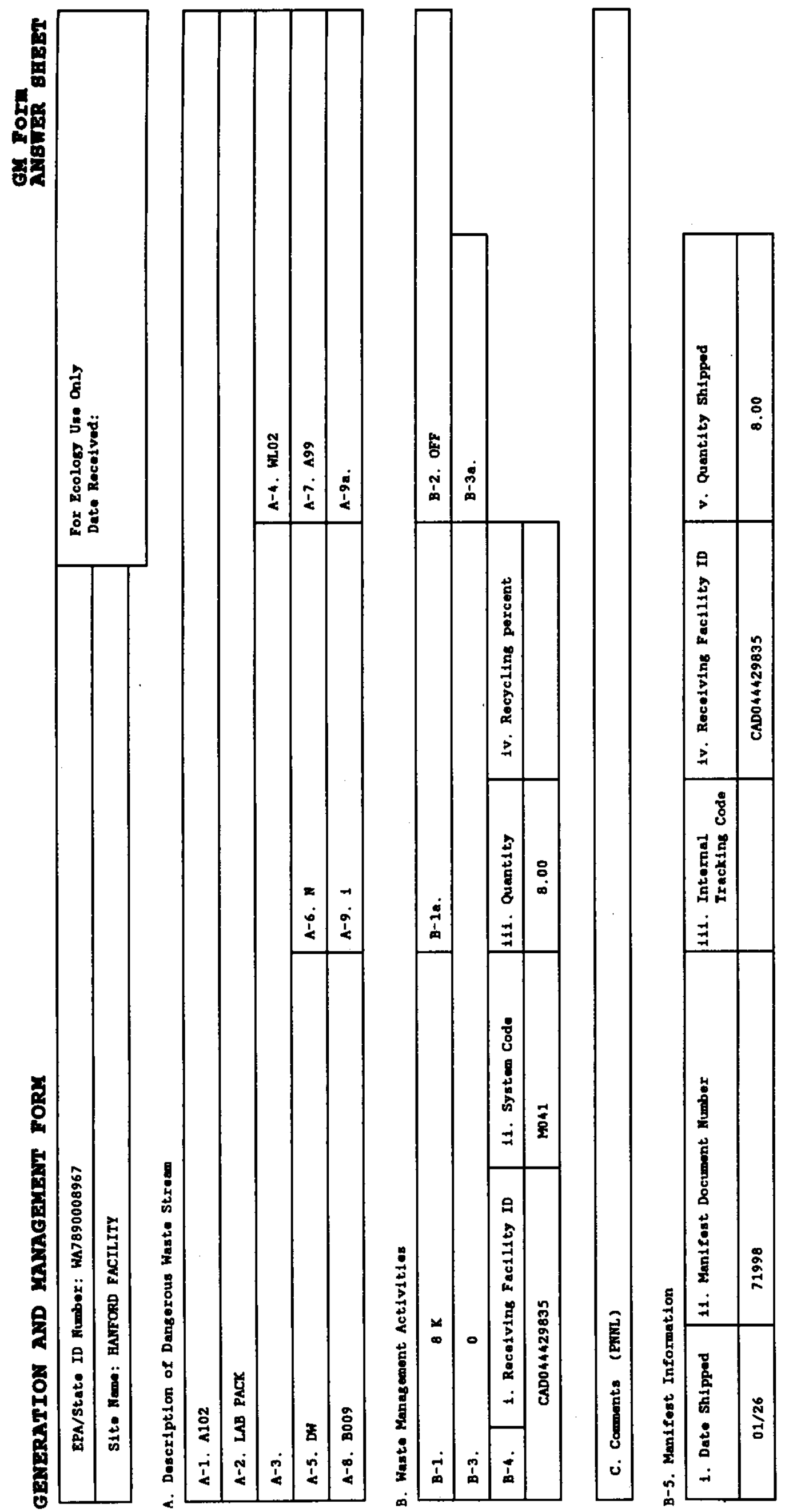


量
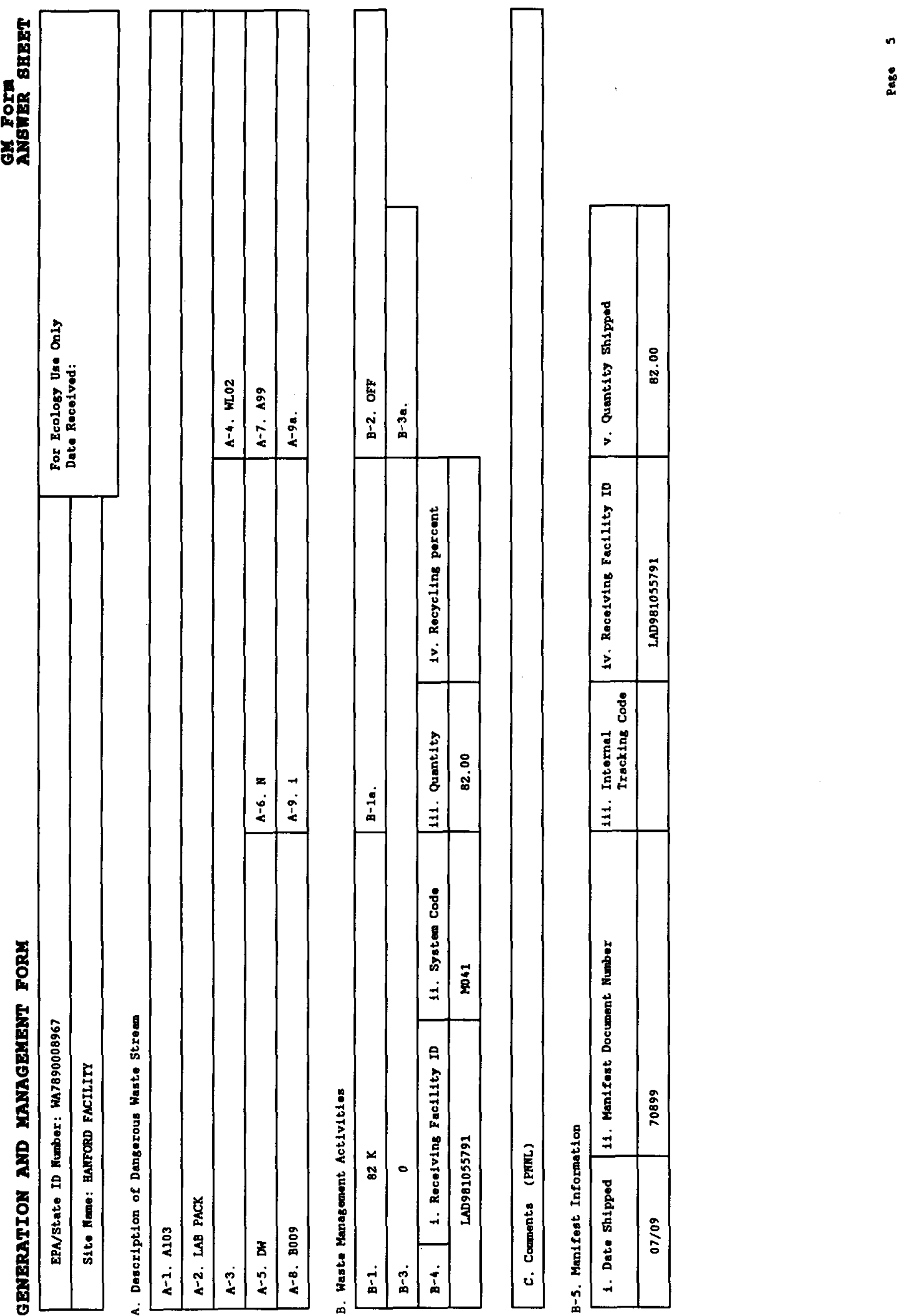


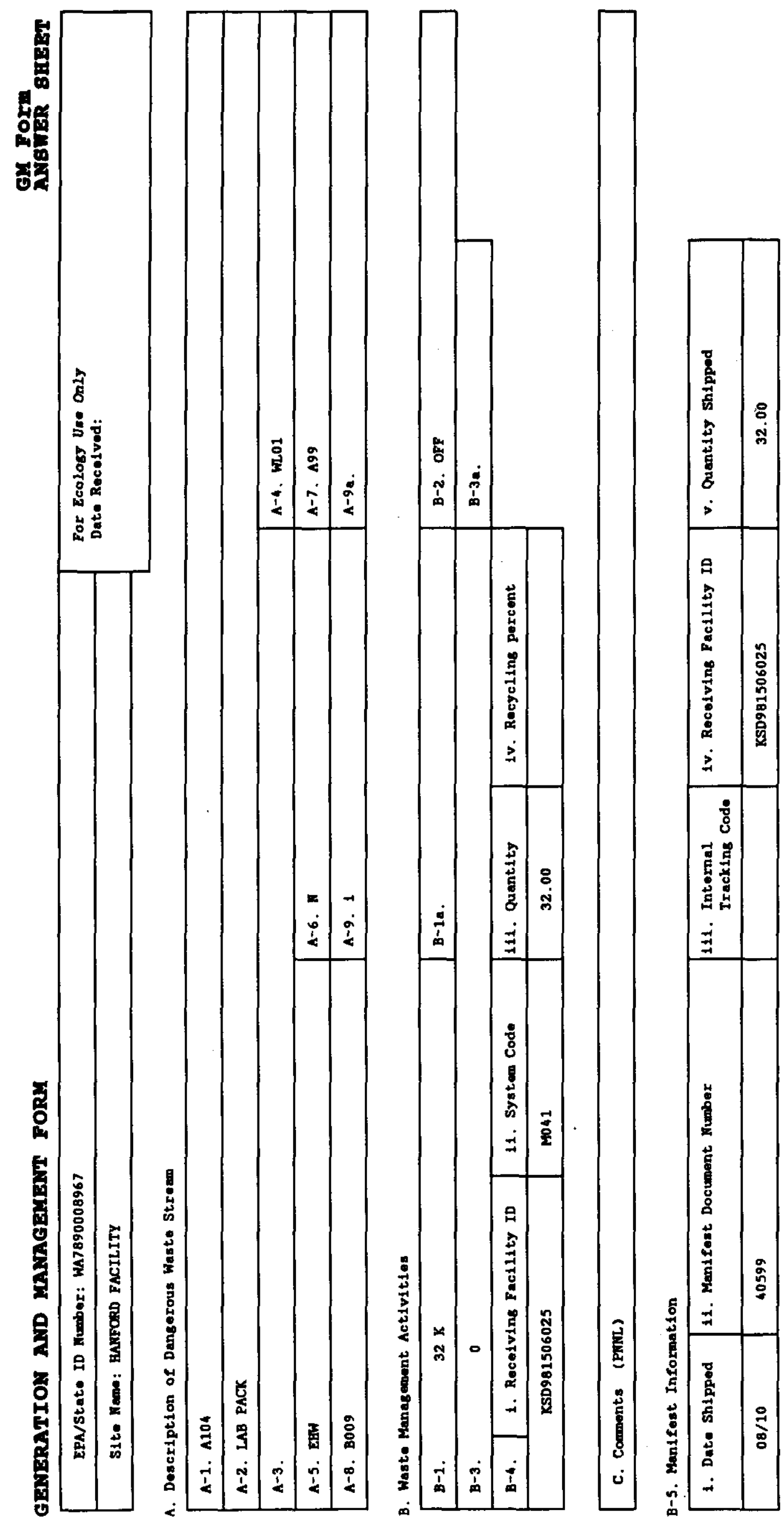




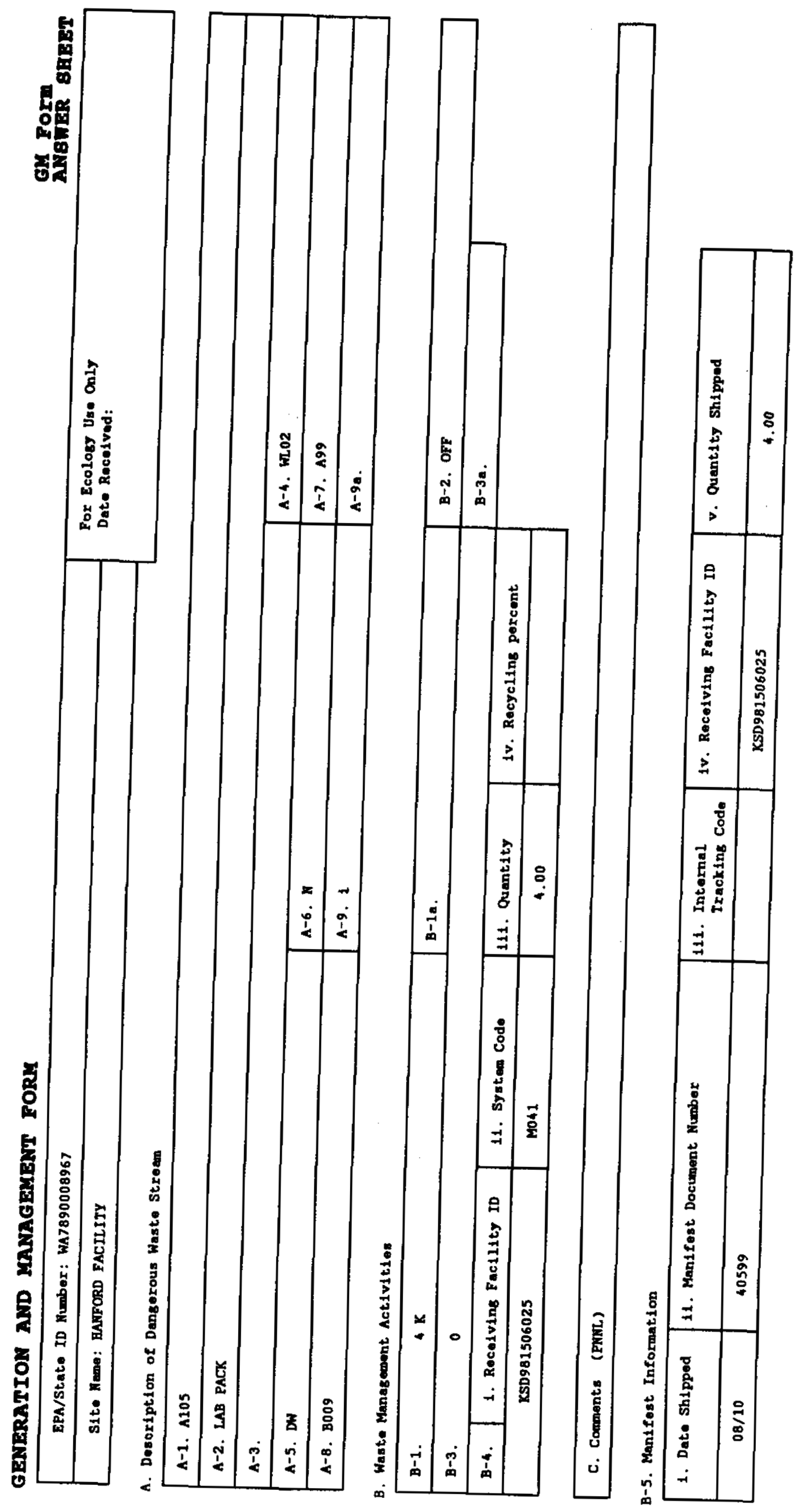



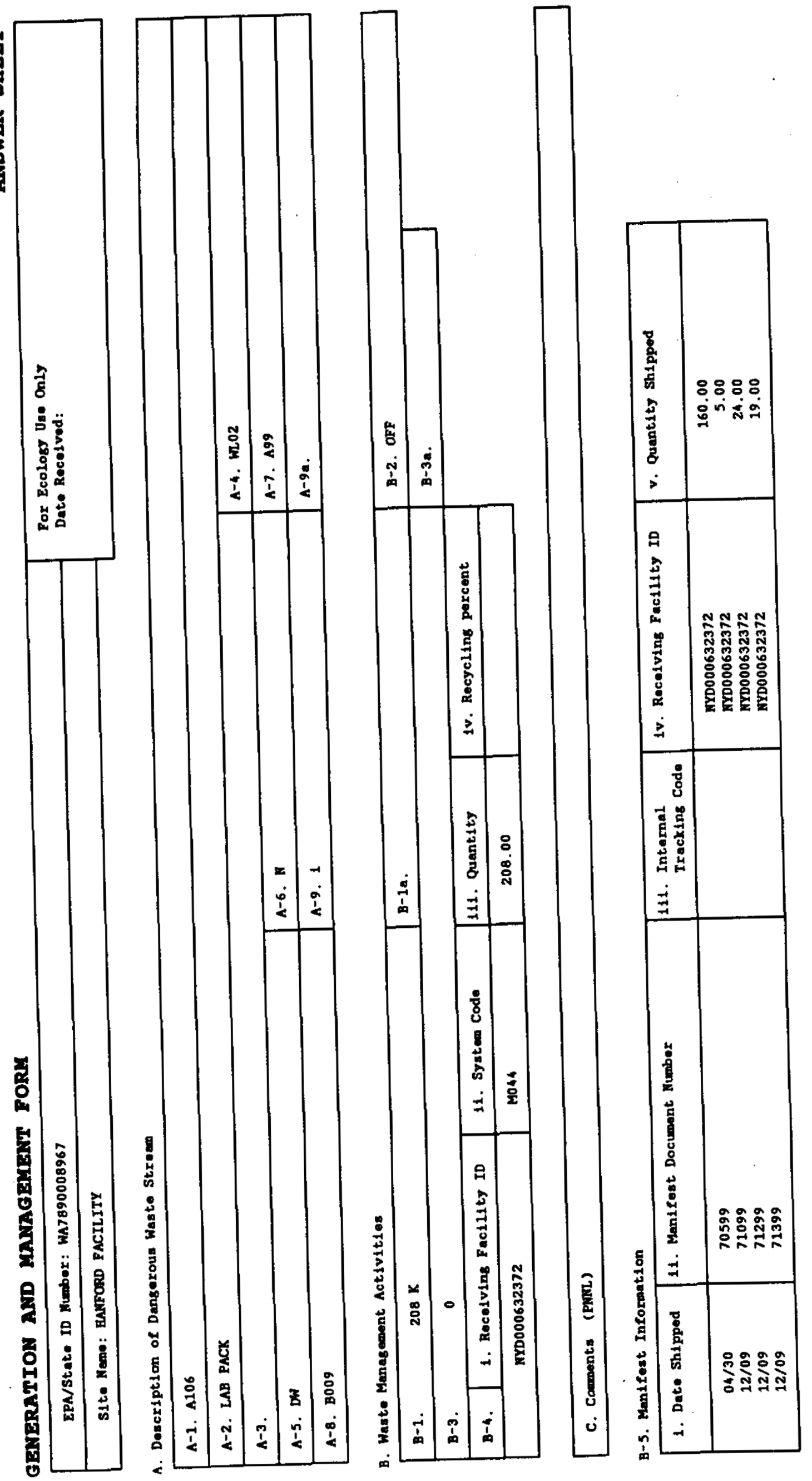


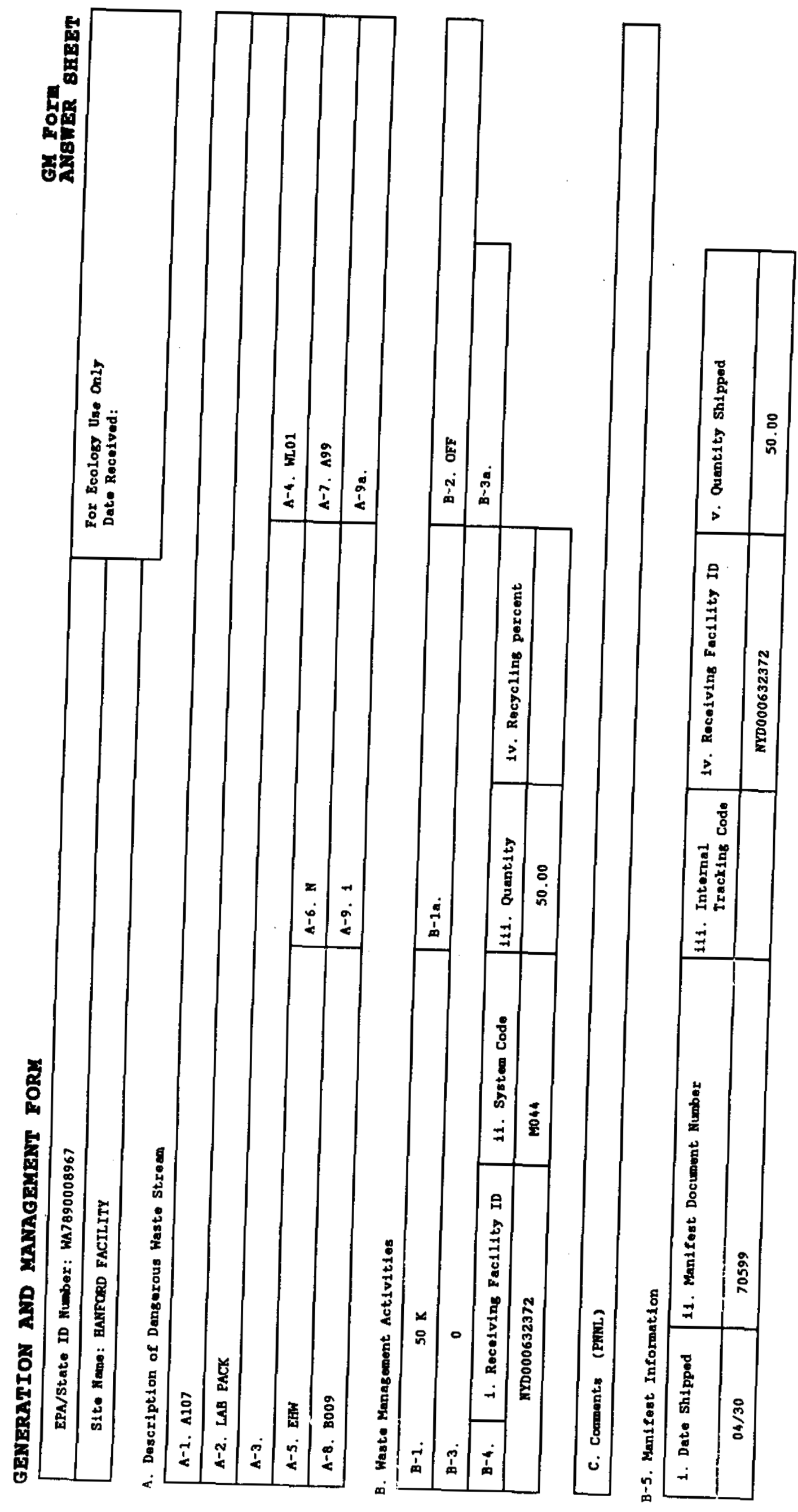


禺
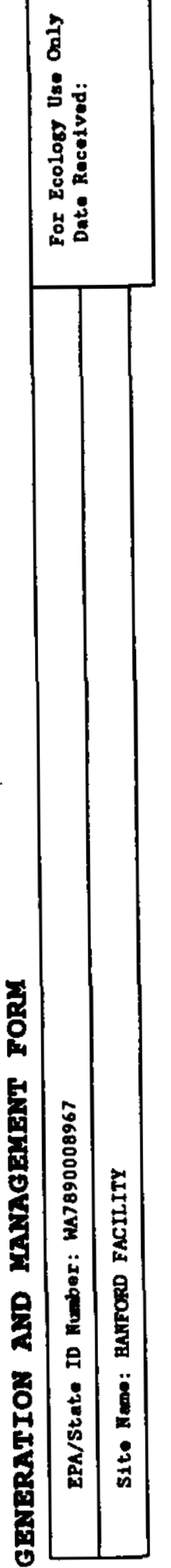
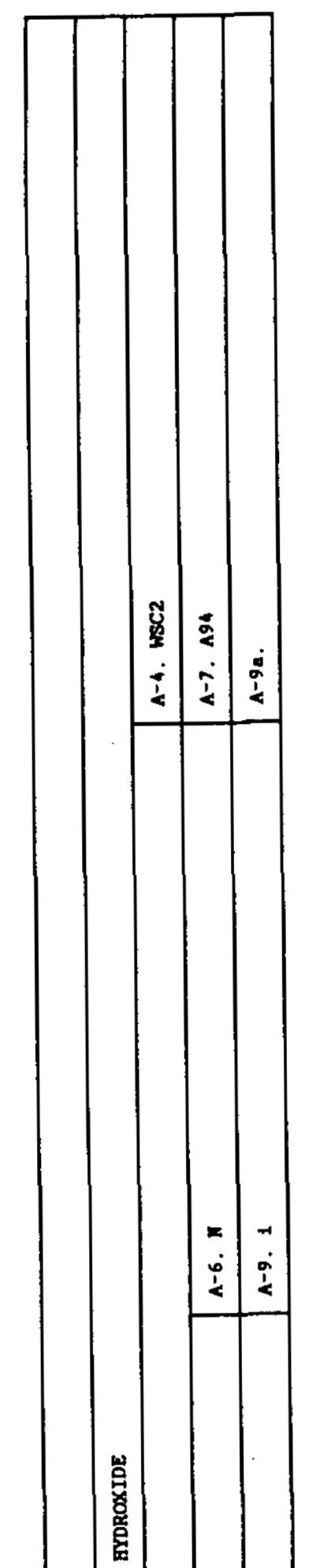

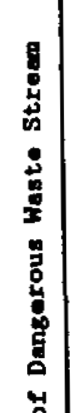

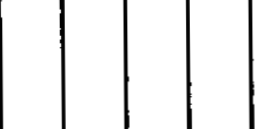

参

点

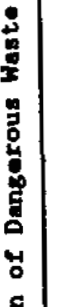

品

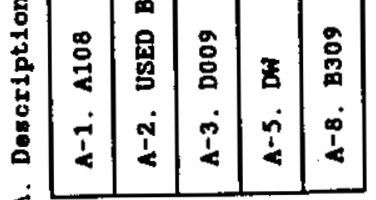
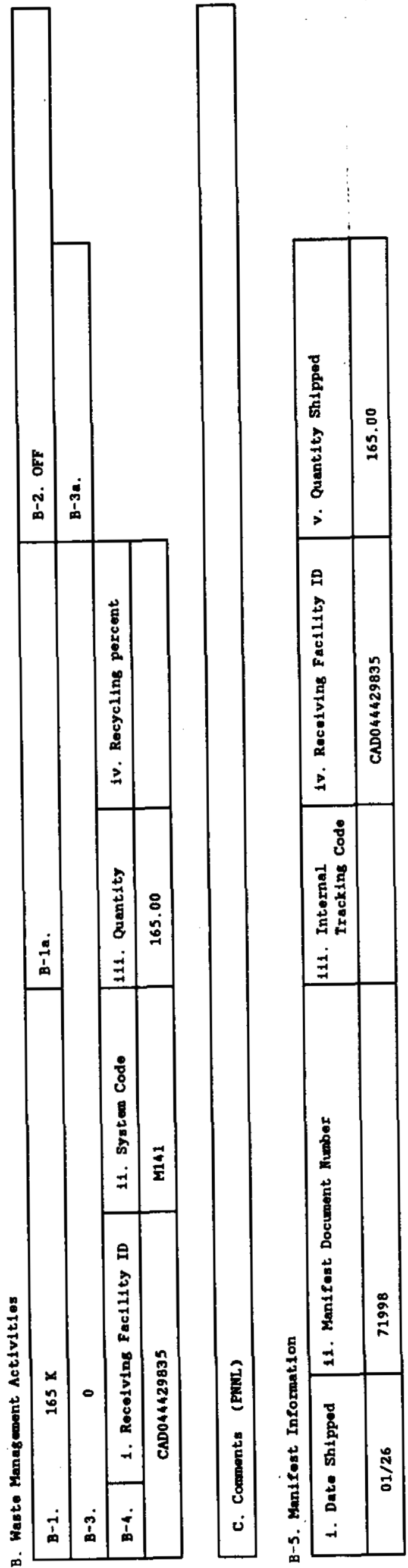


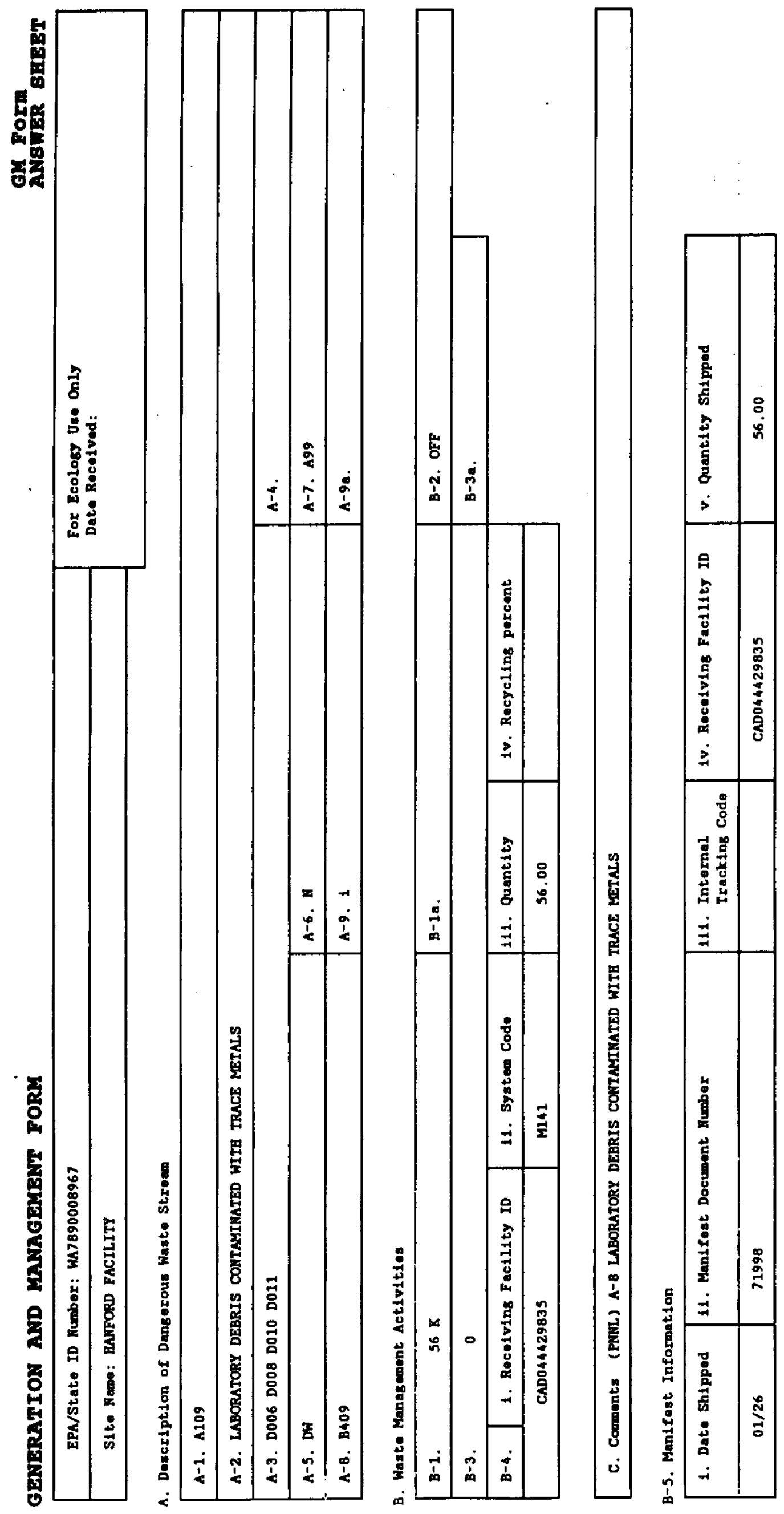




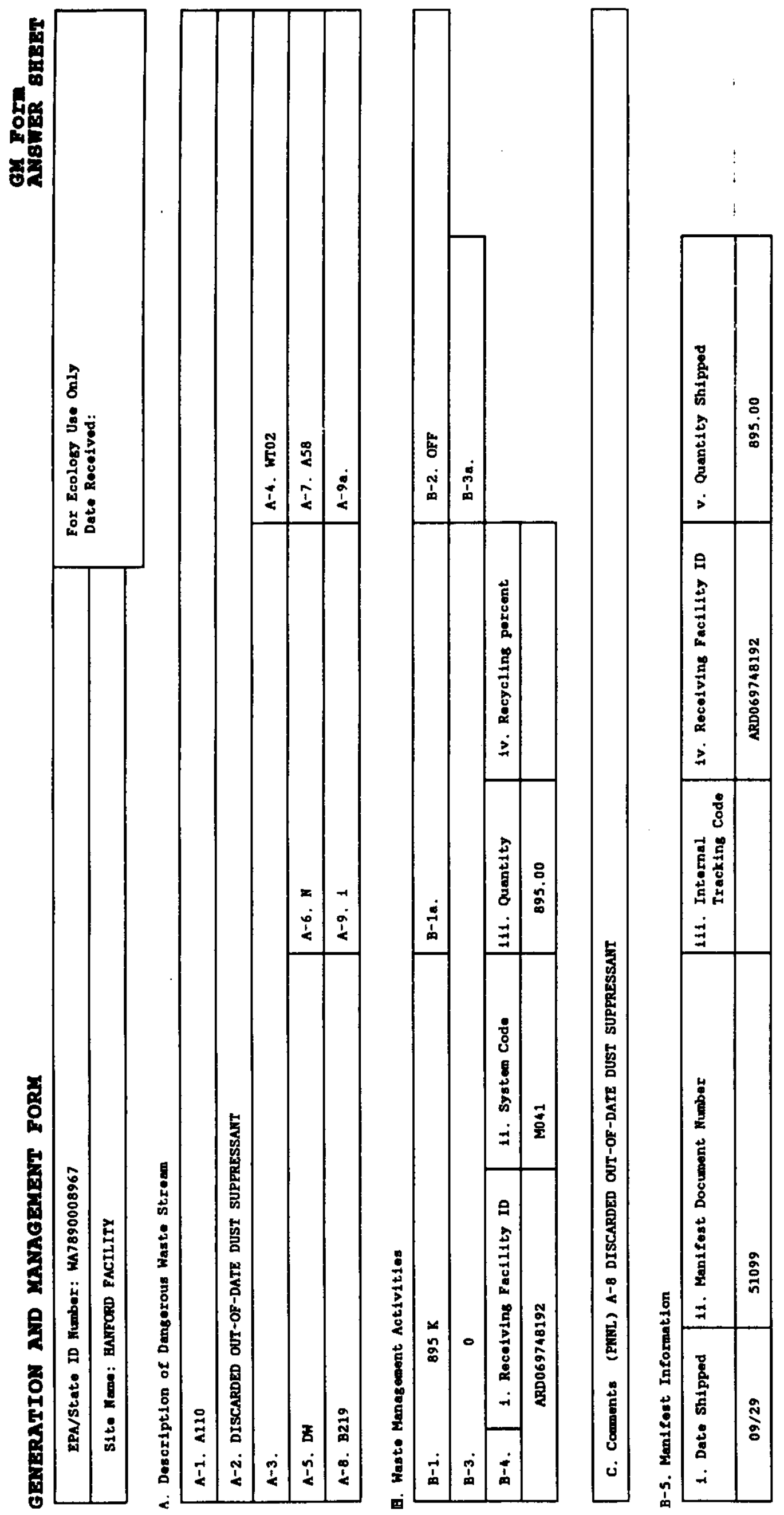




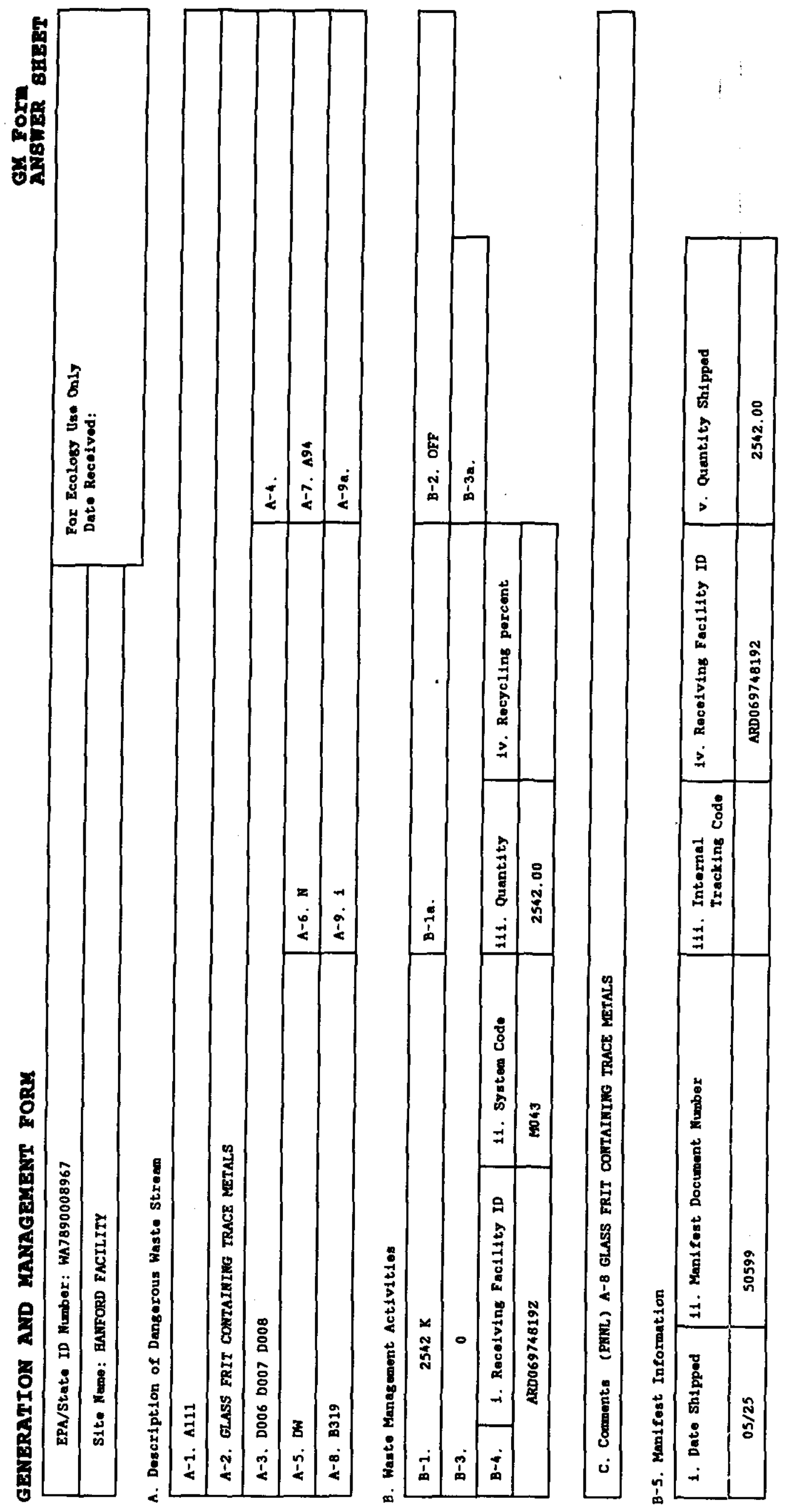




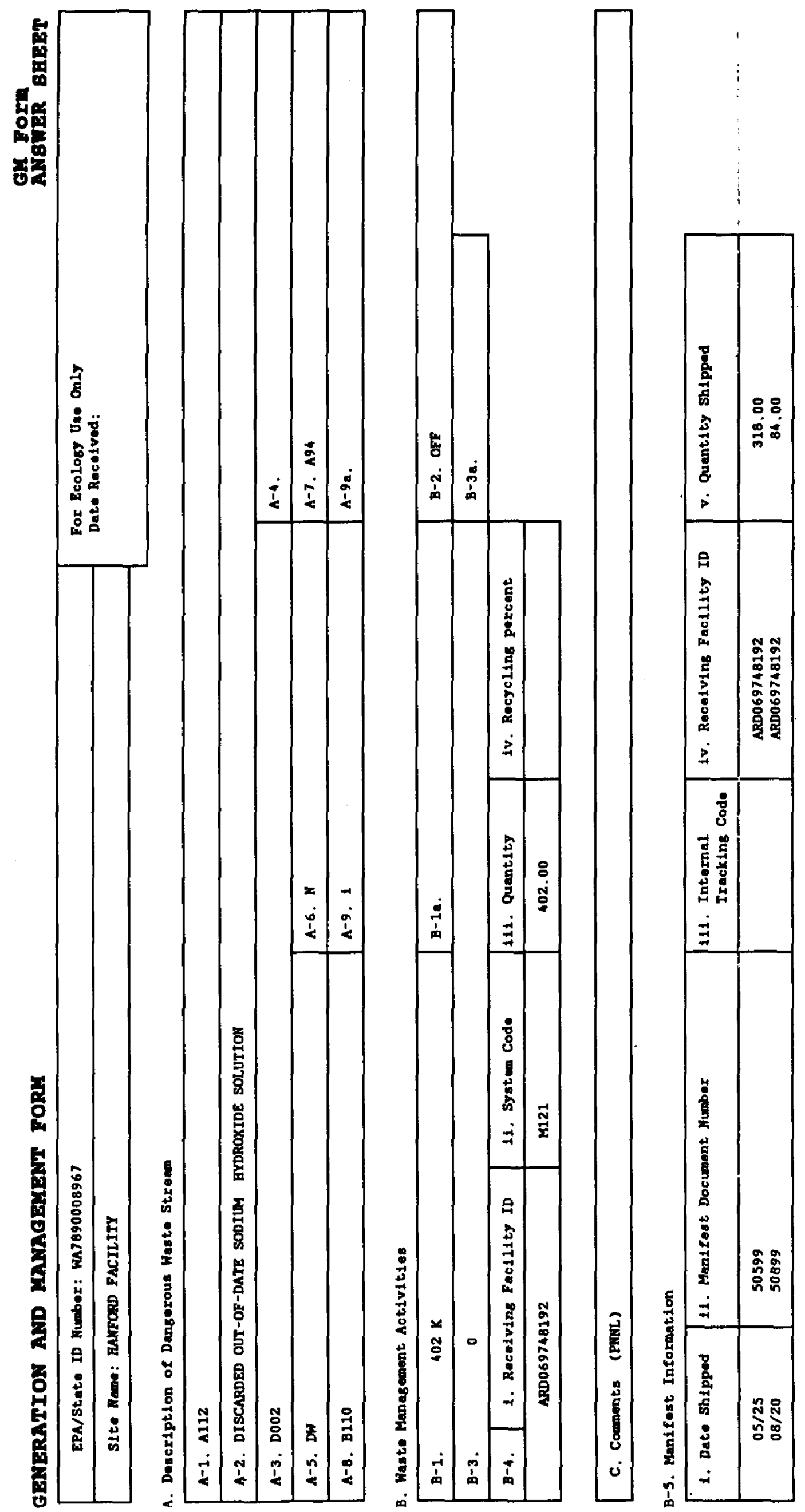




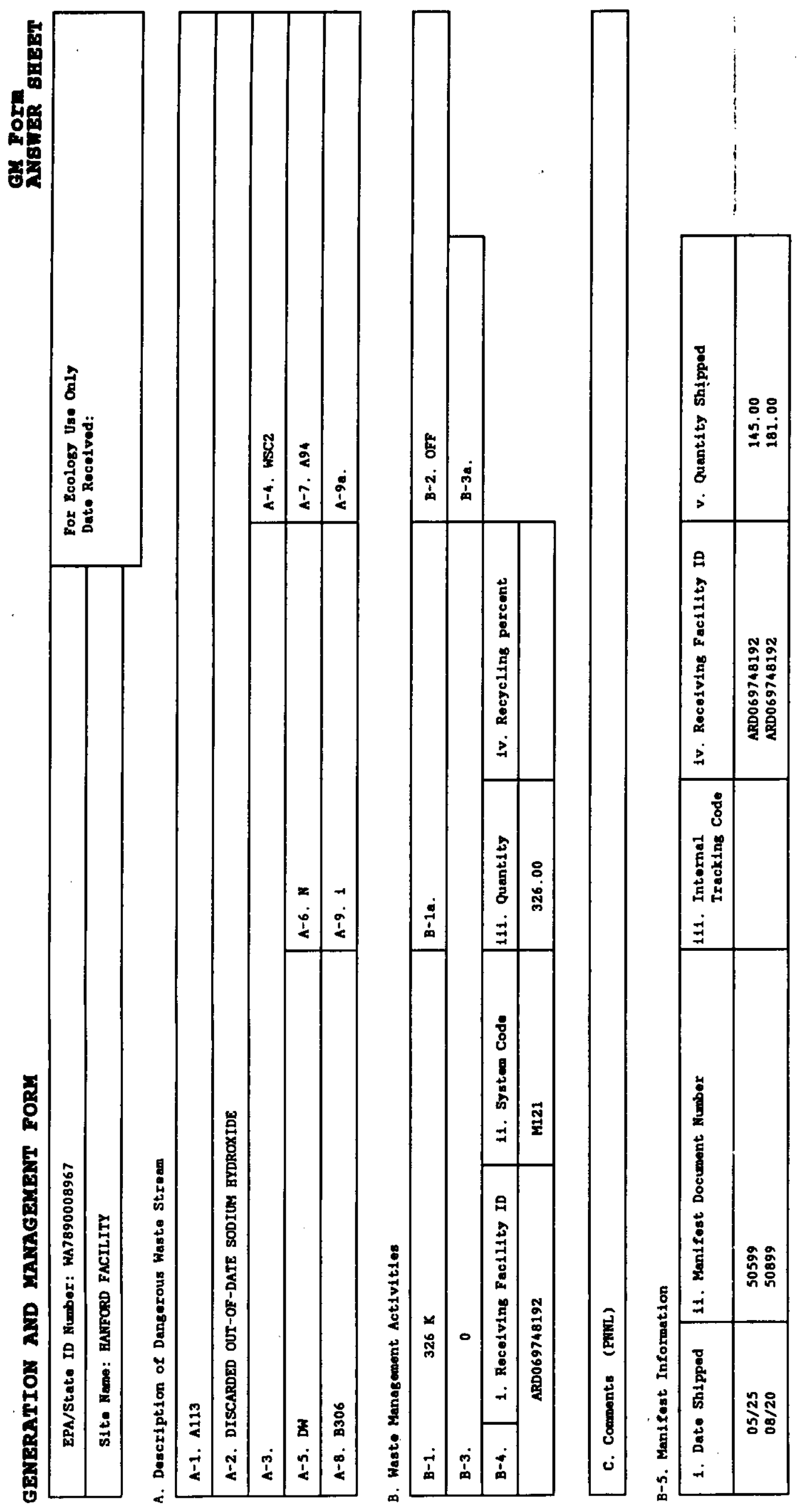




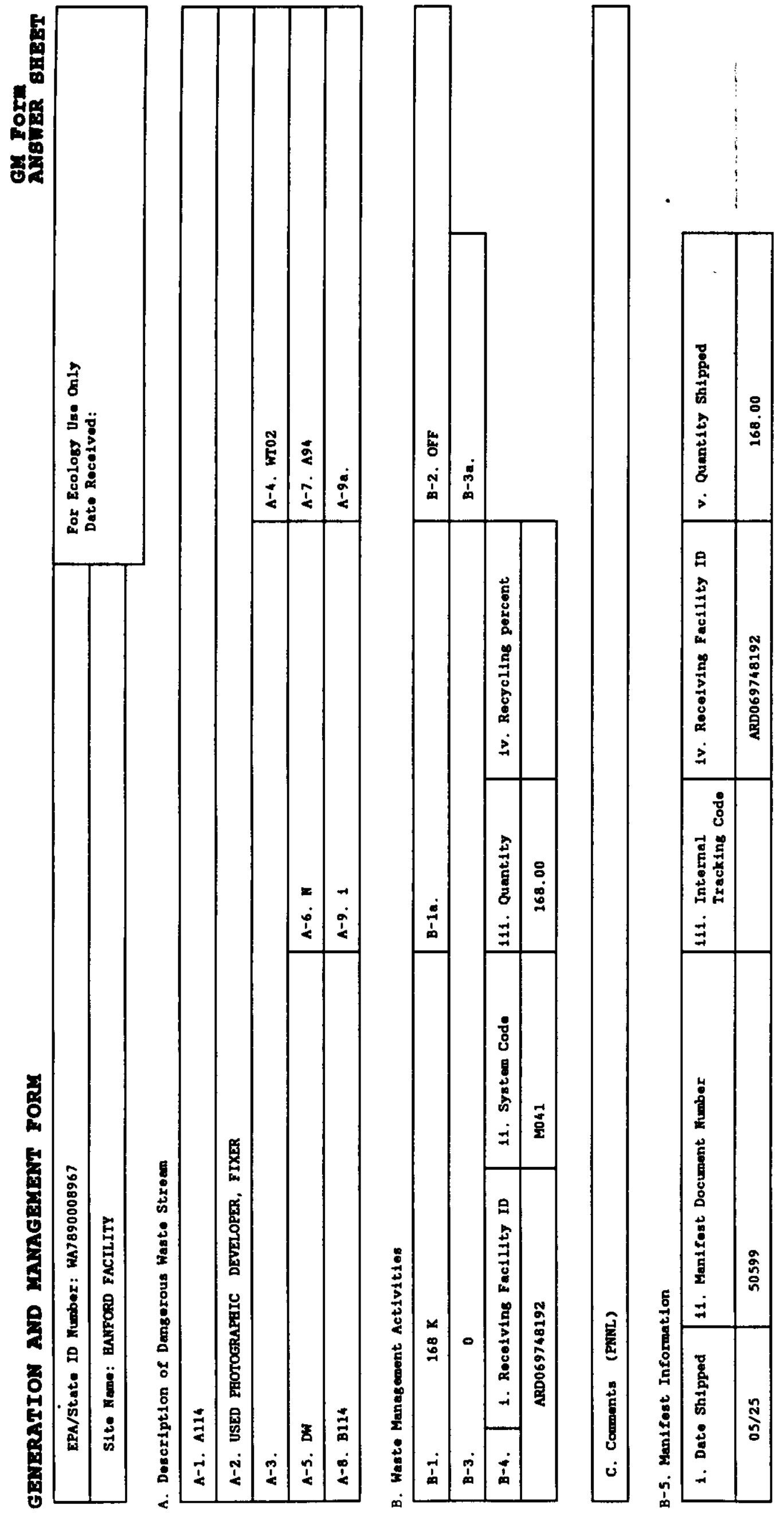




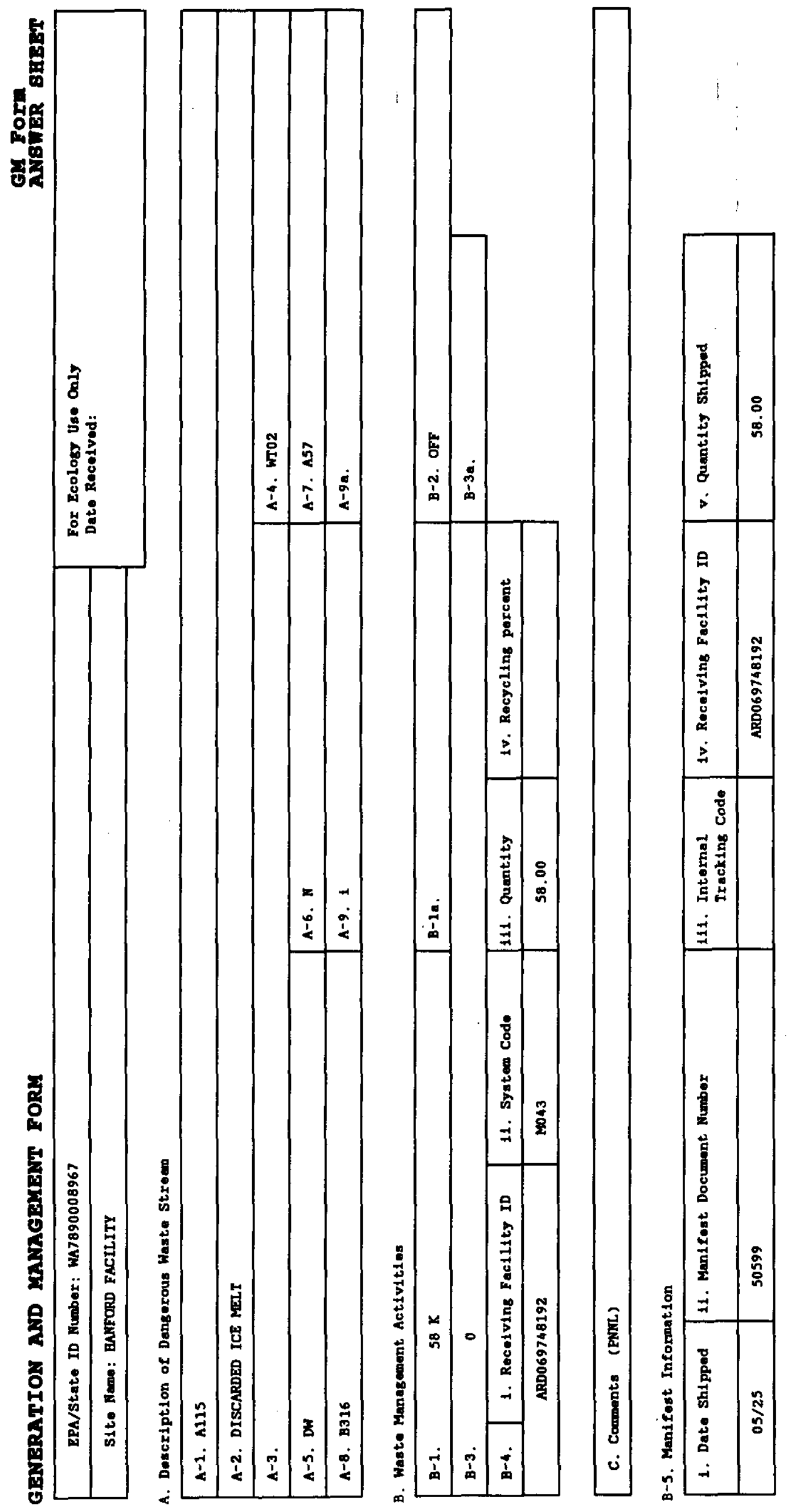




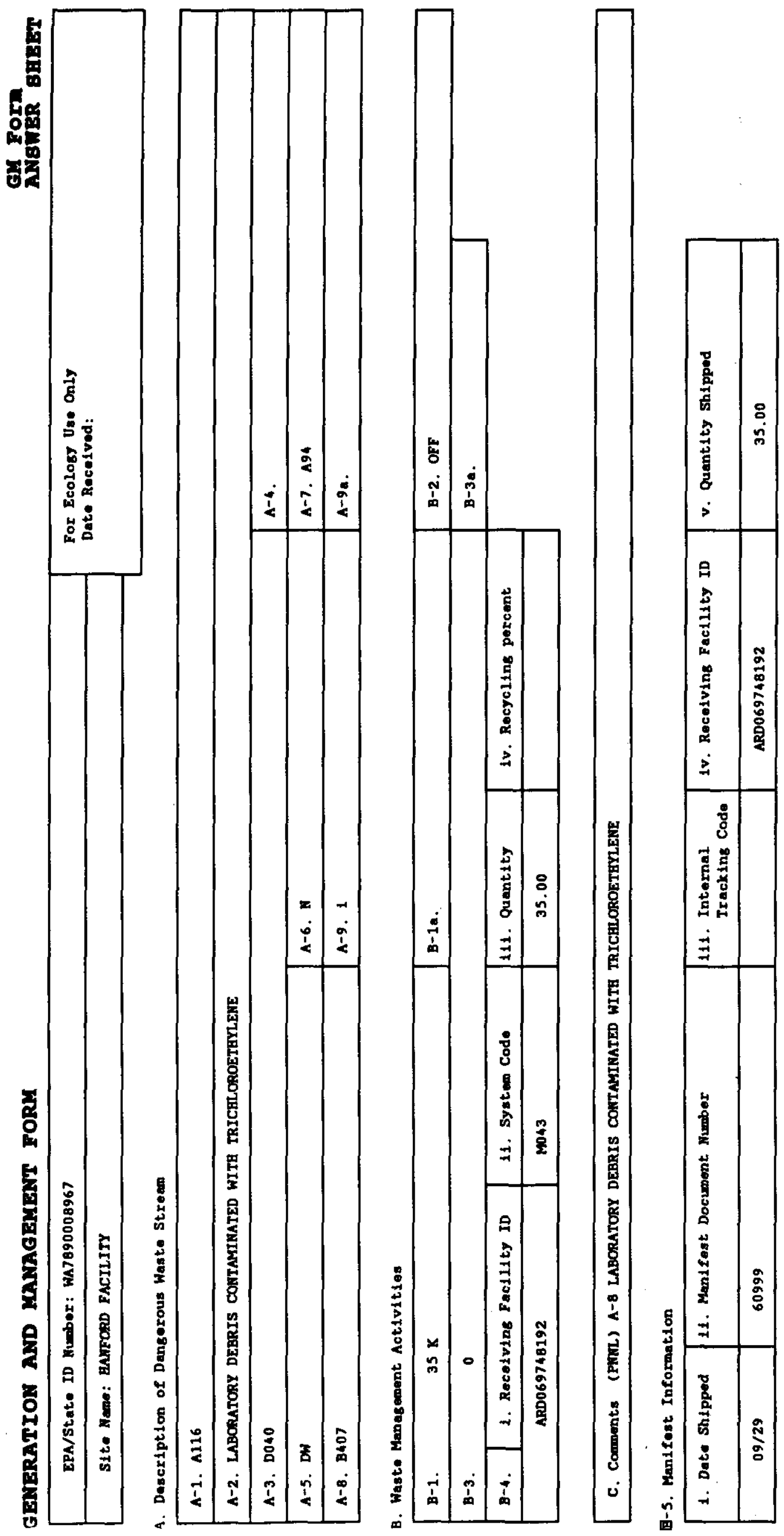




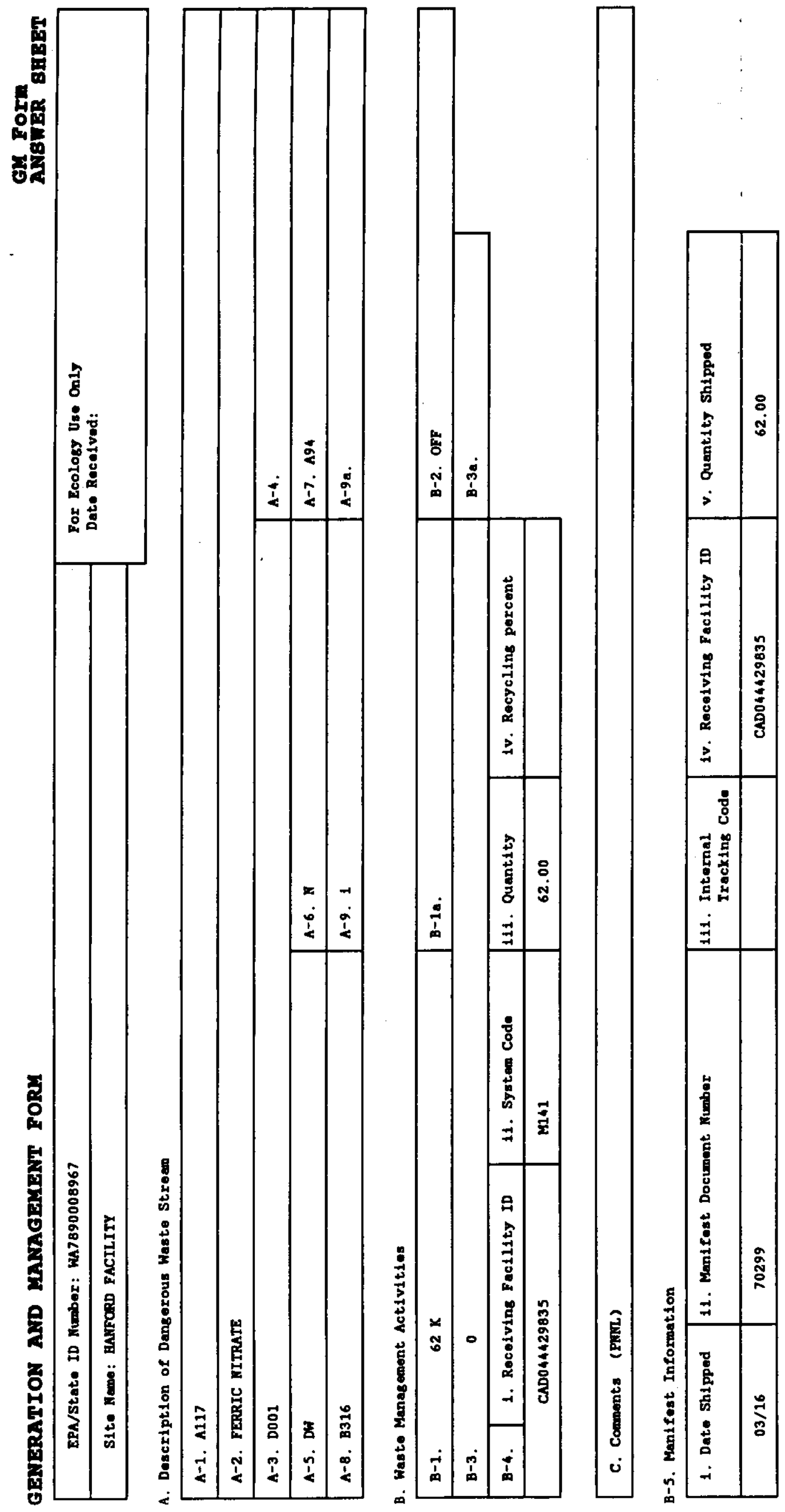



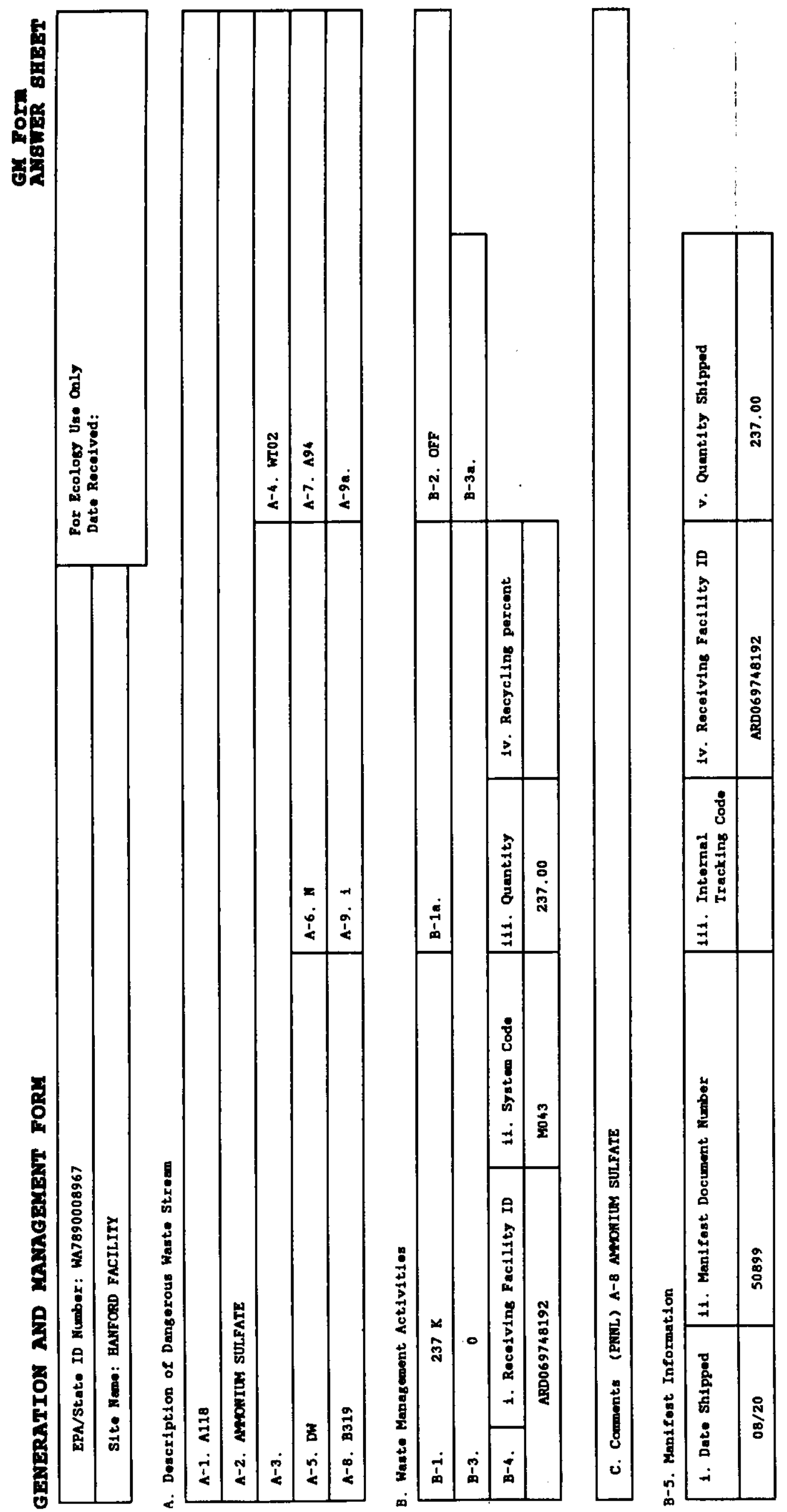

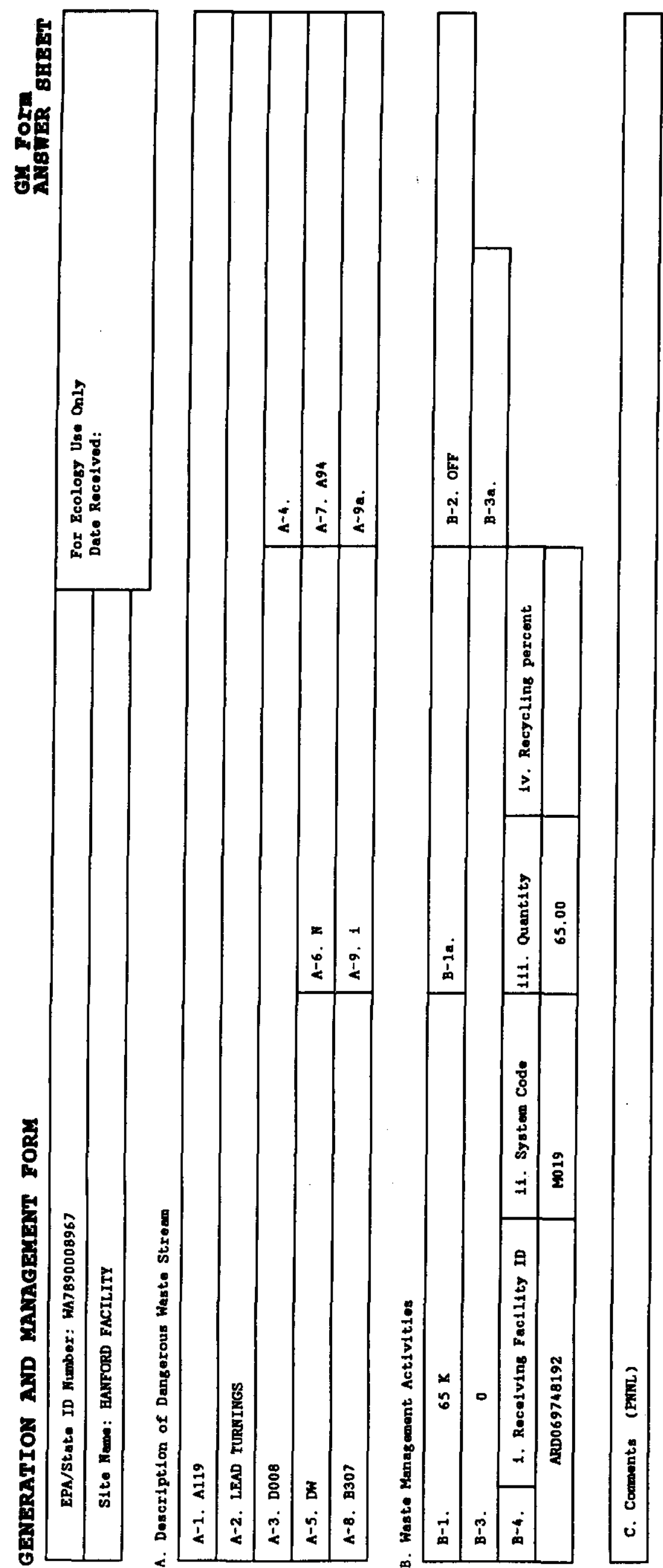

ะั

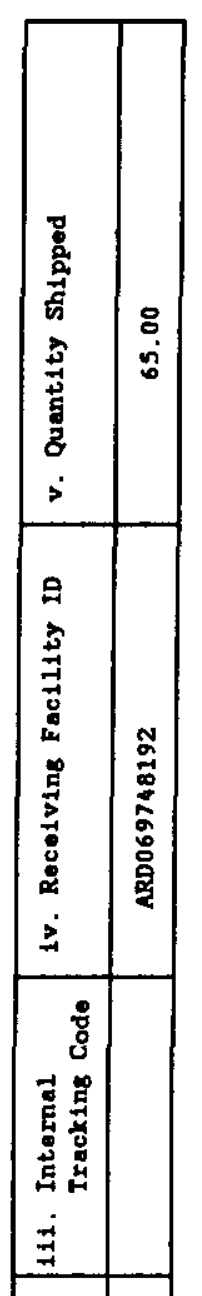




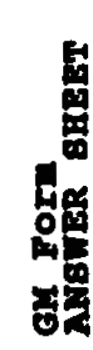


鲎

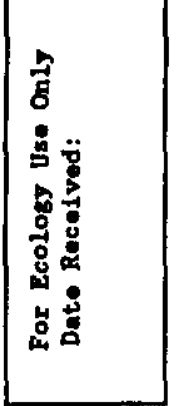

亳

焉
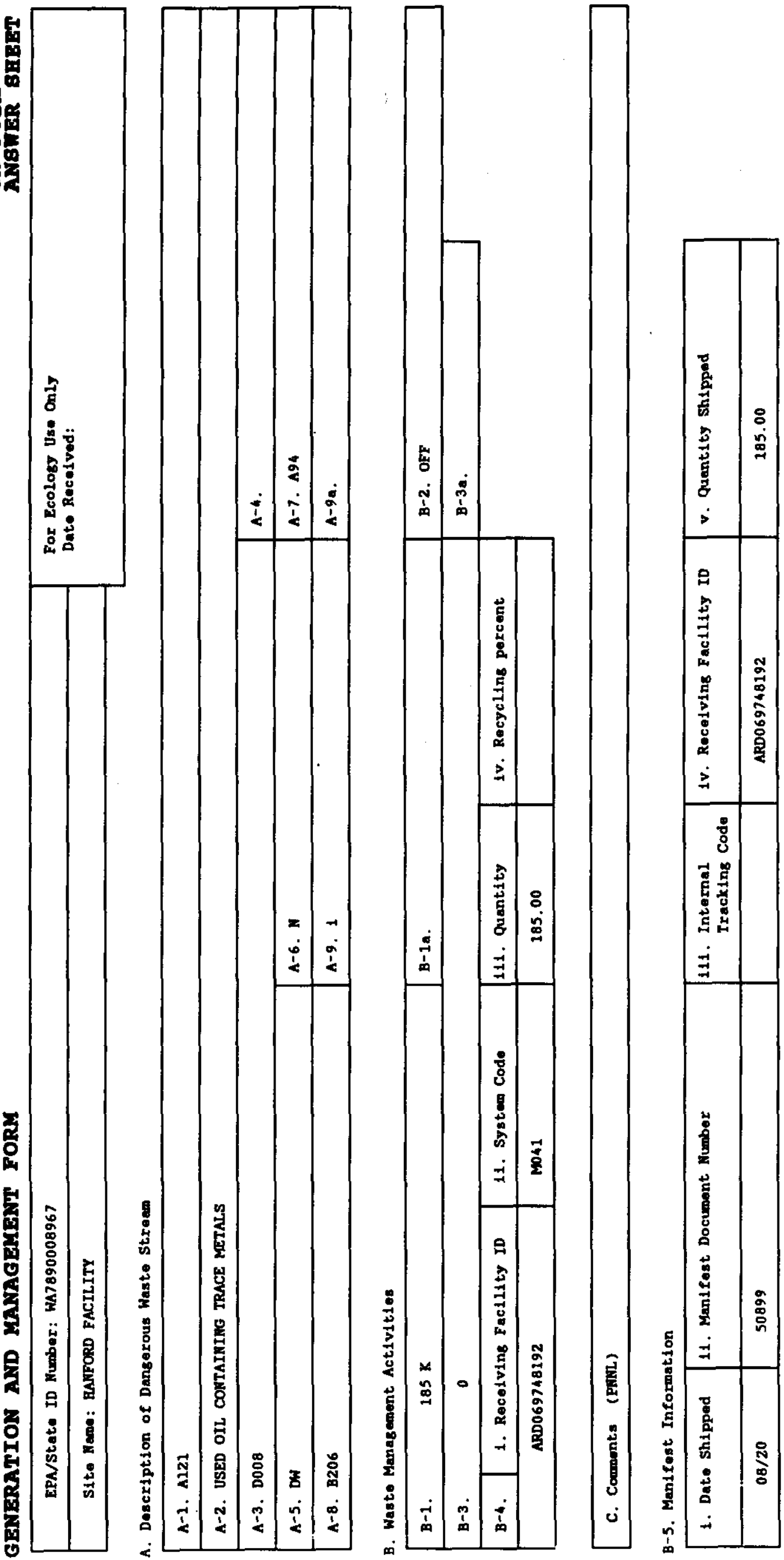

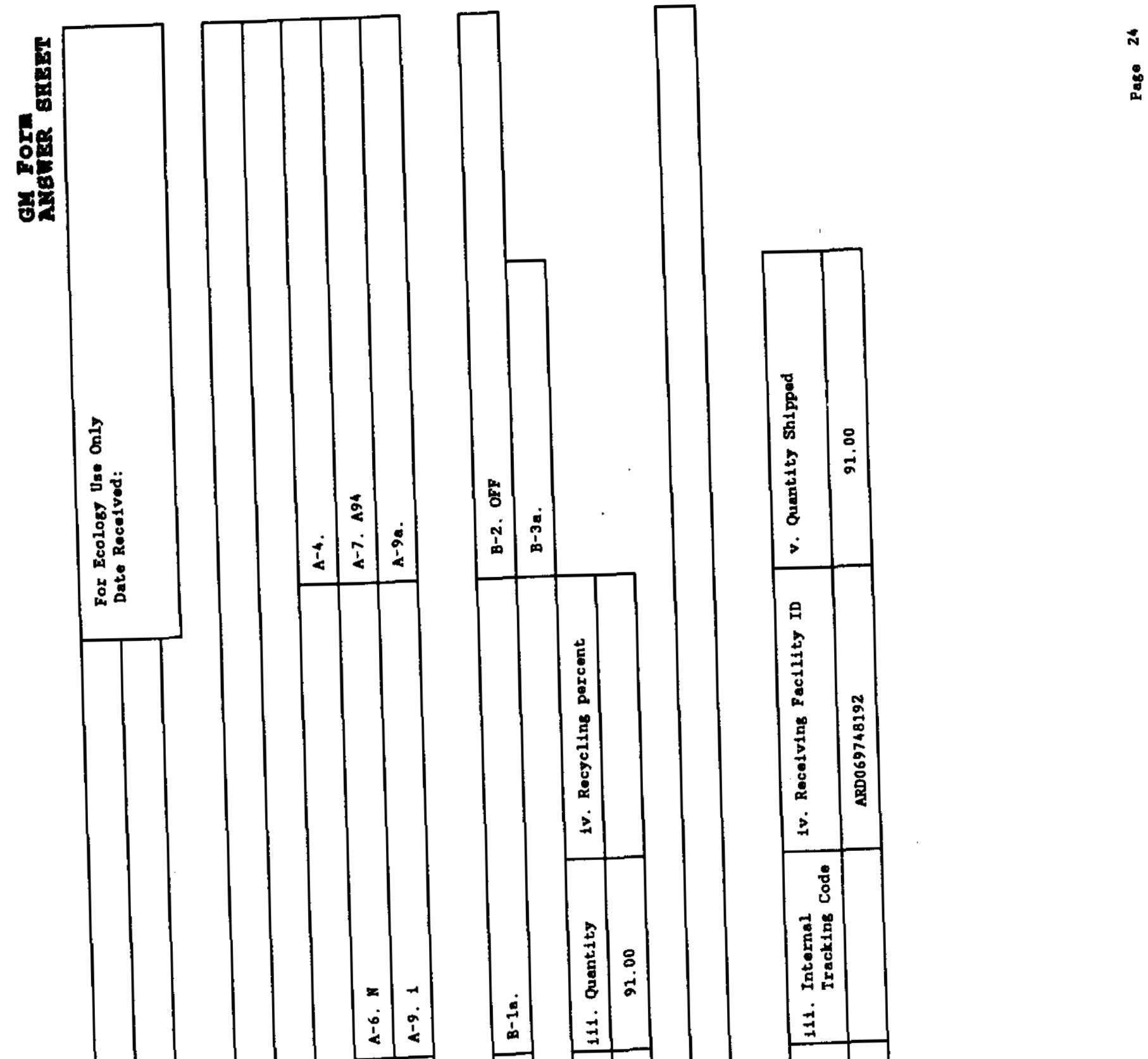

总

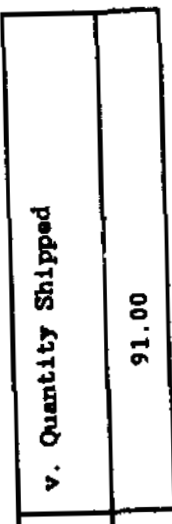

$=1$

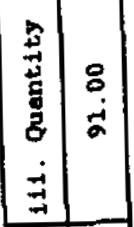

음
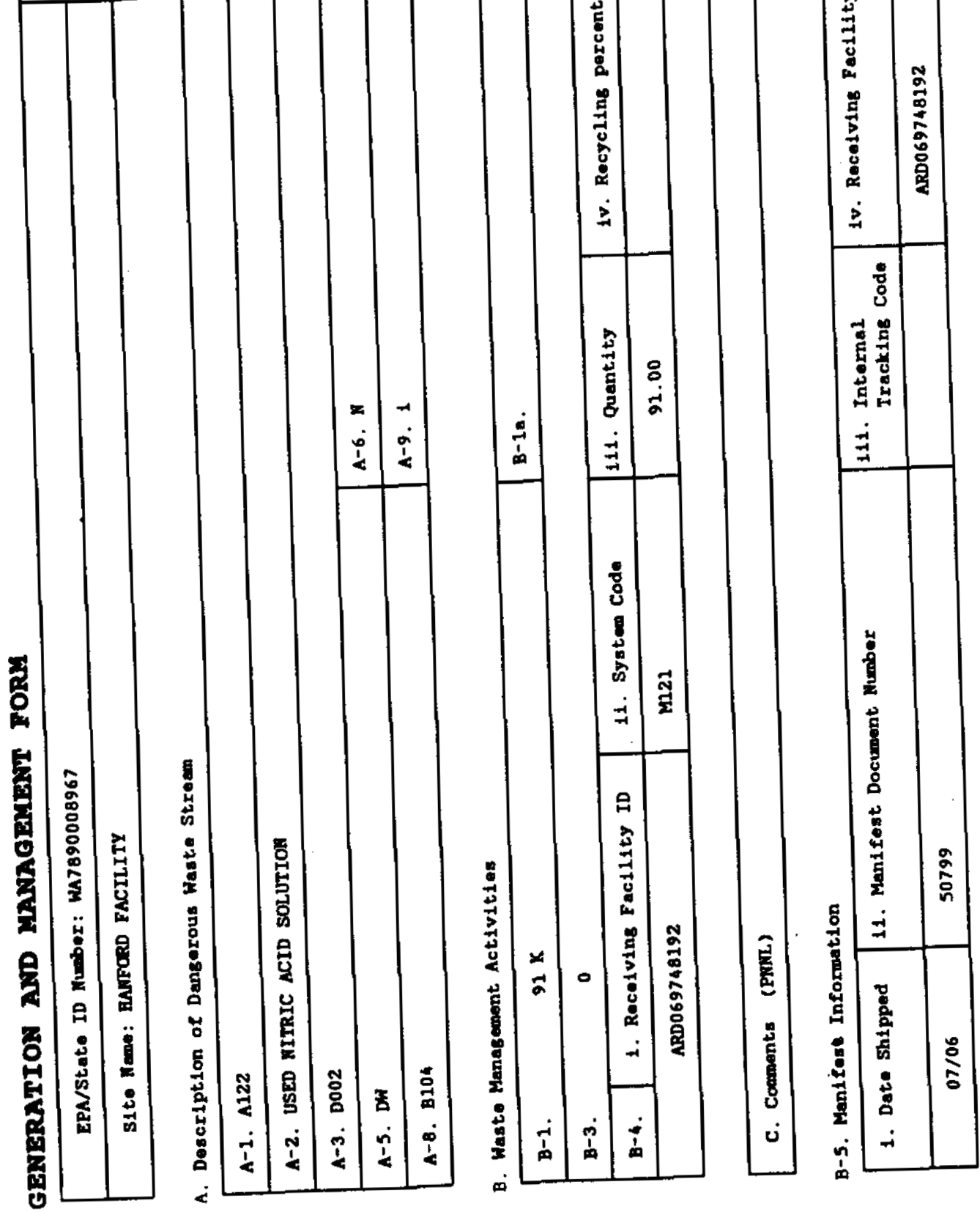


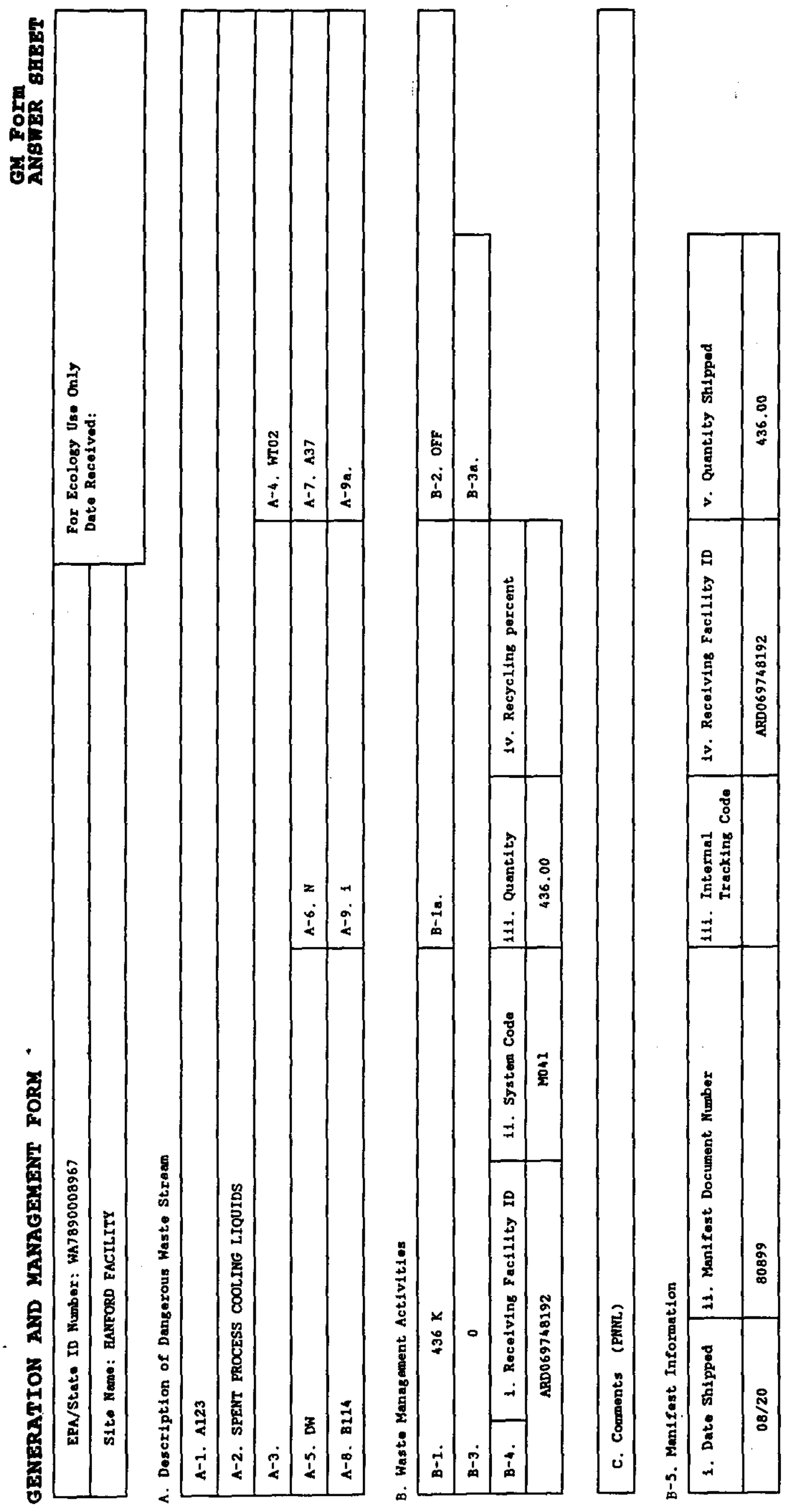



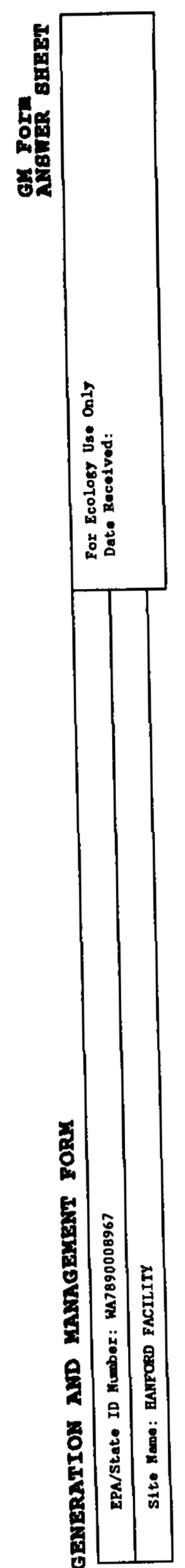
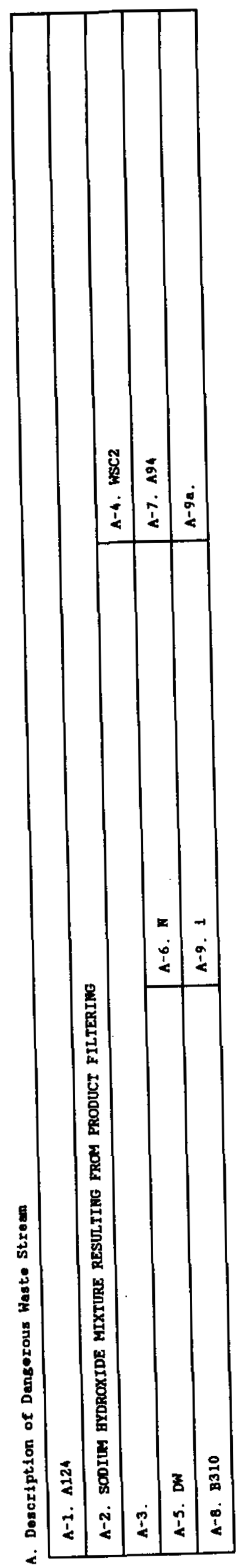

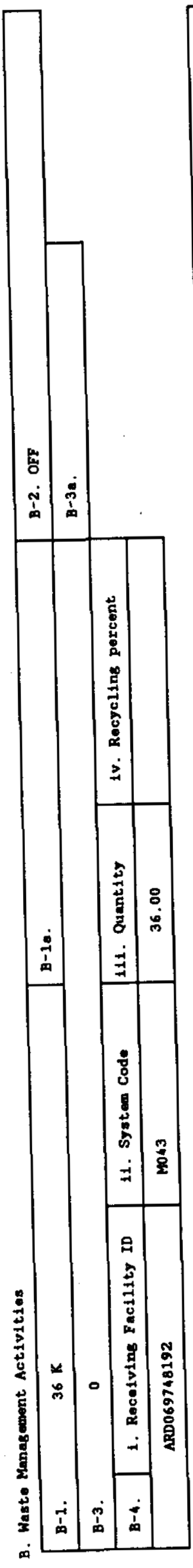

: 


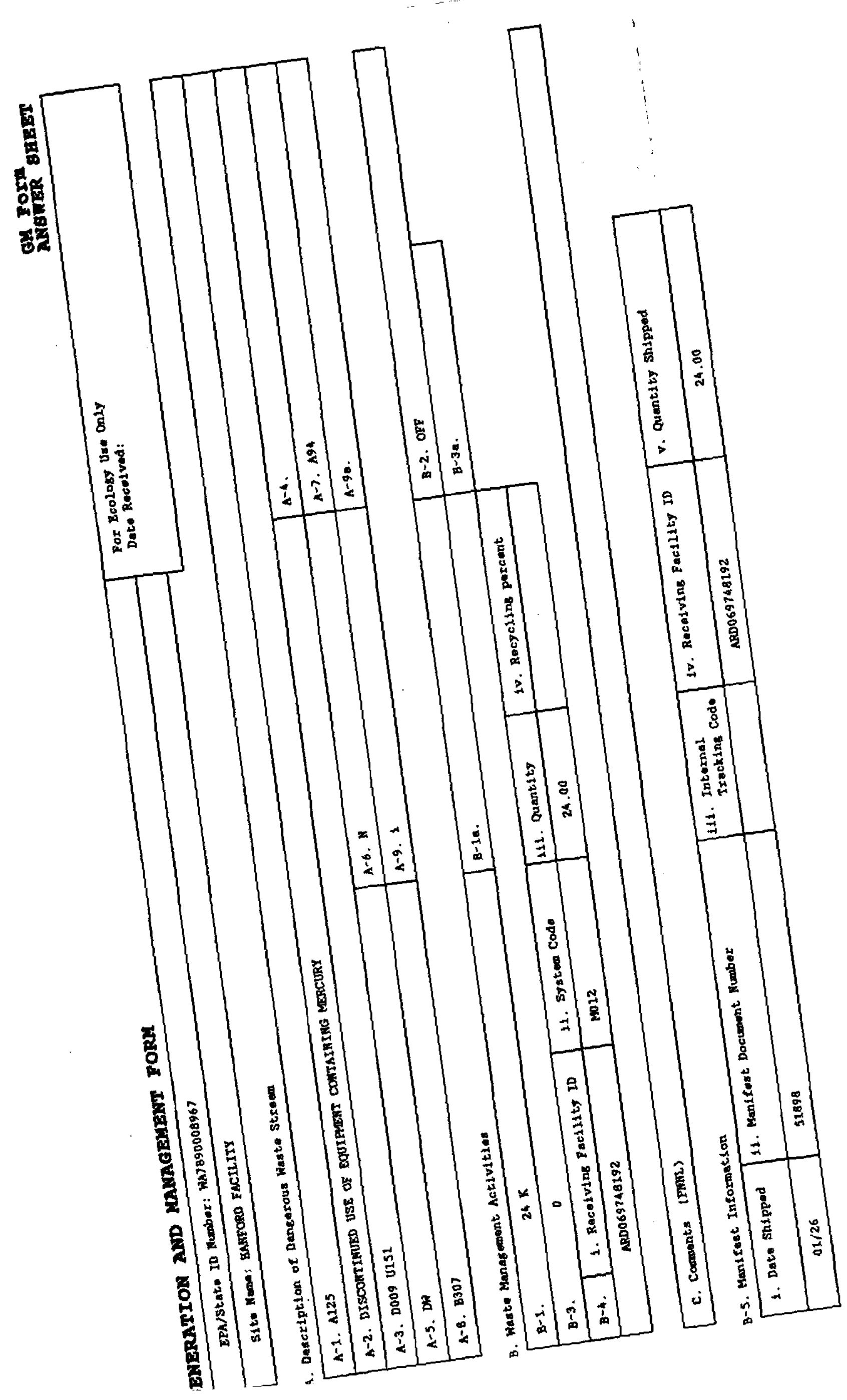




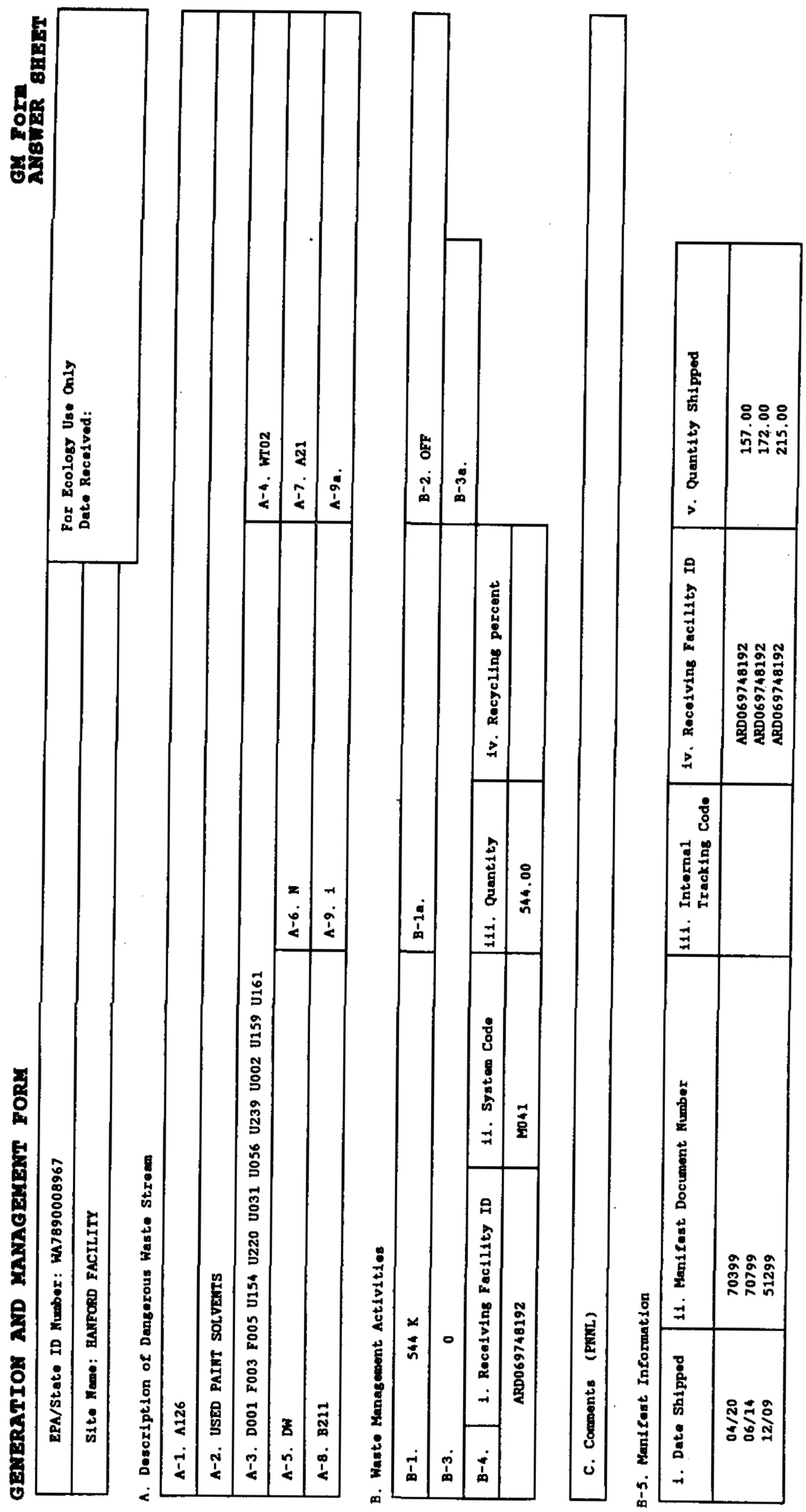




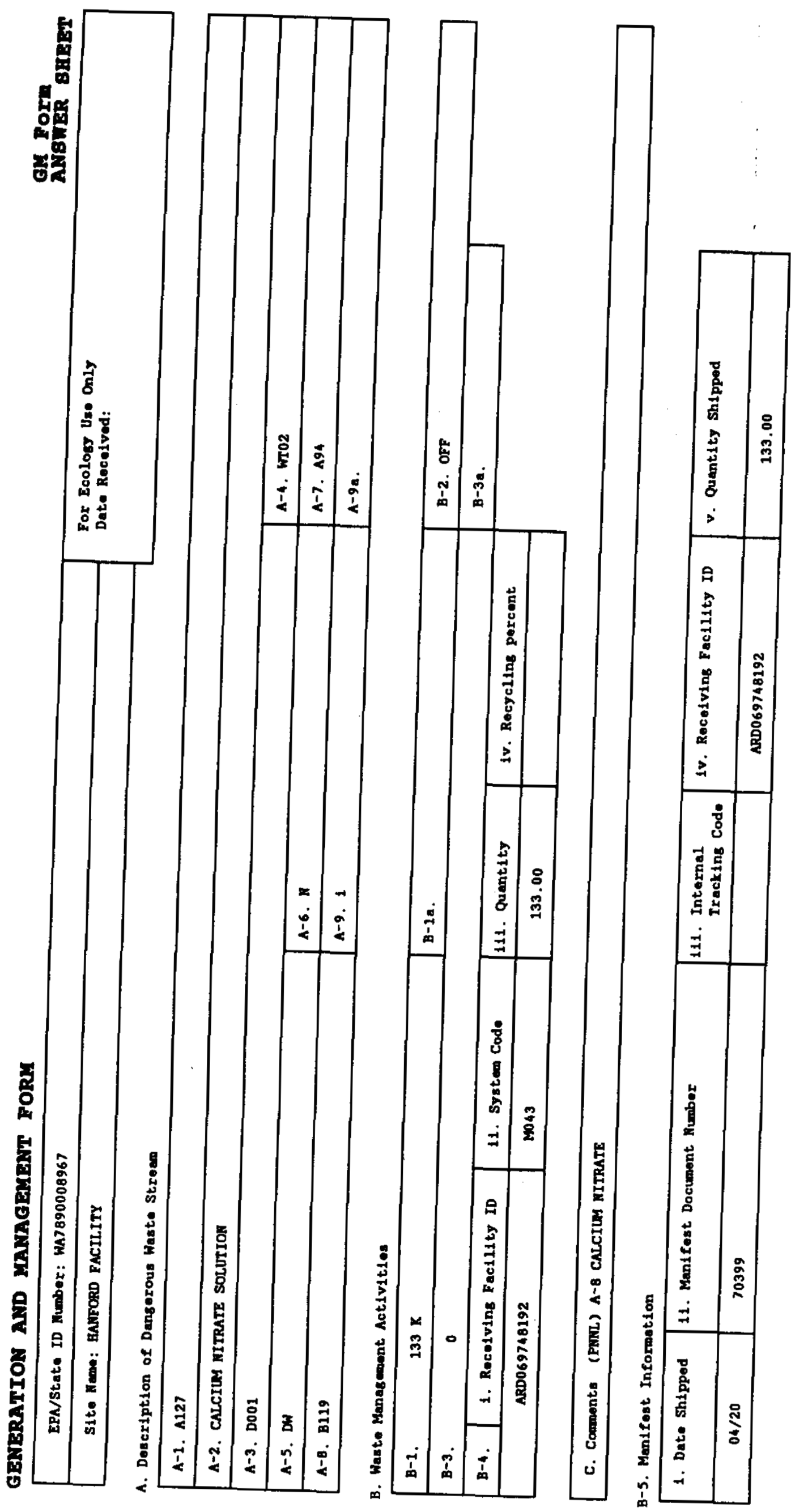

สิ 


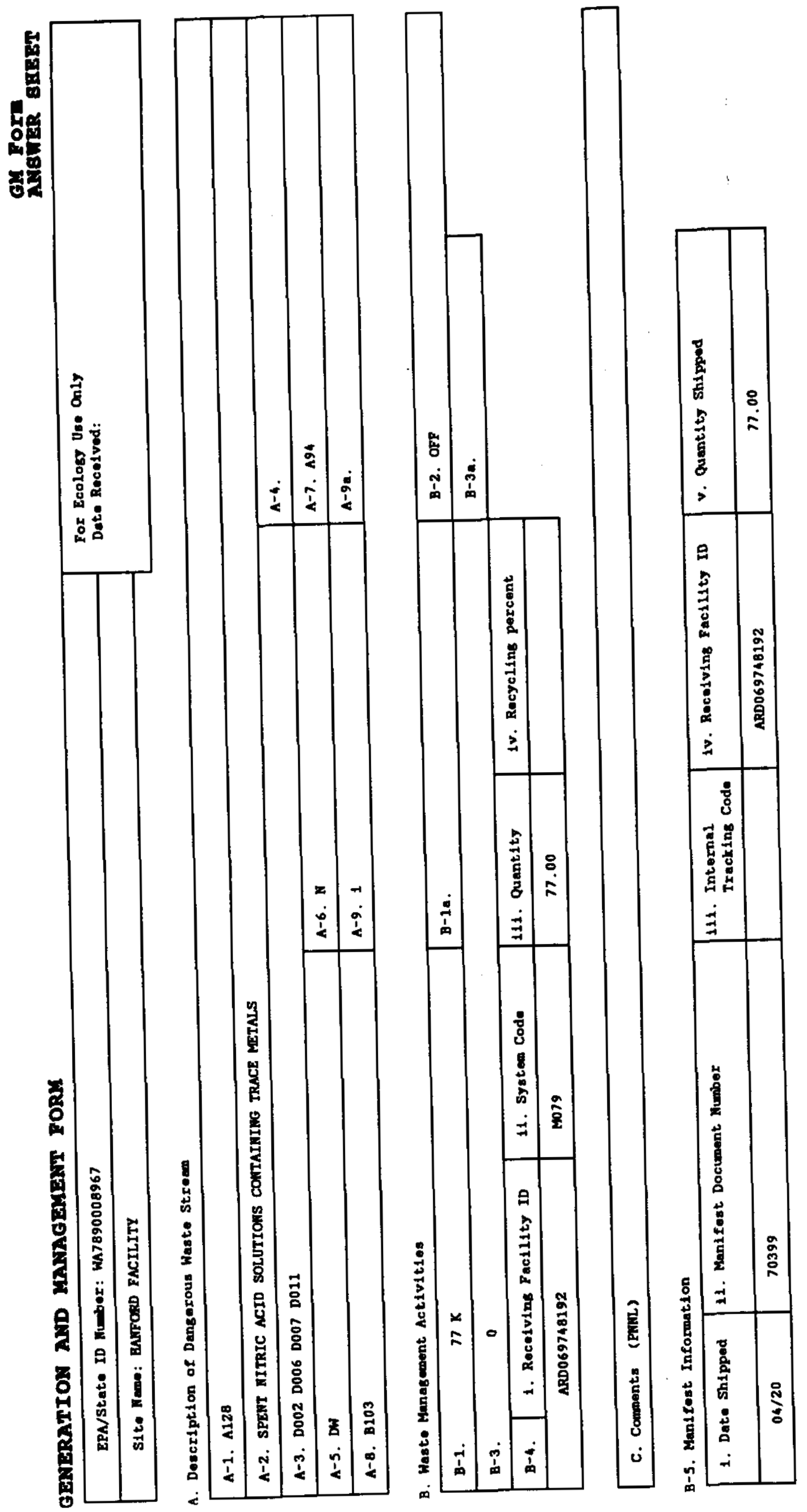


褁
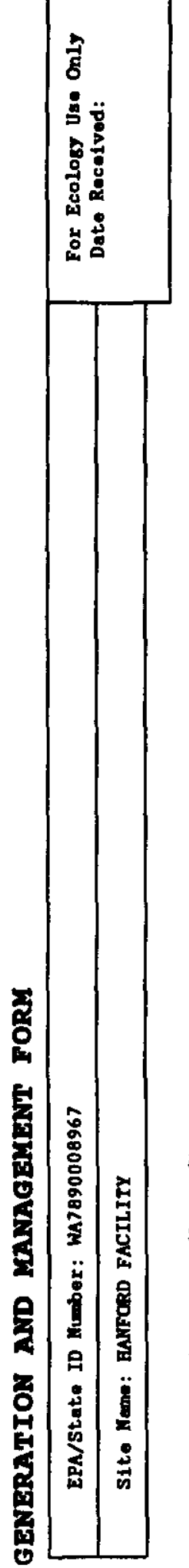
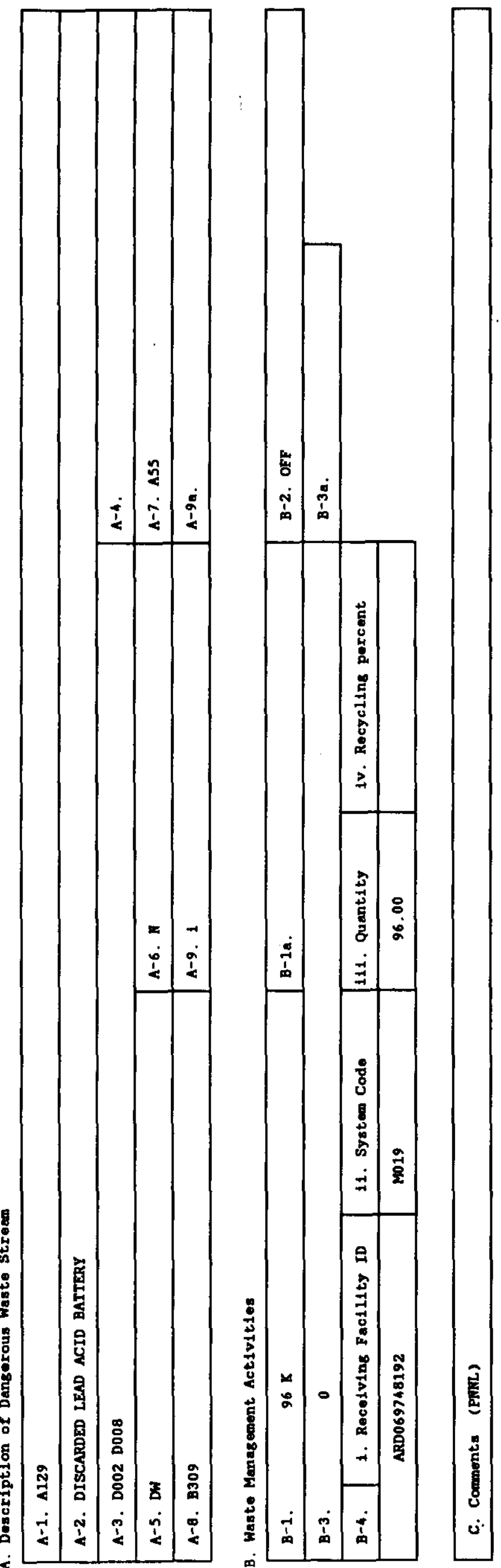

$\vec{m}$
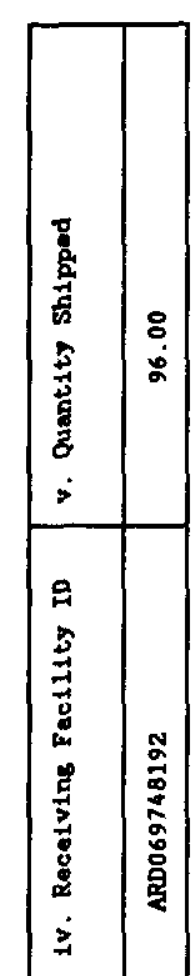

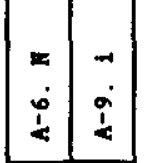

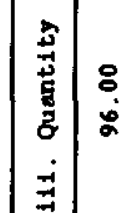

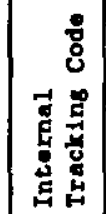

$\stackrel{-1}{\exists}$

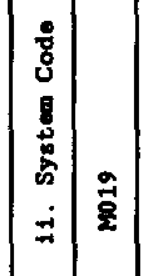

量

穿

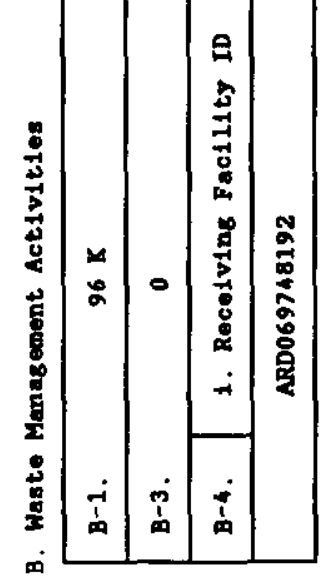

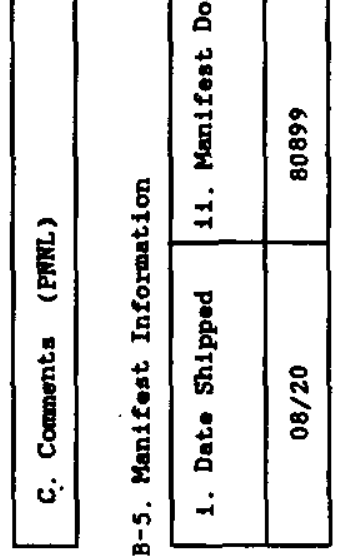




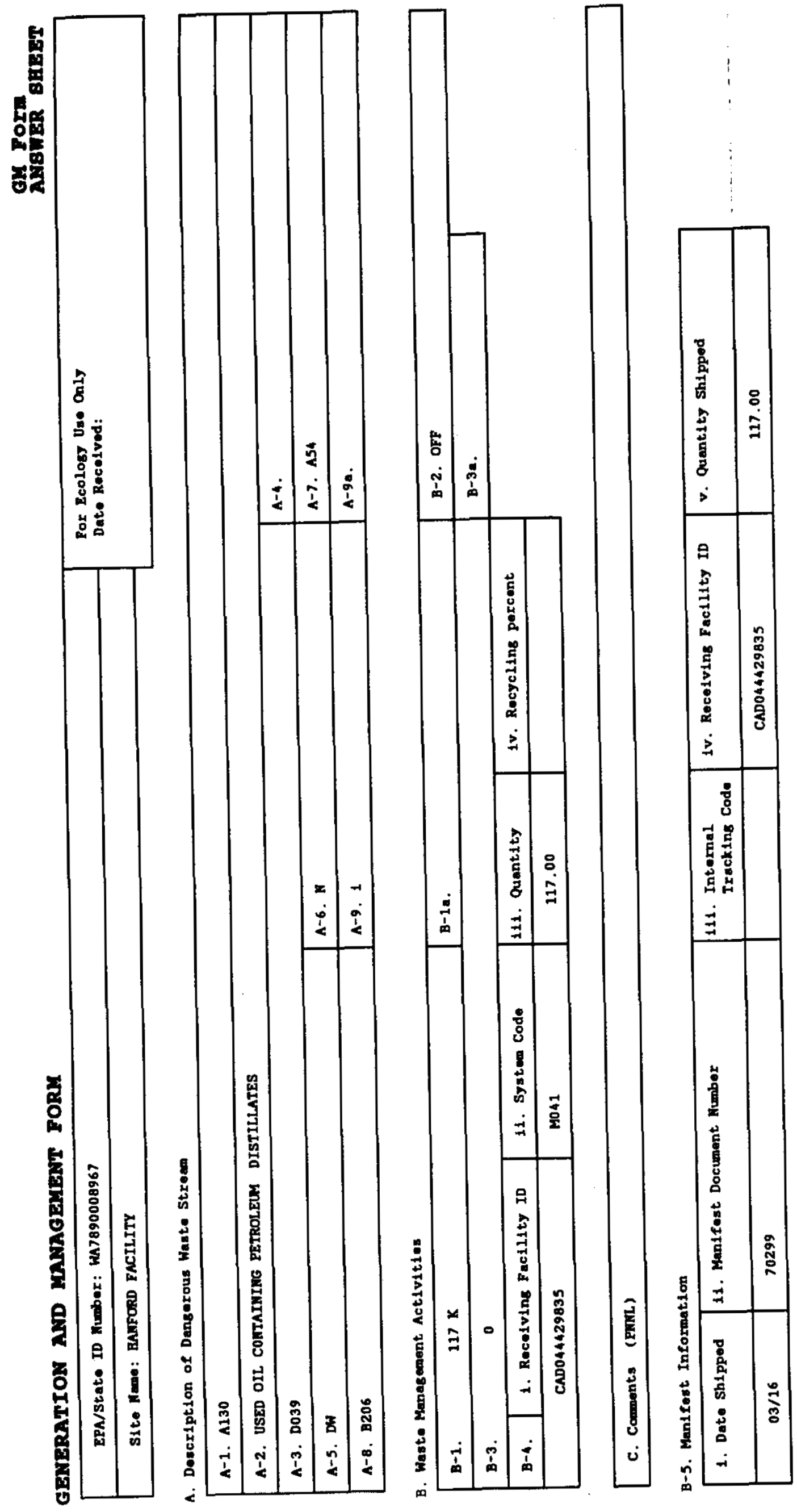




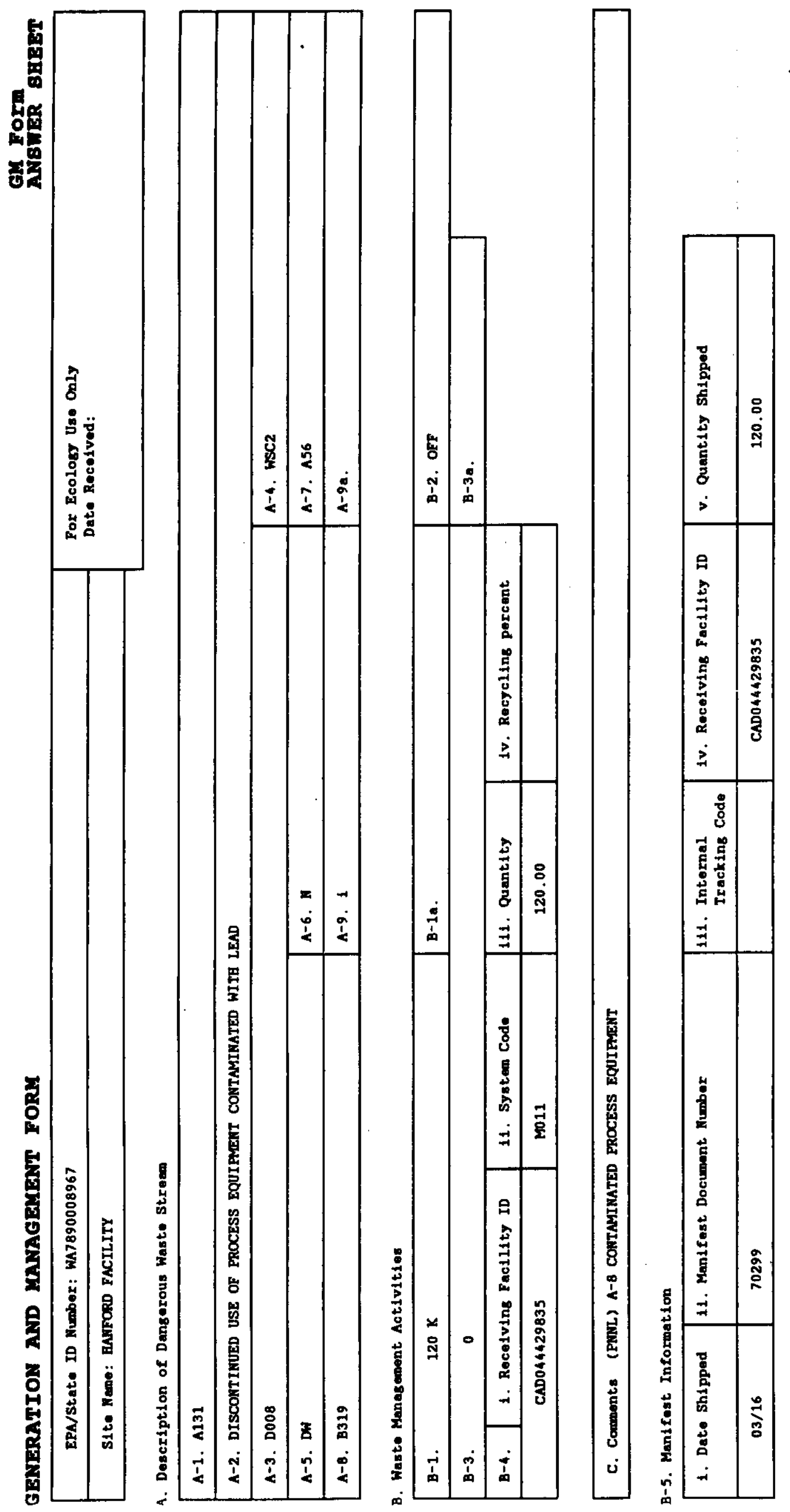




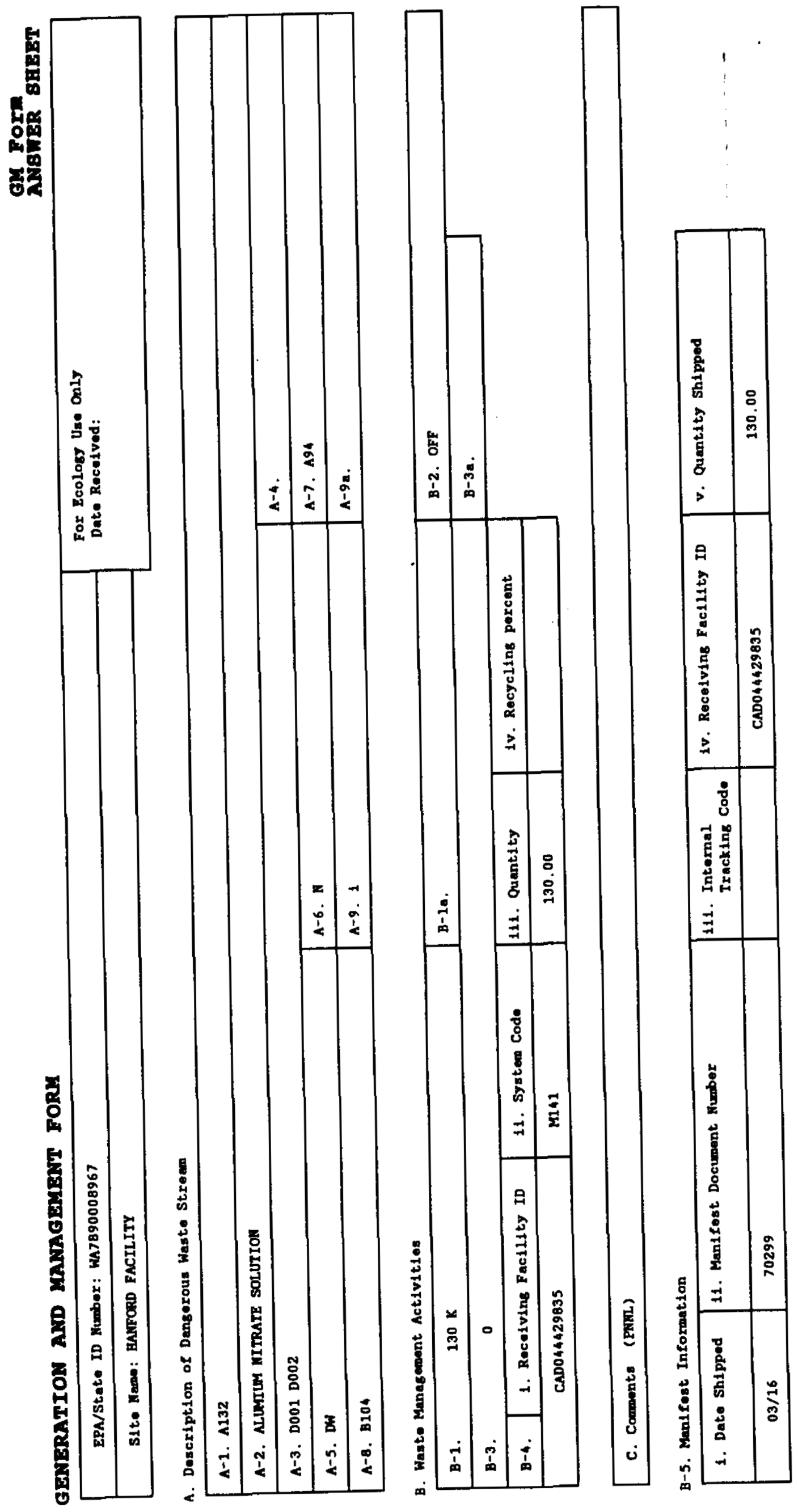




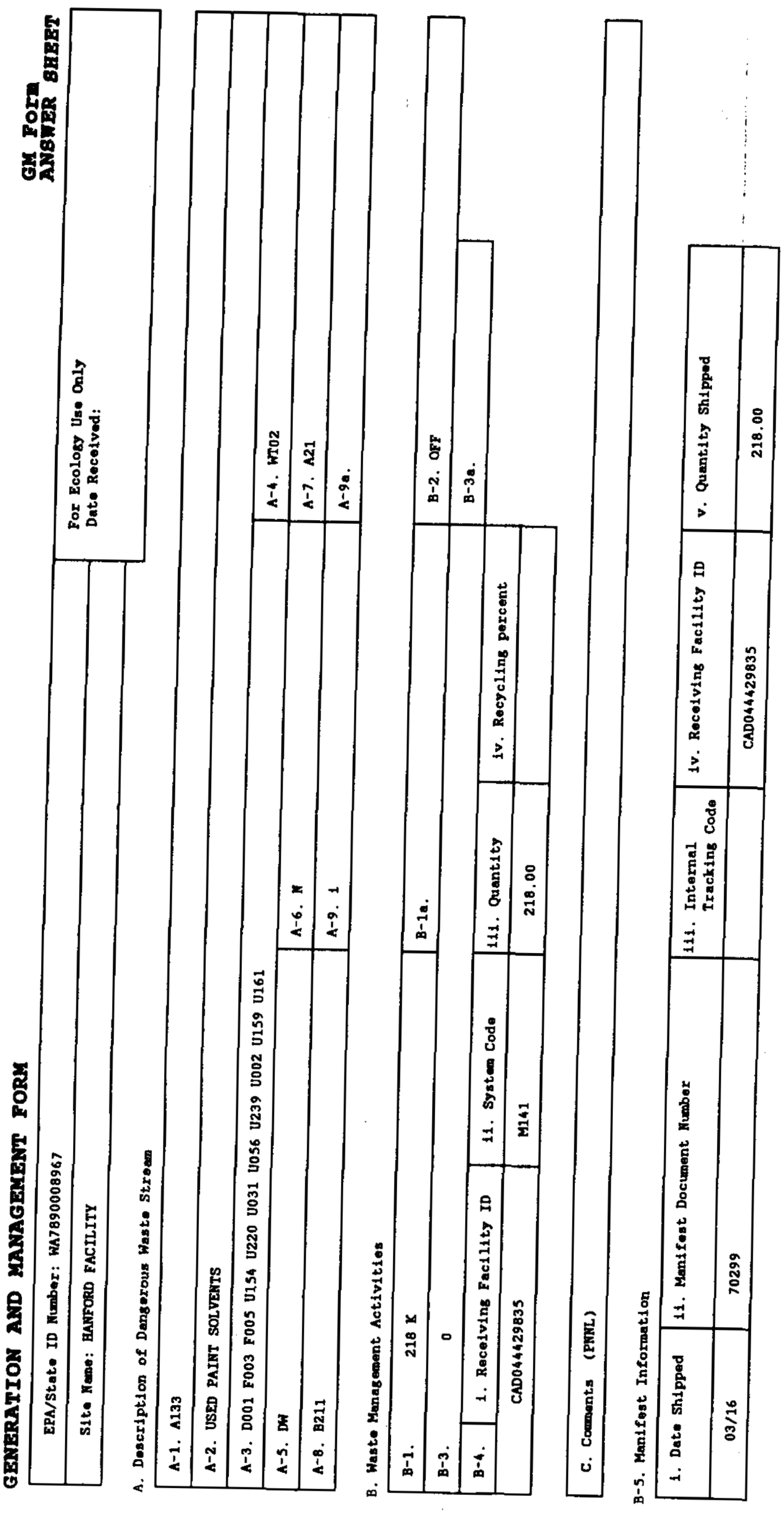




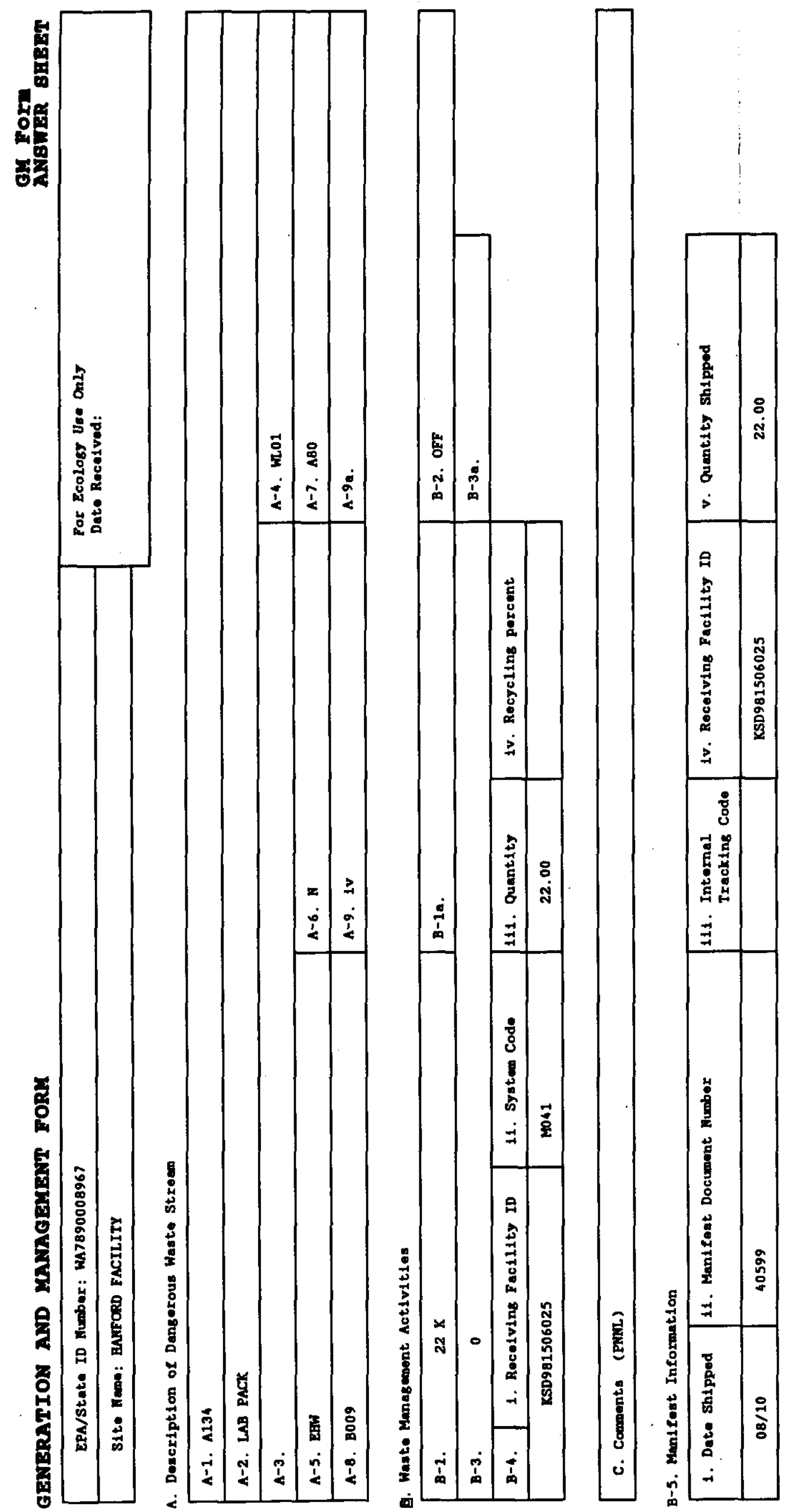

: 


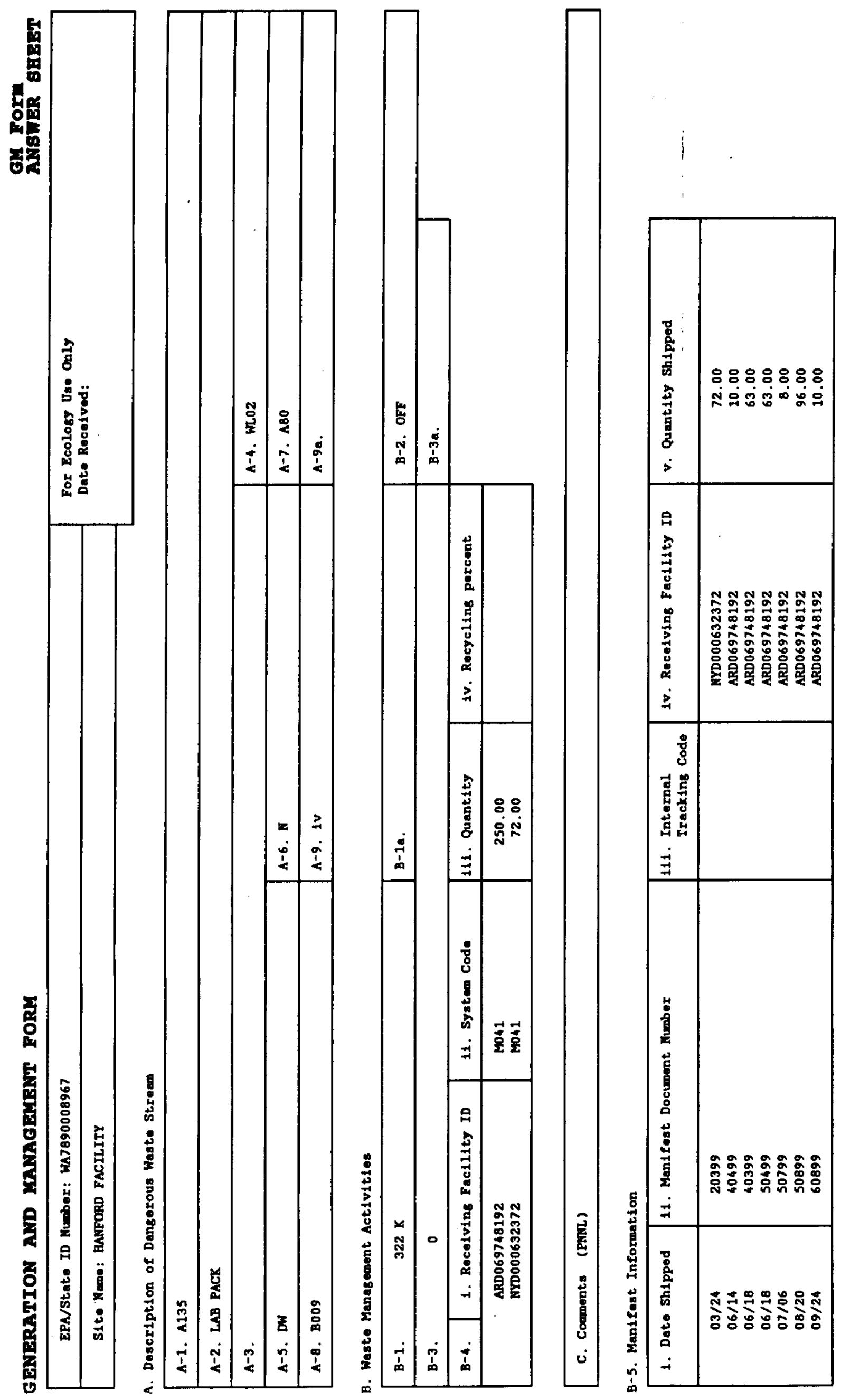




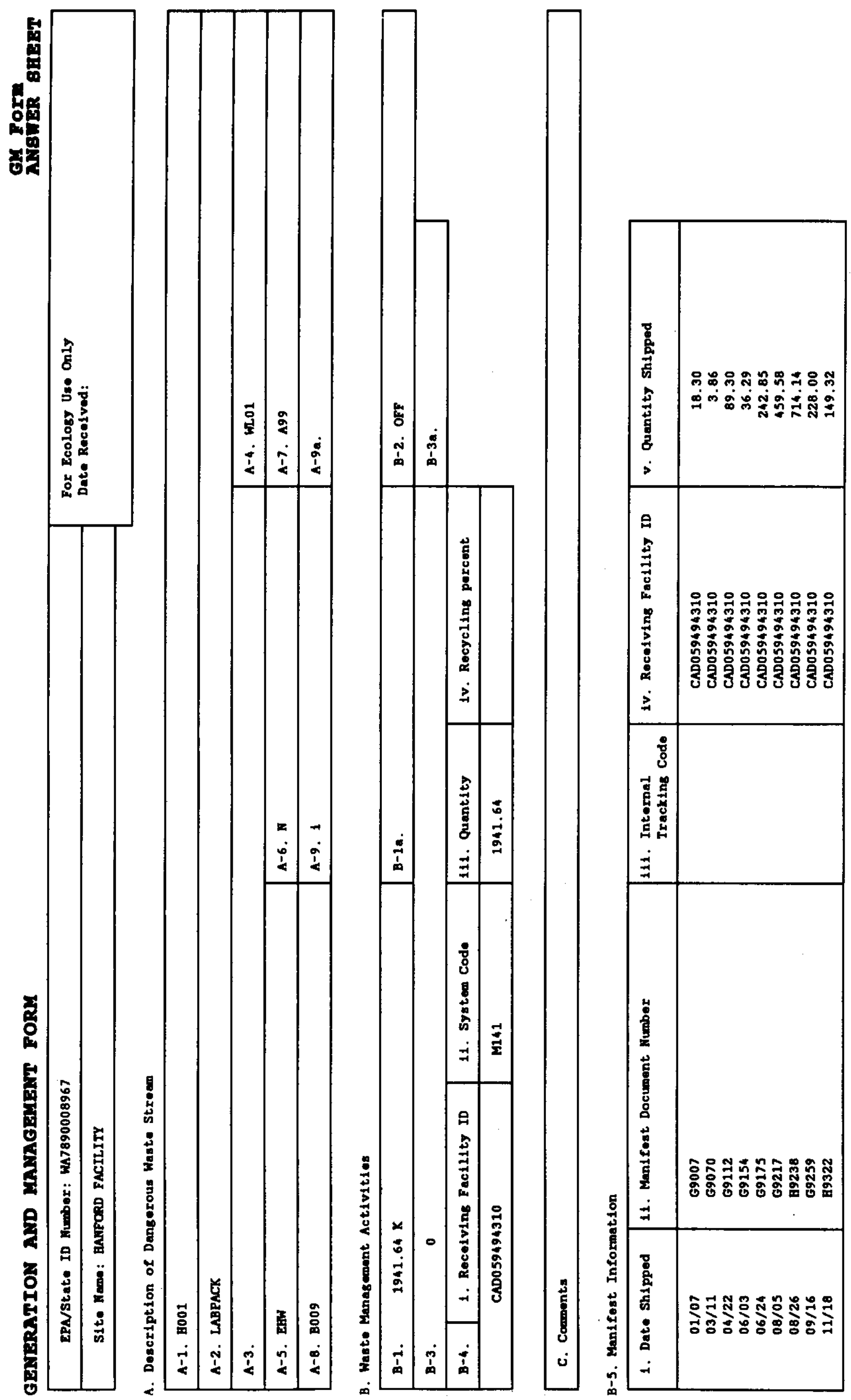


岁起
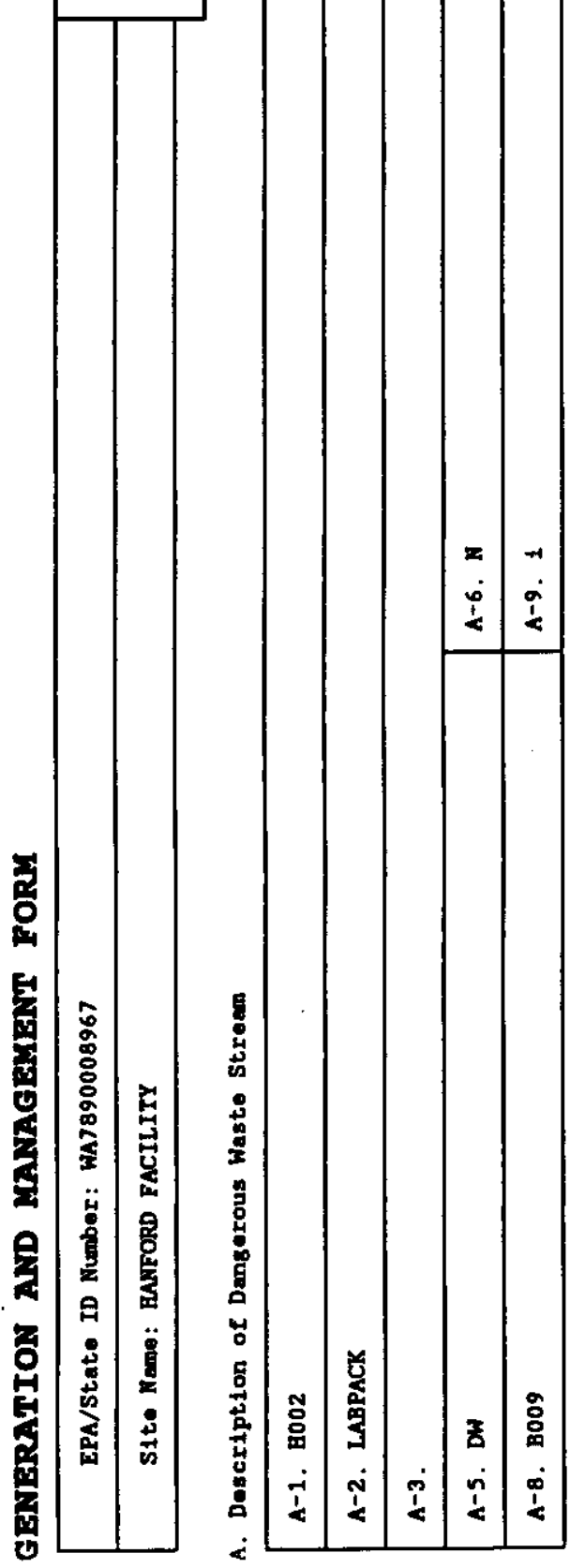
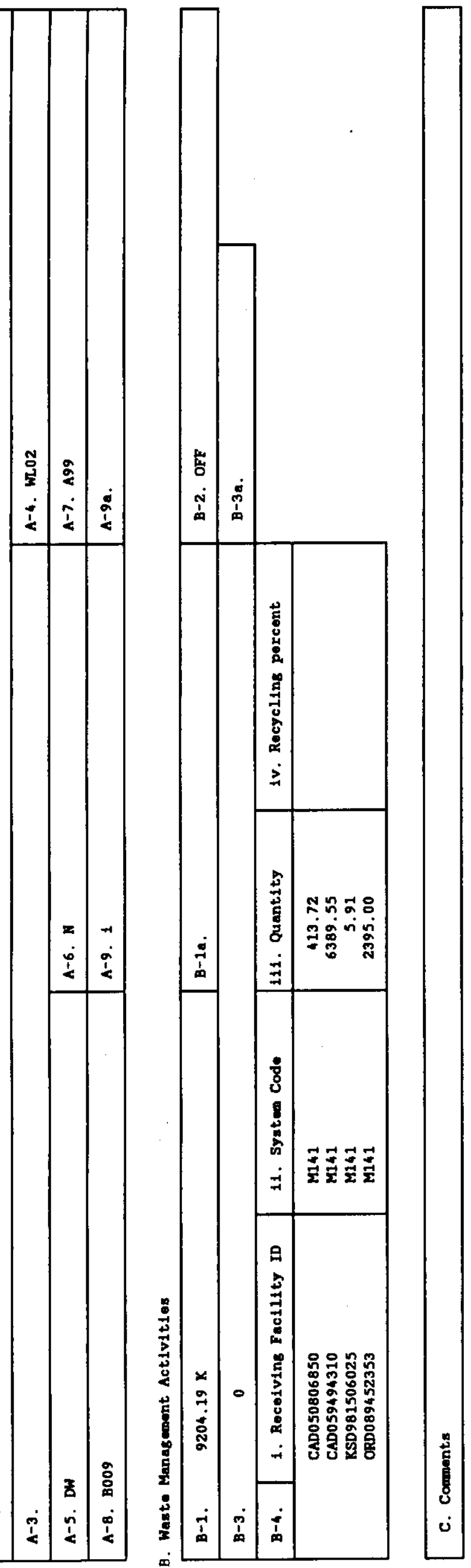

每
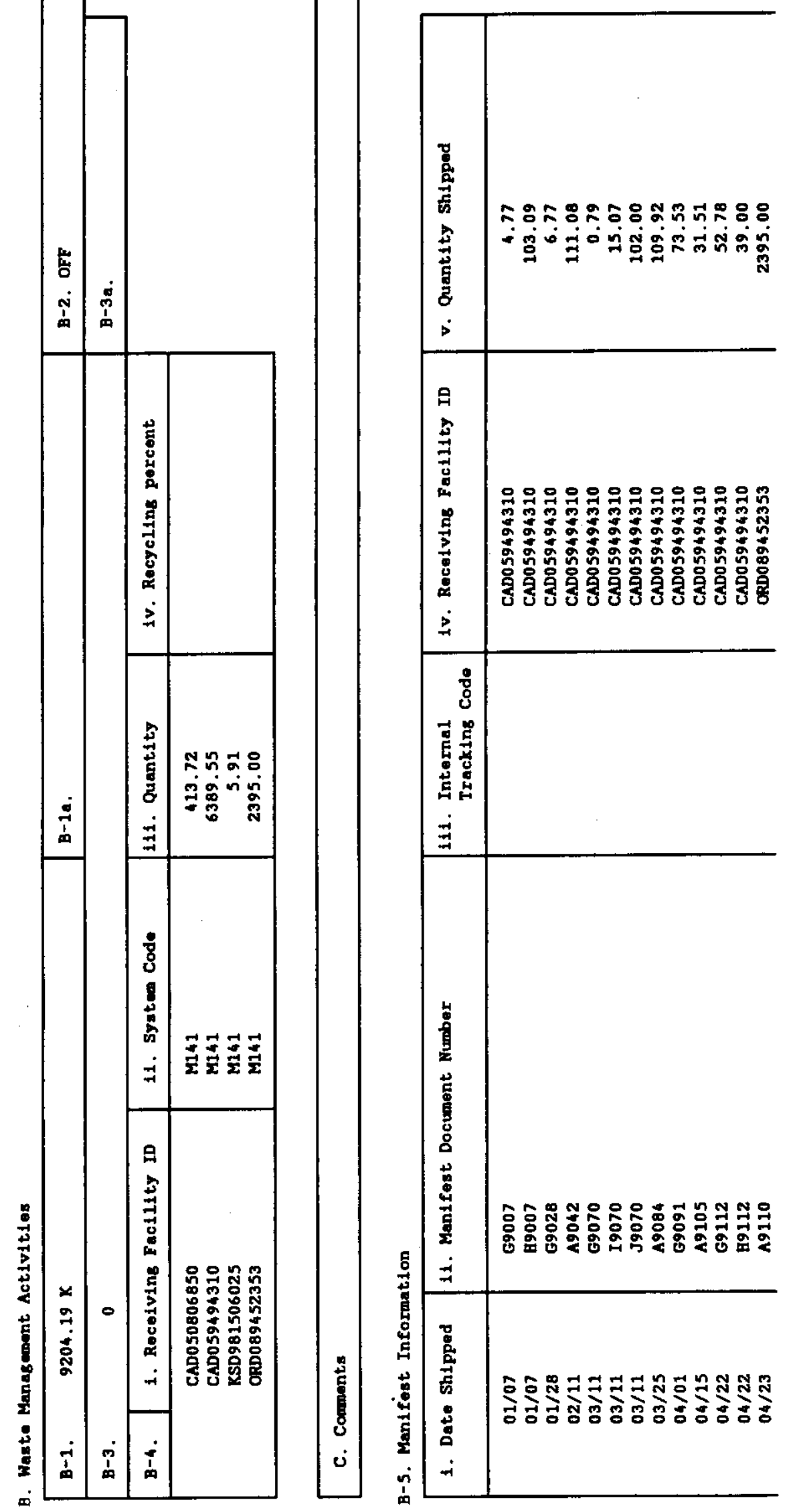


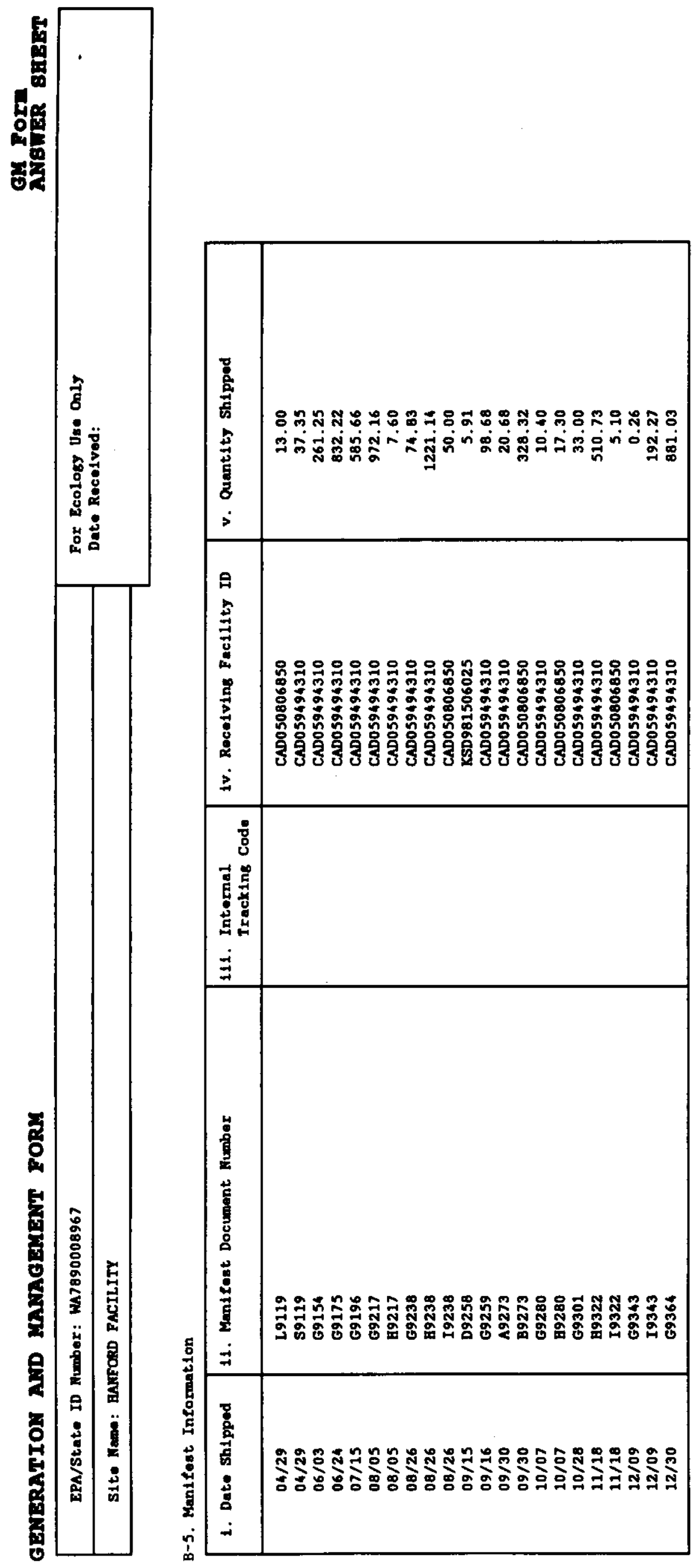



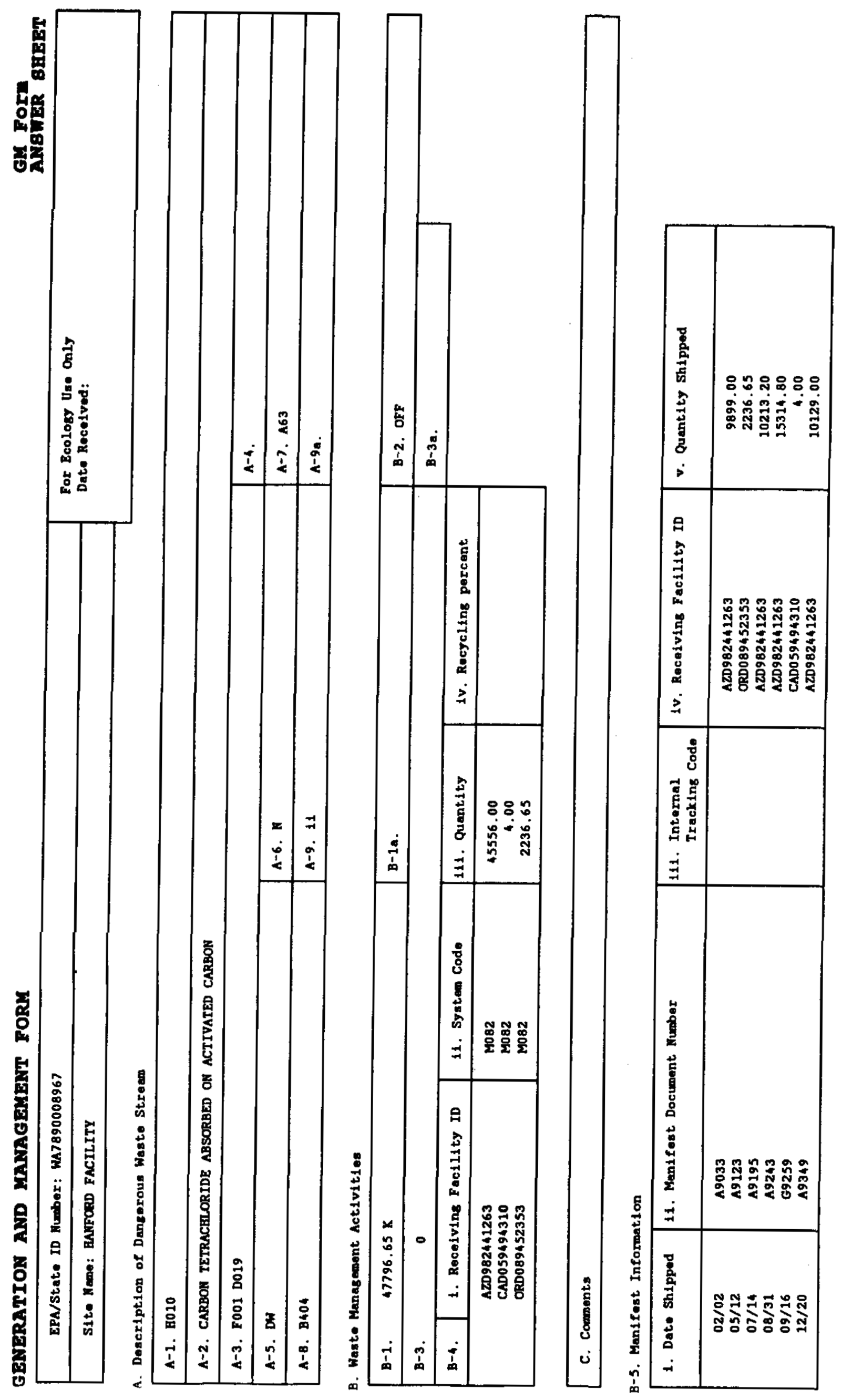


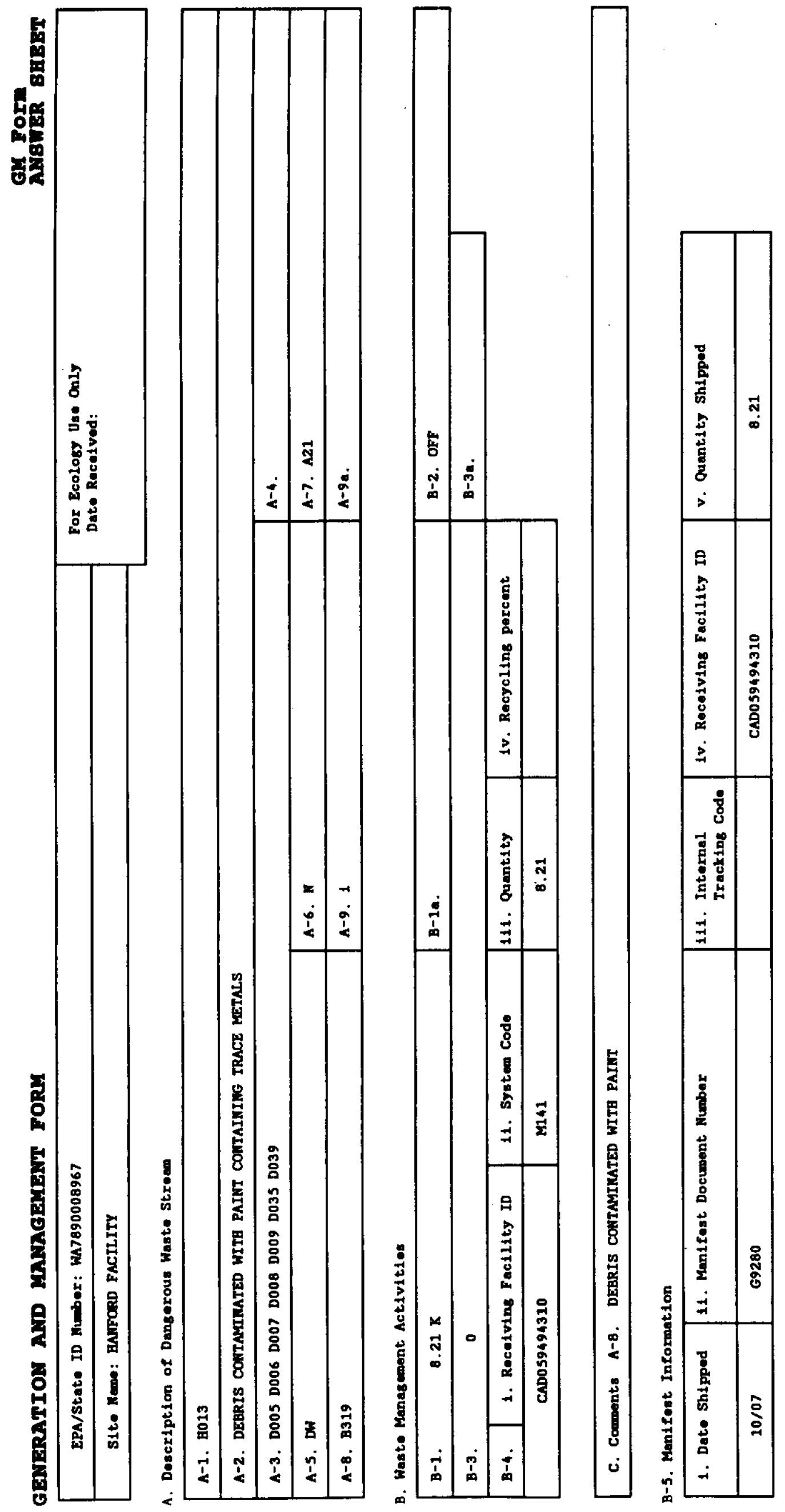




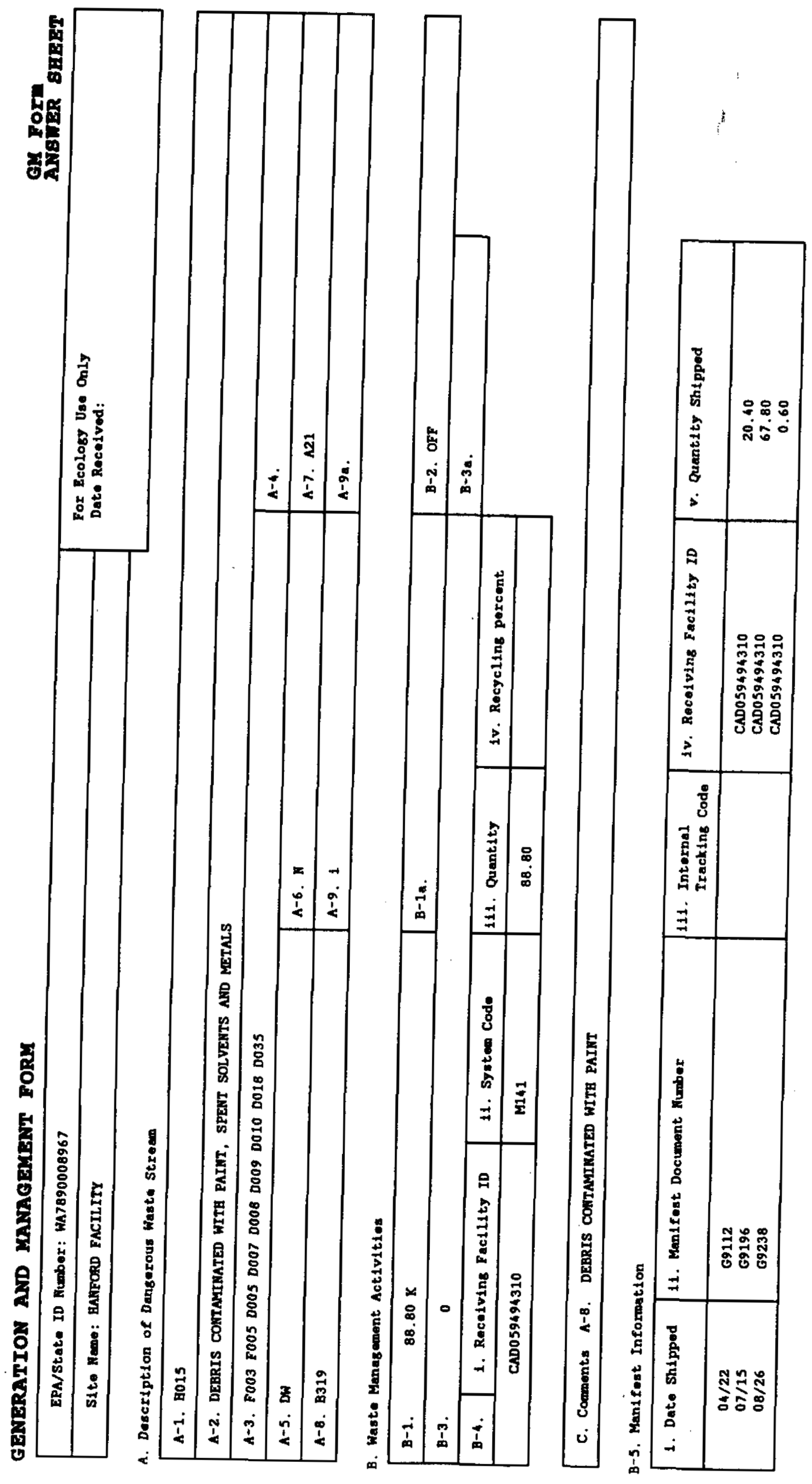




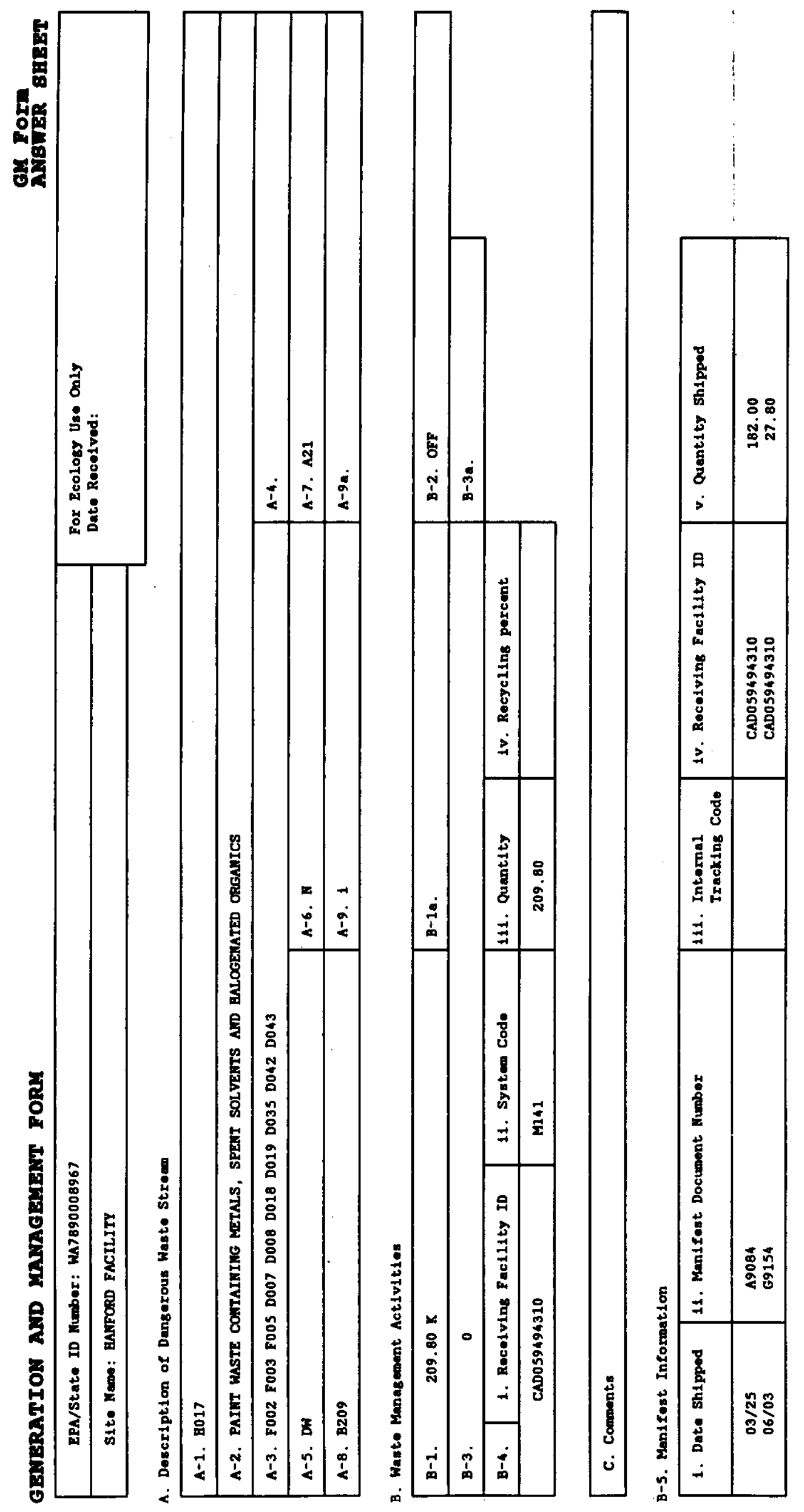




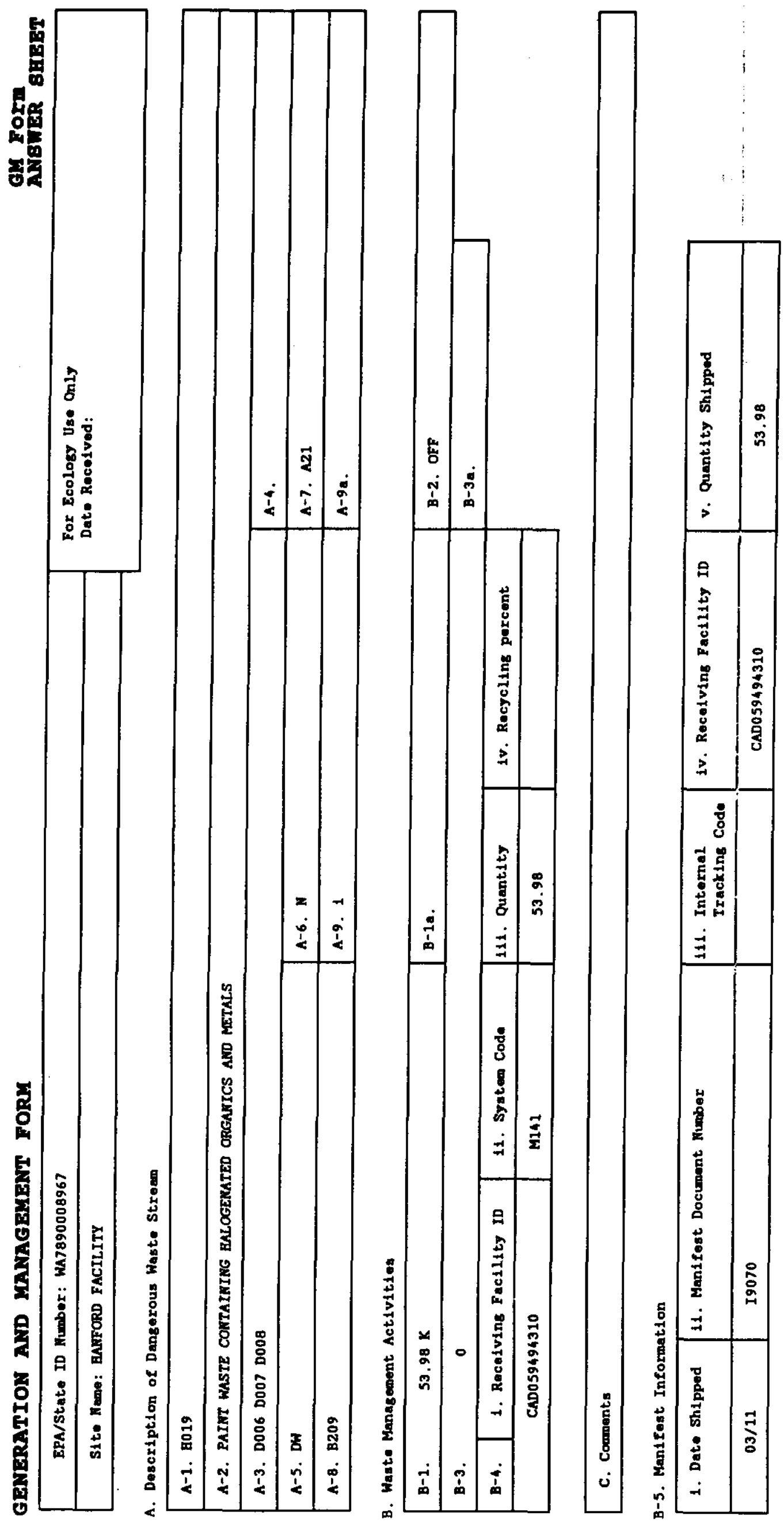



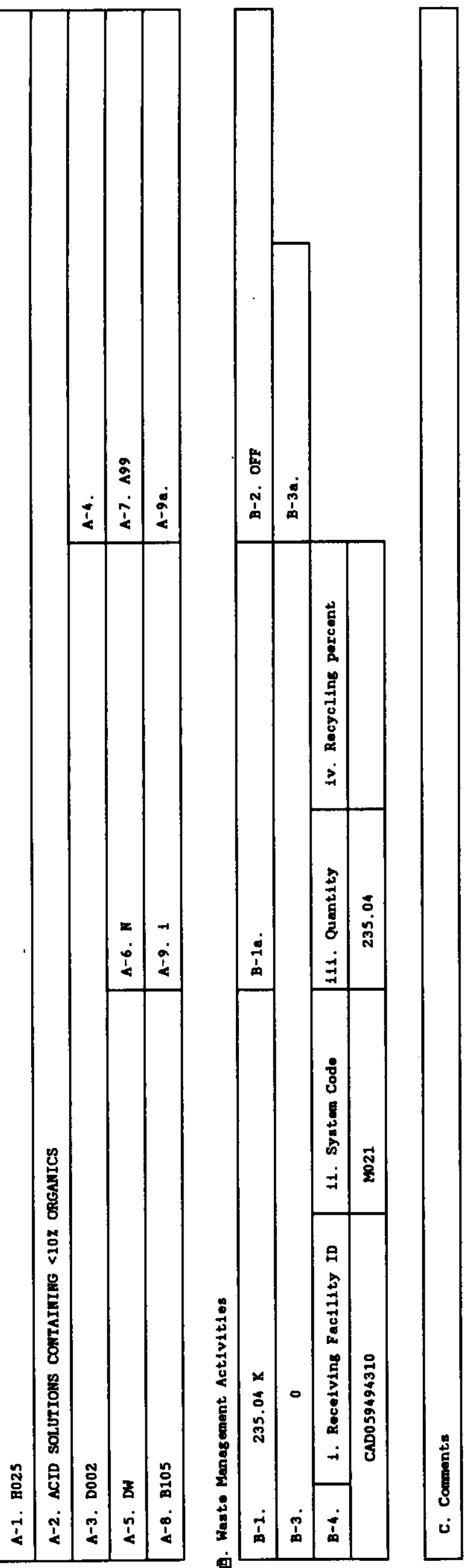

$\stackrel{8}{8}$
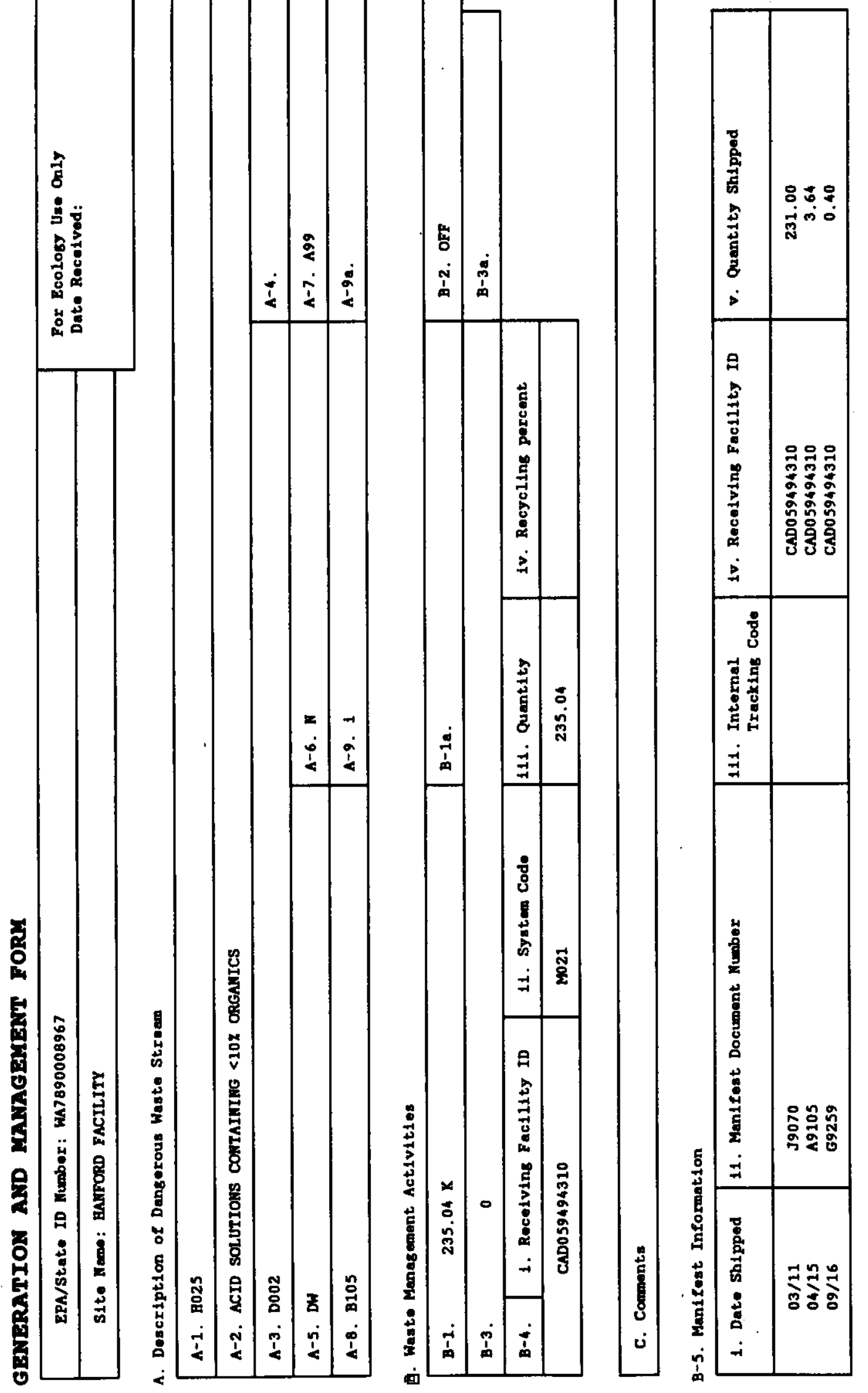
量
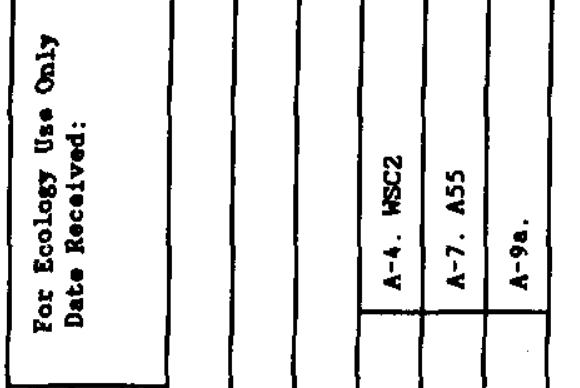

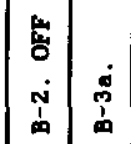
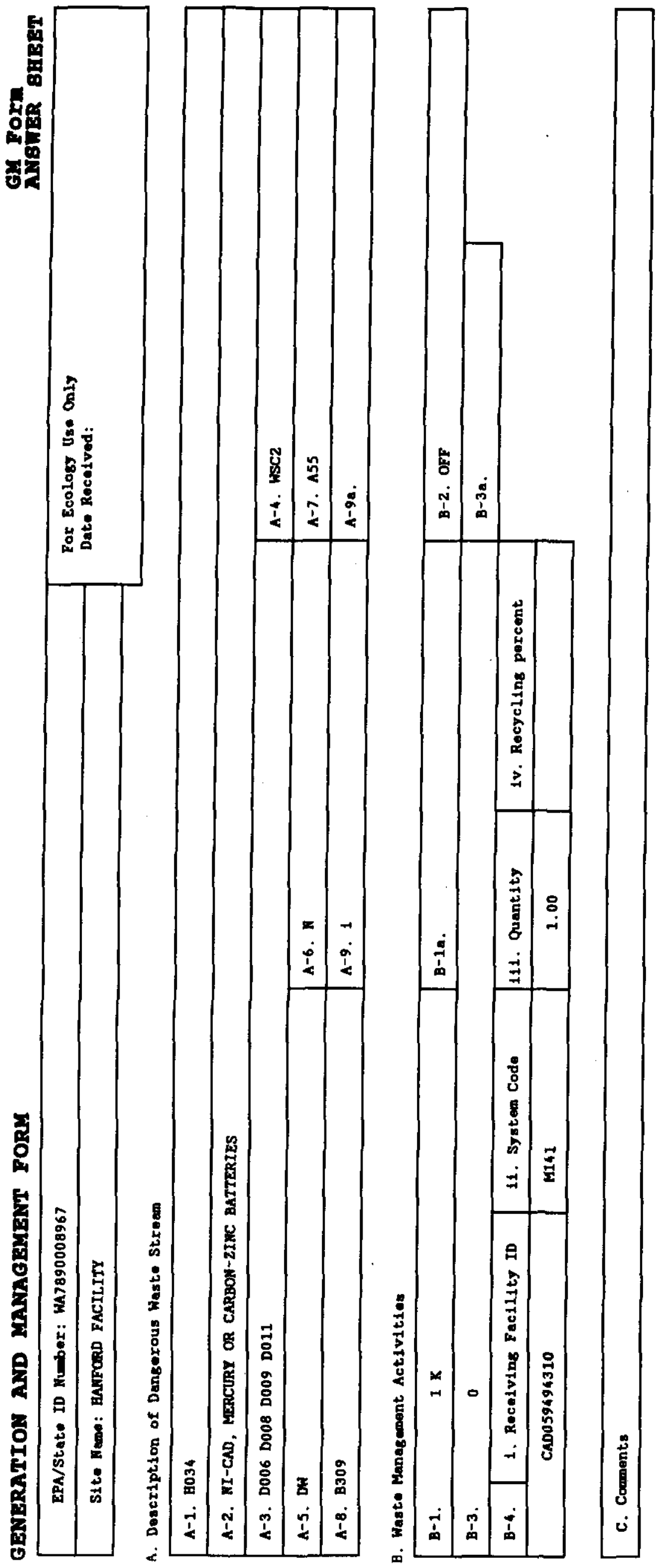

$=$
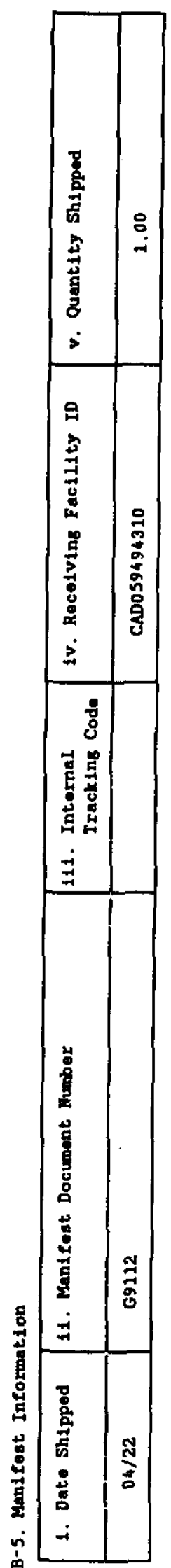


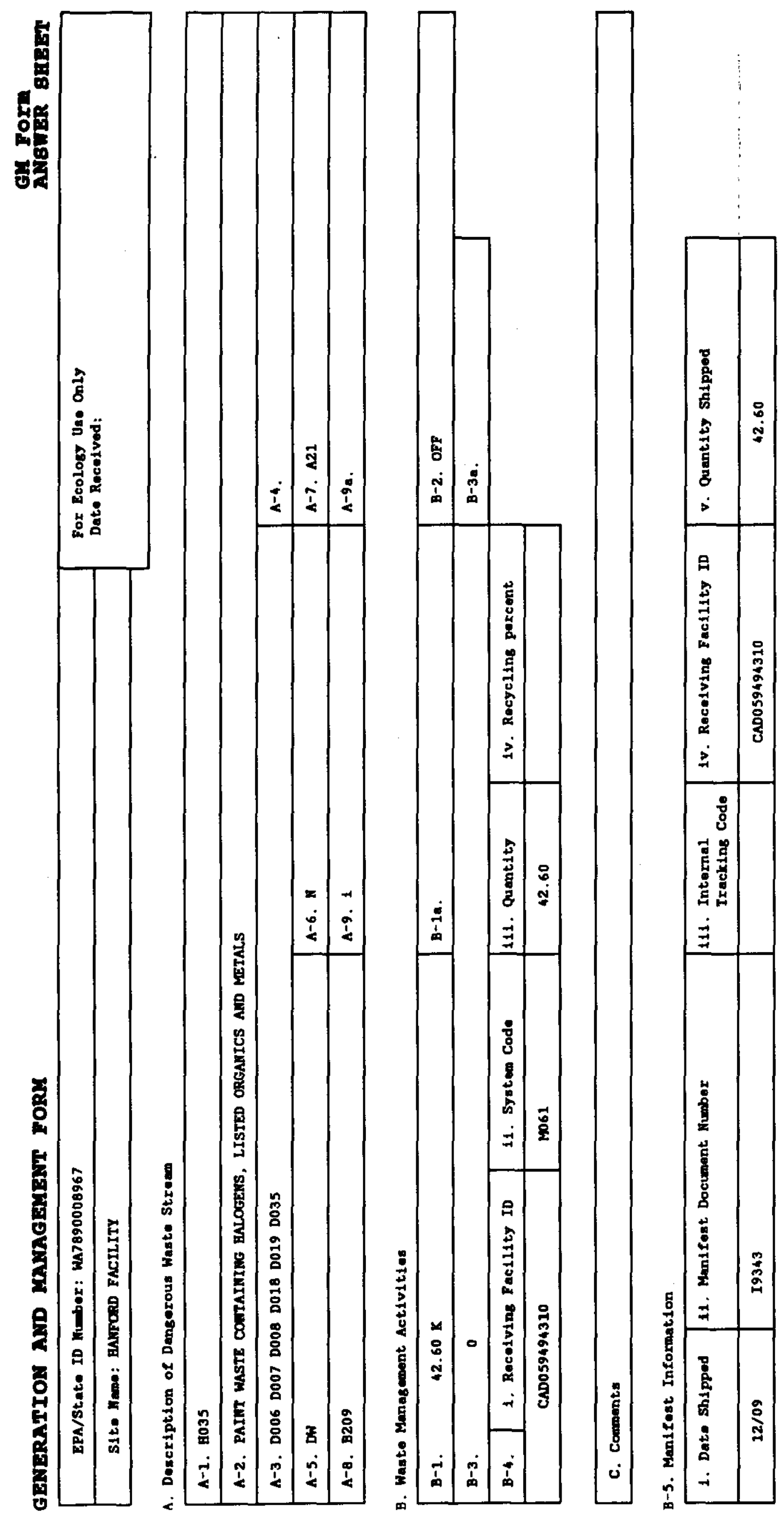




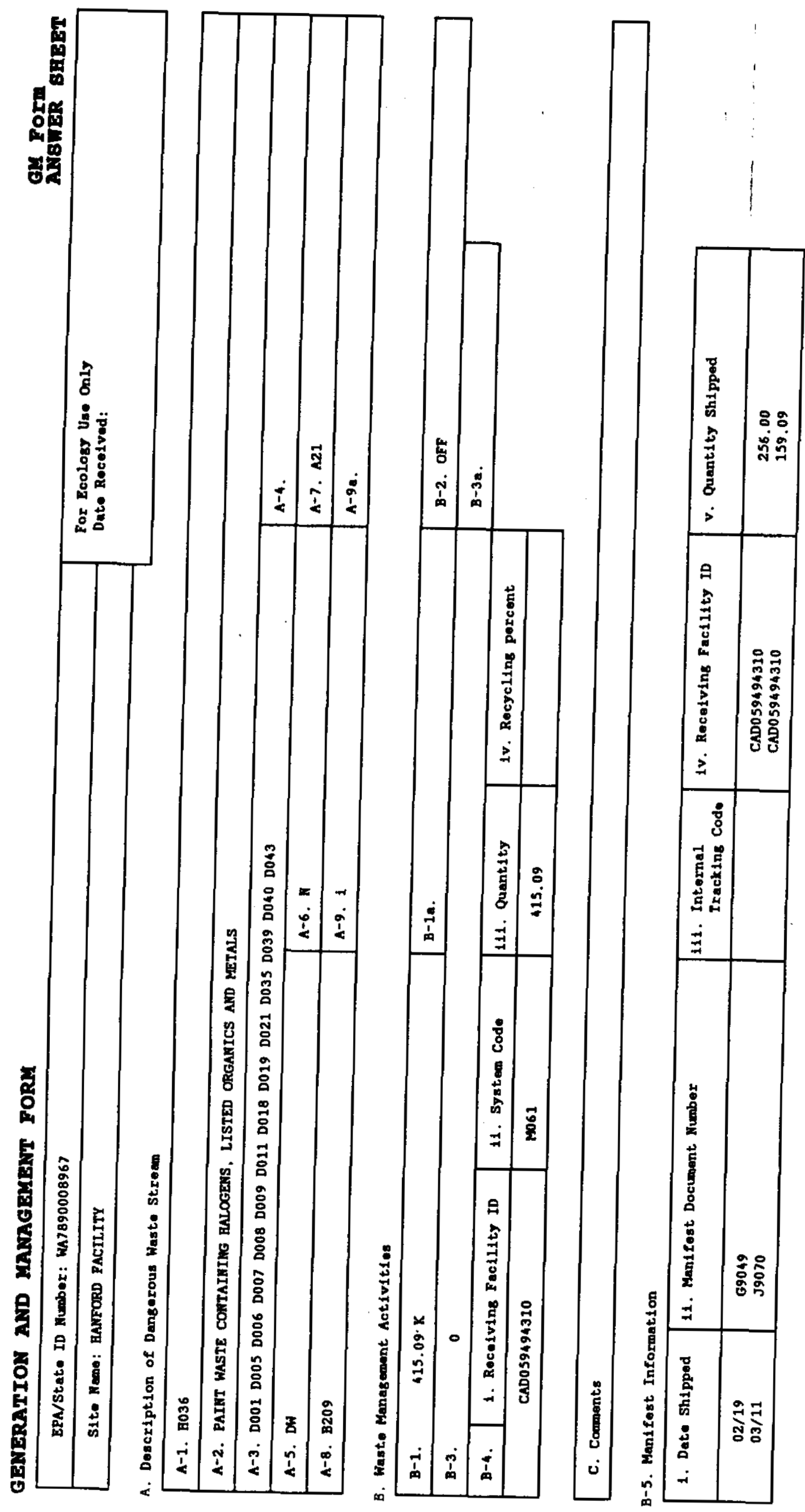




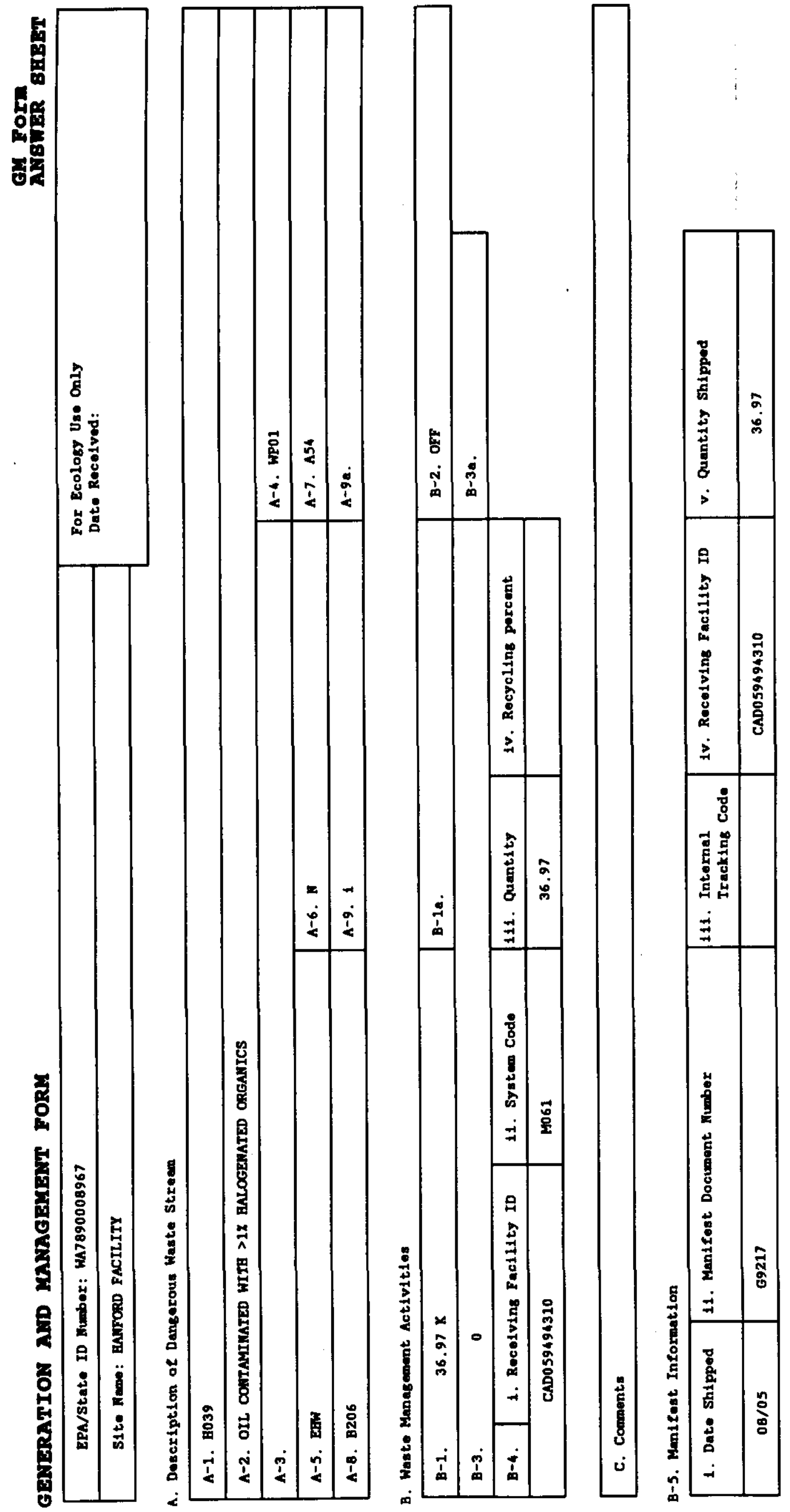




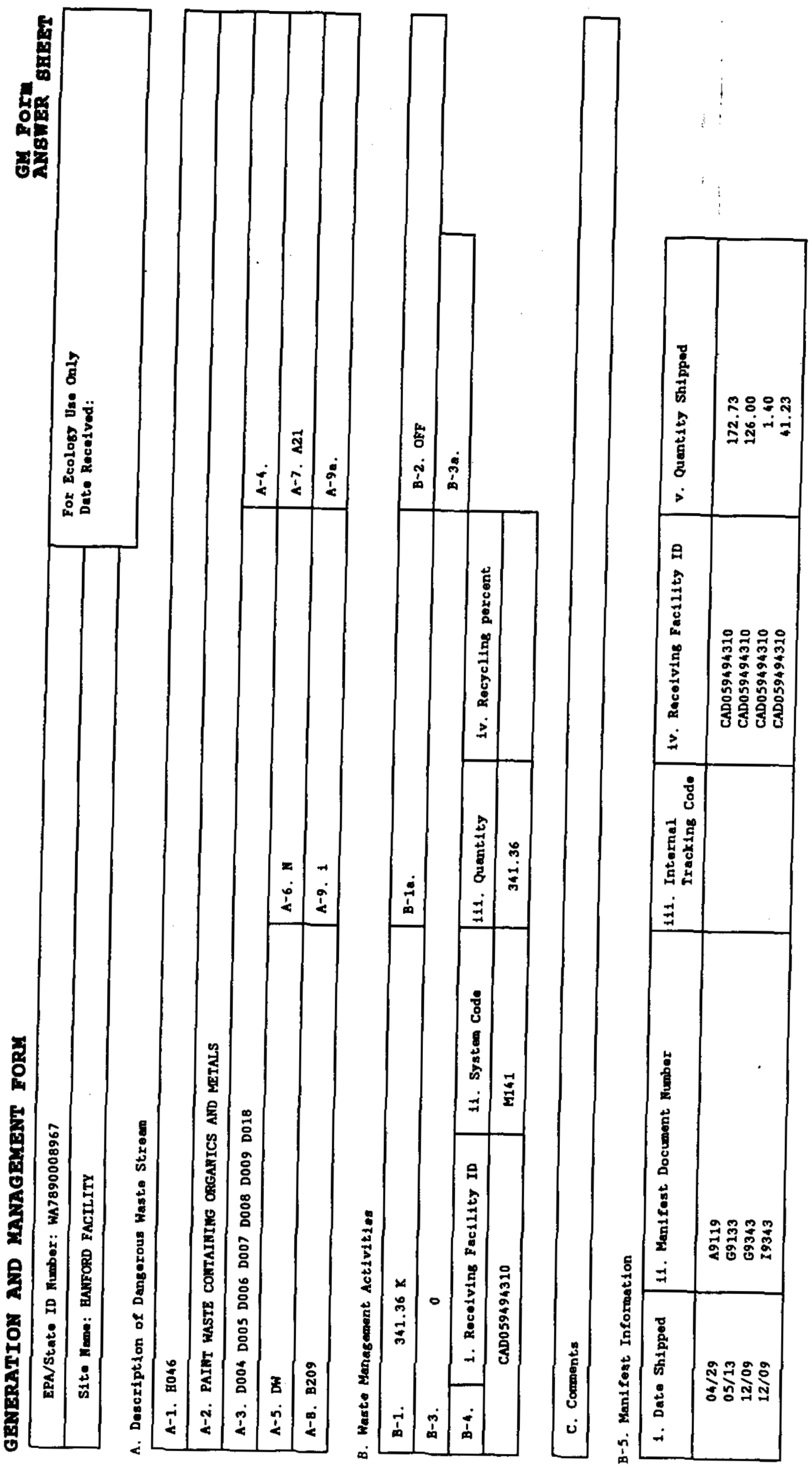

홍 


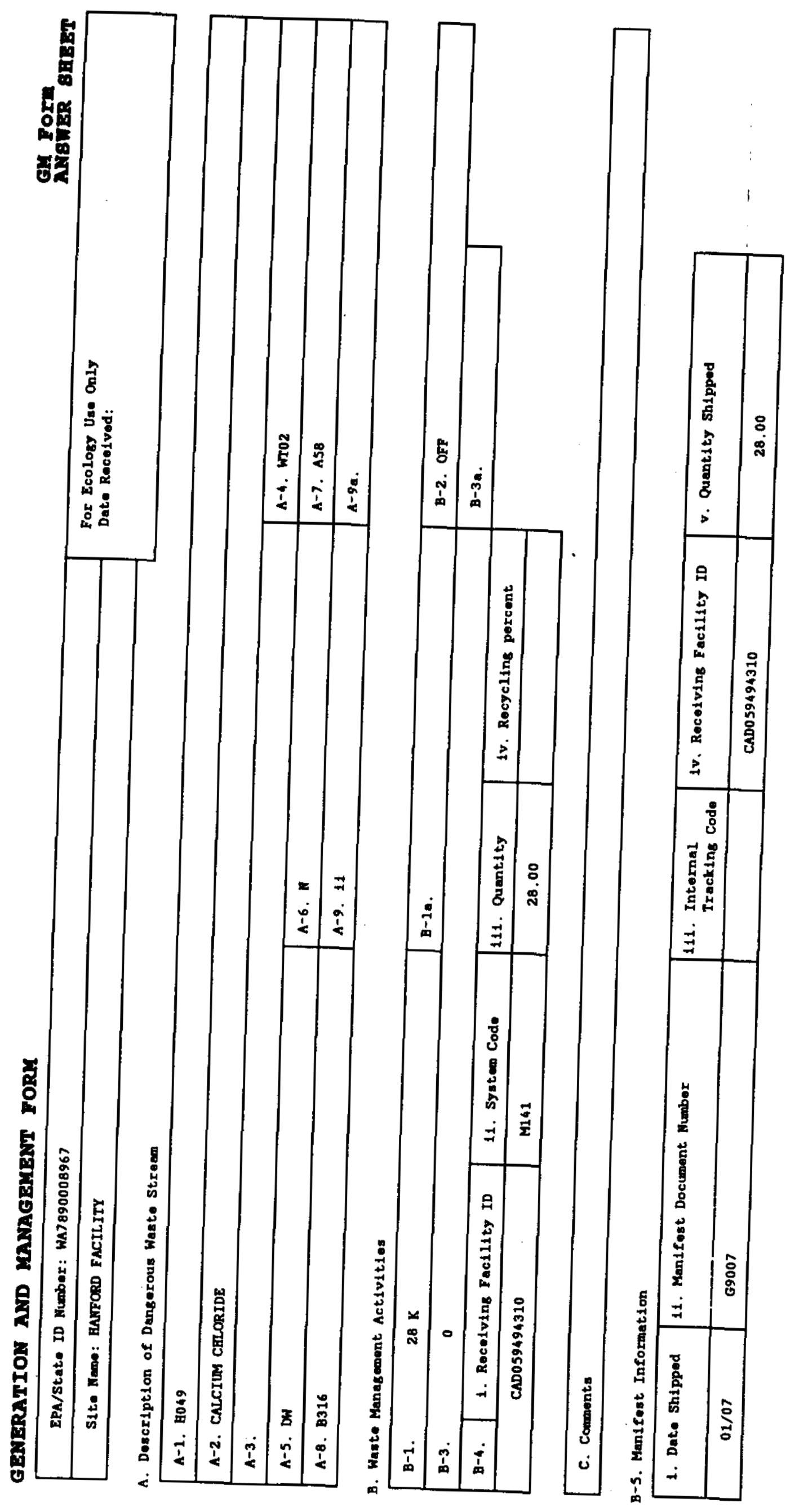




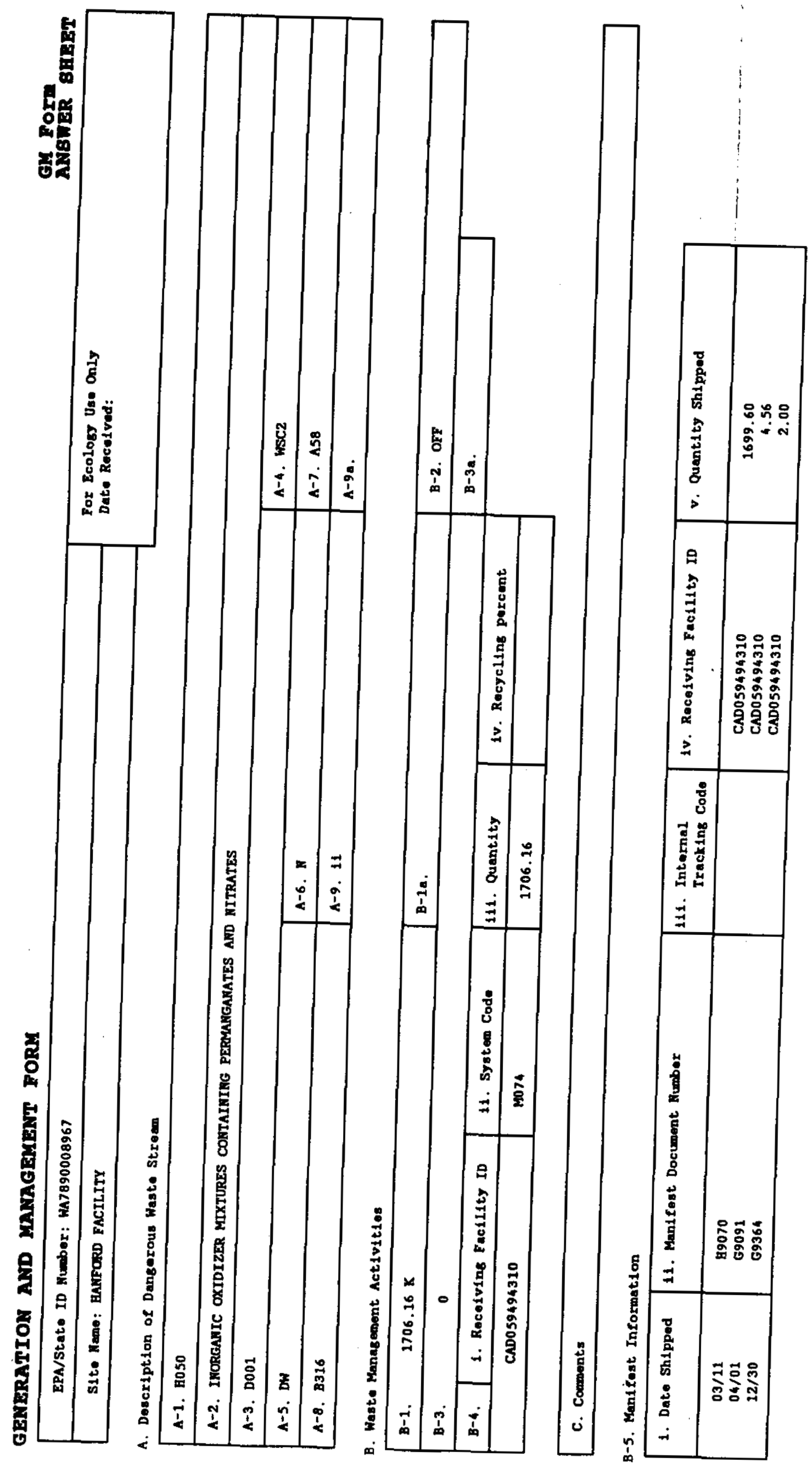




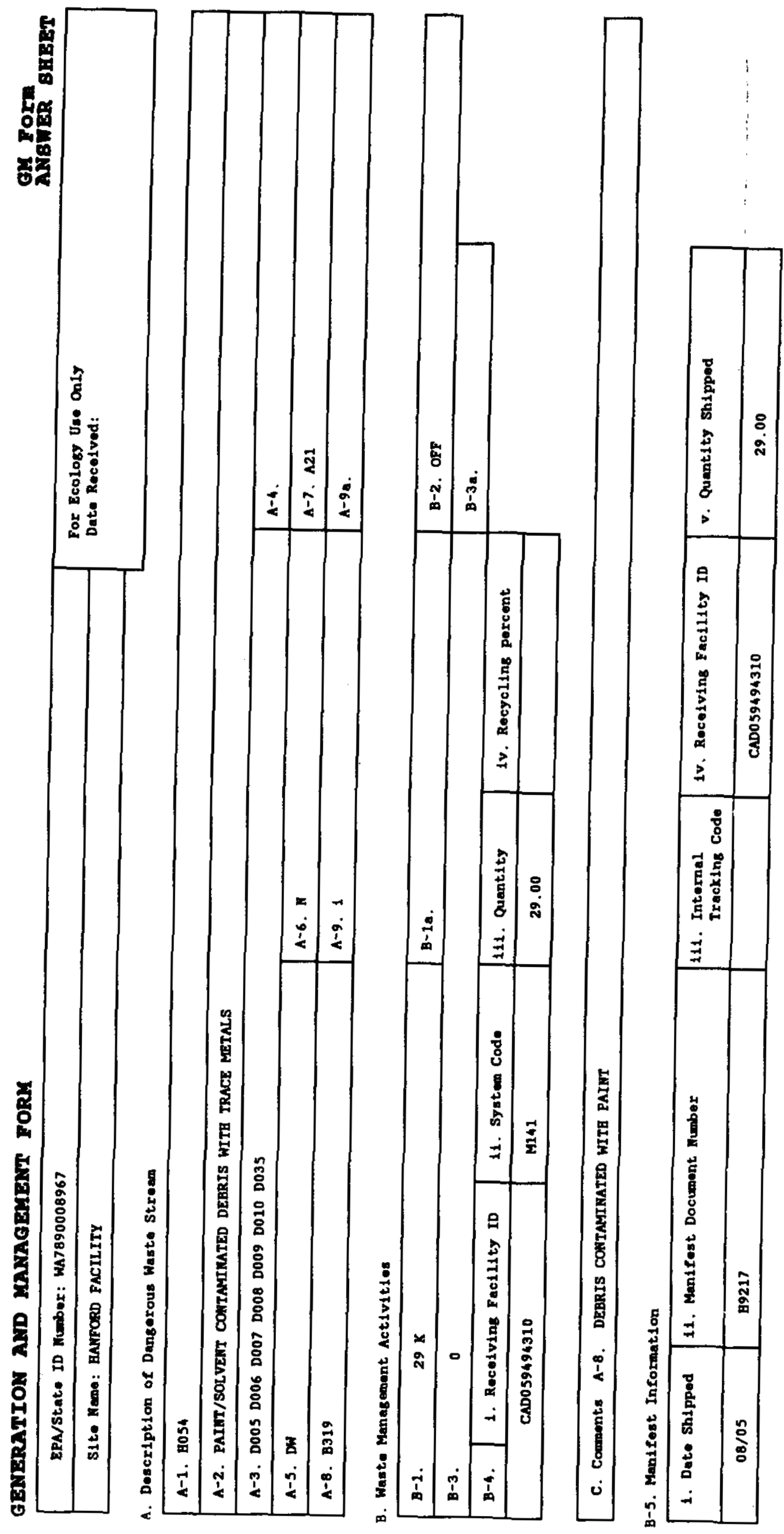




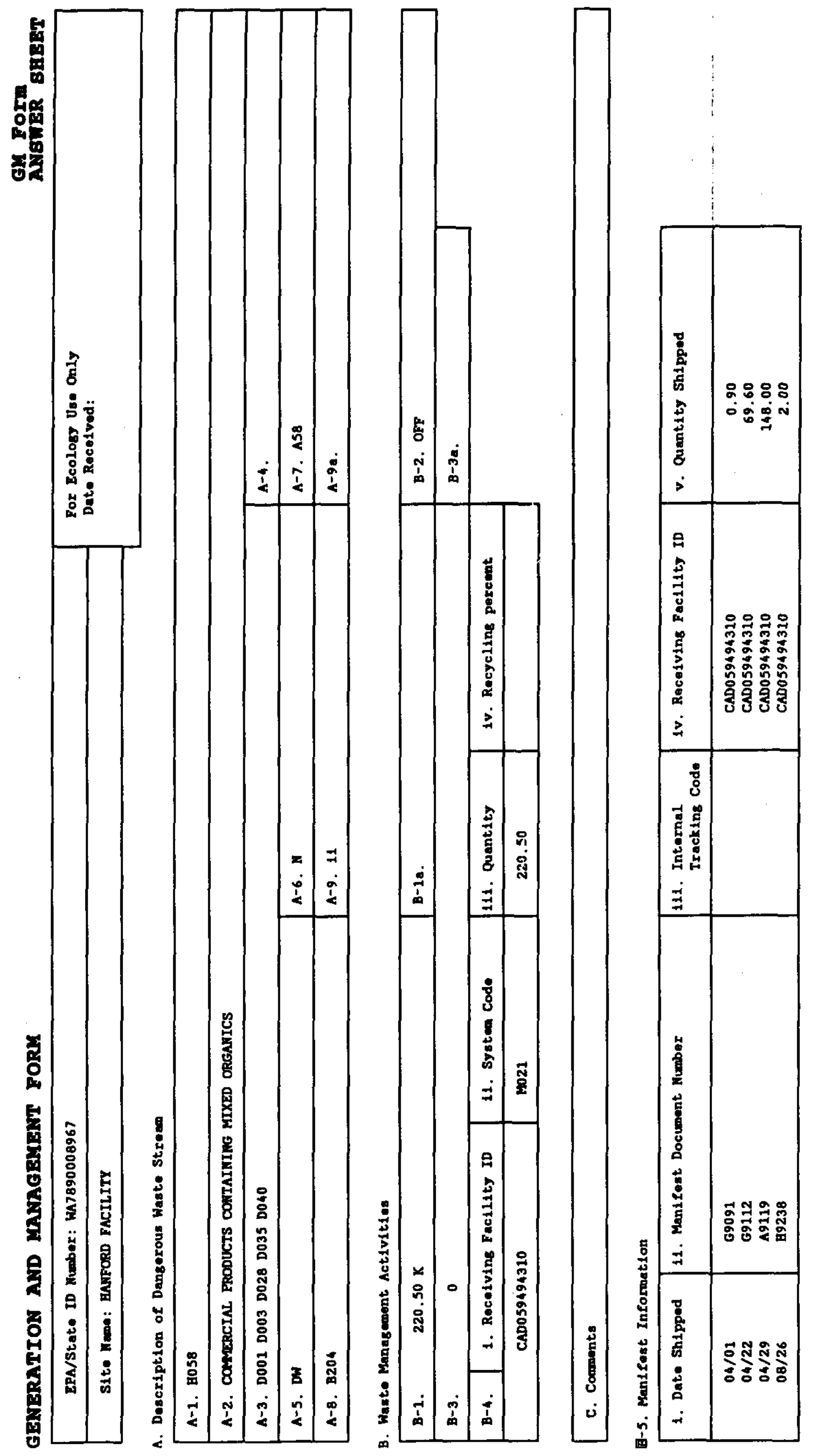




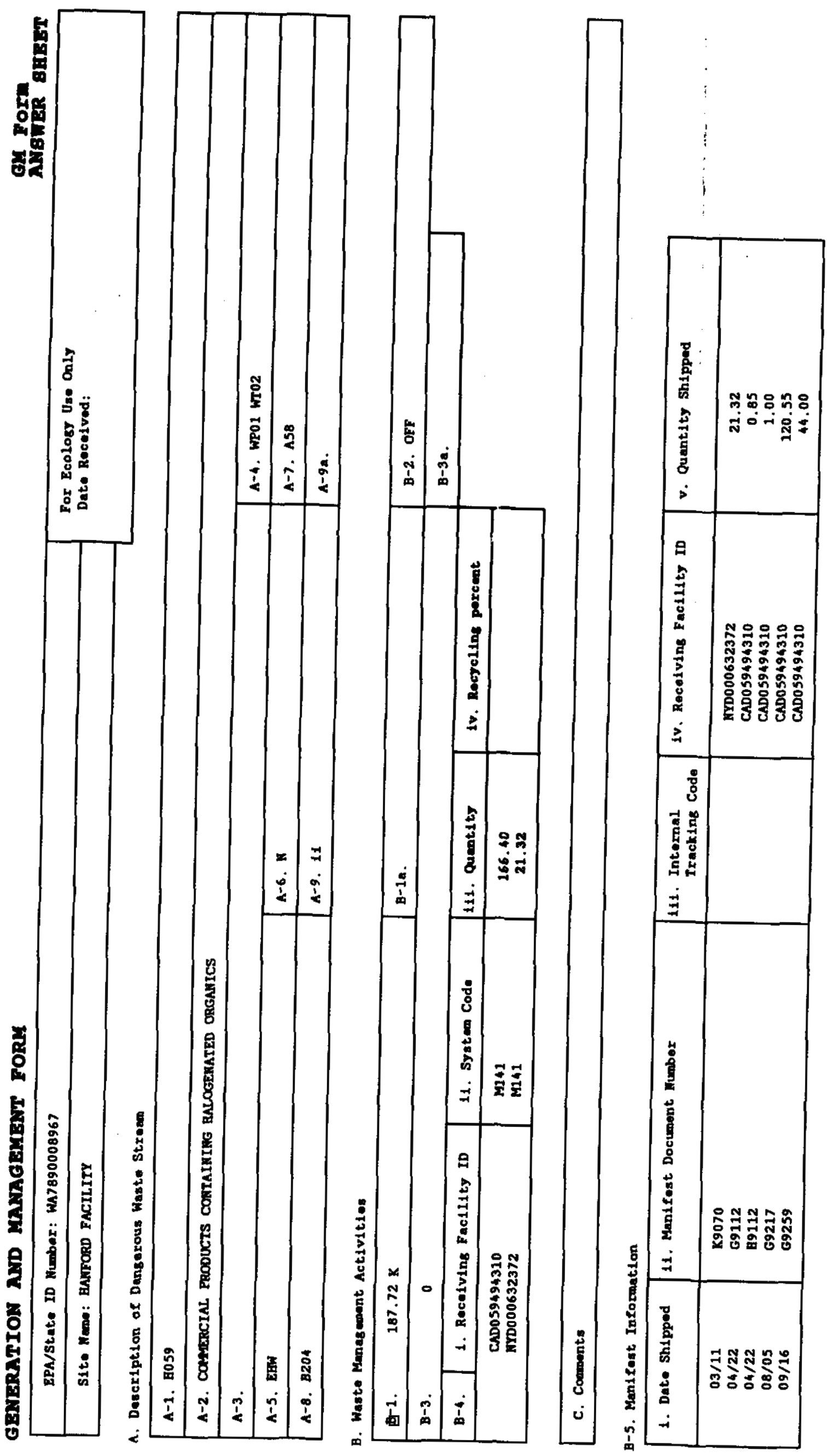




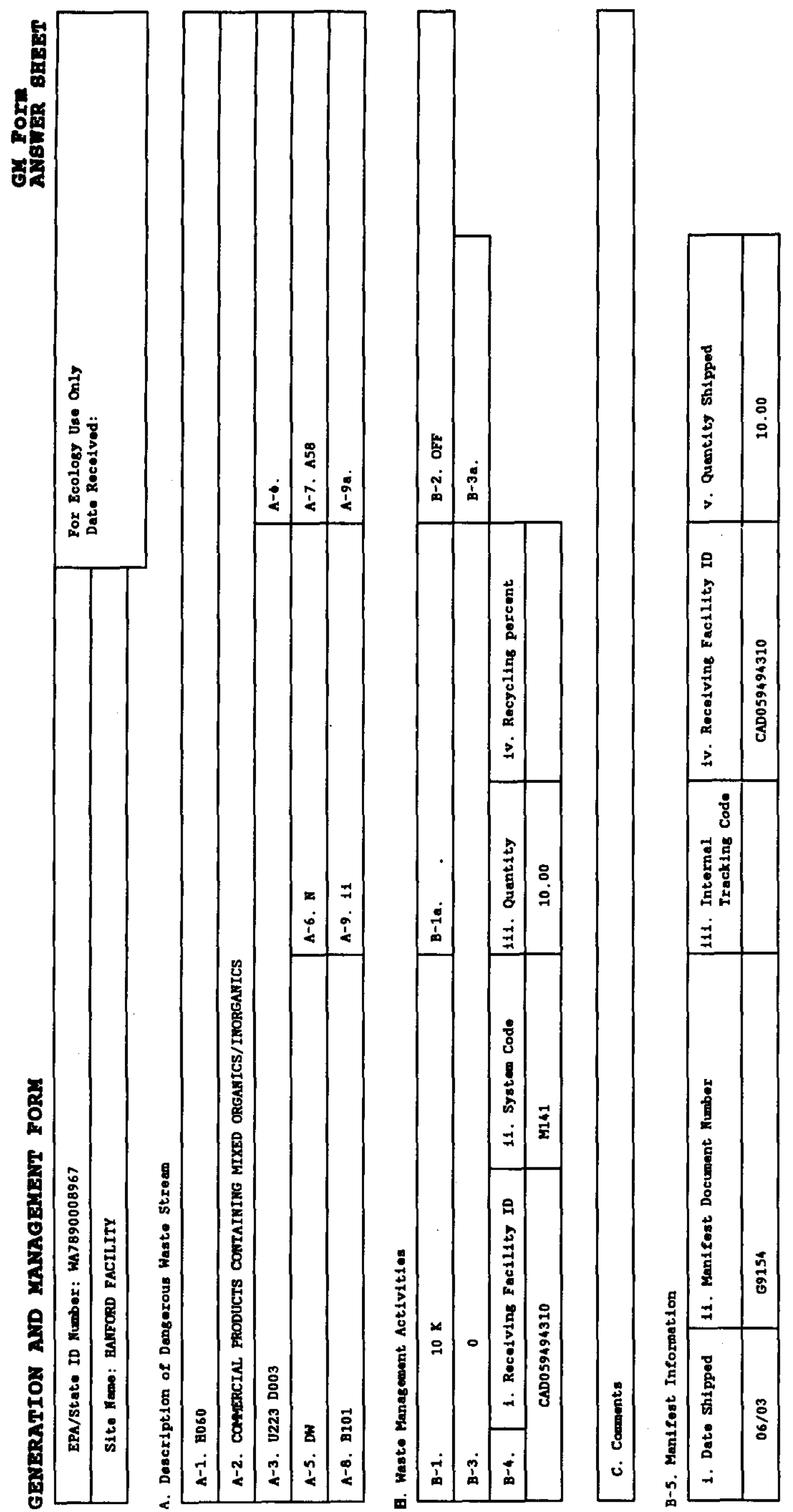



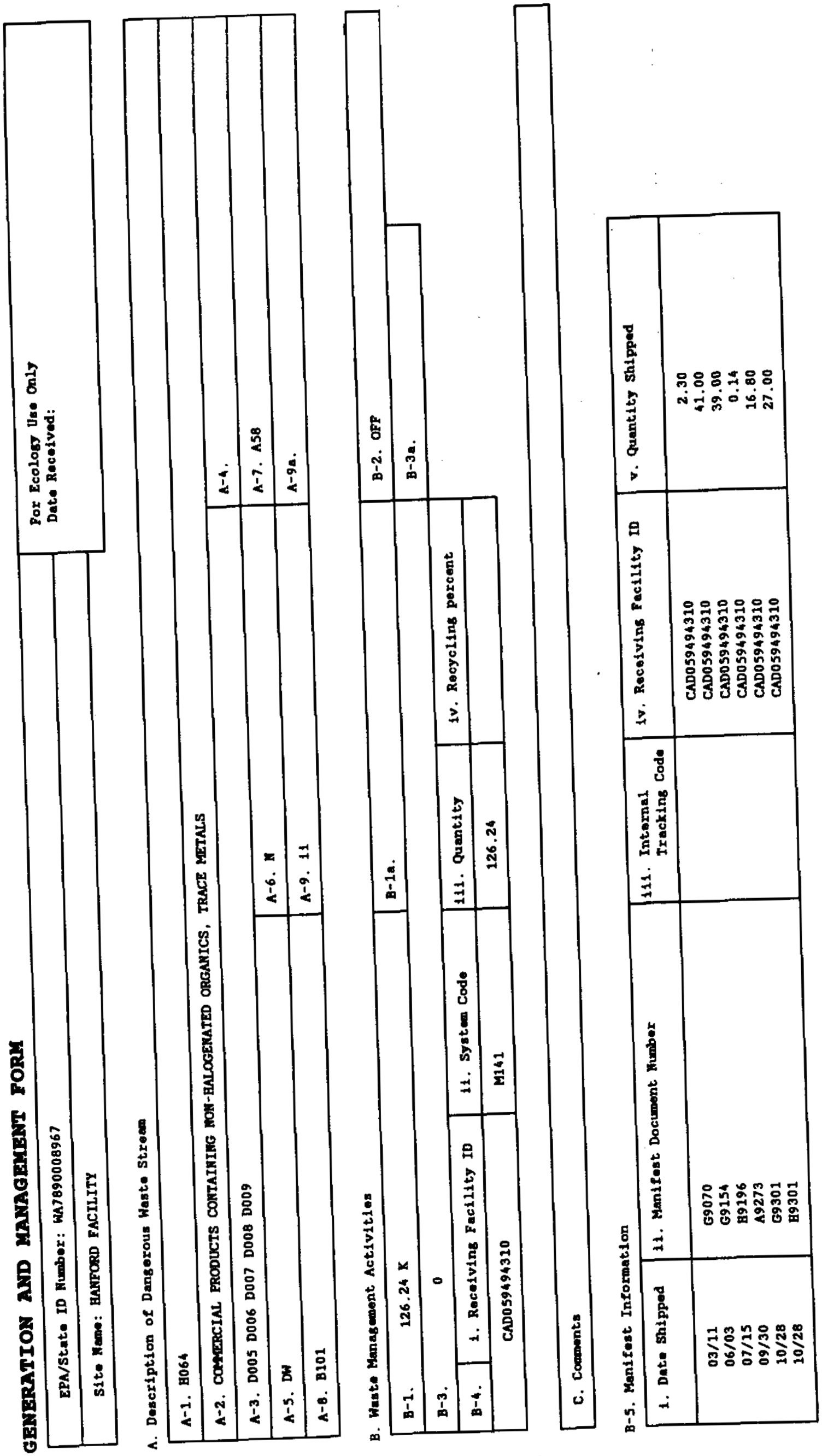


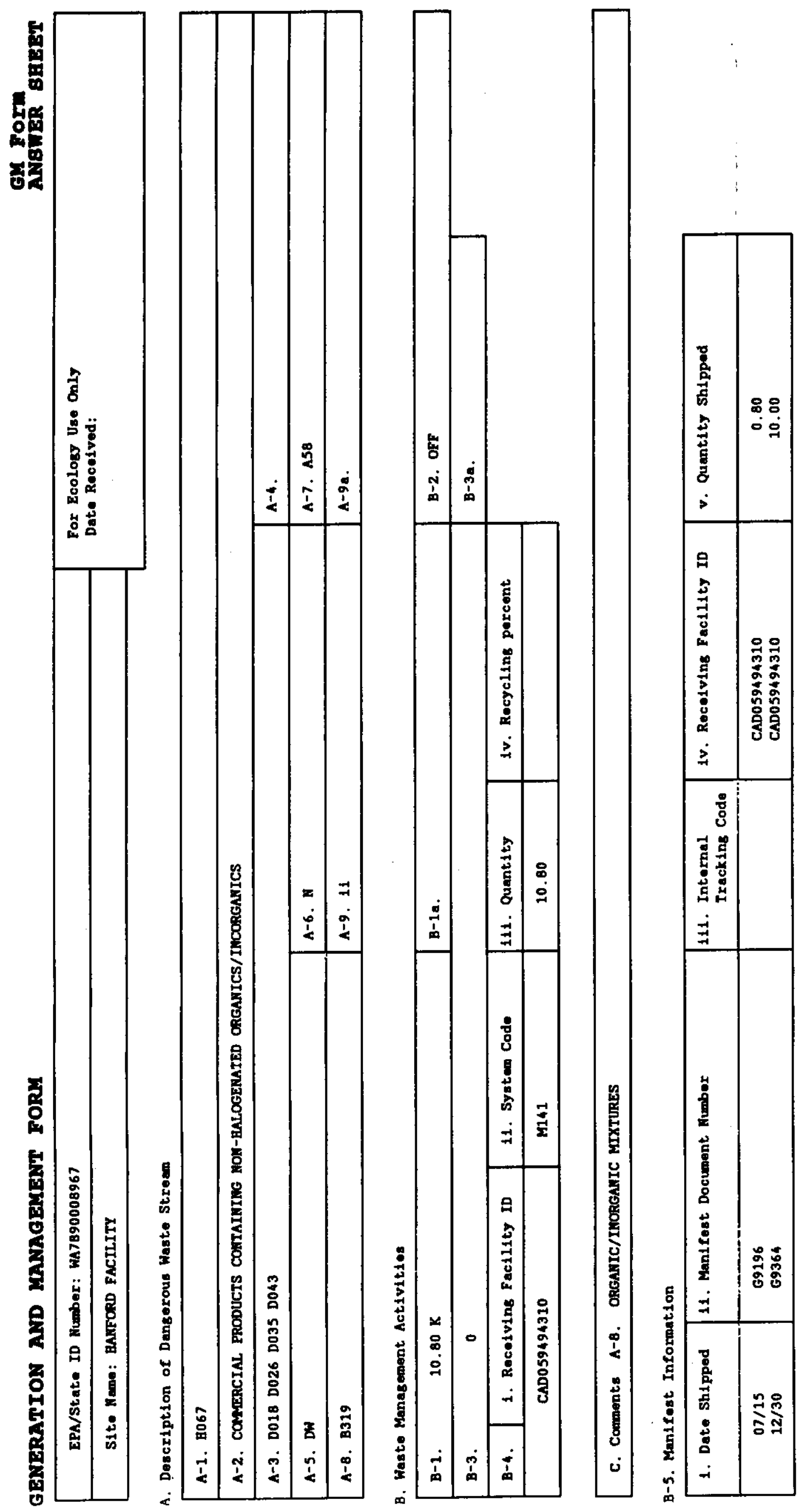




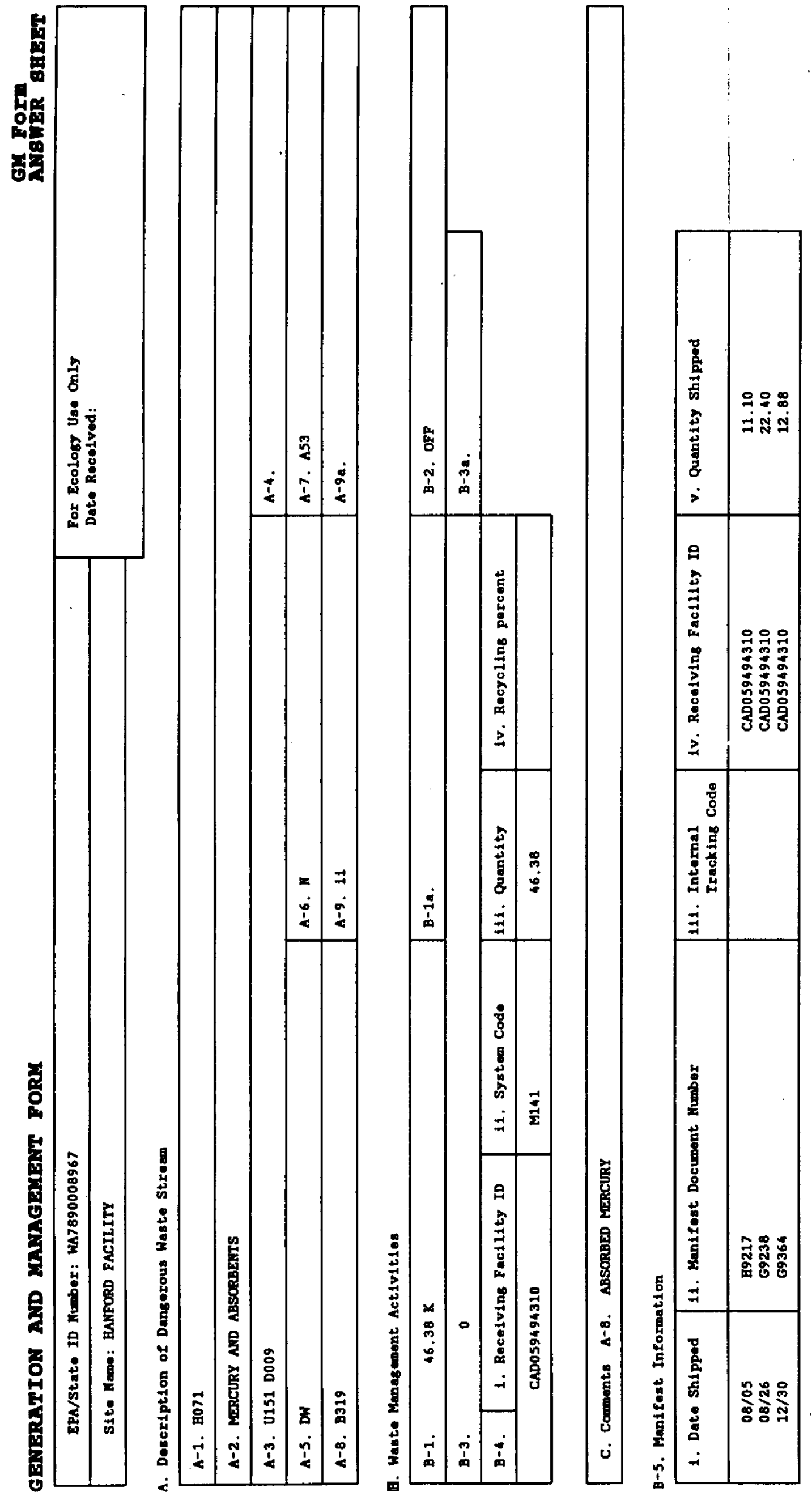




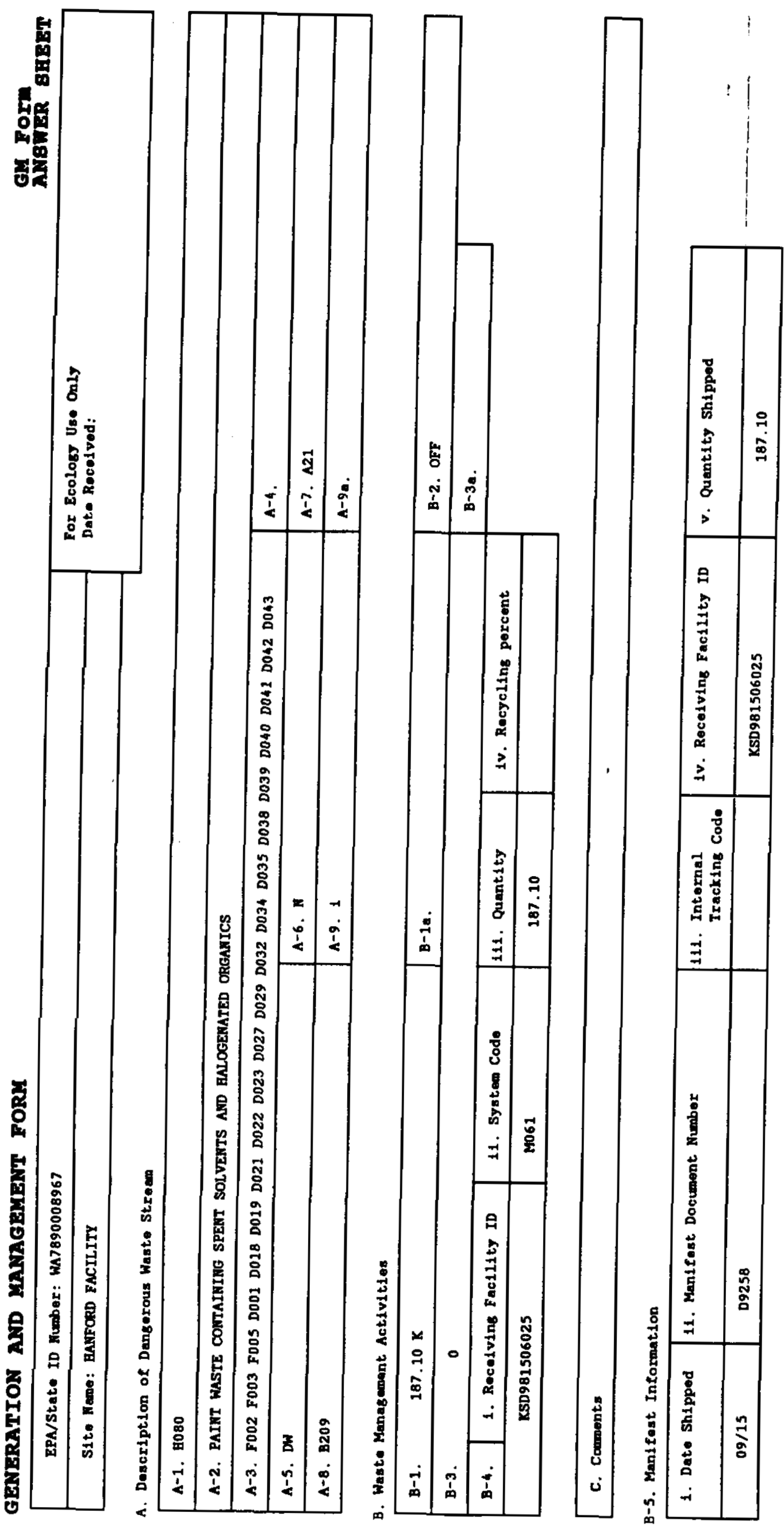




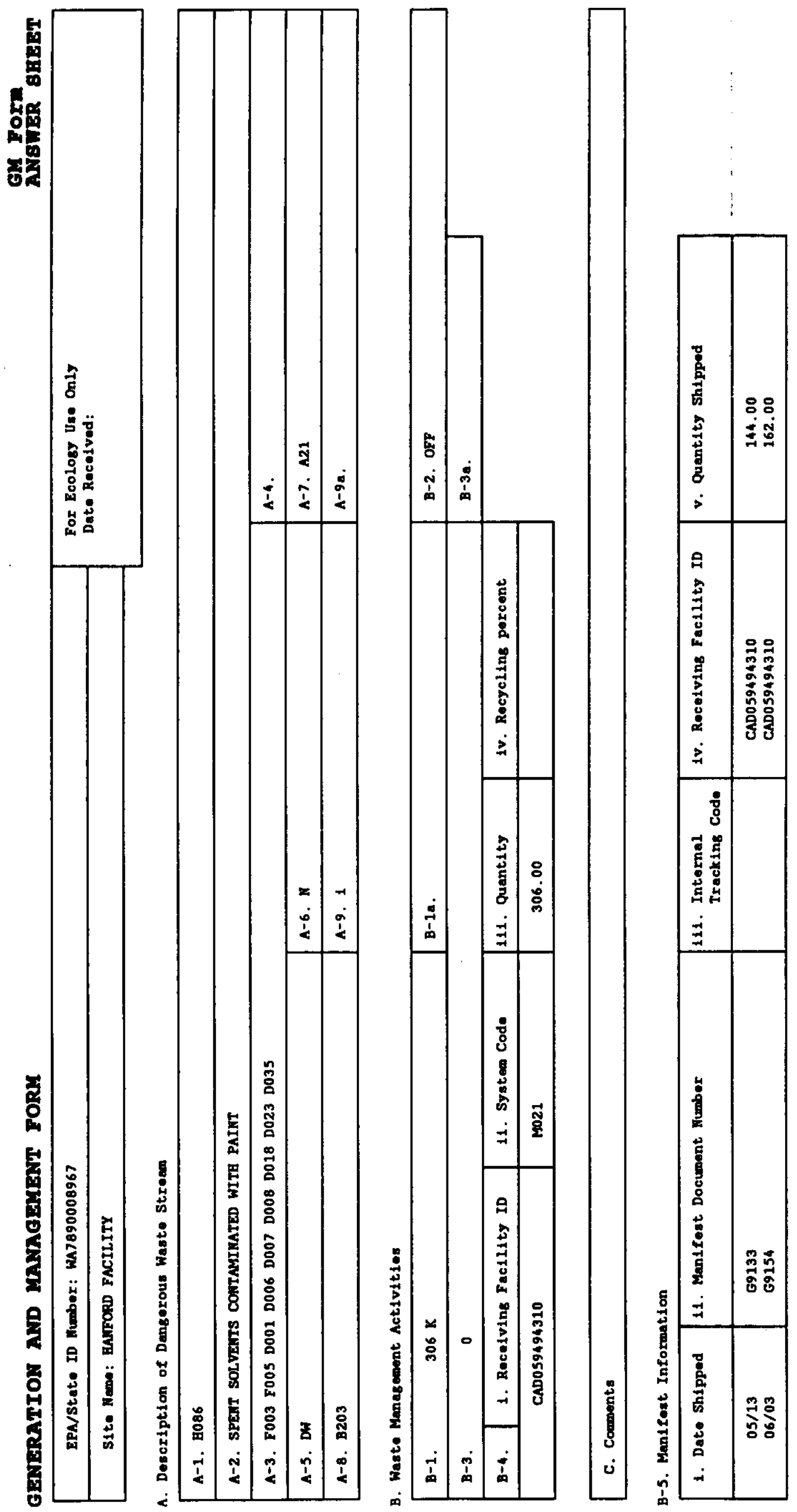




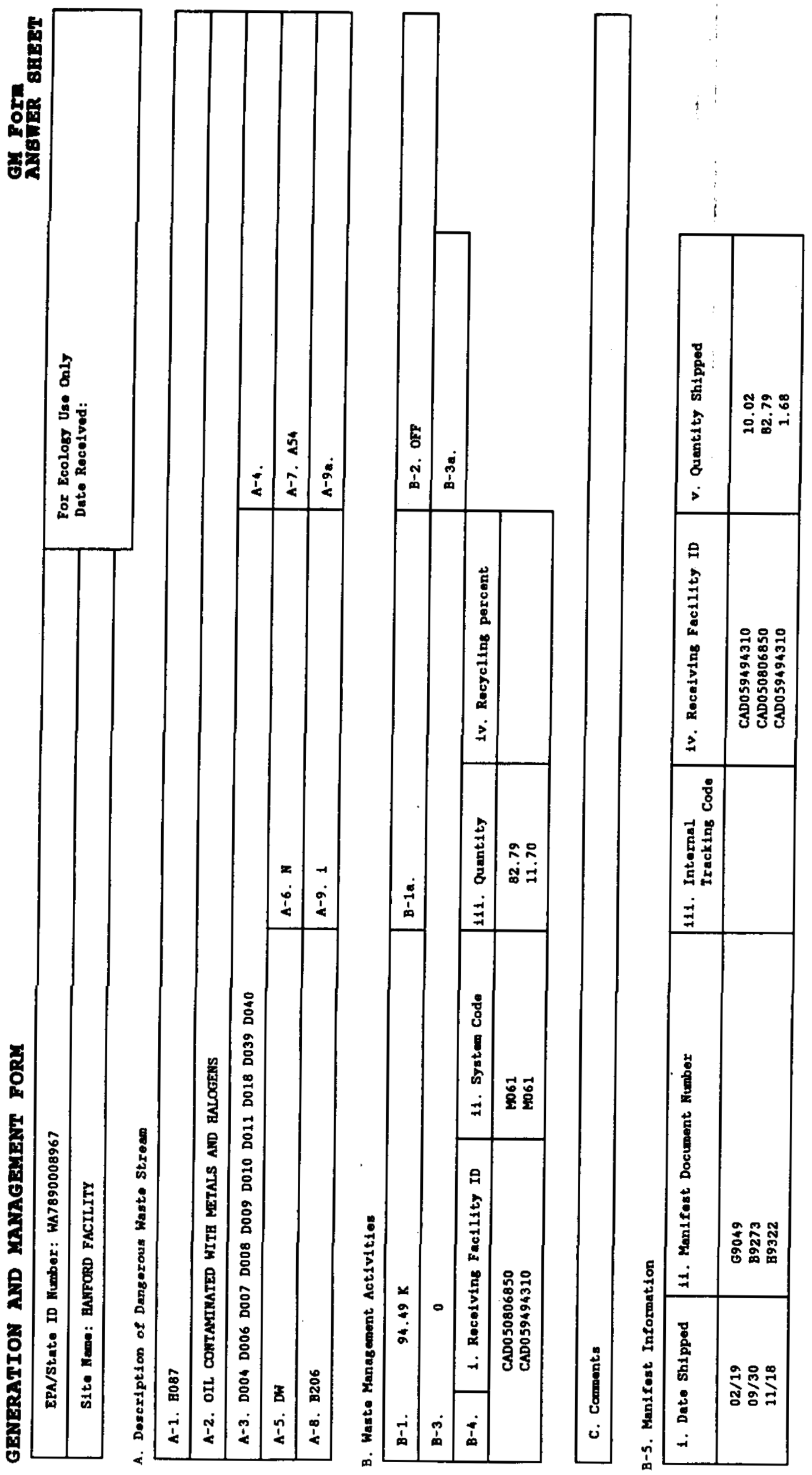




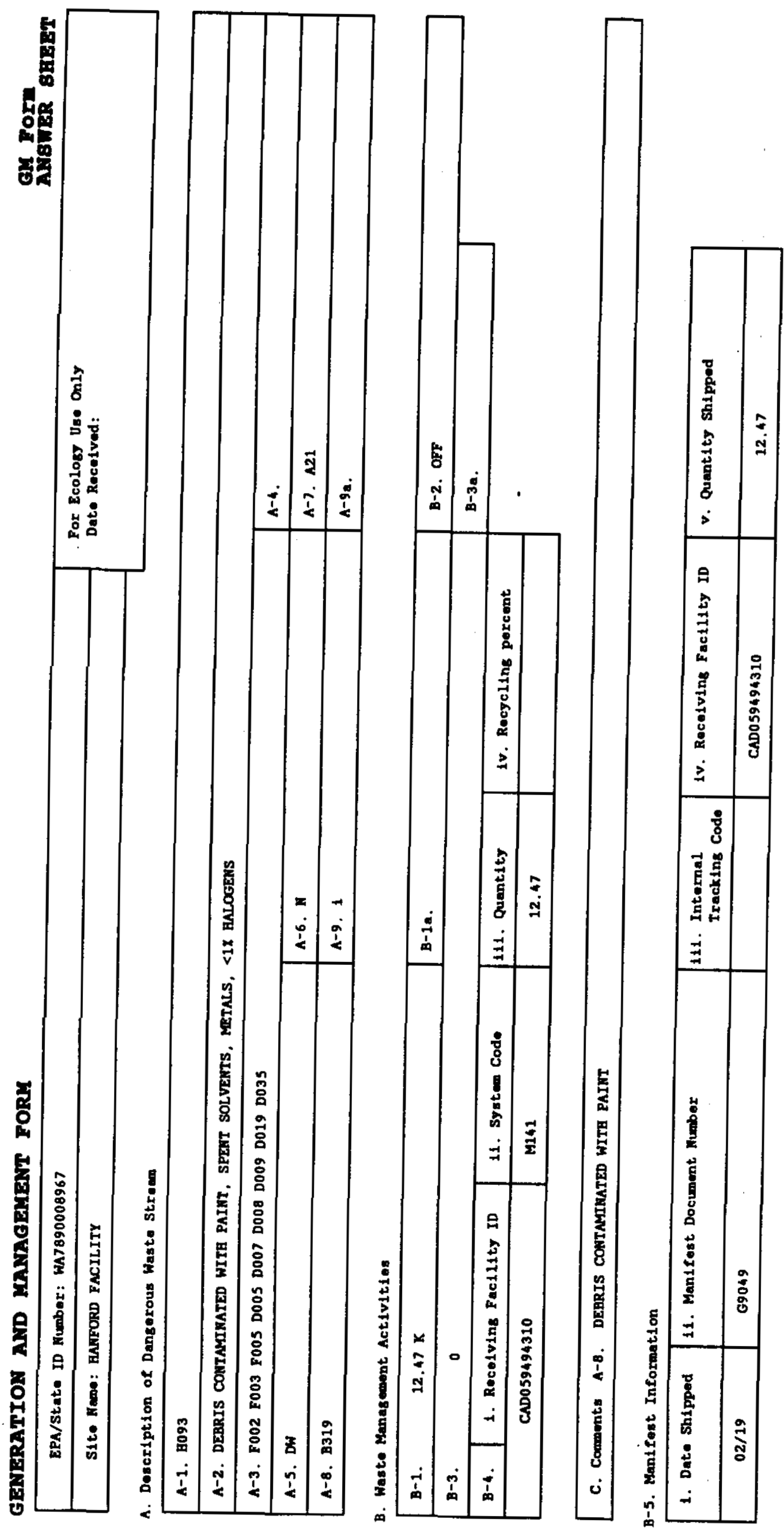




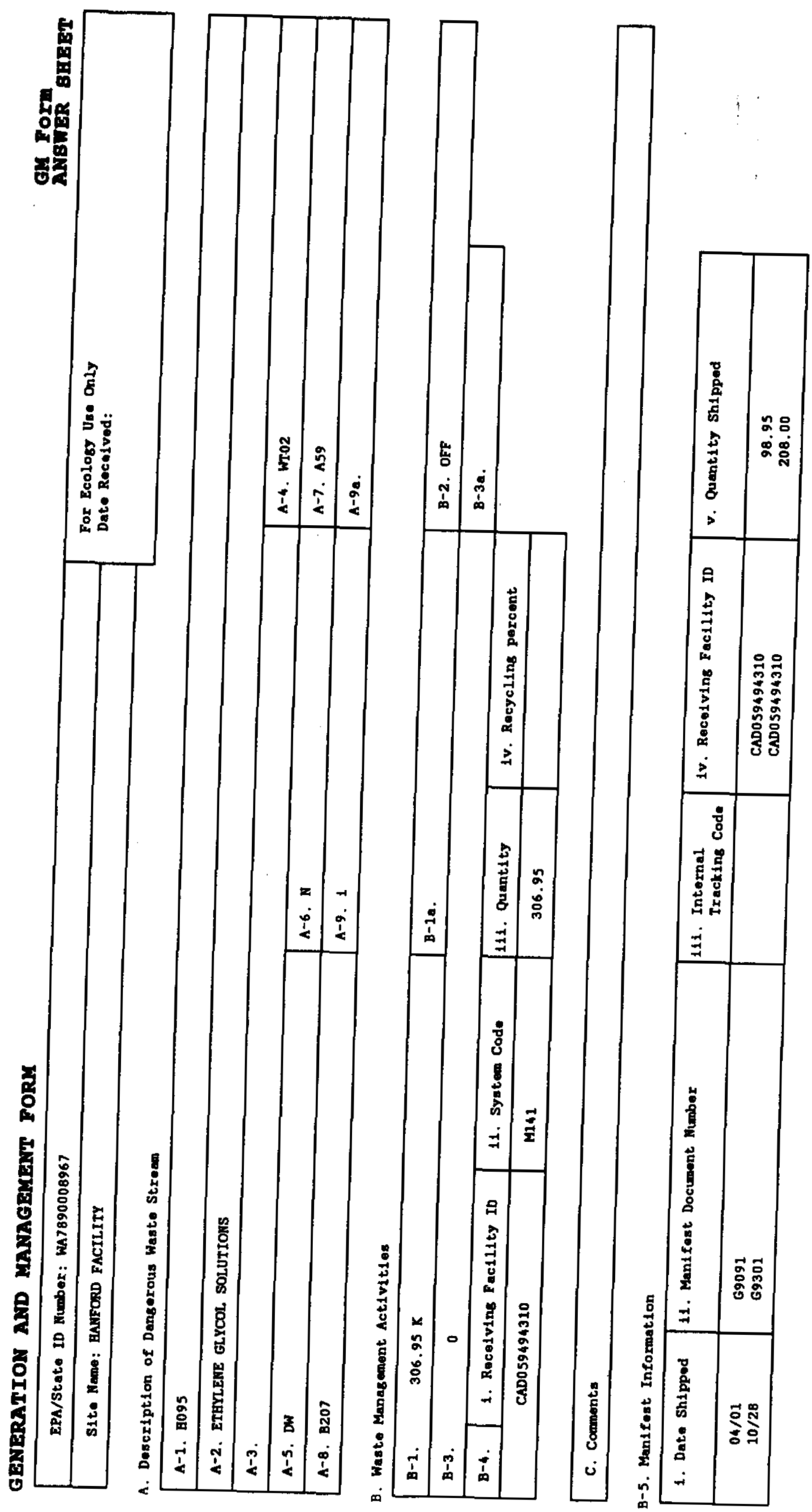



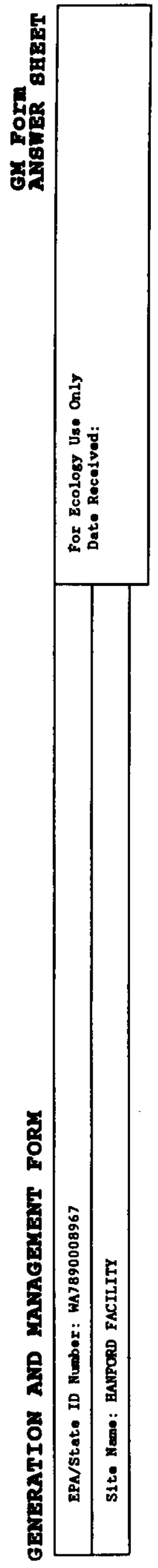
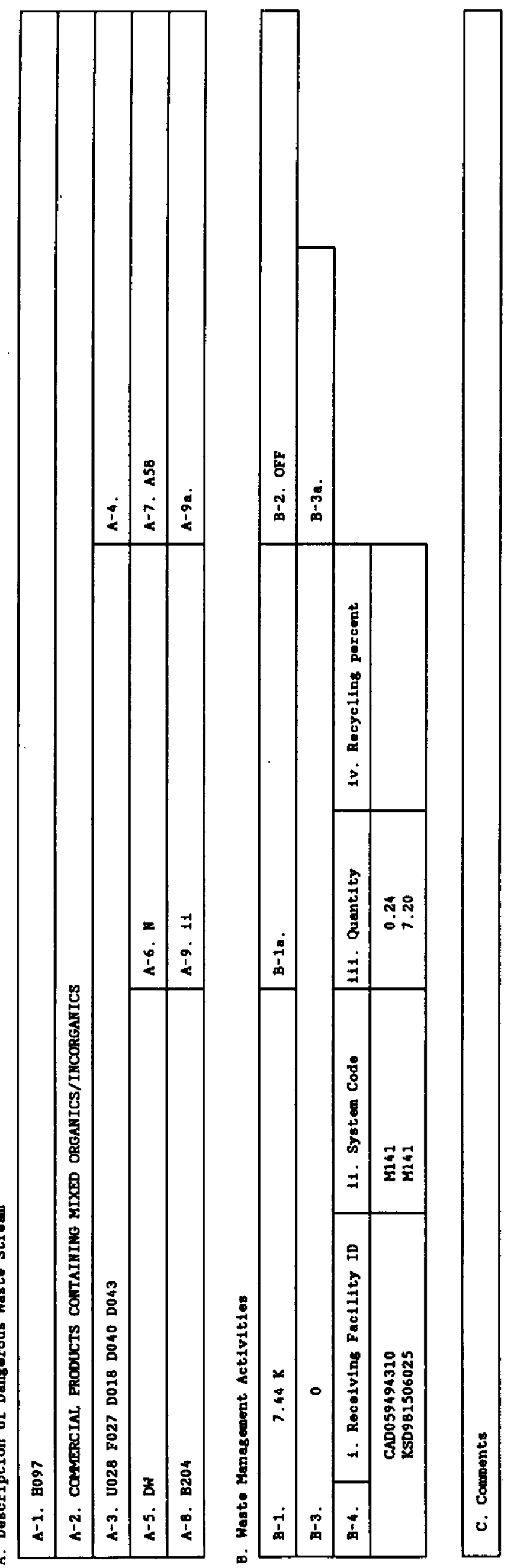

:
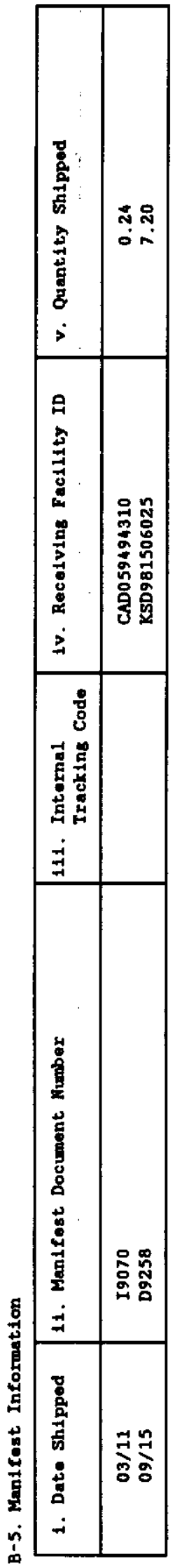

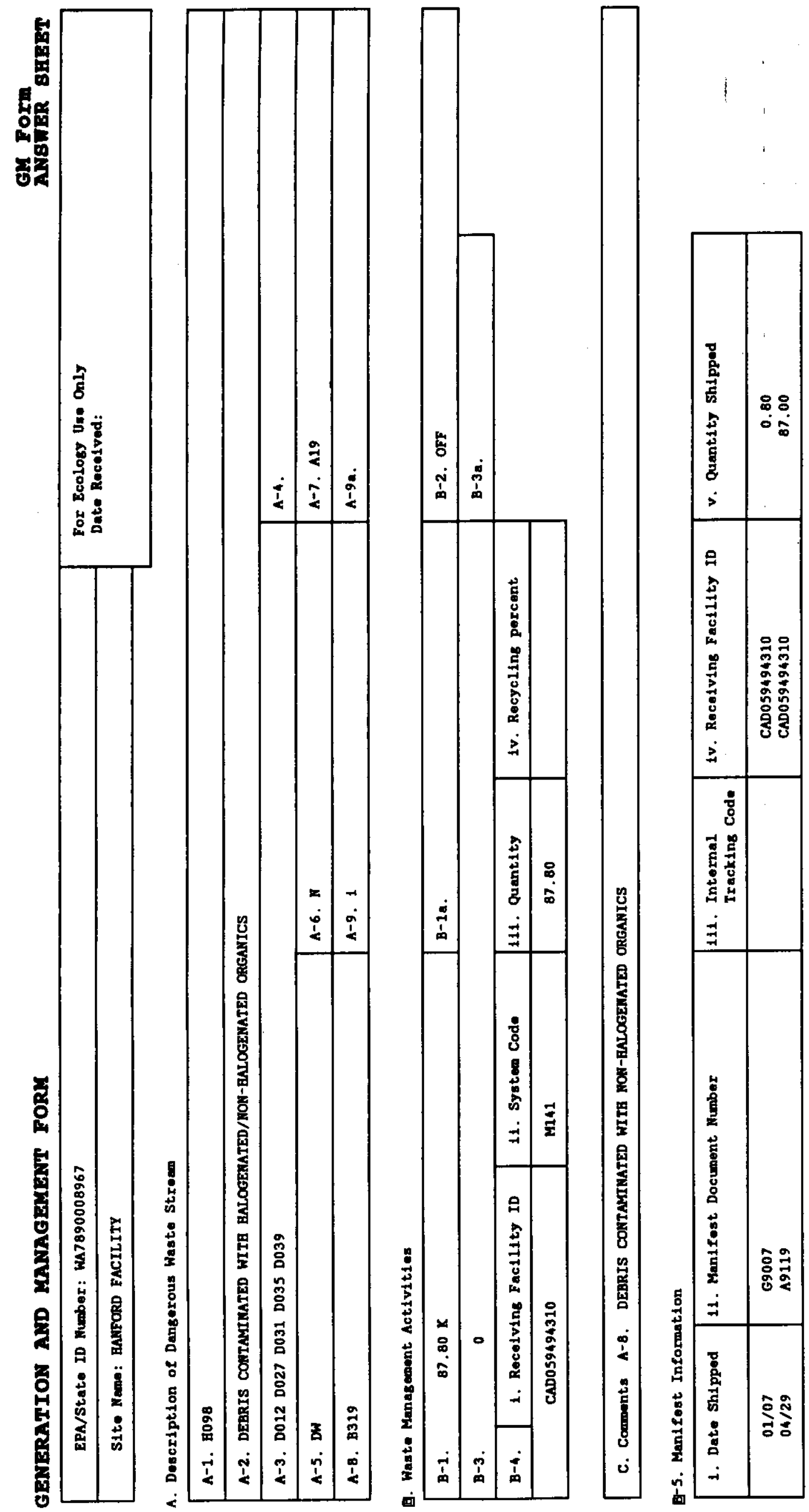


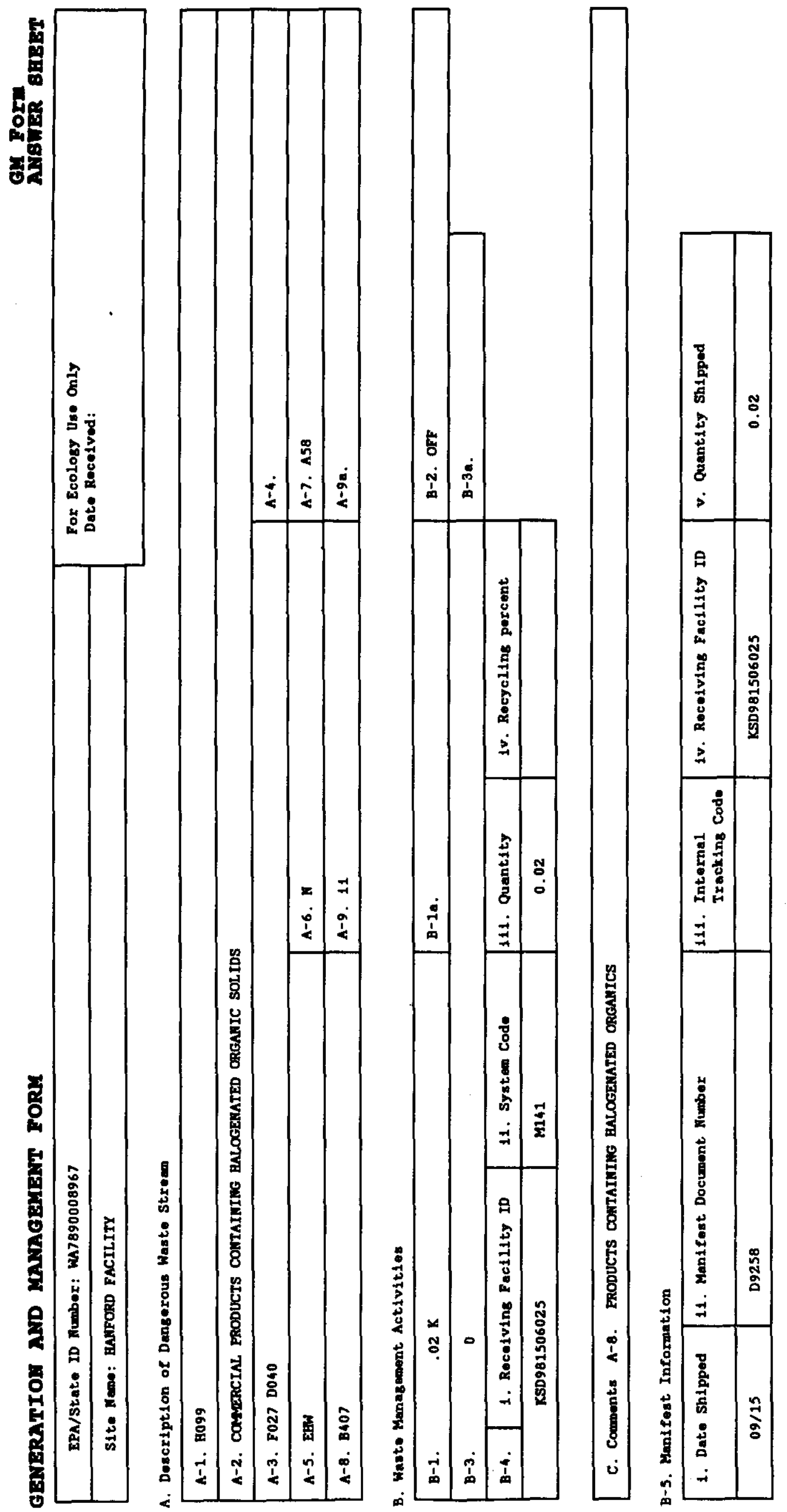




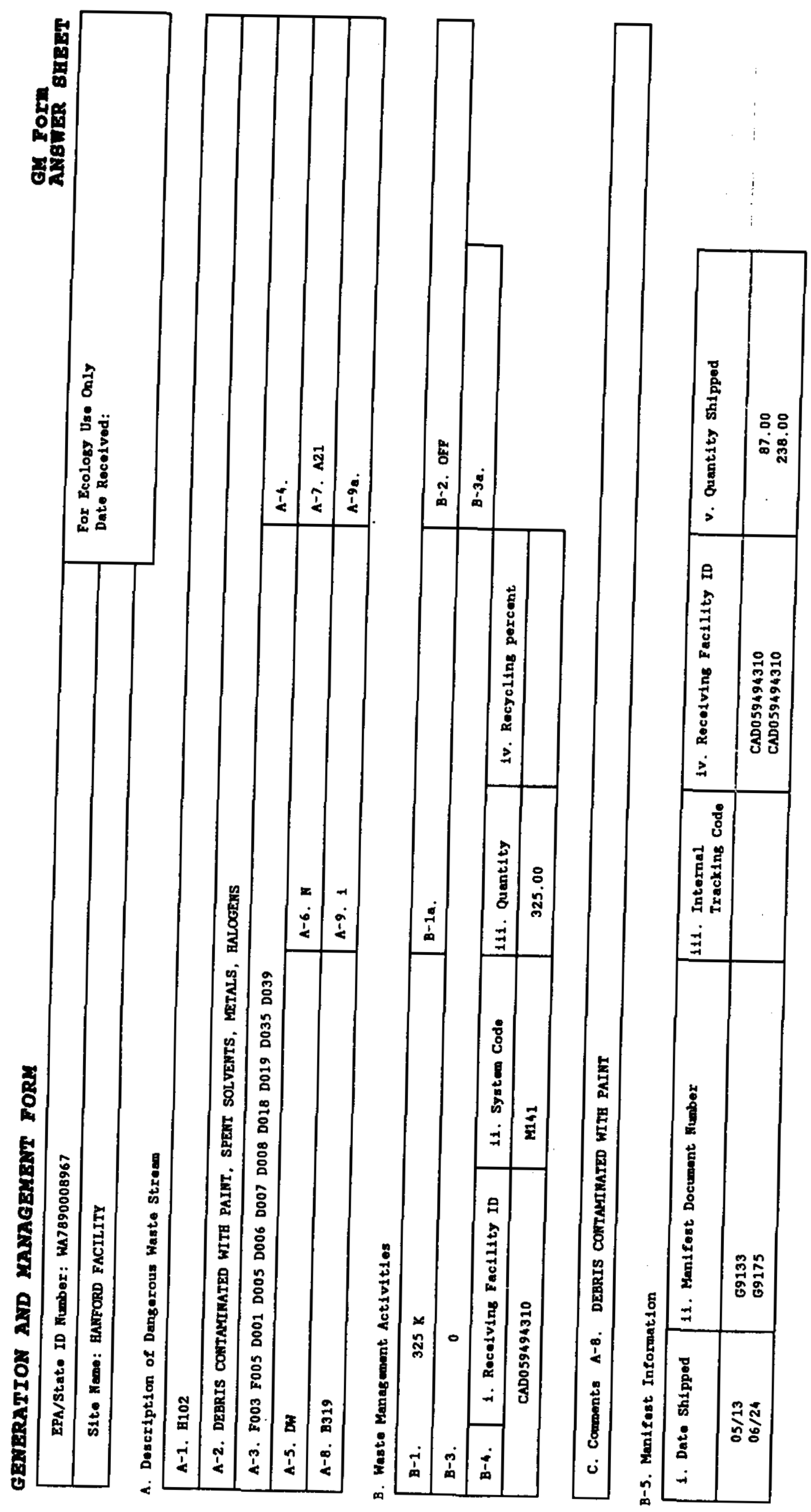



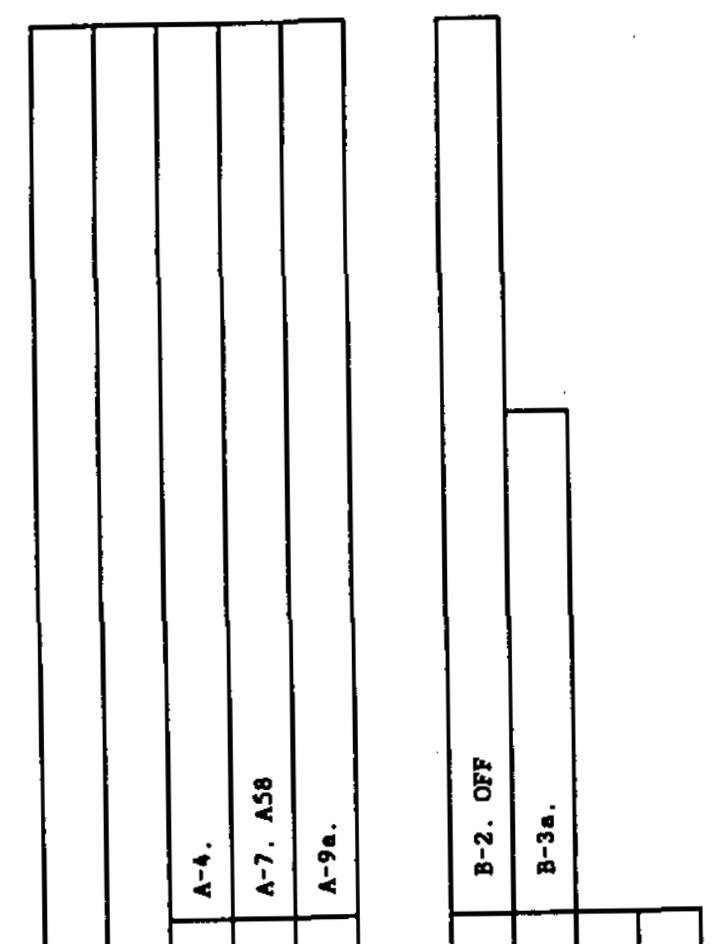

2
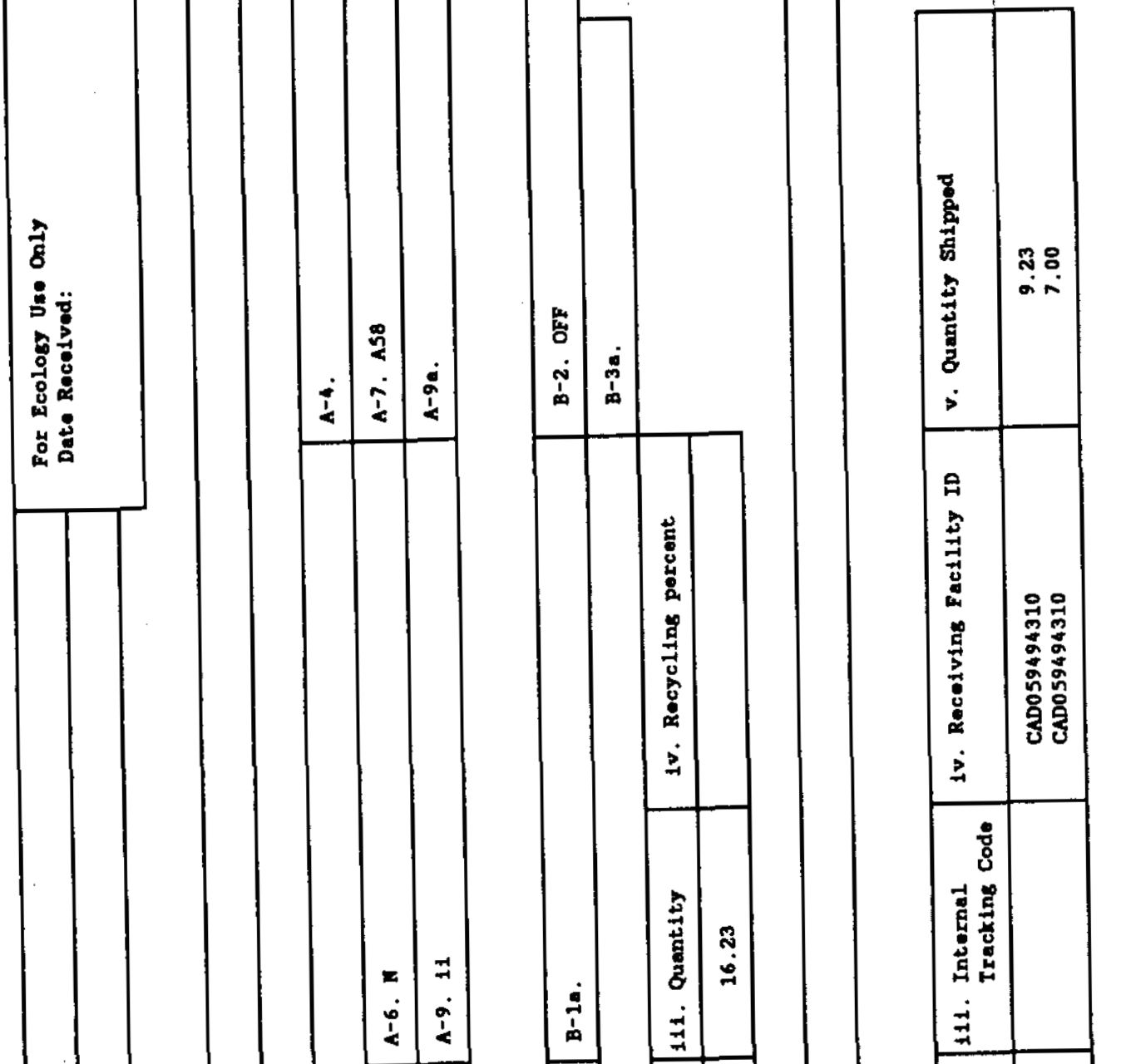

:

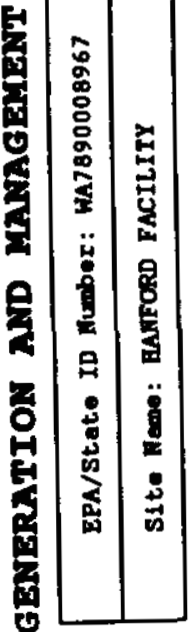

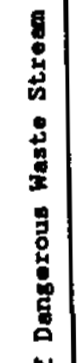

훔

官

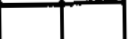
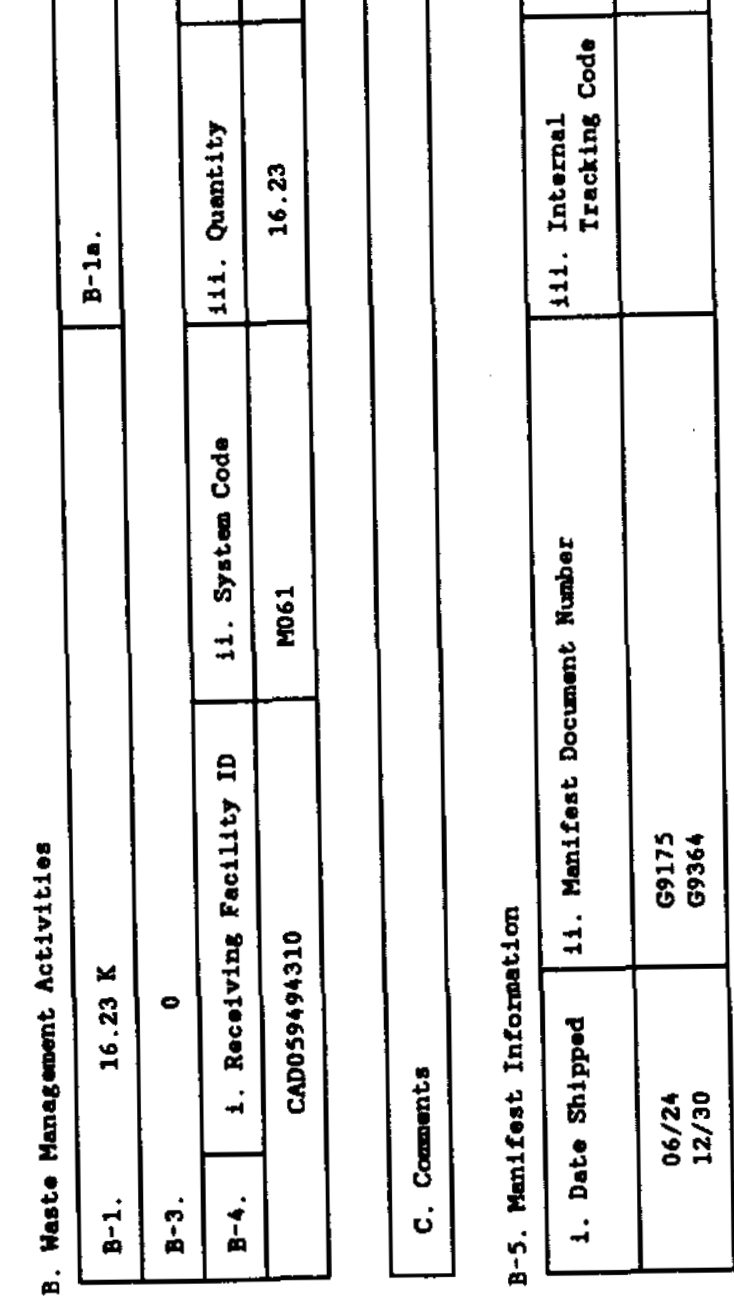


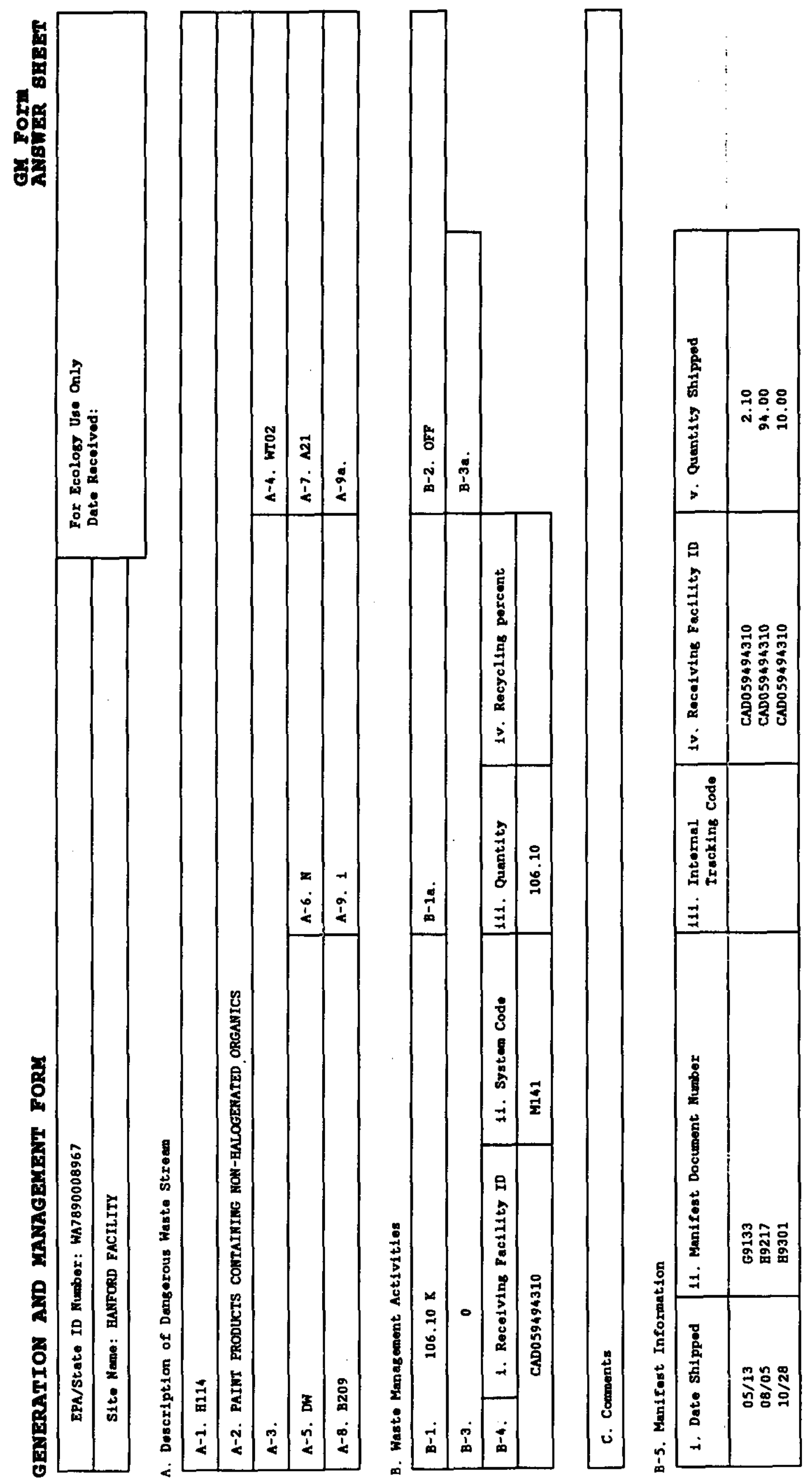




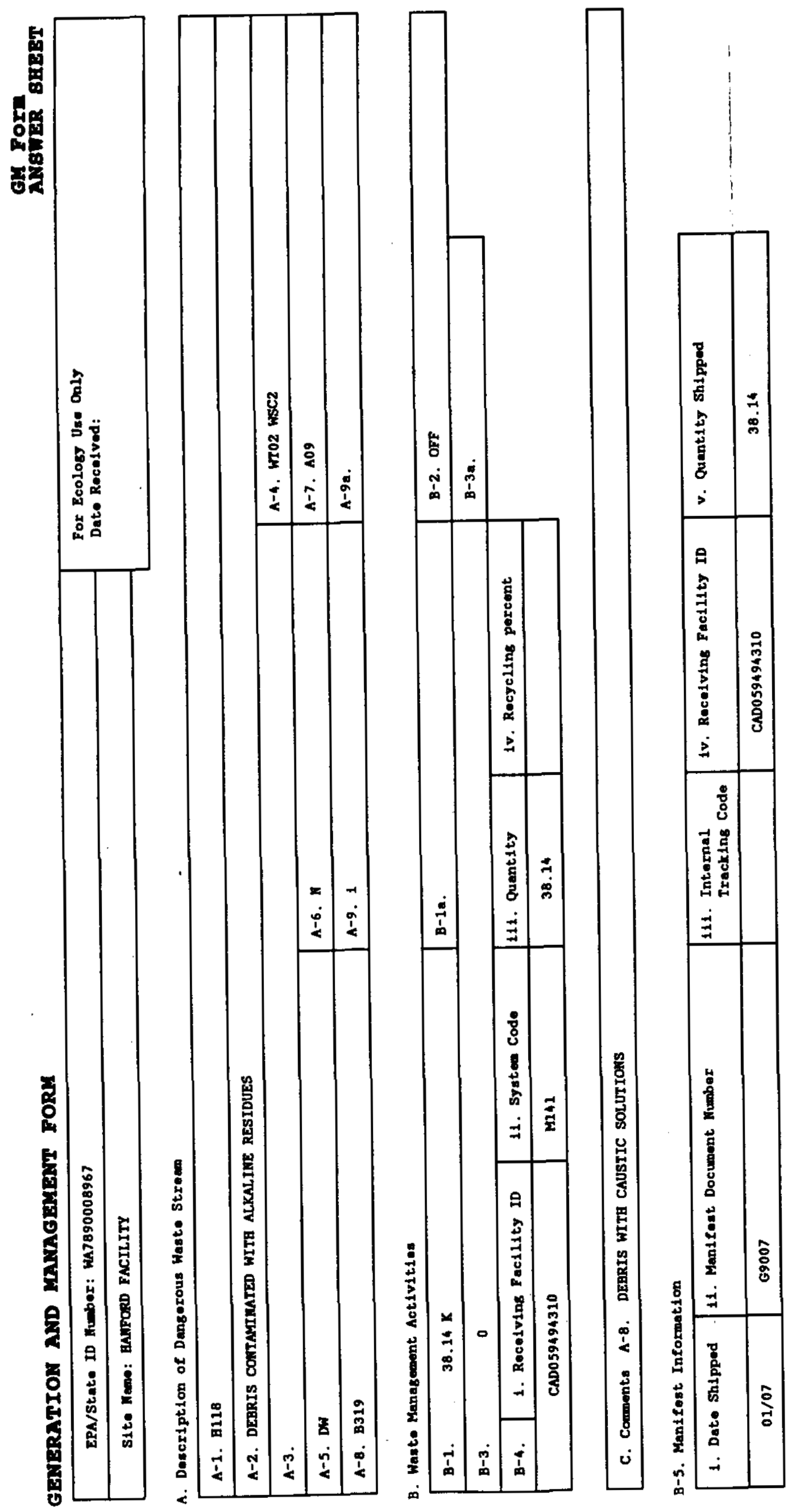

N 


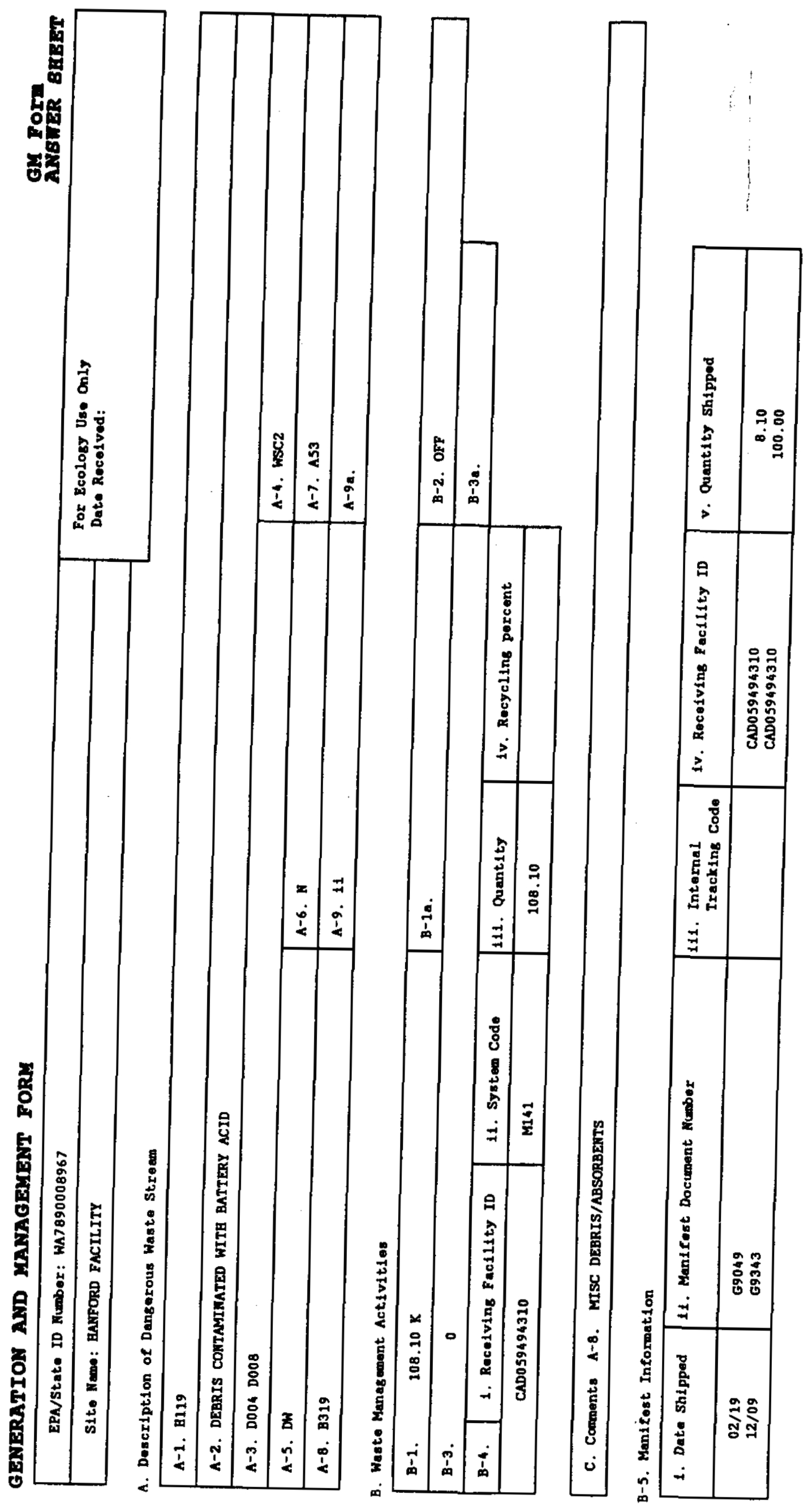




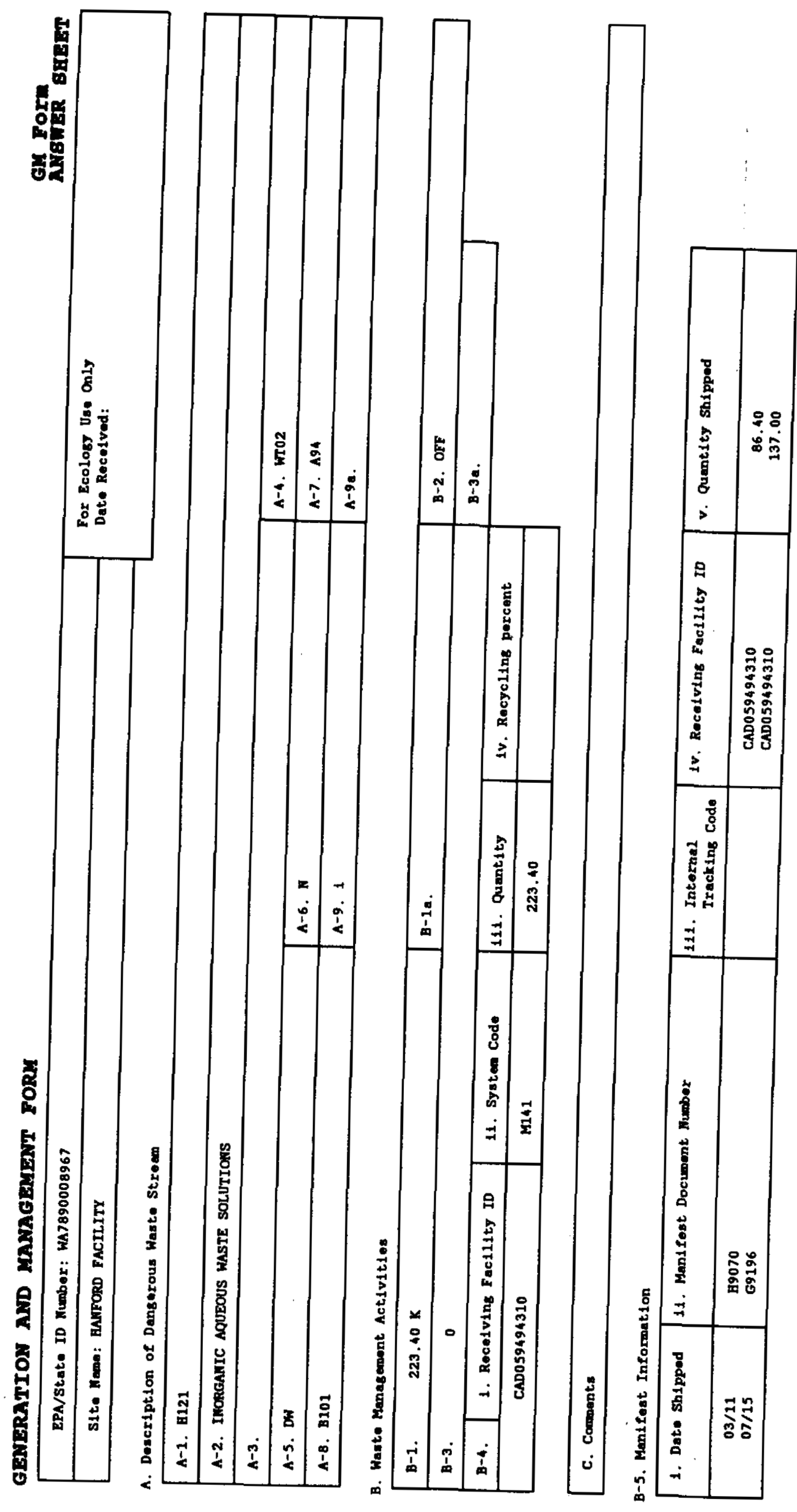




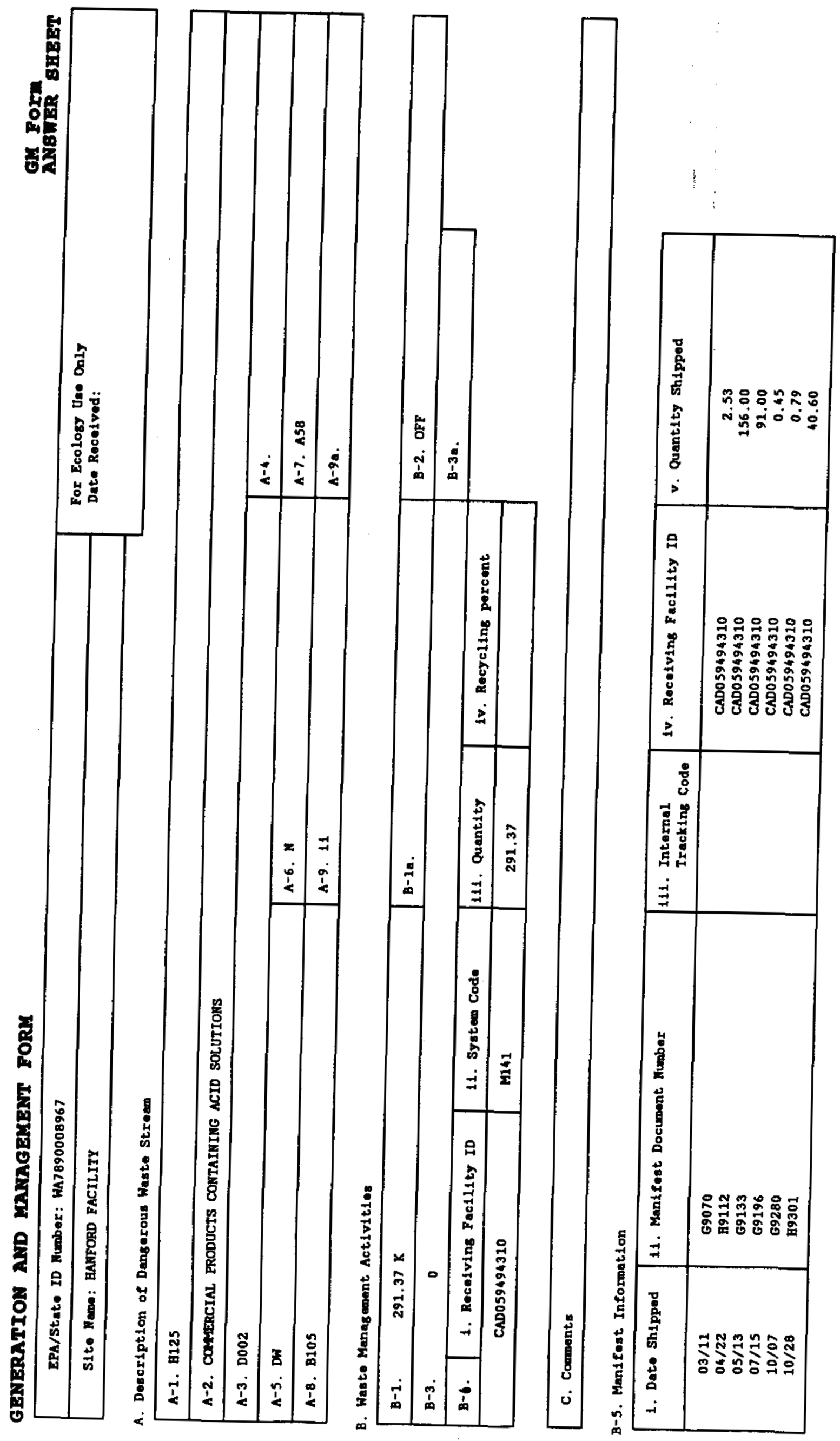




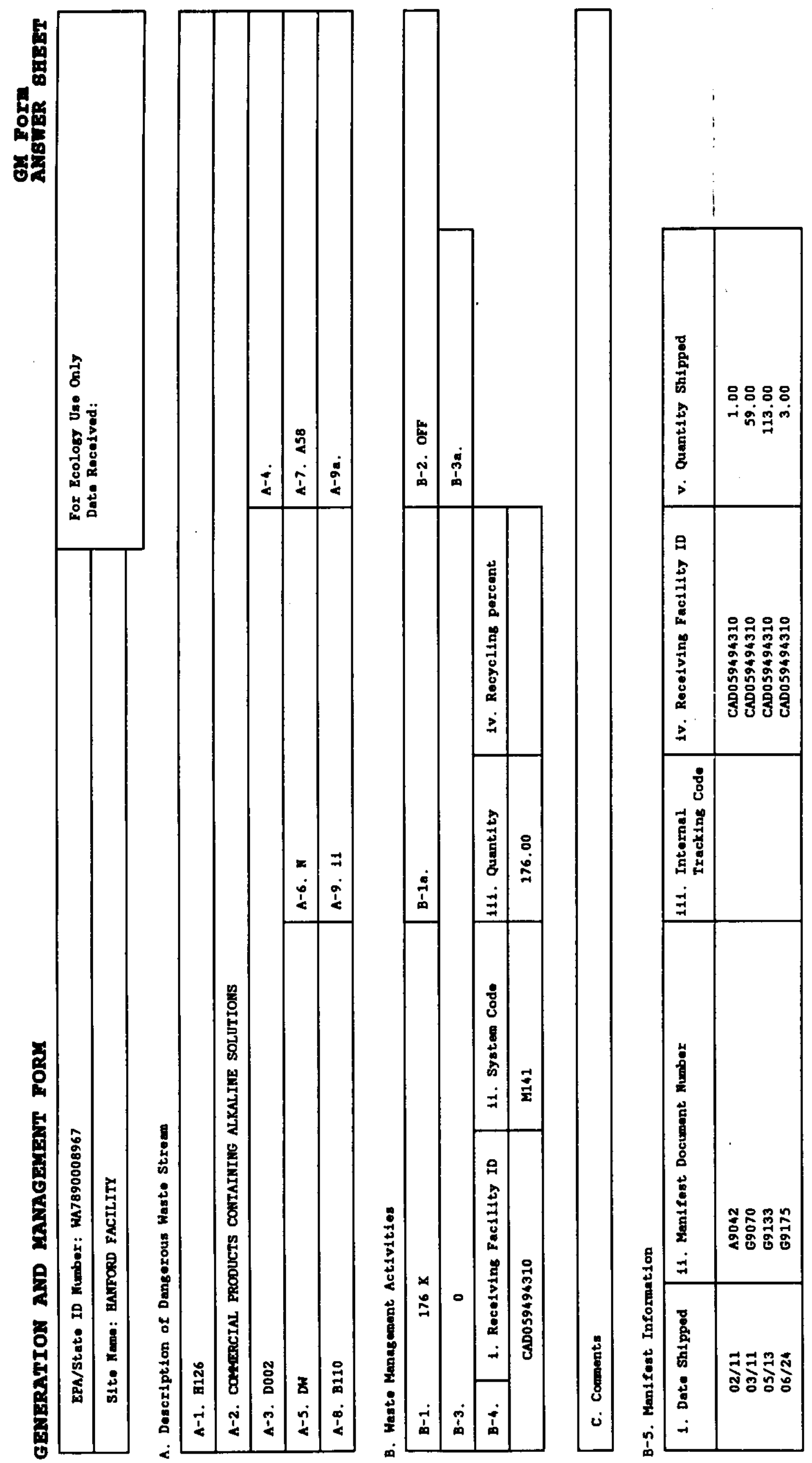




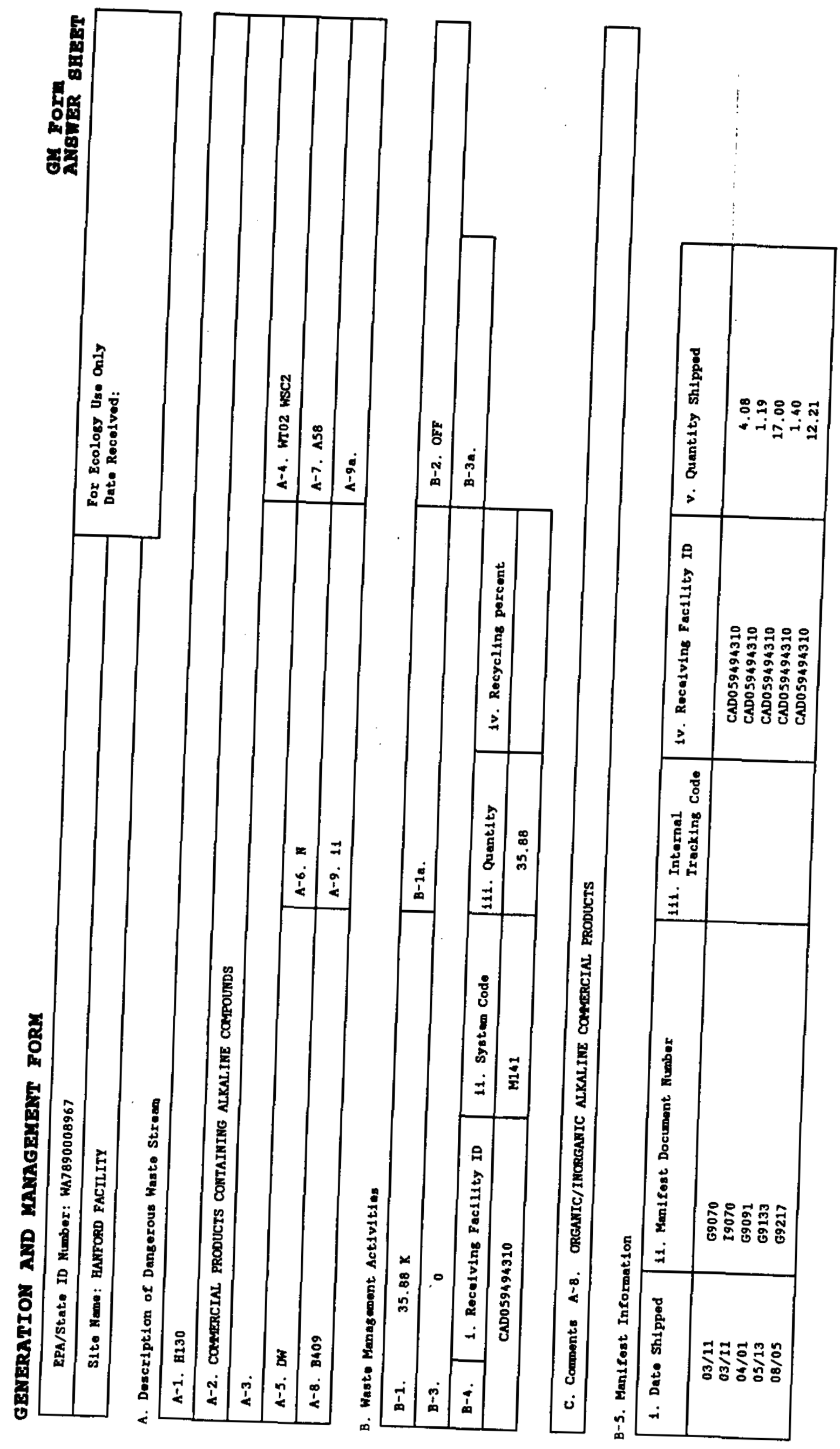




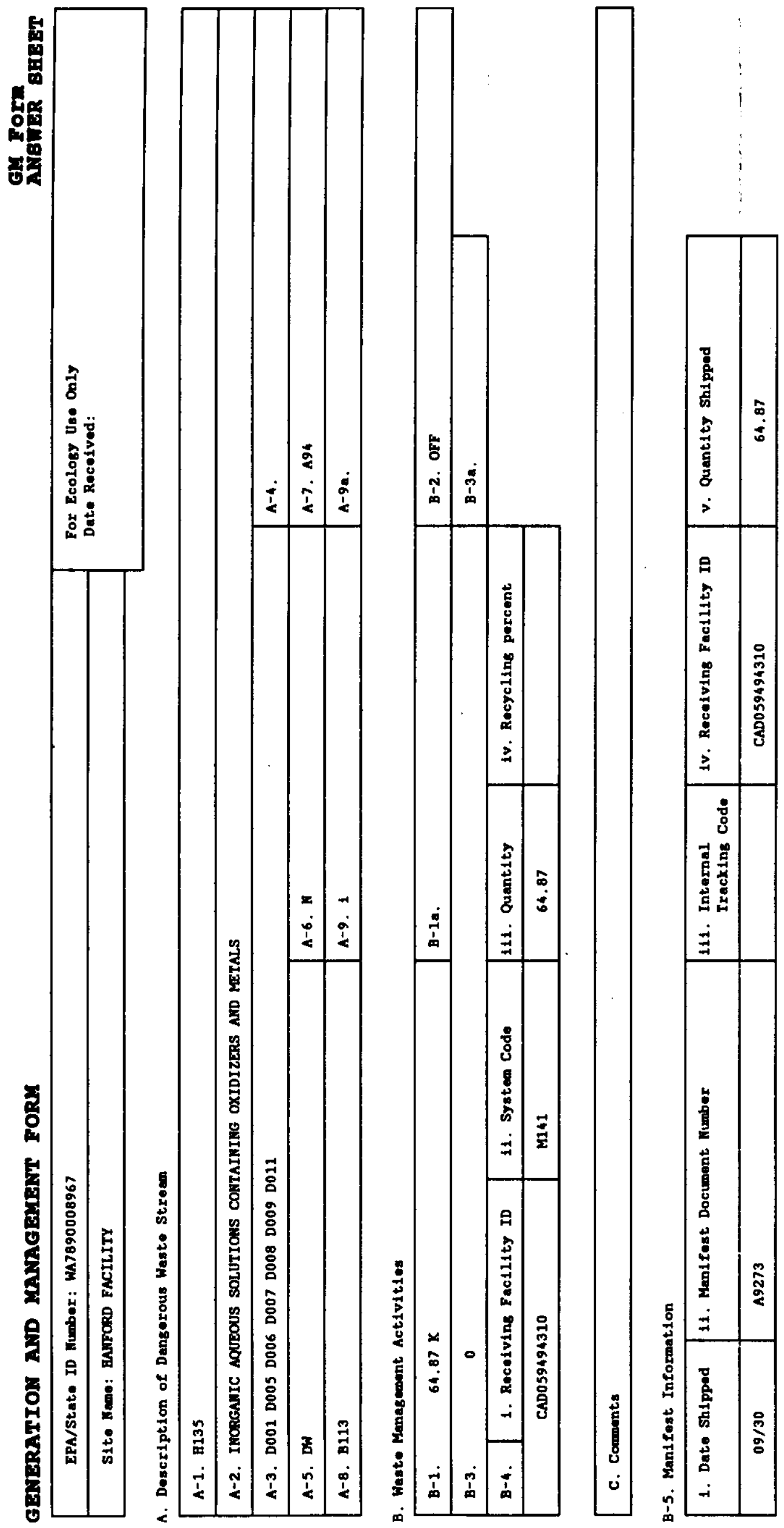




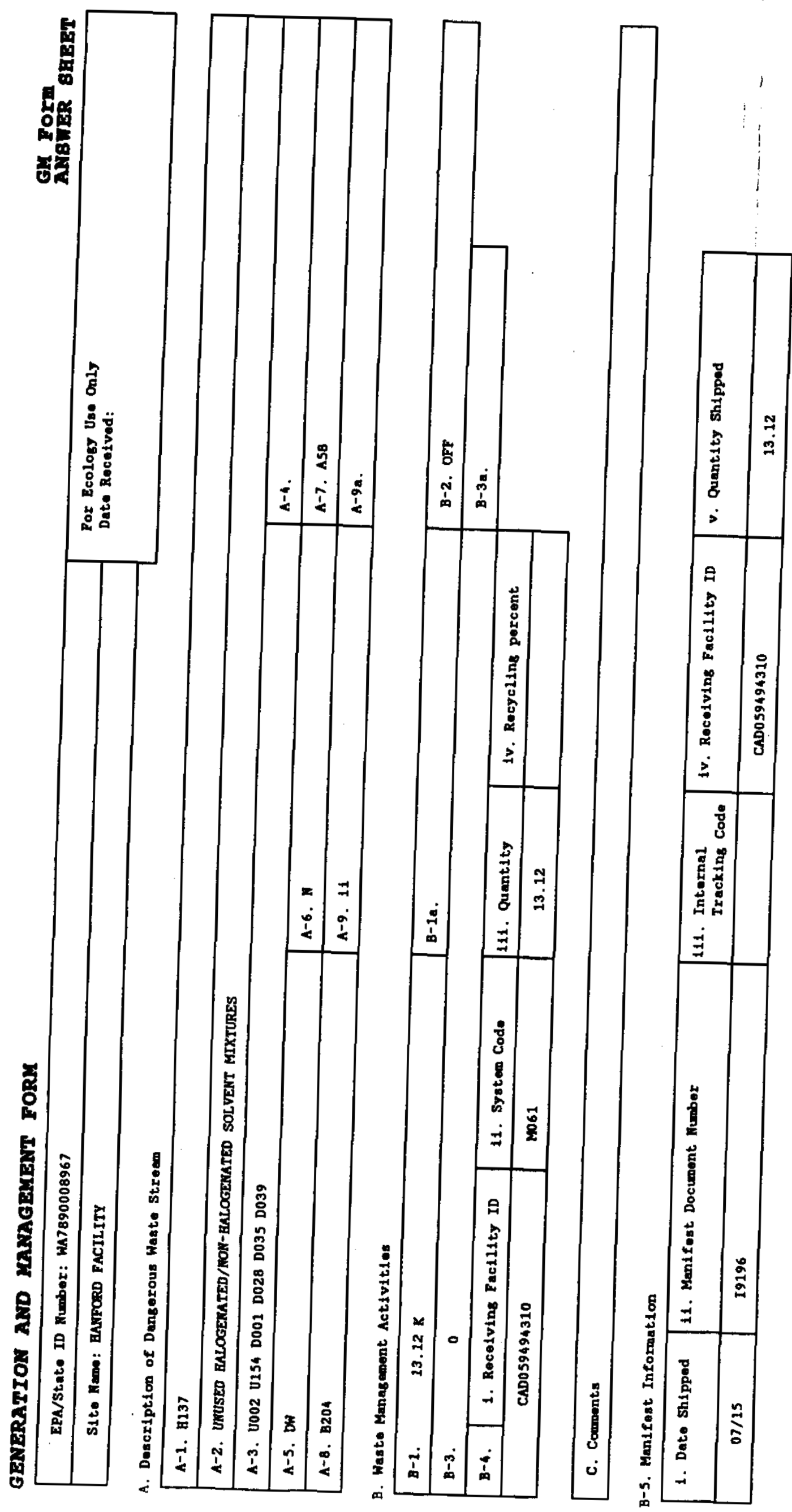



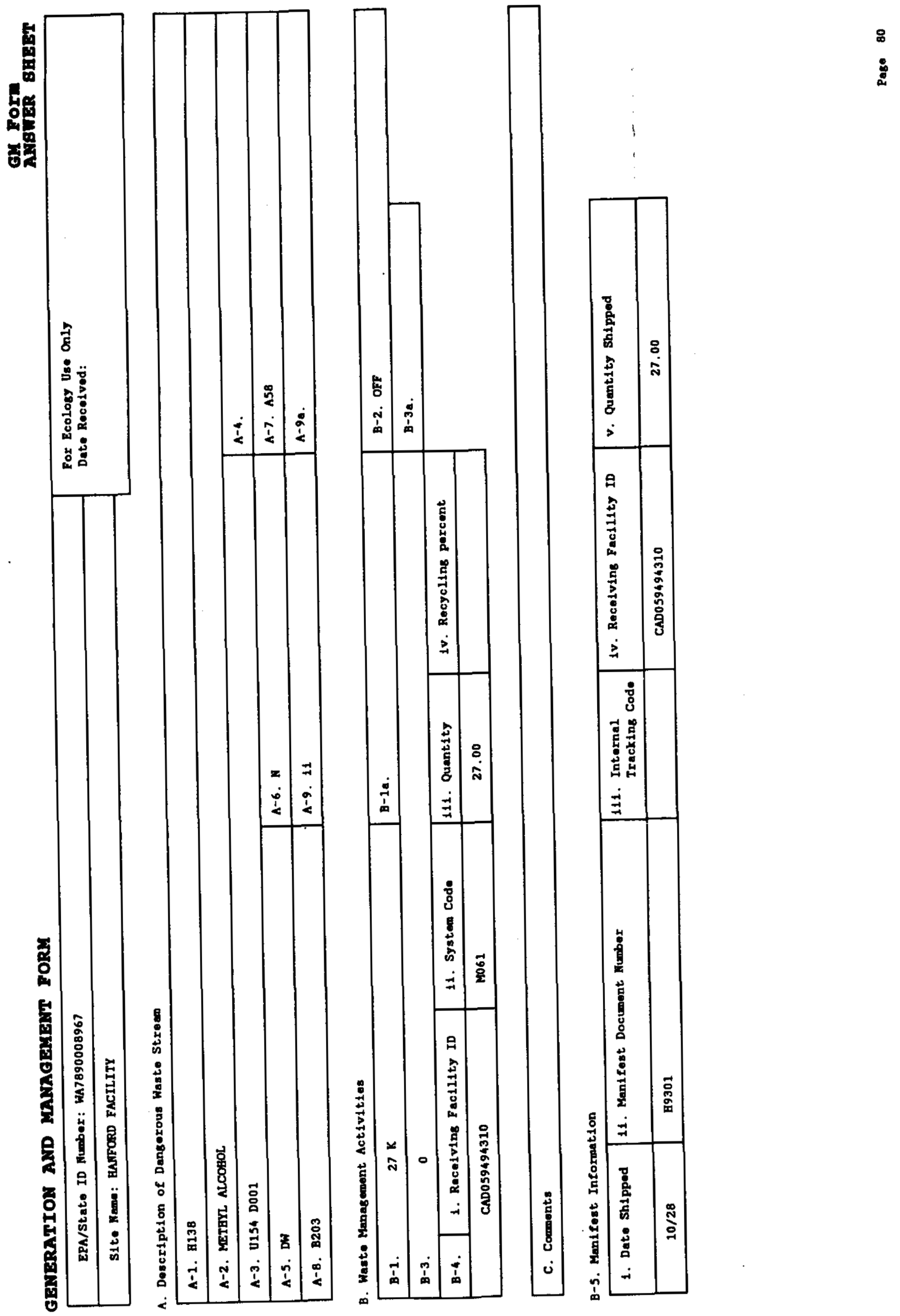


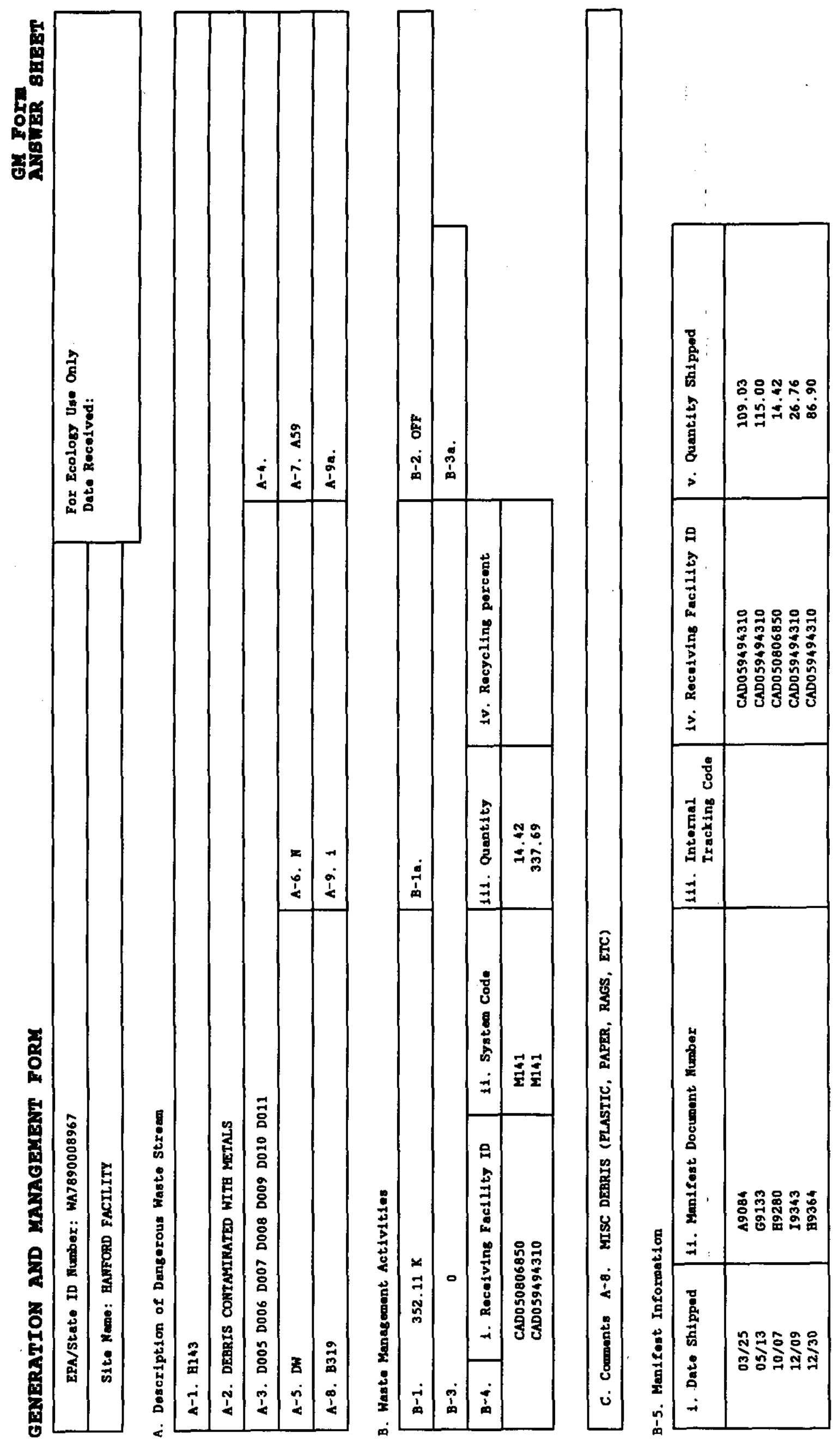



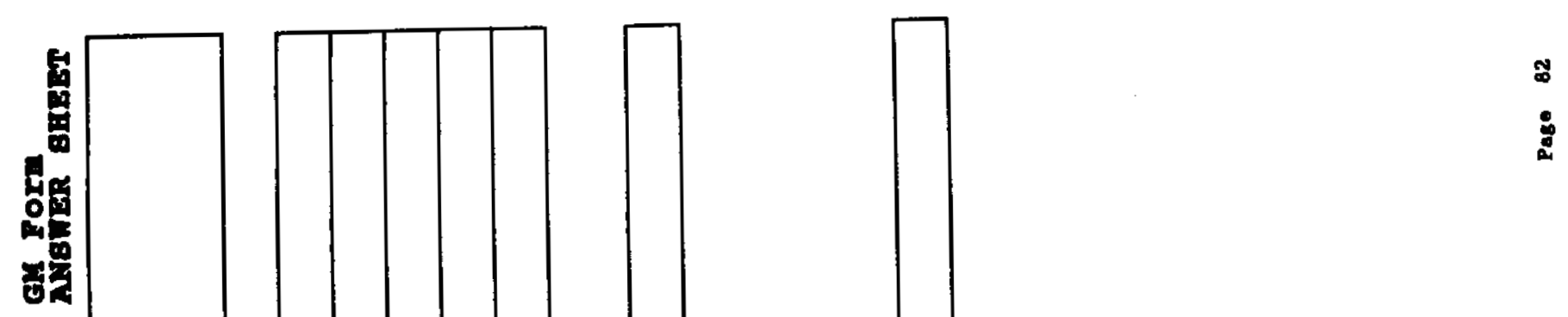

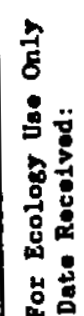
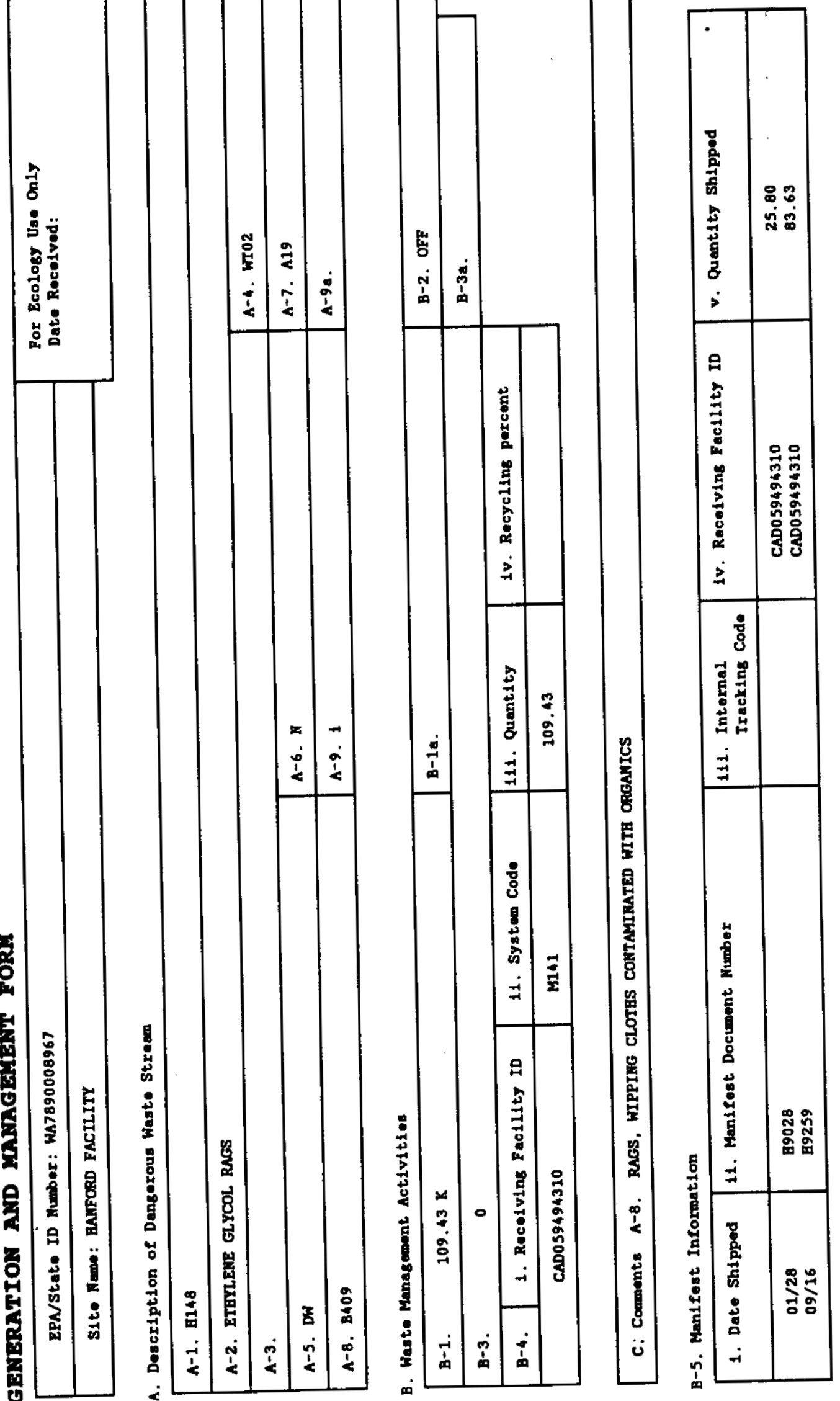


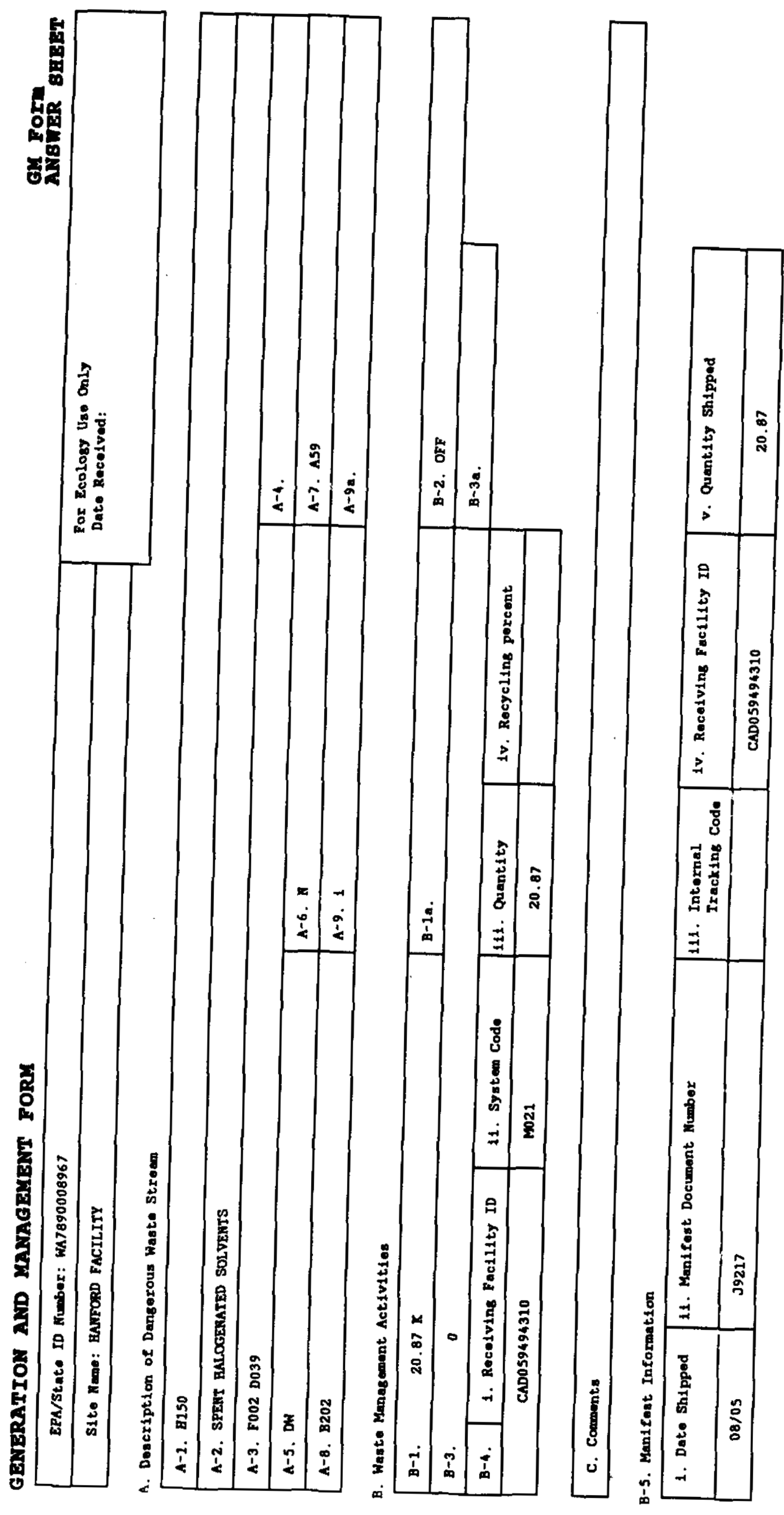




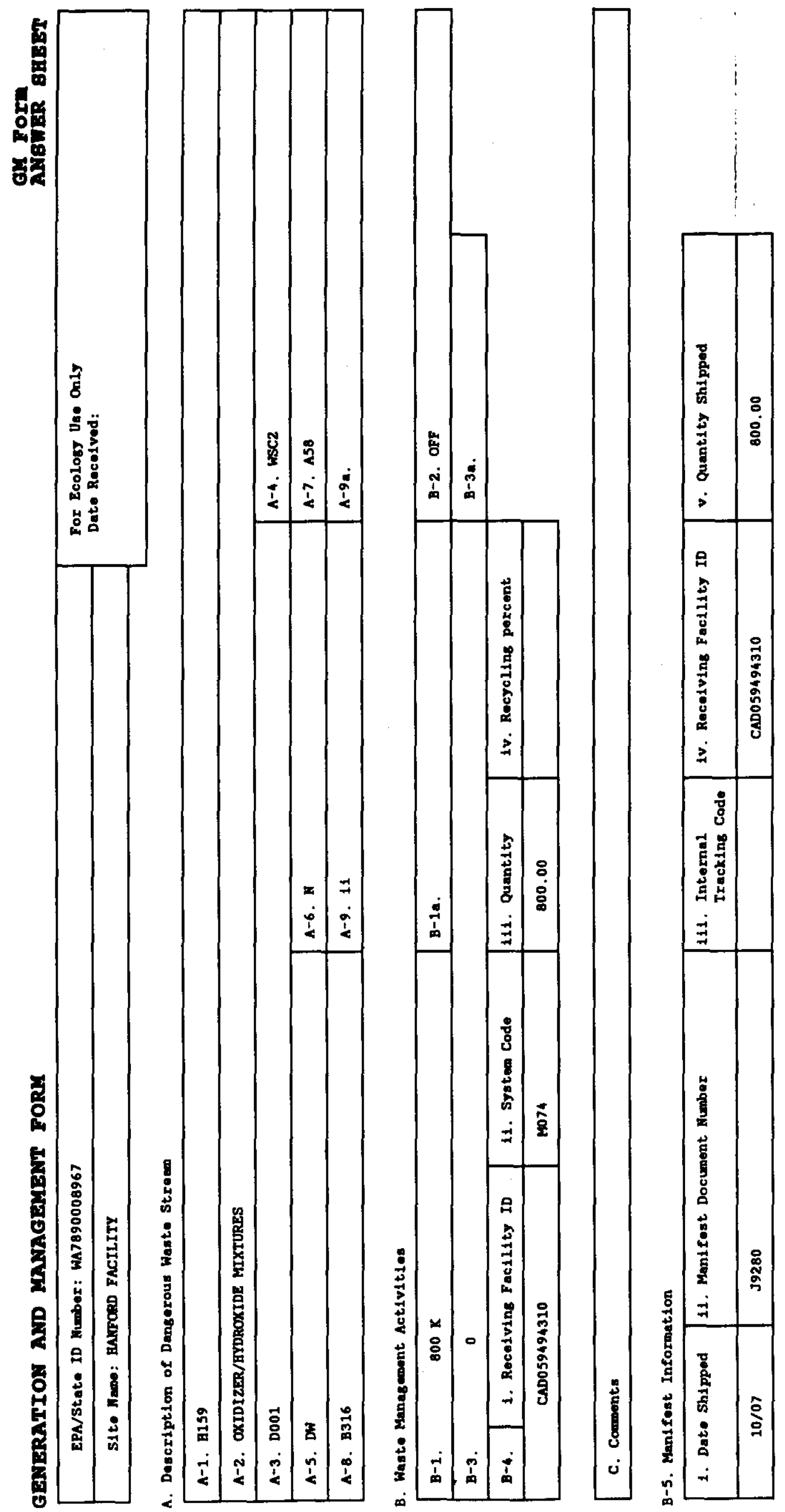




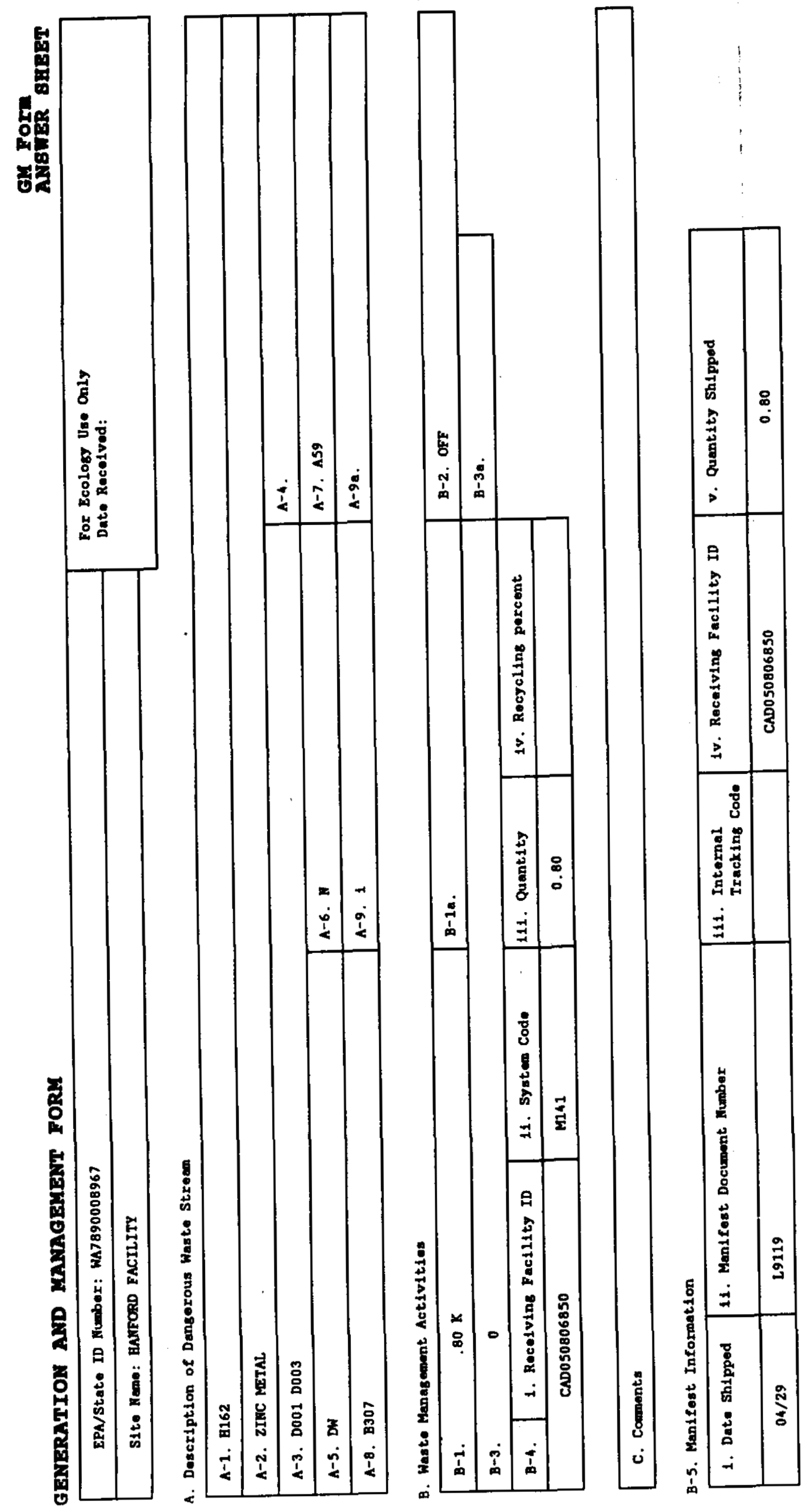




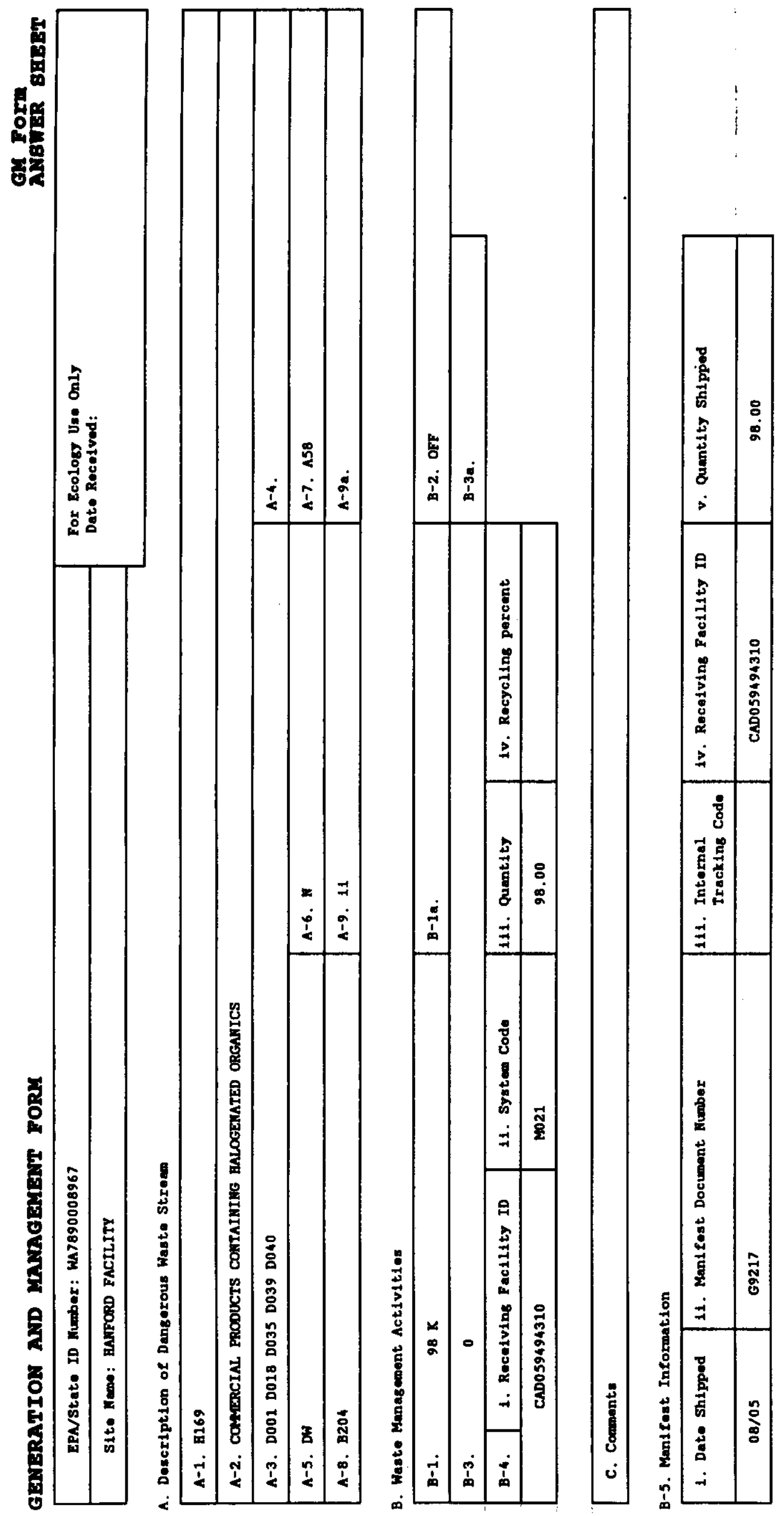


禺

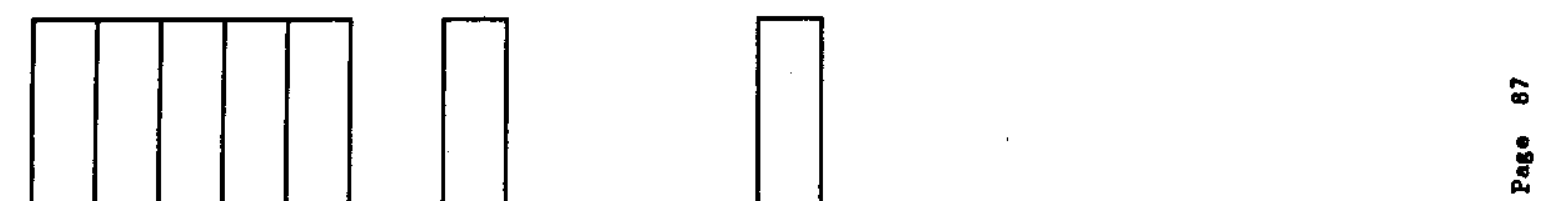

ڤ

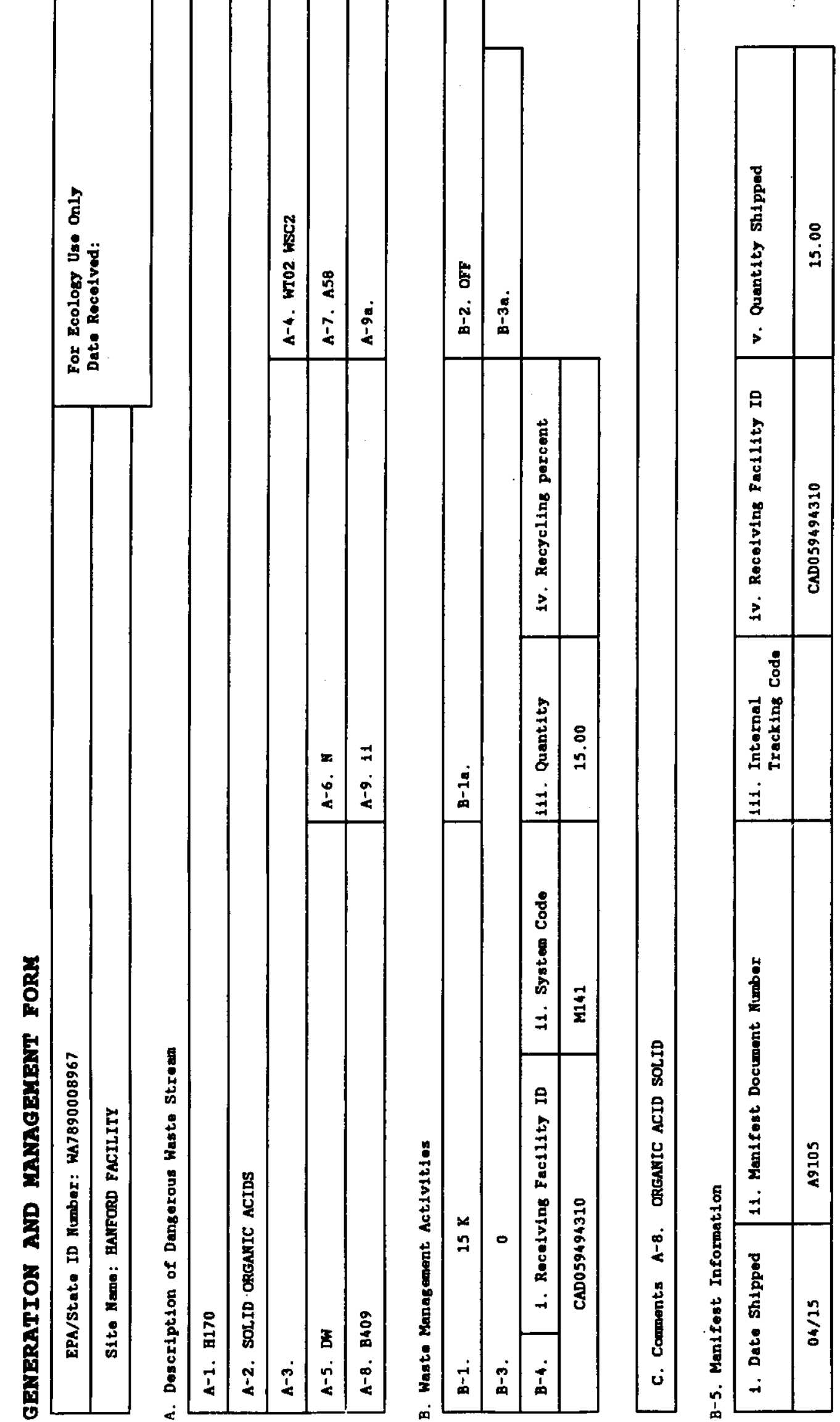



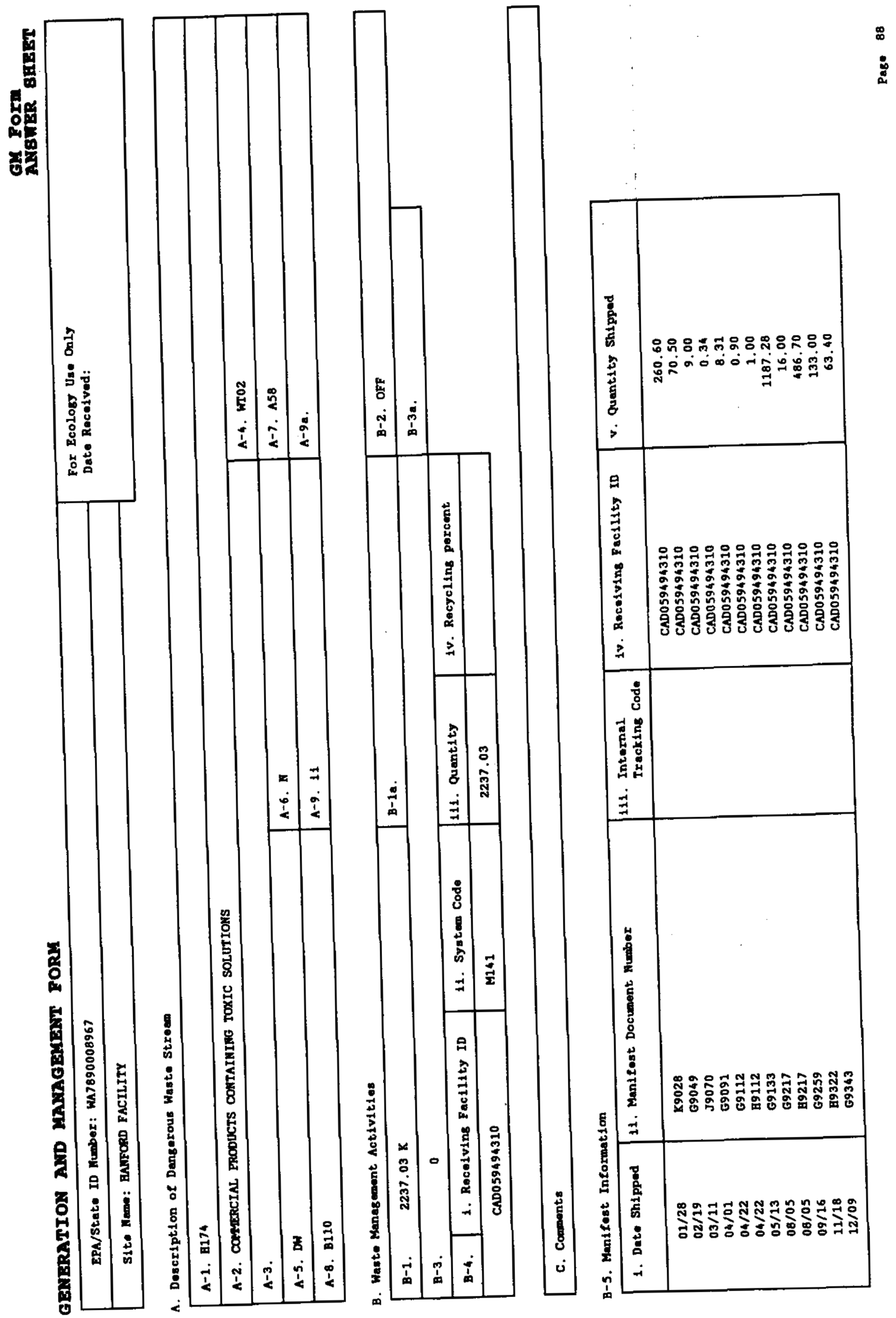

站

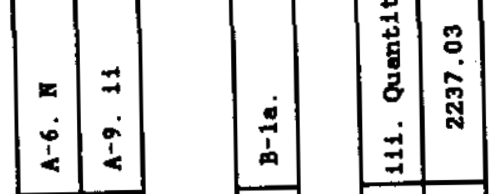
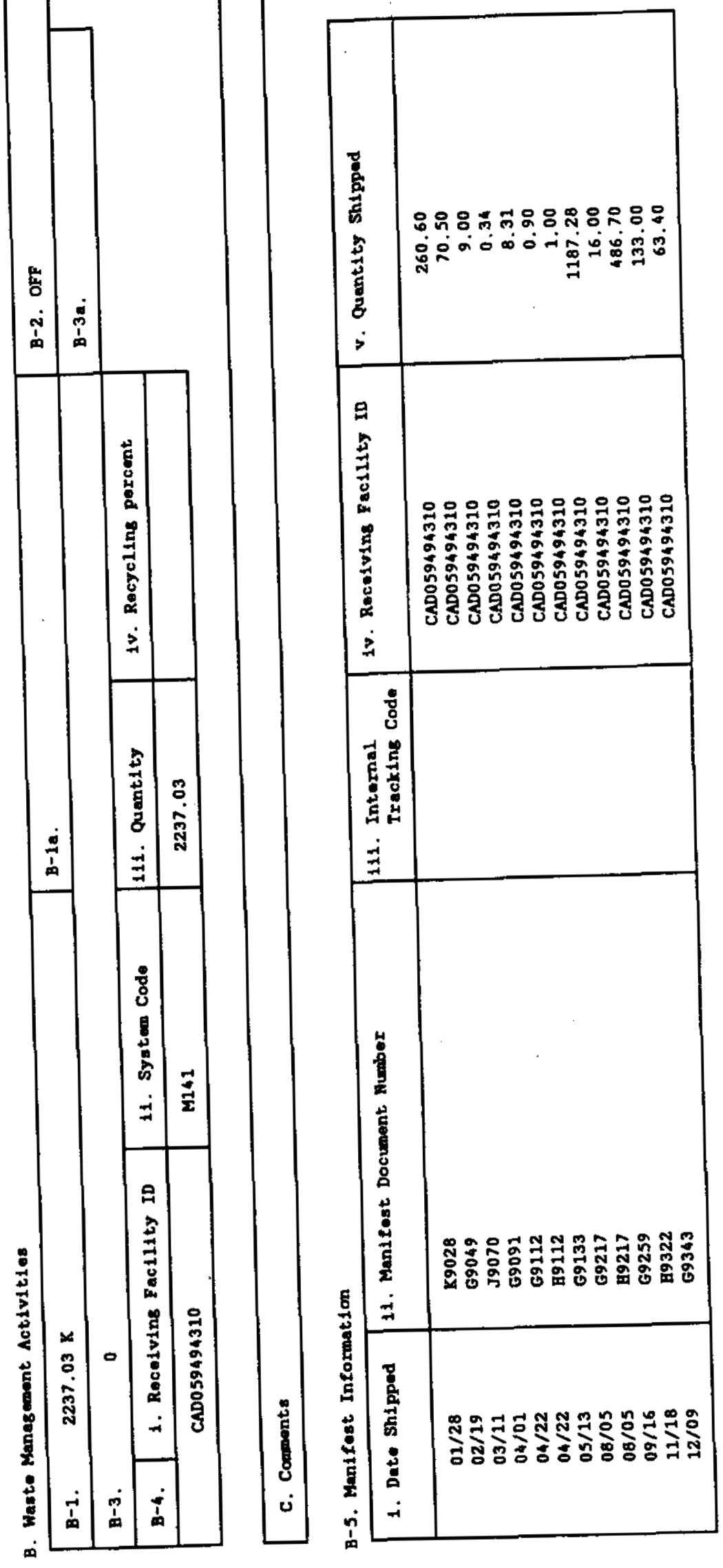

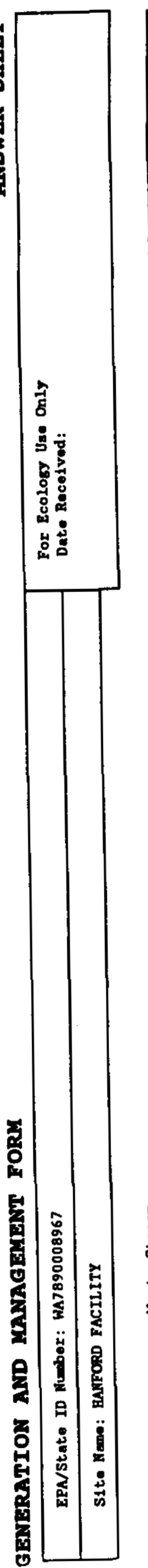
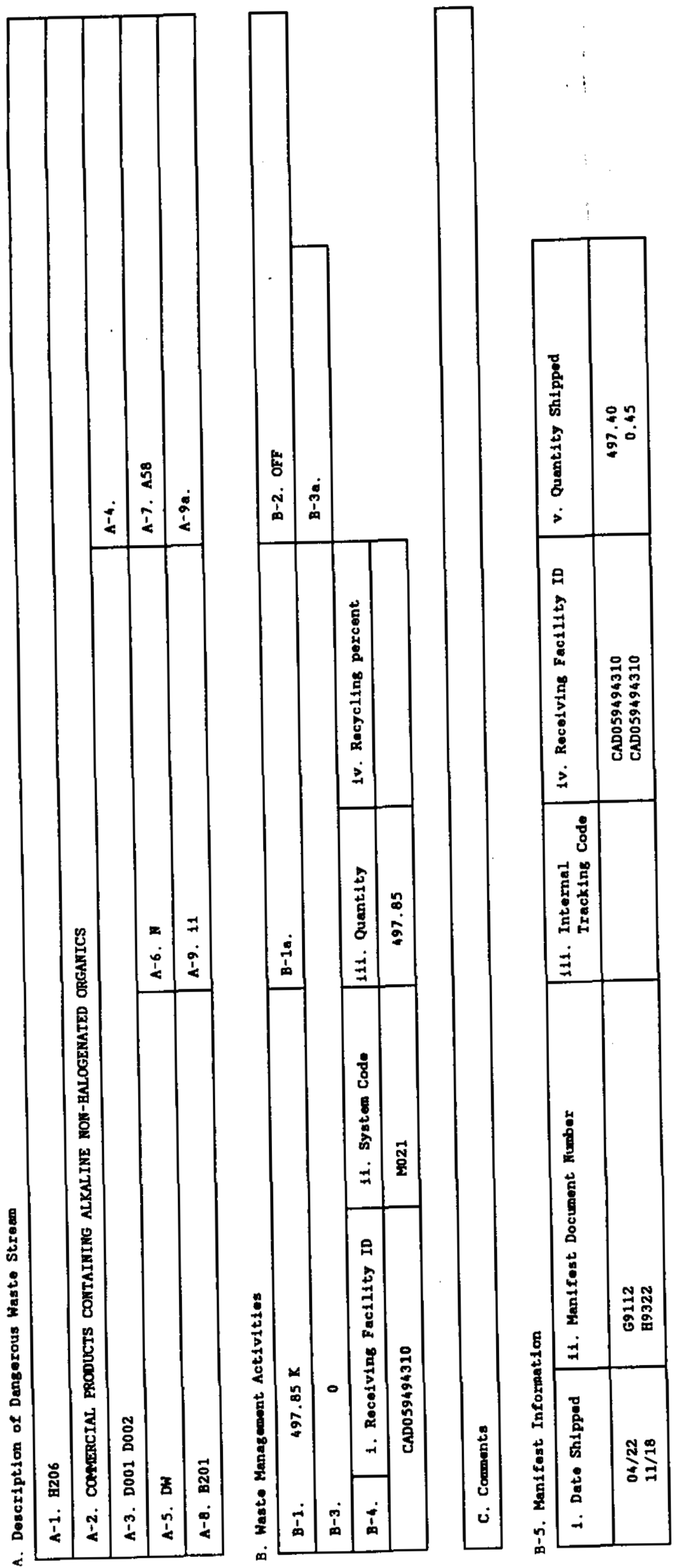


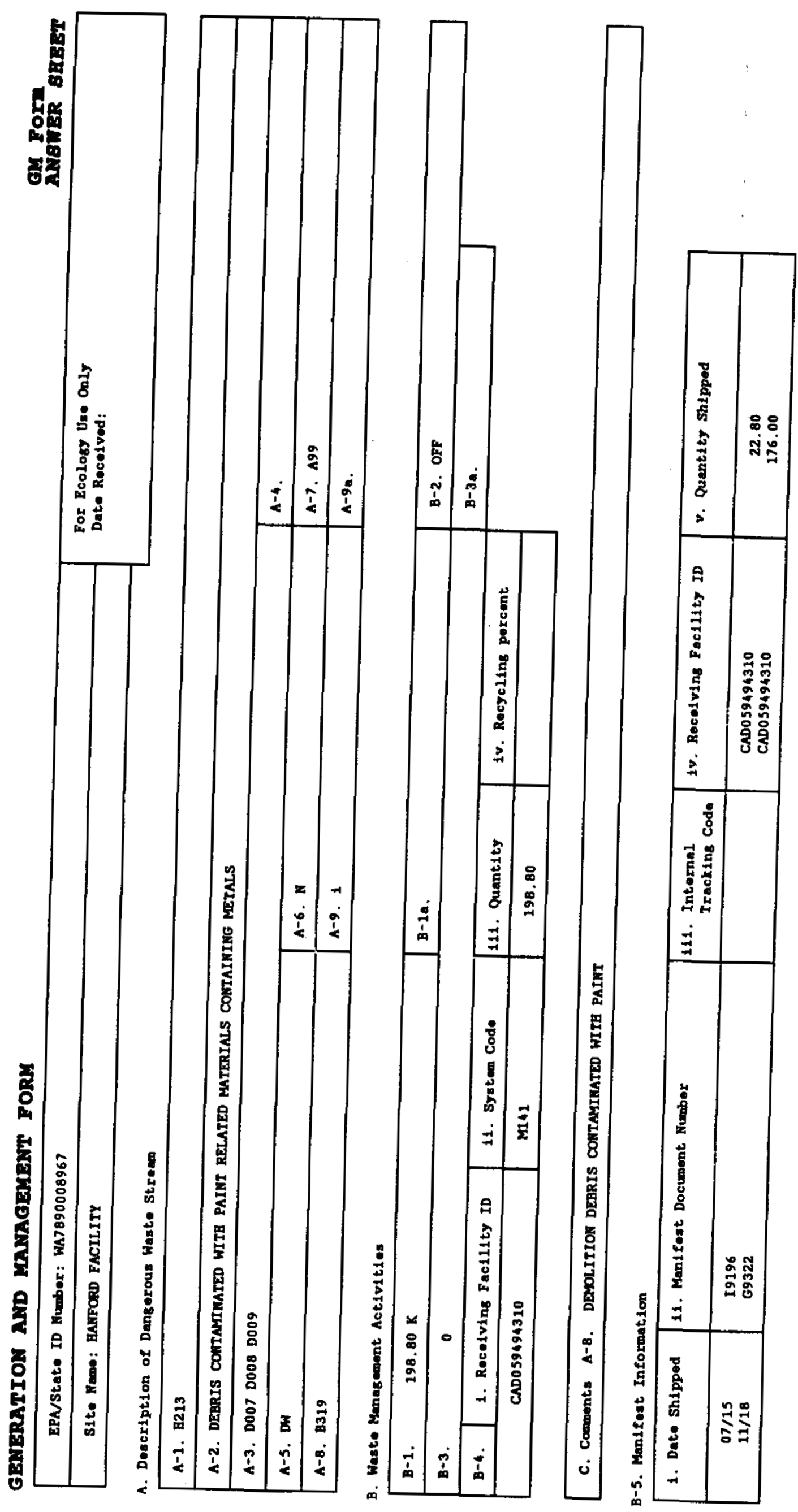




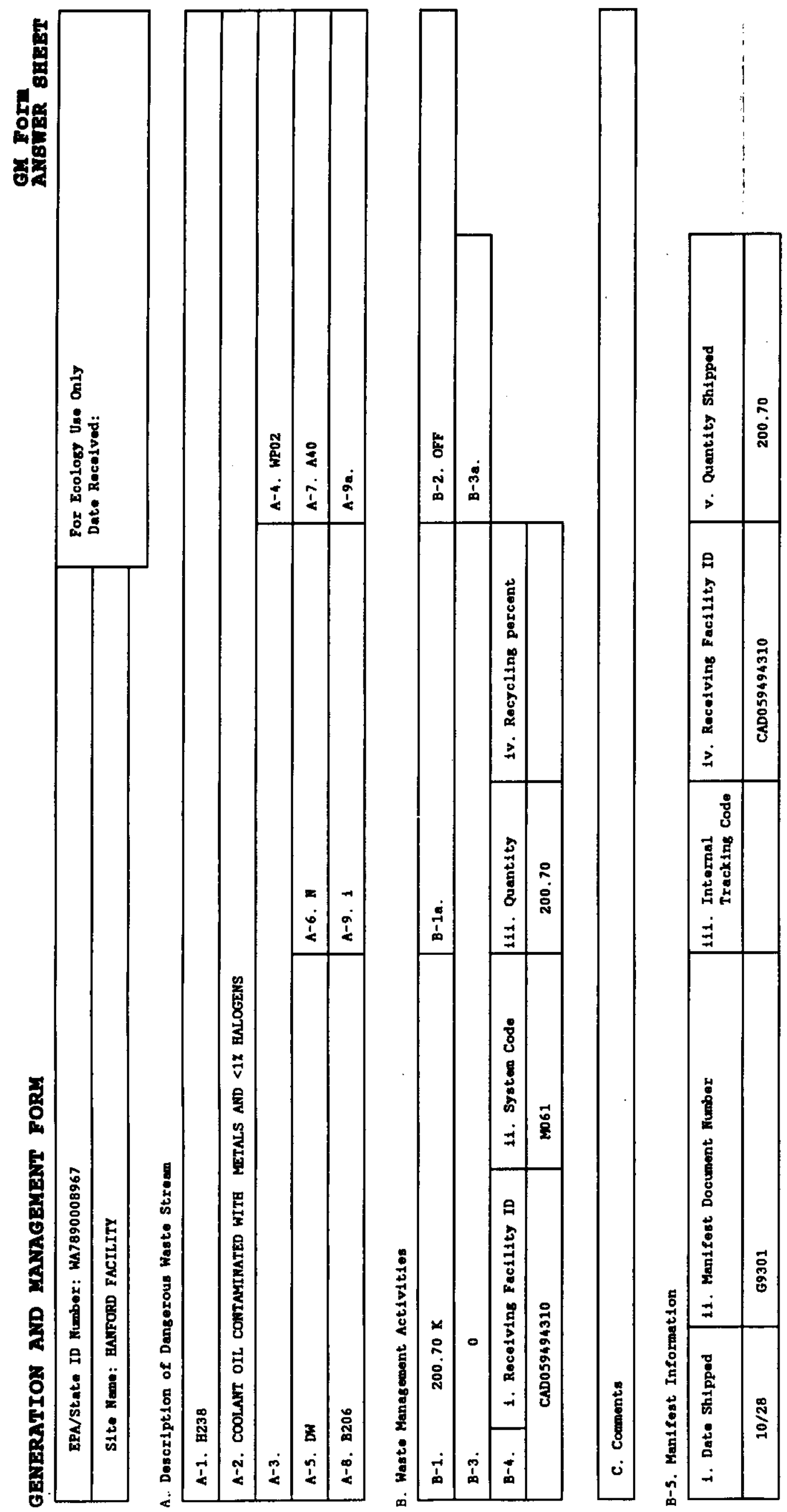



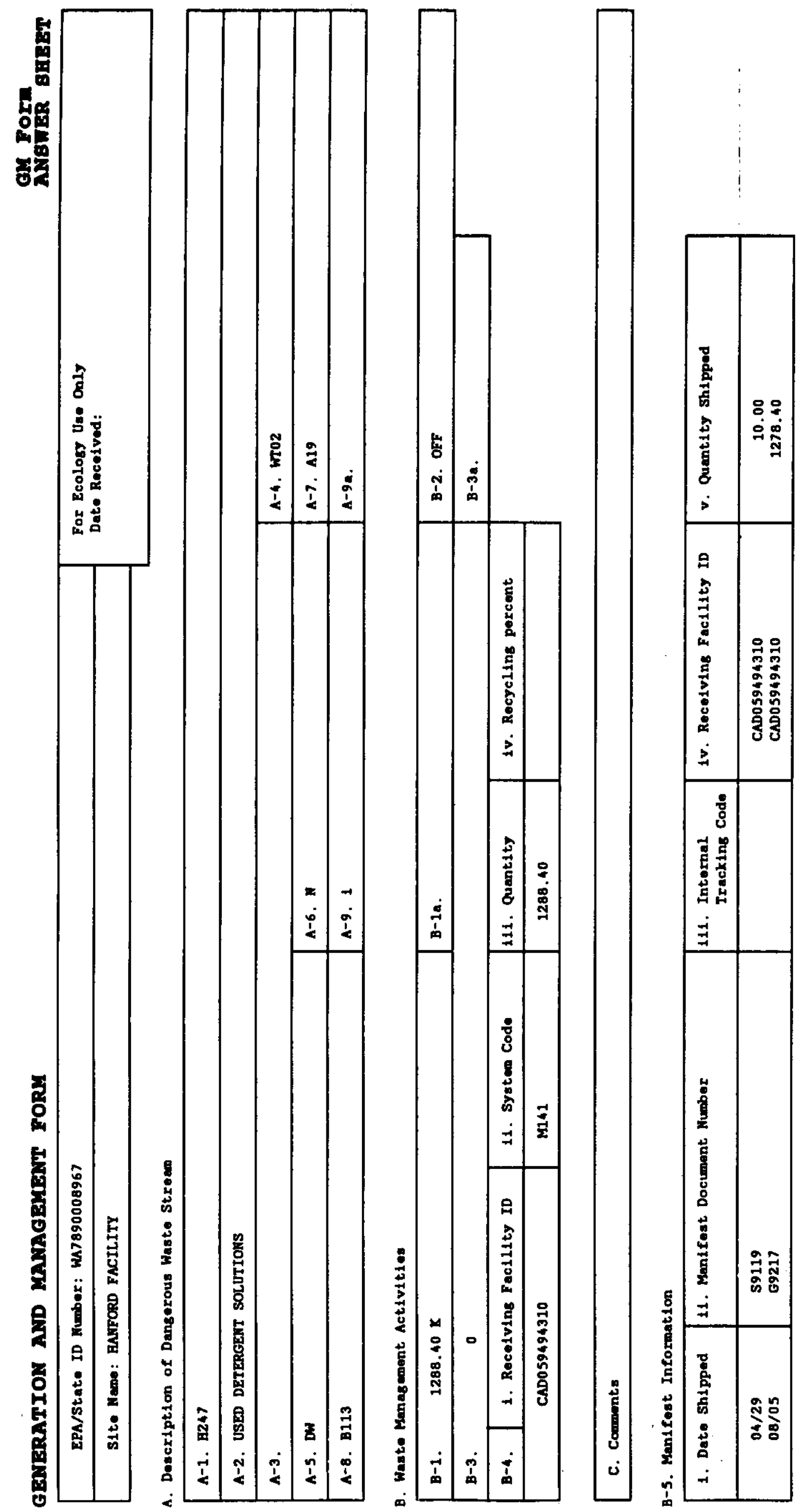

$\stackrel{2}{3}$

:

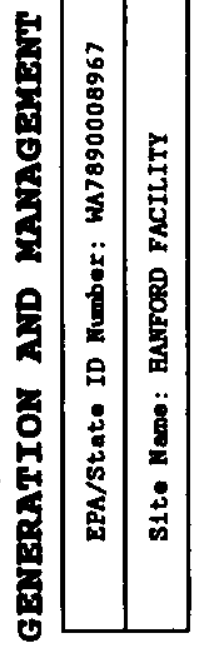

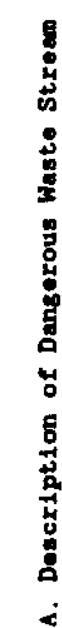

a. 


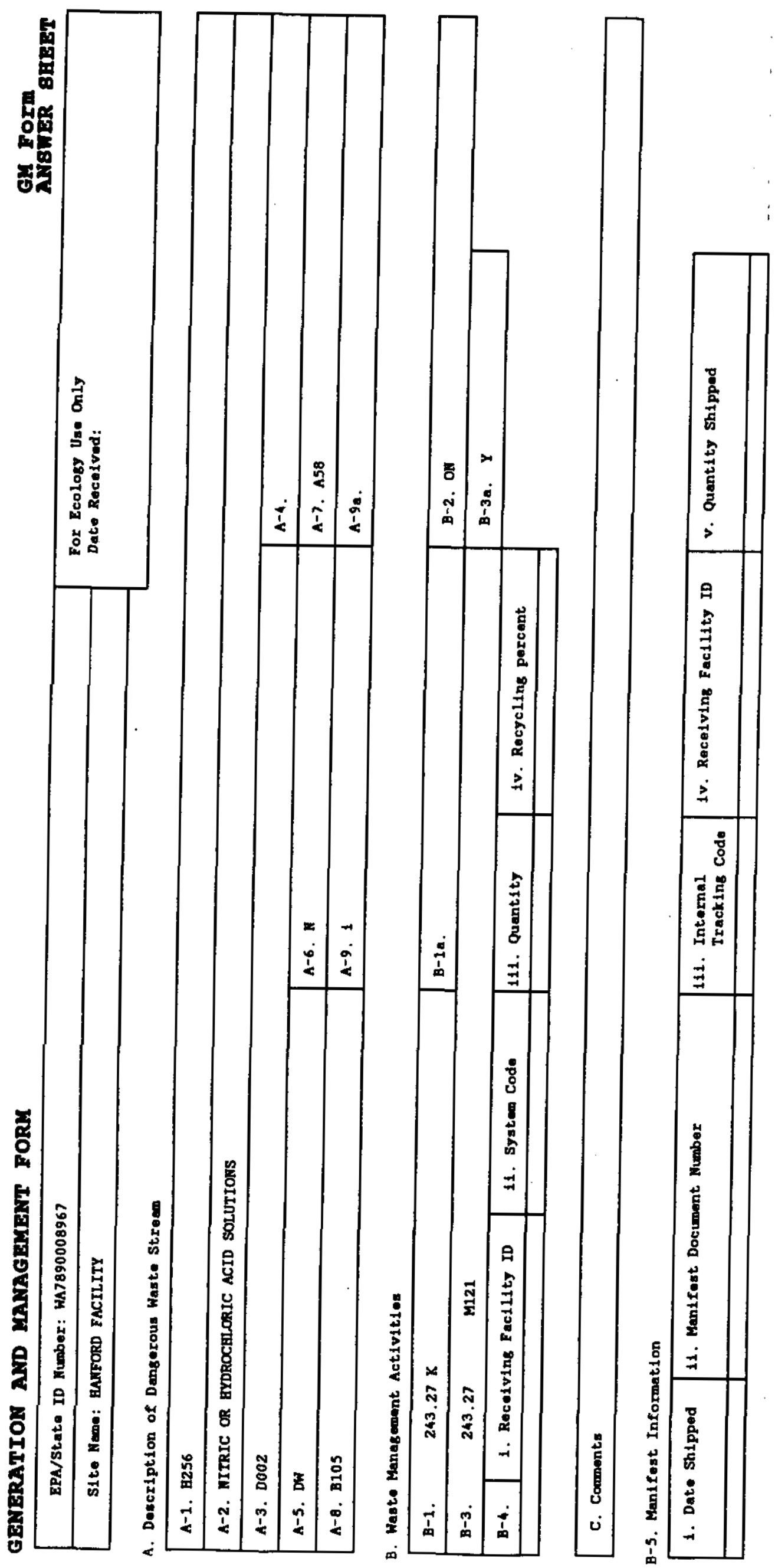




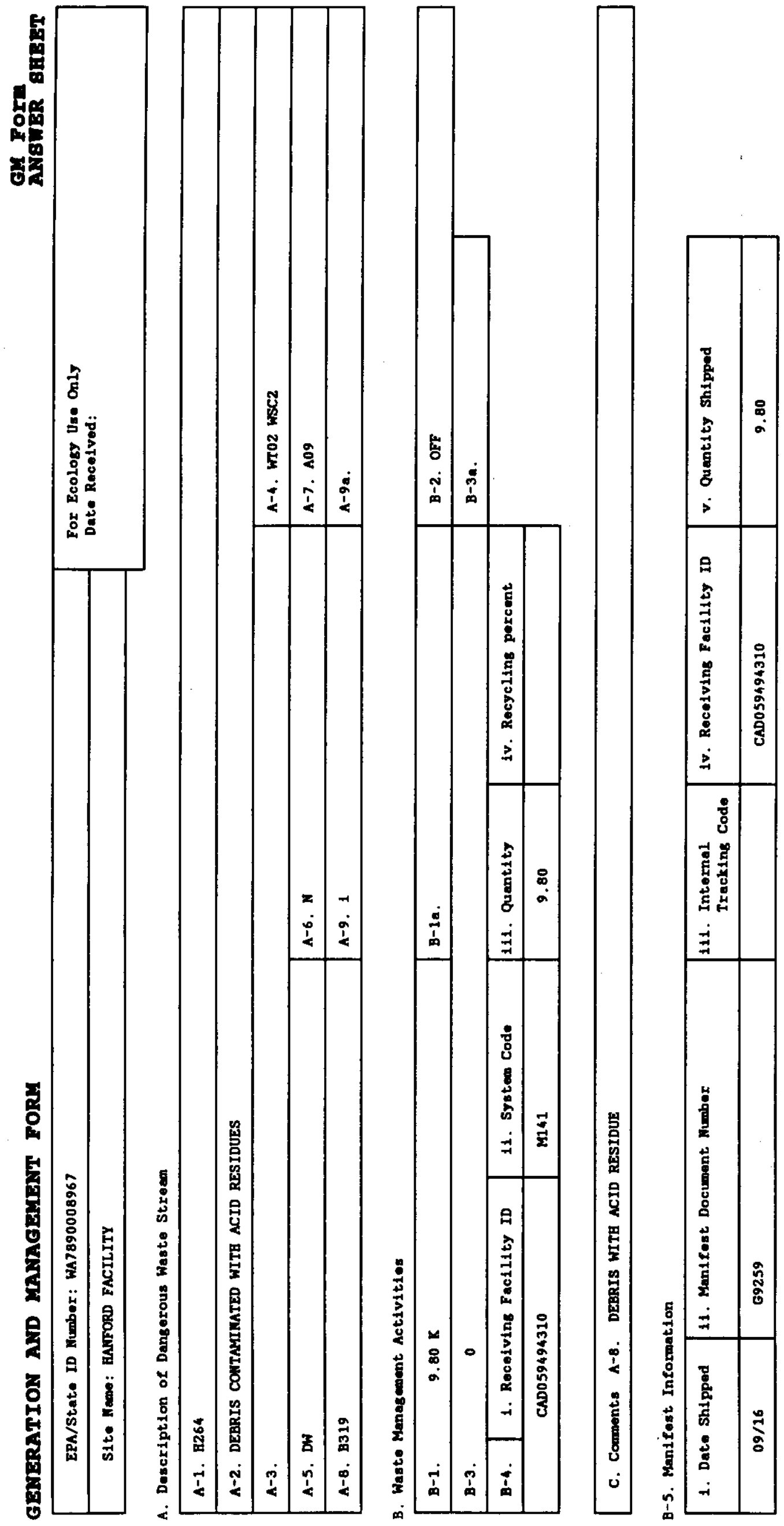



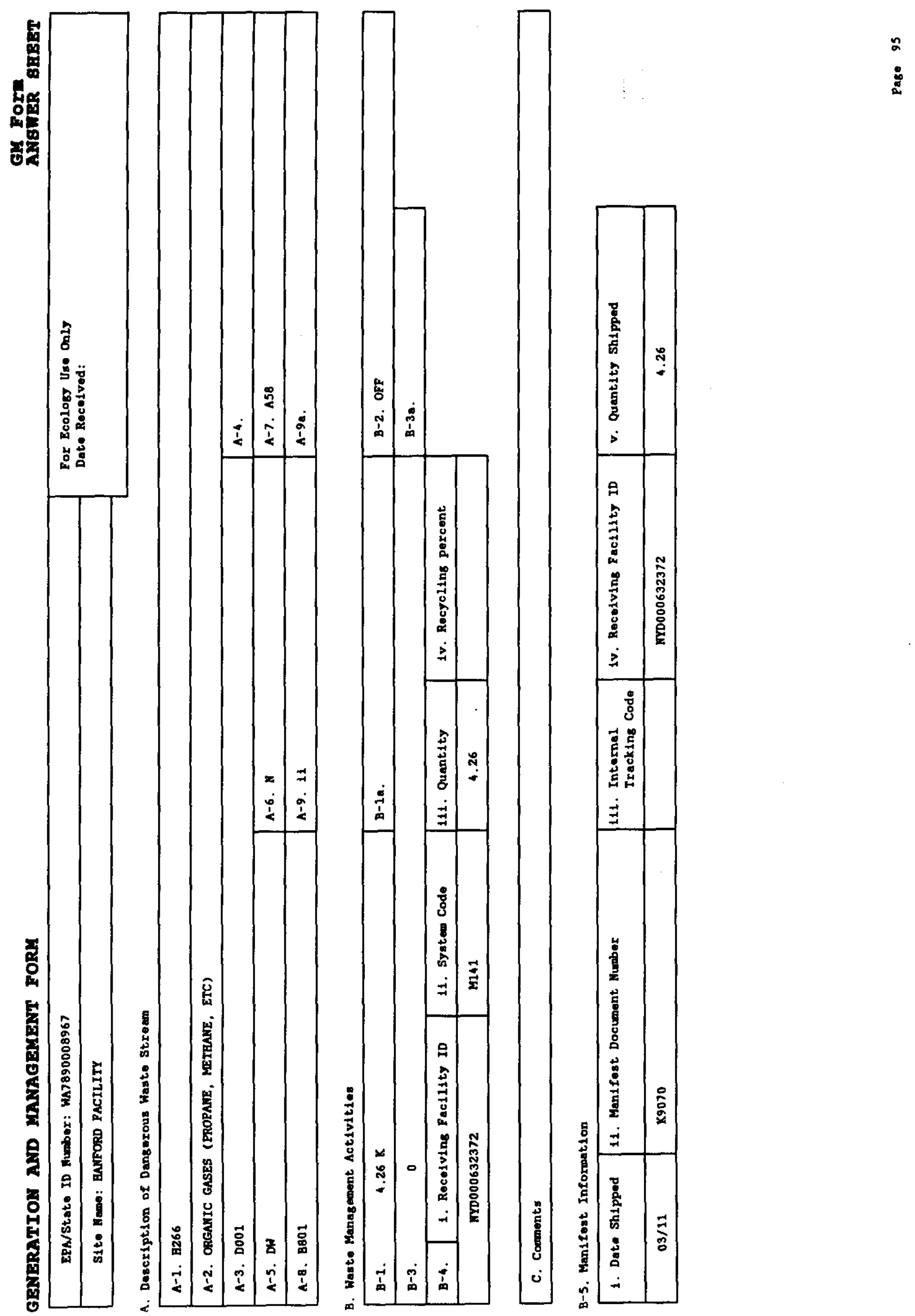


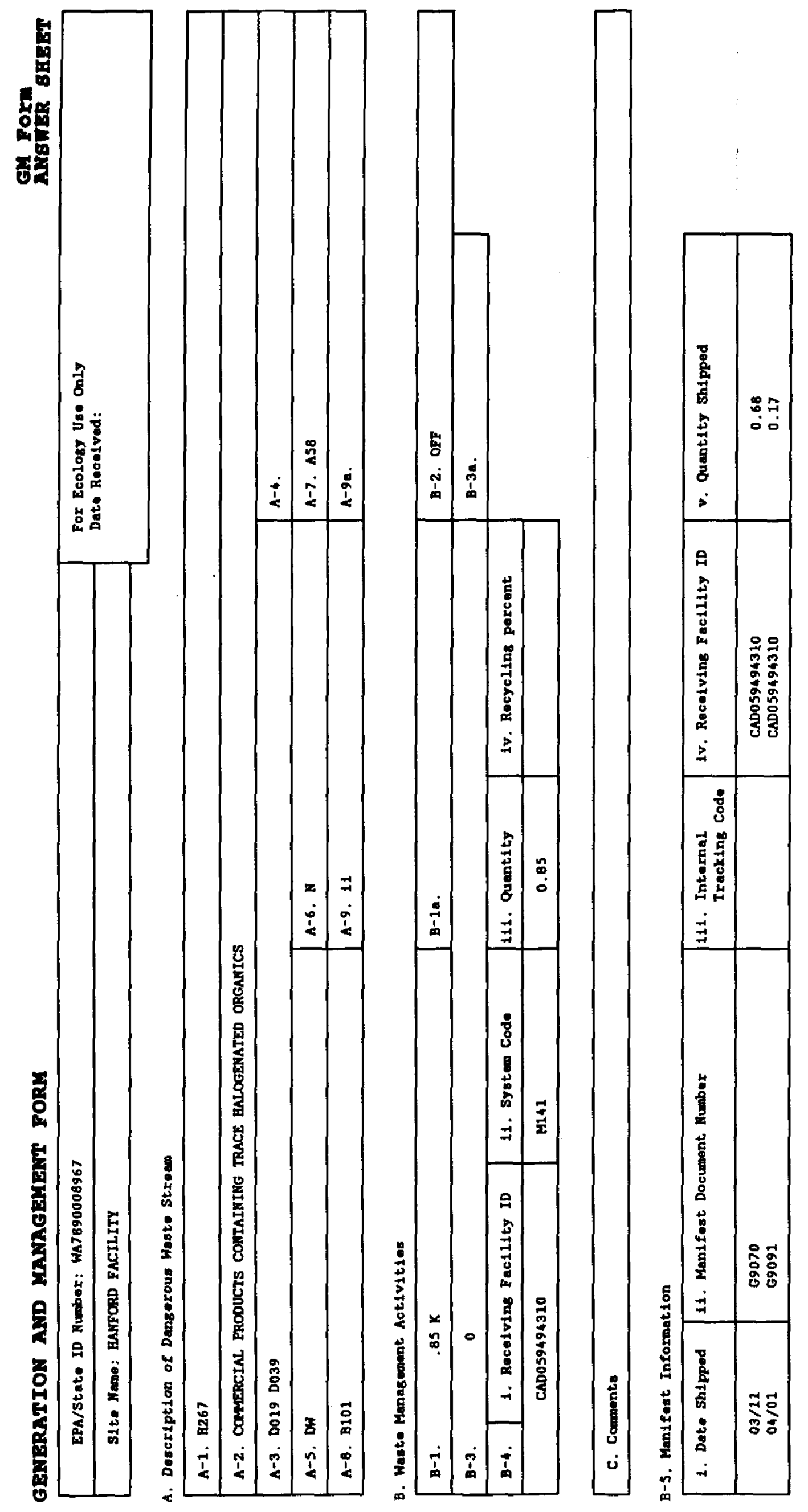



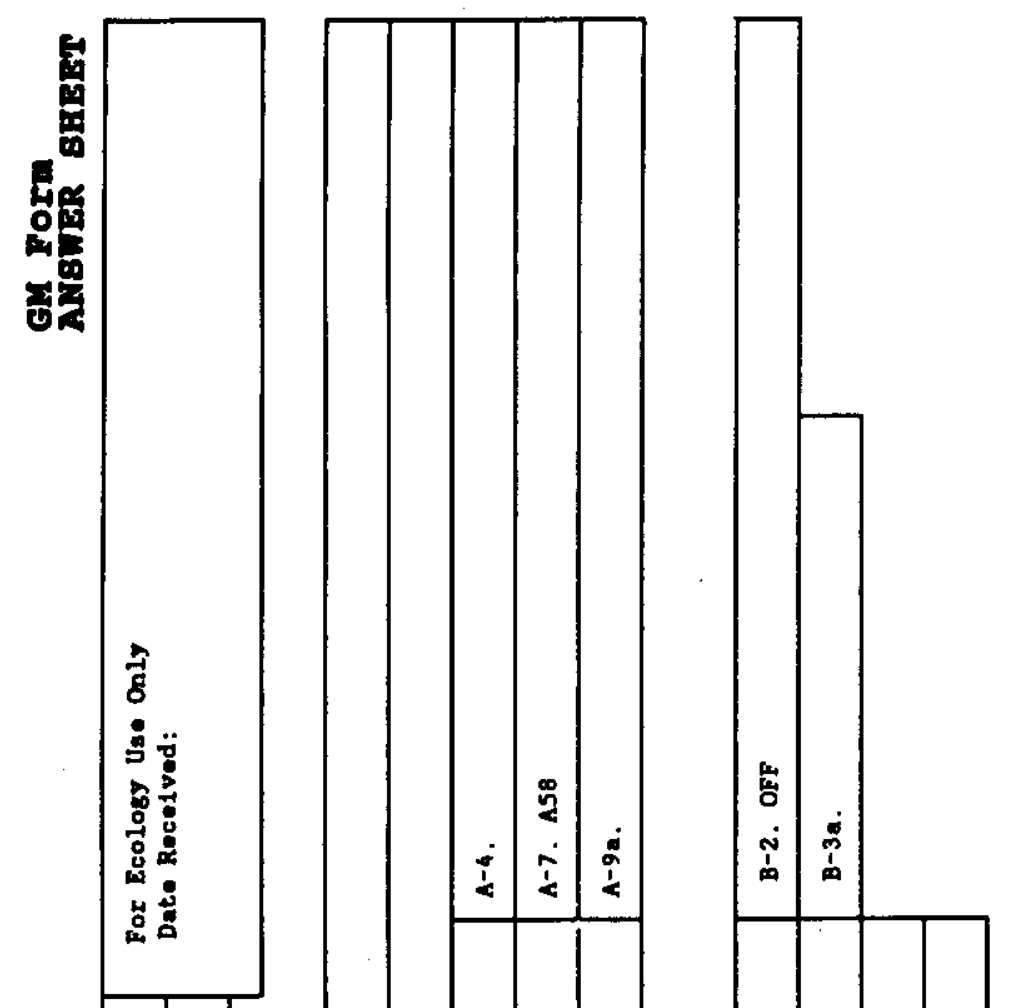

a
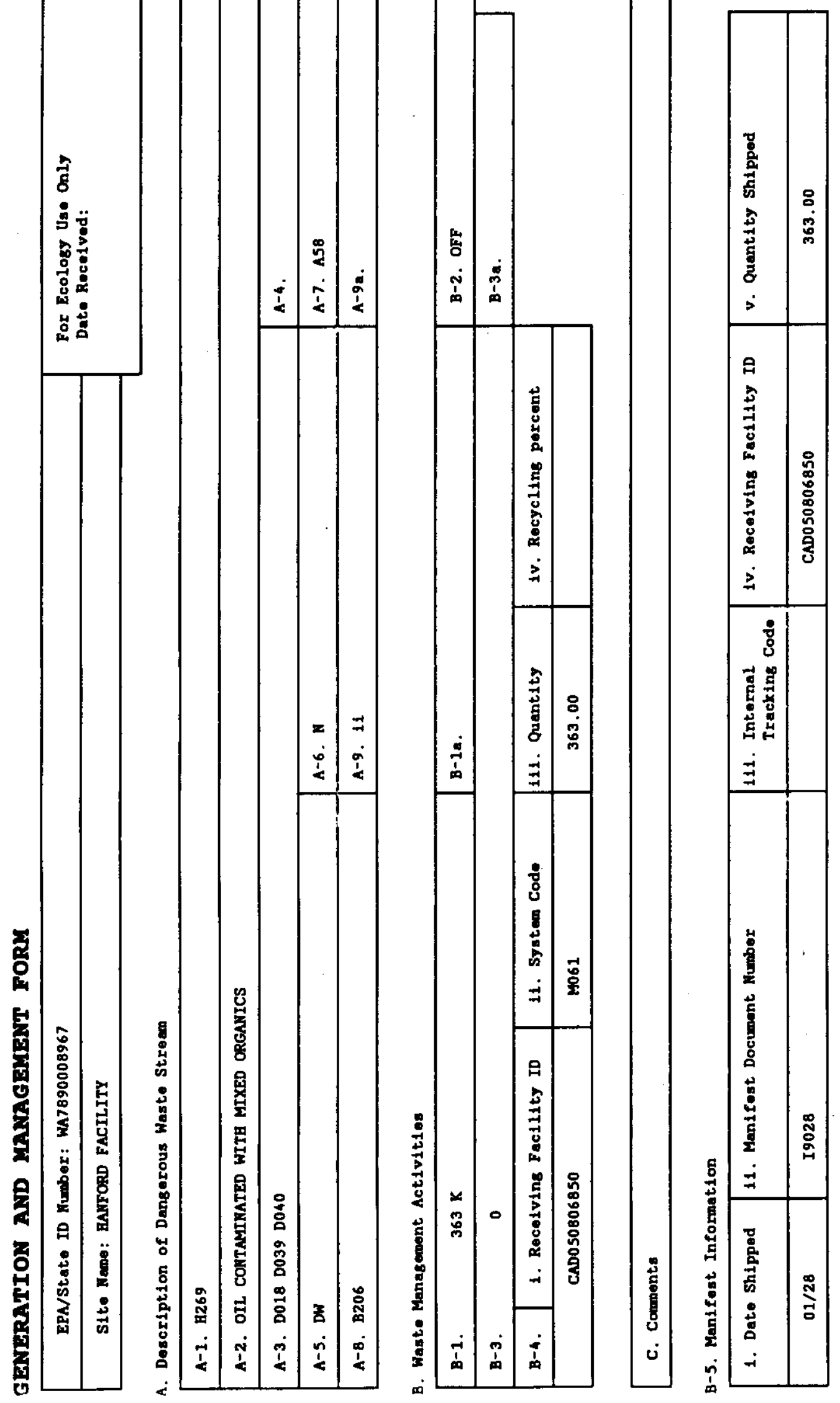


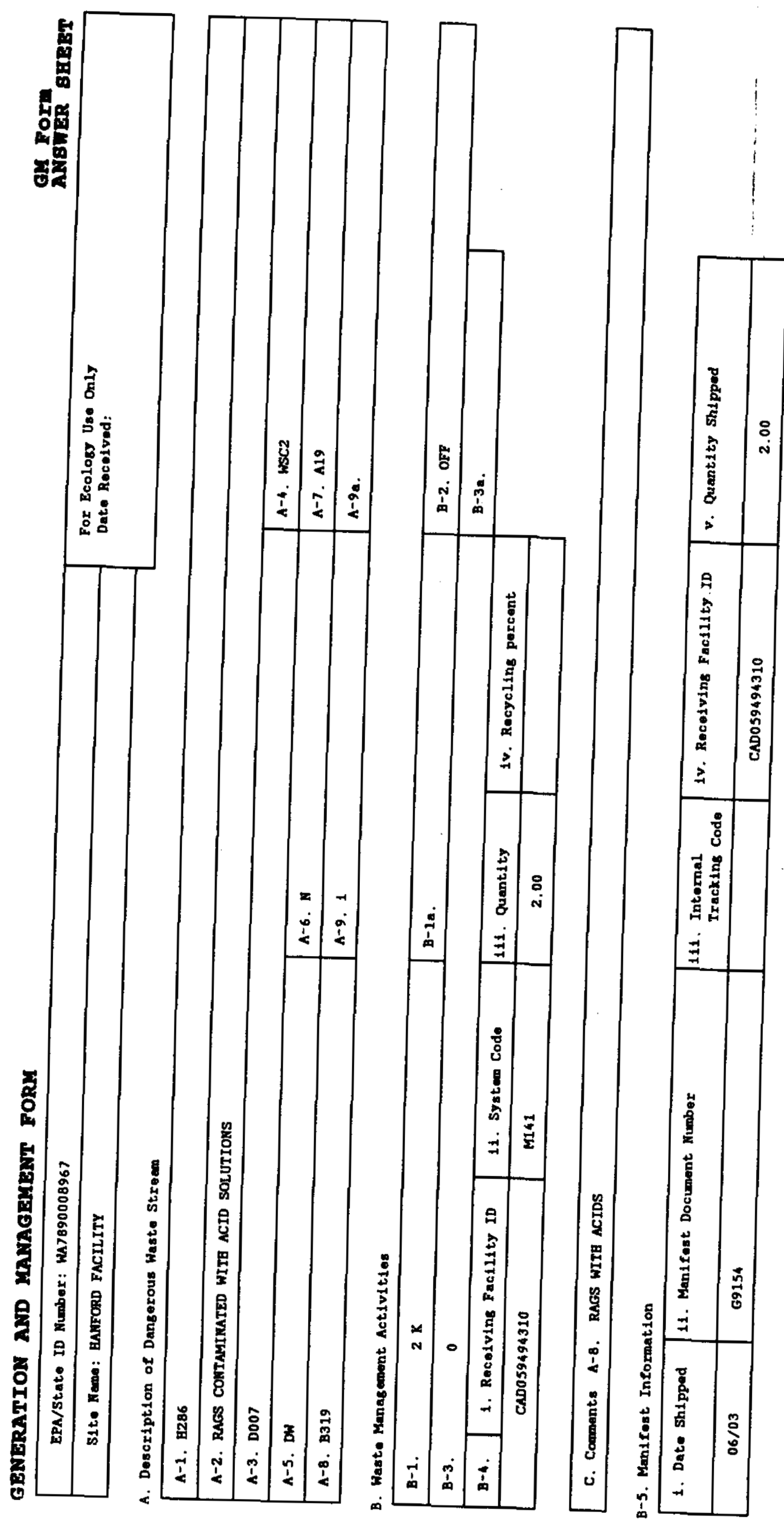




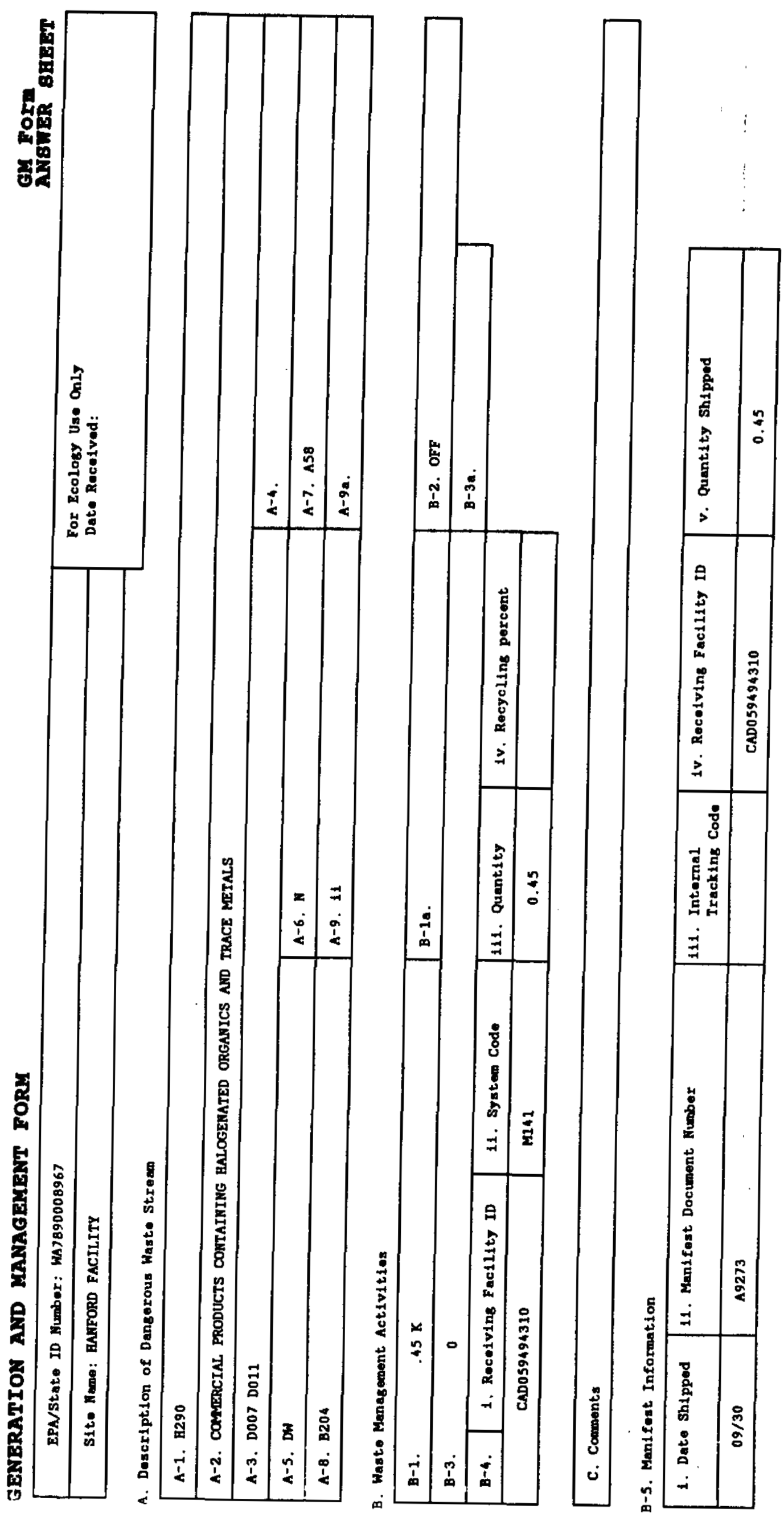




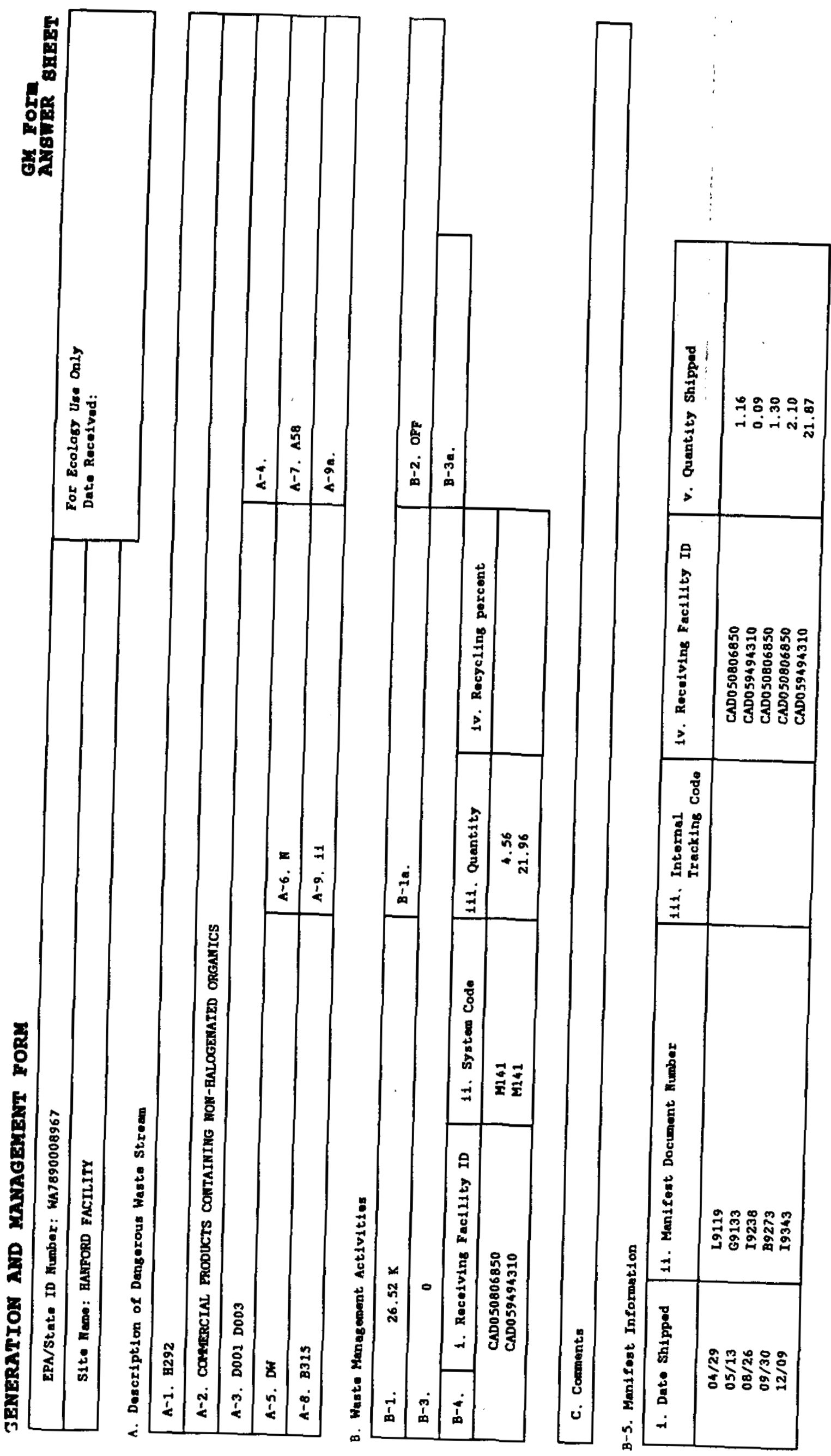




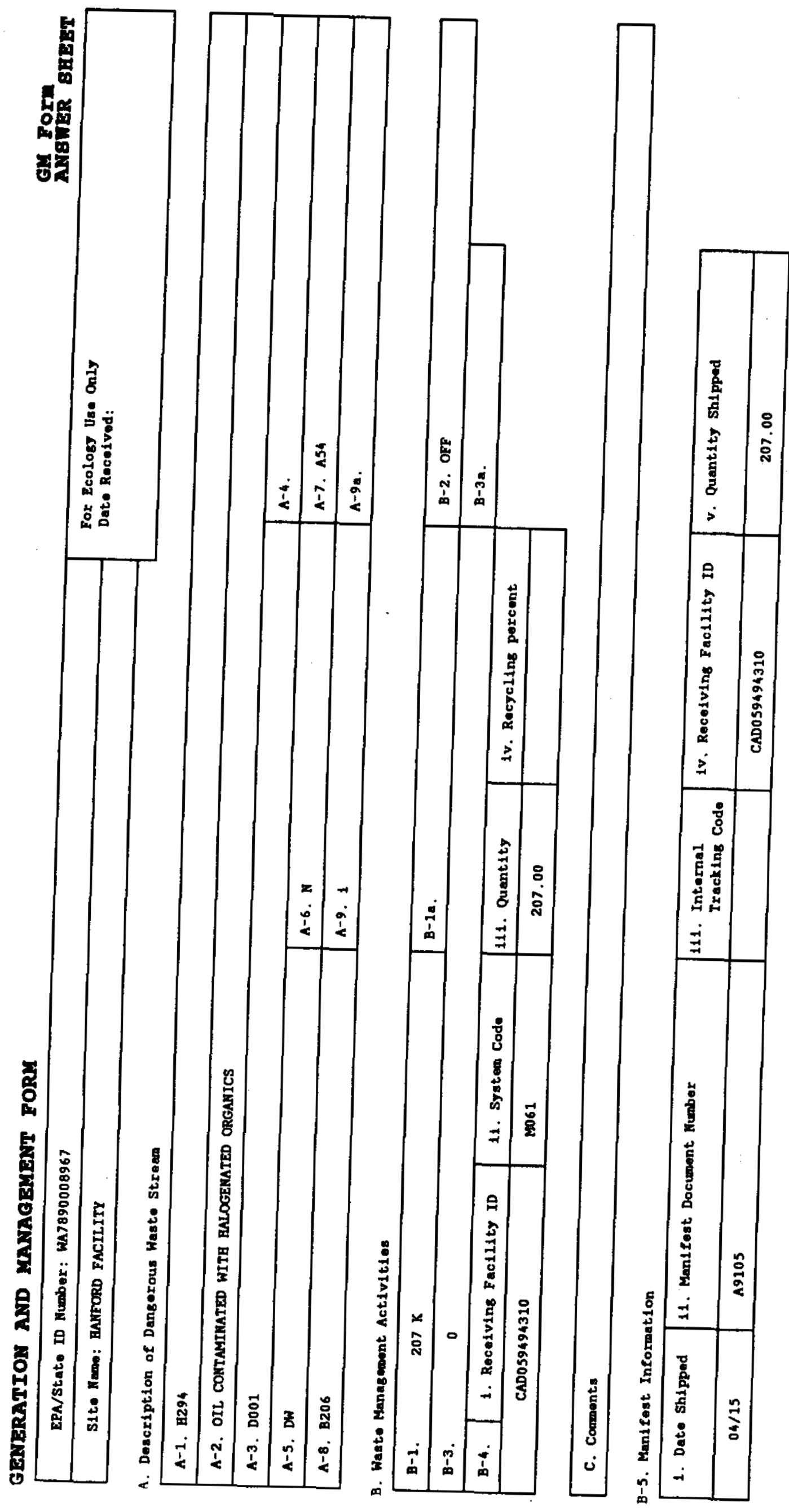




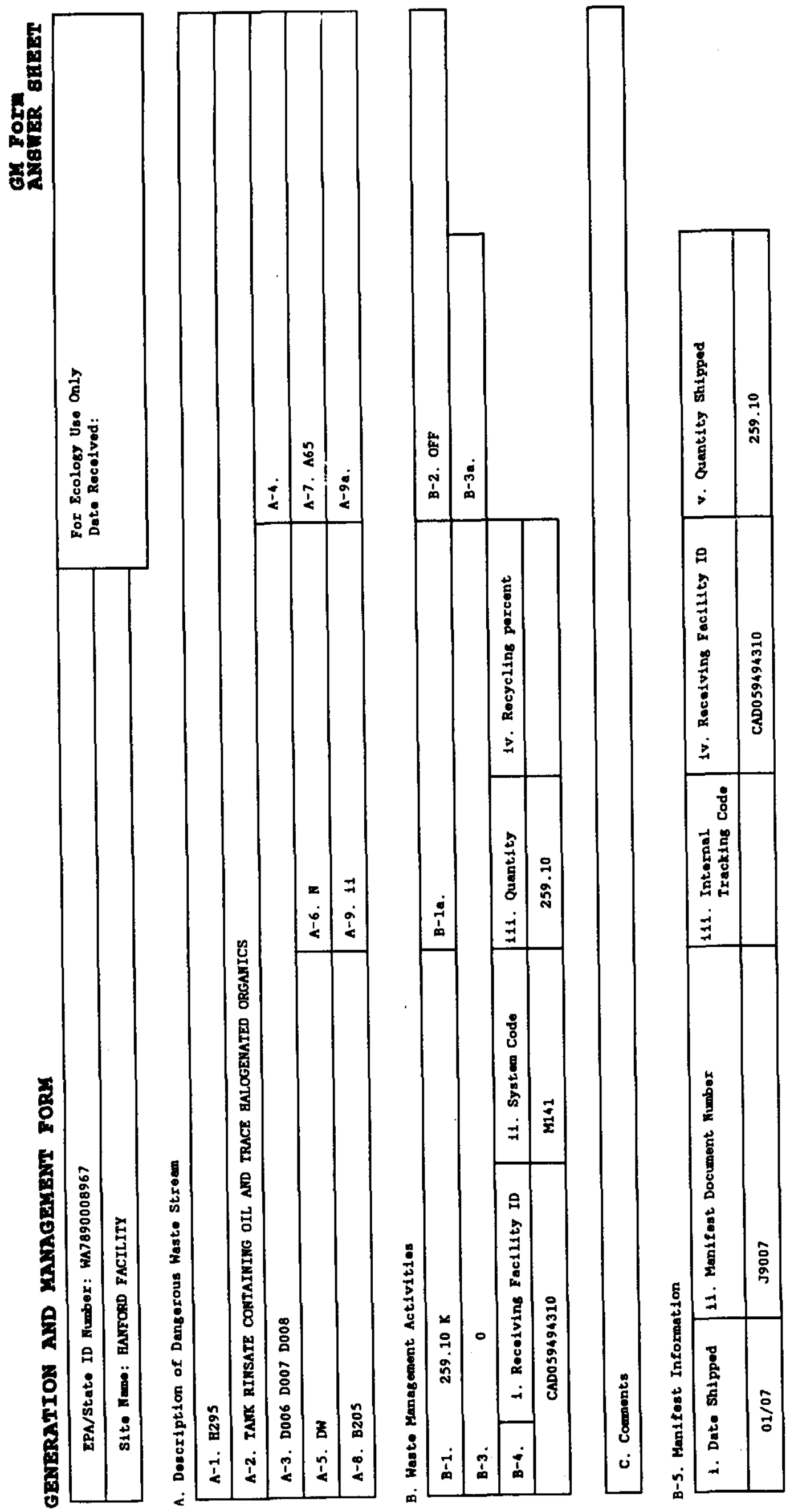




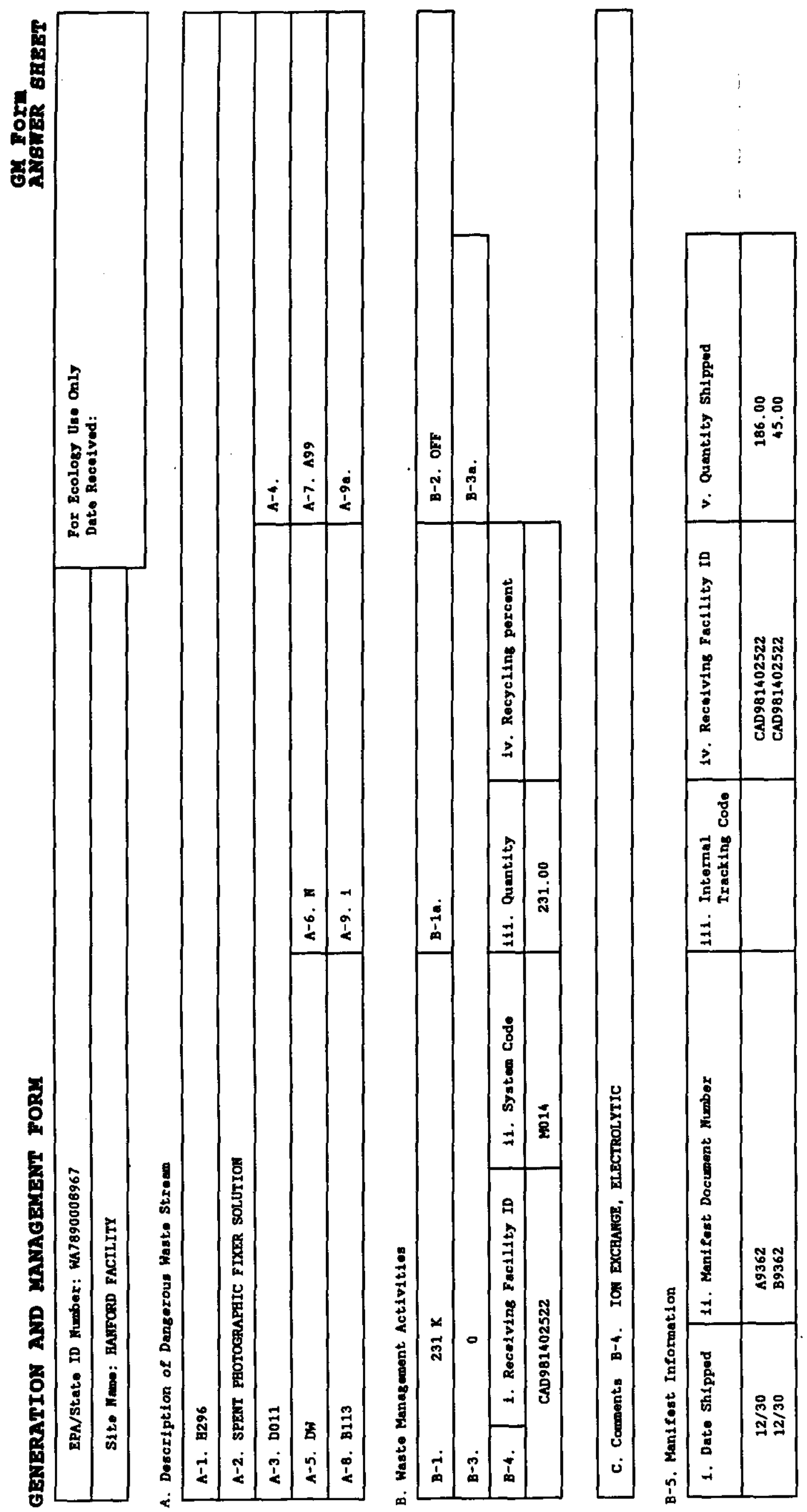




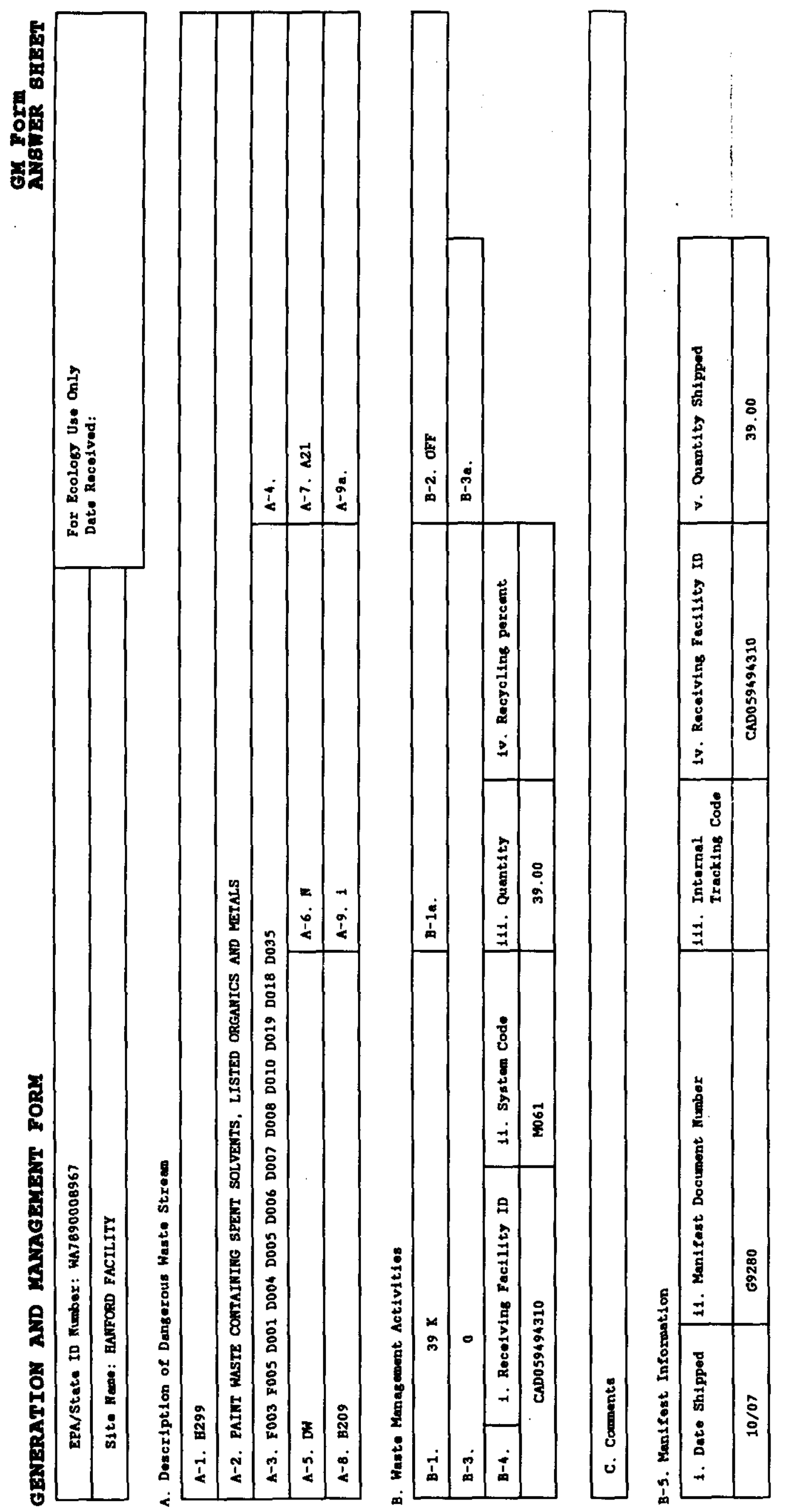




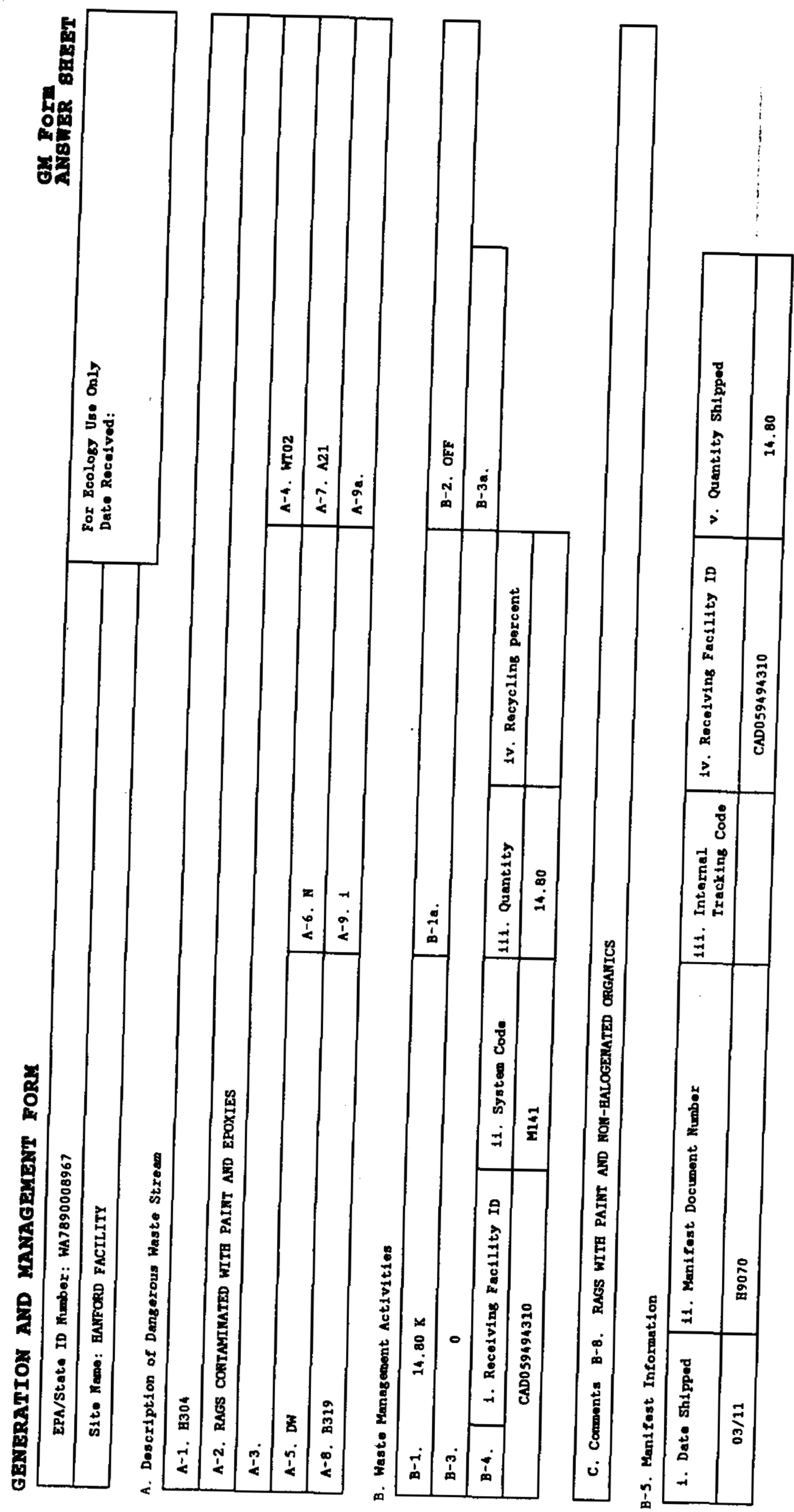




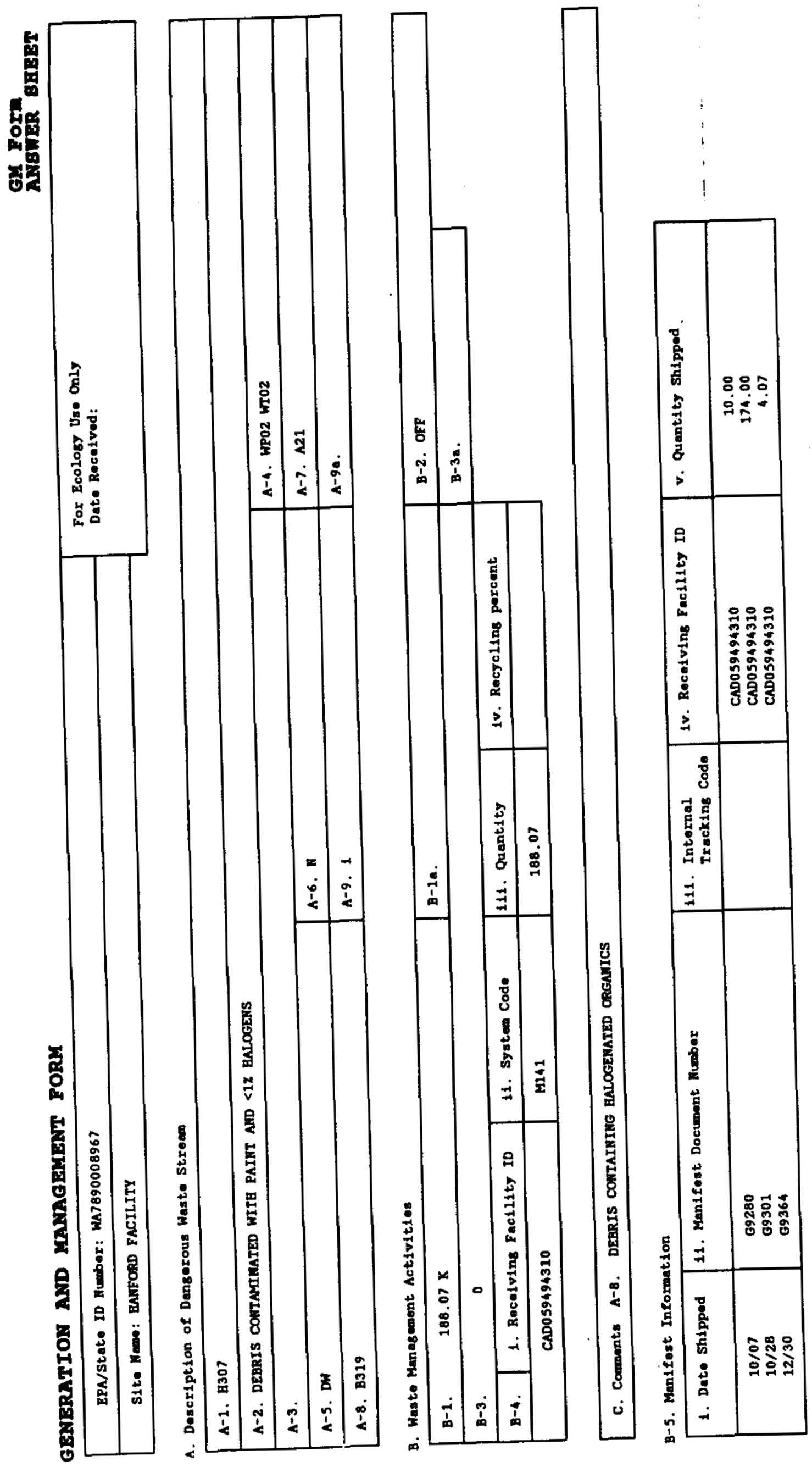




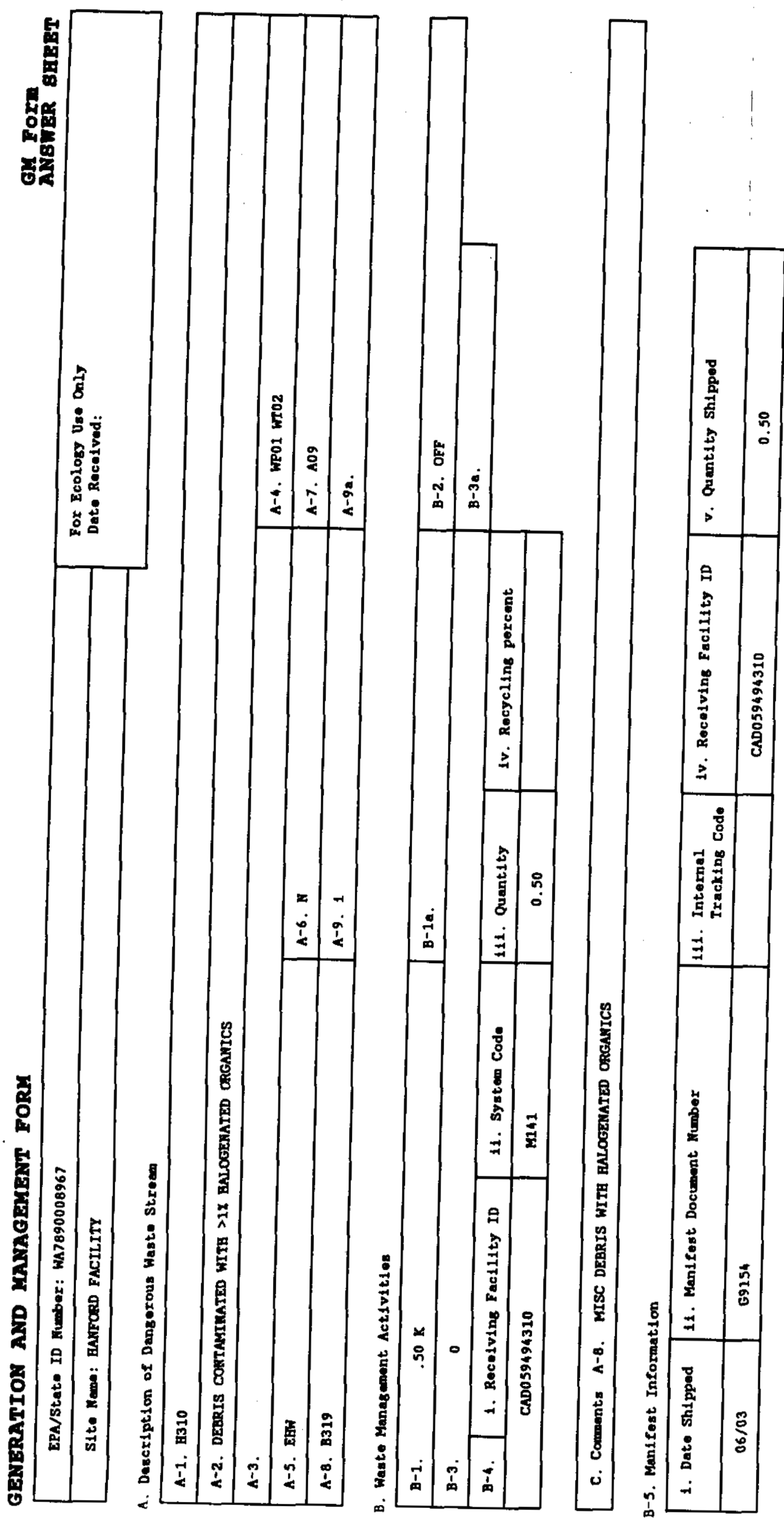




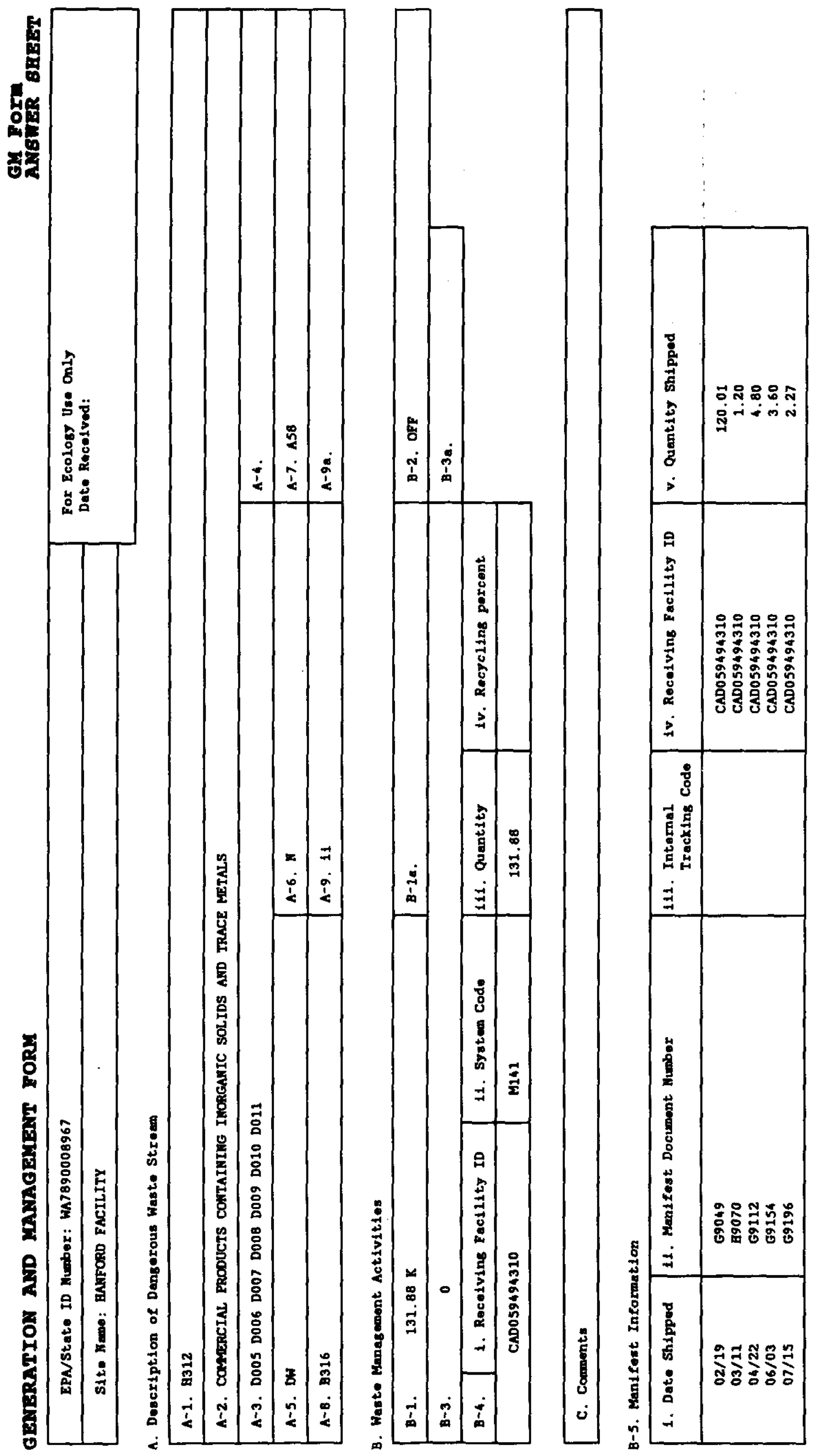




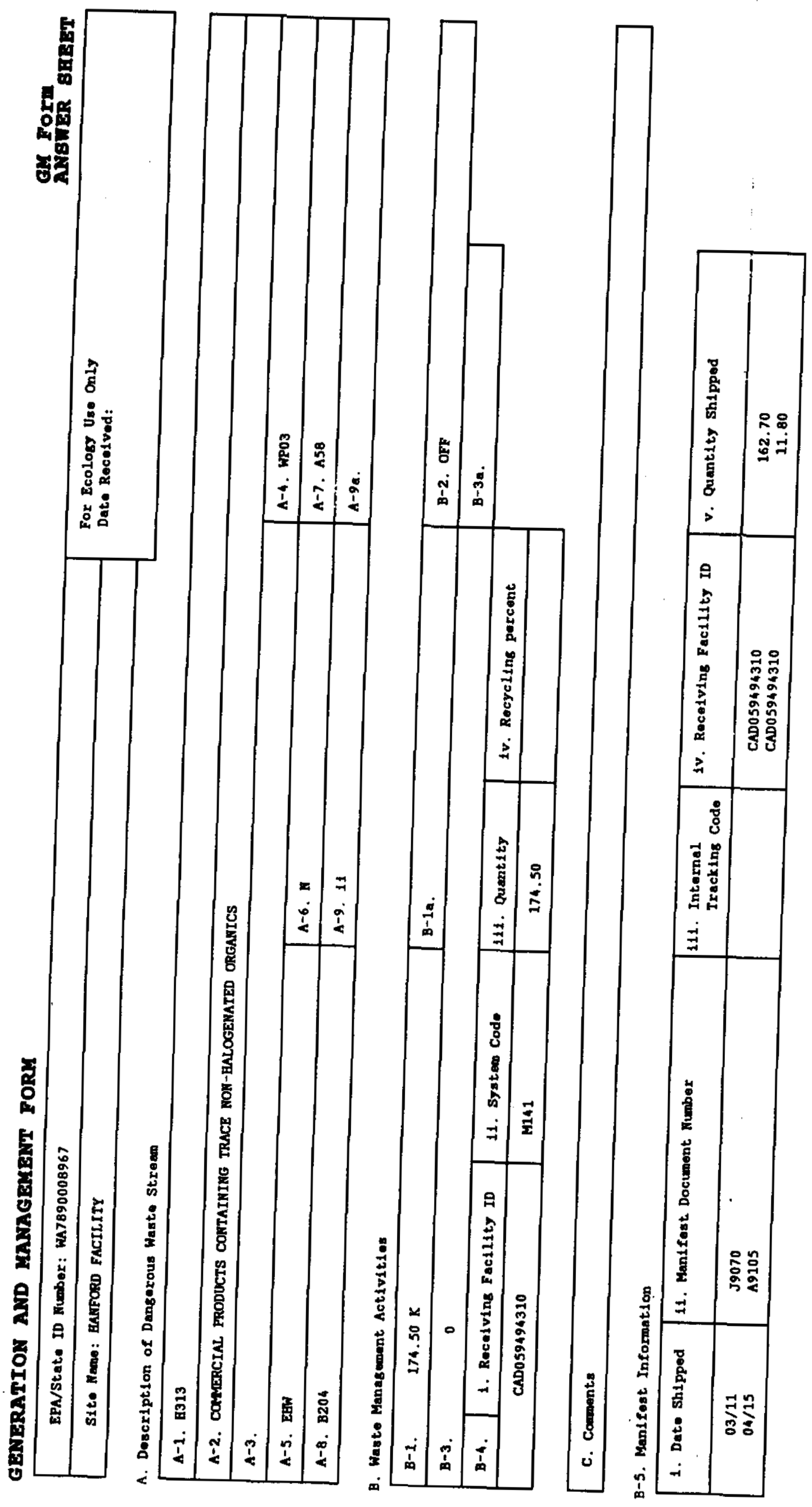




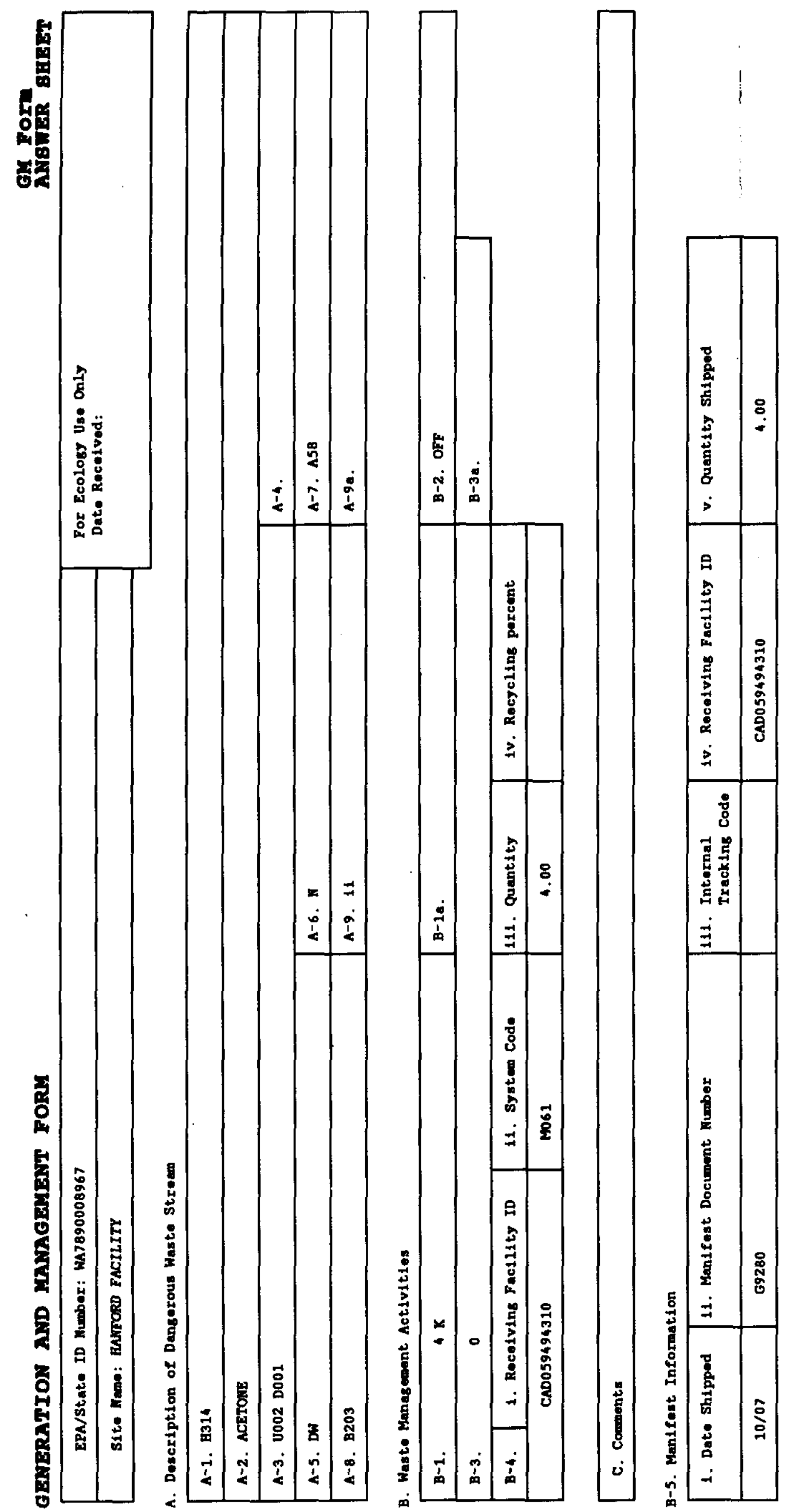




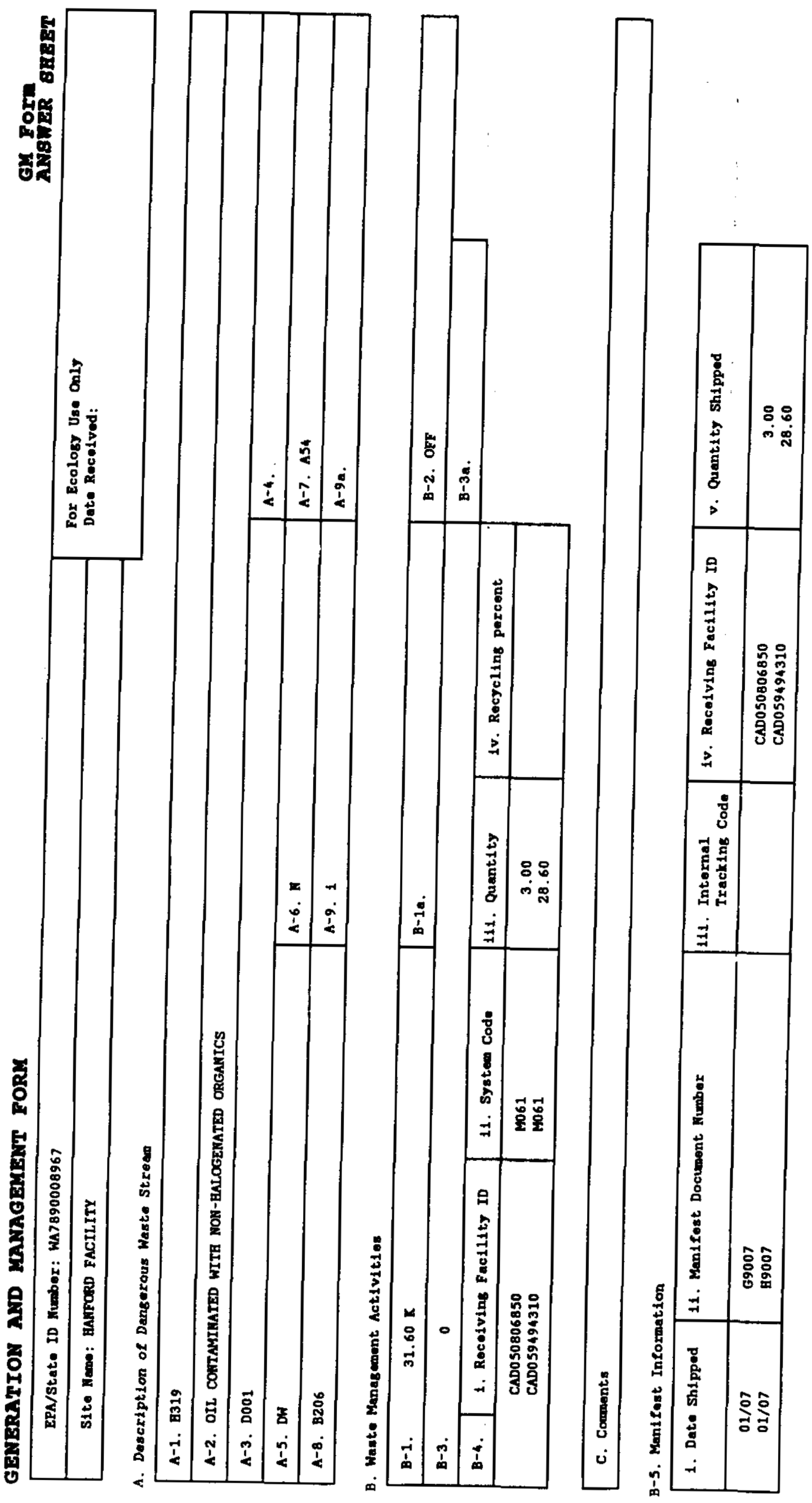



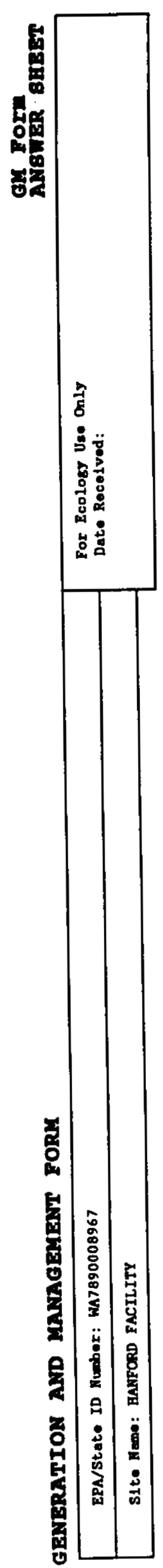
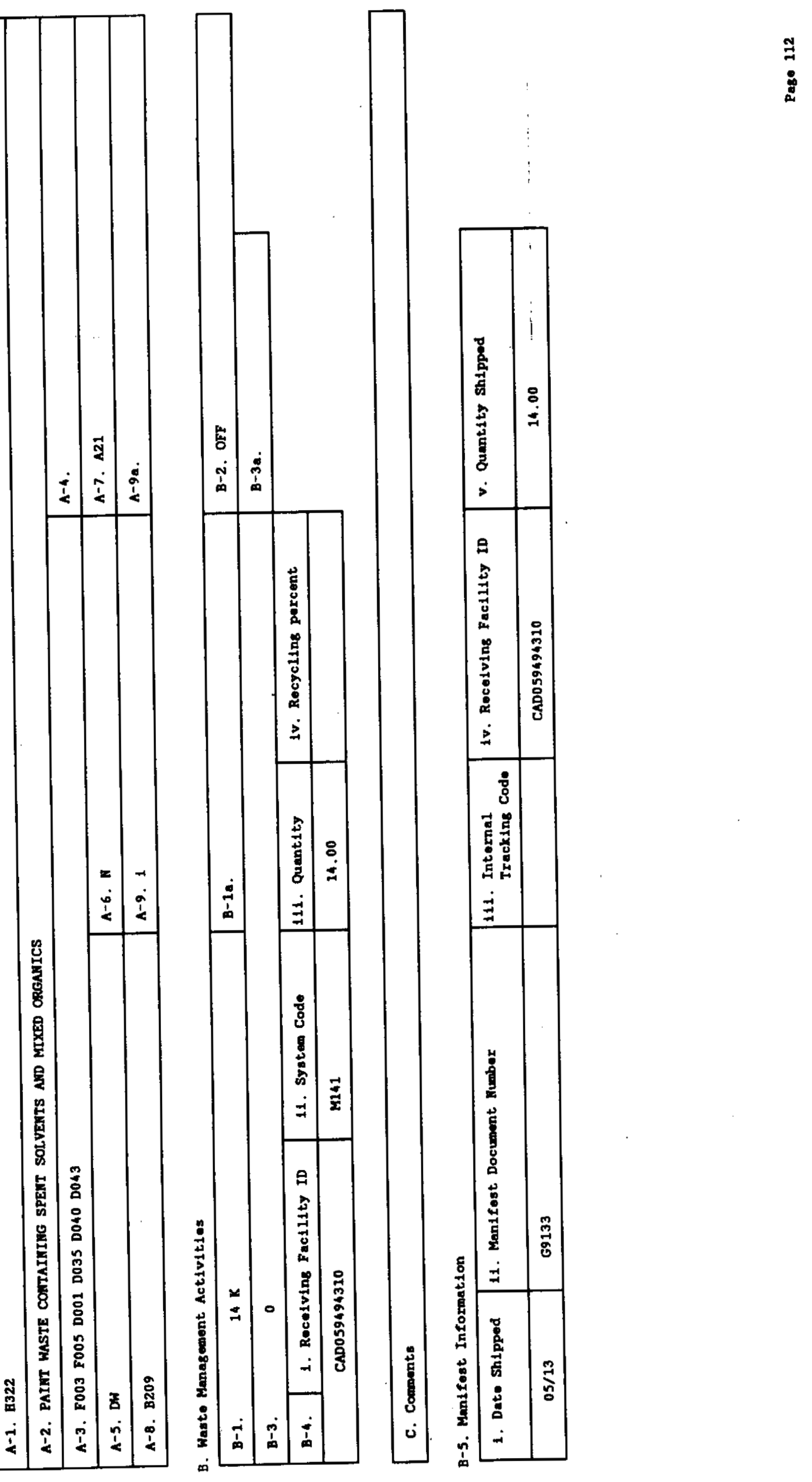


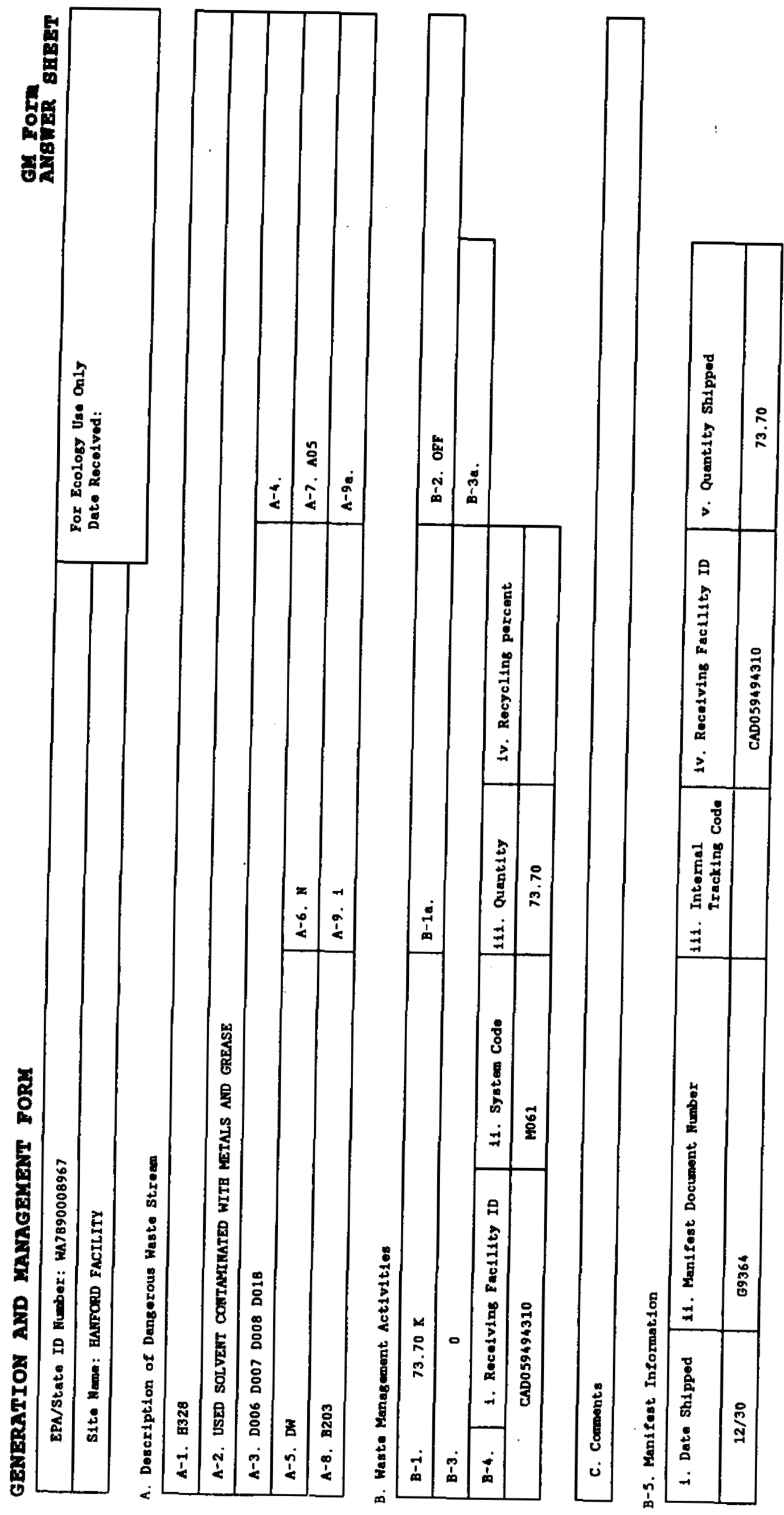



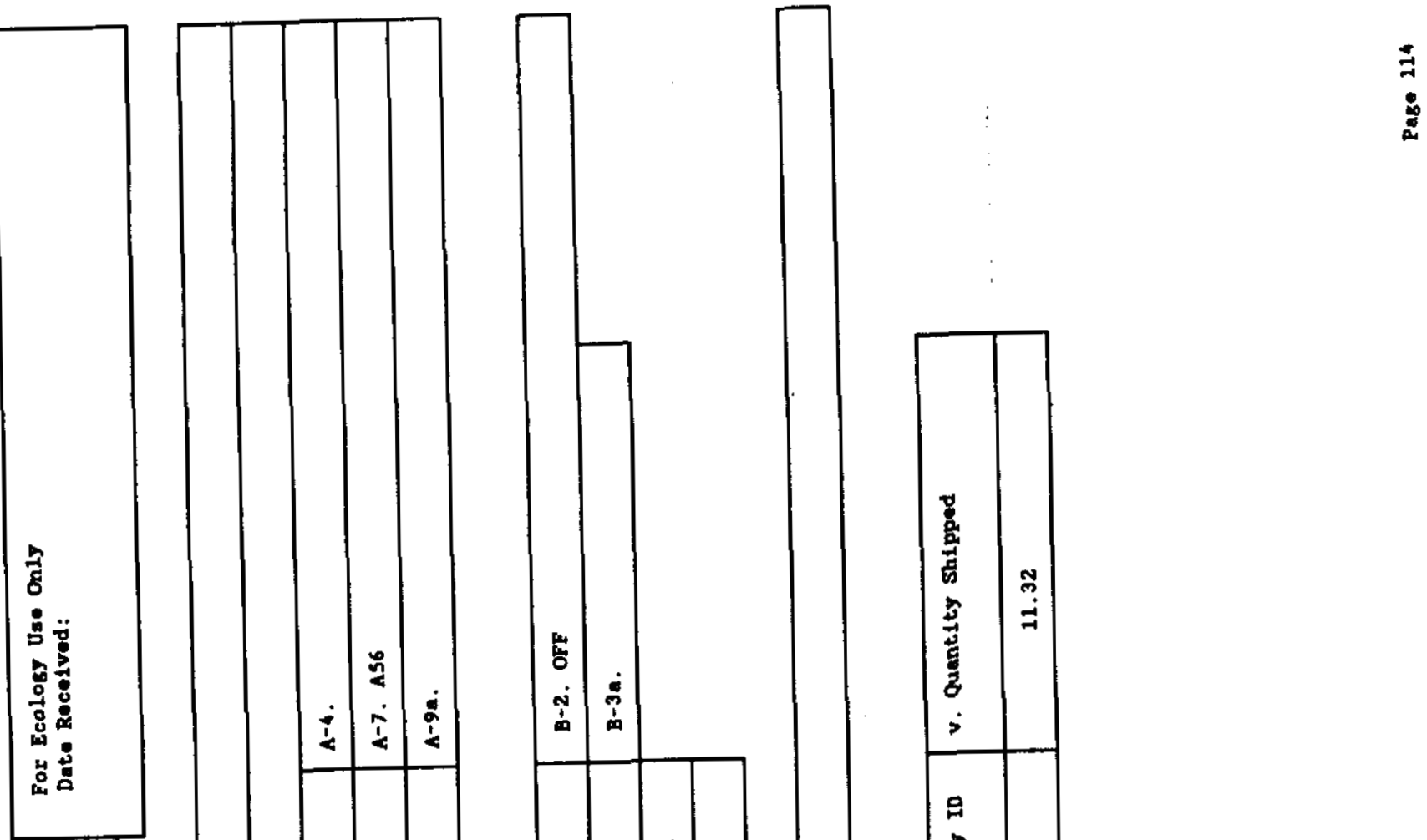

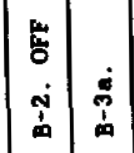
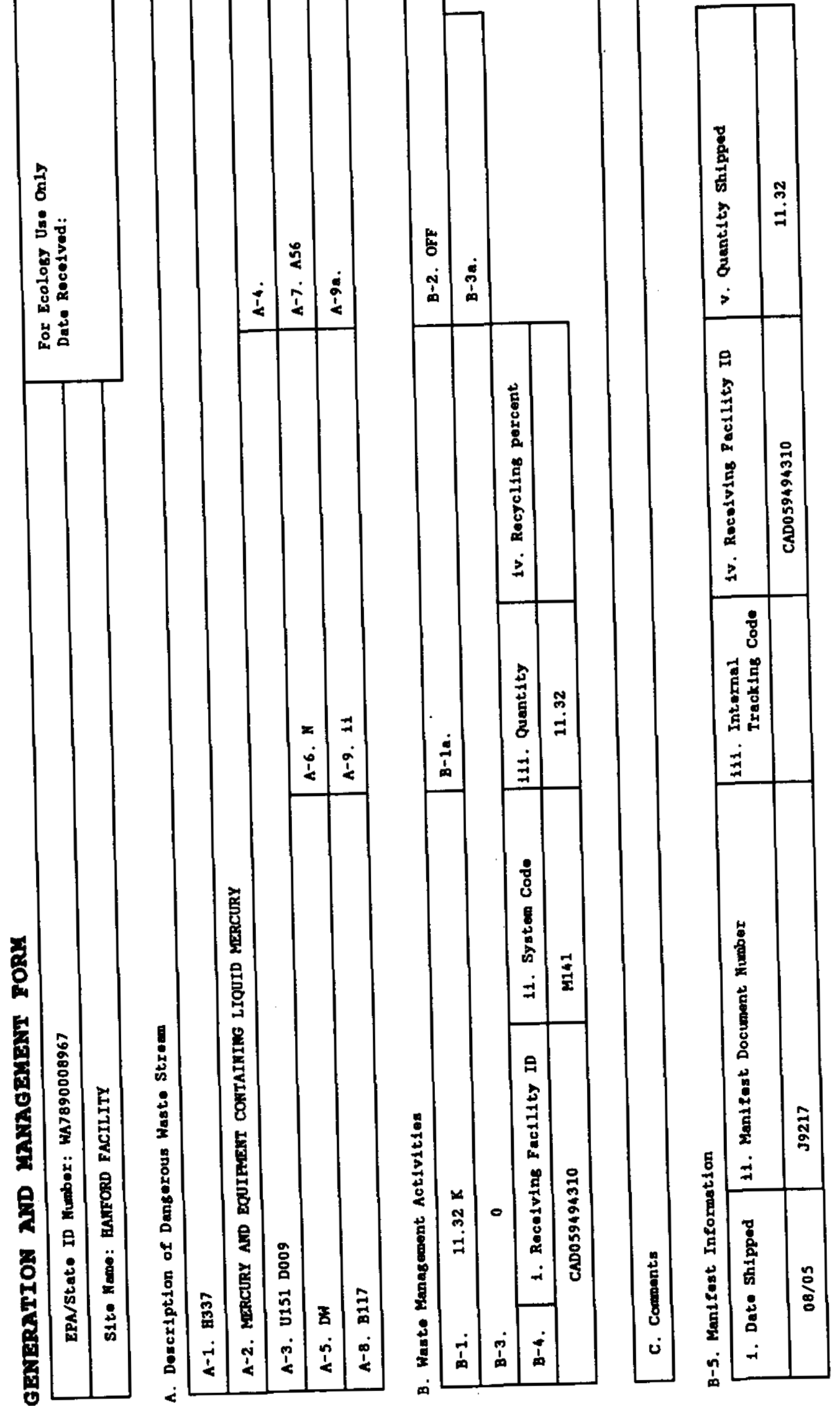
象

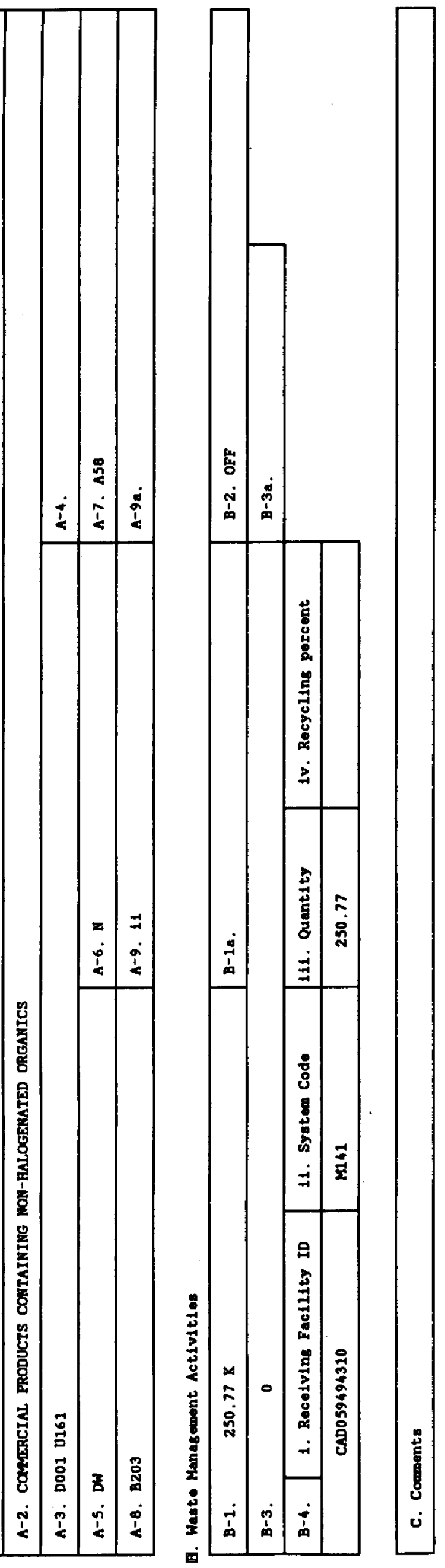

$\stackrel{n}{a}$

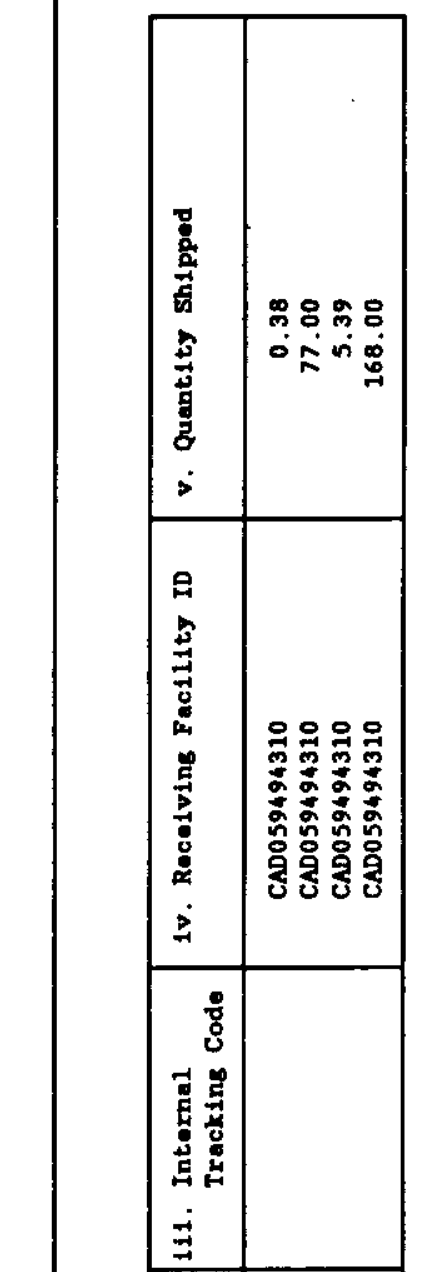

总

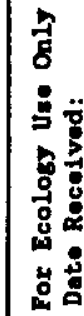
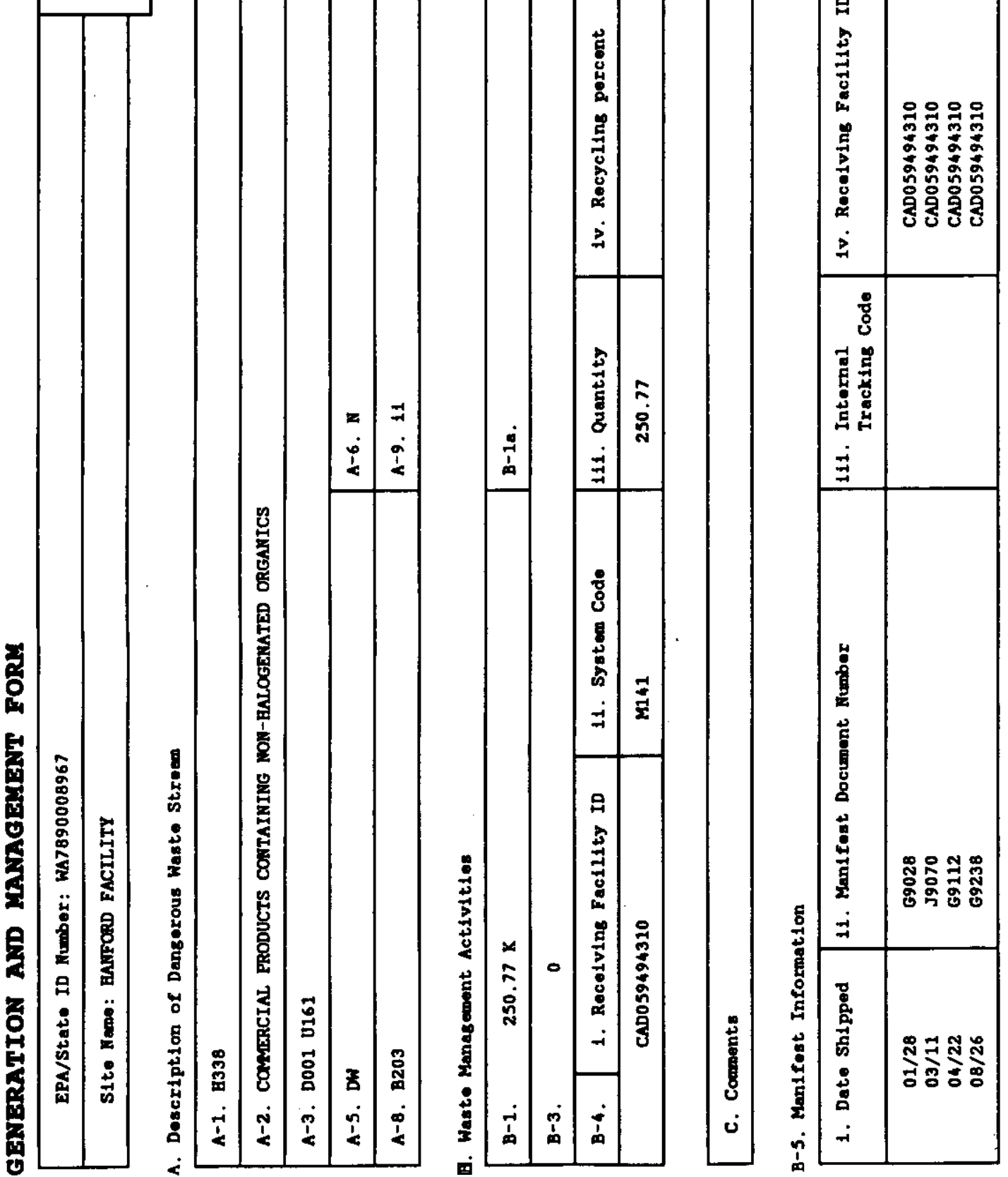

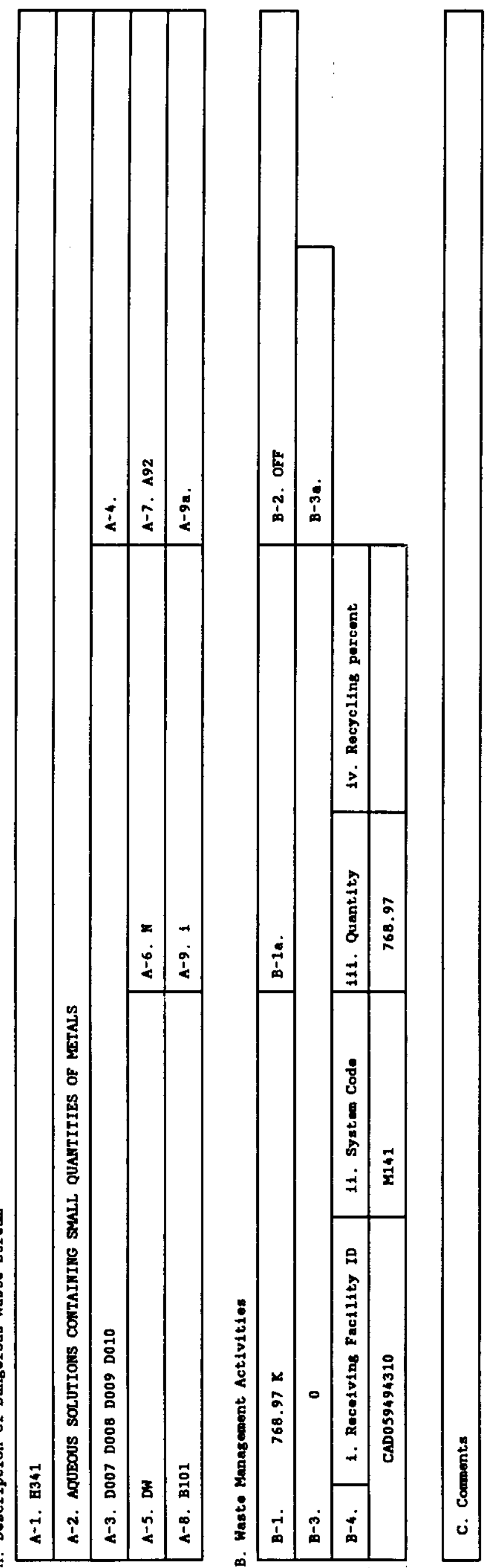

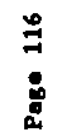

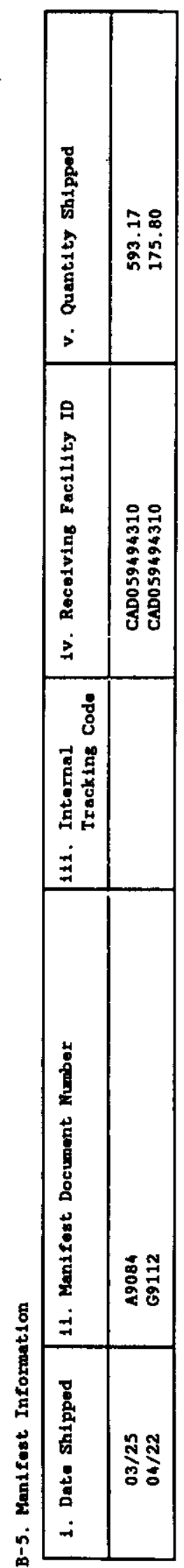




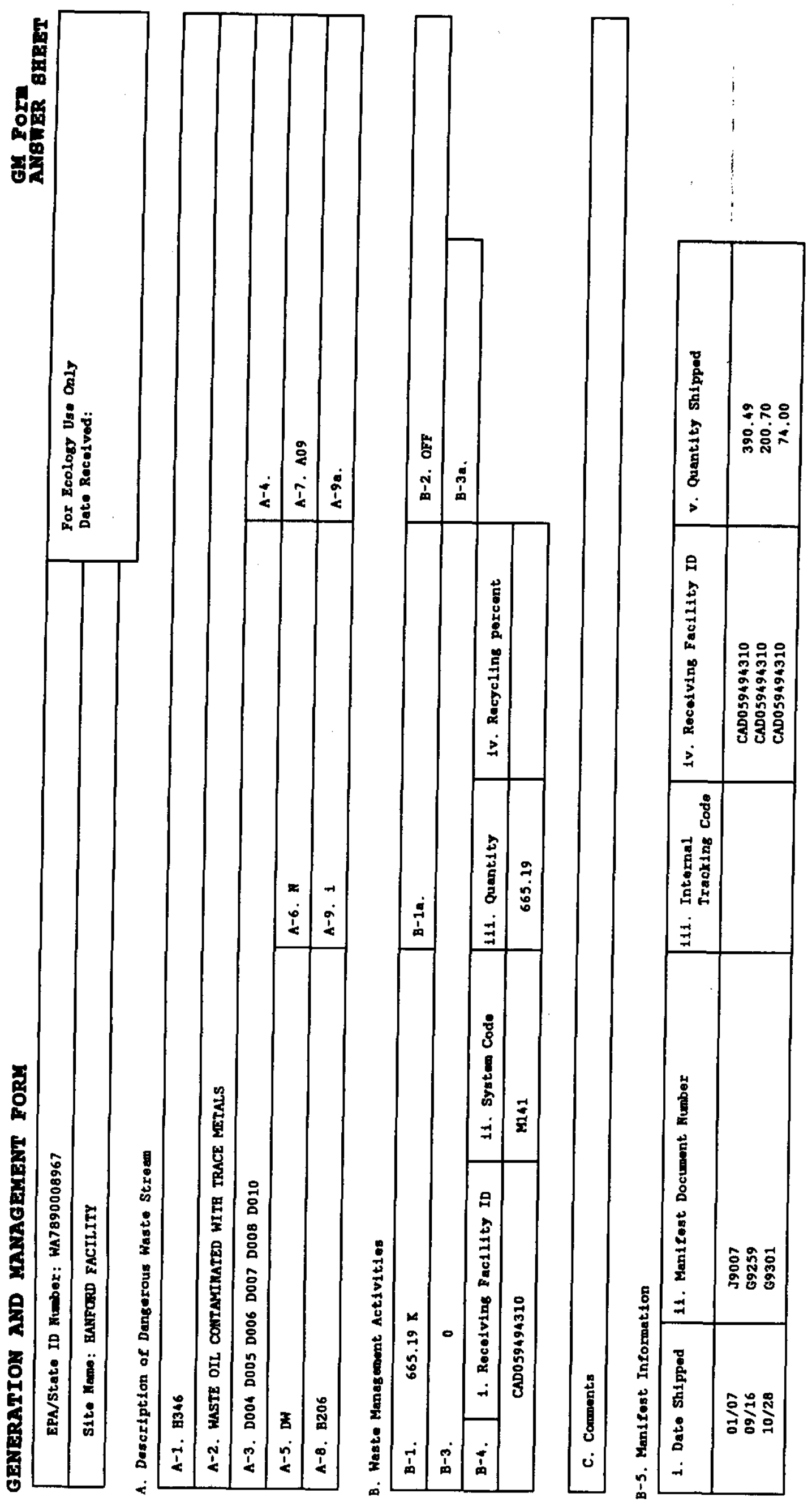



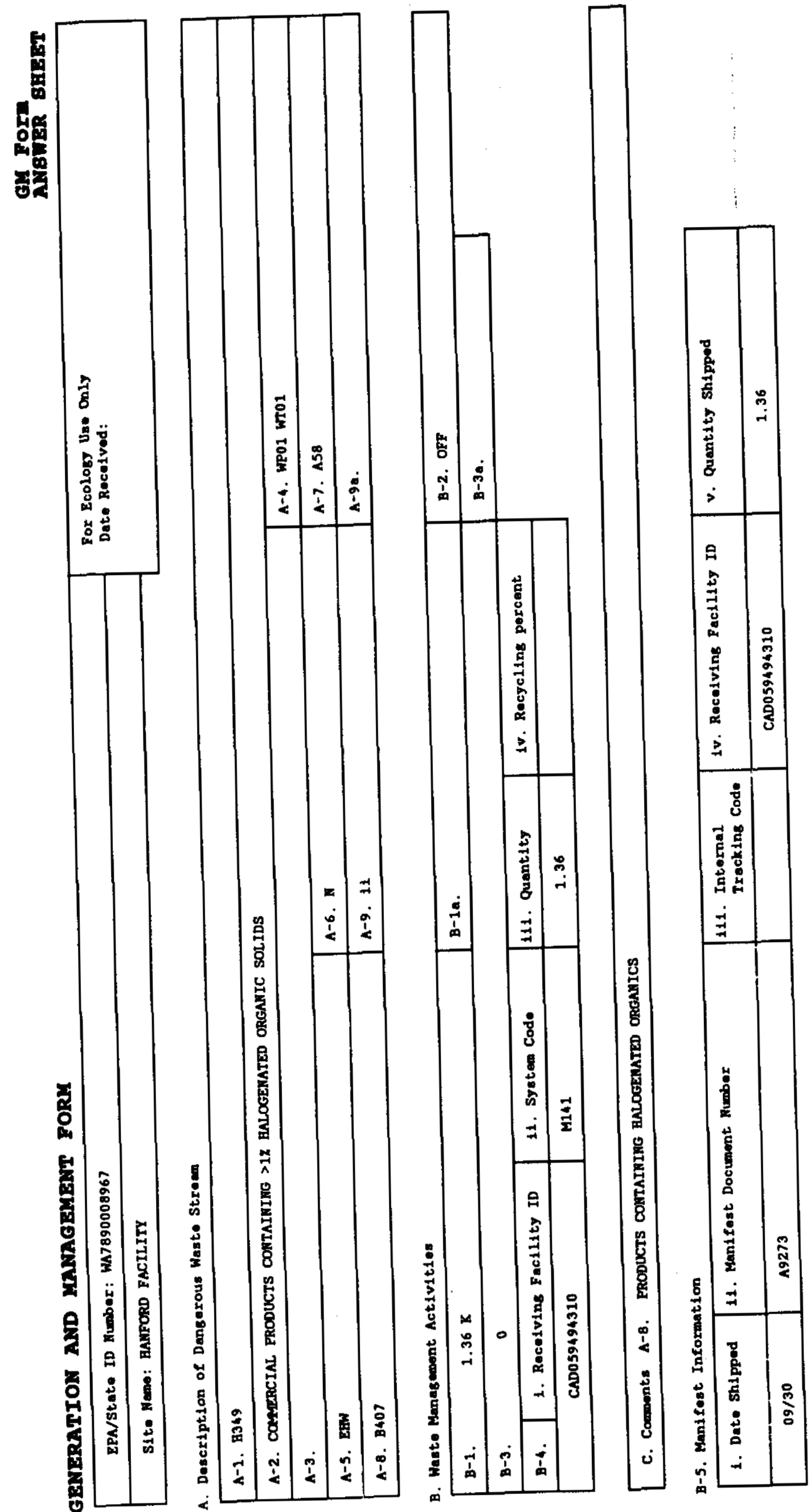


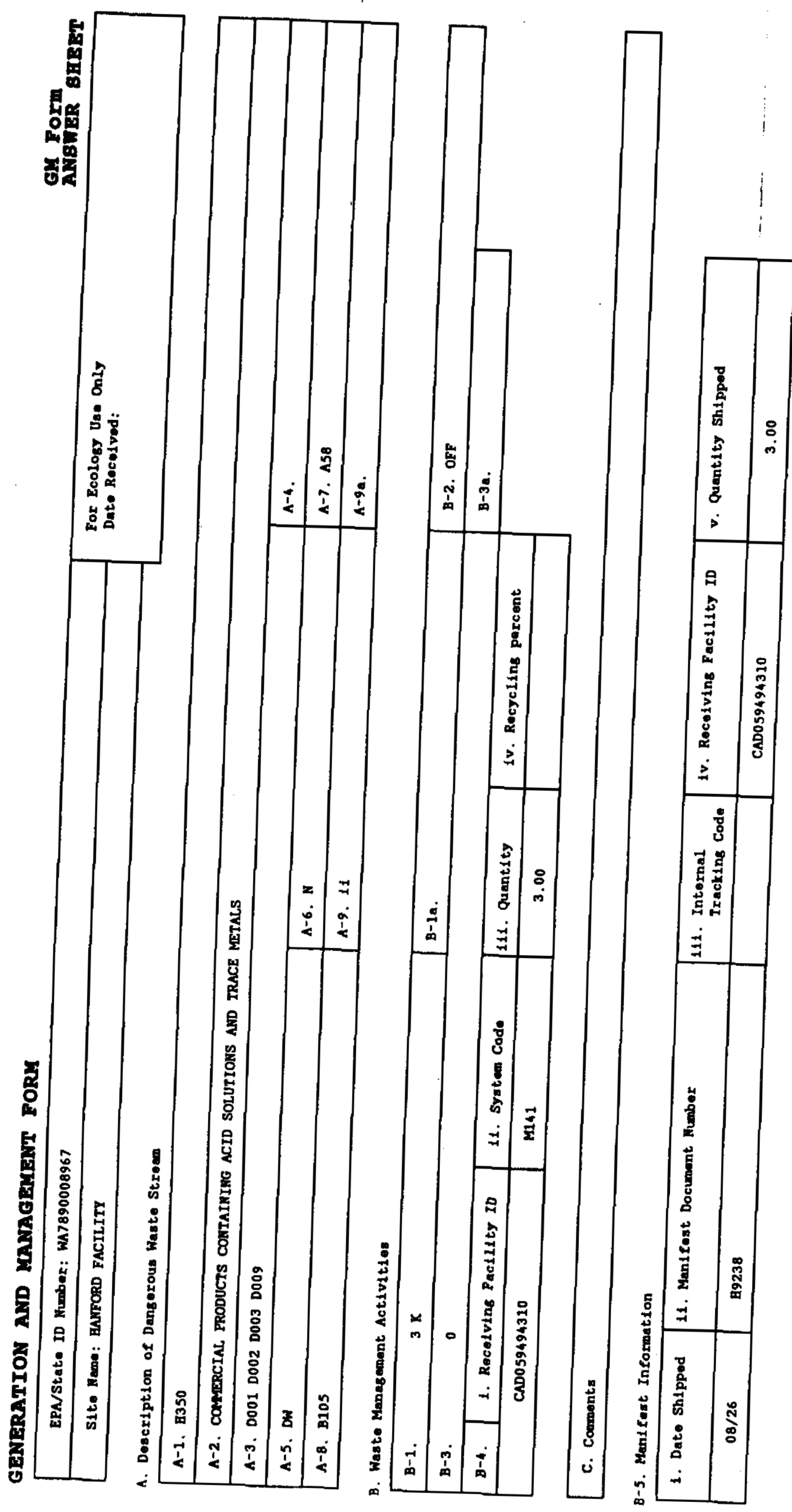




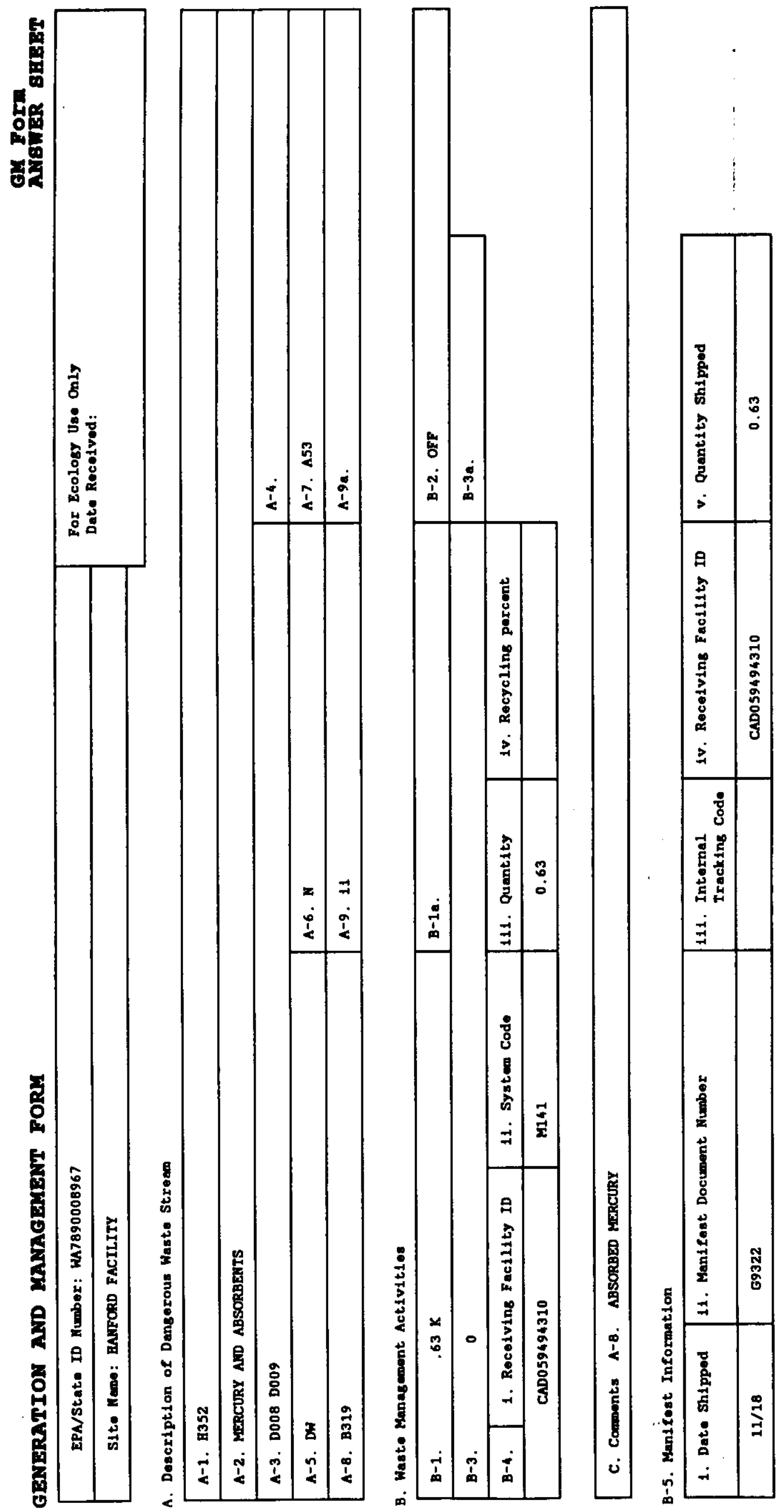




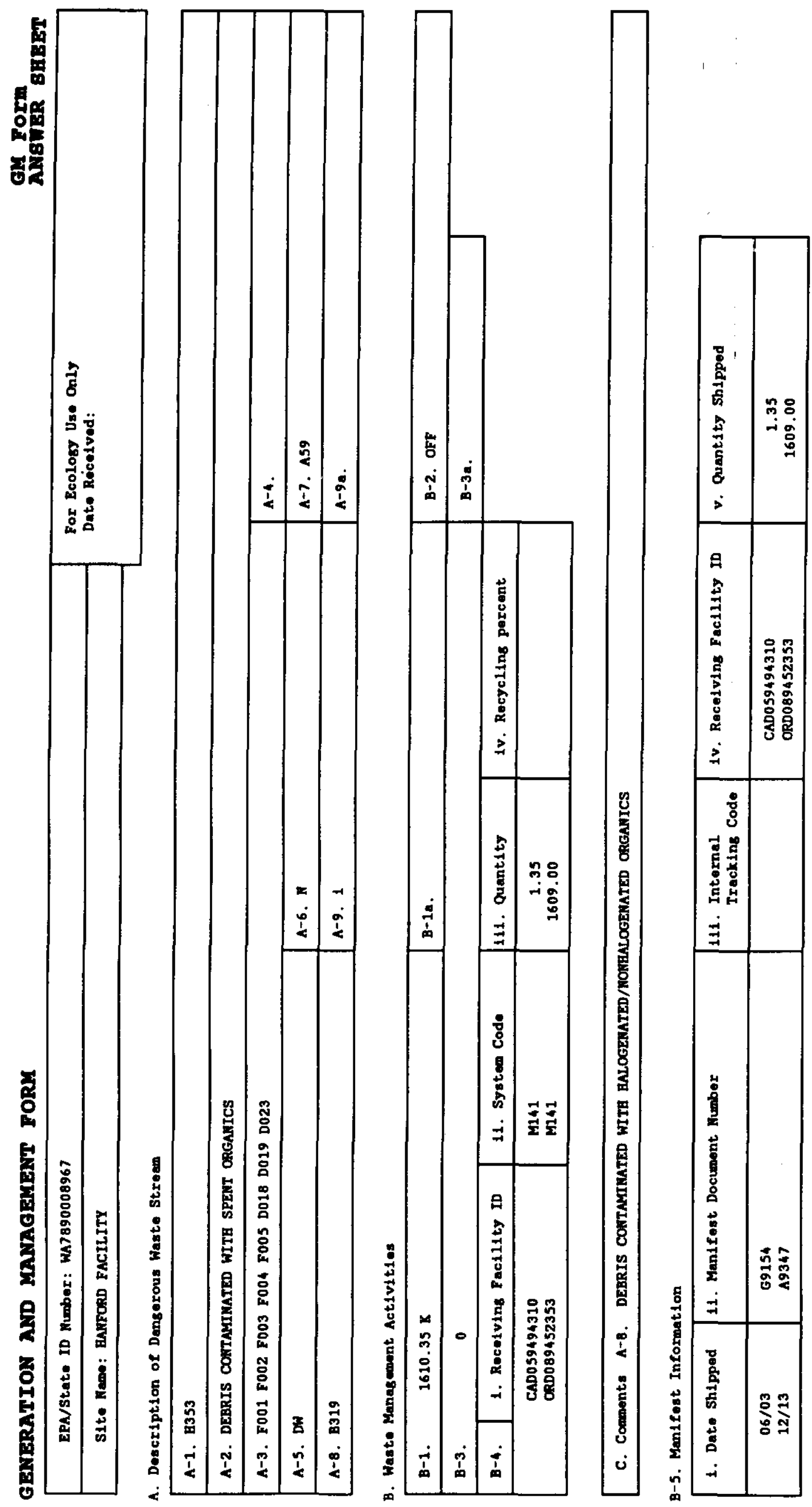




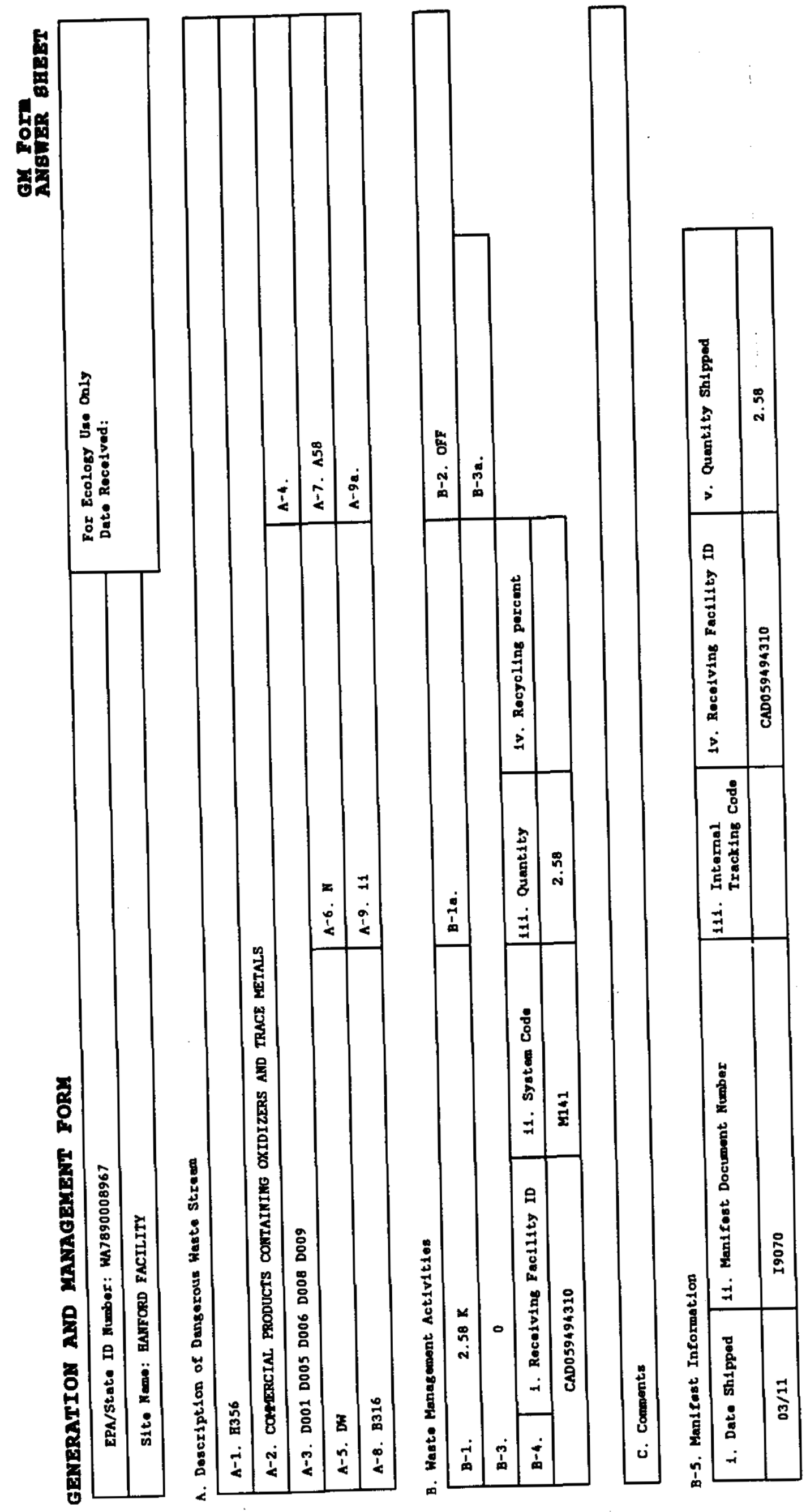




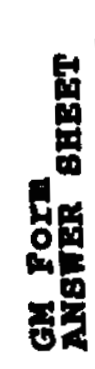

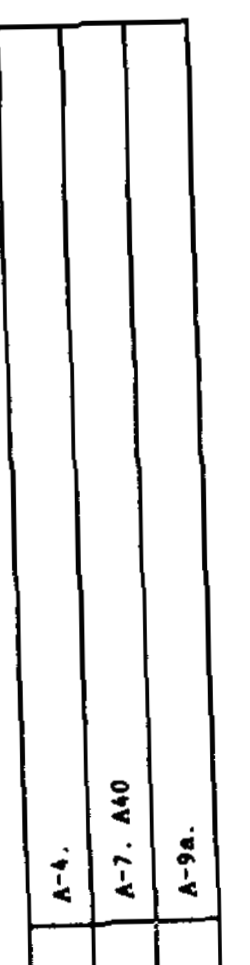

$\square \square$

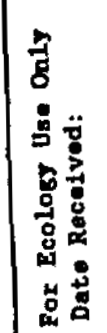

涪

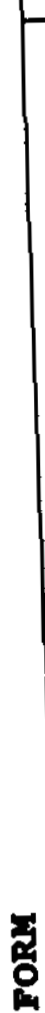

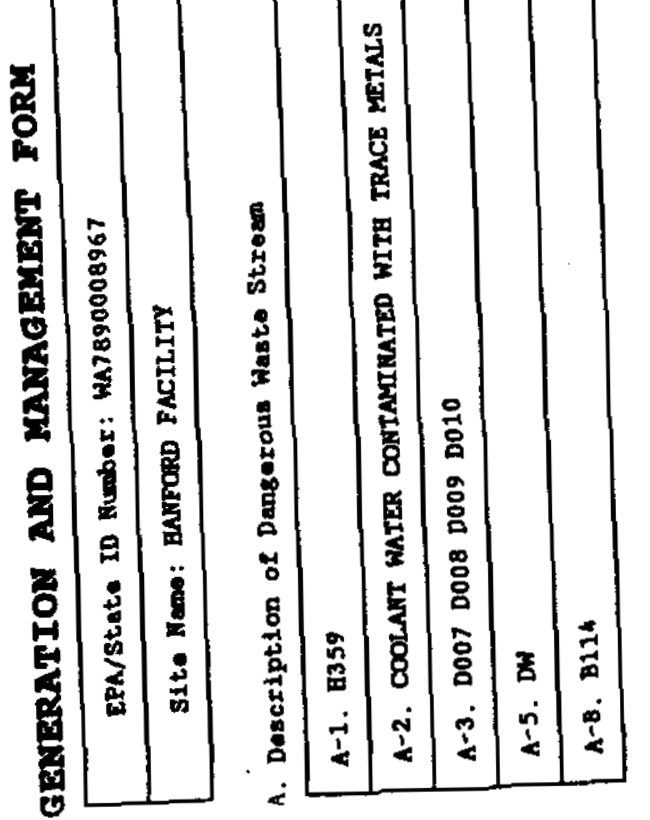

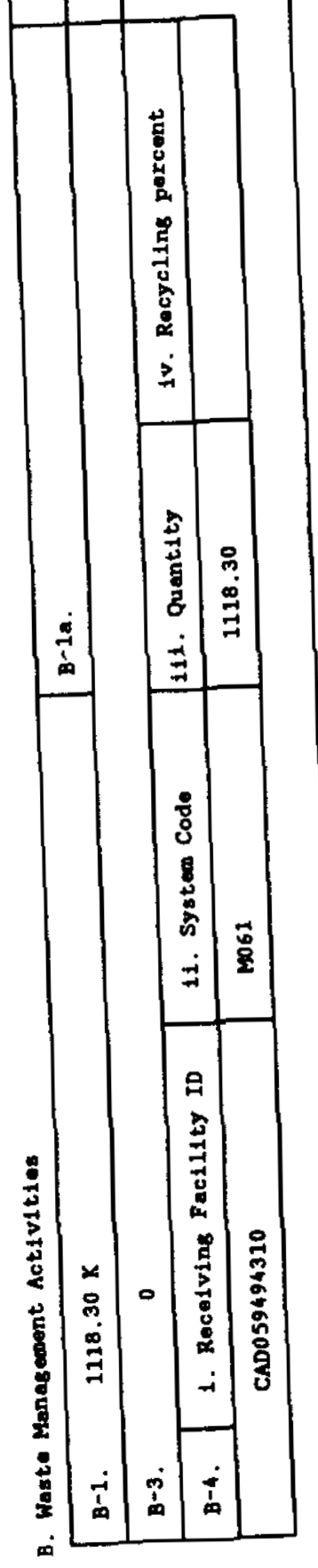

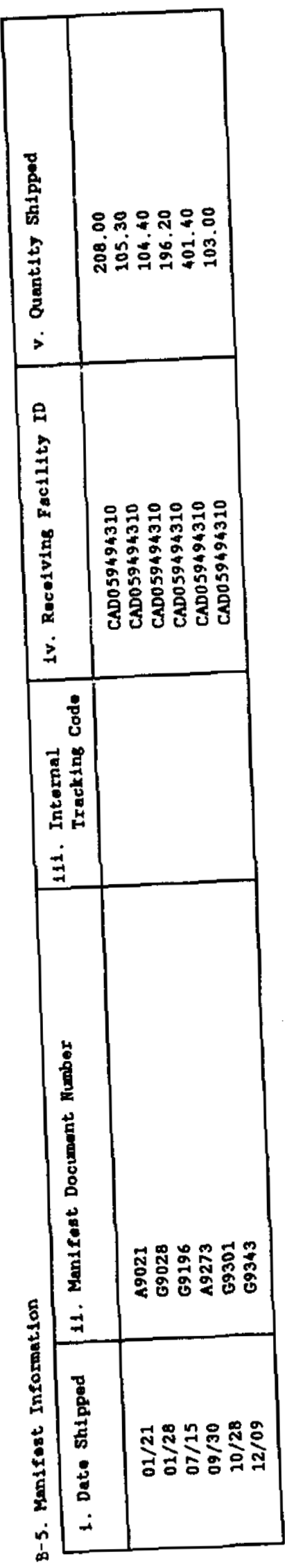




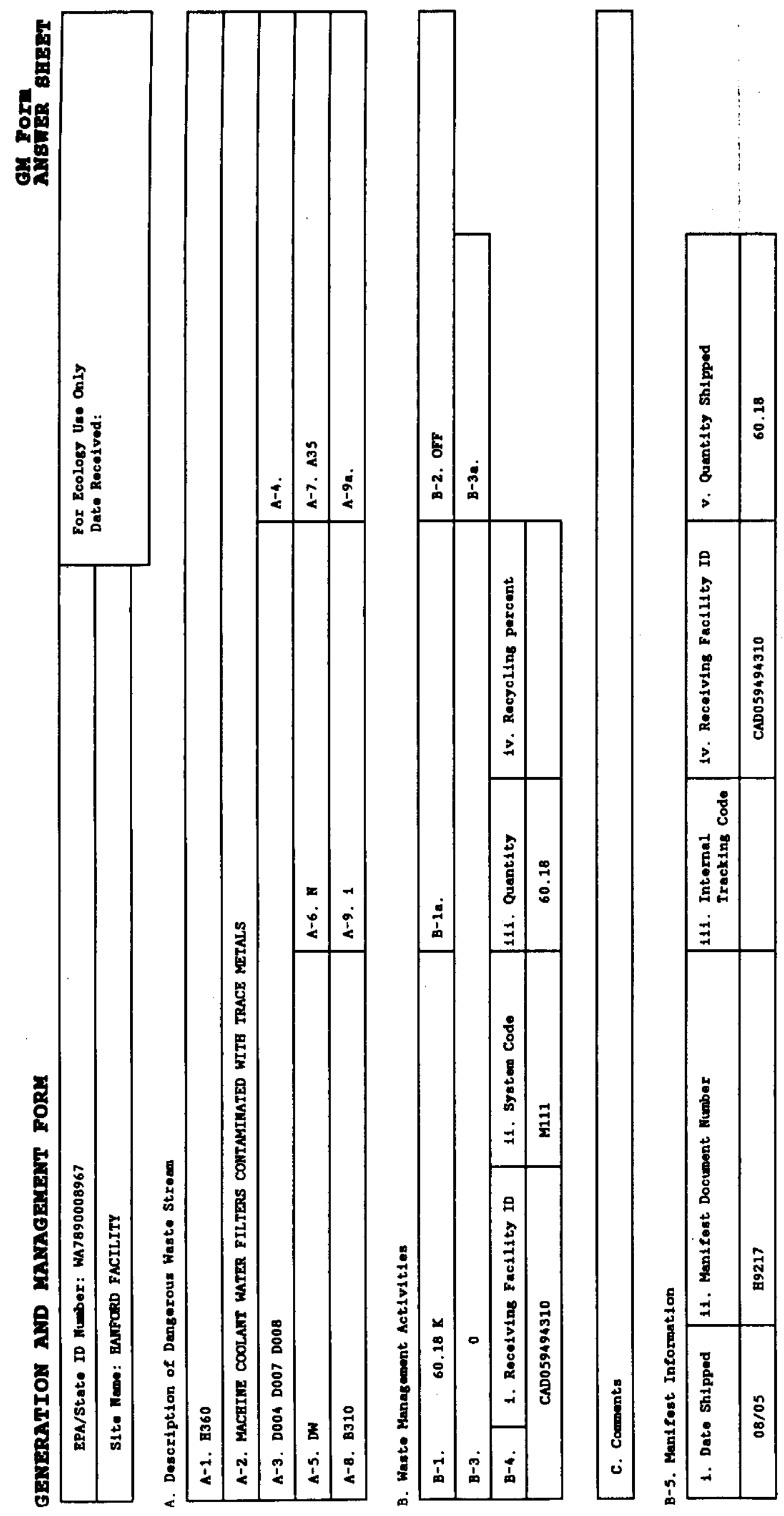




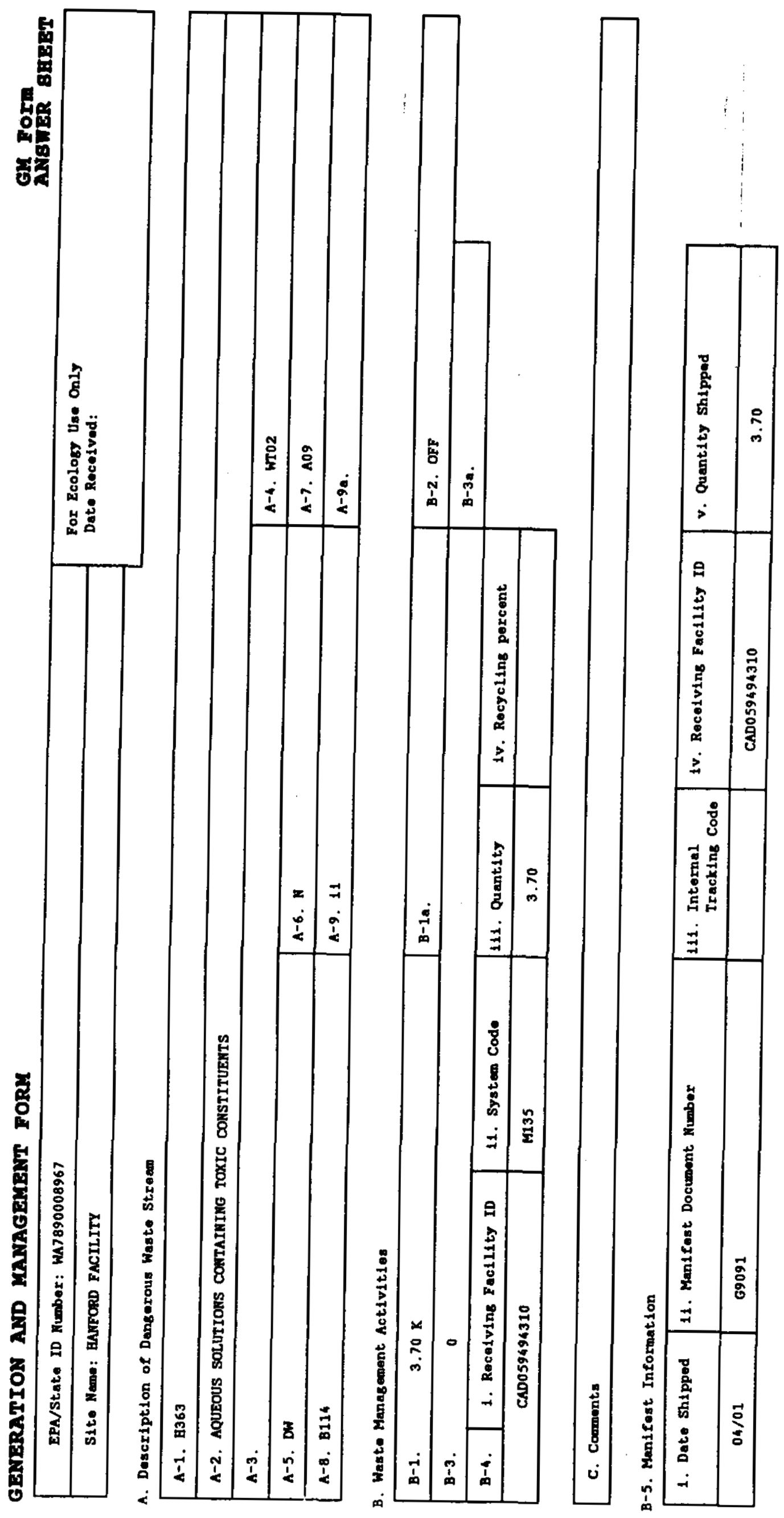



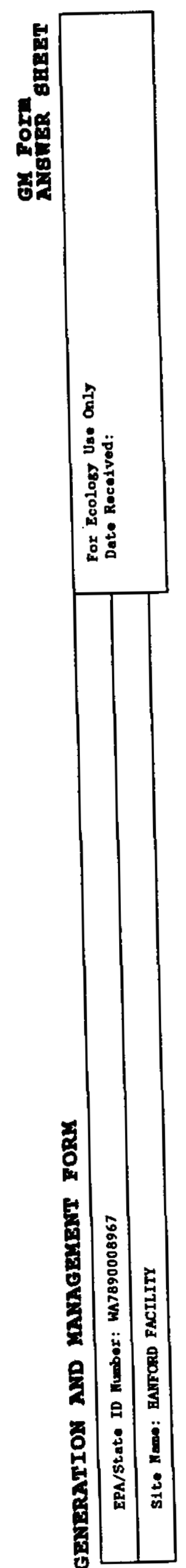
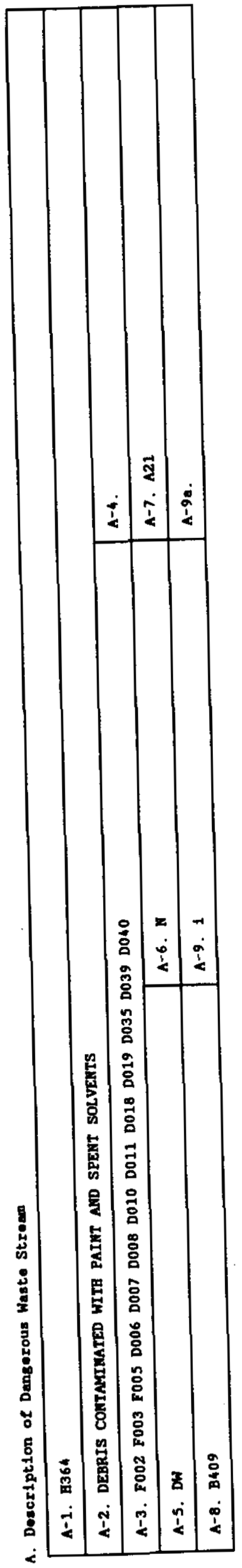

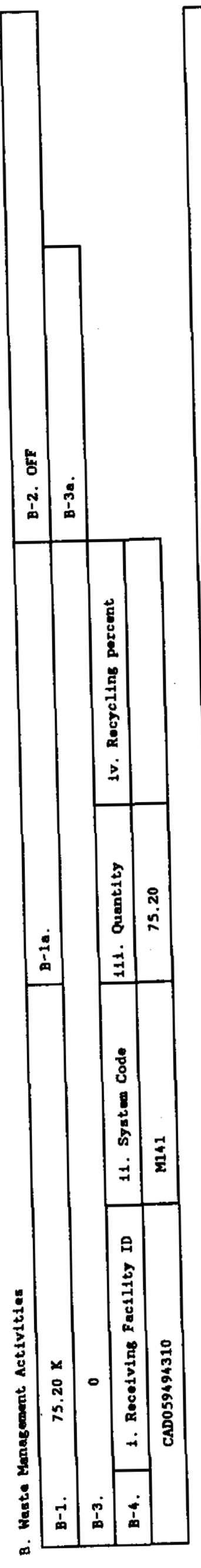

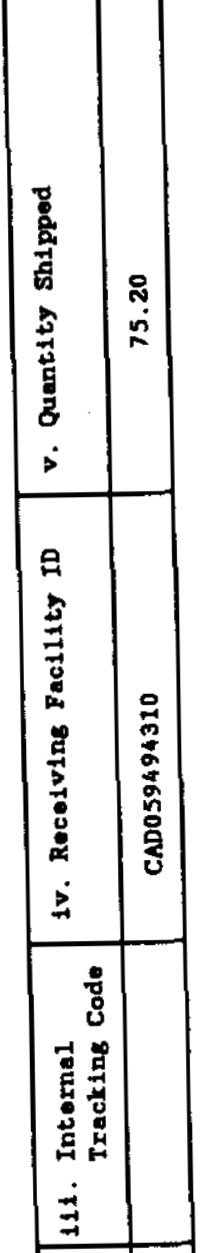

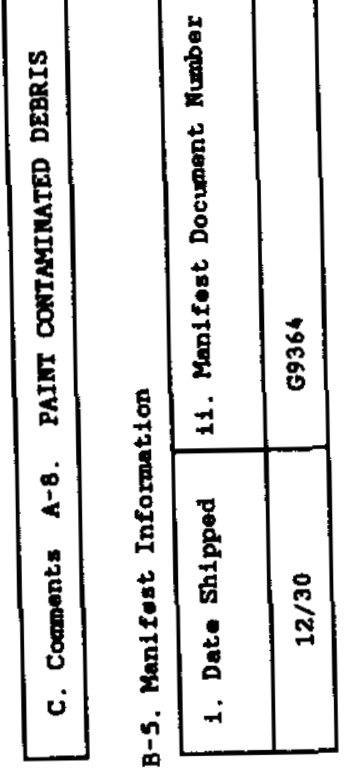




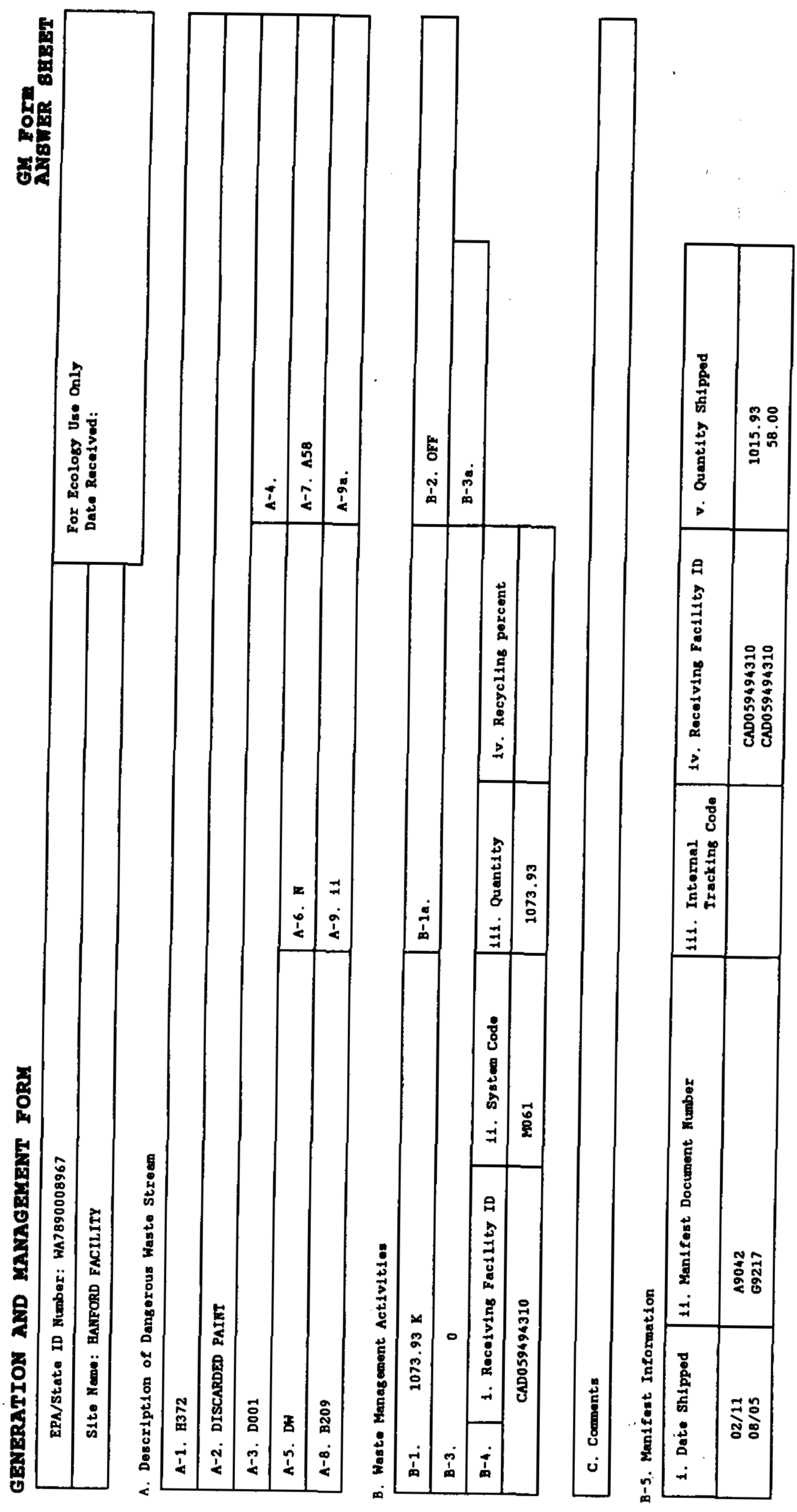




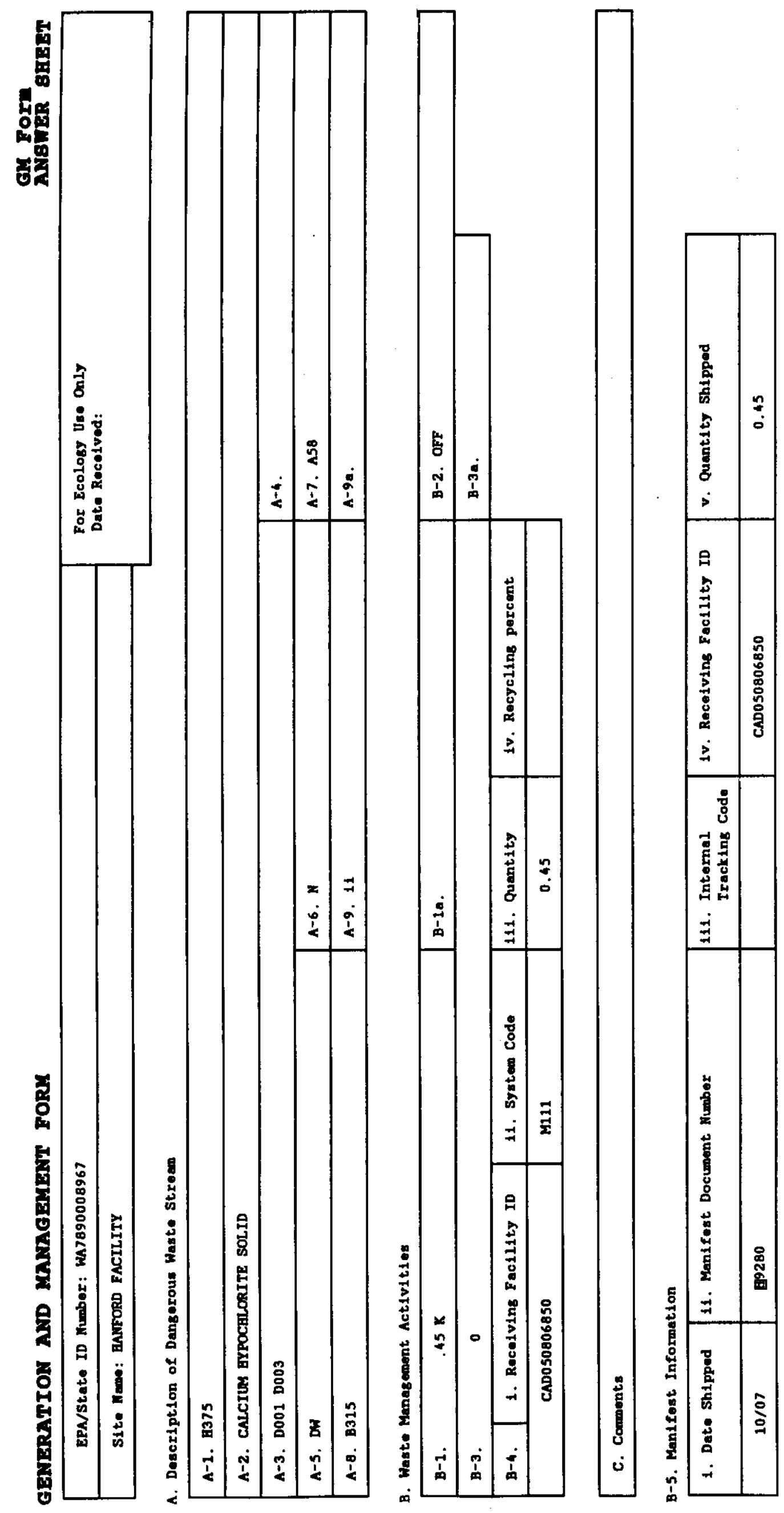




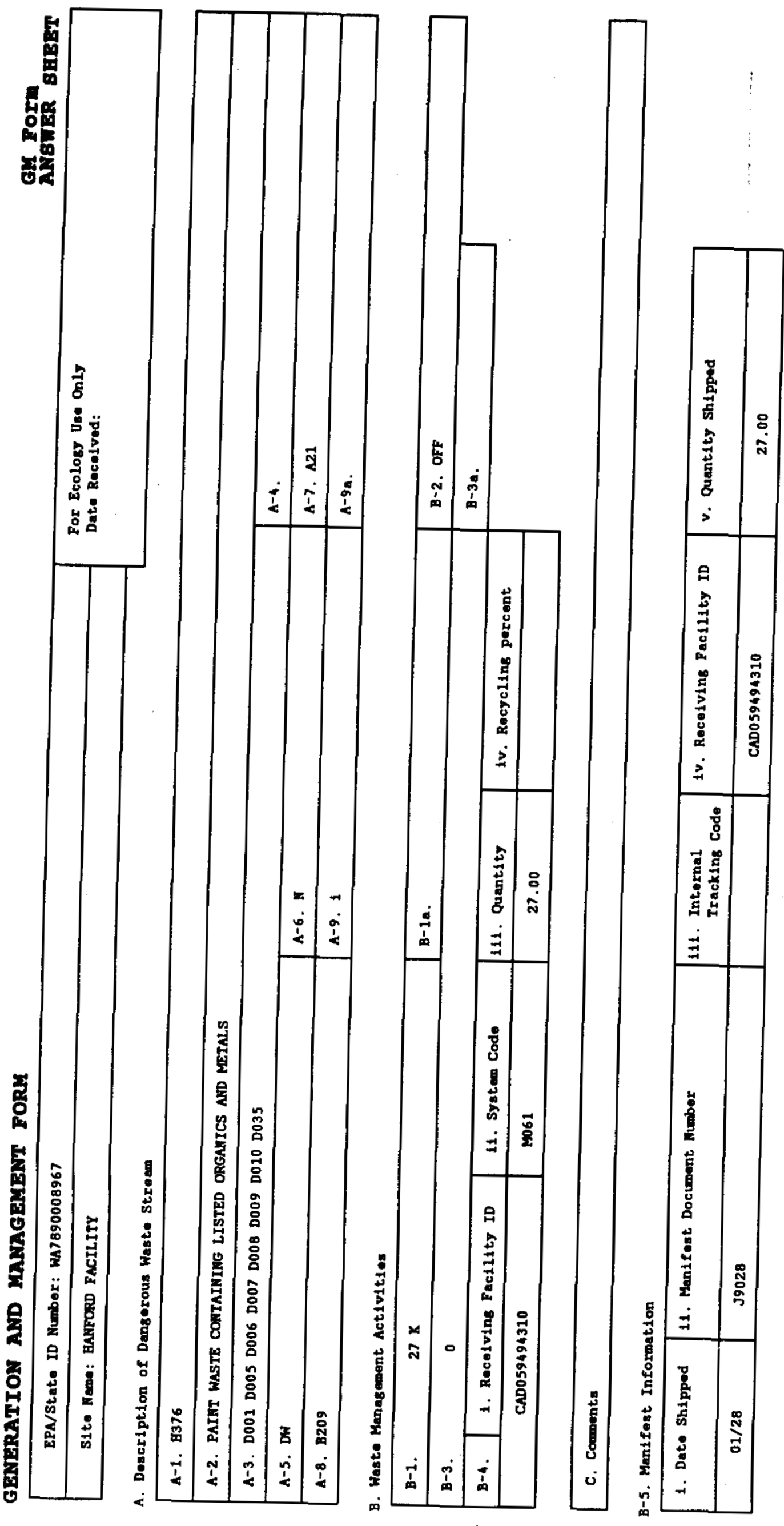



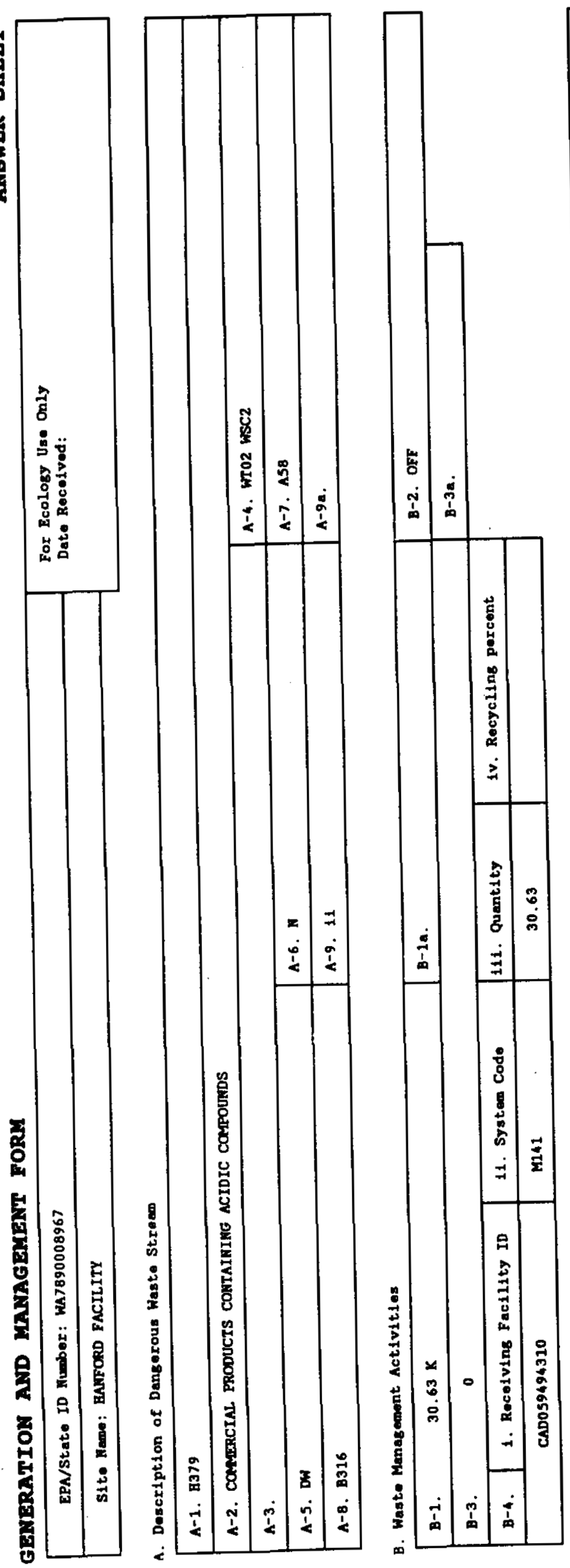


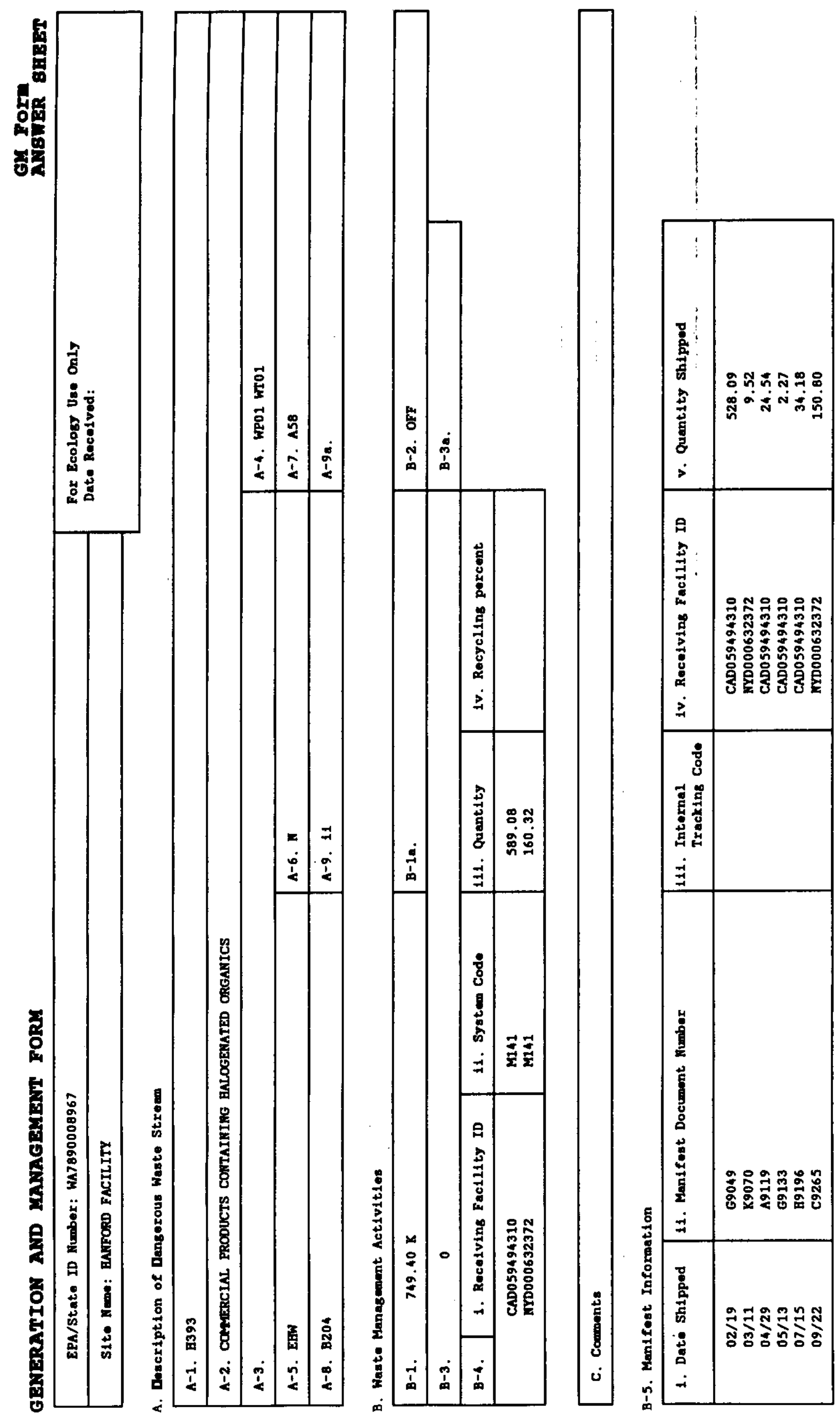




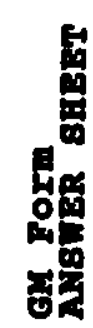

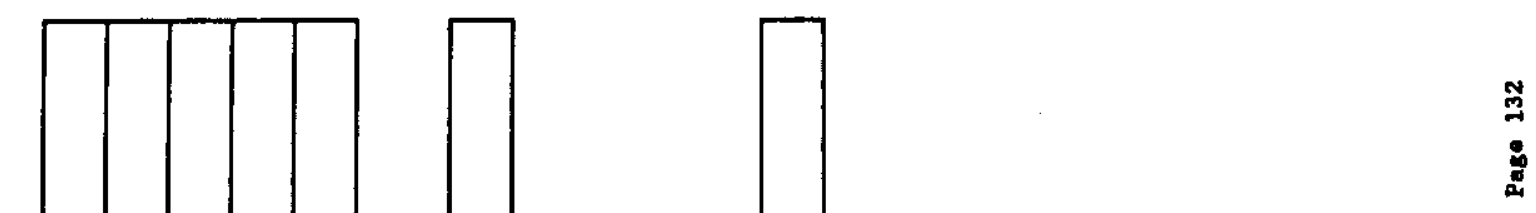

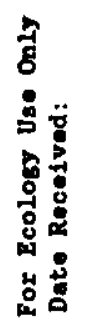

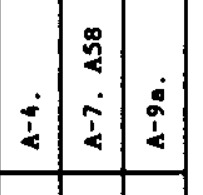

鮥
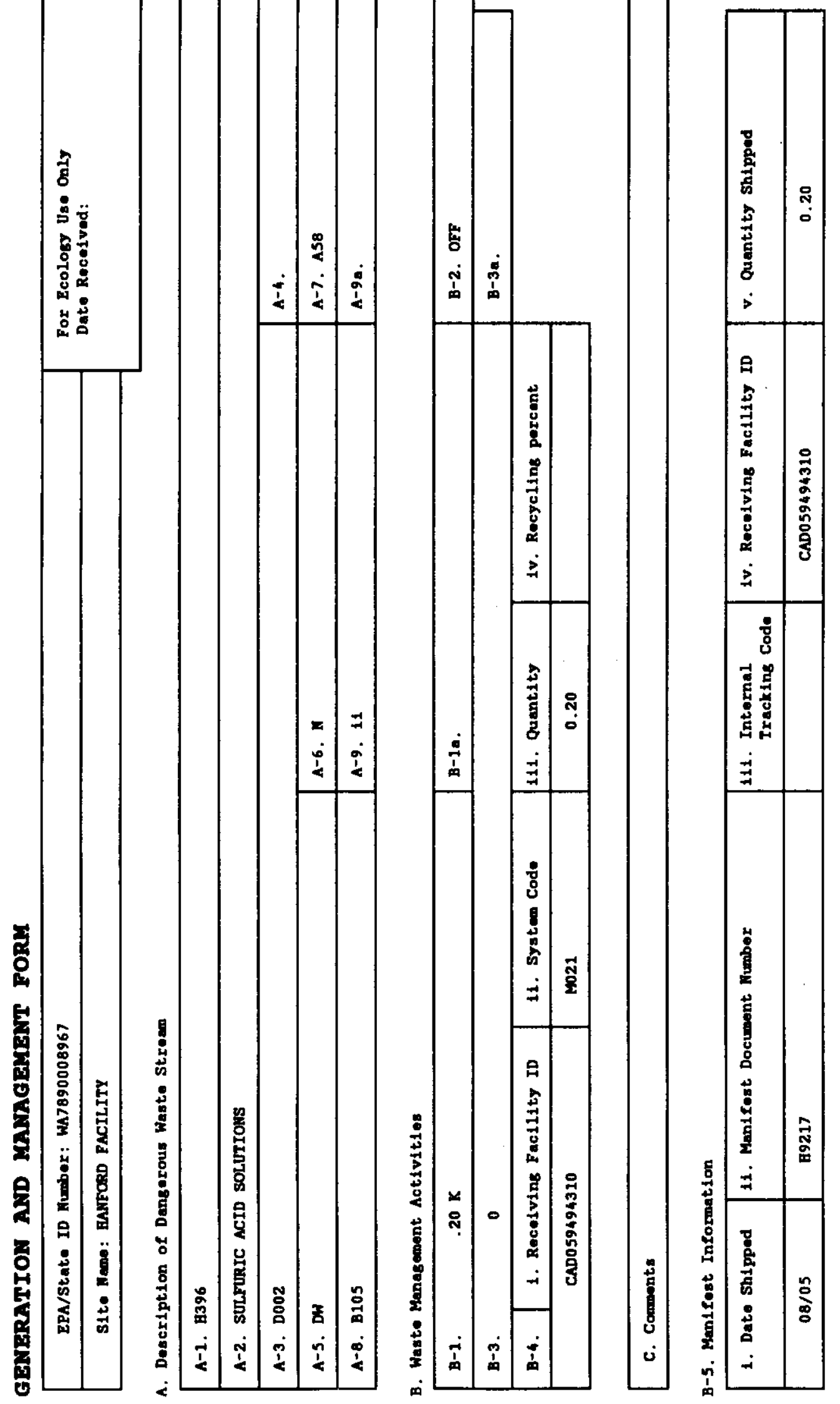


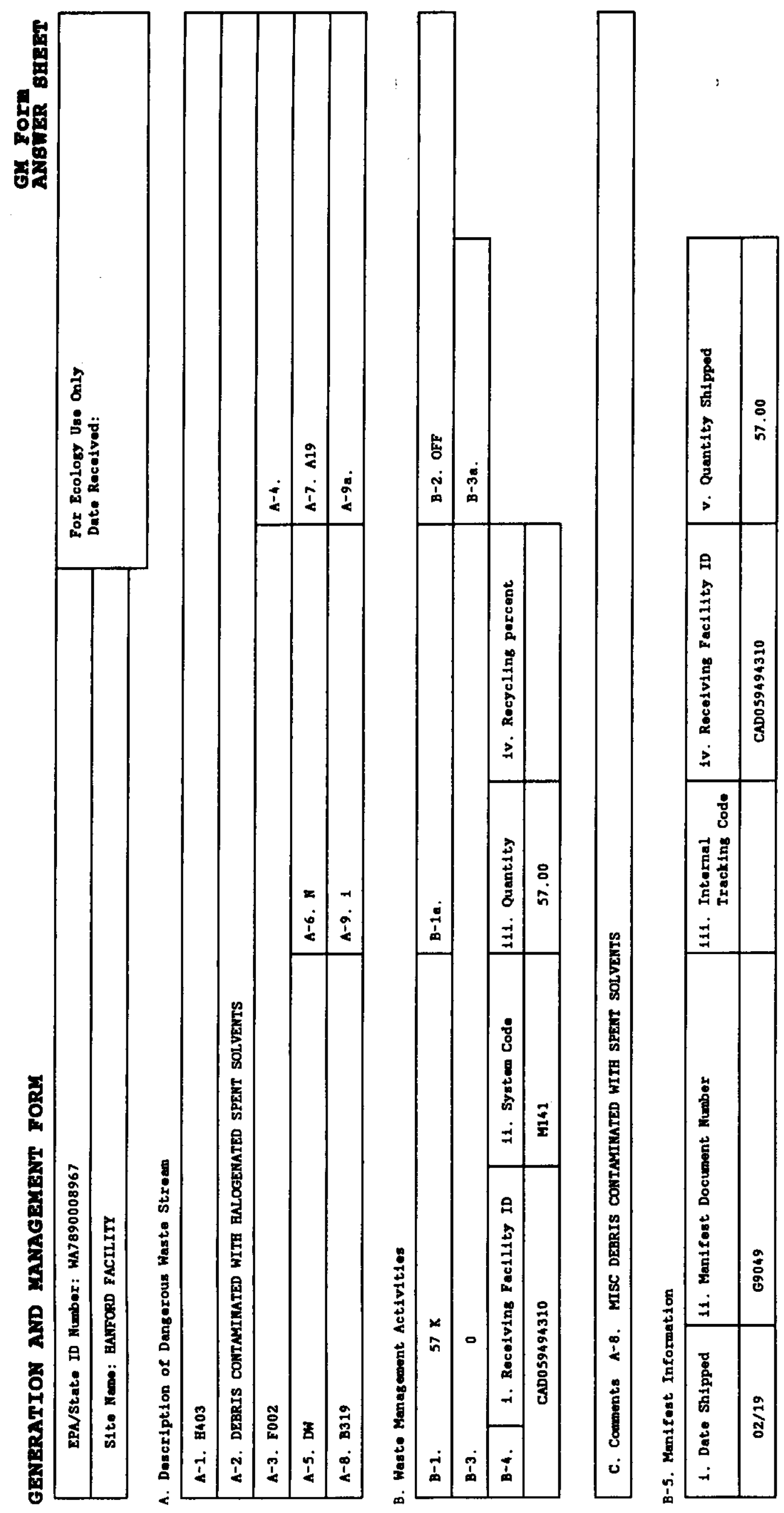




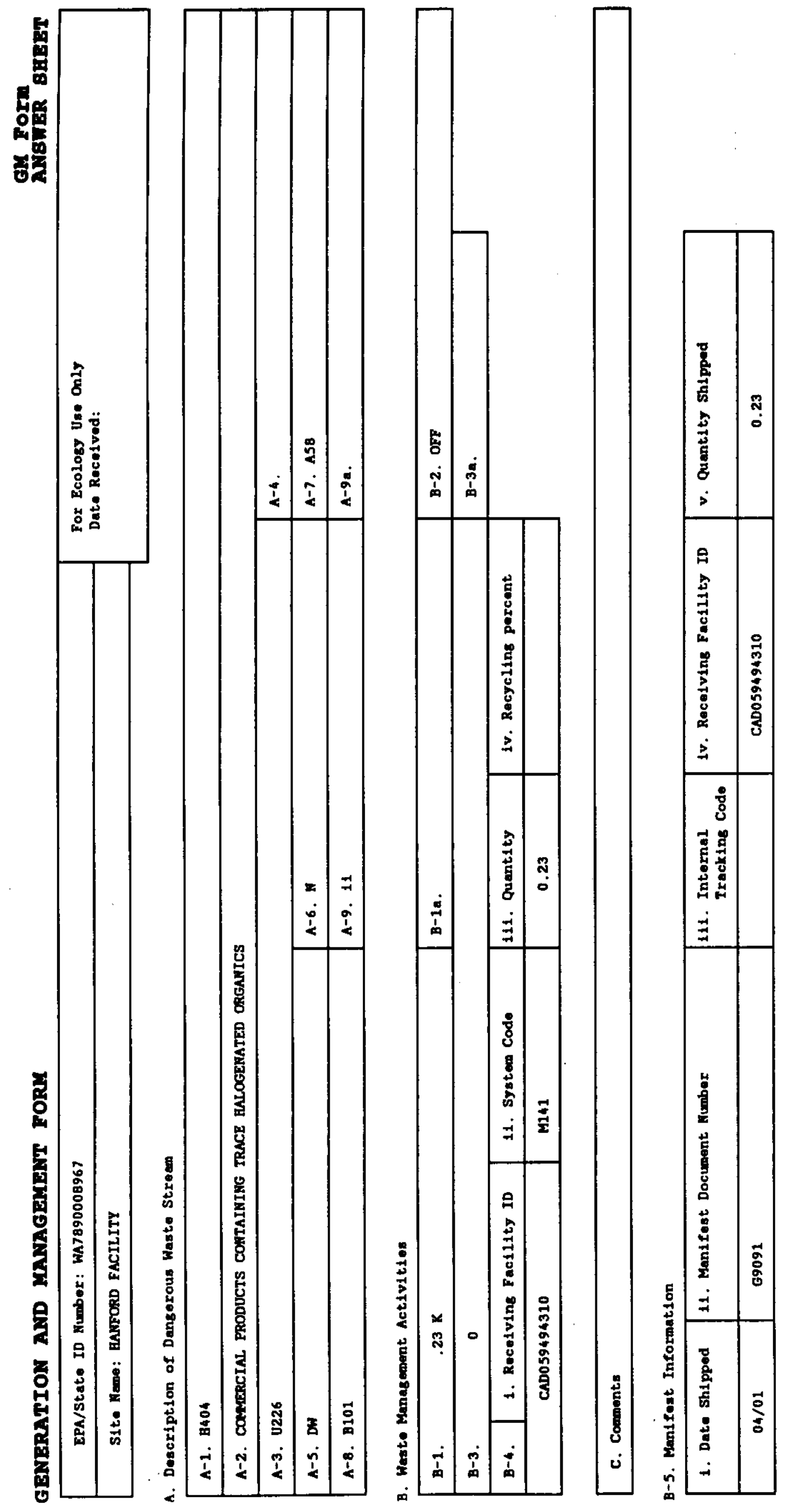




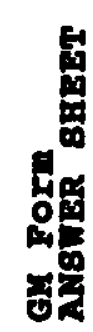
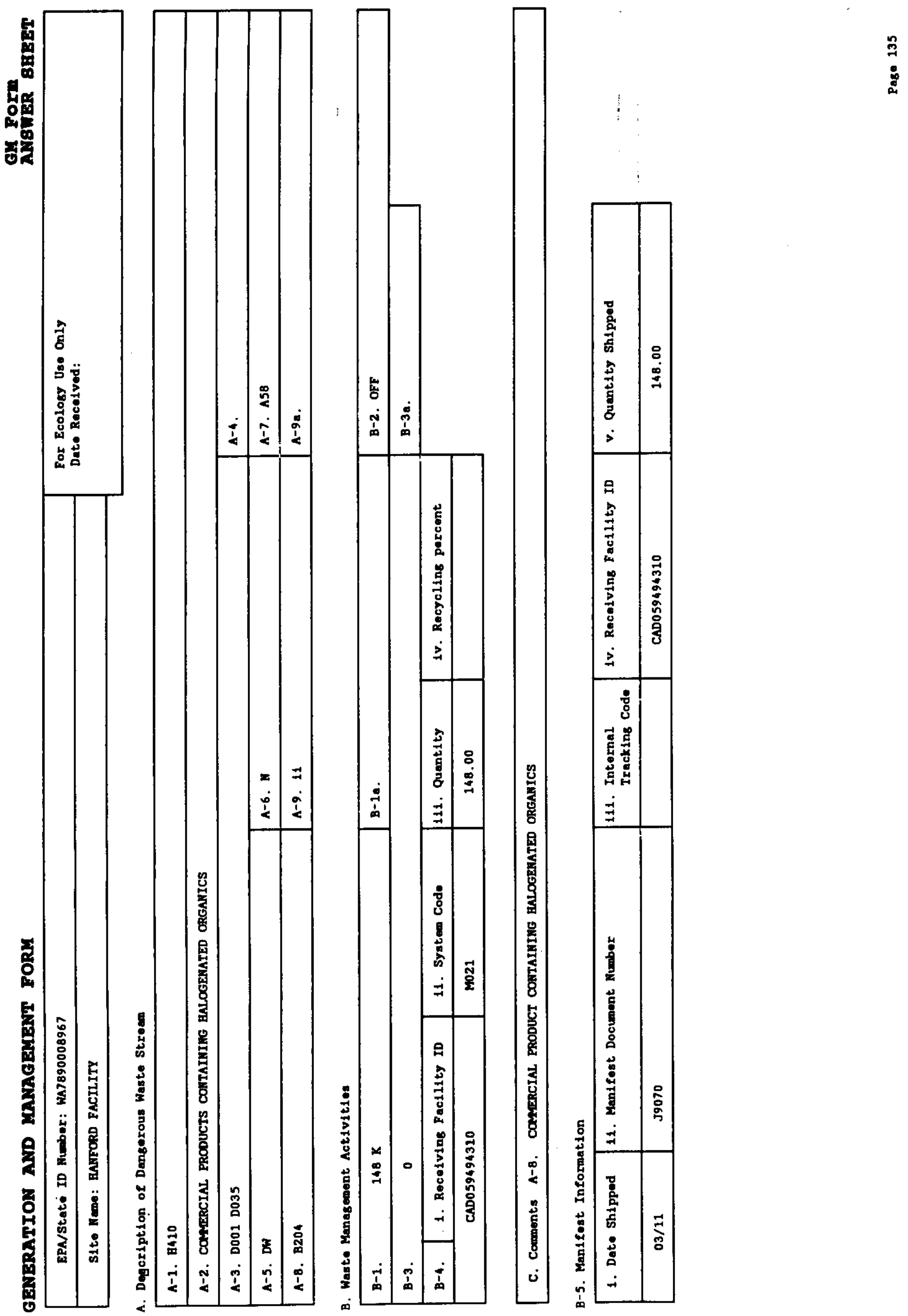

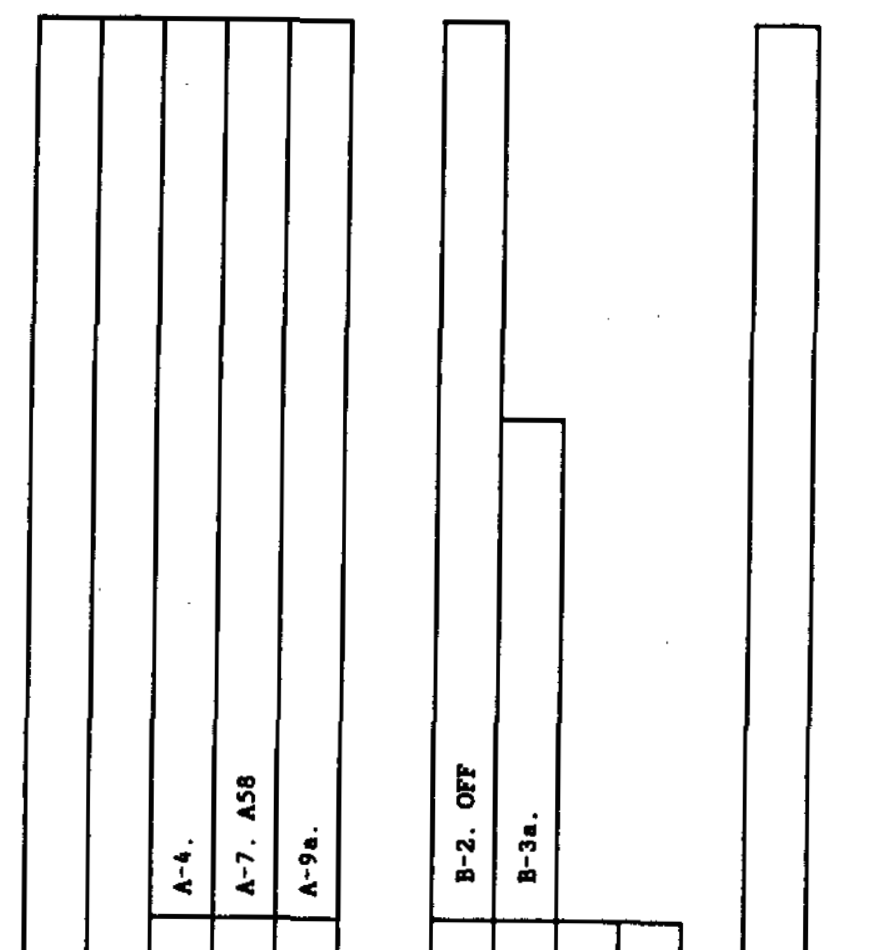

$\stackrel{\stackrel{9}{9}}{8}$
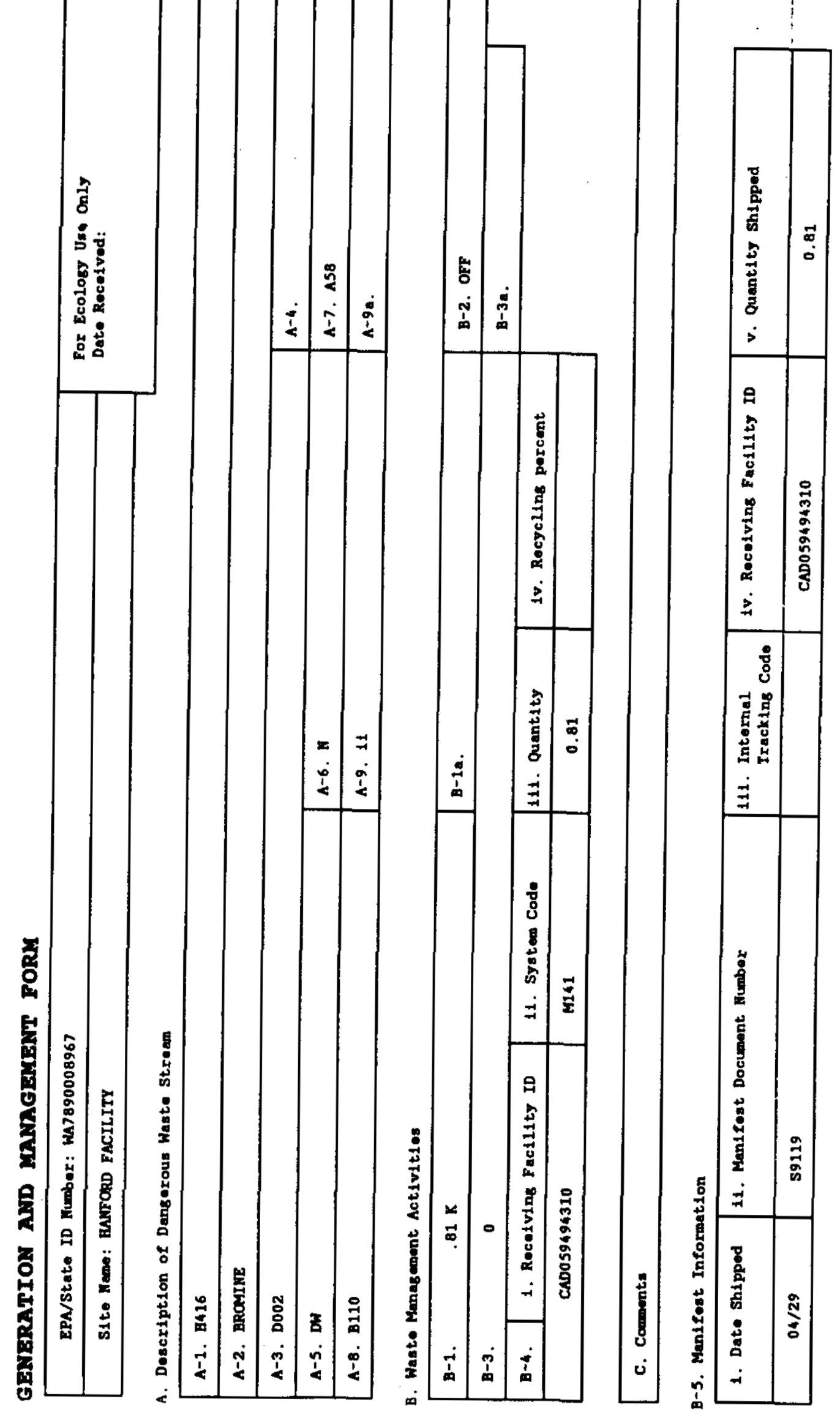


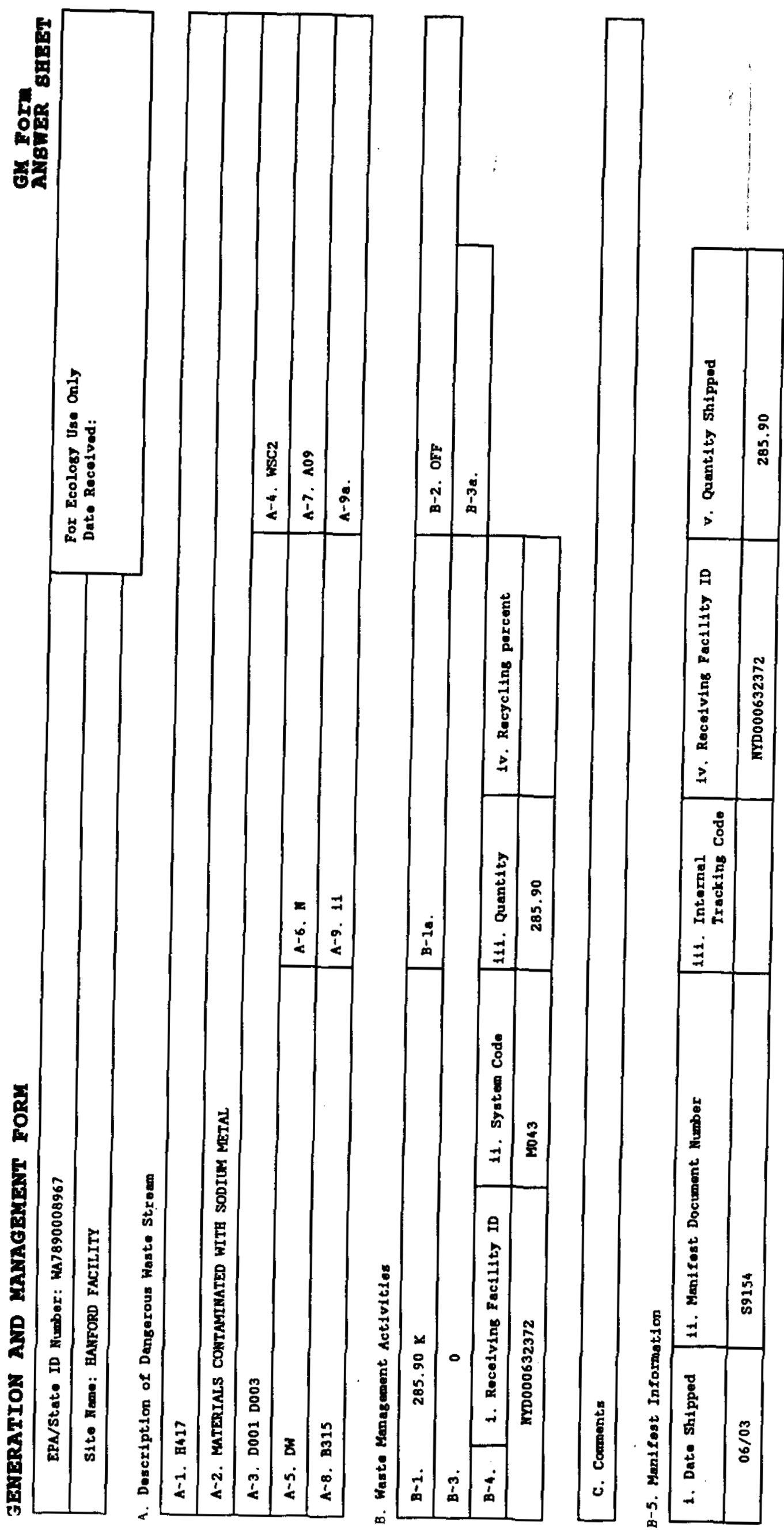

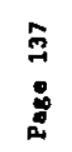




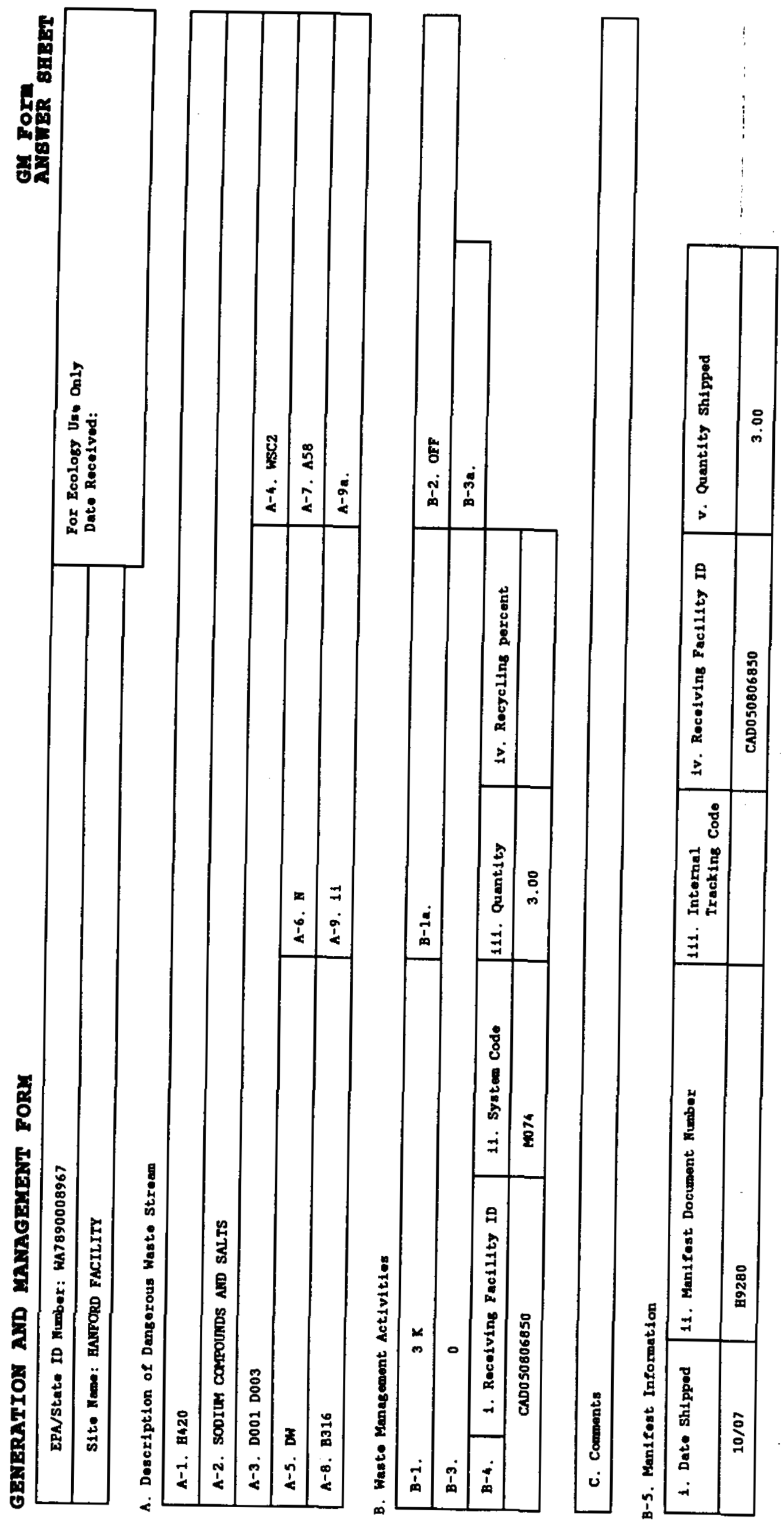




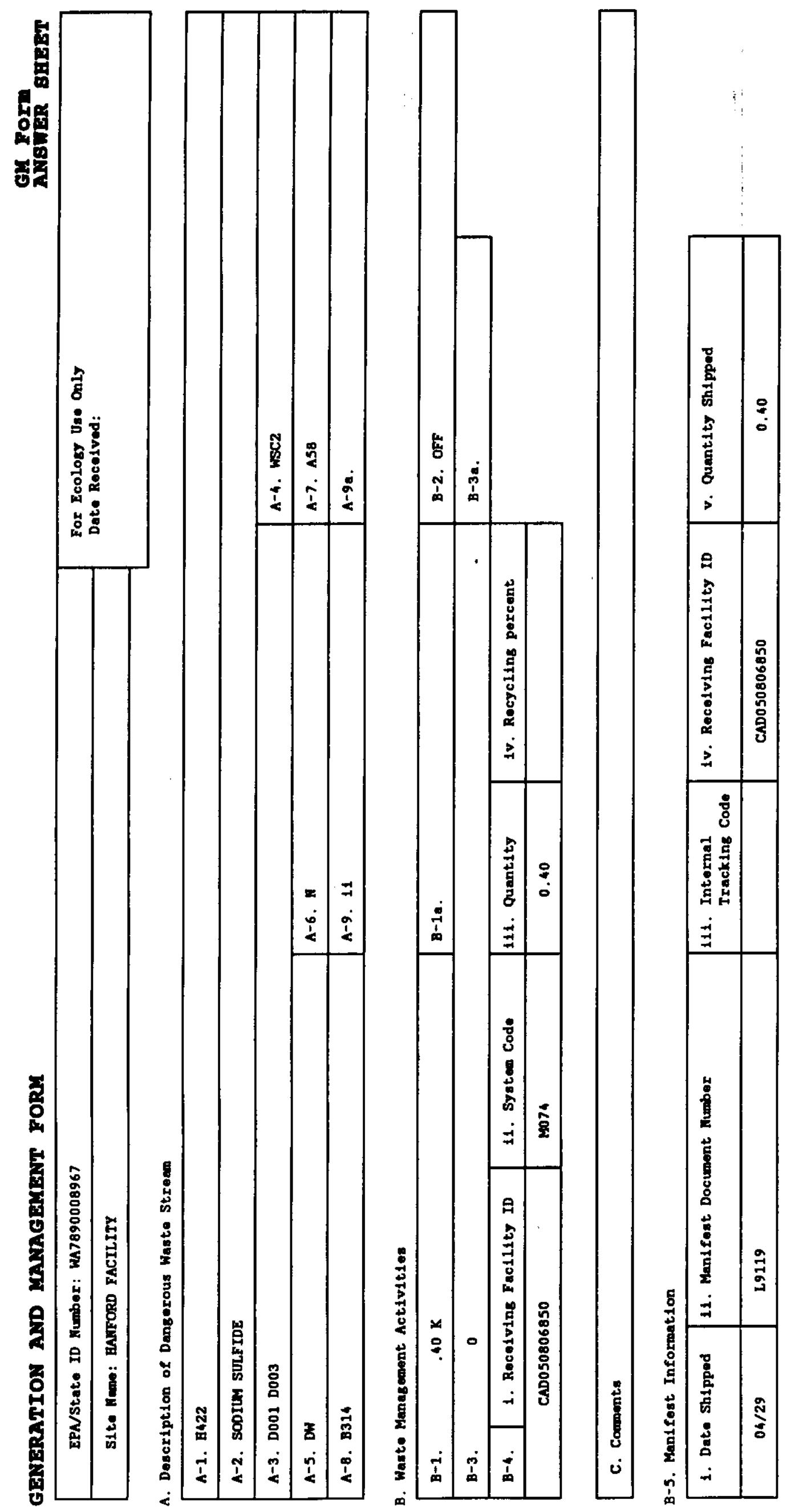




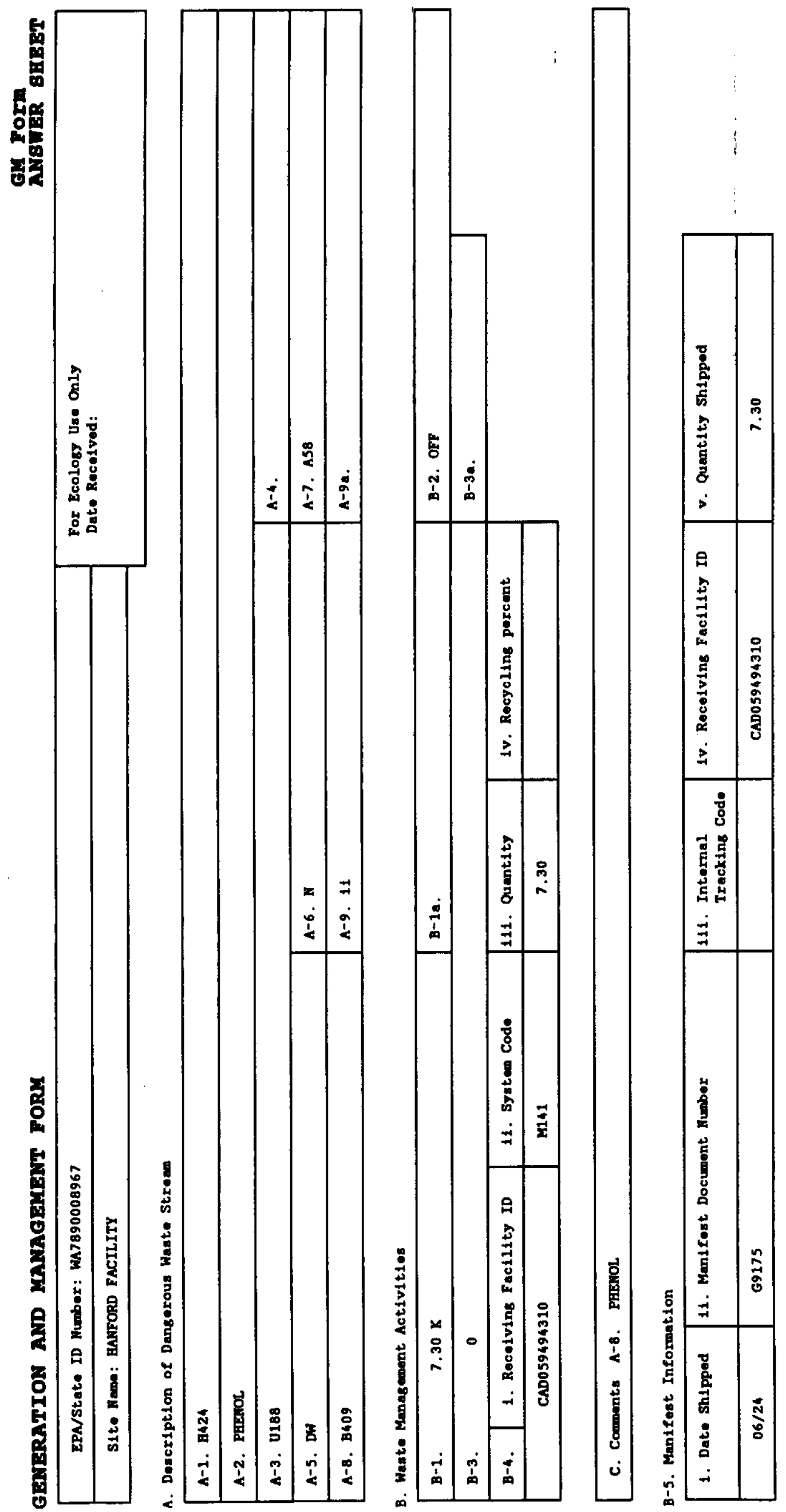



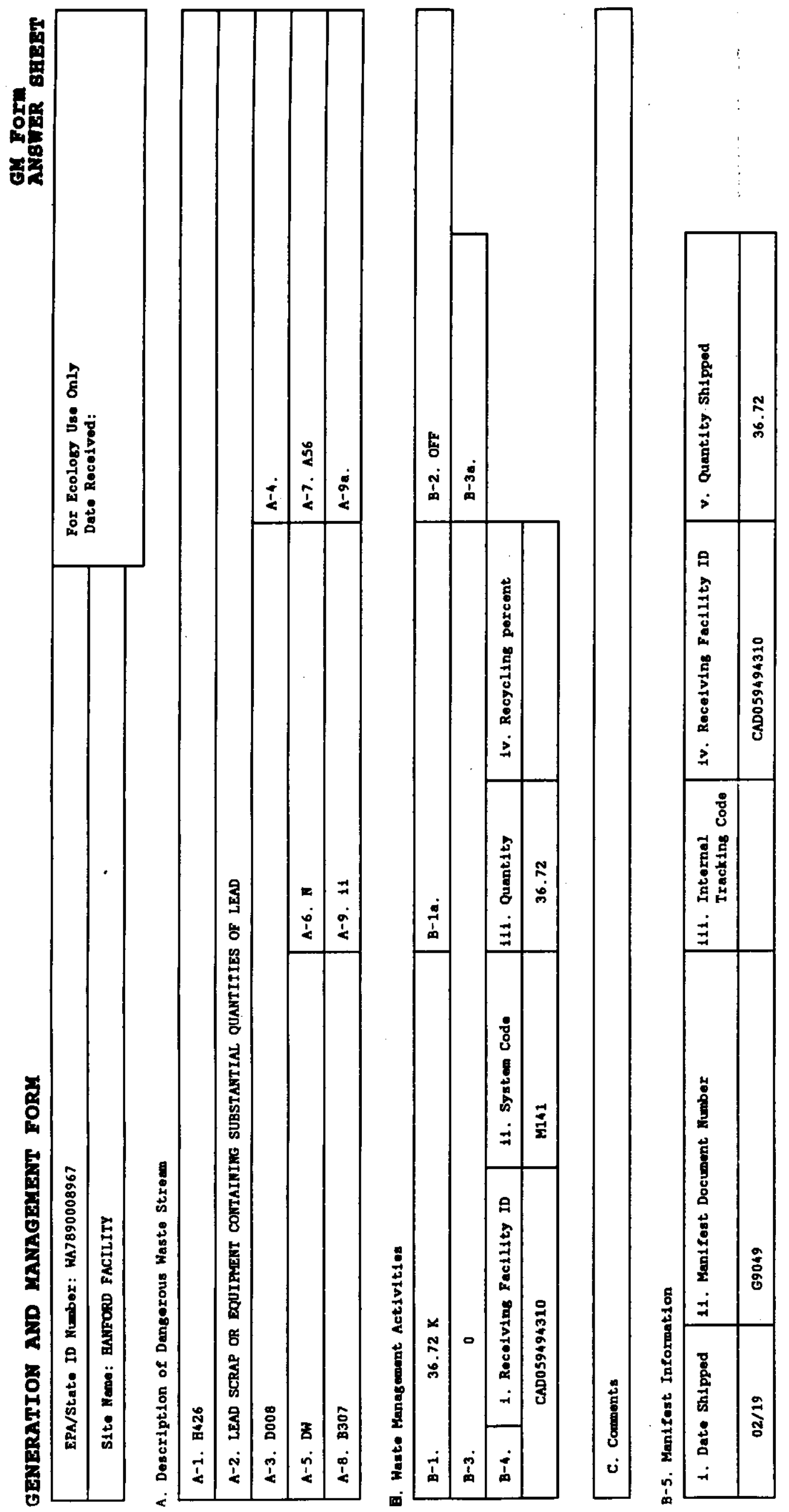


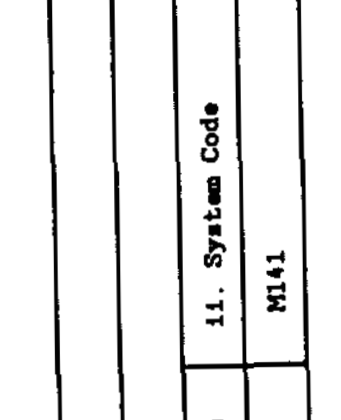

: 焉蒡

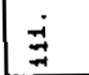

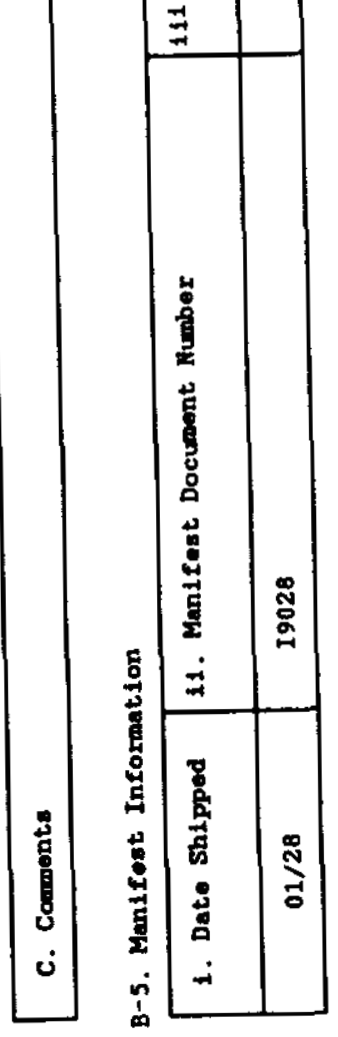




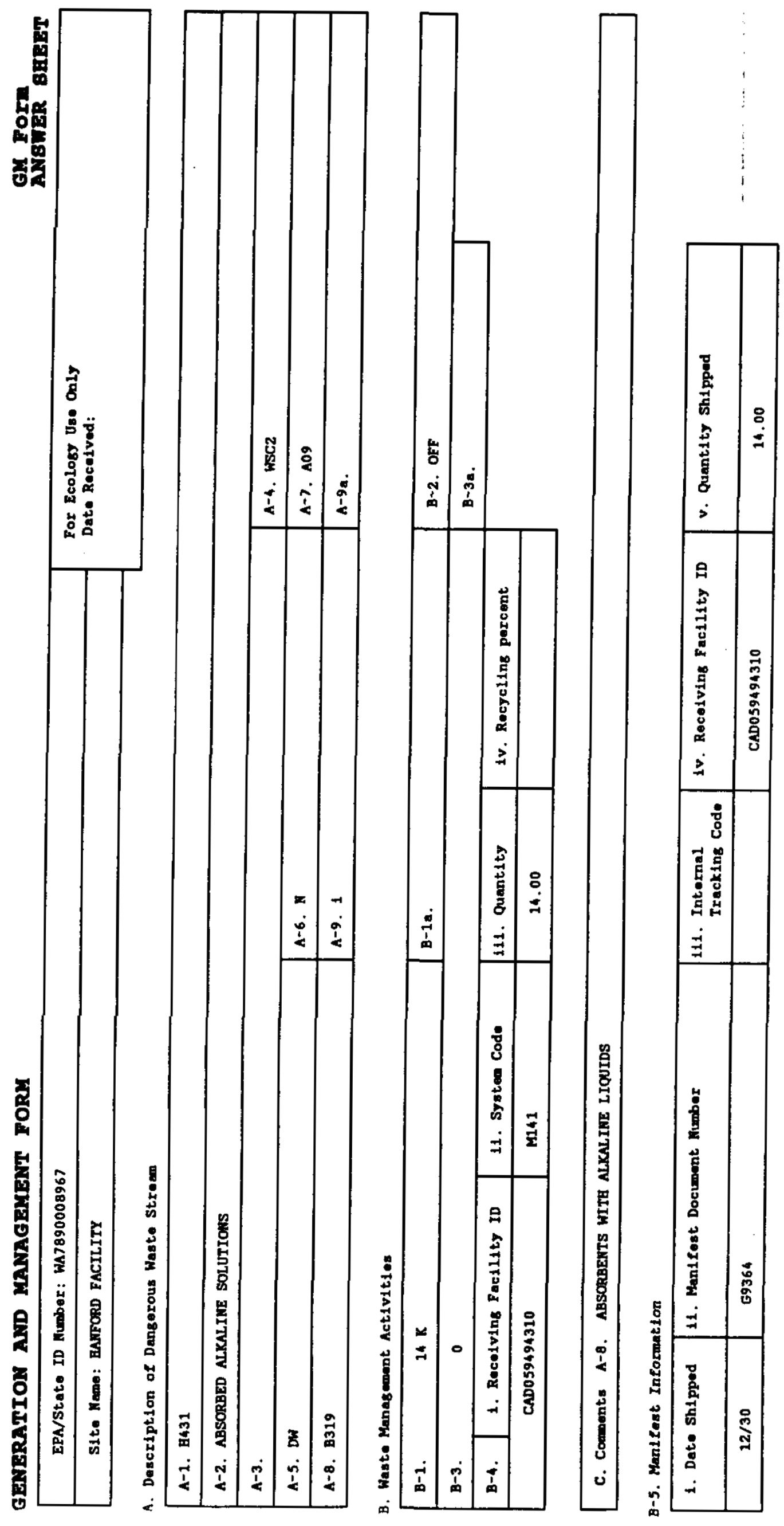




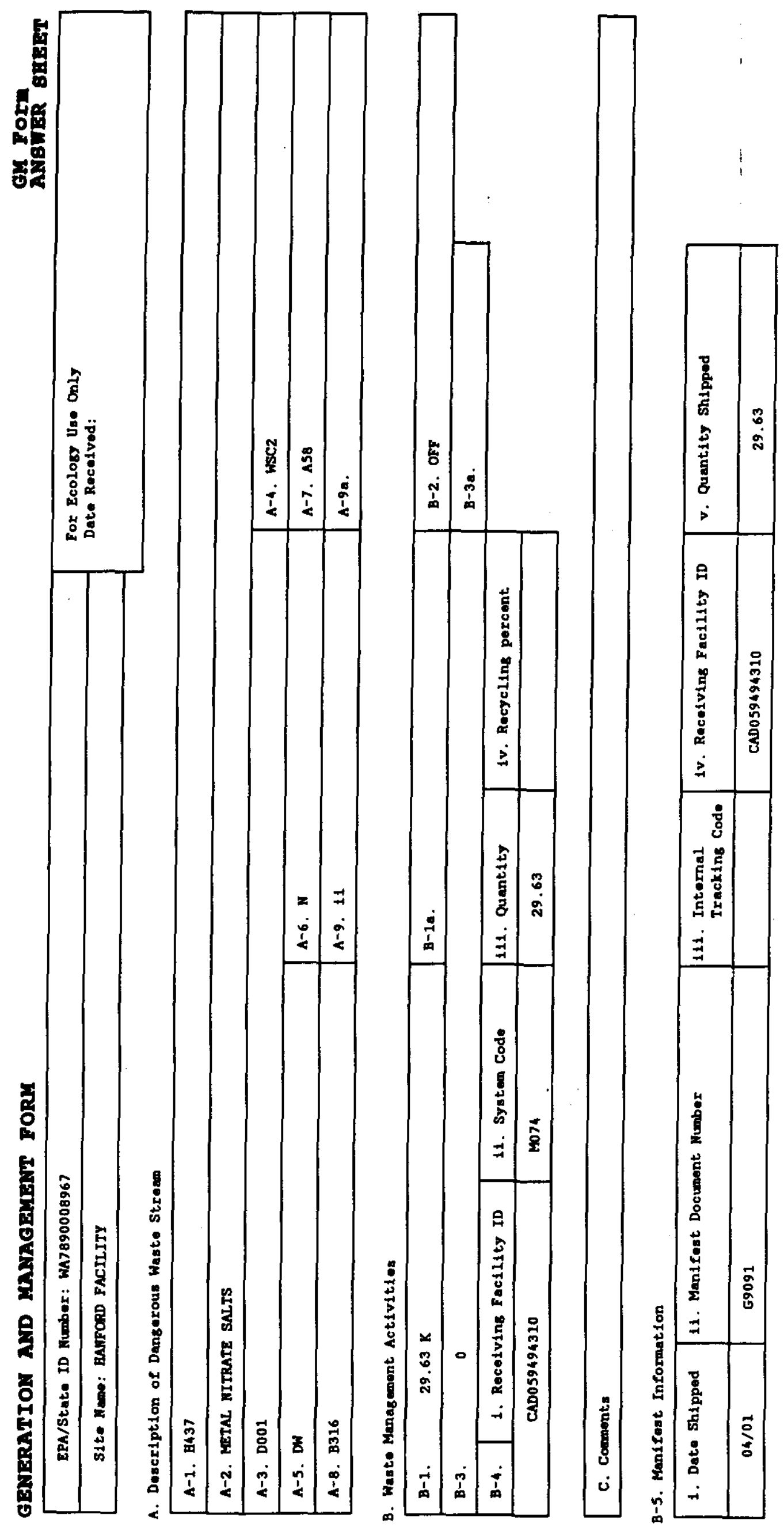




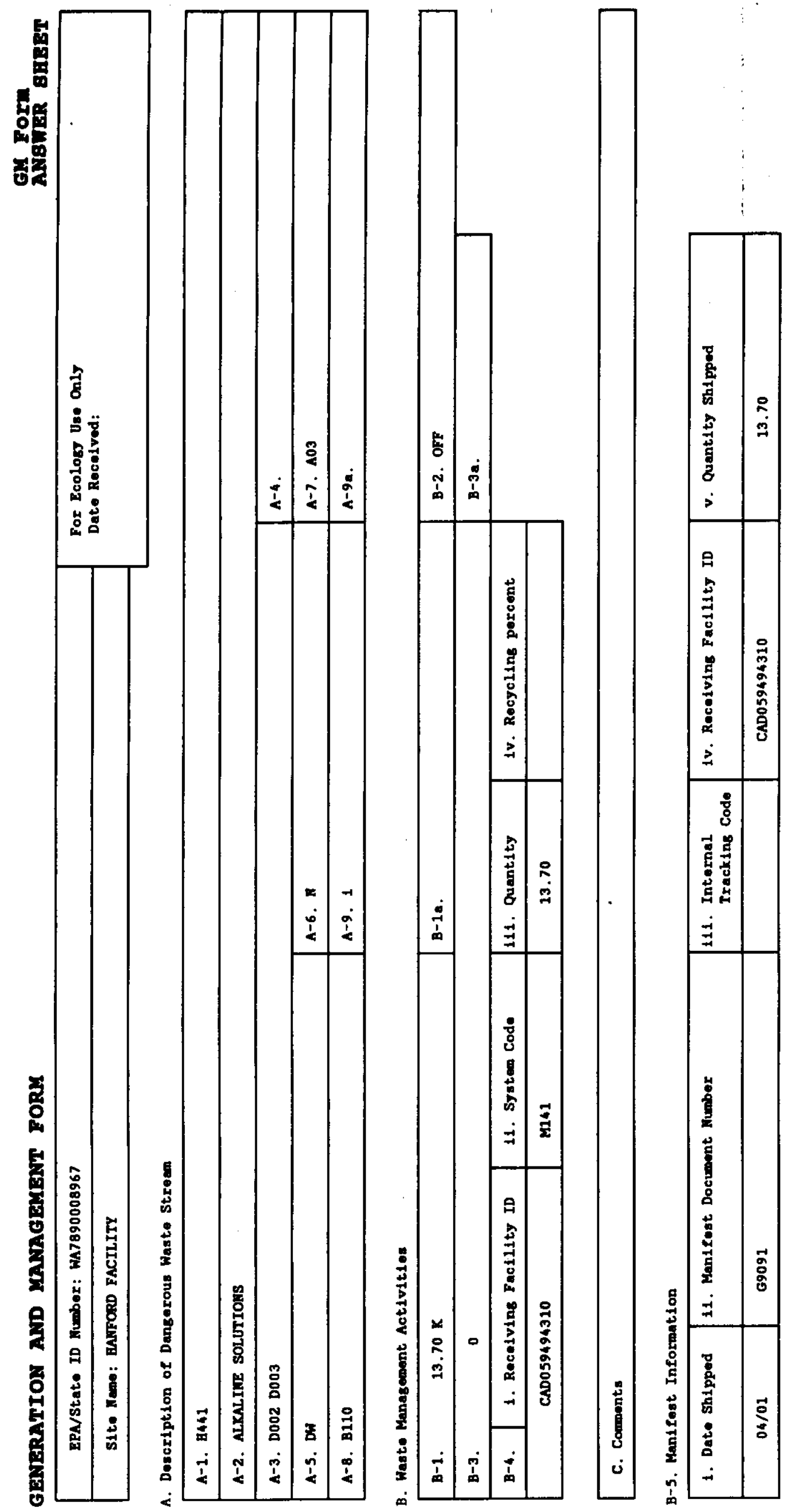



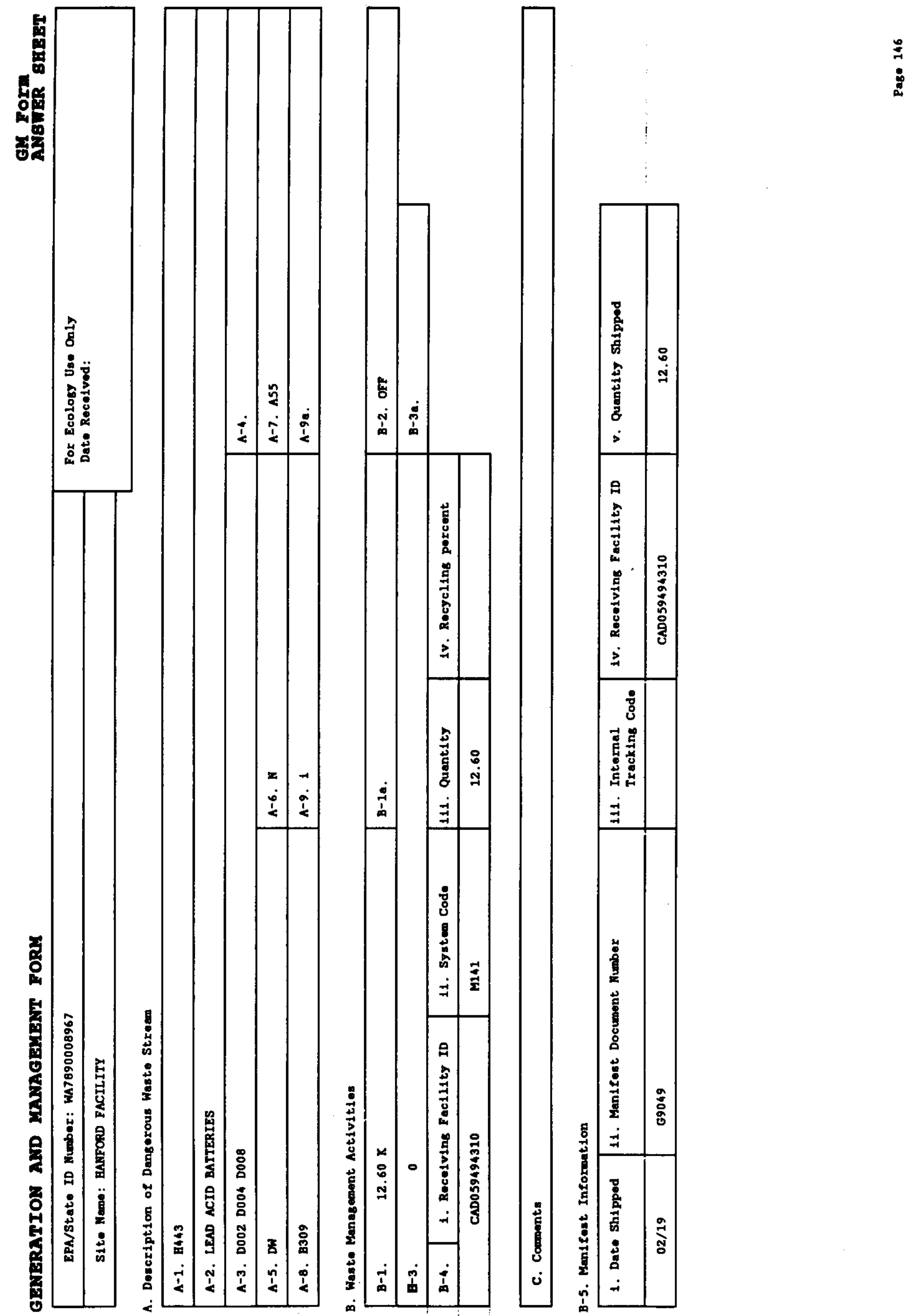

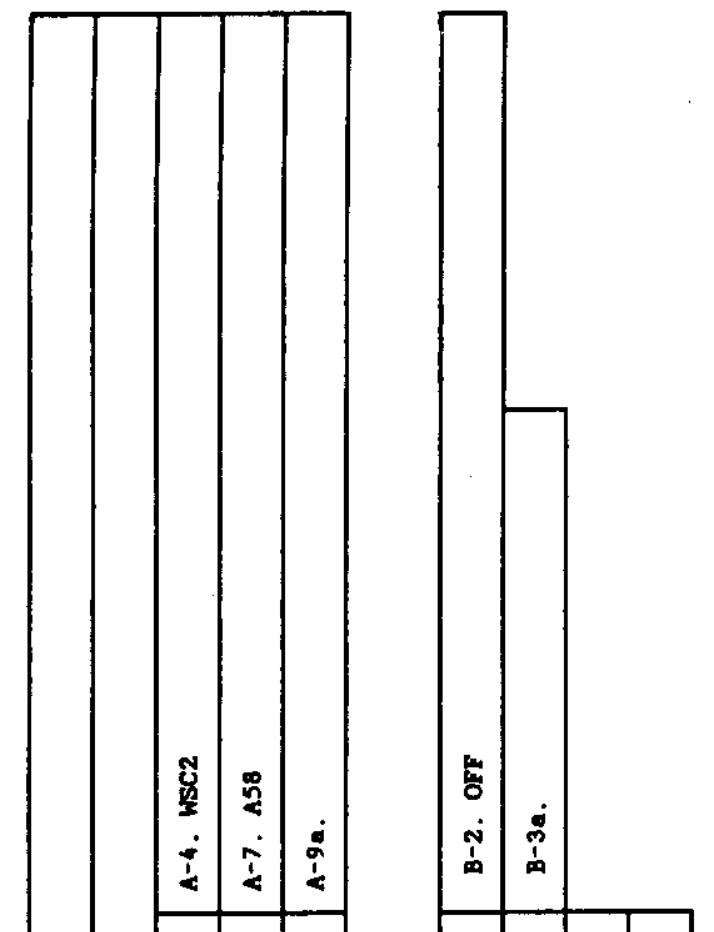

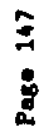
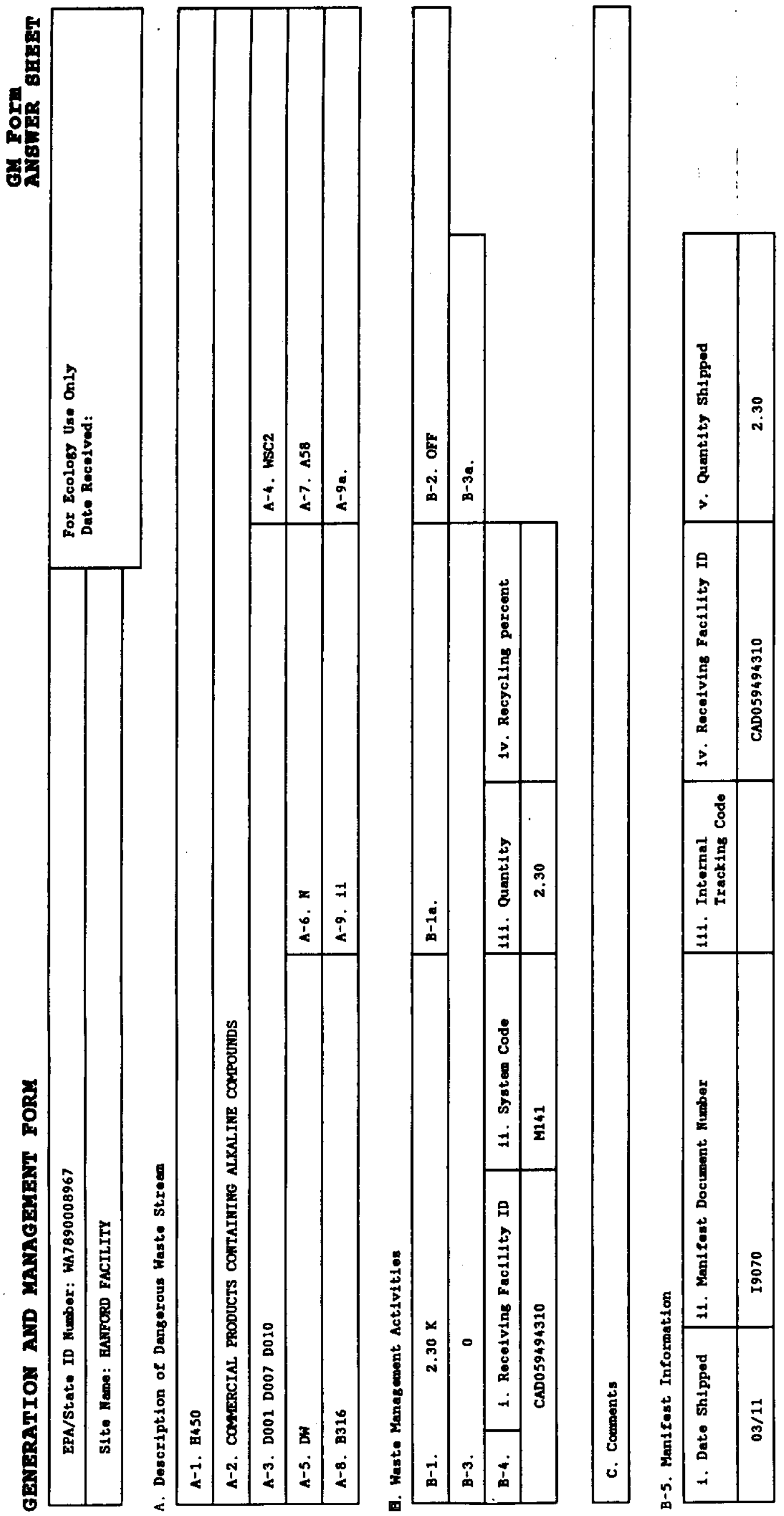
㑹
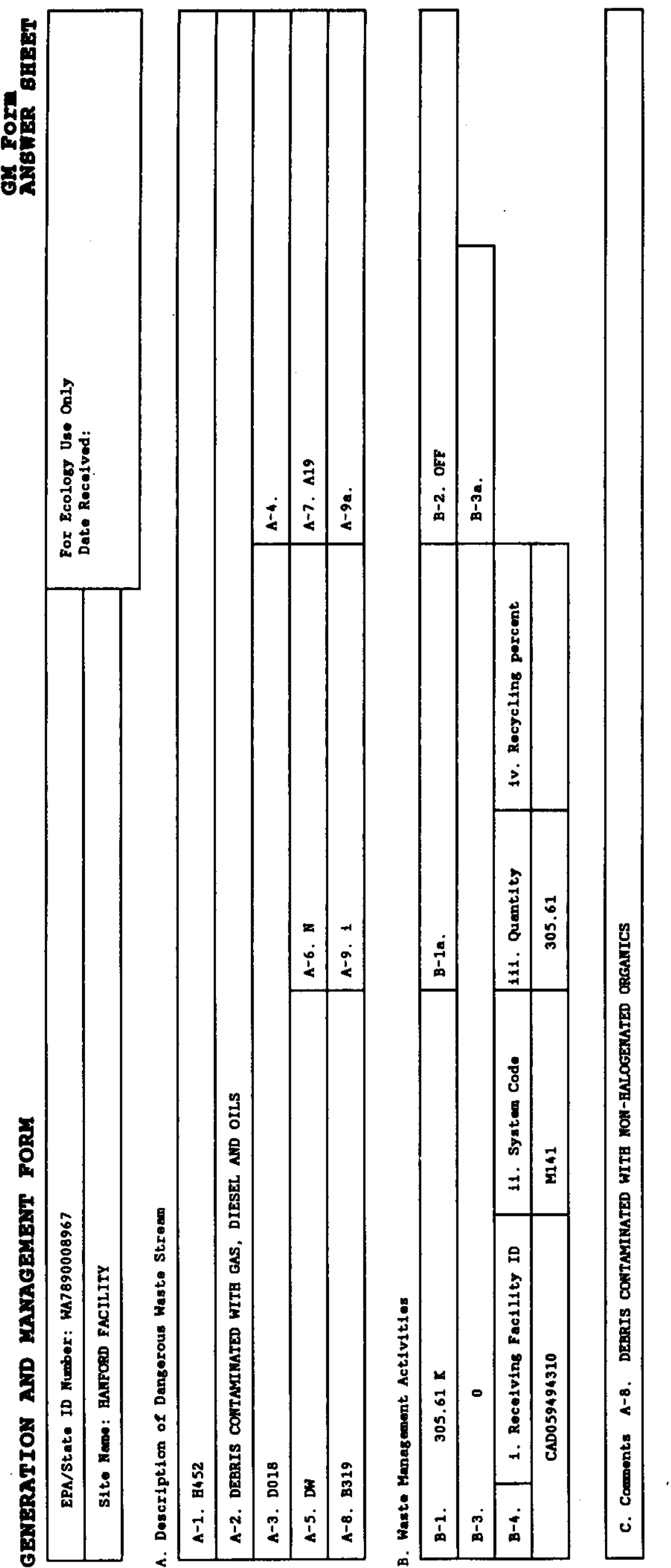


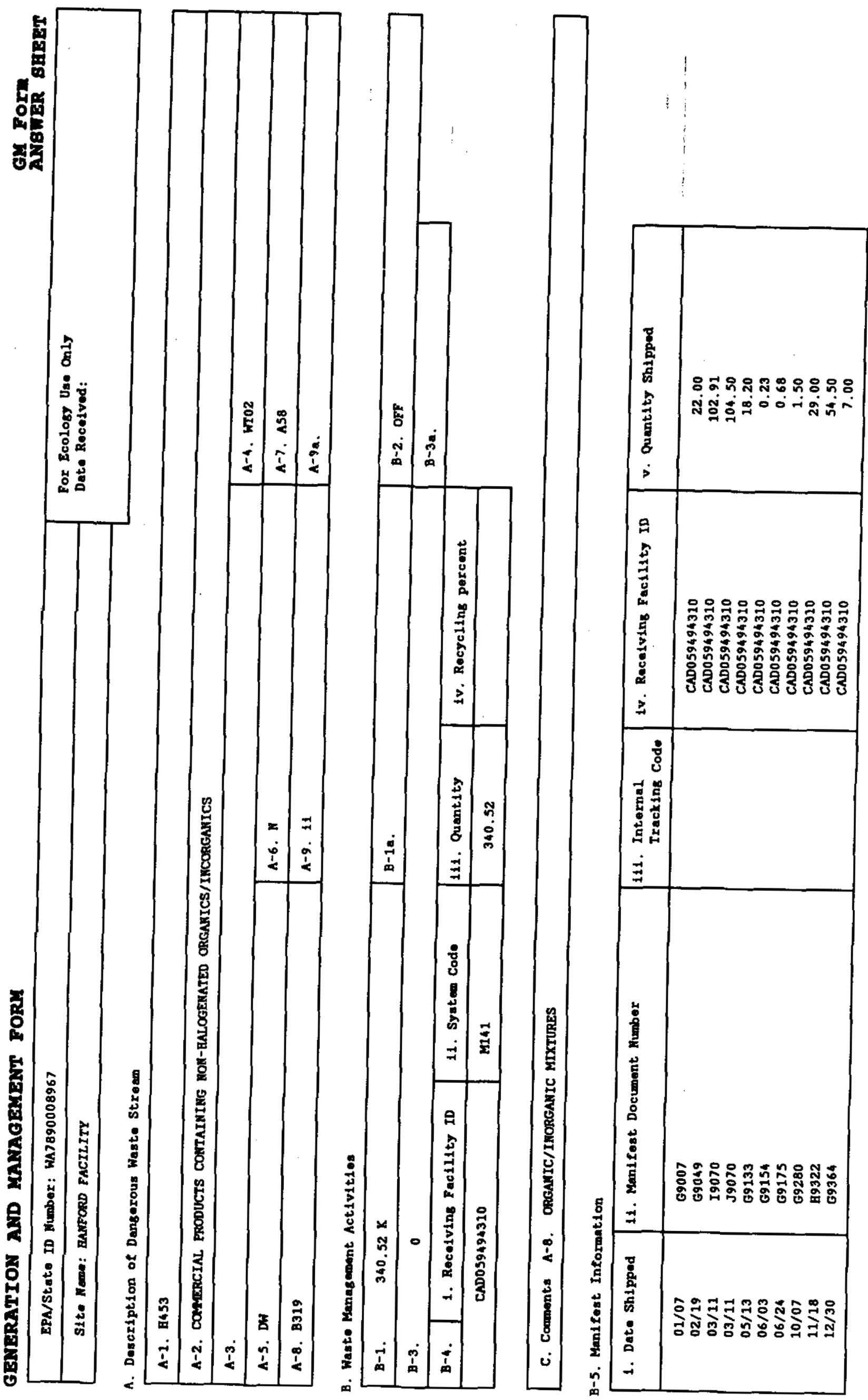




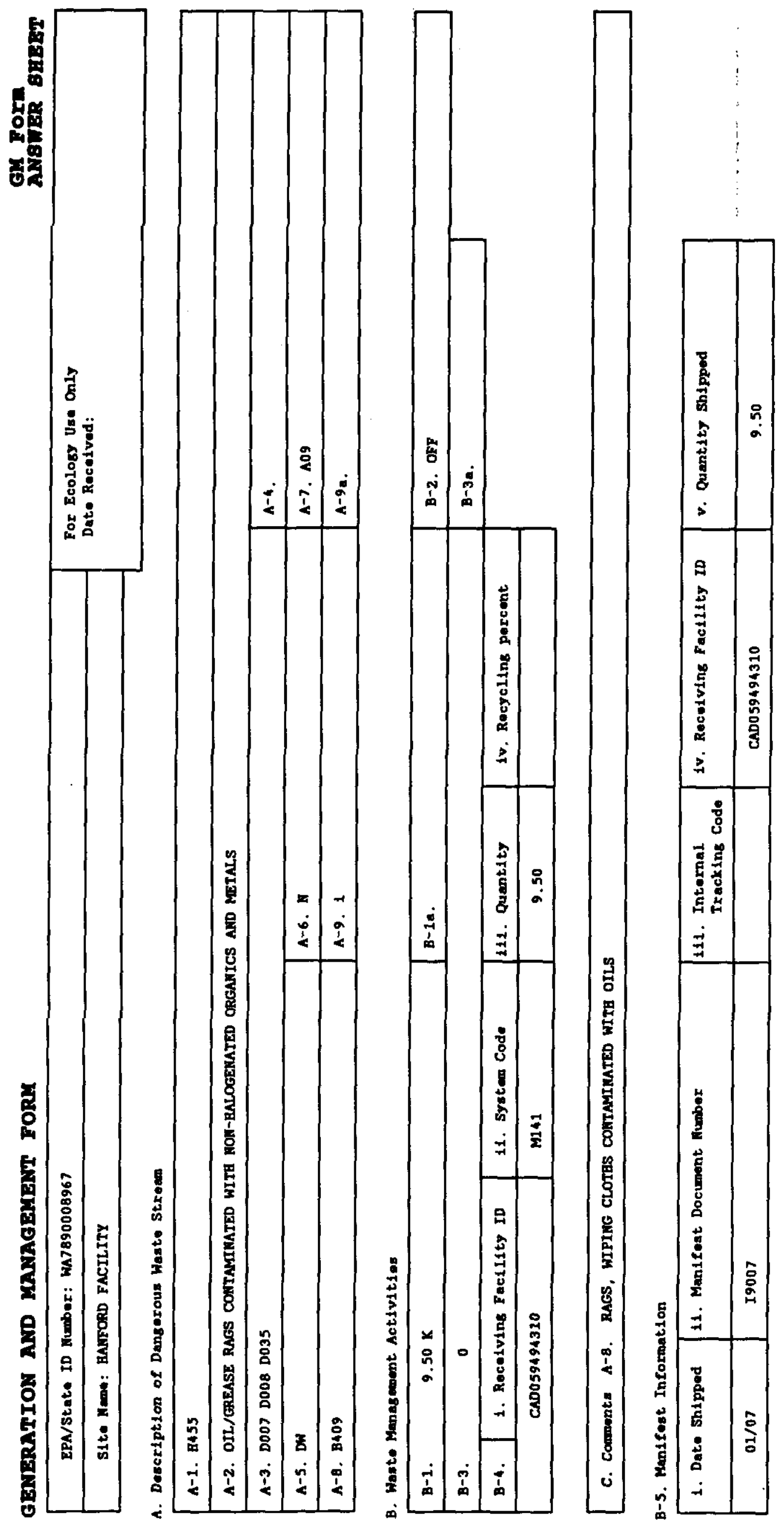




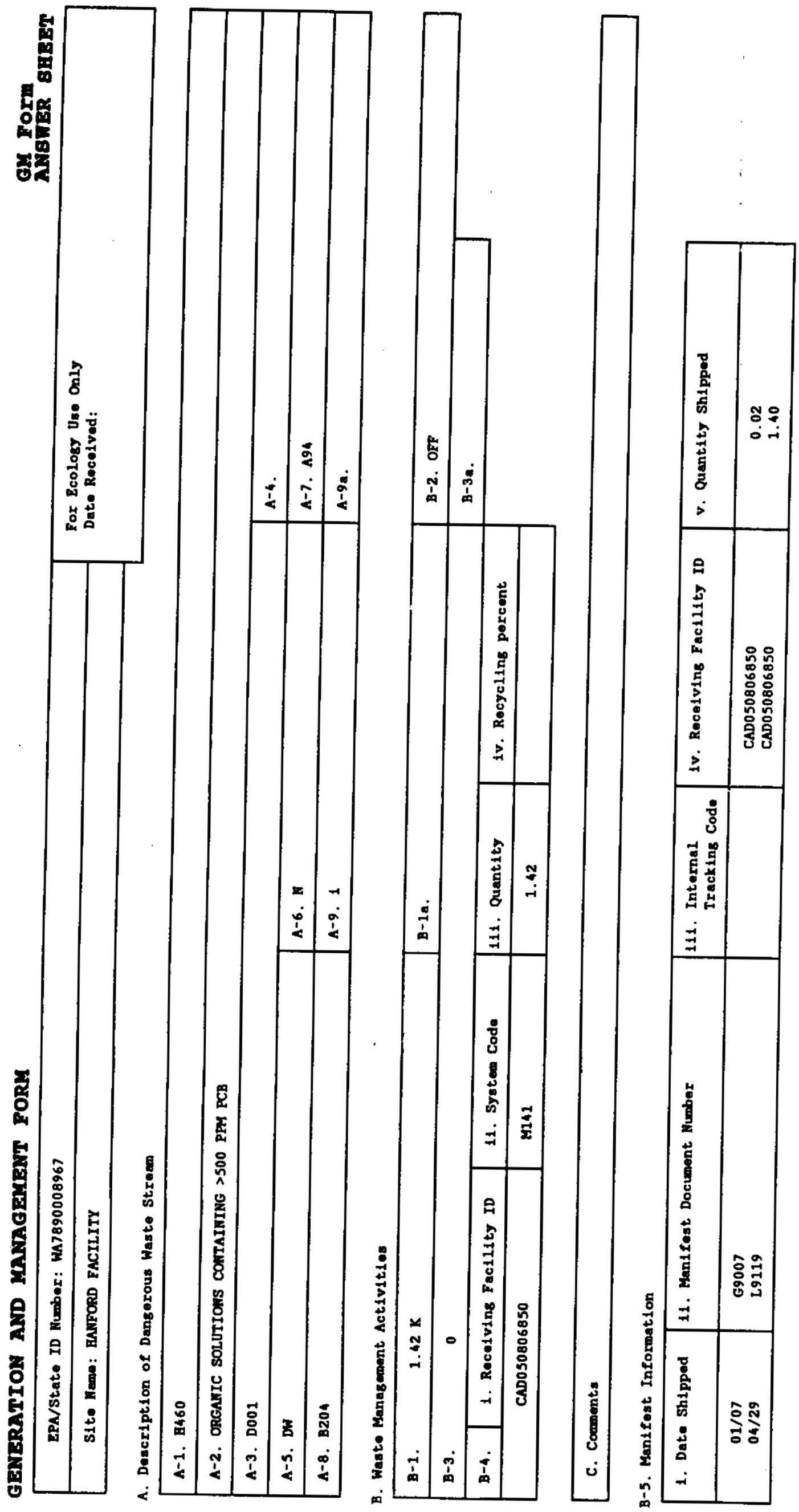




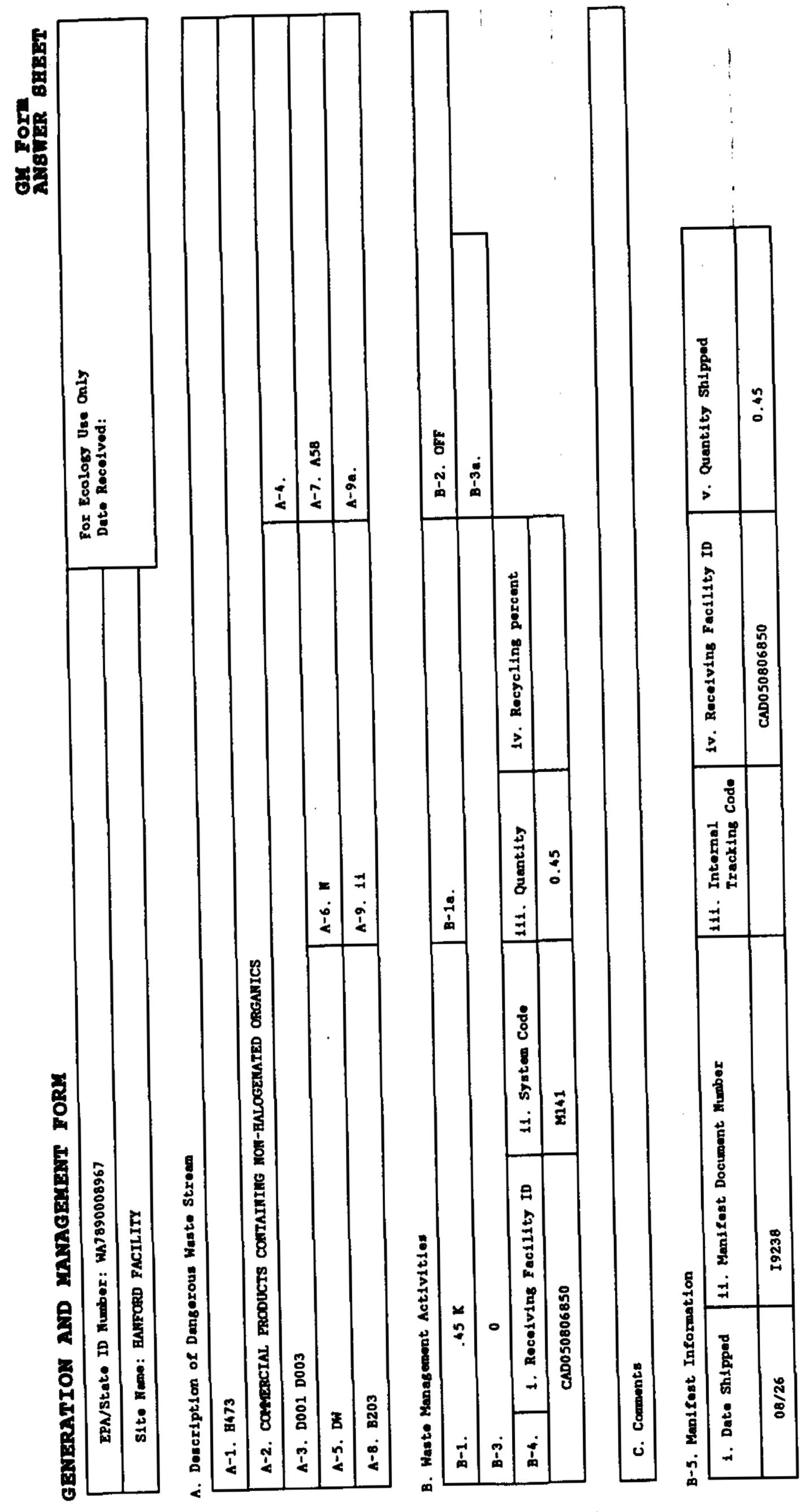




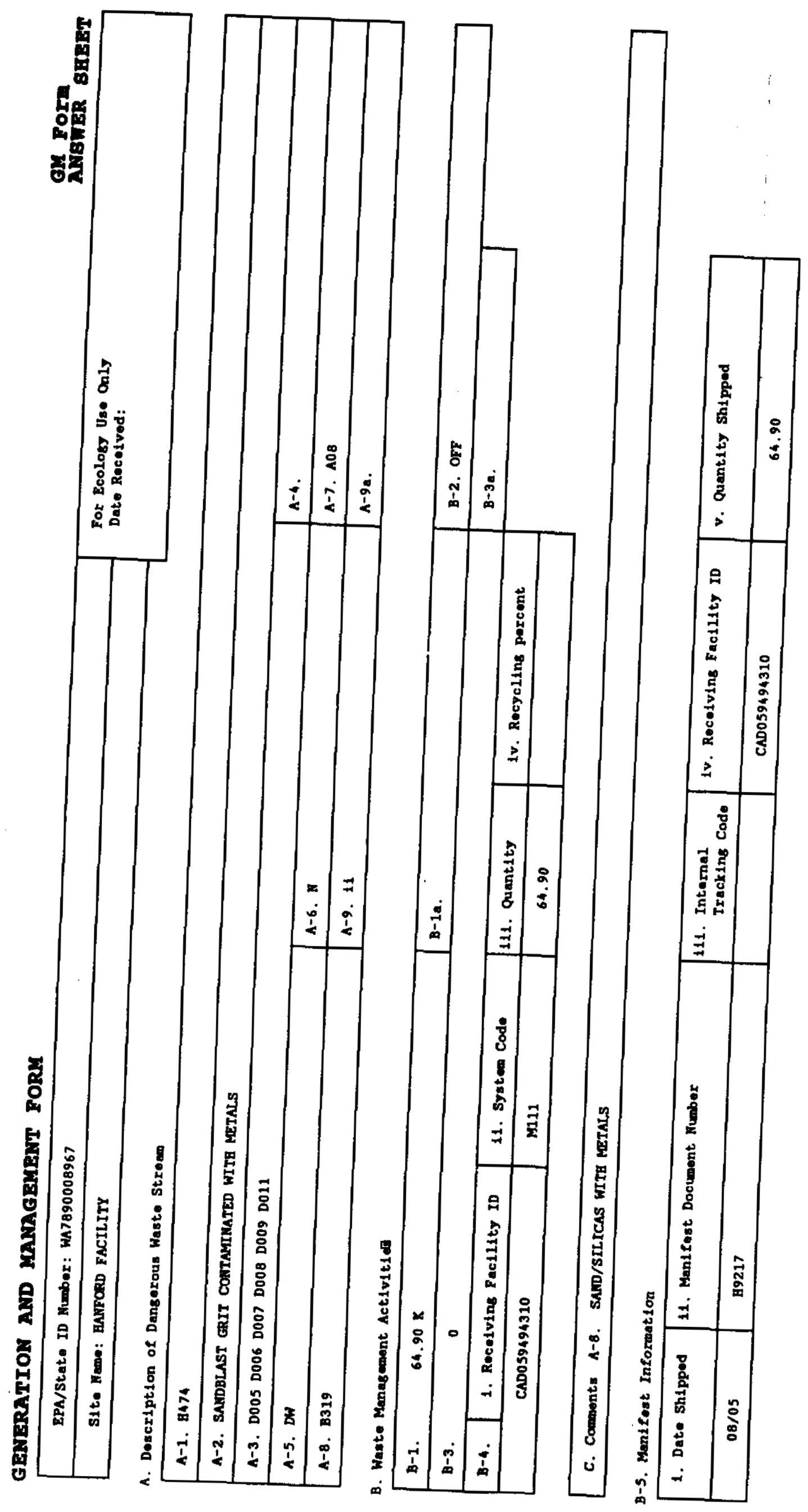

骂 

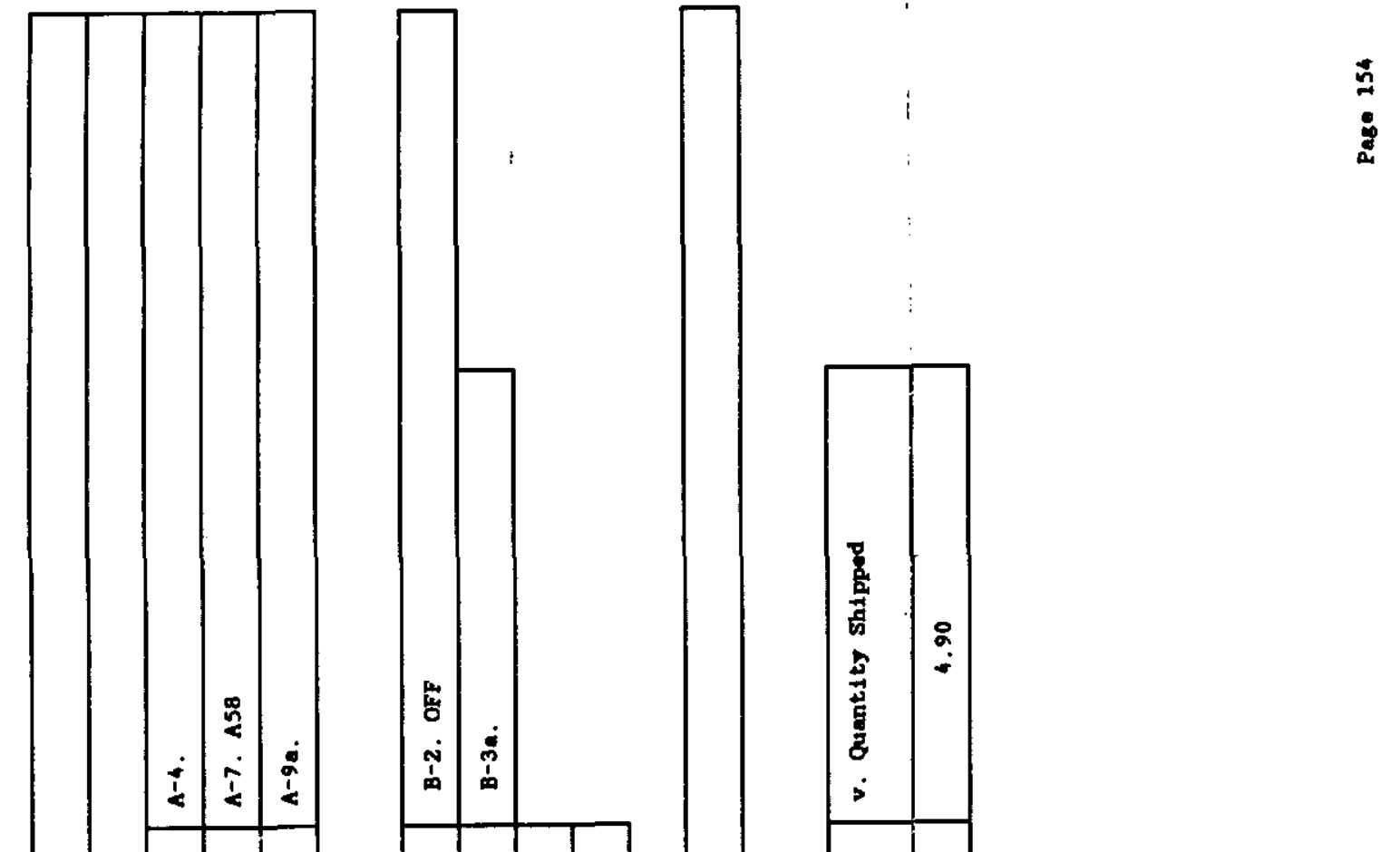

\section{容}

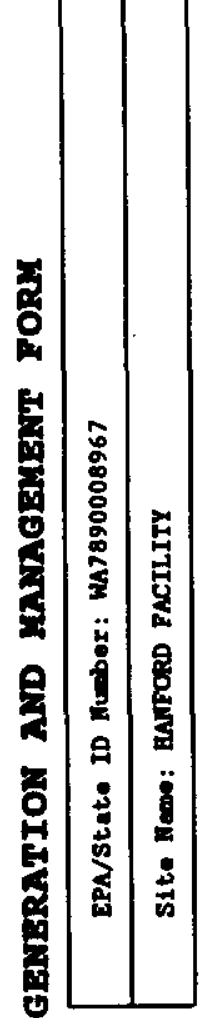

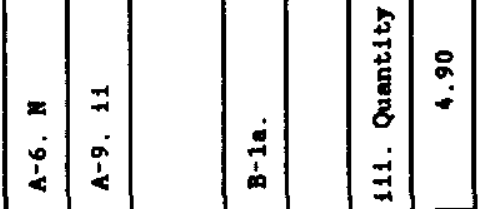
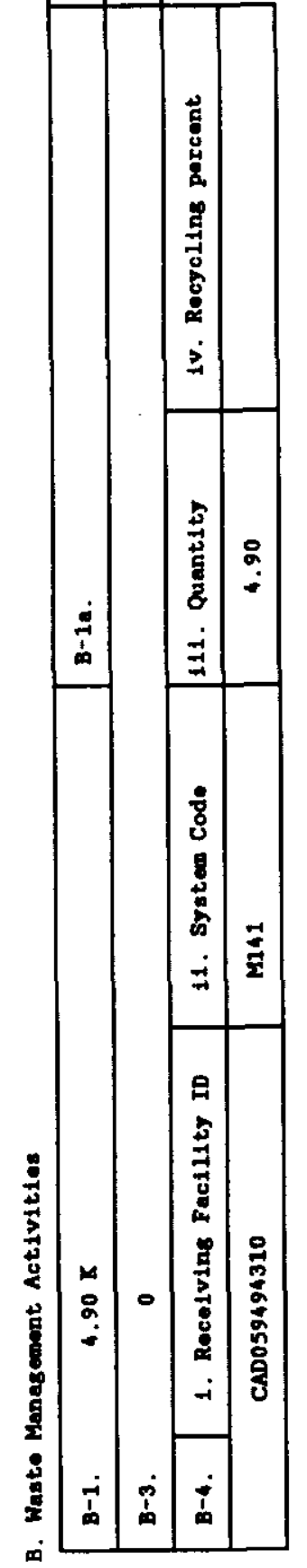

.

5

$\frac{8}{3}$

总

范 峕

它 营

兽

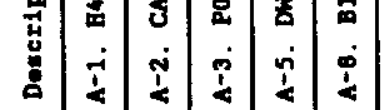
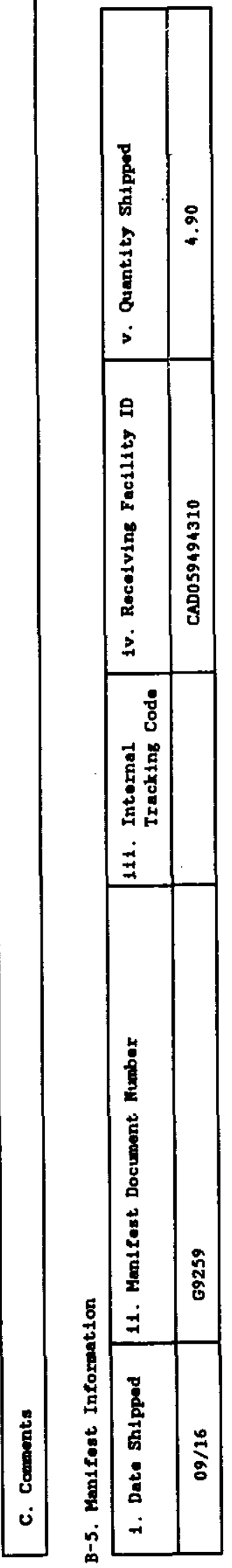


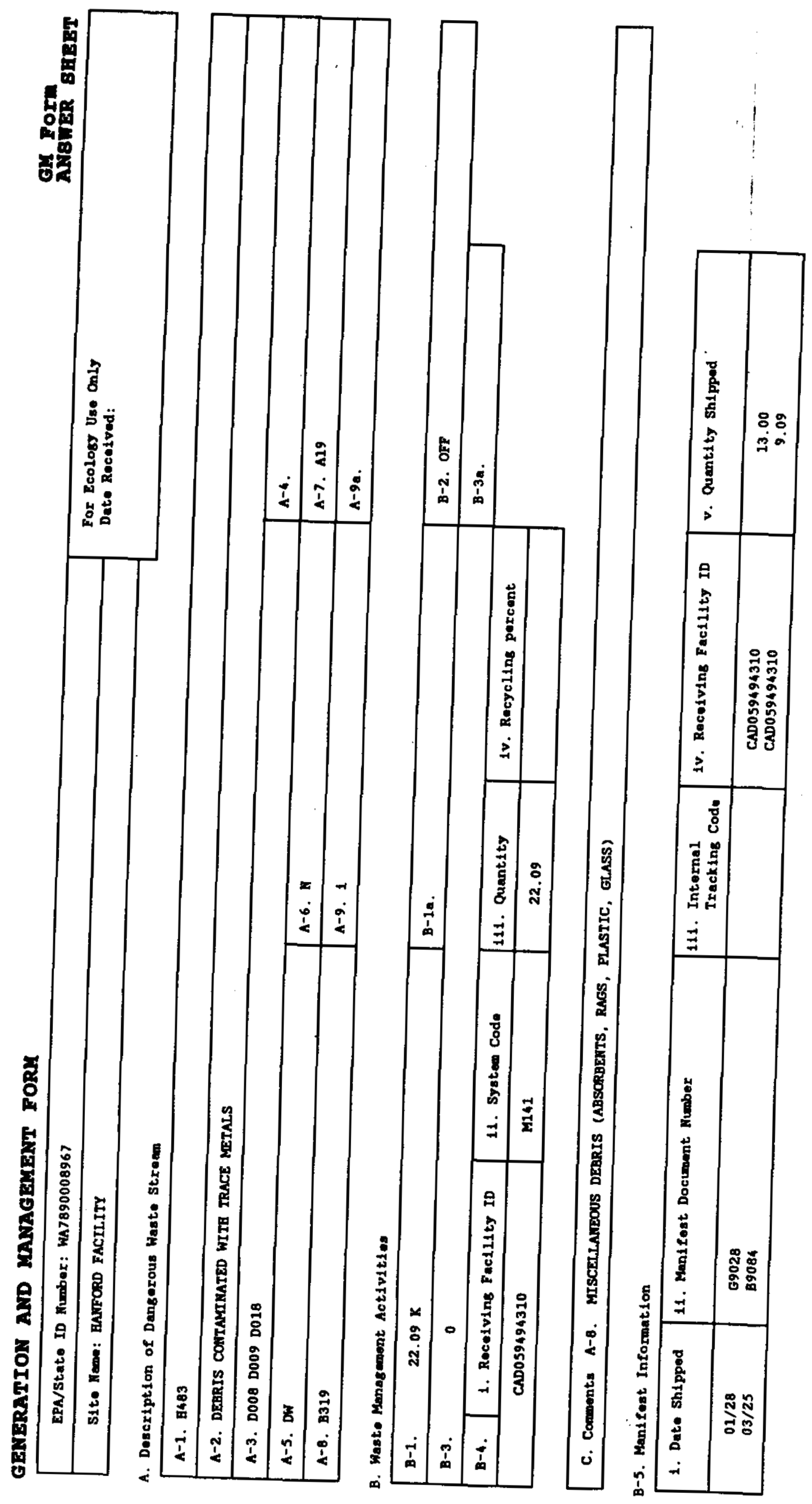




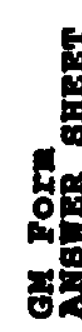
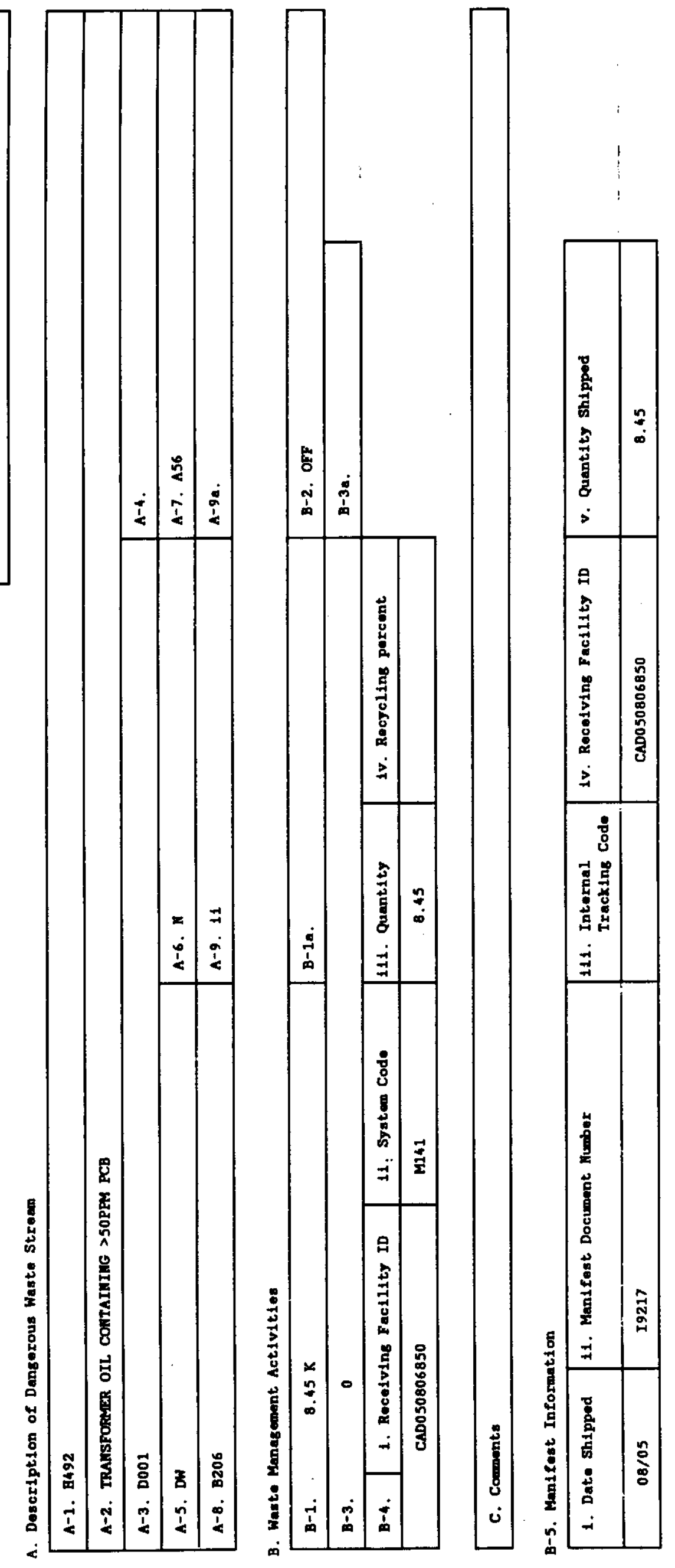

ถั

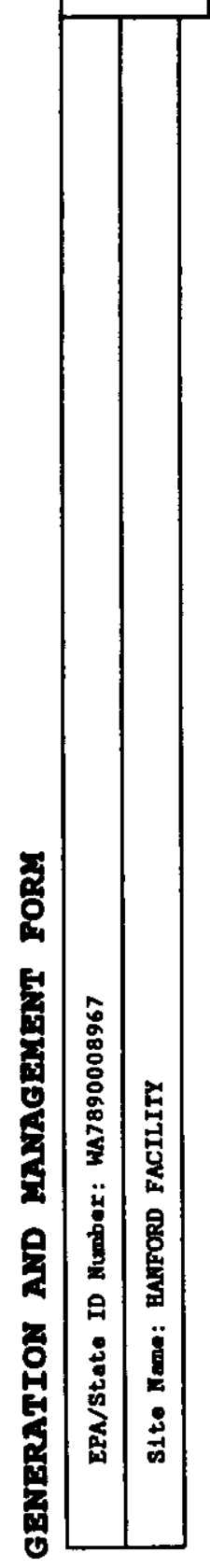




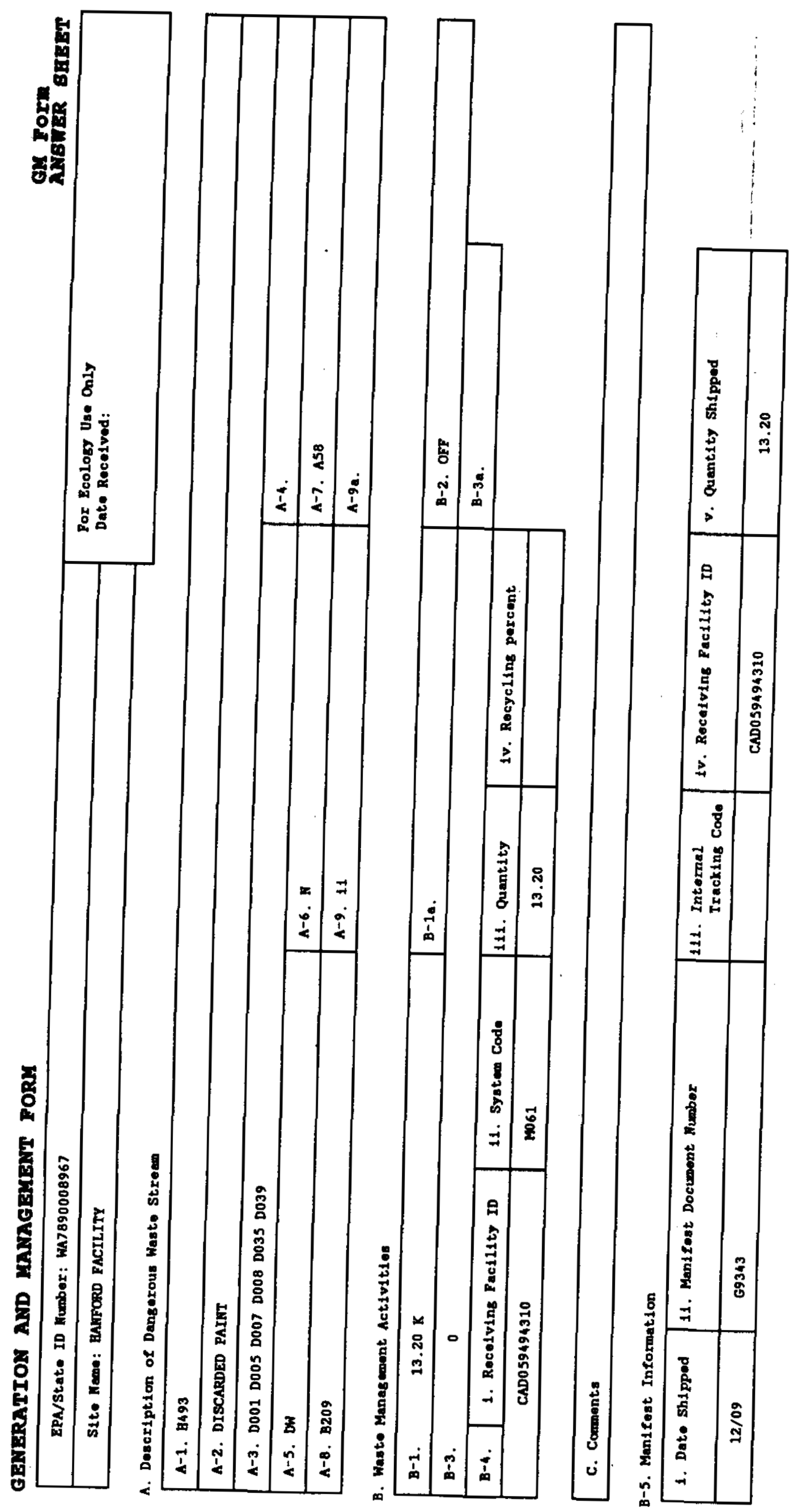




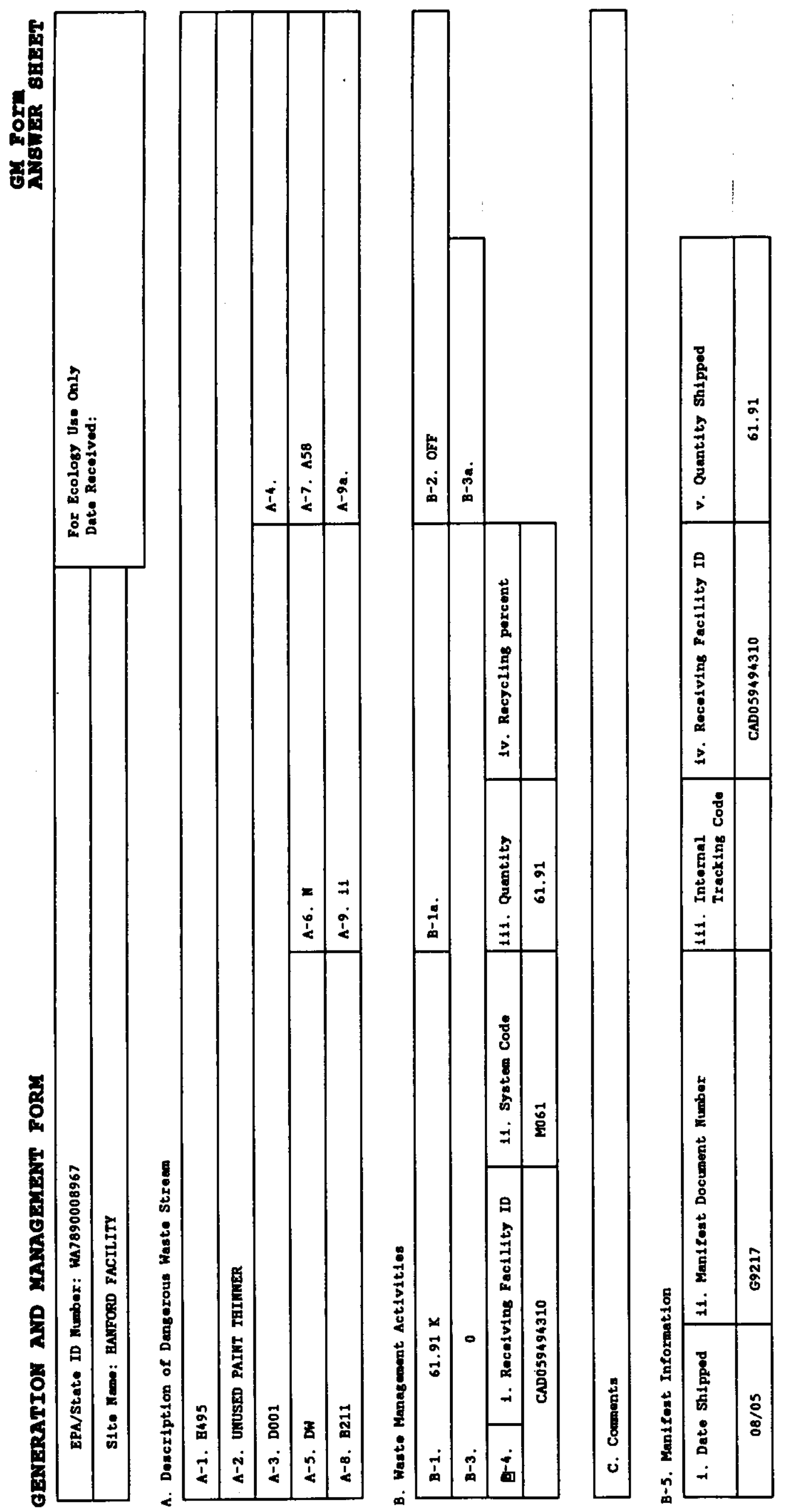




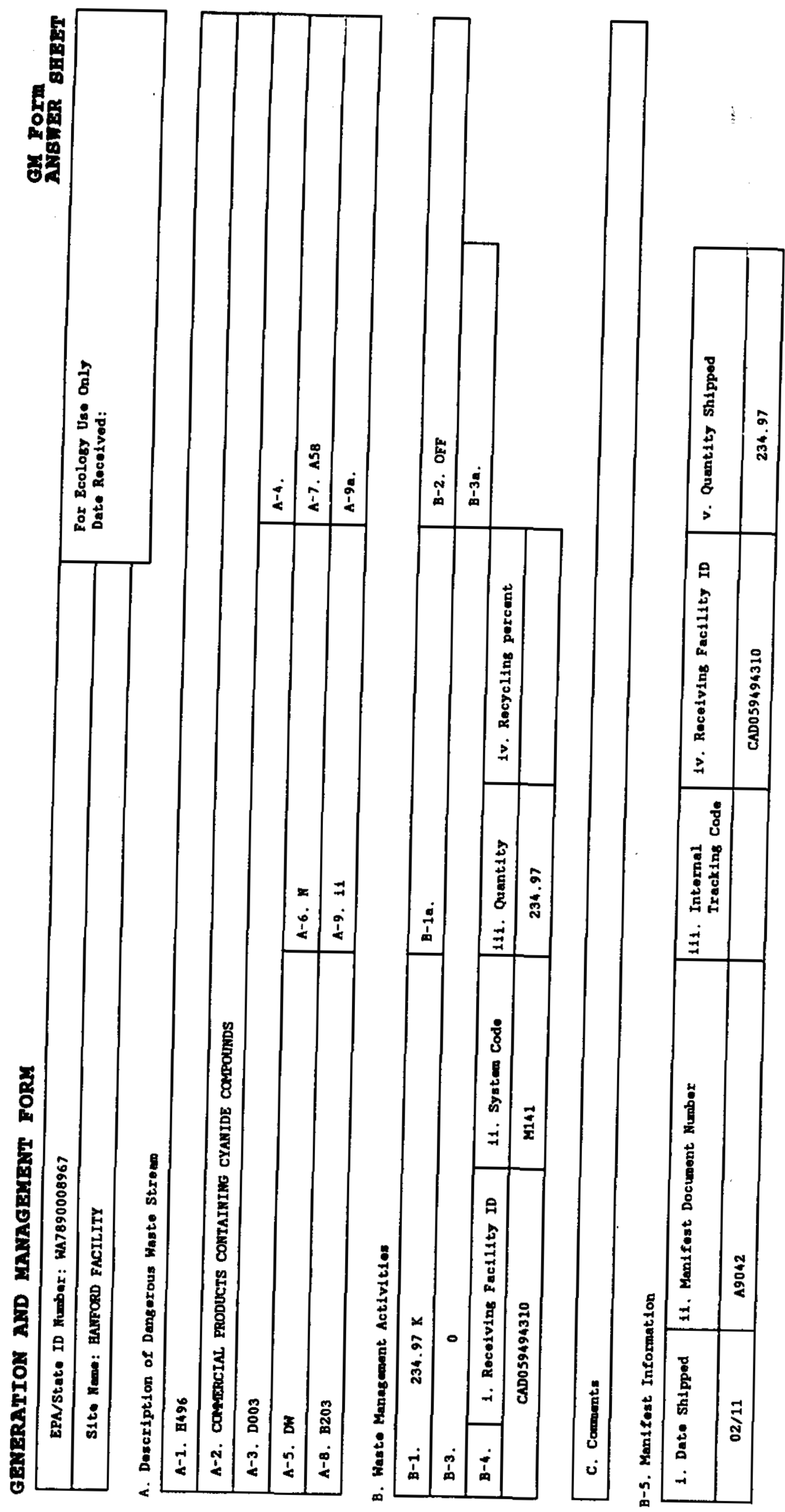




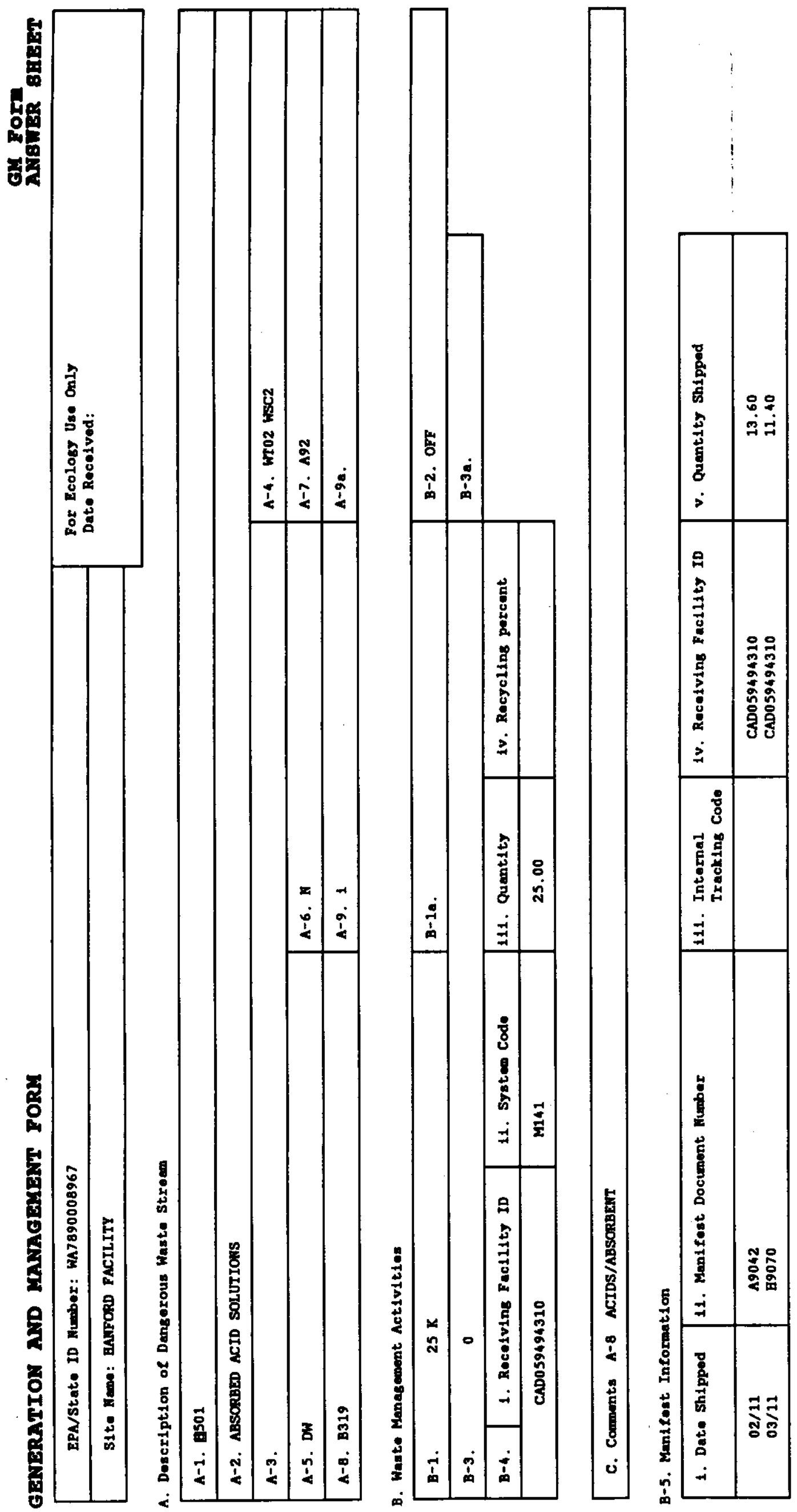




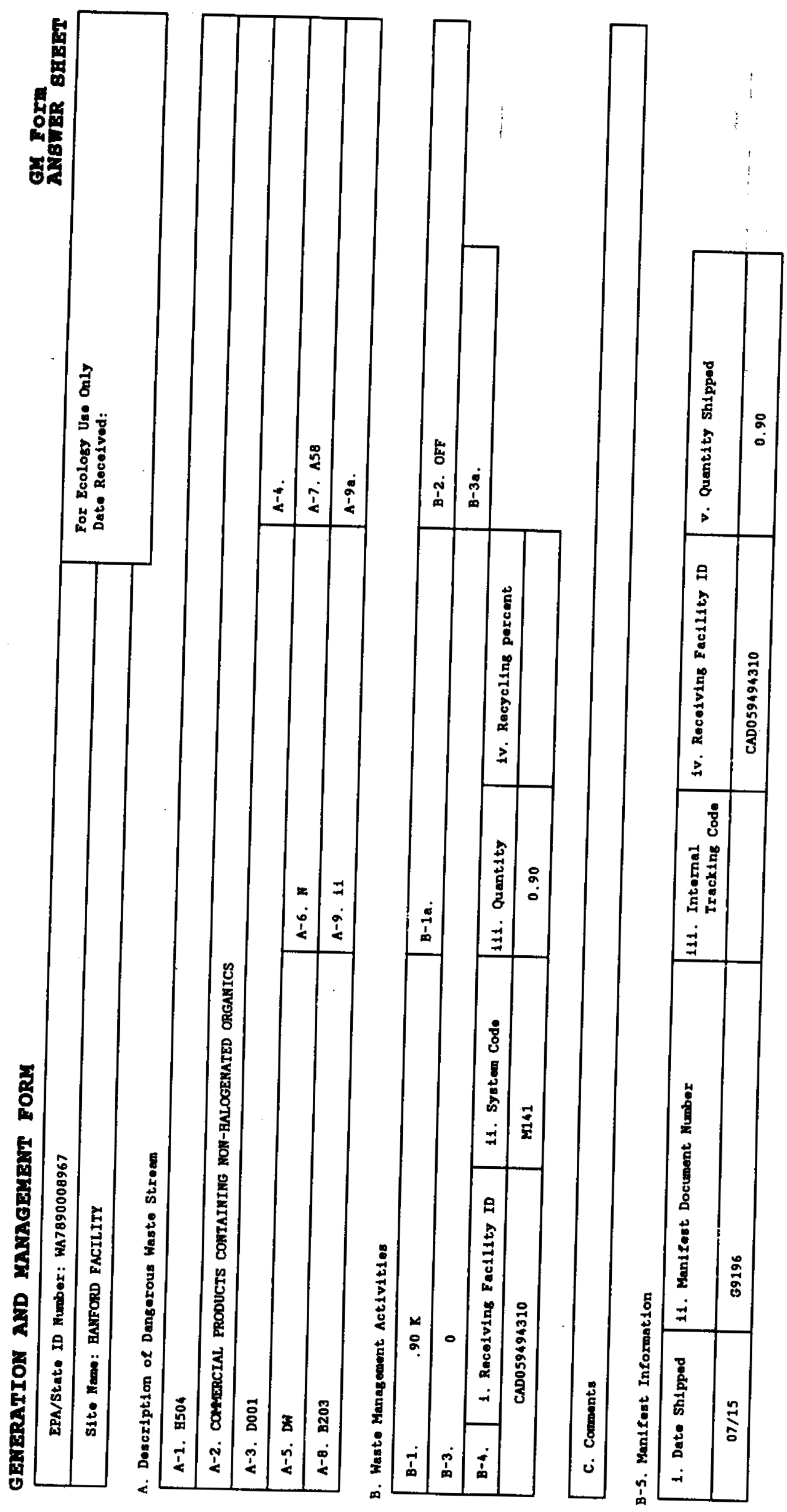




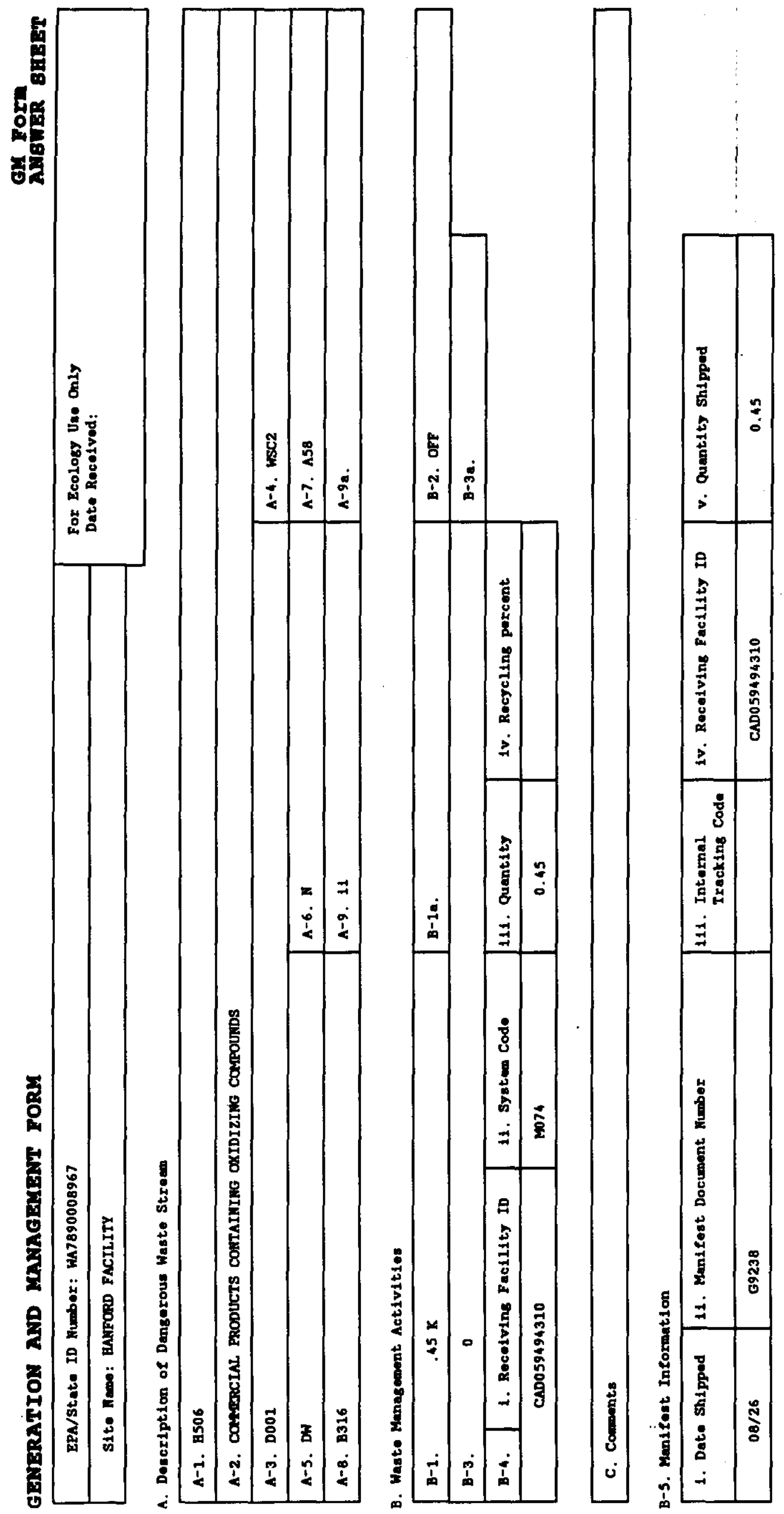




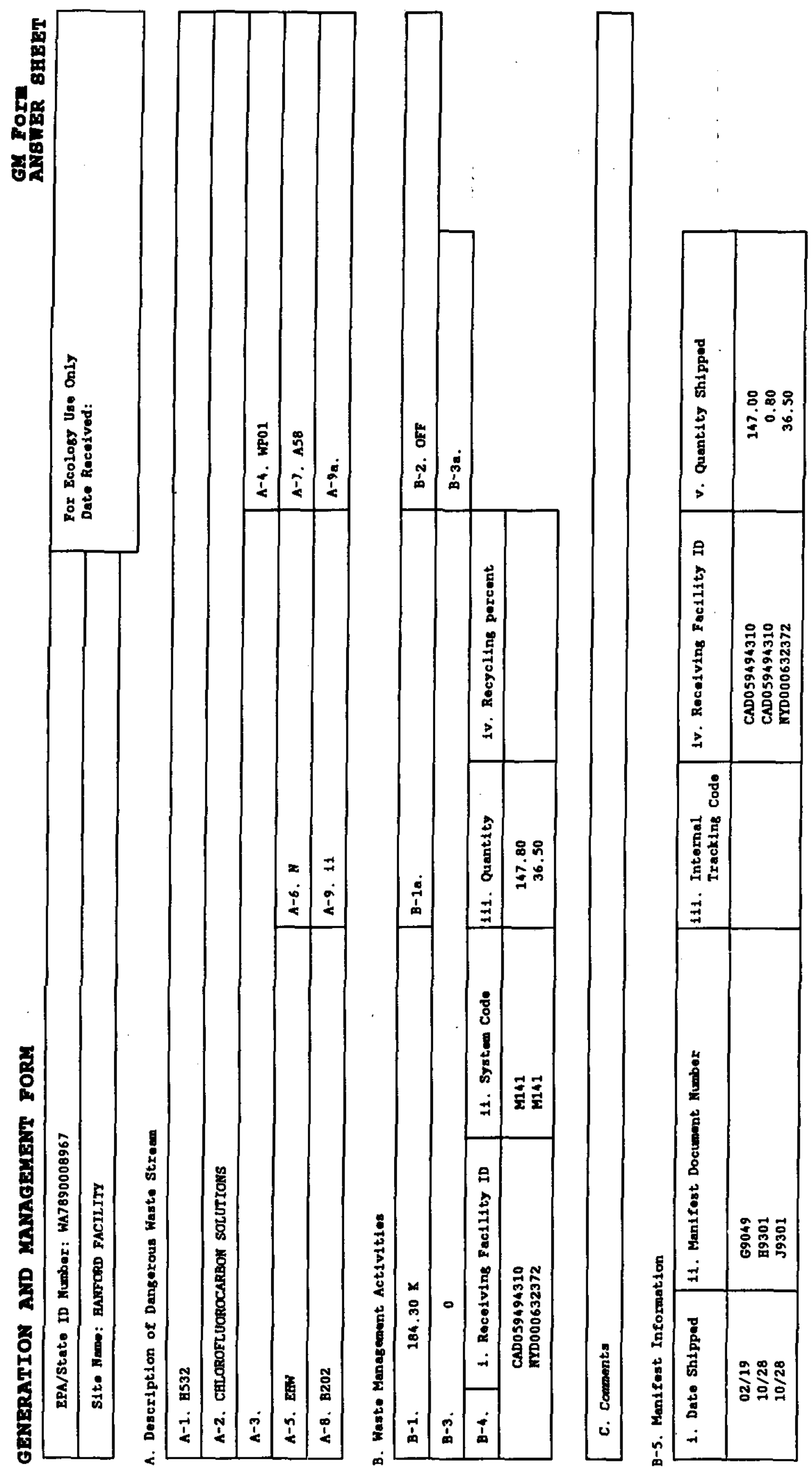




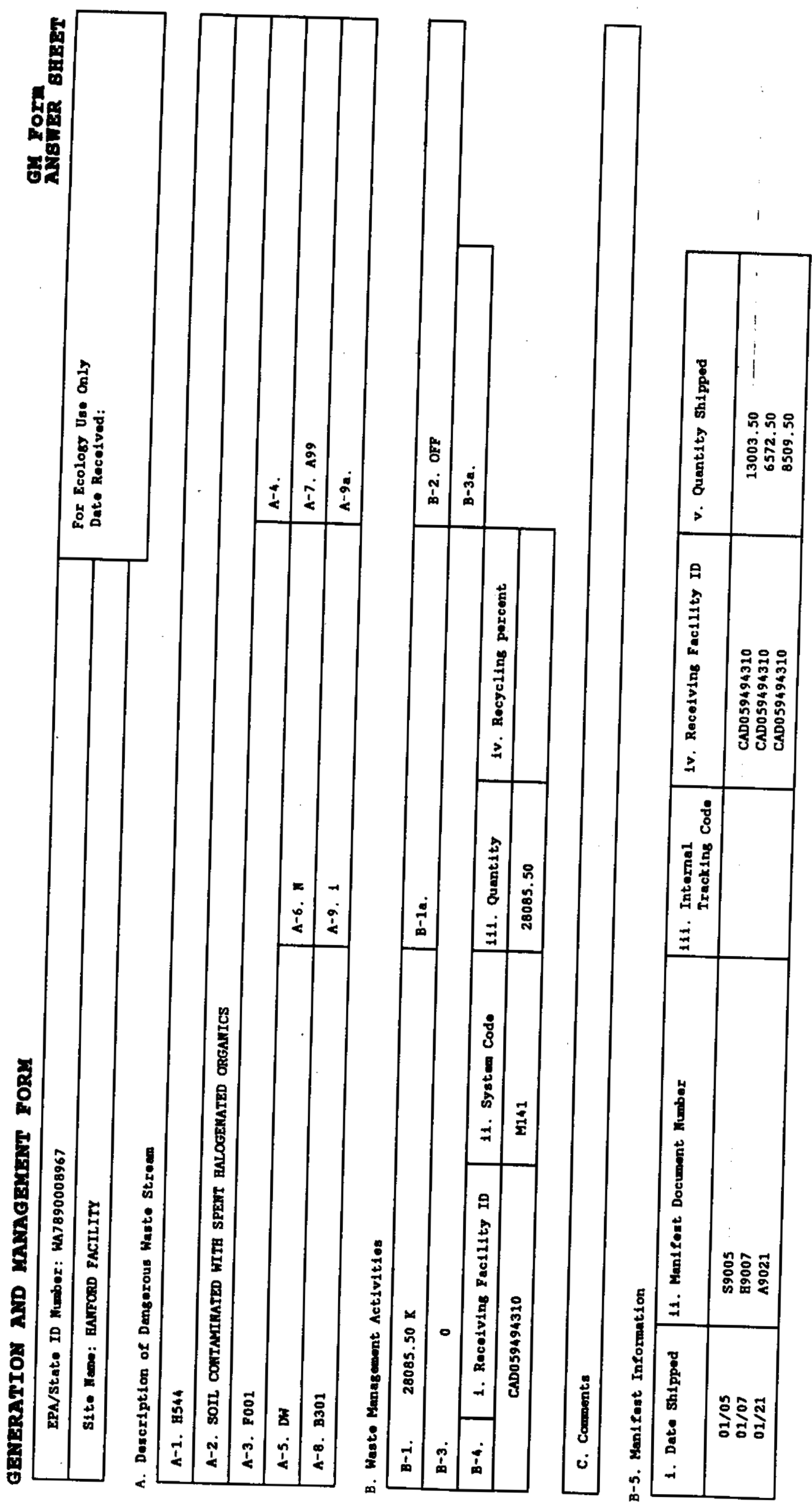


离
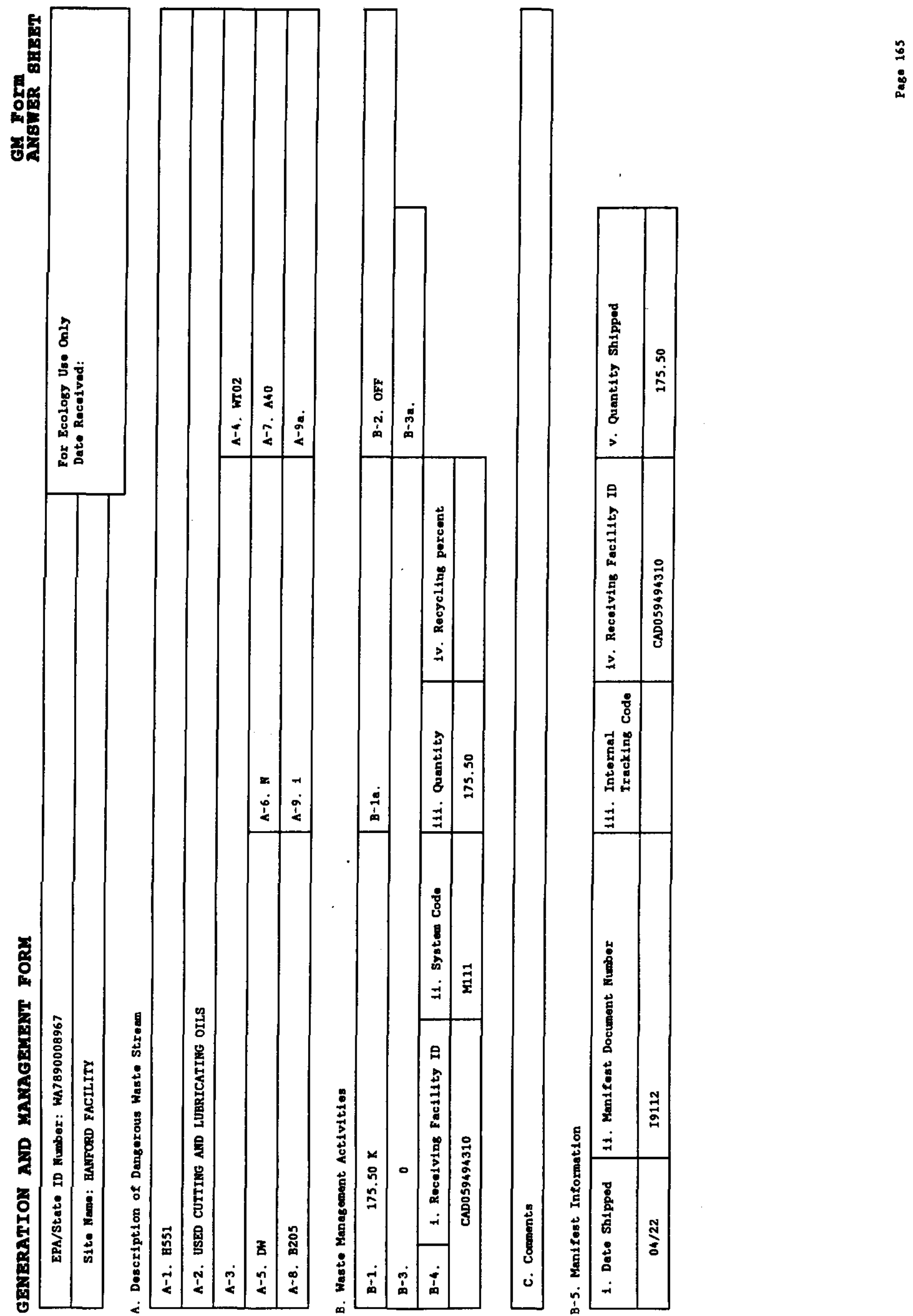

蓉
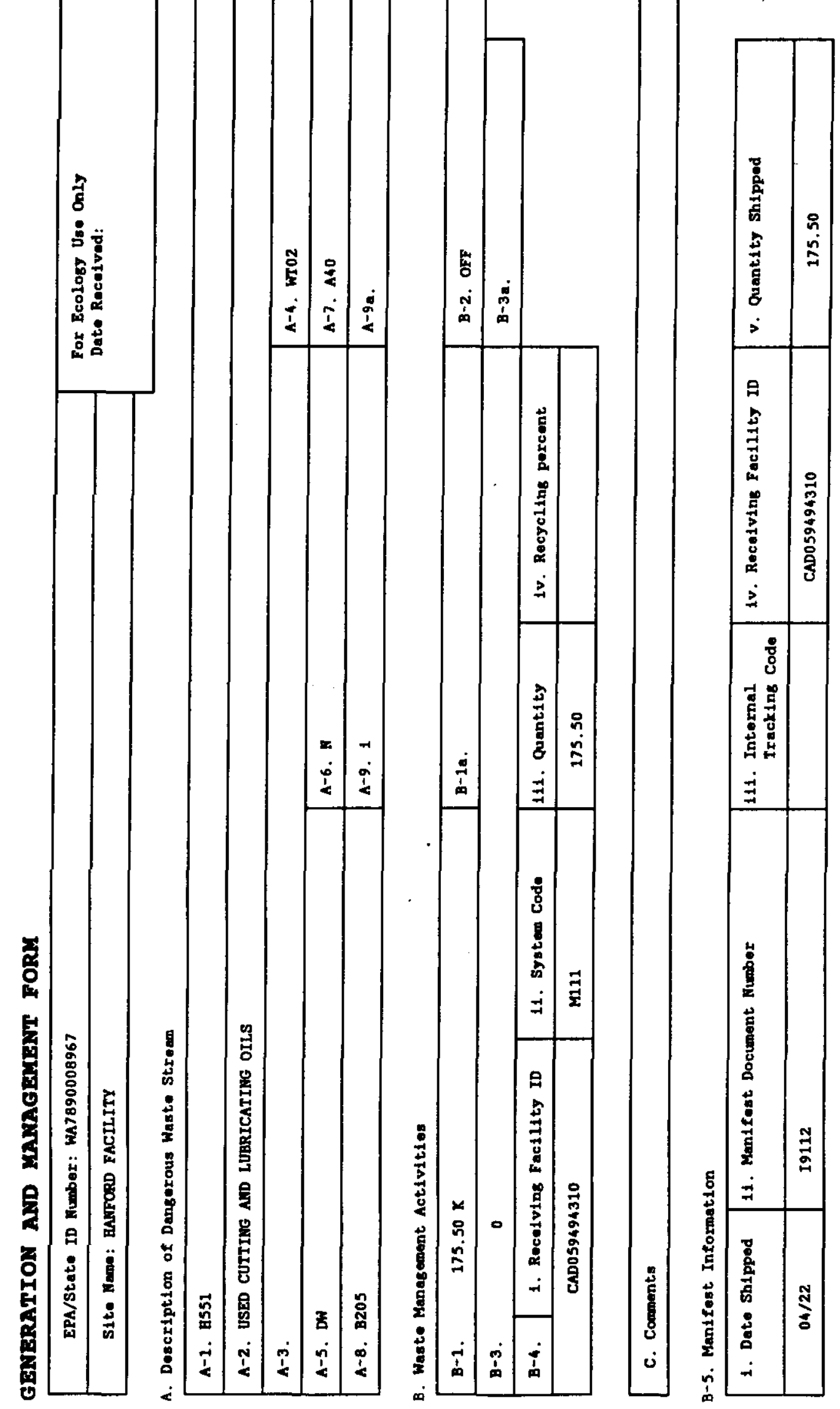


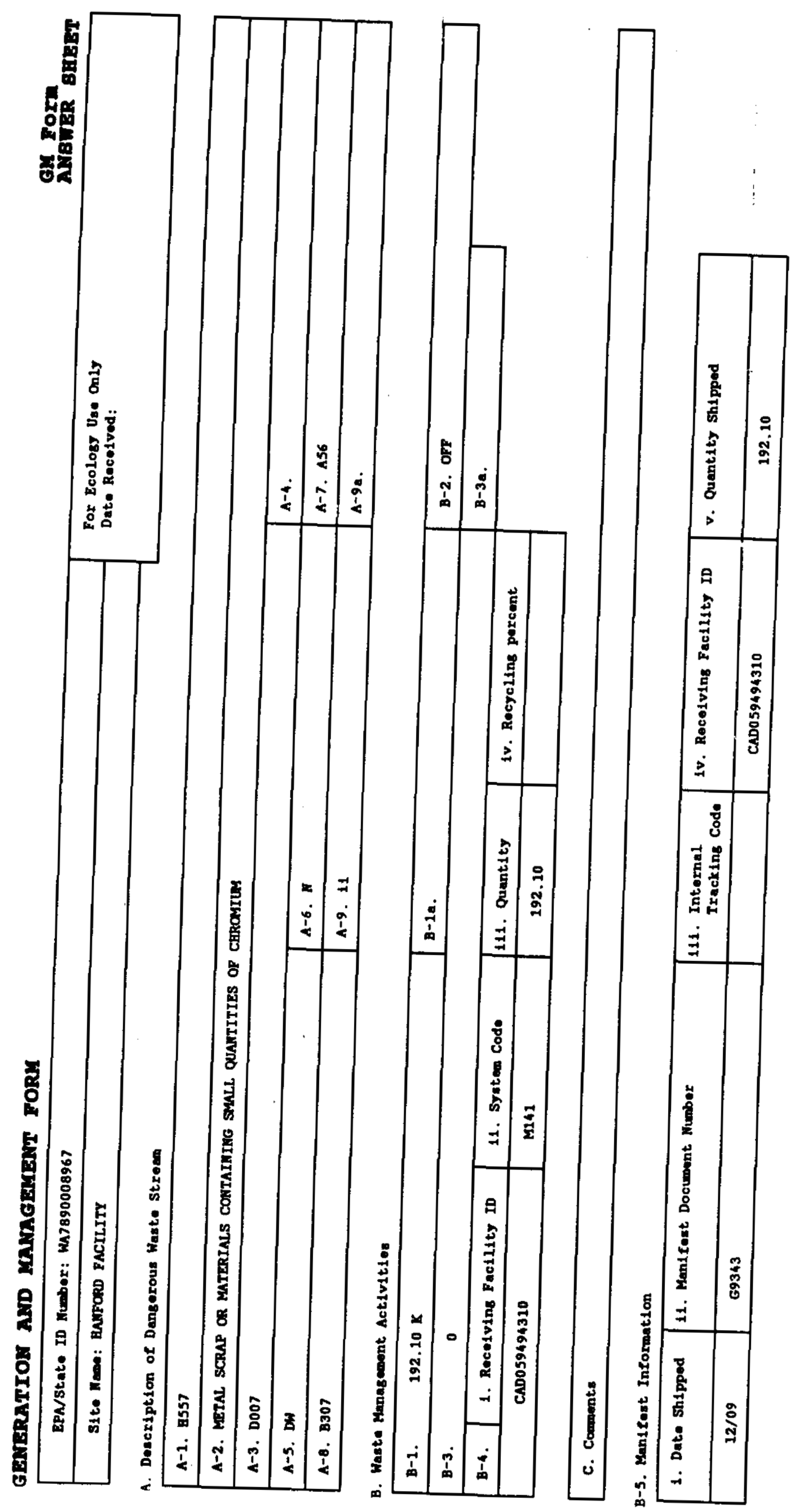




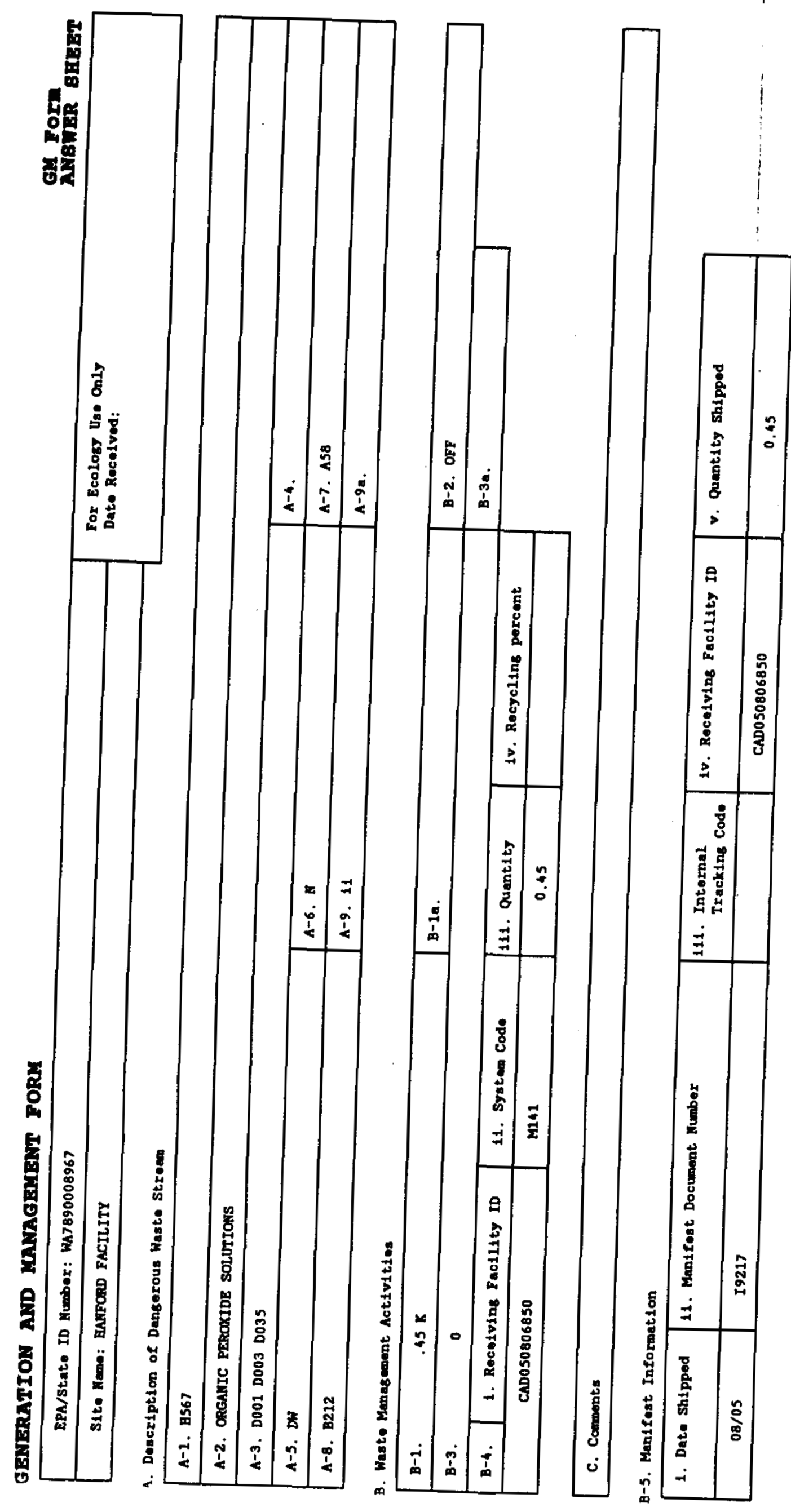




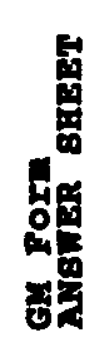
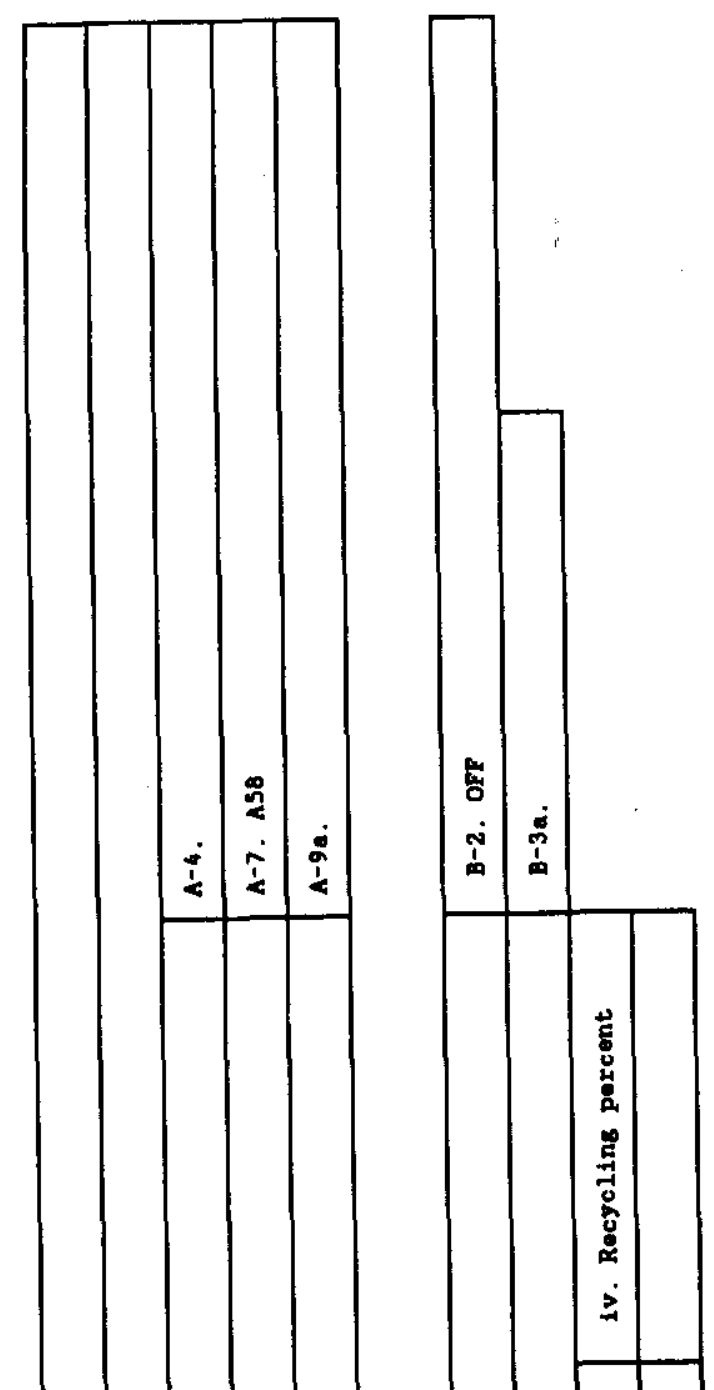

$\stackrel{8}{8}$
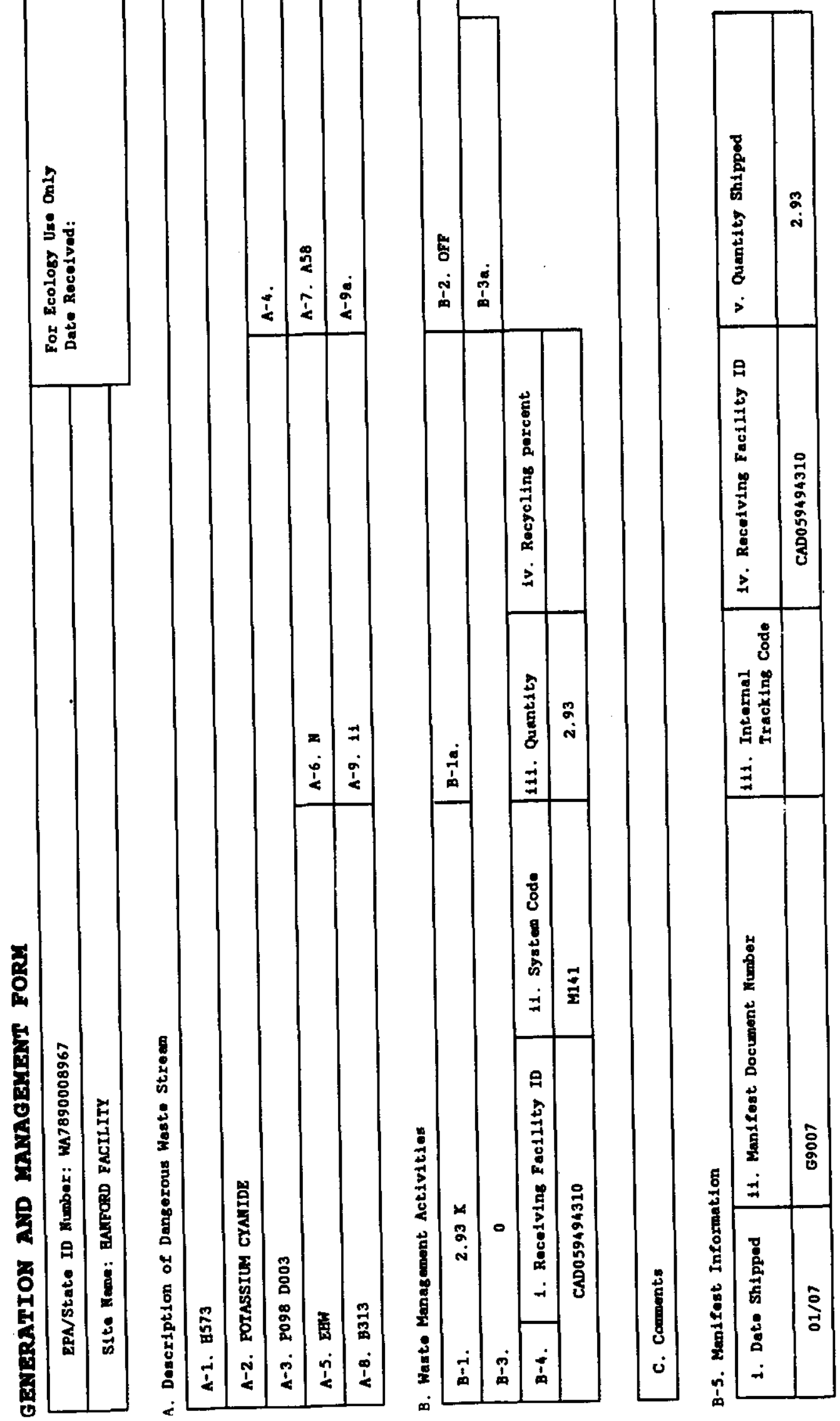


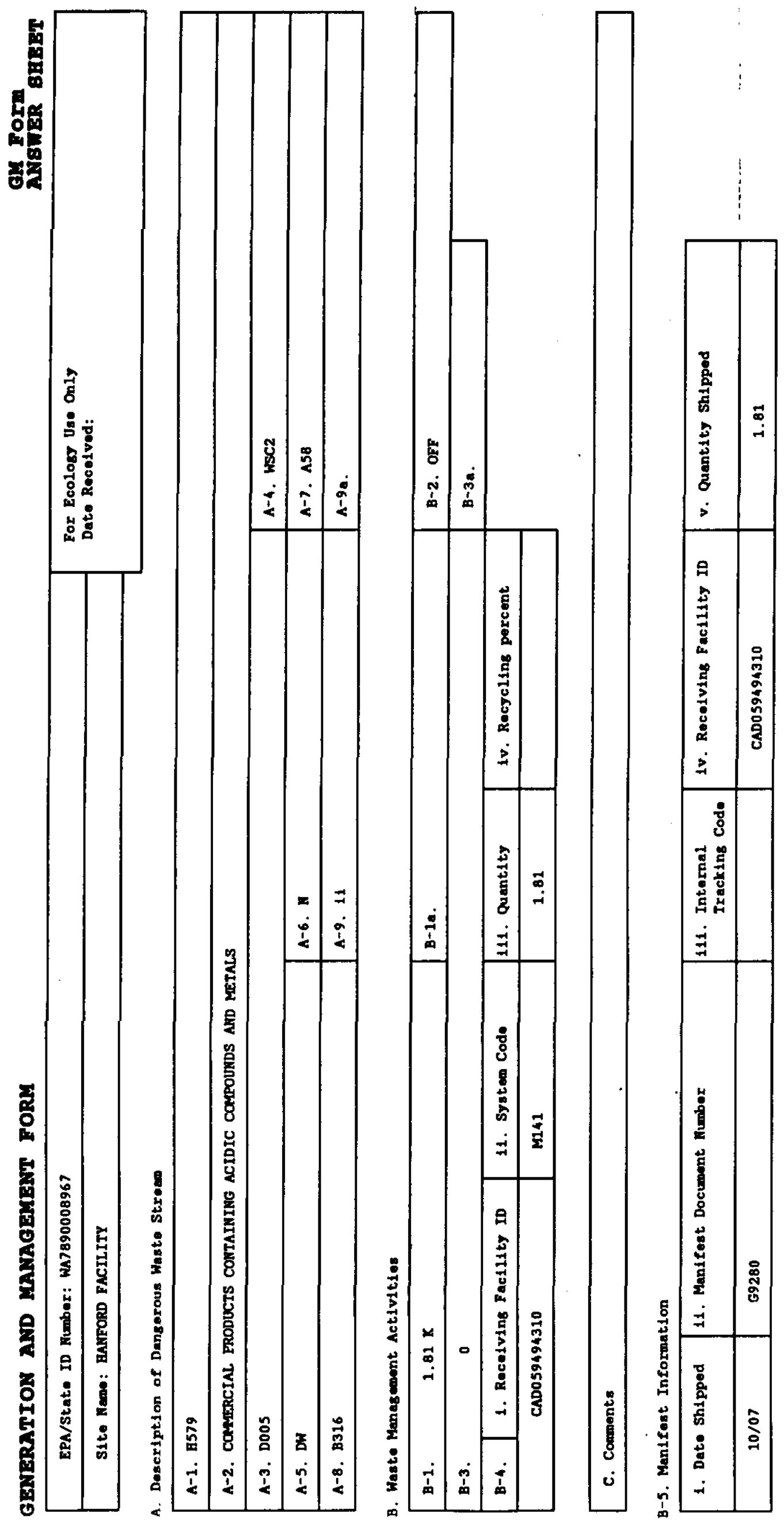




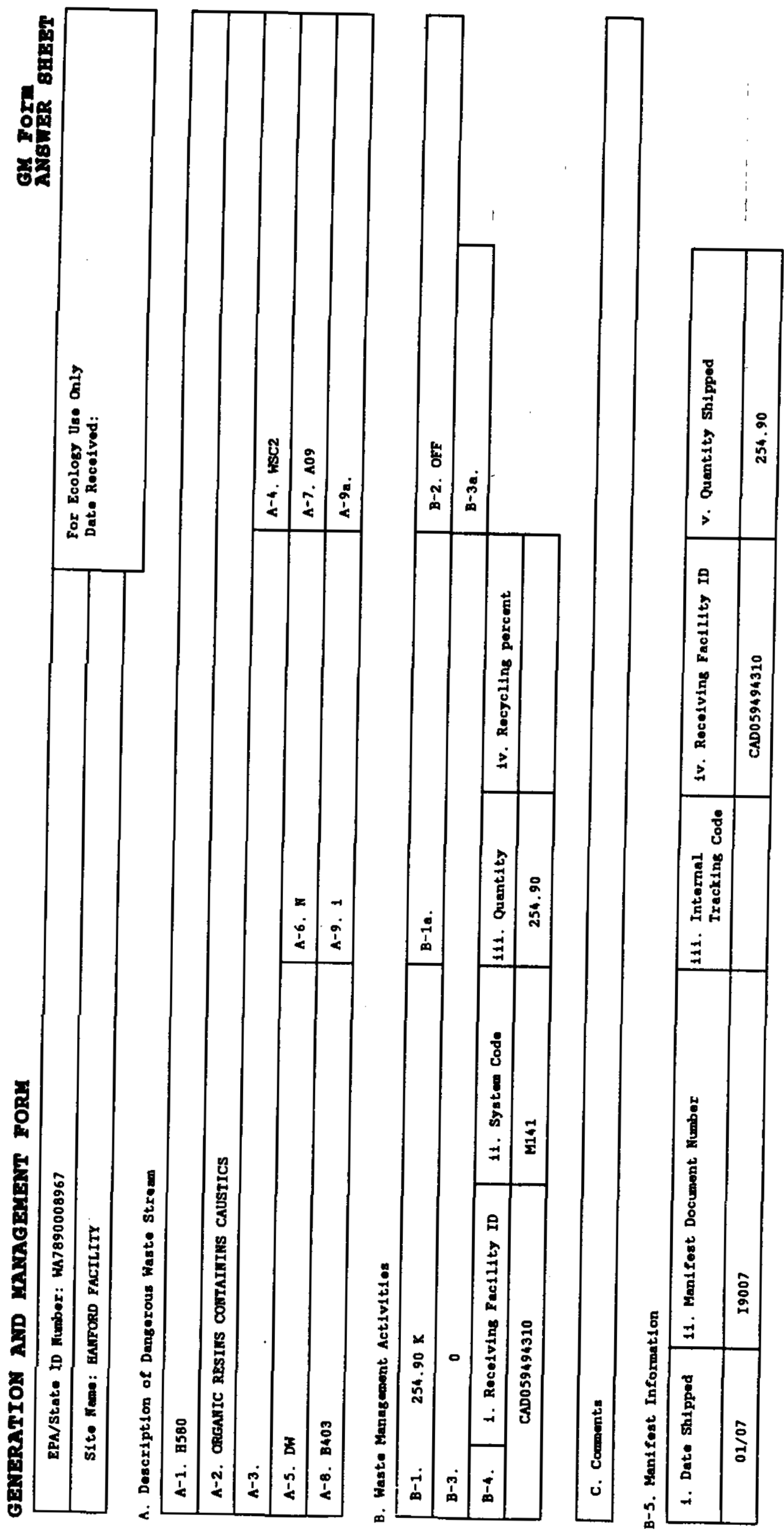




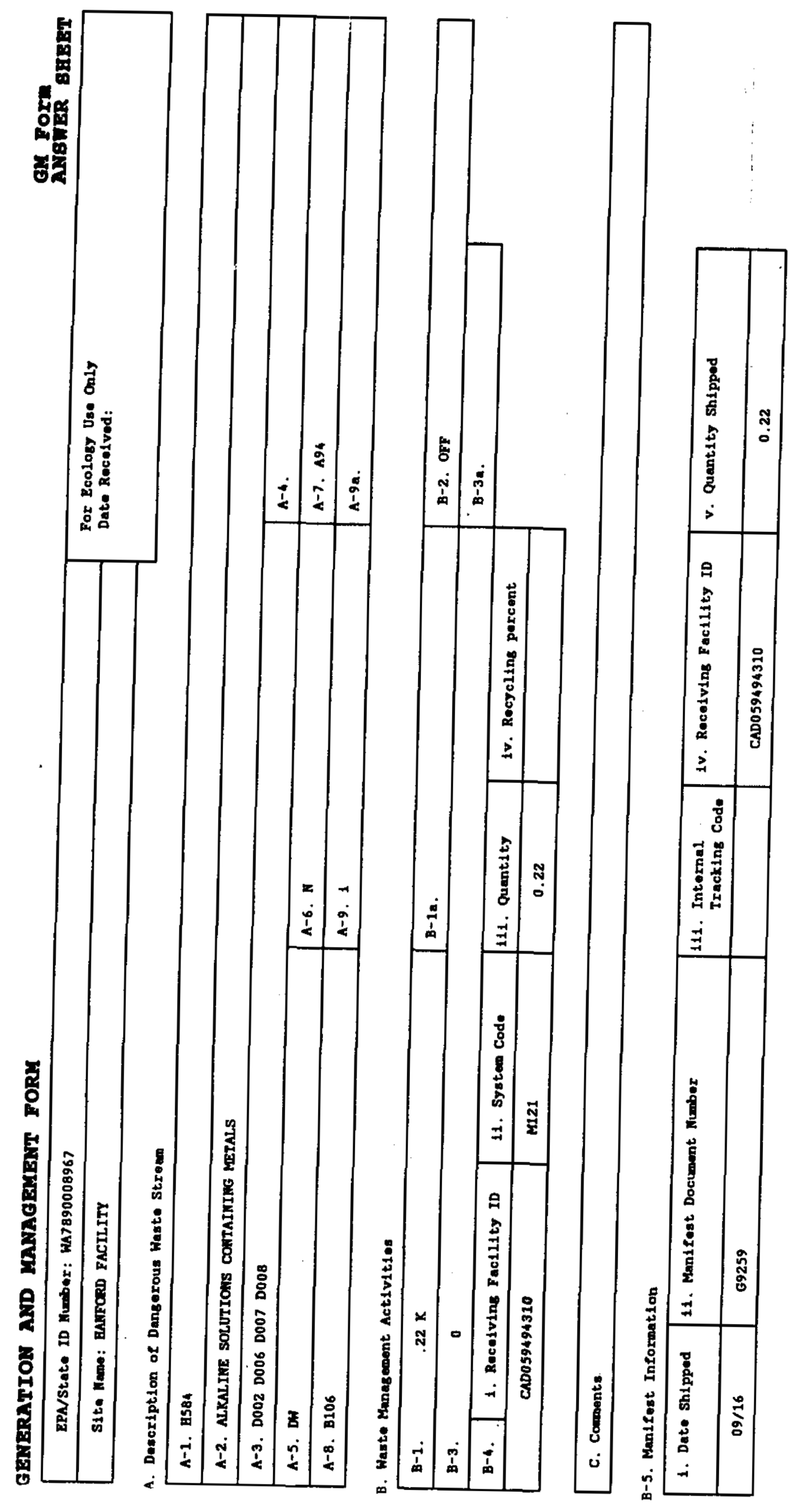



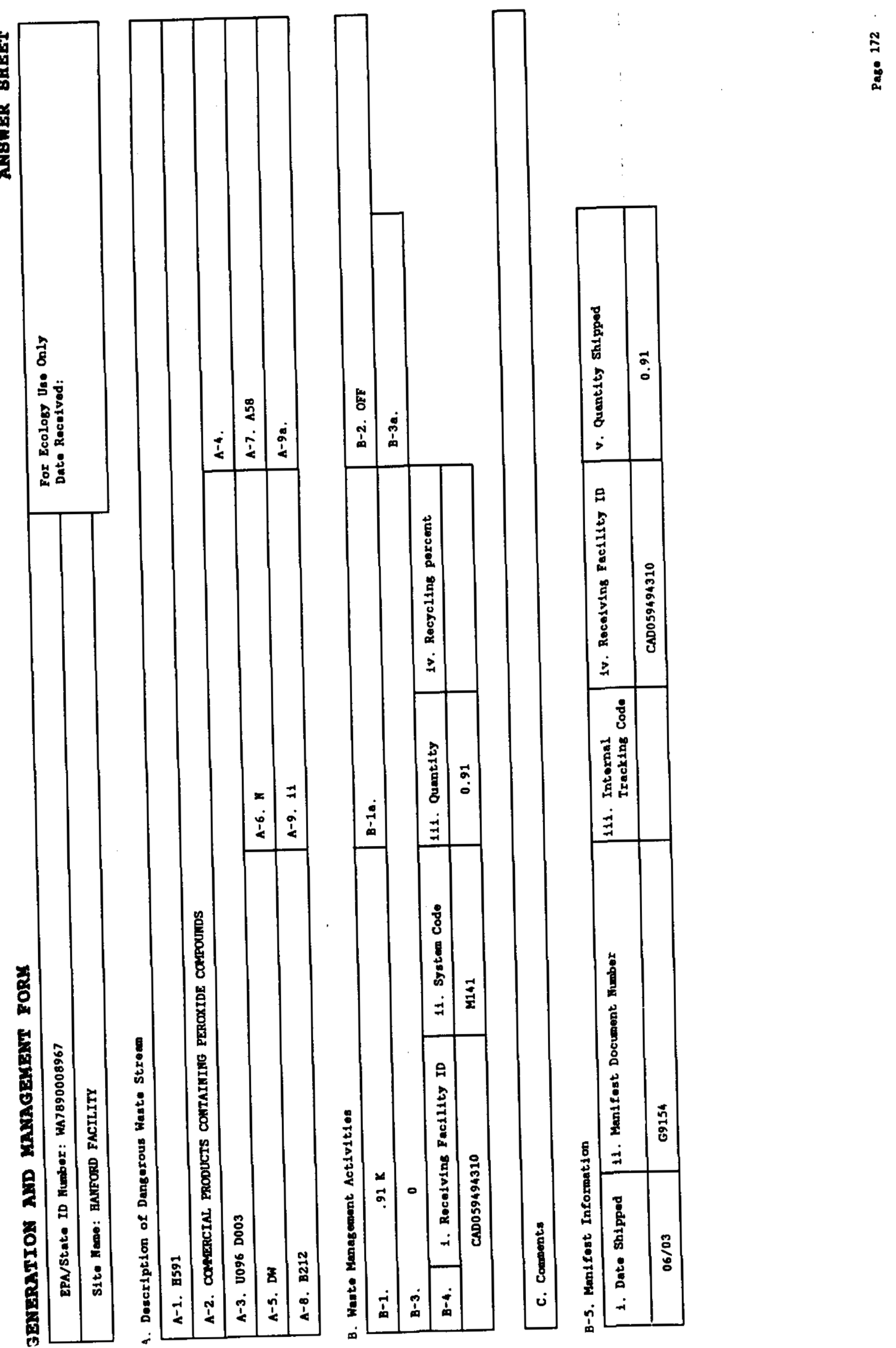


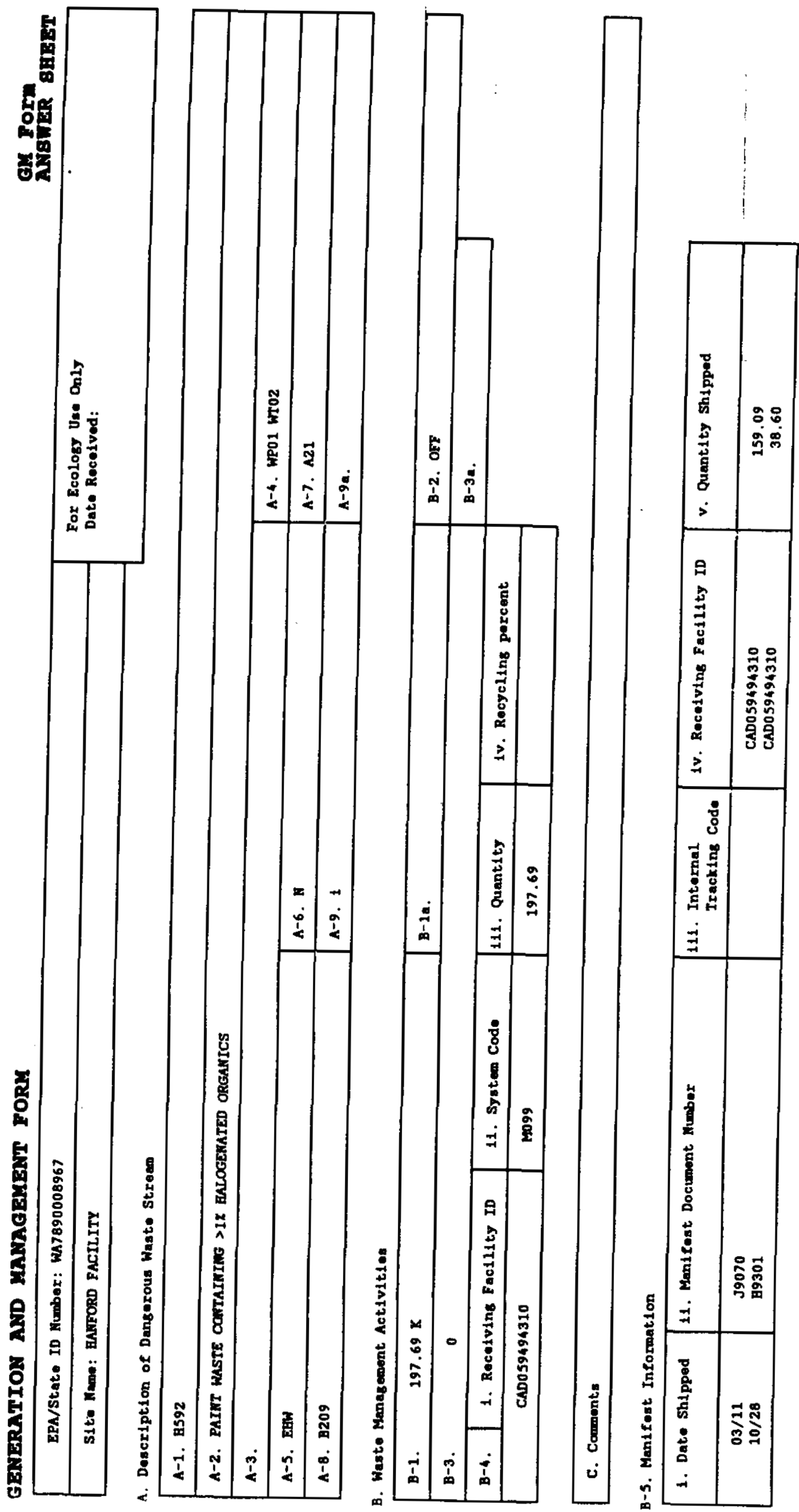




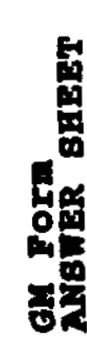




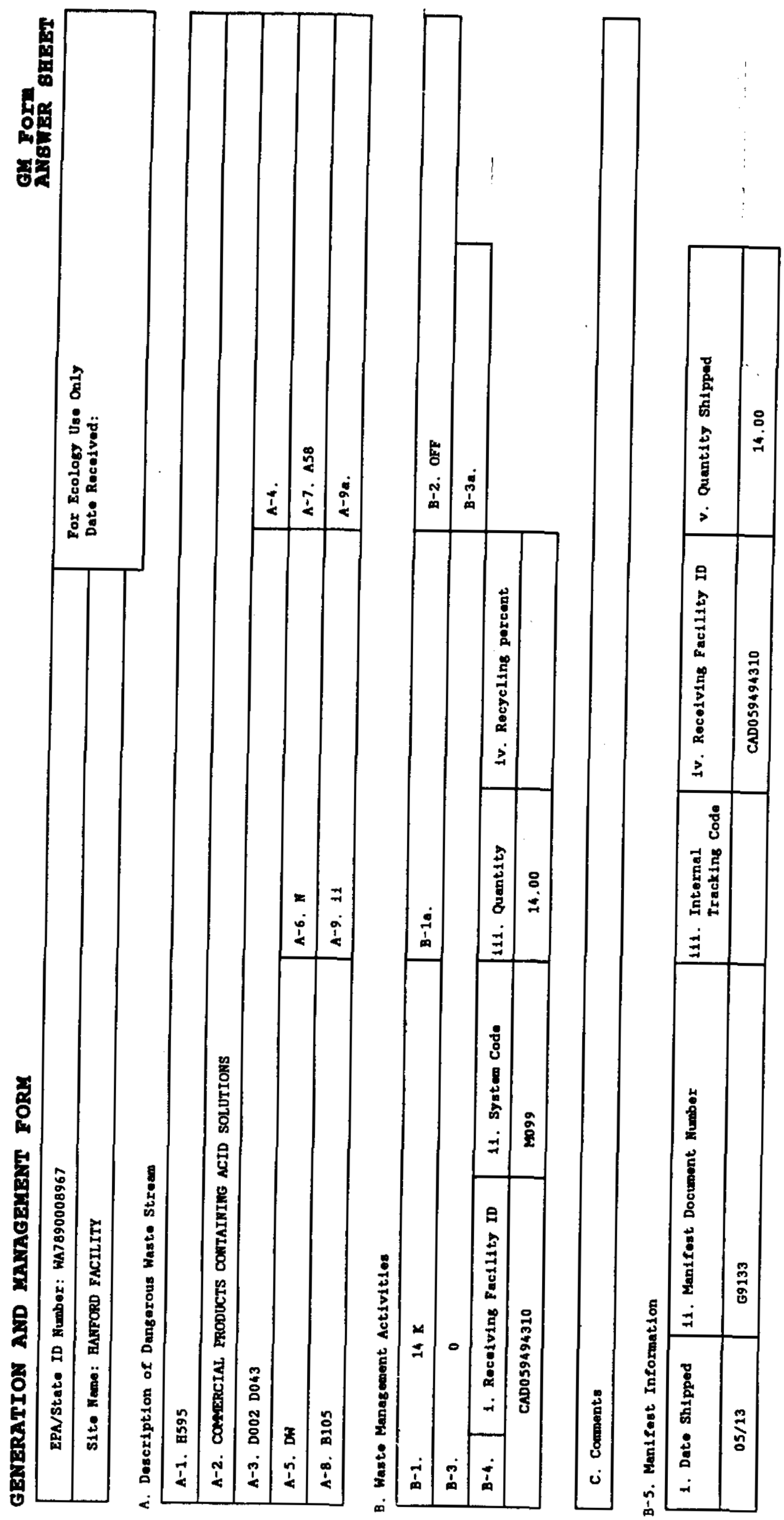




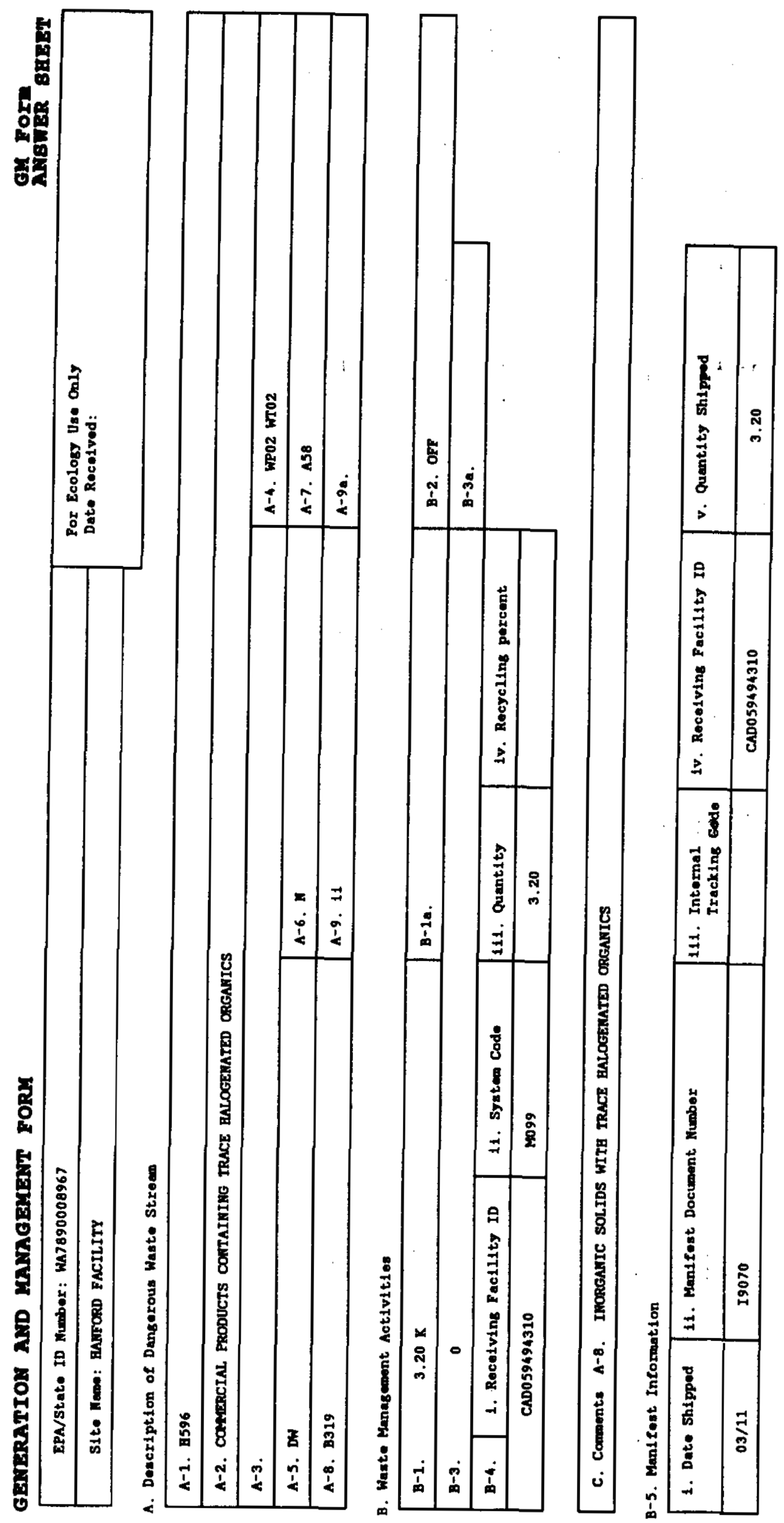




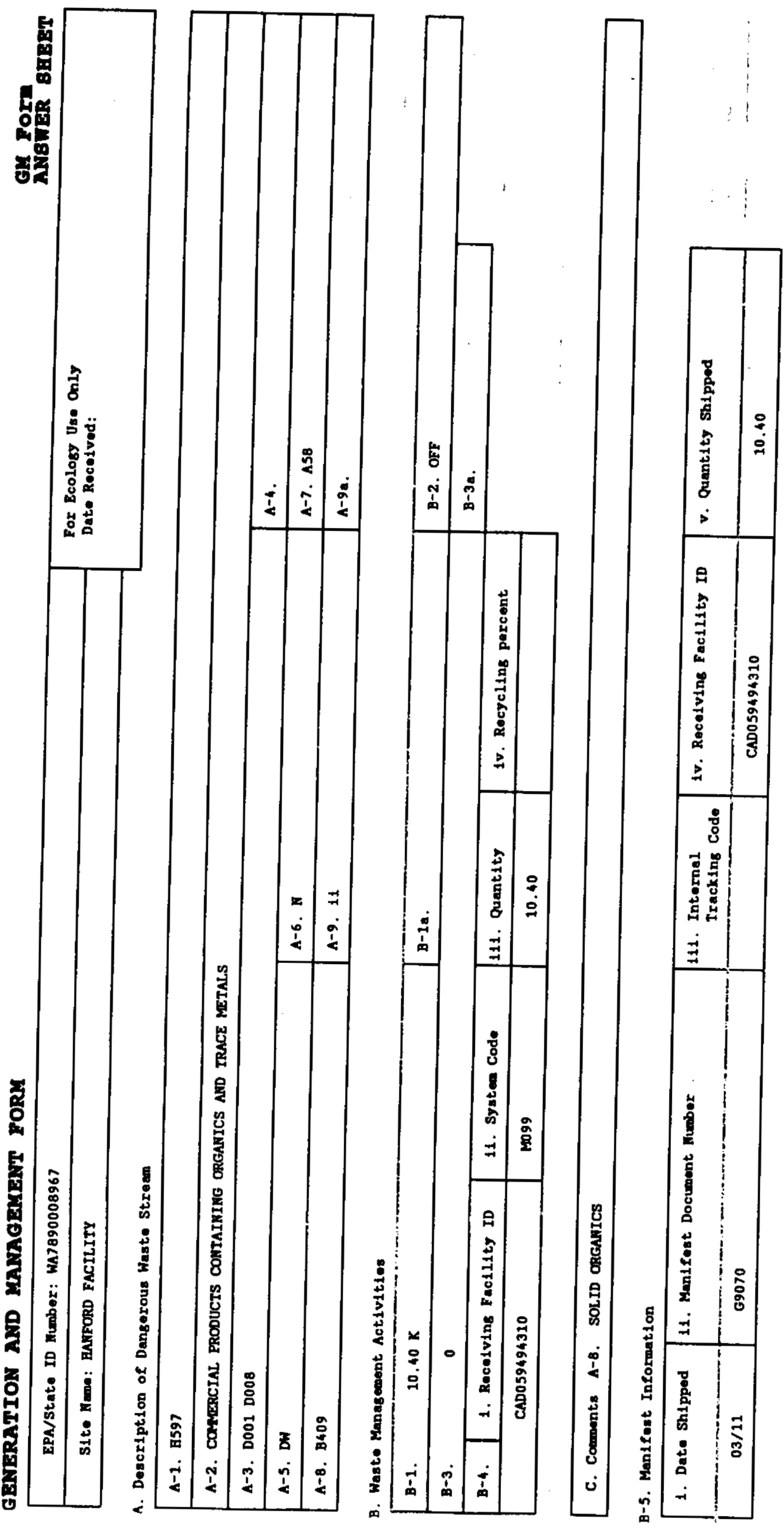




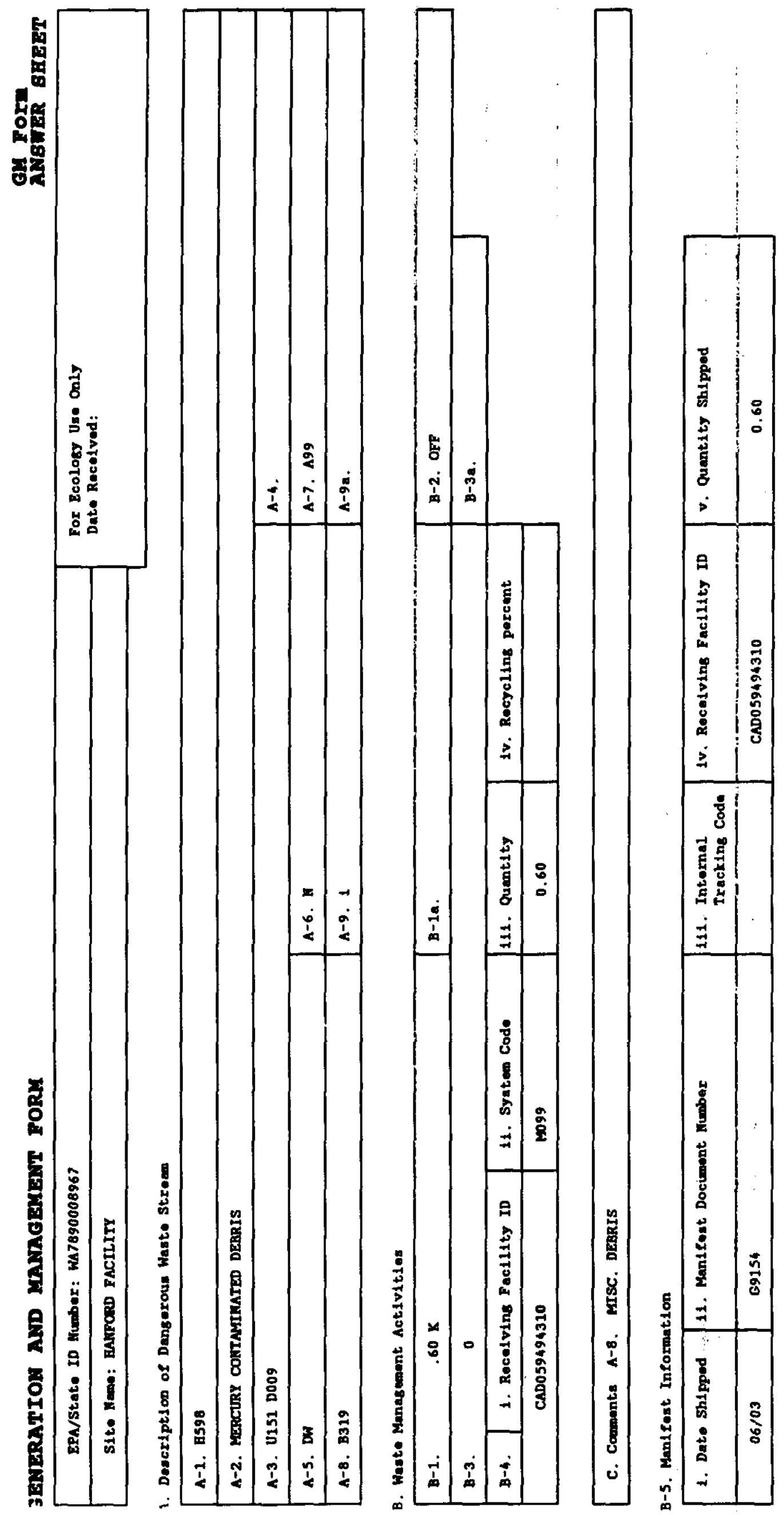




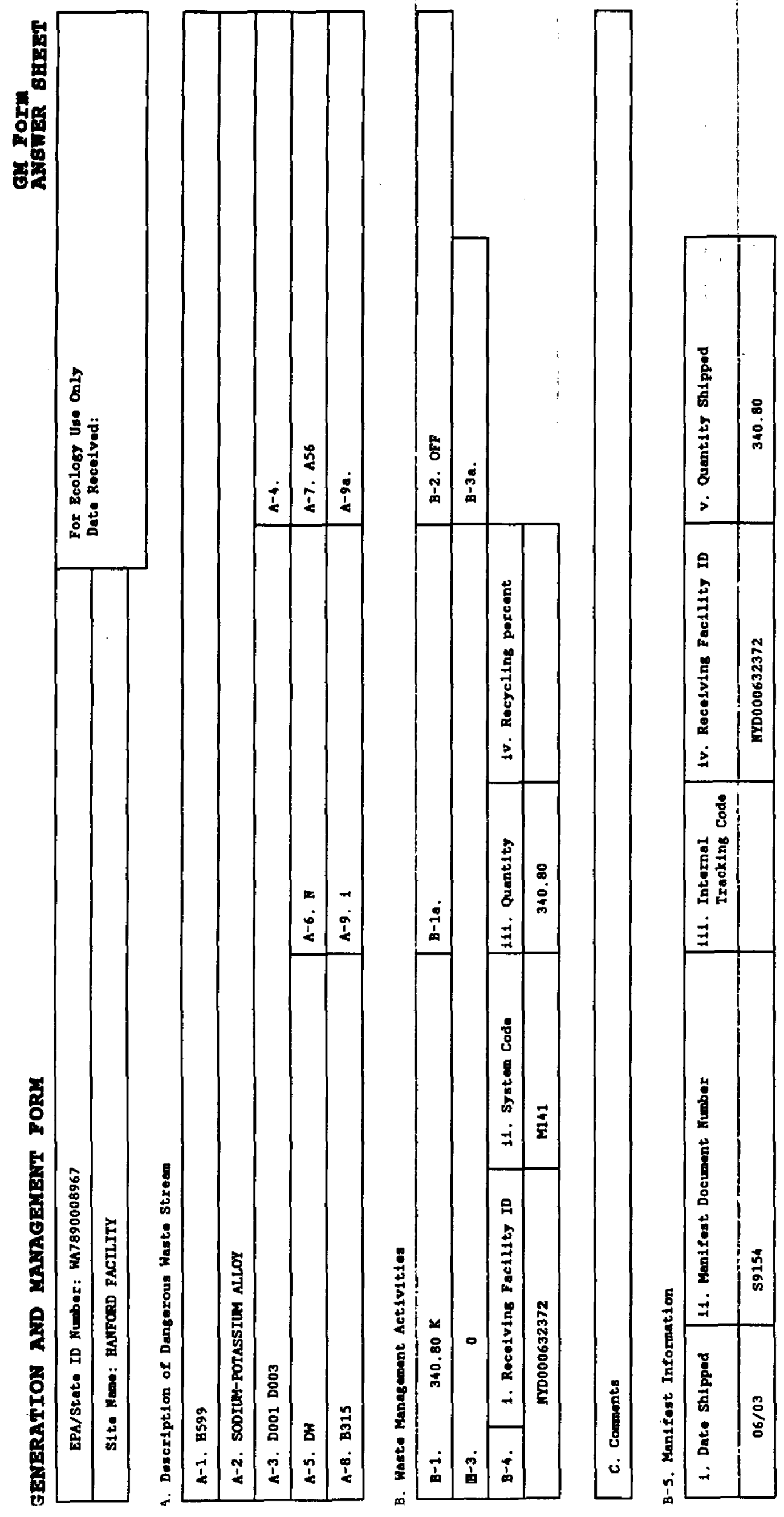




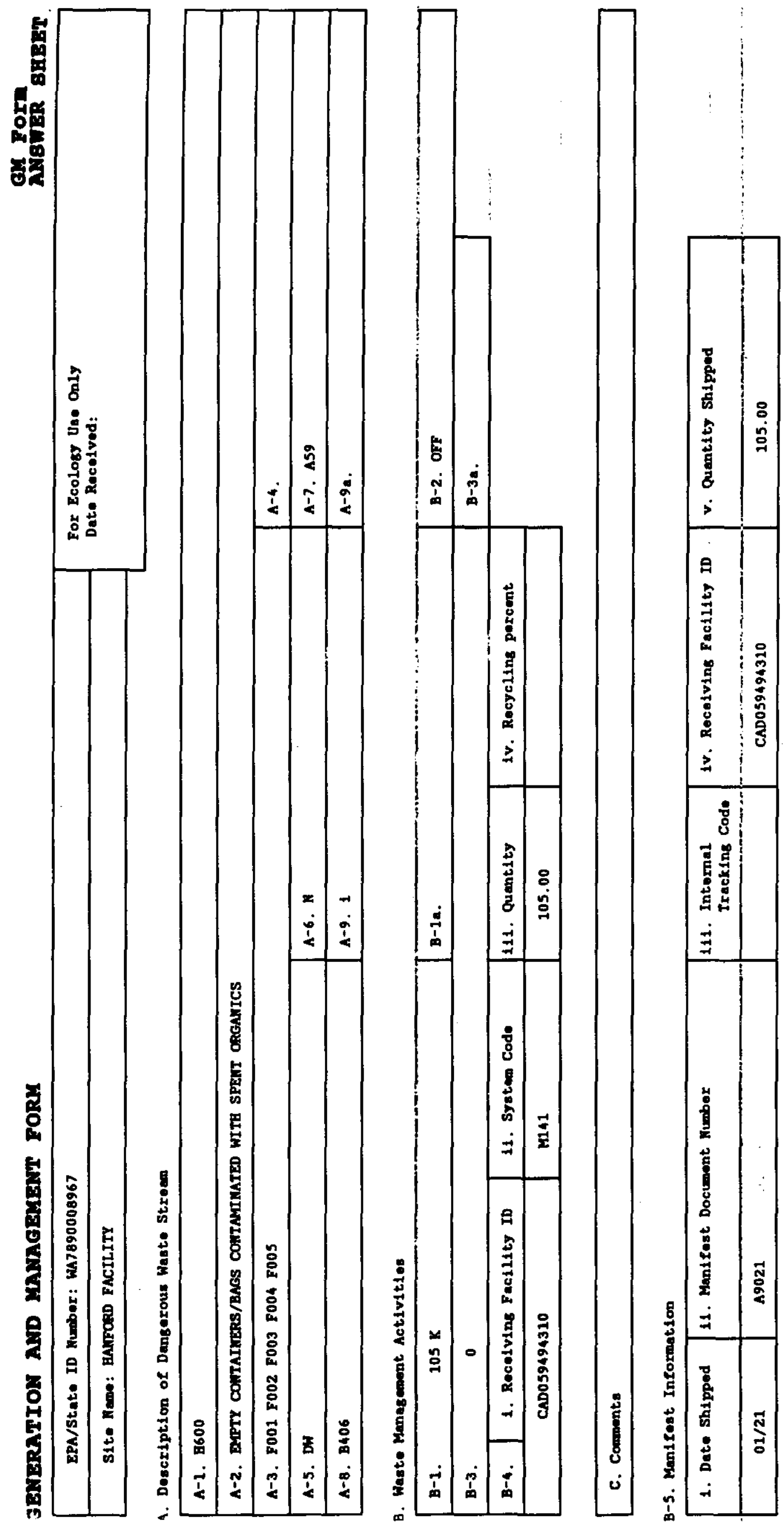




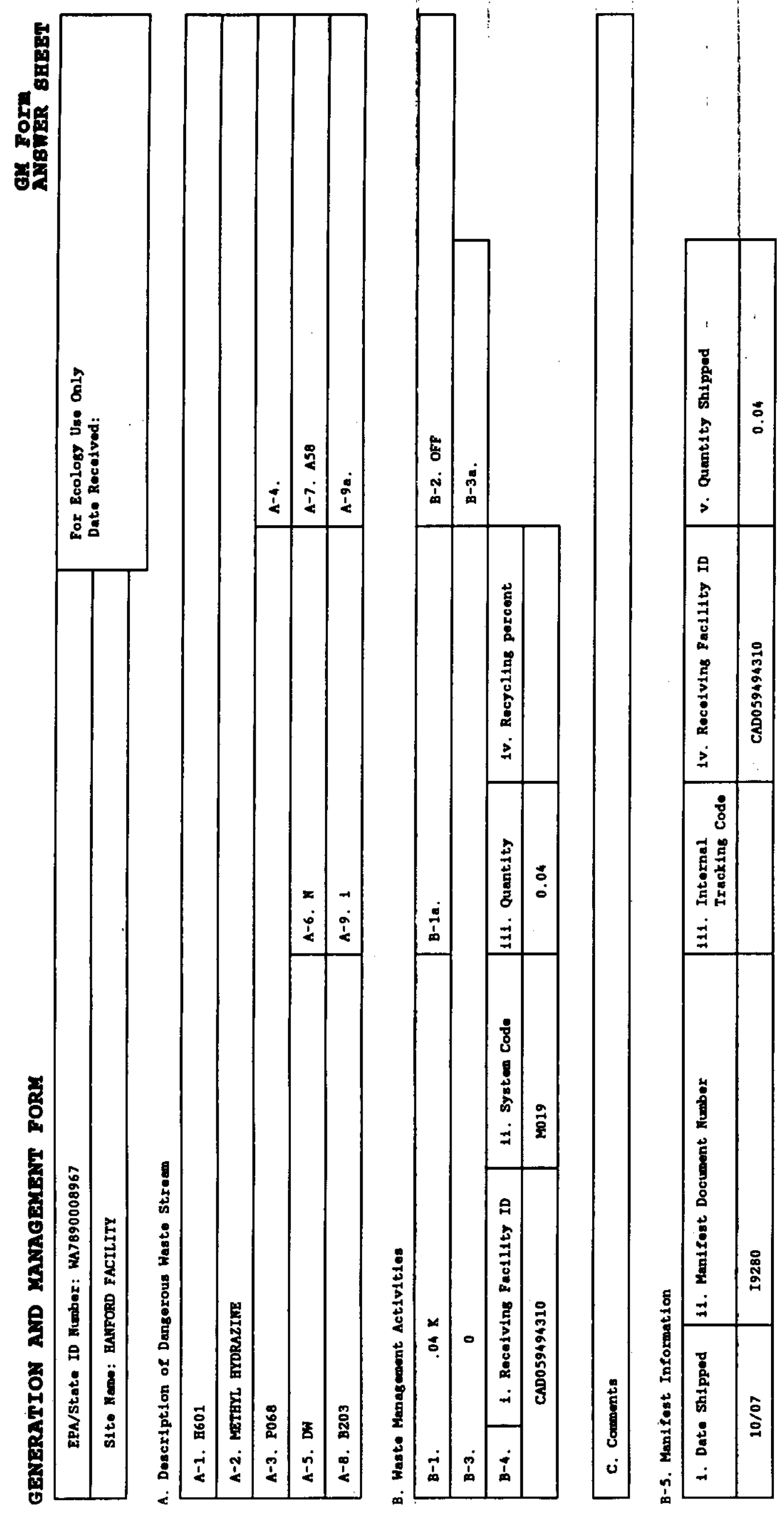




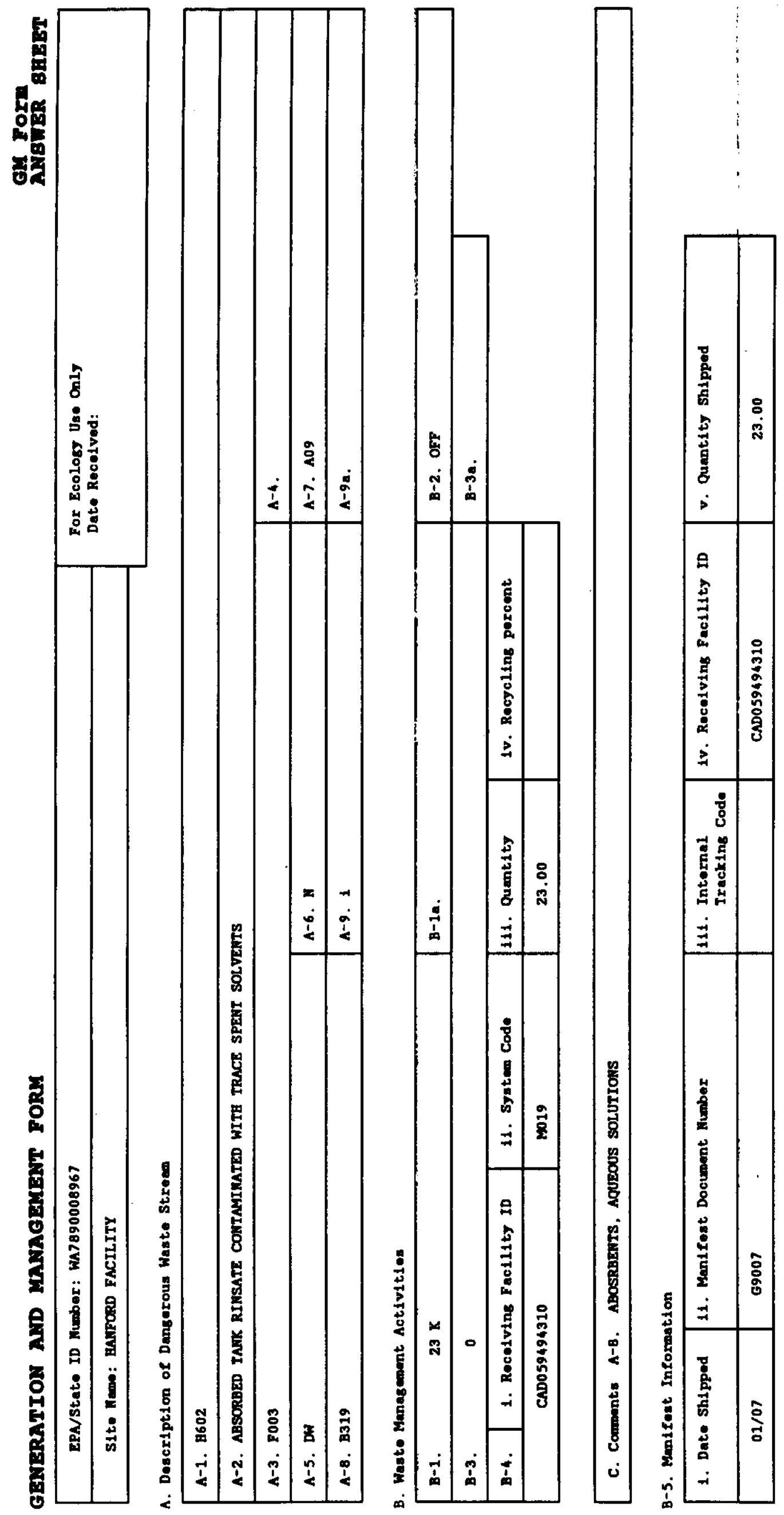




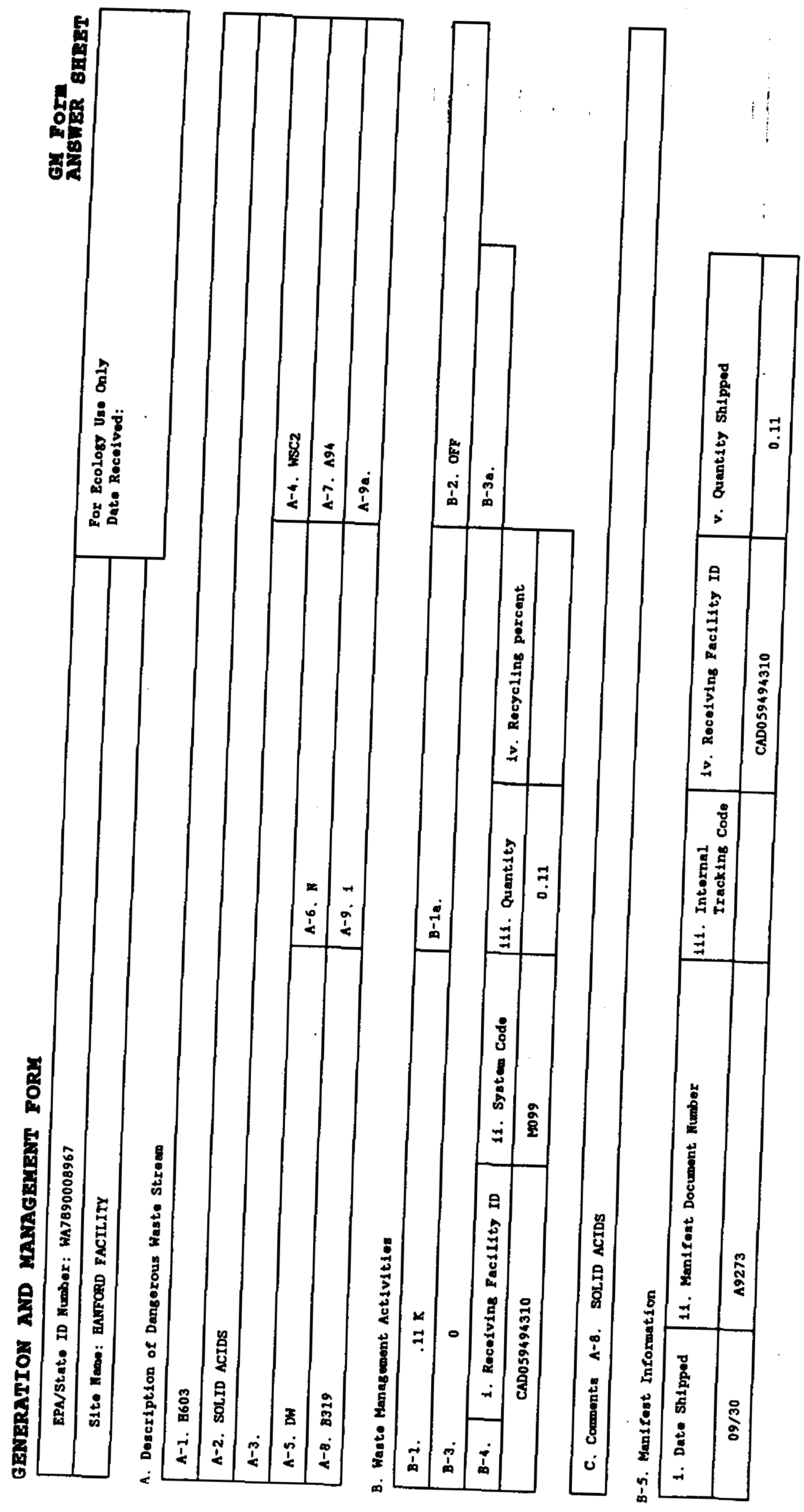

$\stackrel{8}{8}$ 


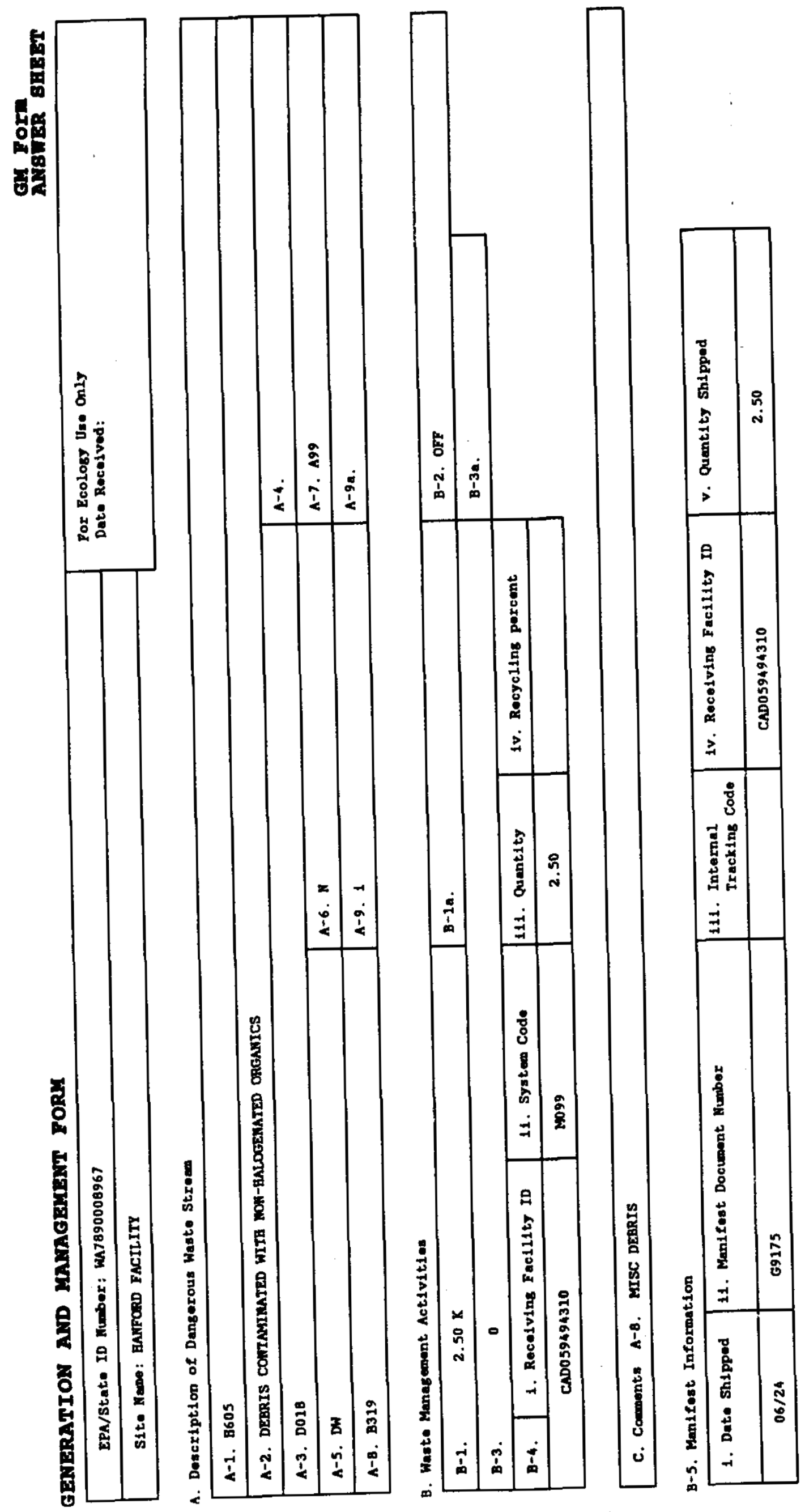




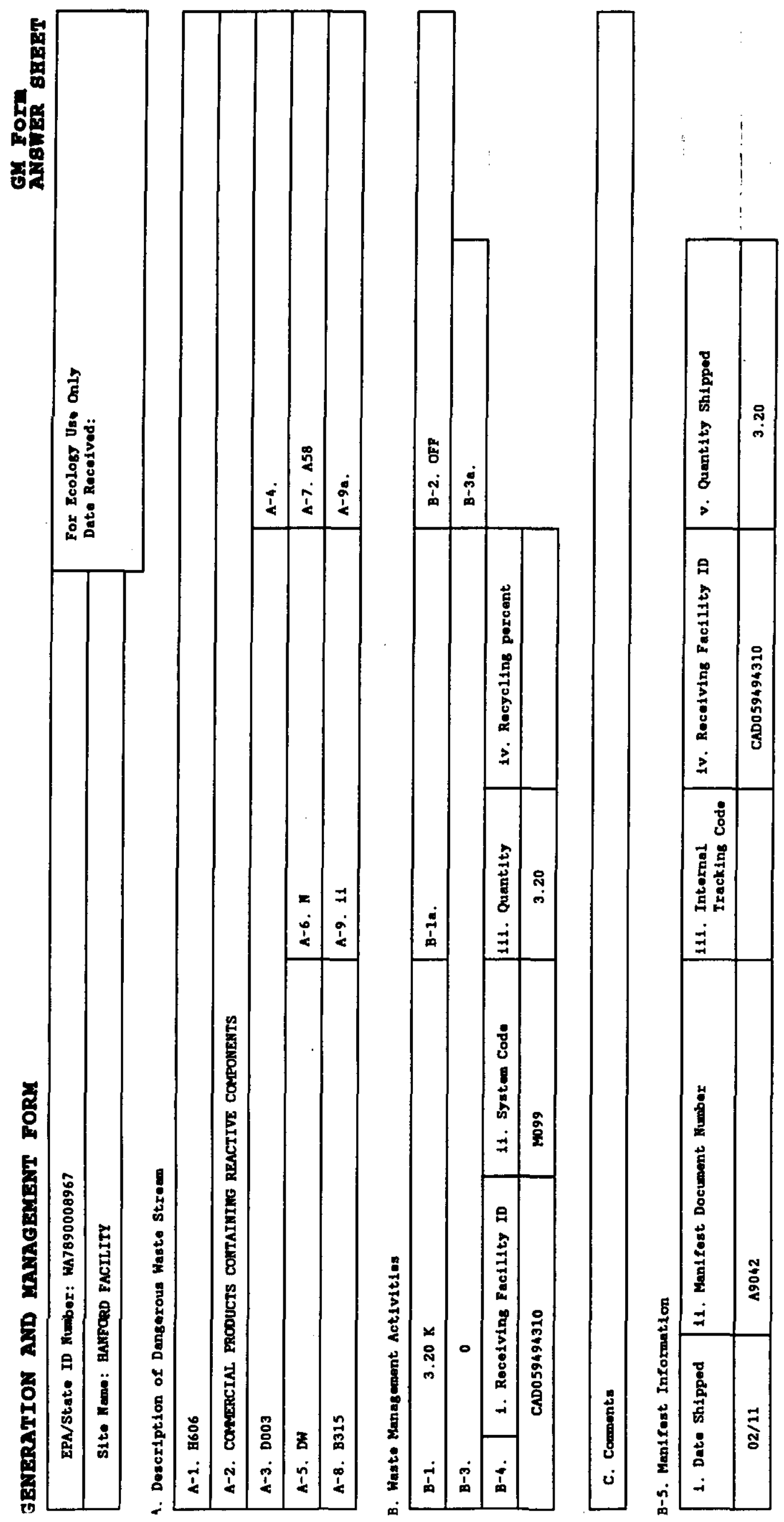




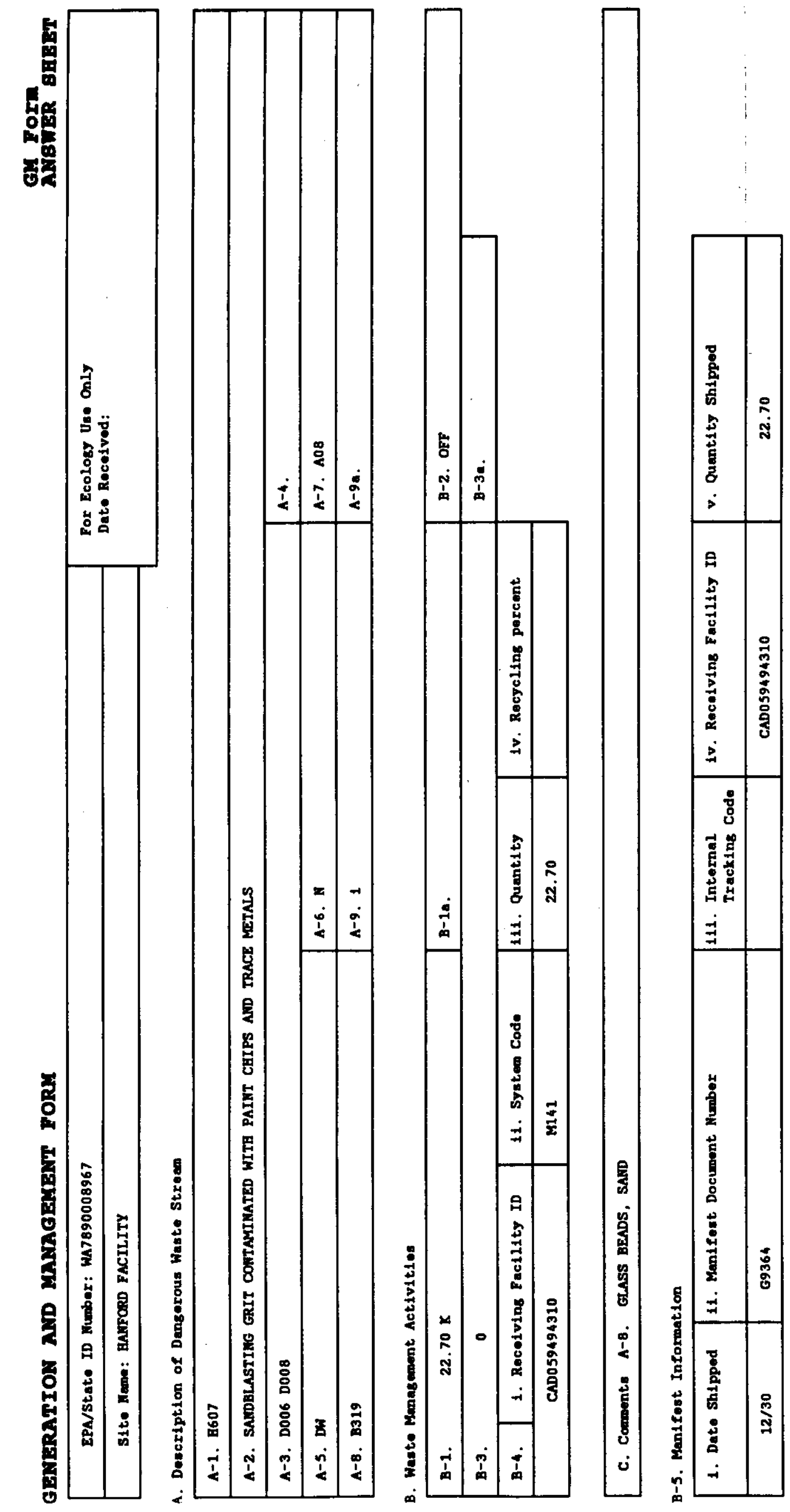




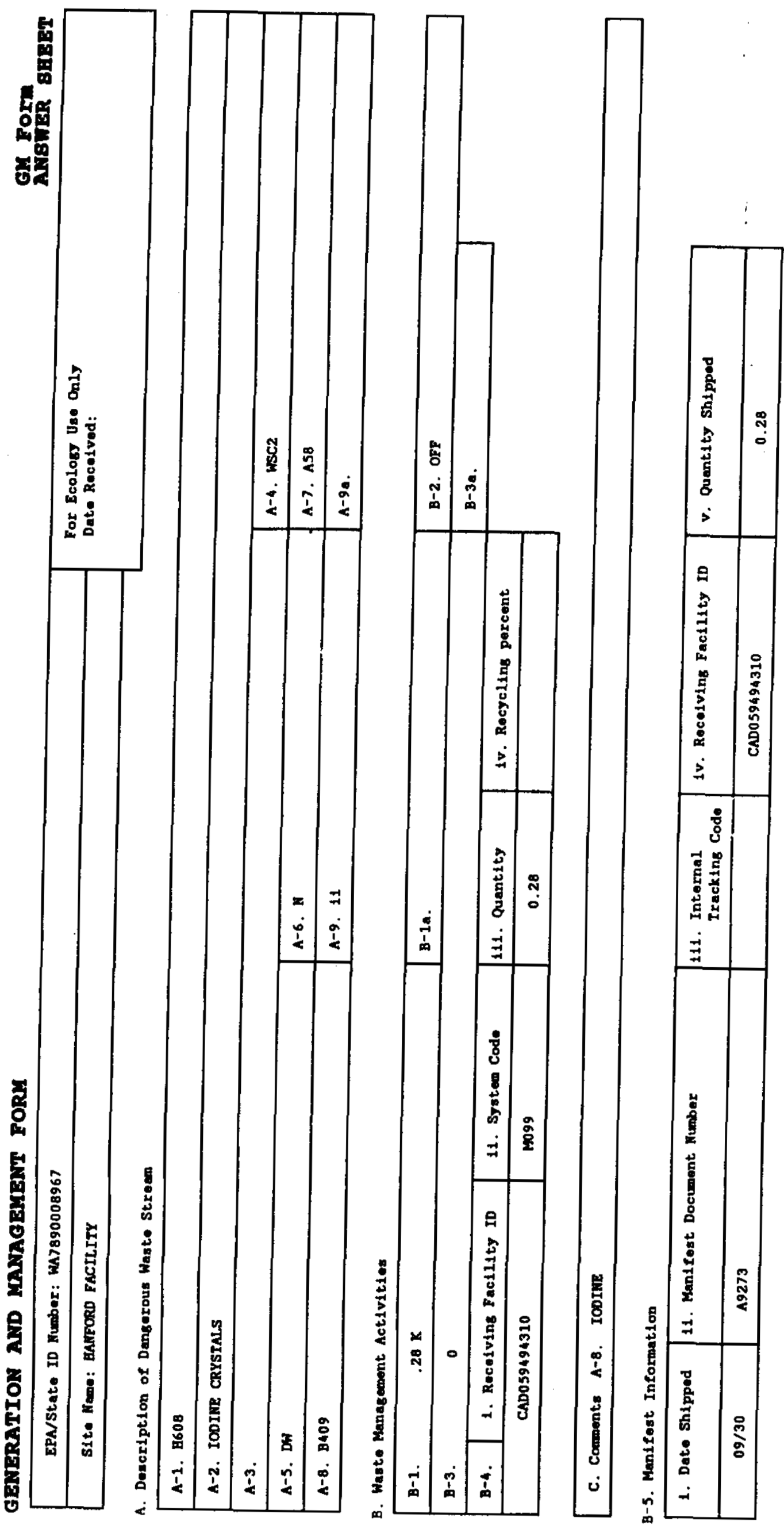

$\vdots$ 

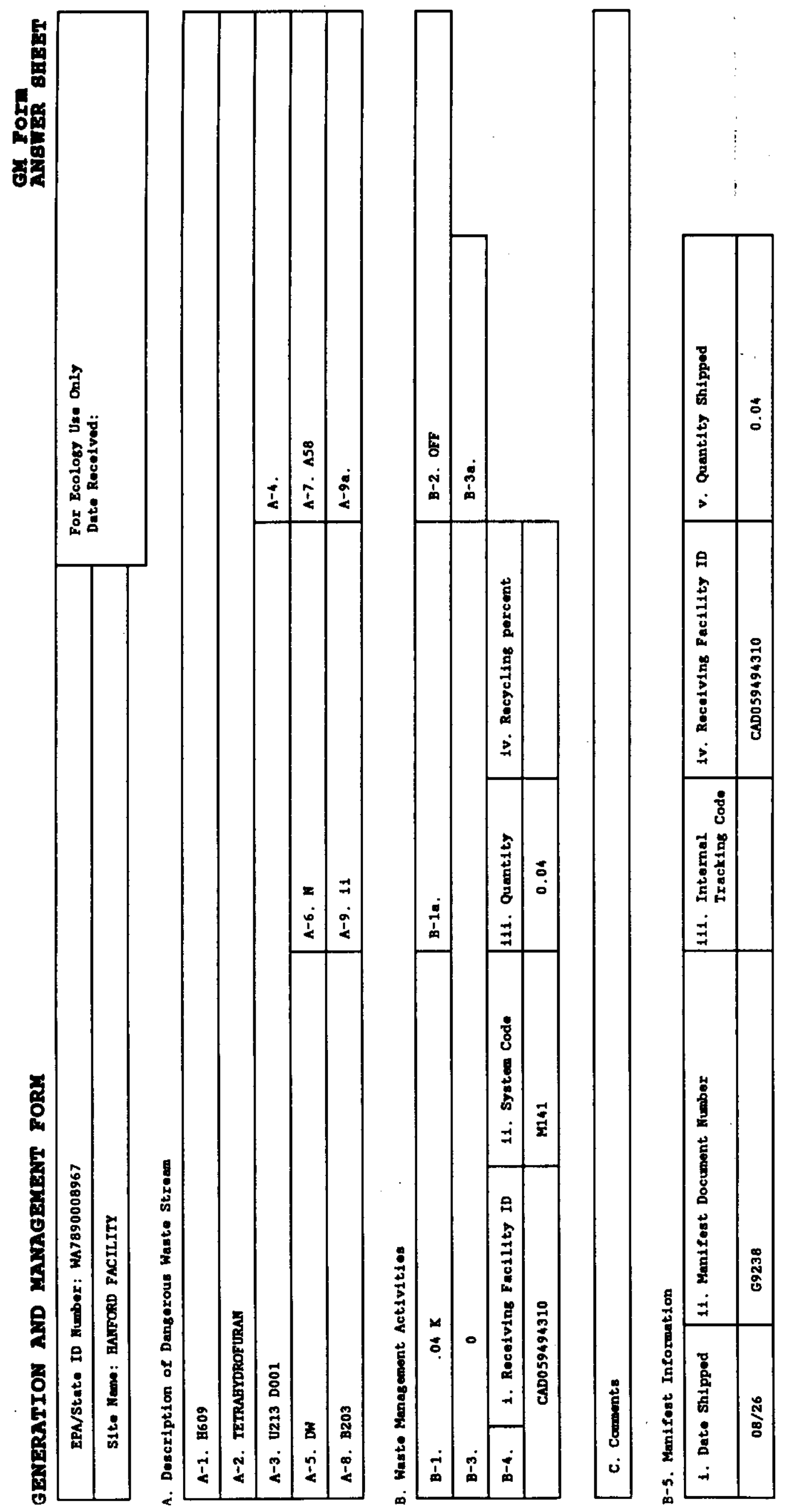

$\stackrel{\$}{\sharp}$

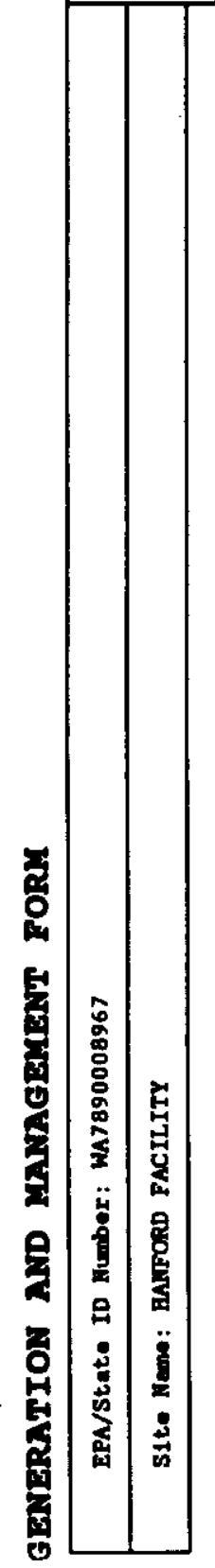




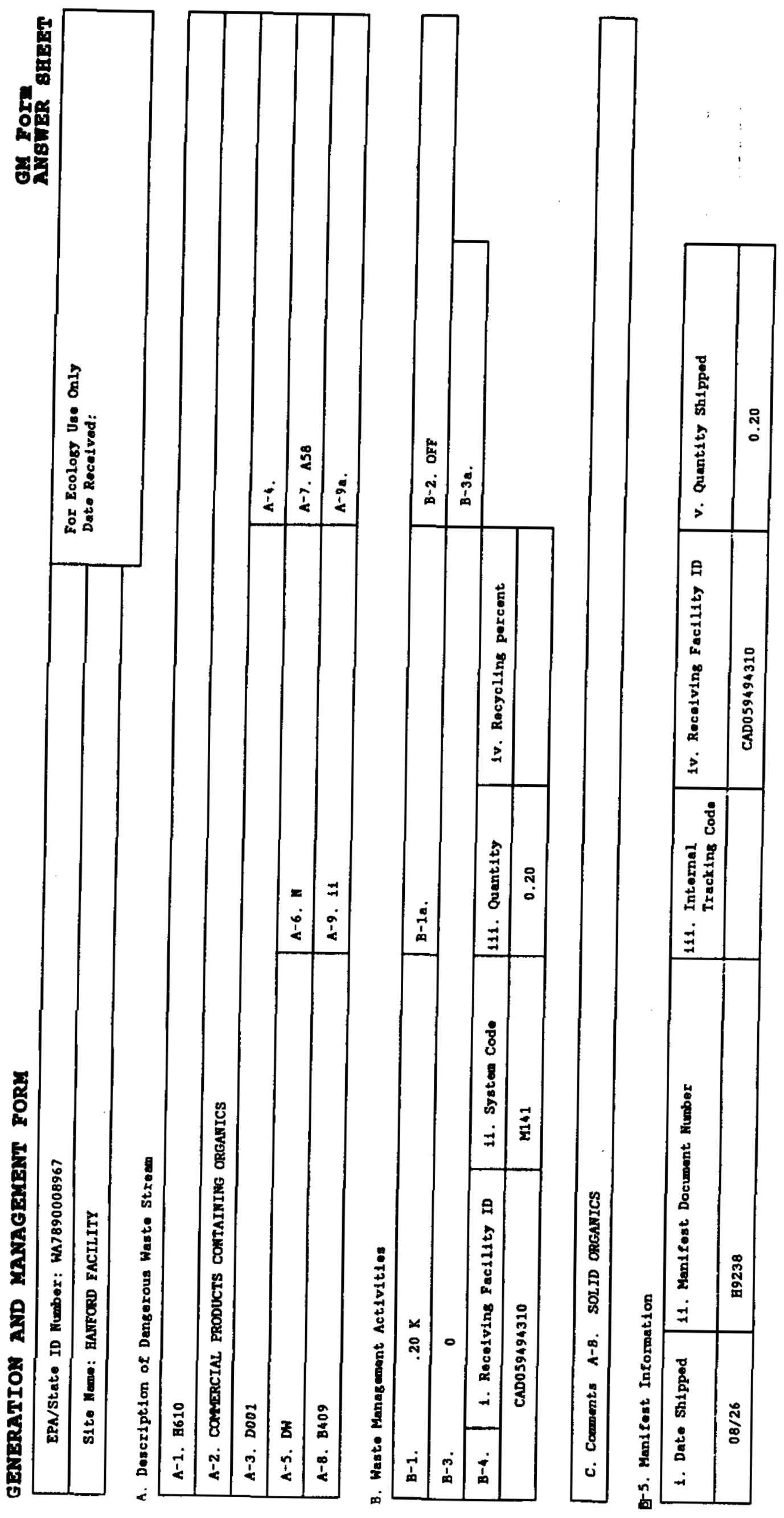




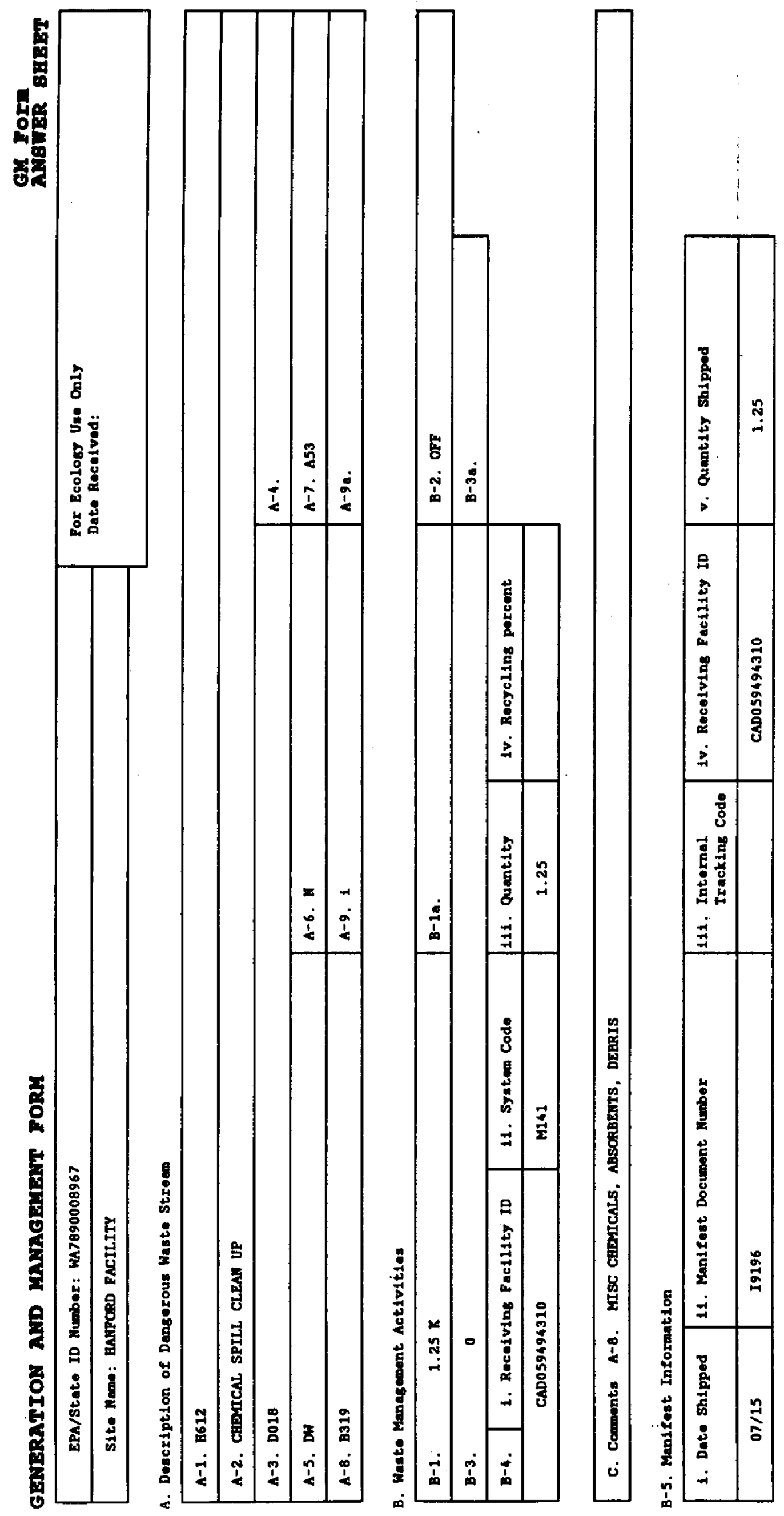




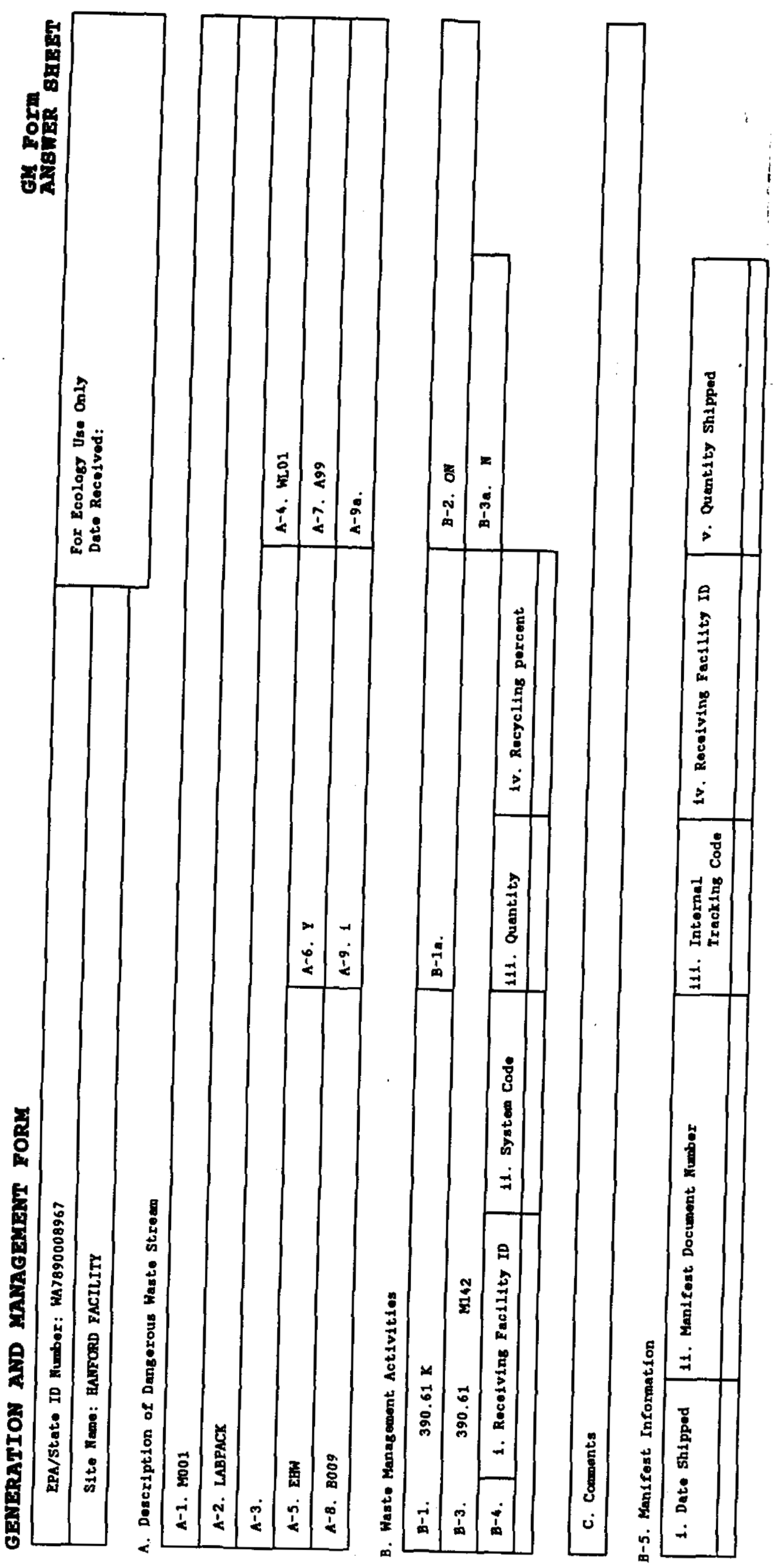



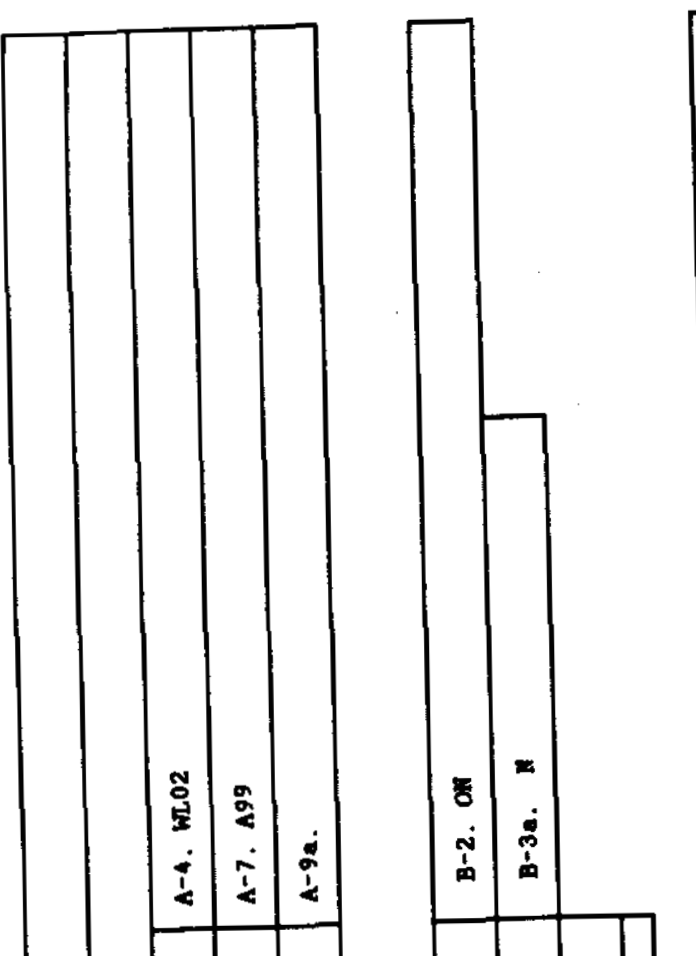

$\stackrel{N}{3}$
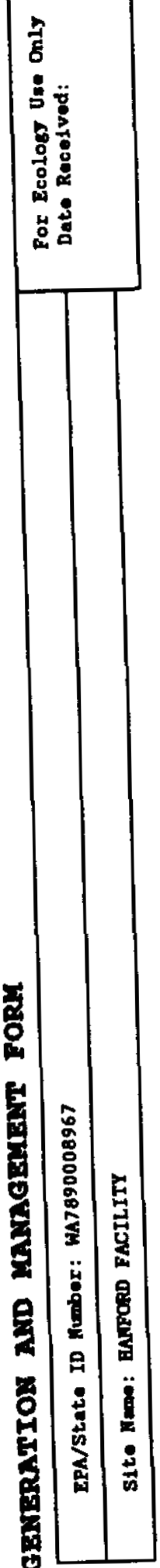
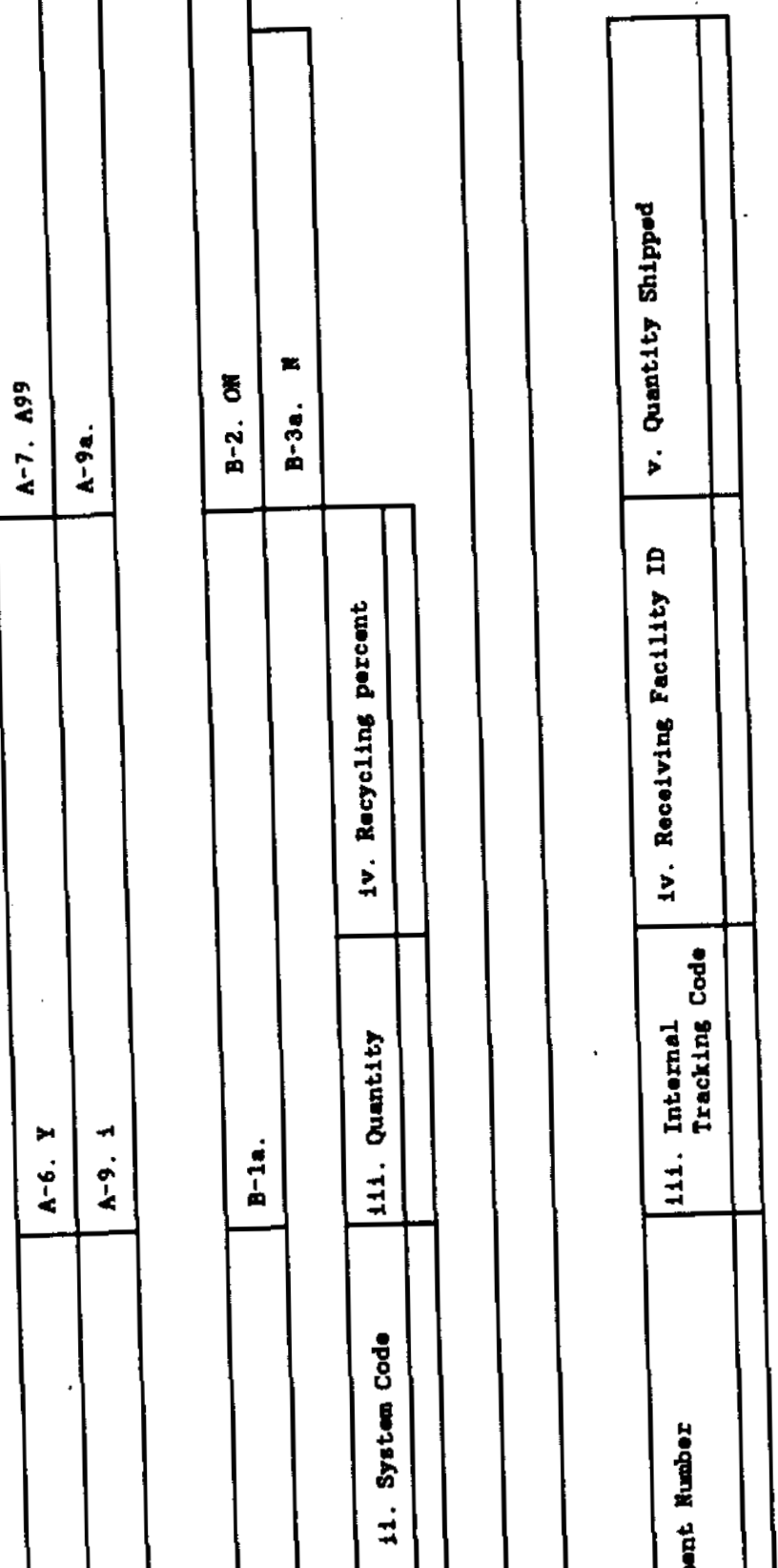

.

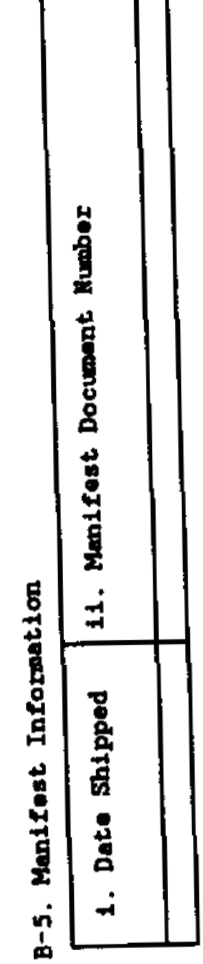



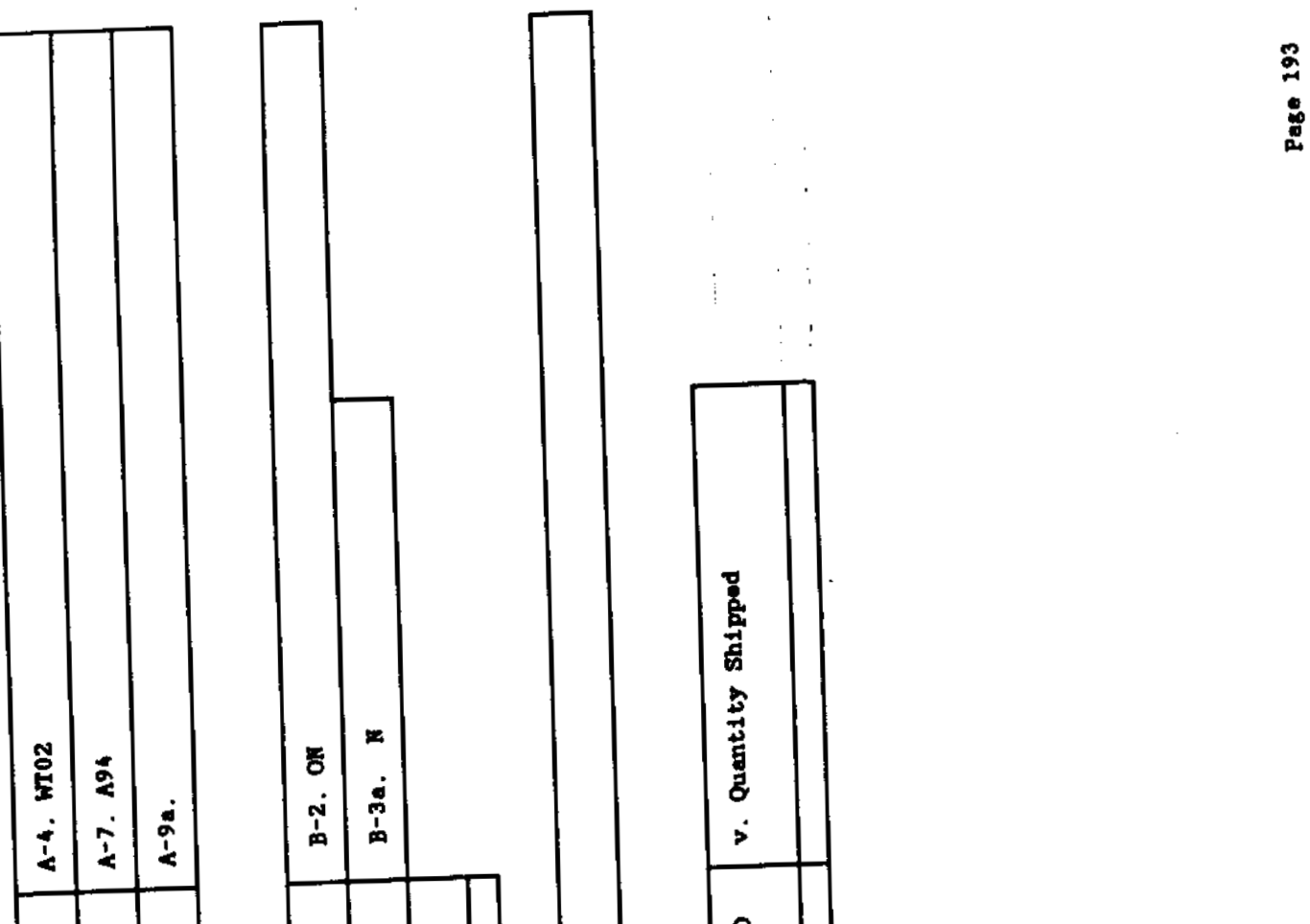

务

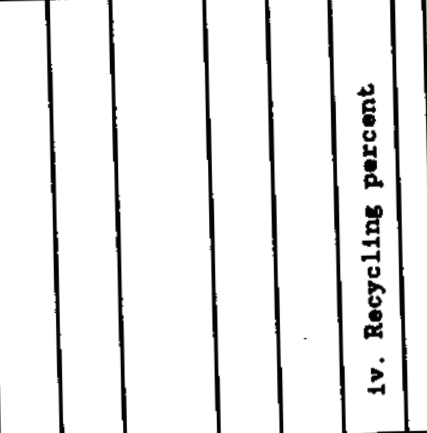

\begin{tabular}{rl}
-1 \\
$i$ & $\dot{1}$ \\
$\dot{i}$ & $i$ \\
\hline
\end{tabular}
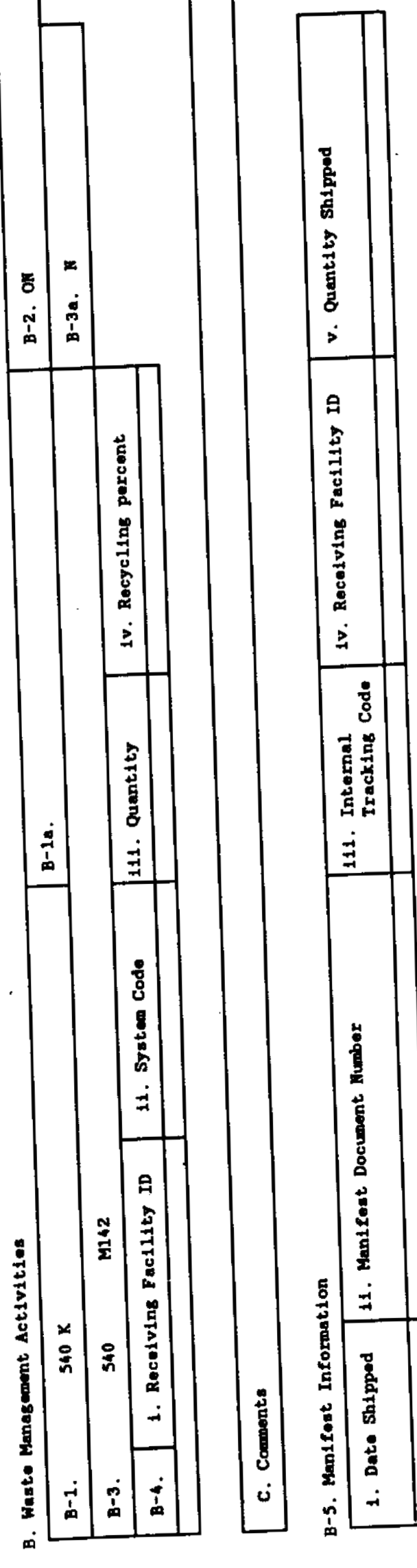

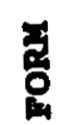

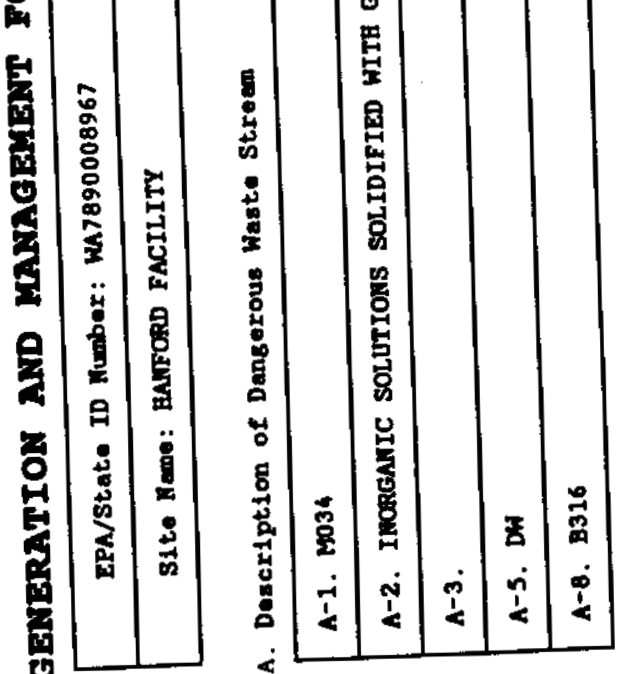

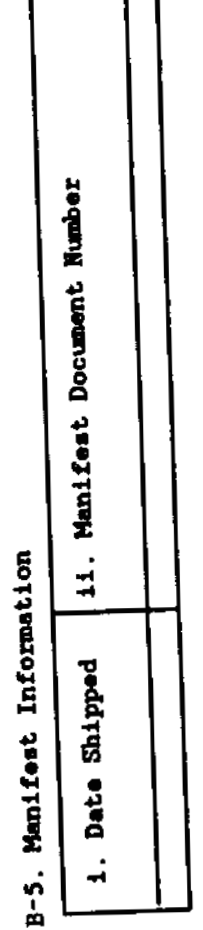



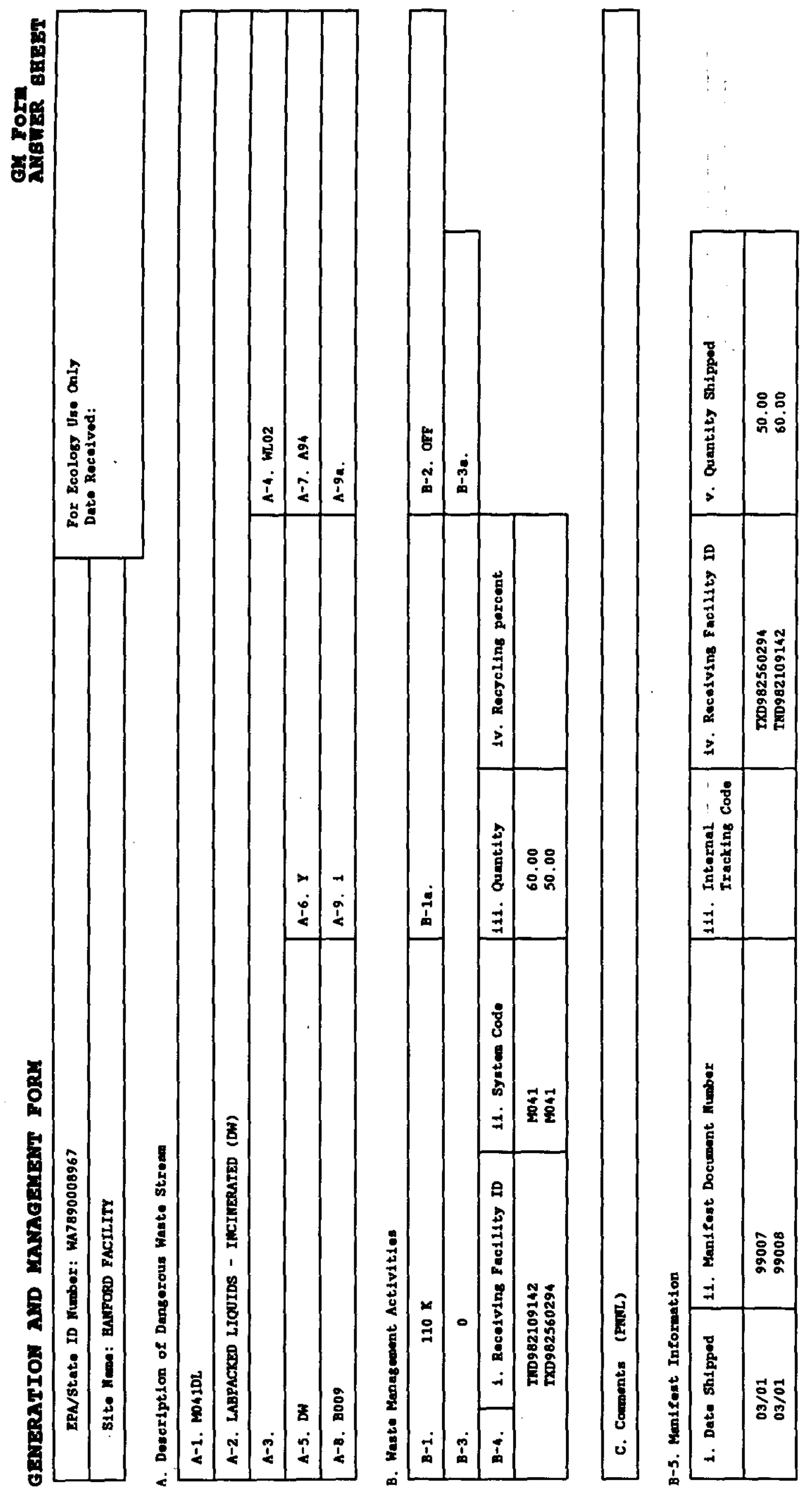

a
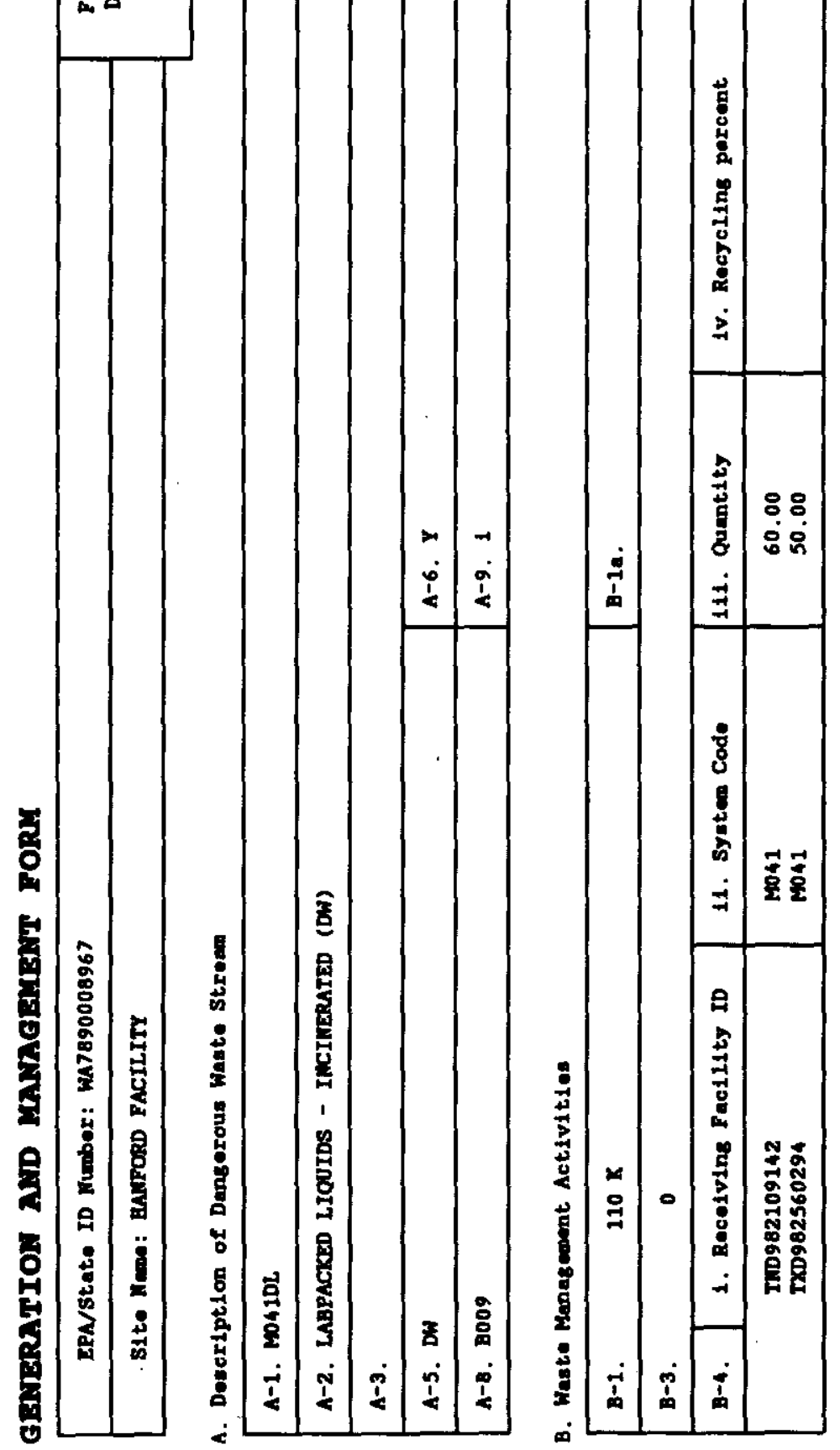

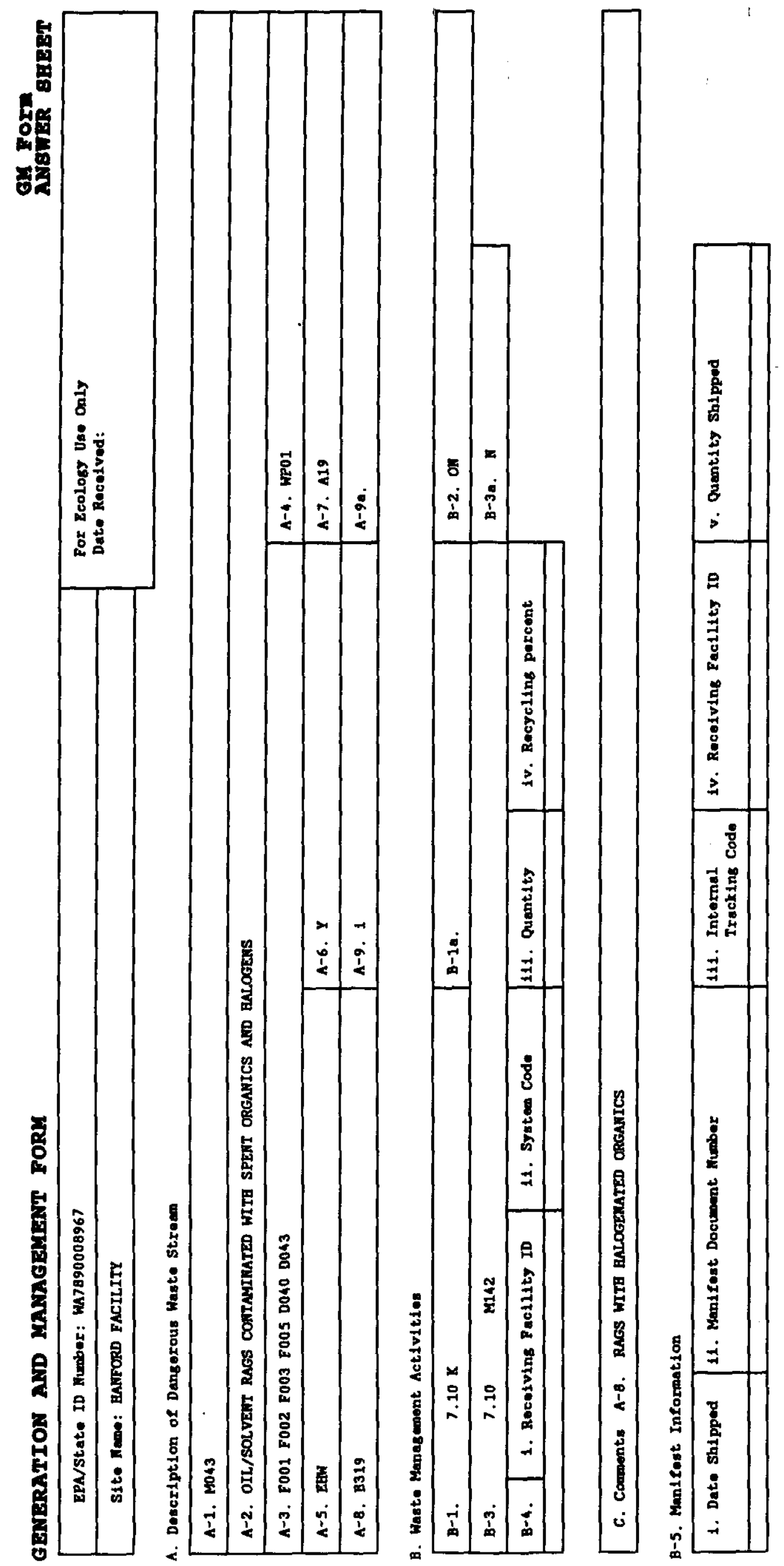

$\stackrel{2}{2}$
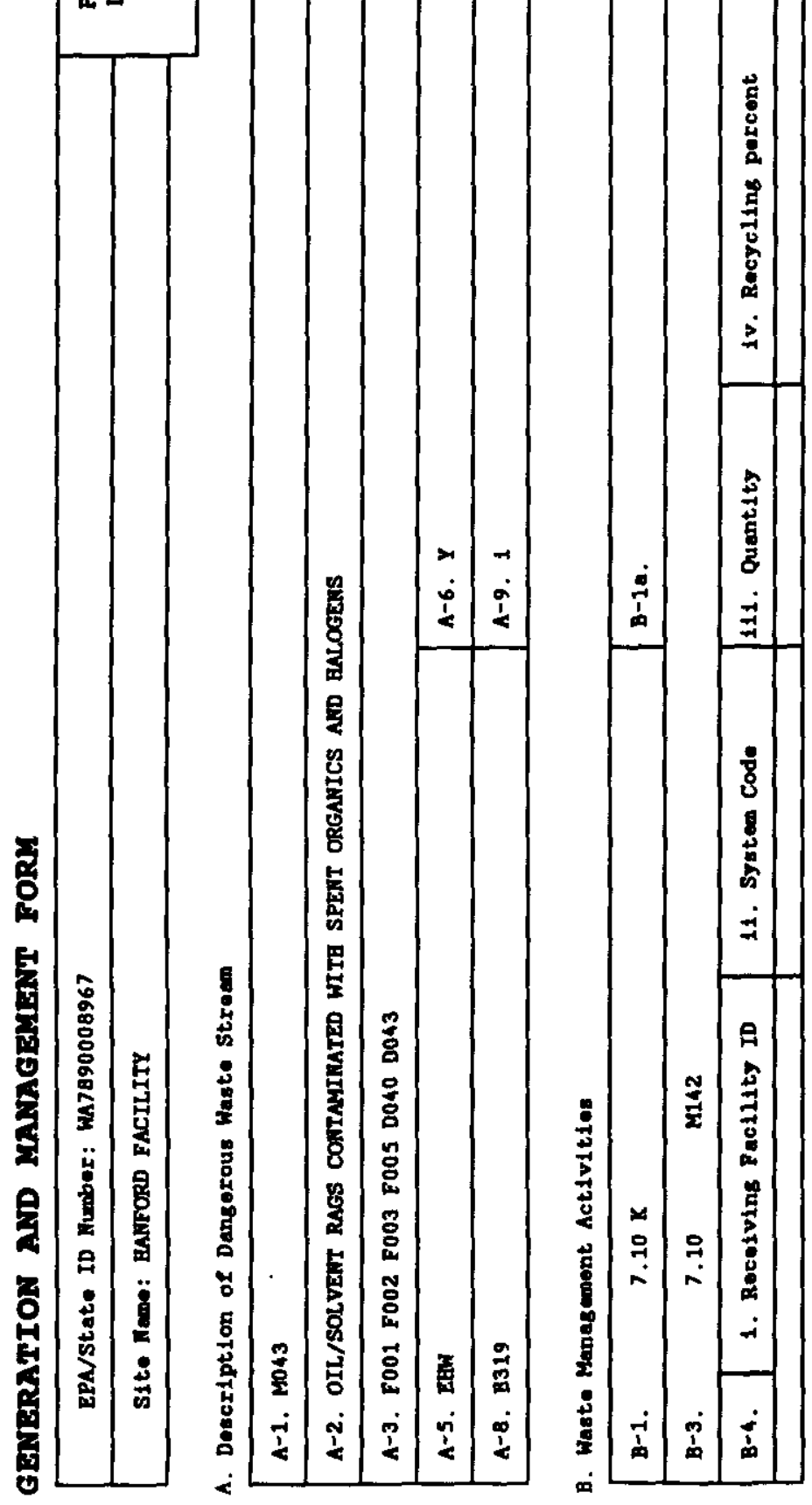


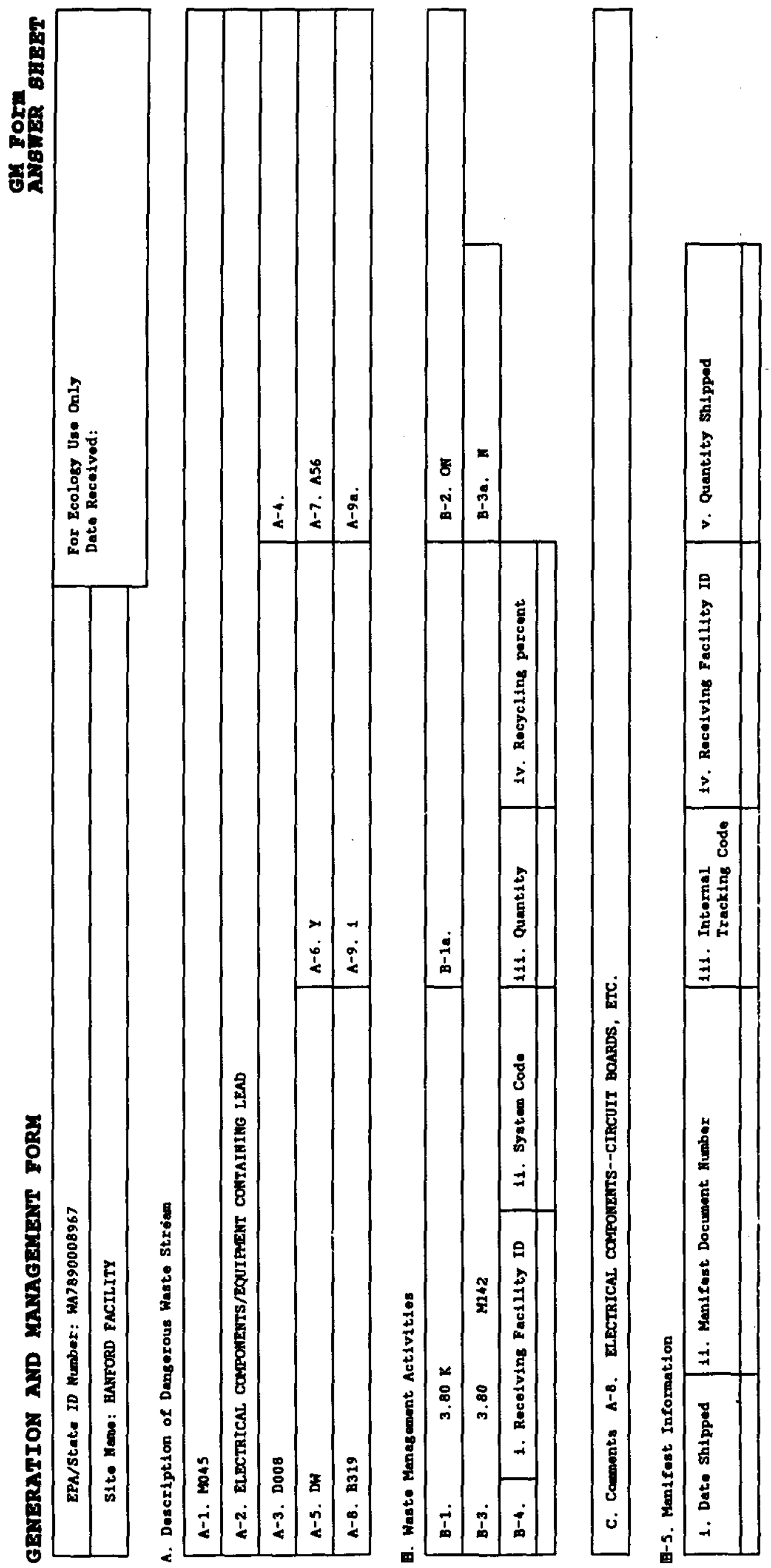




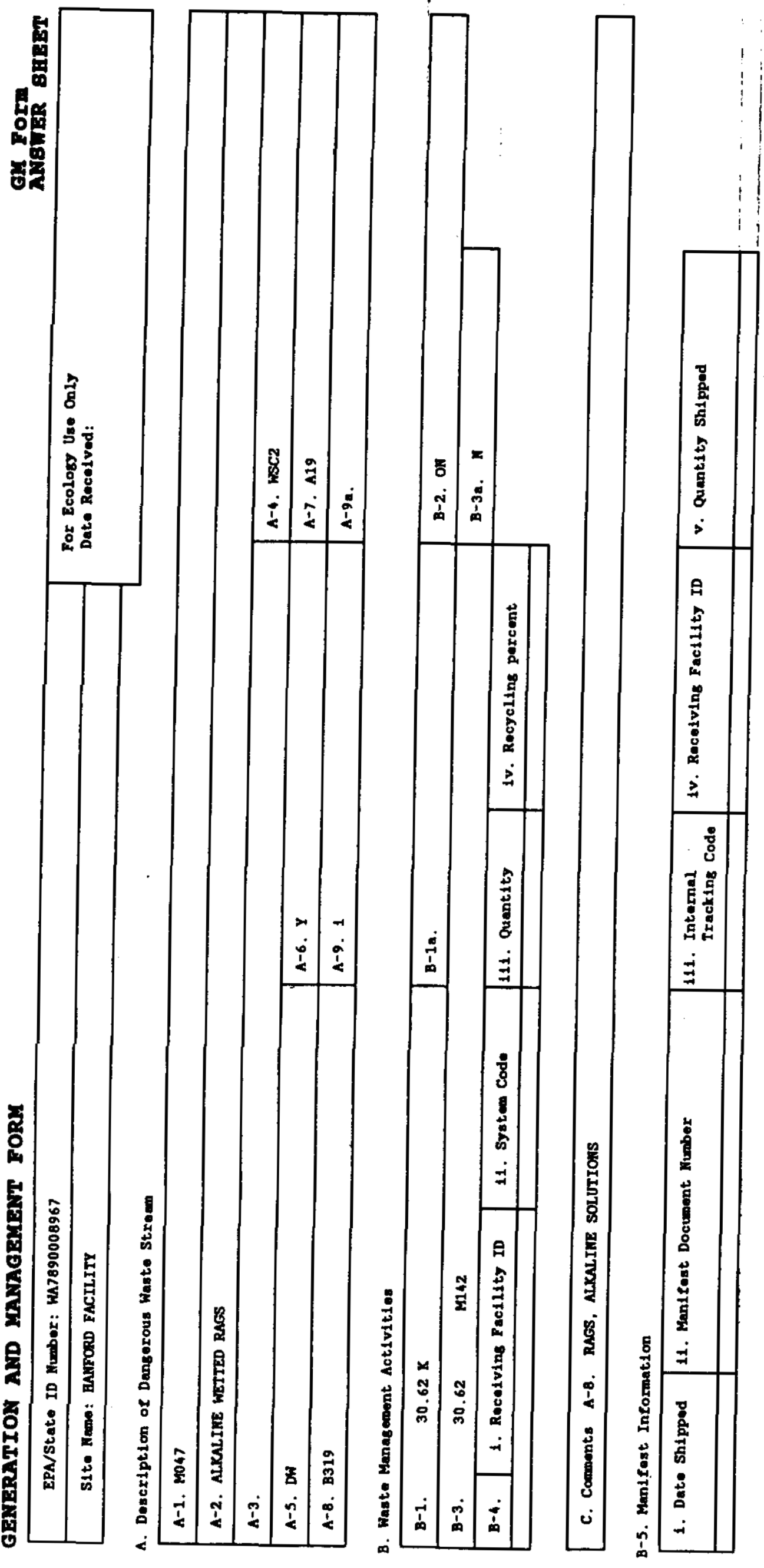




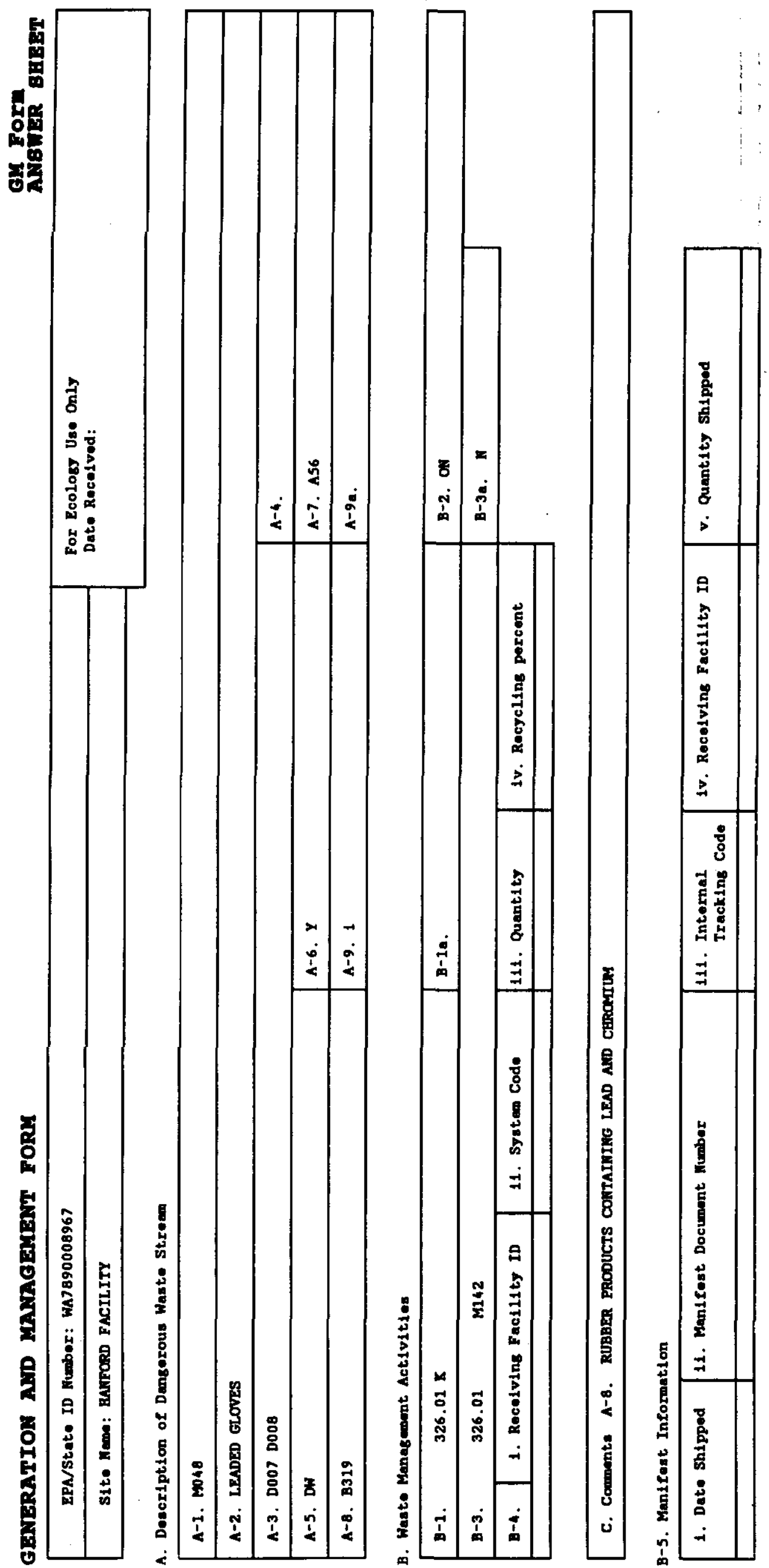



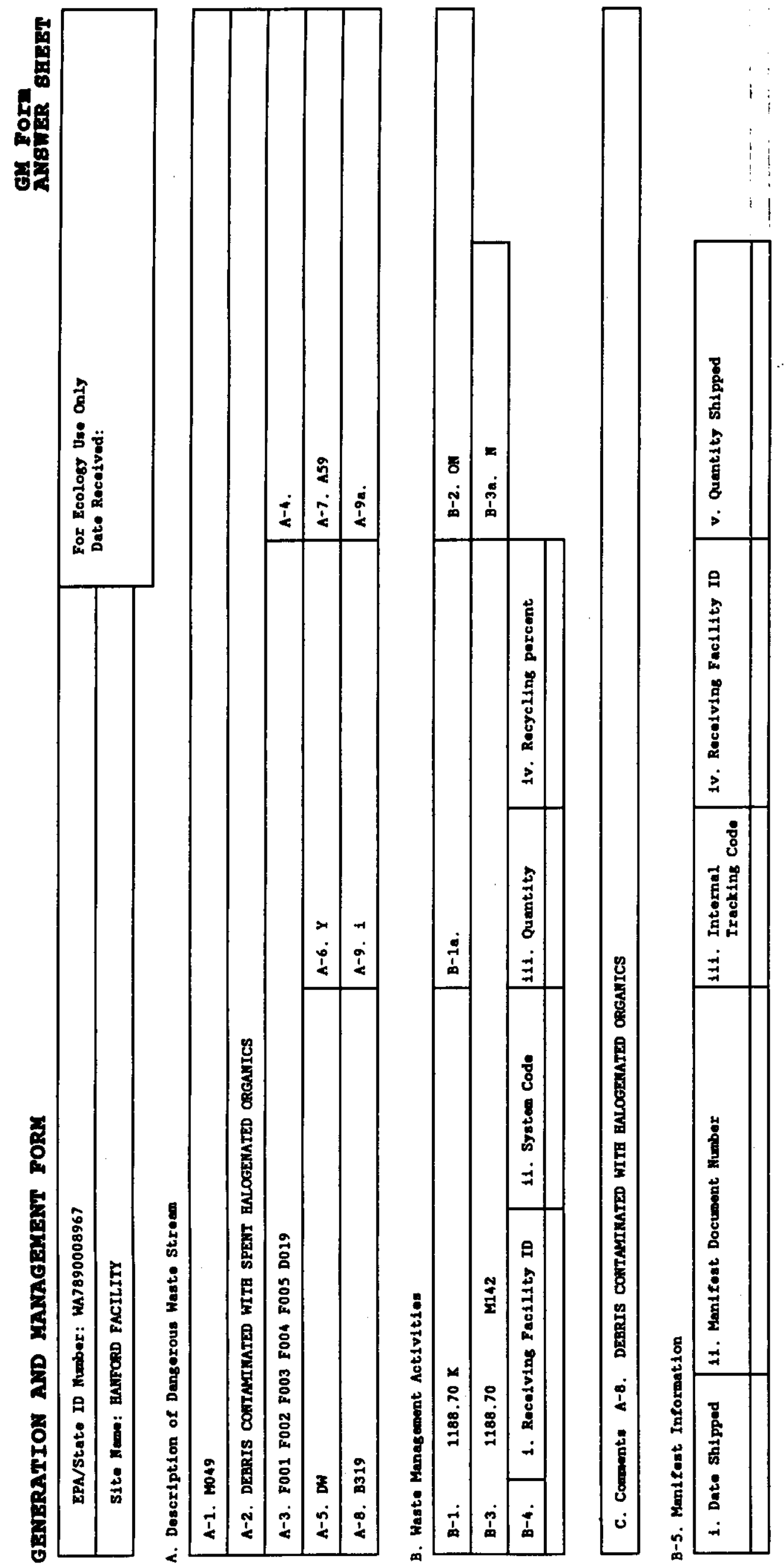

$\stackrel{0}{2}$
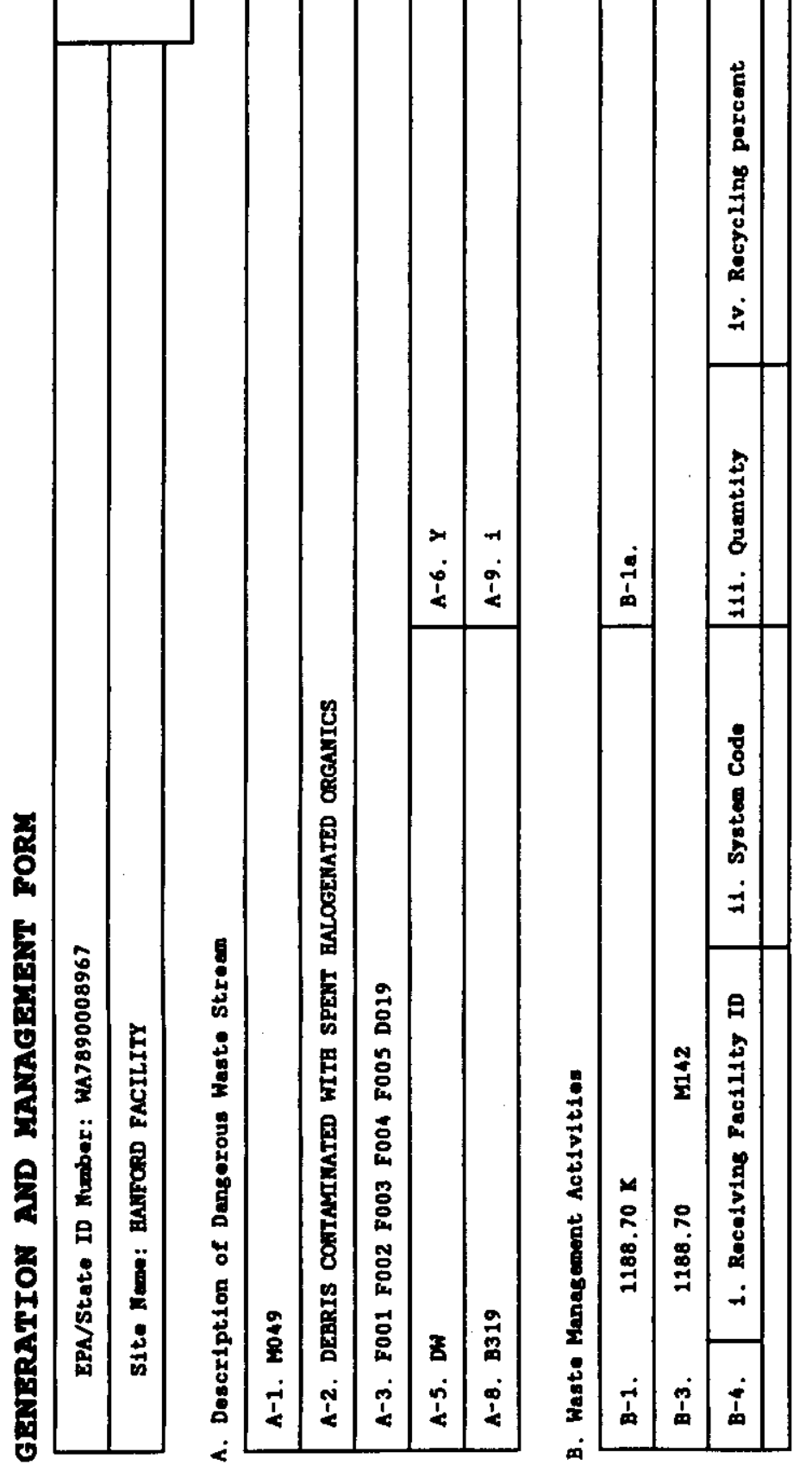


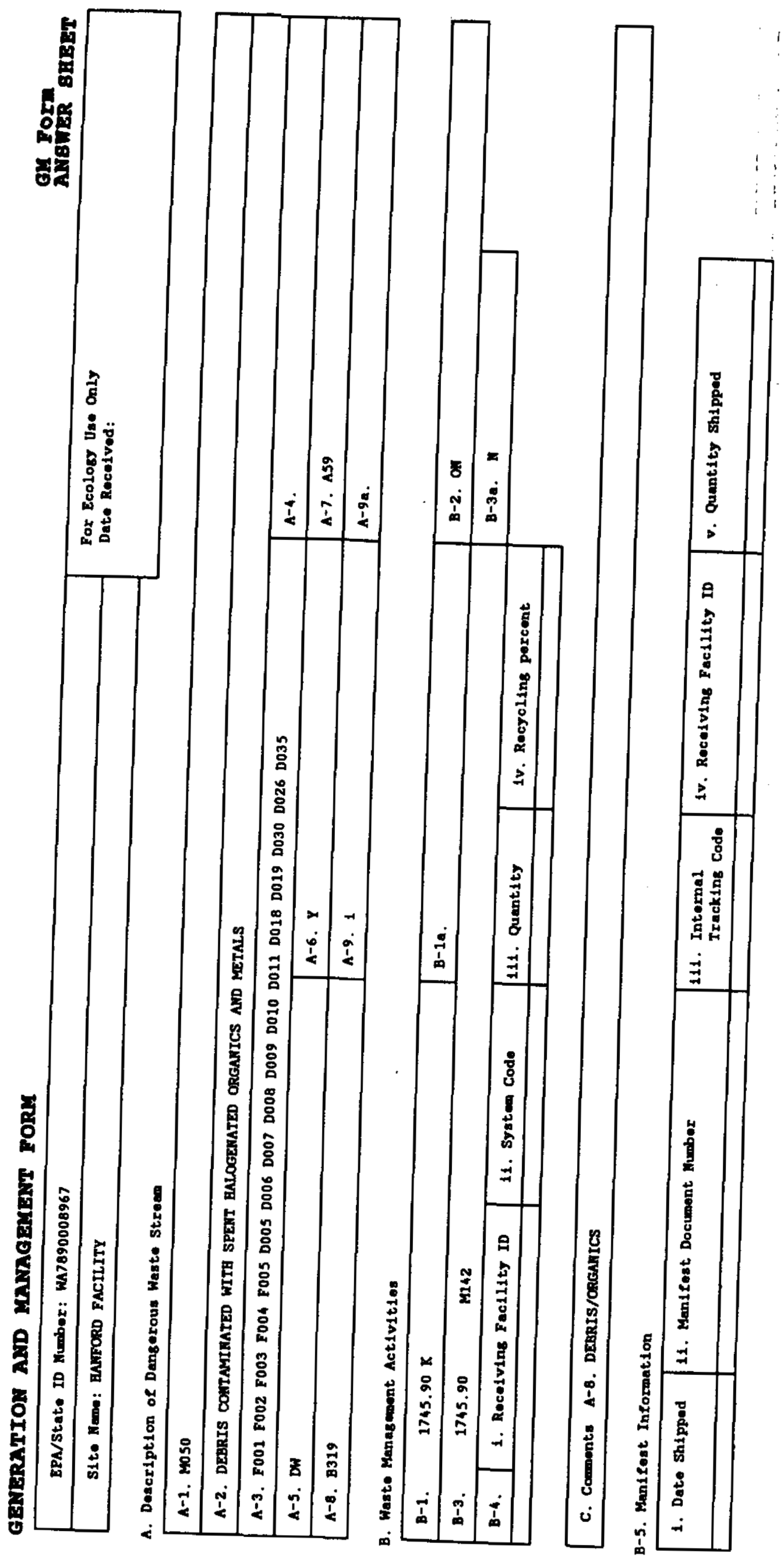




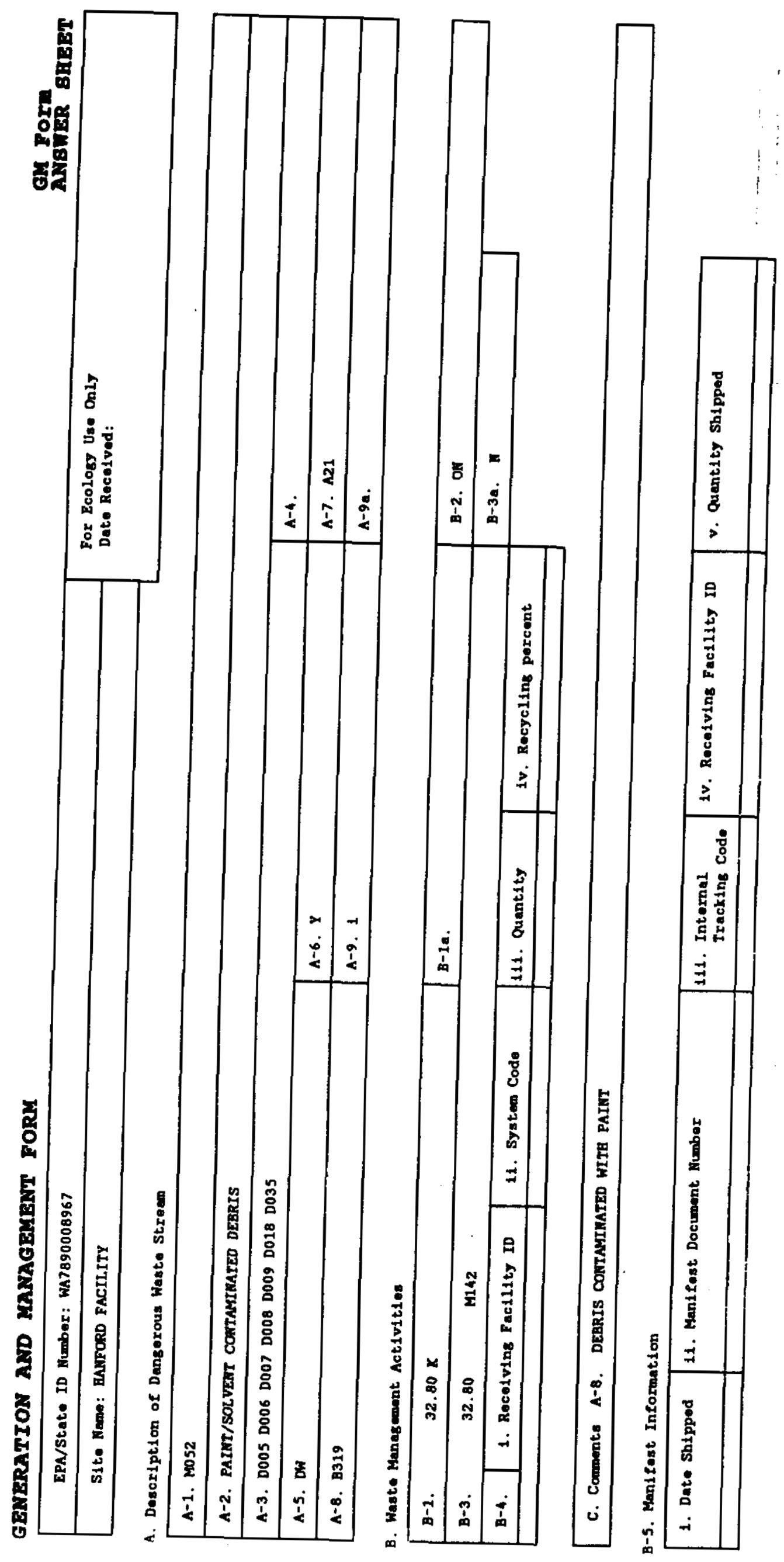




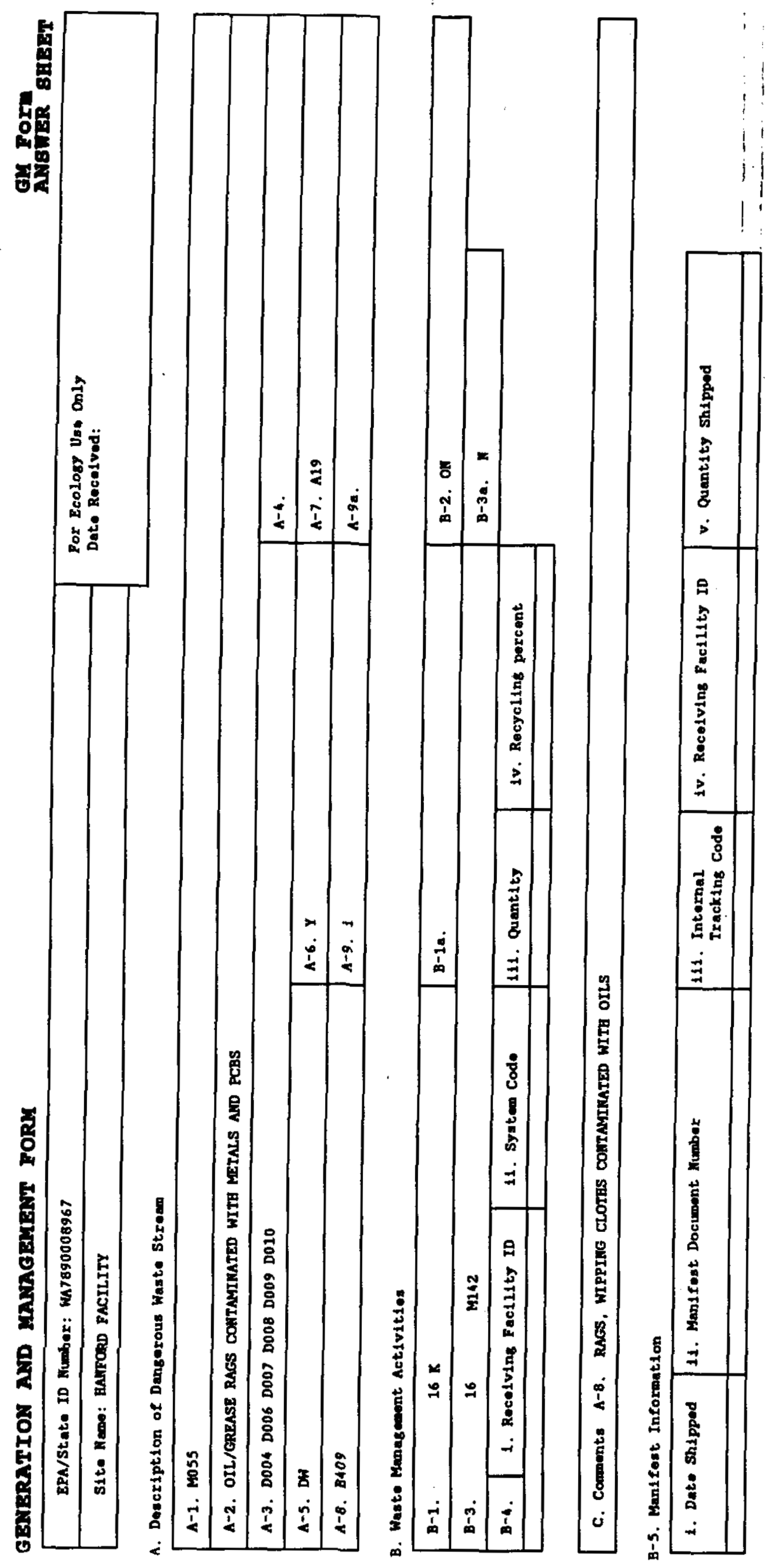




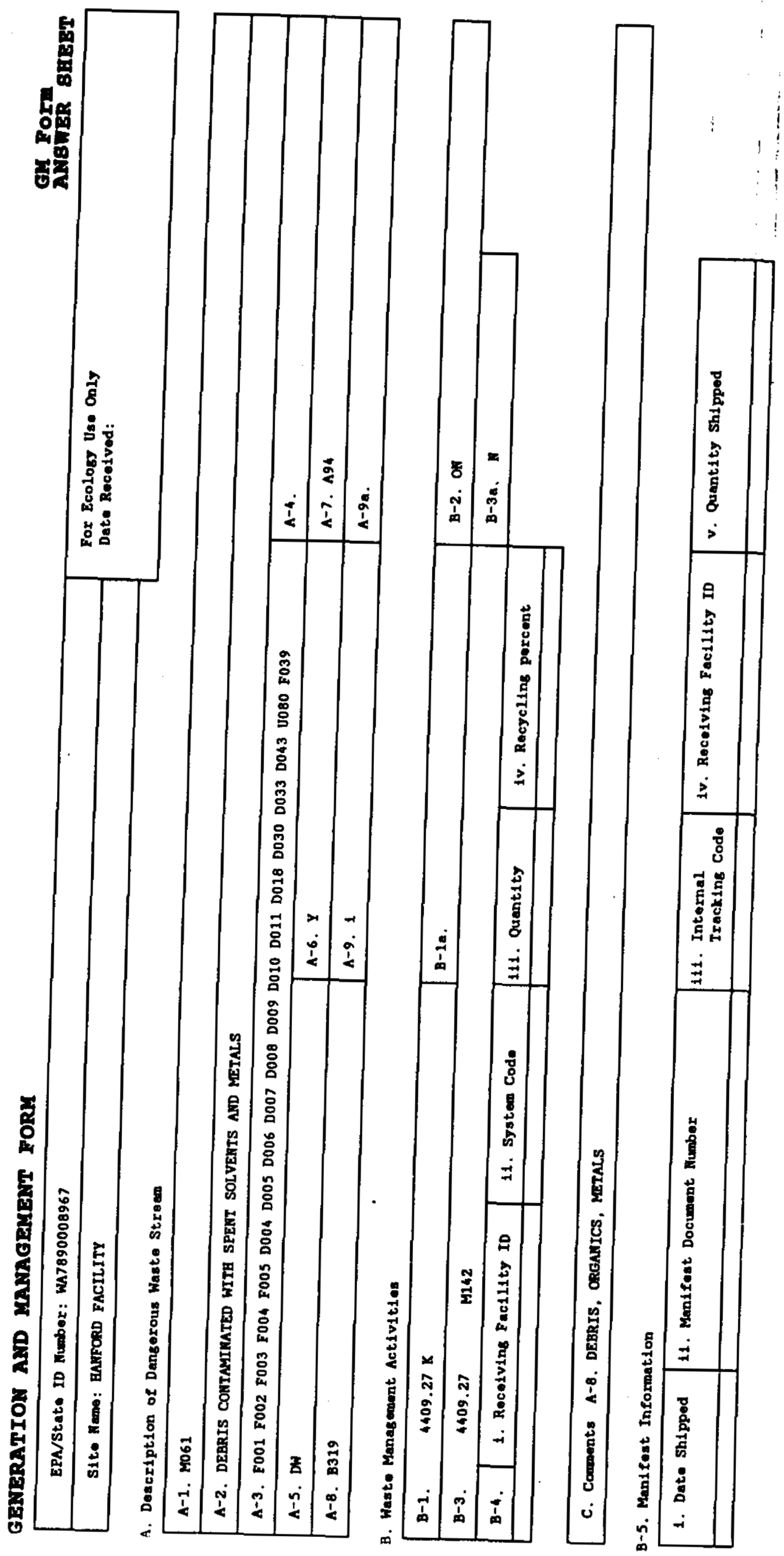

s.
$\vdots$
$\vdots$ 


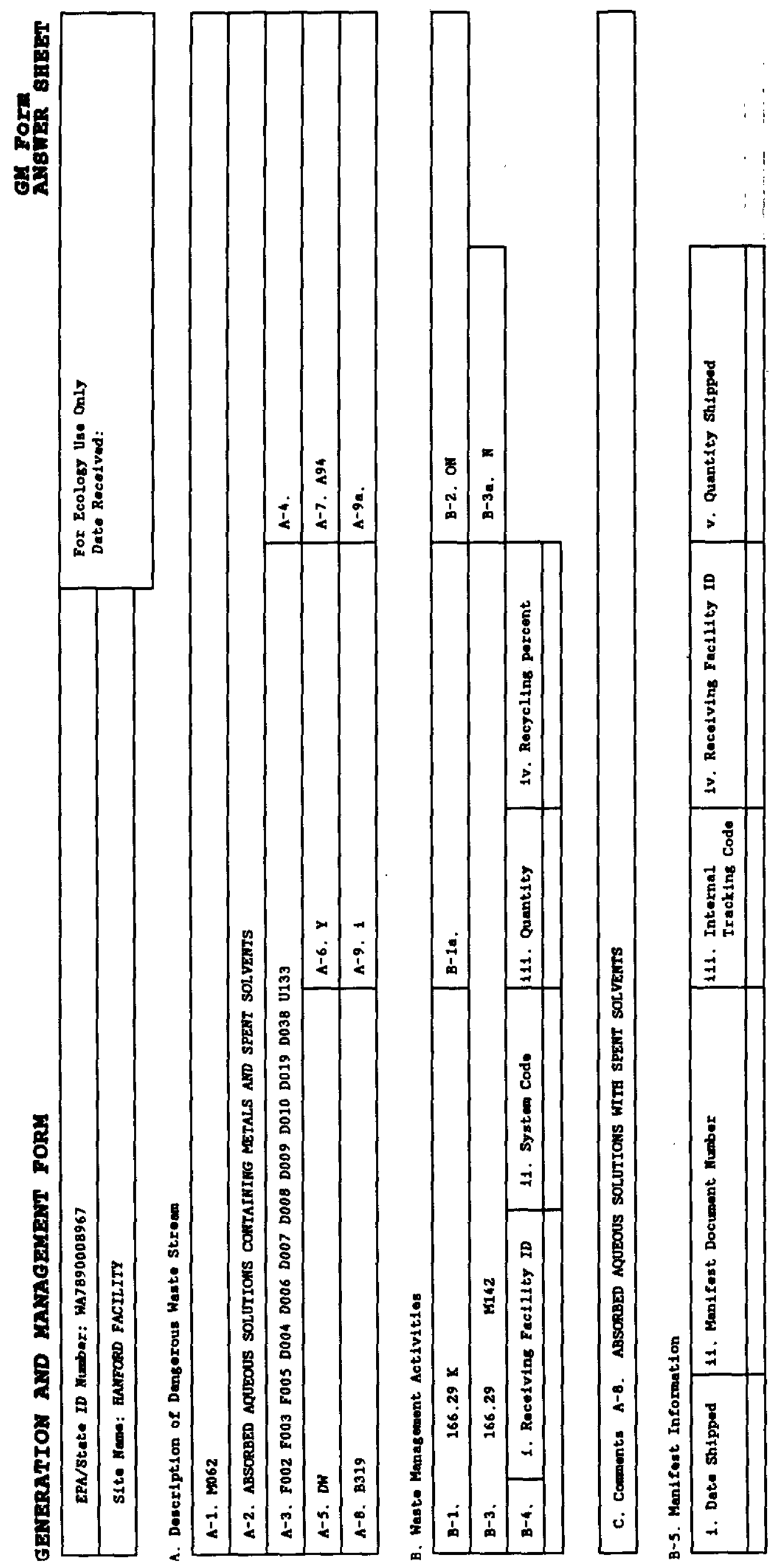




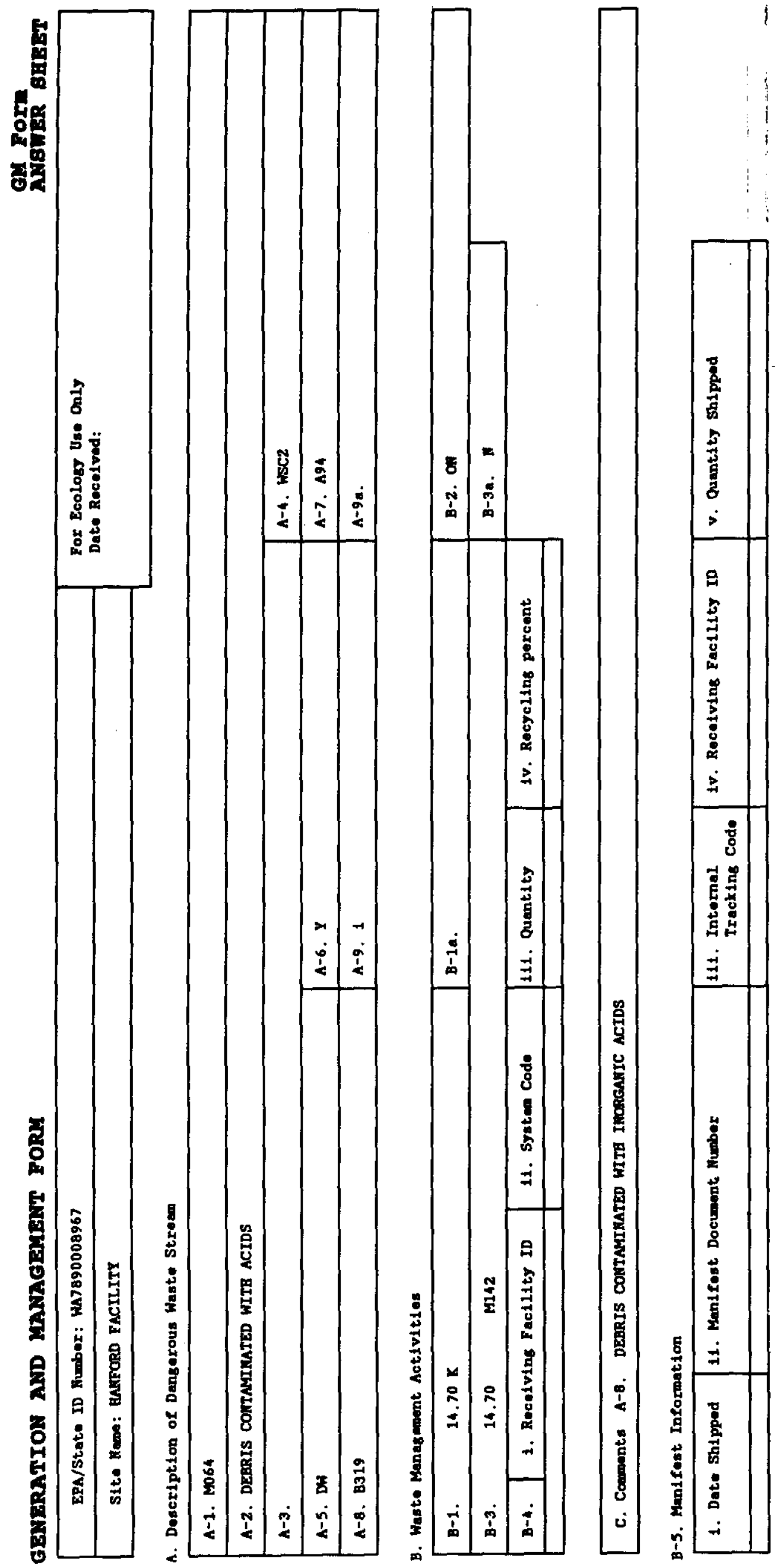




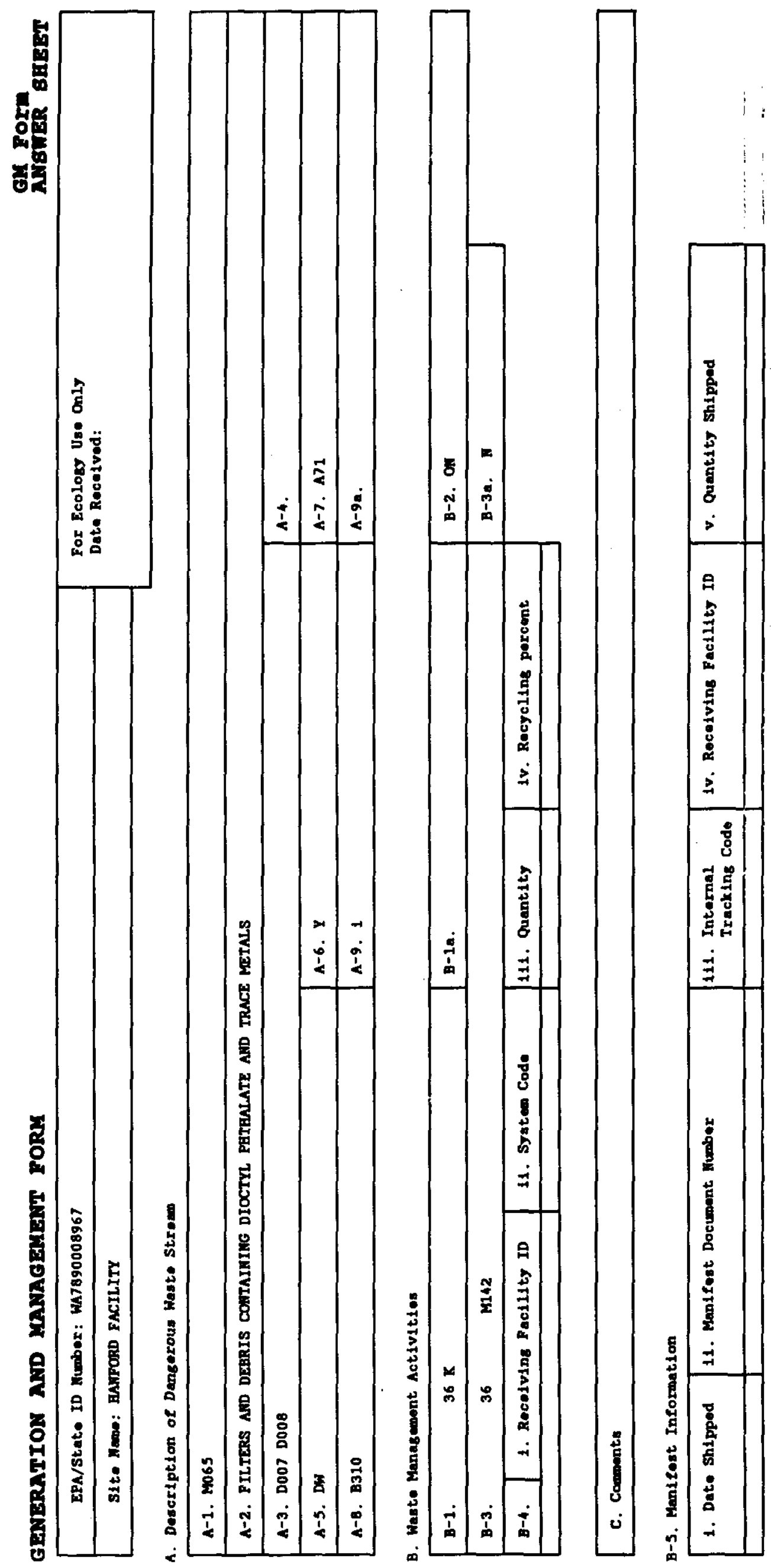




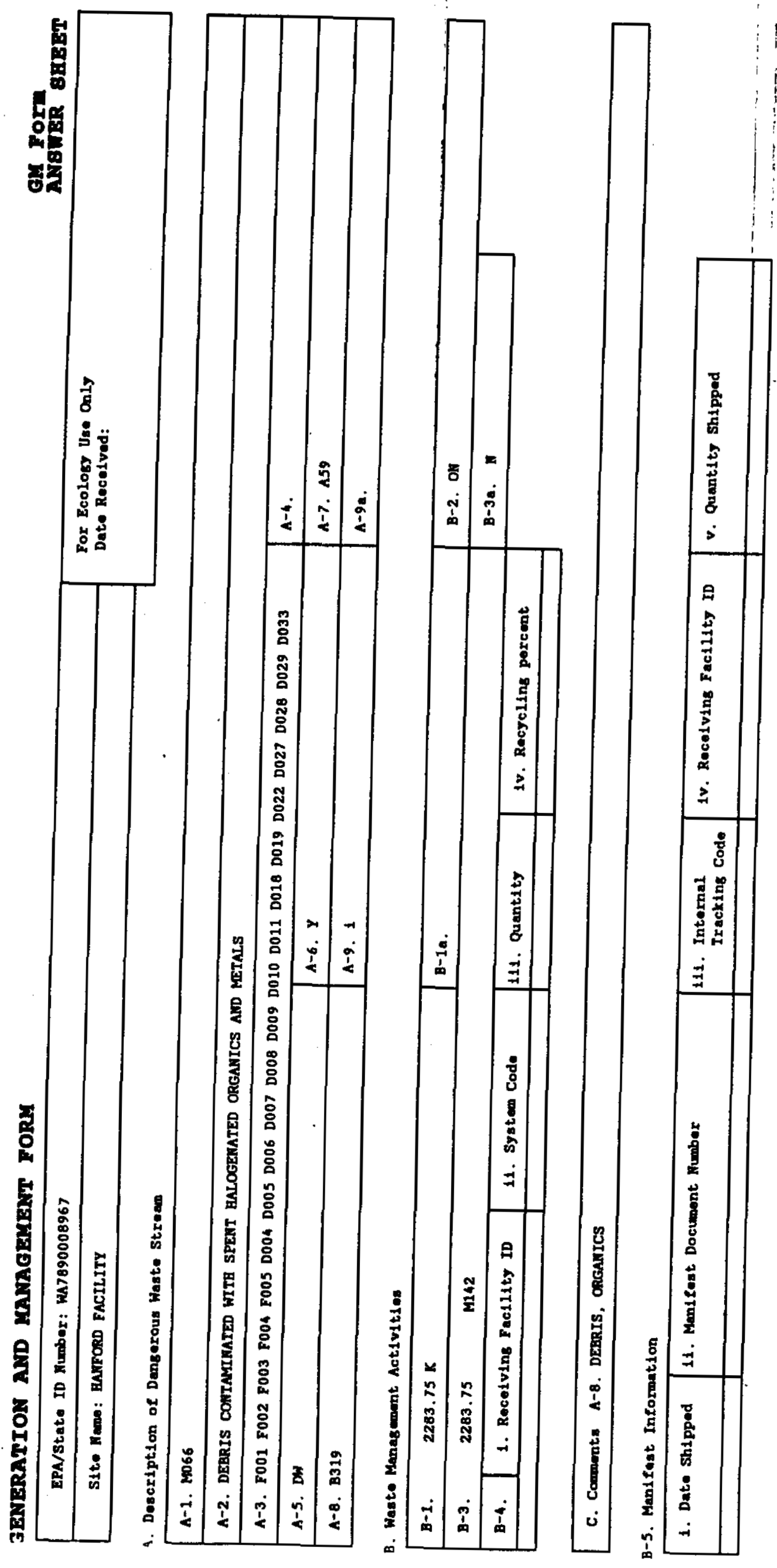




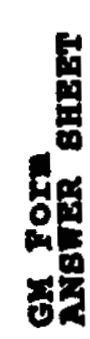
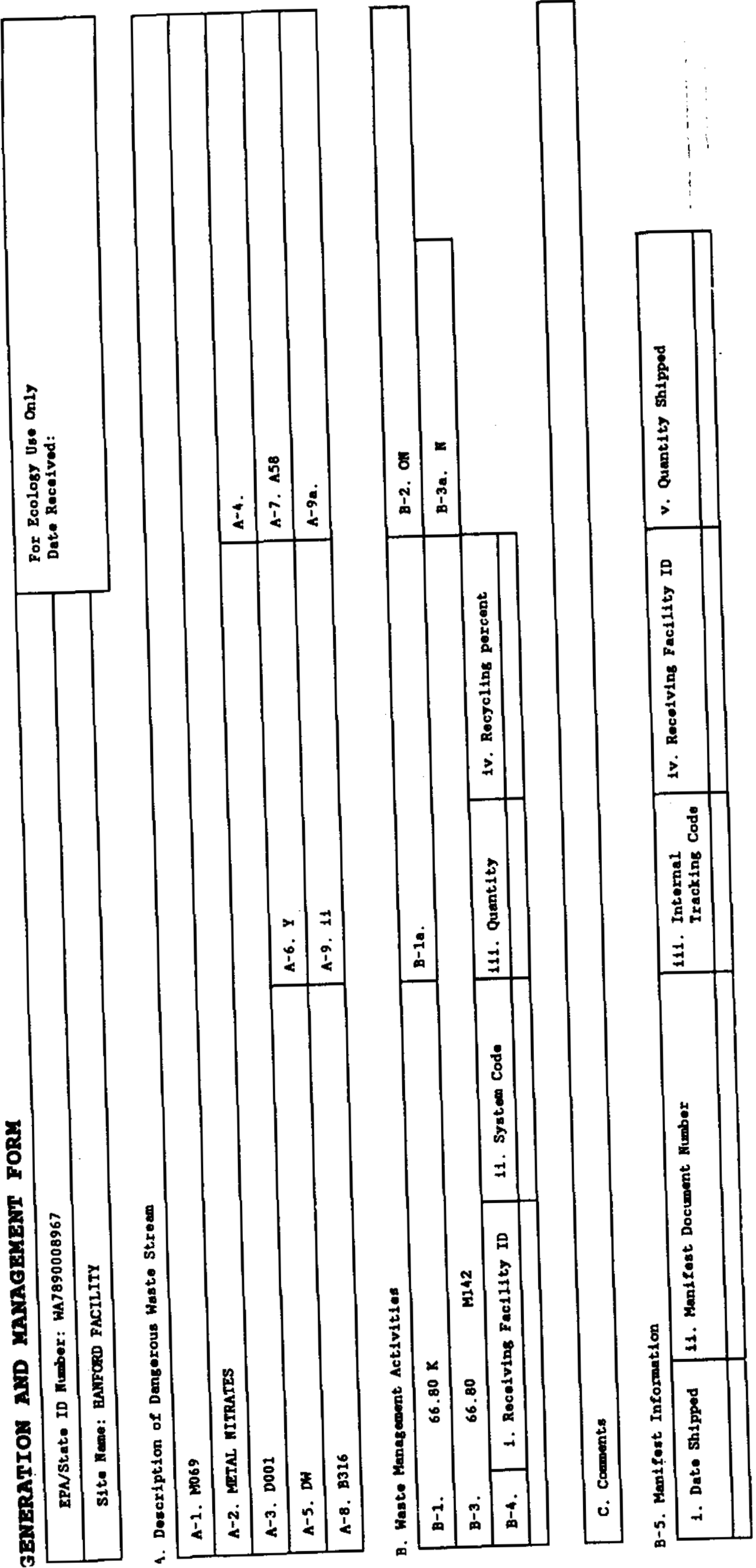


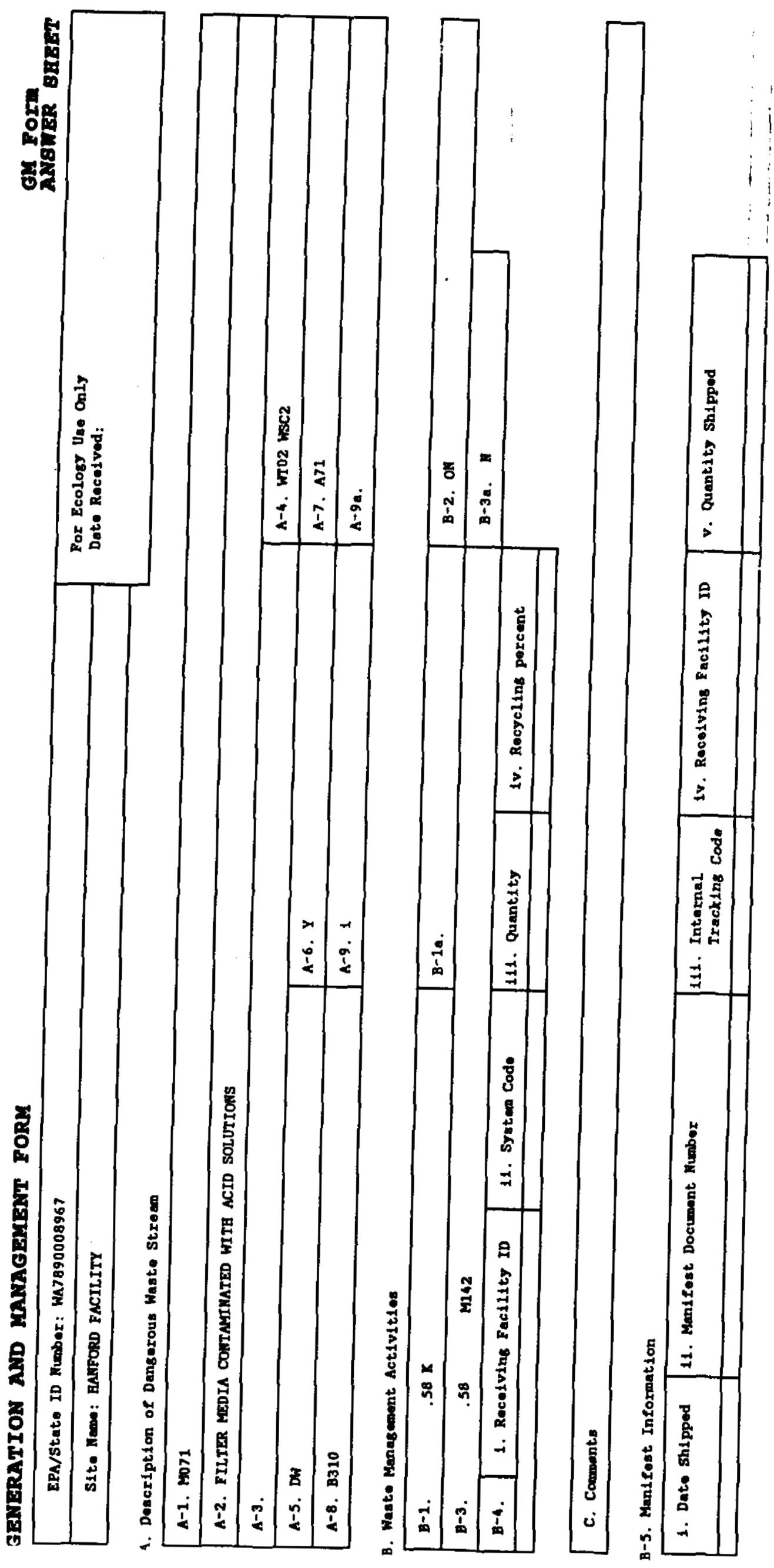




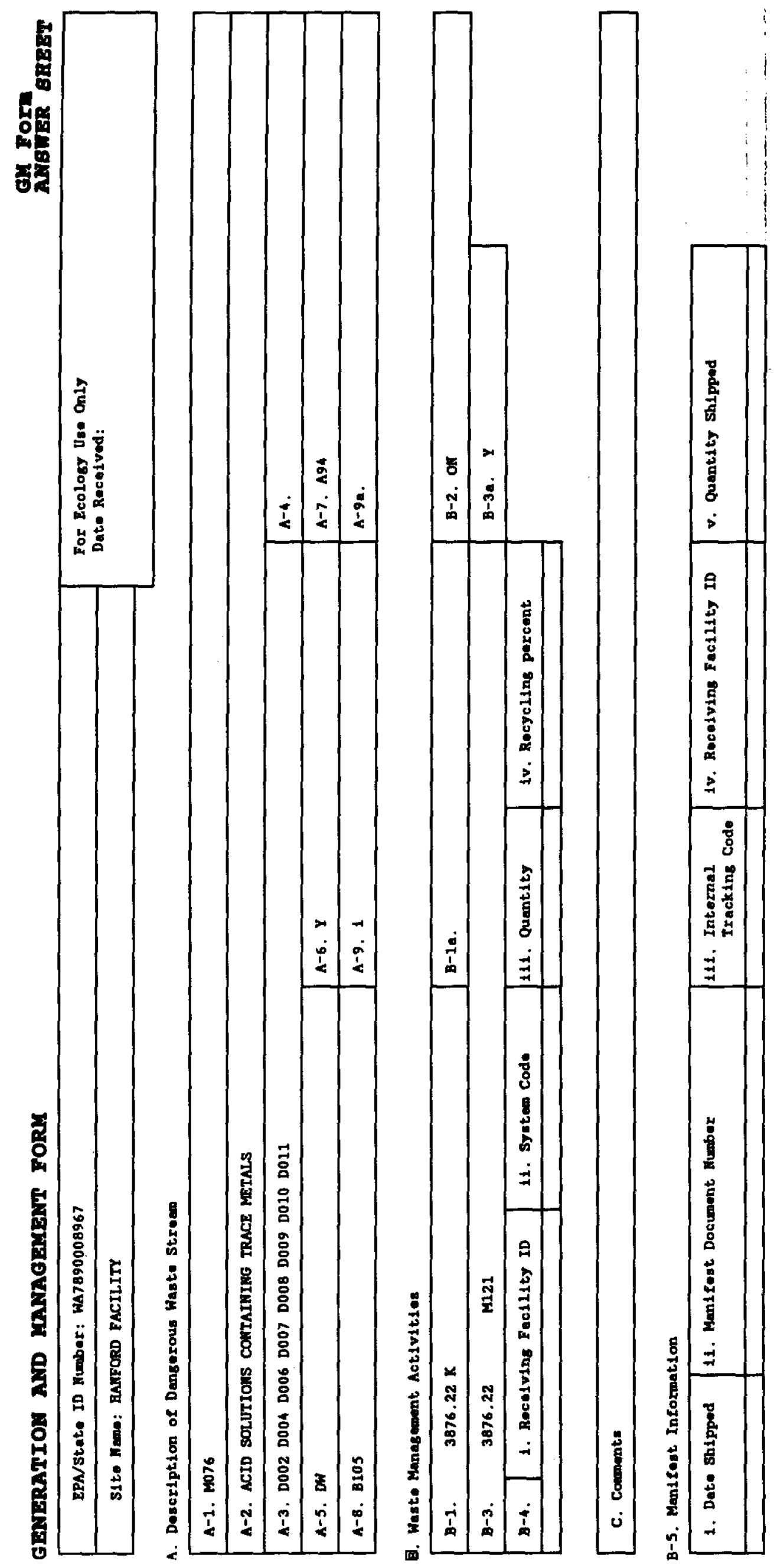




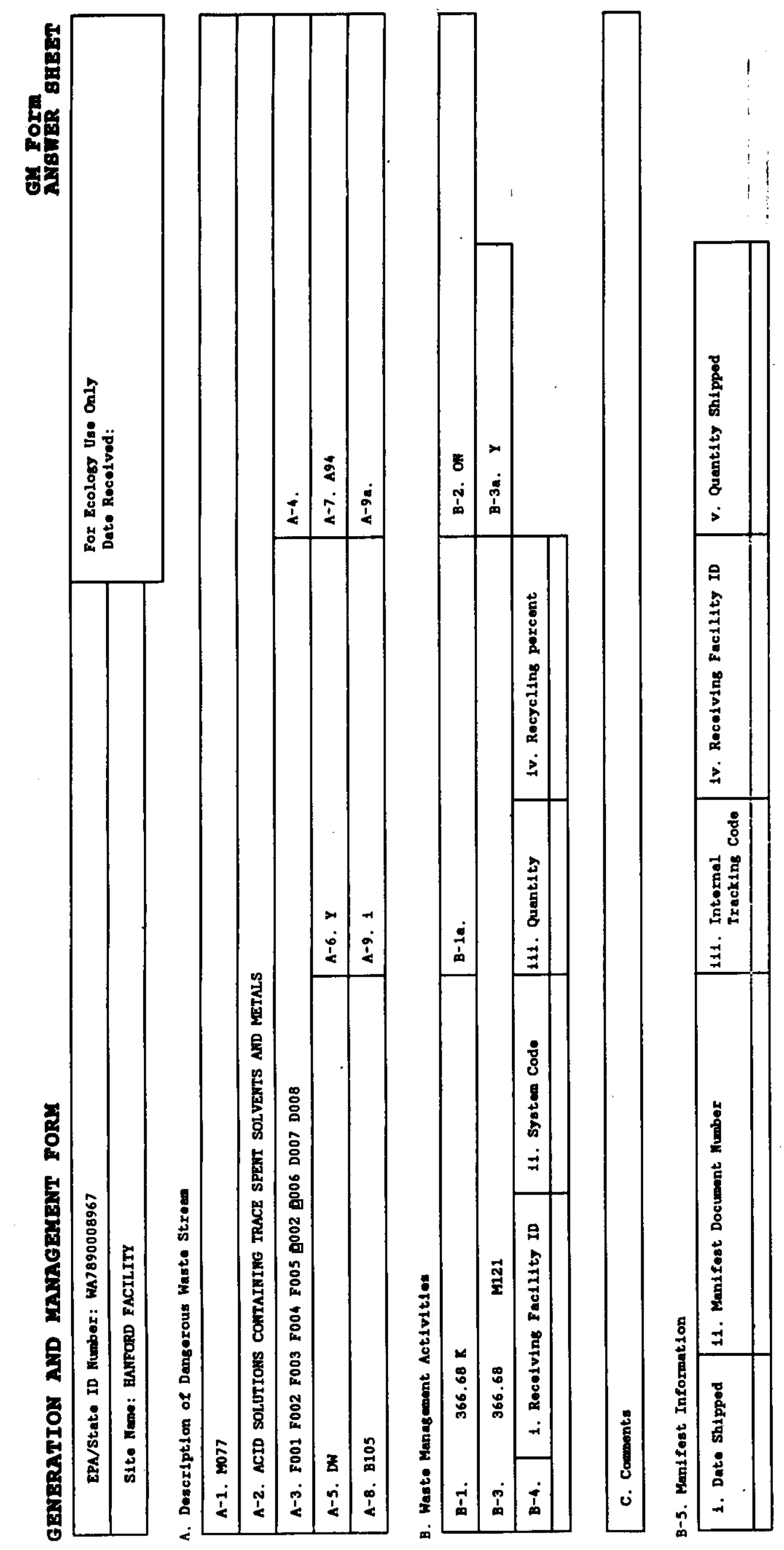




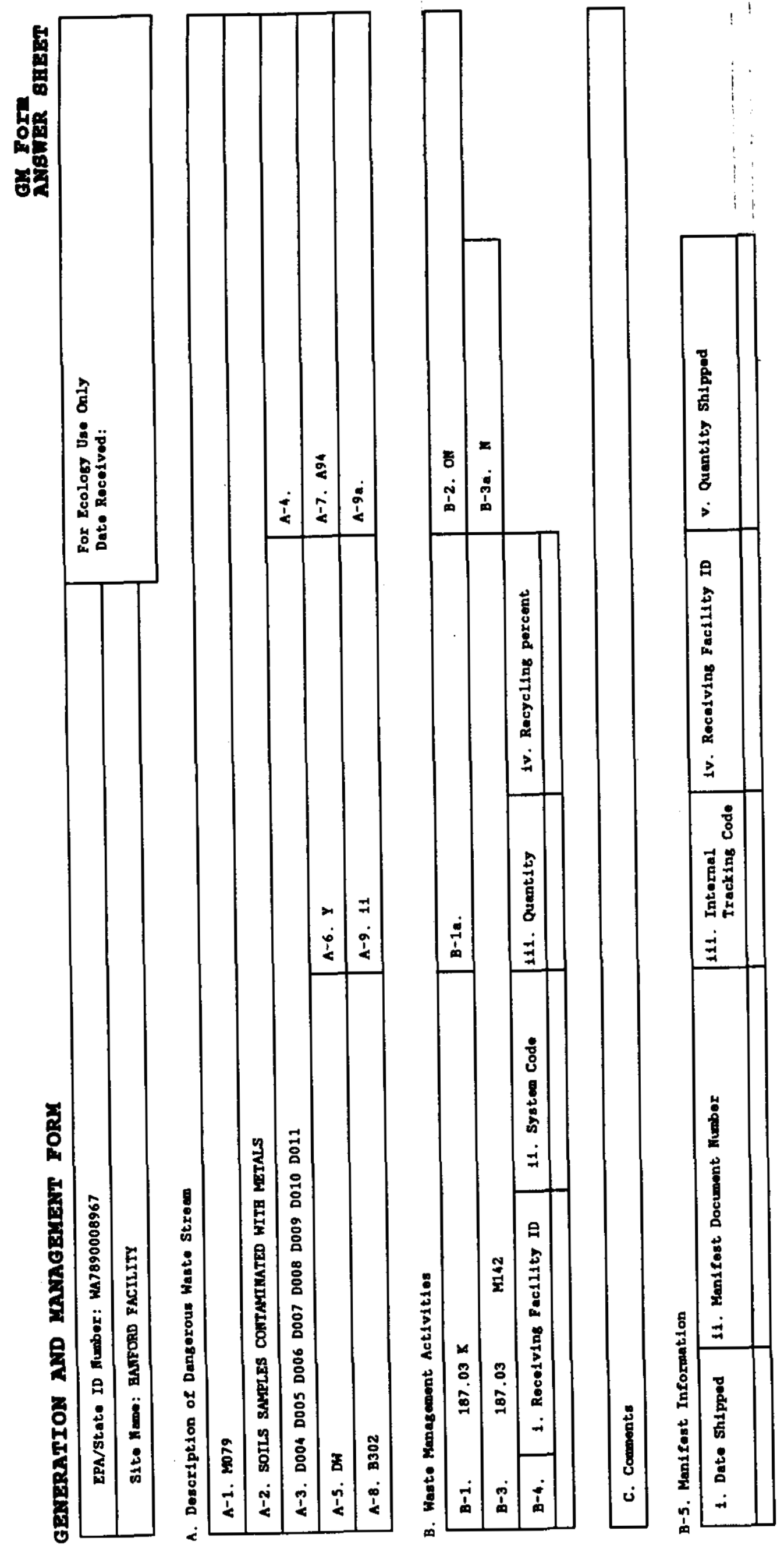




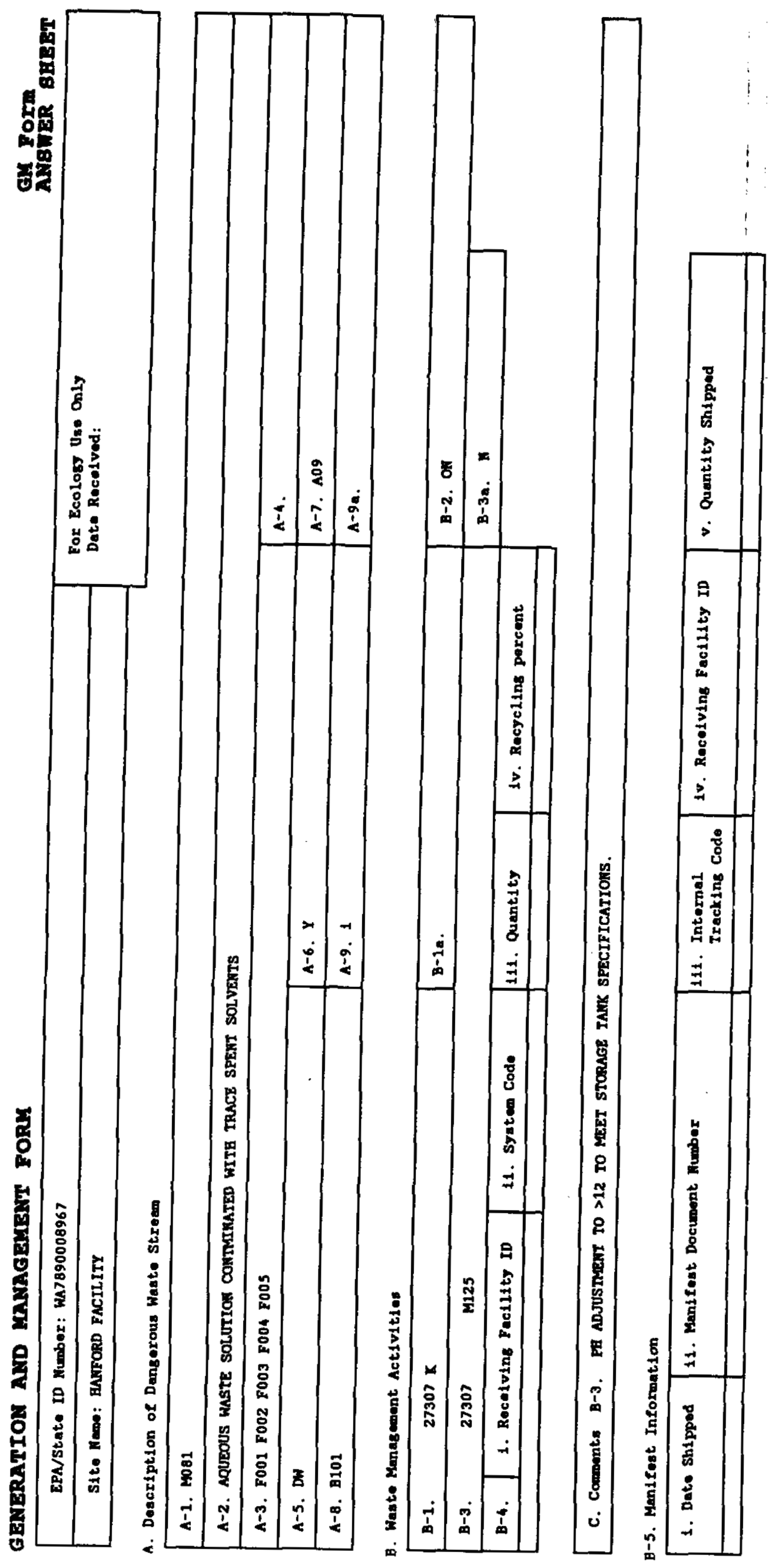




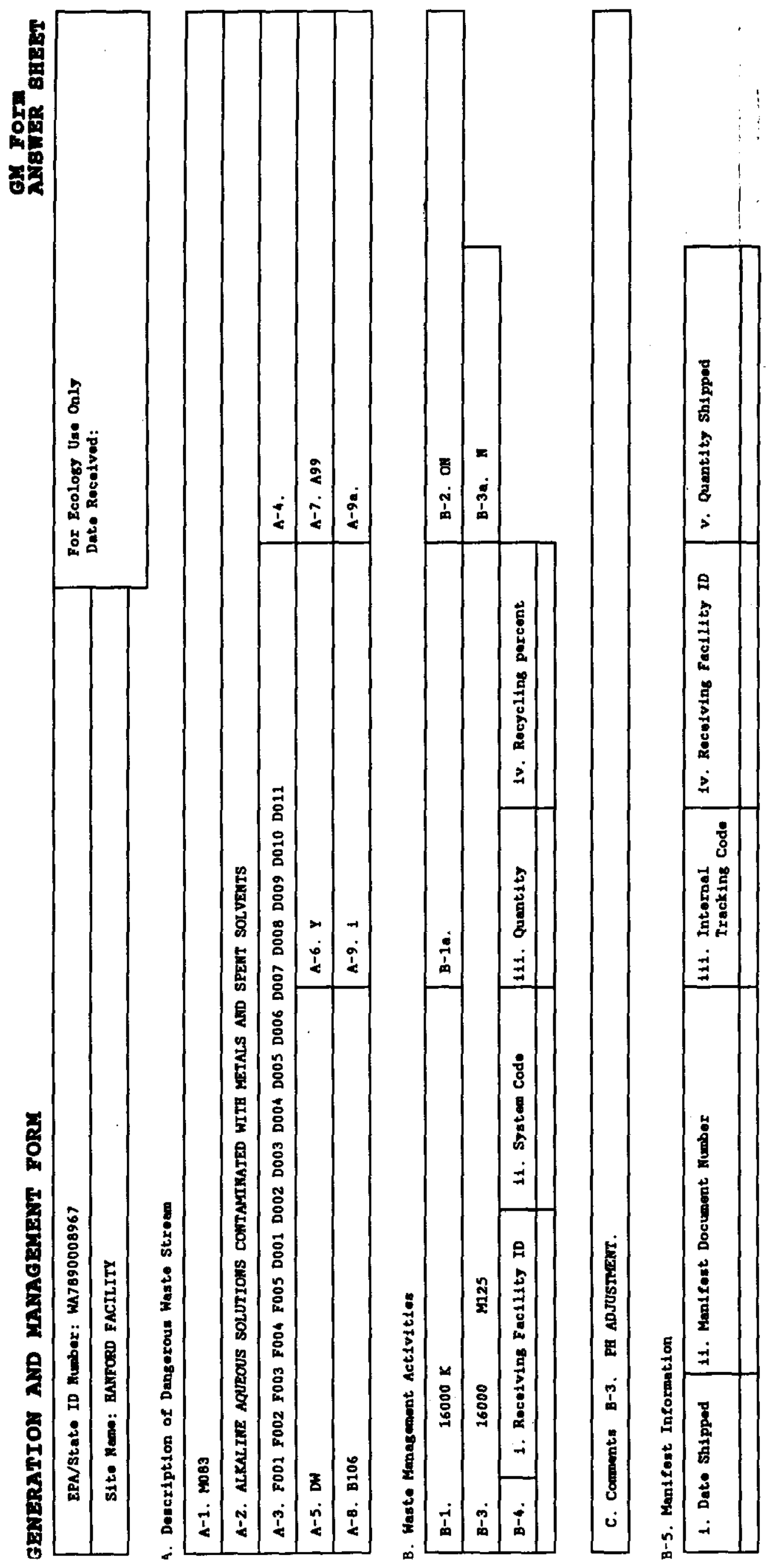




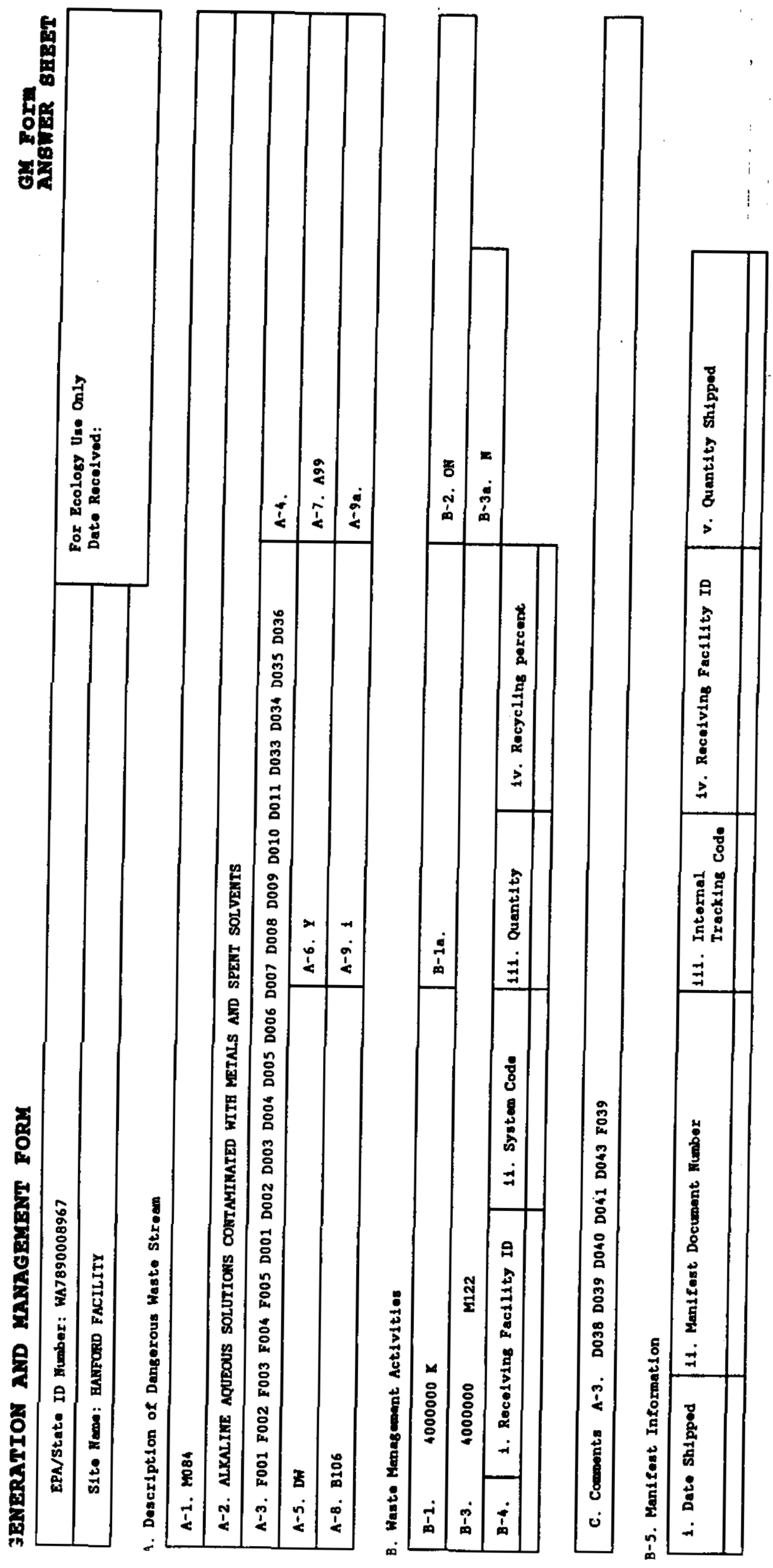



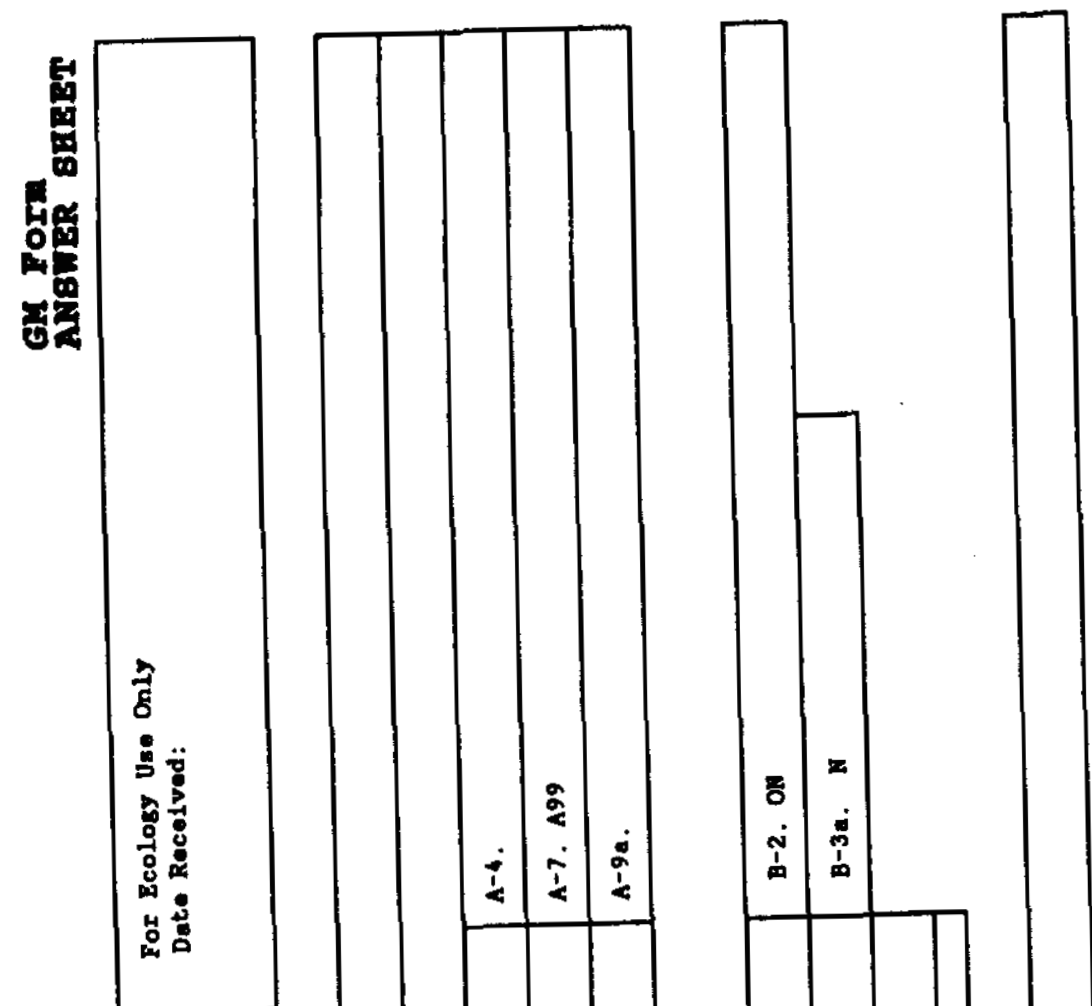

$\stackrel{a}{a}$
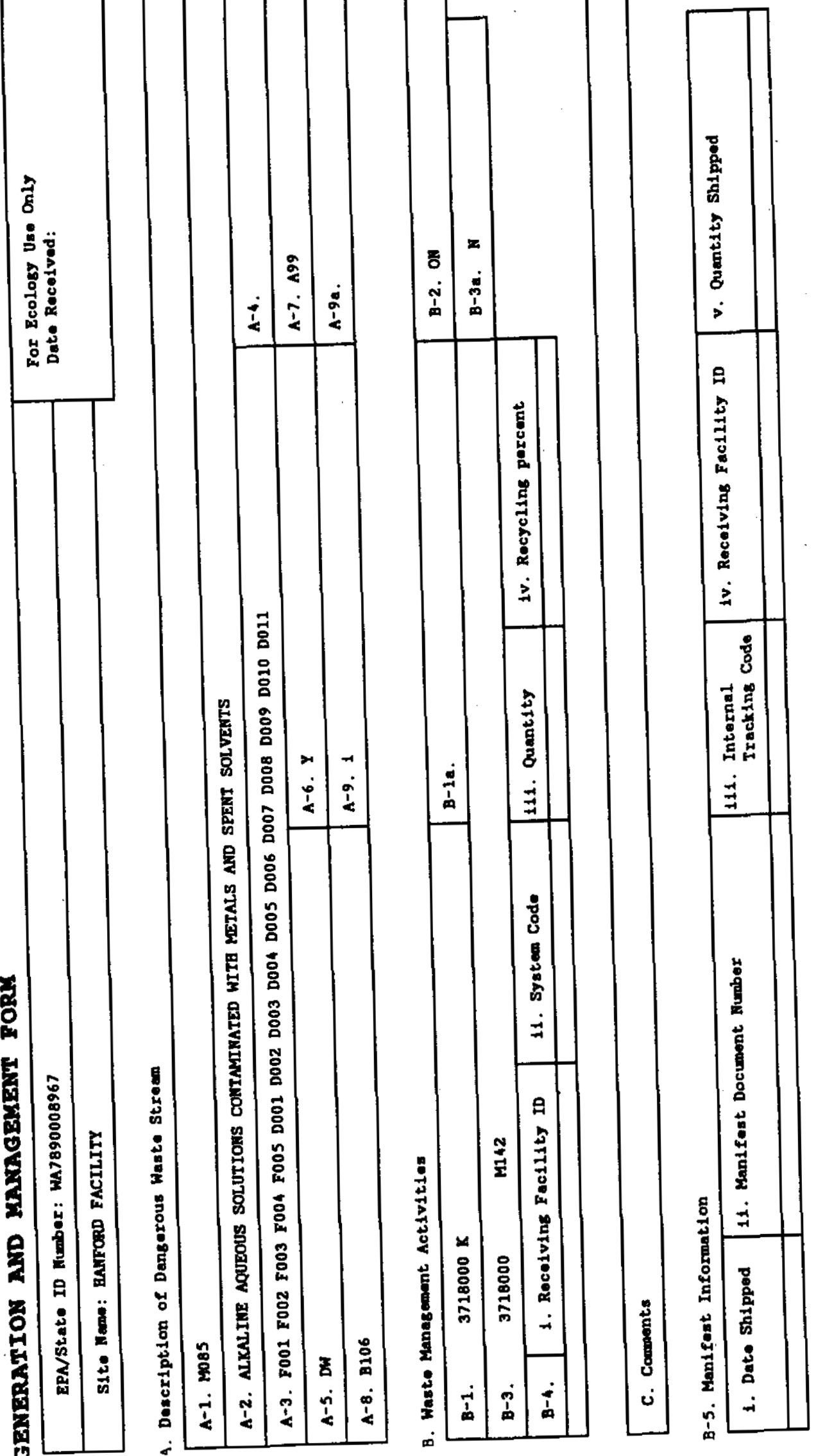


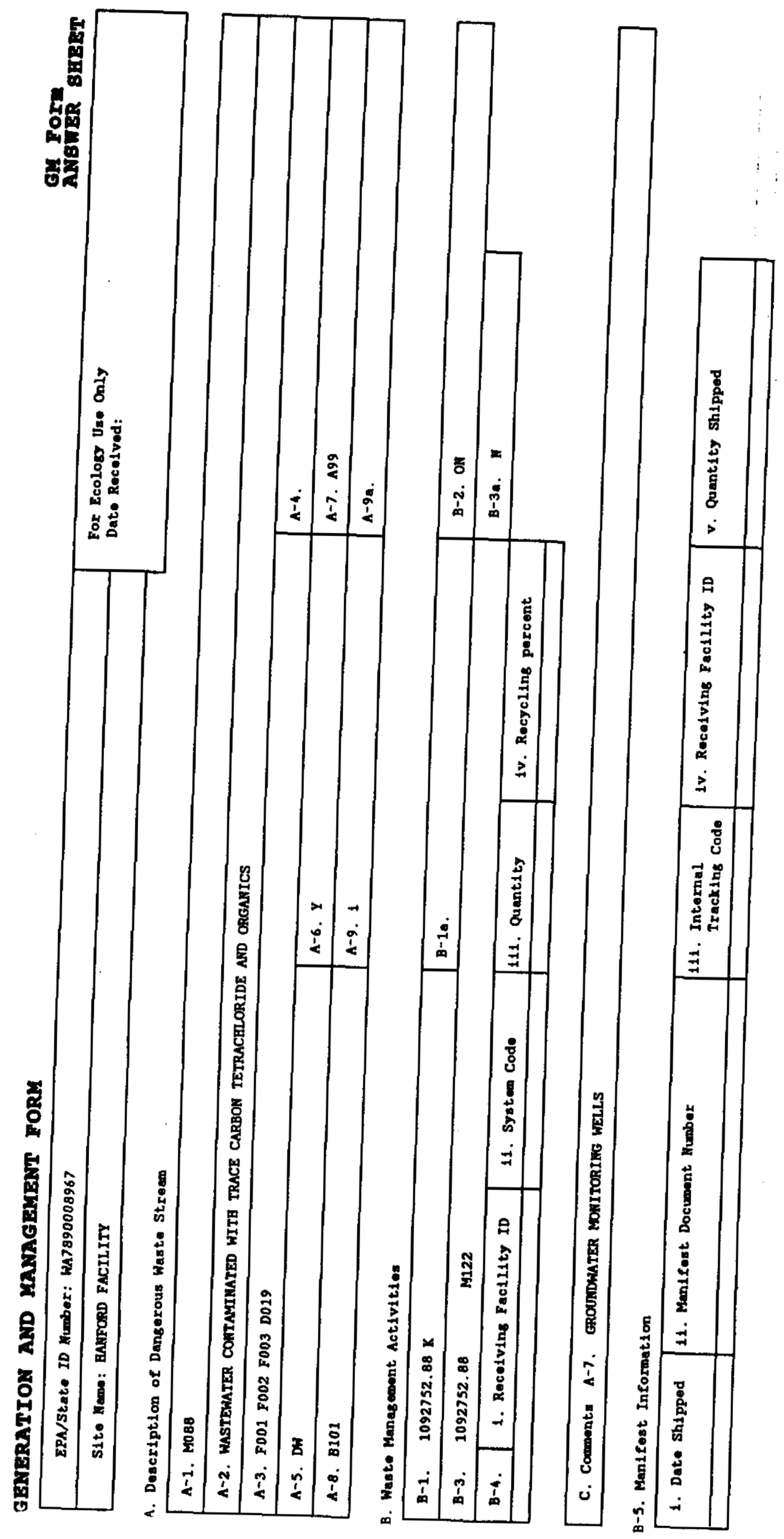

$\stackrel{3}{*}$ 


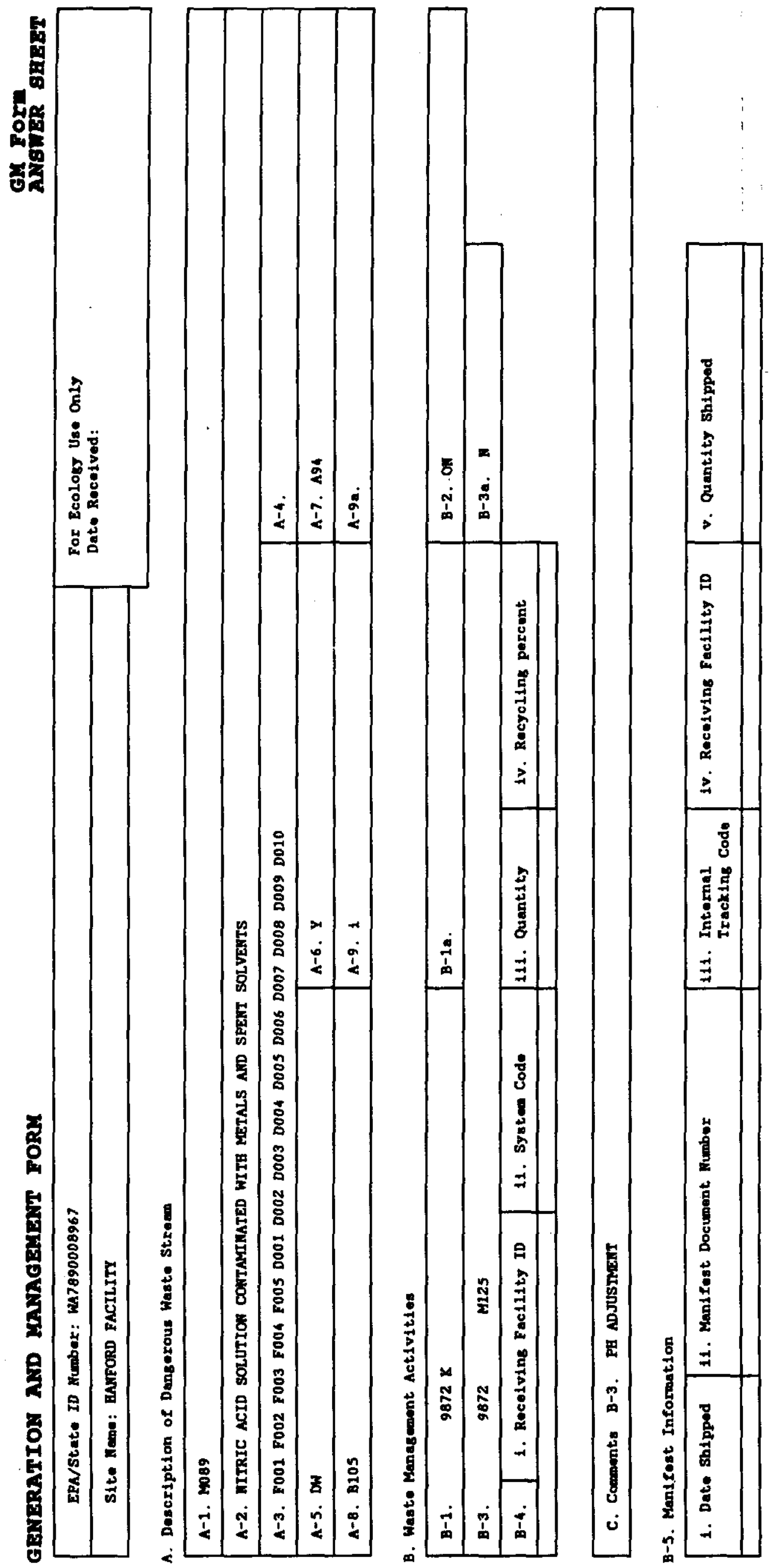




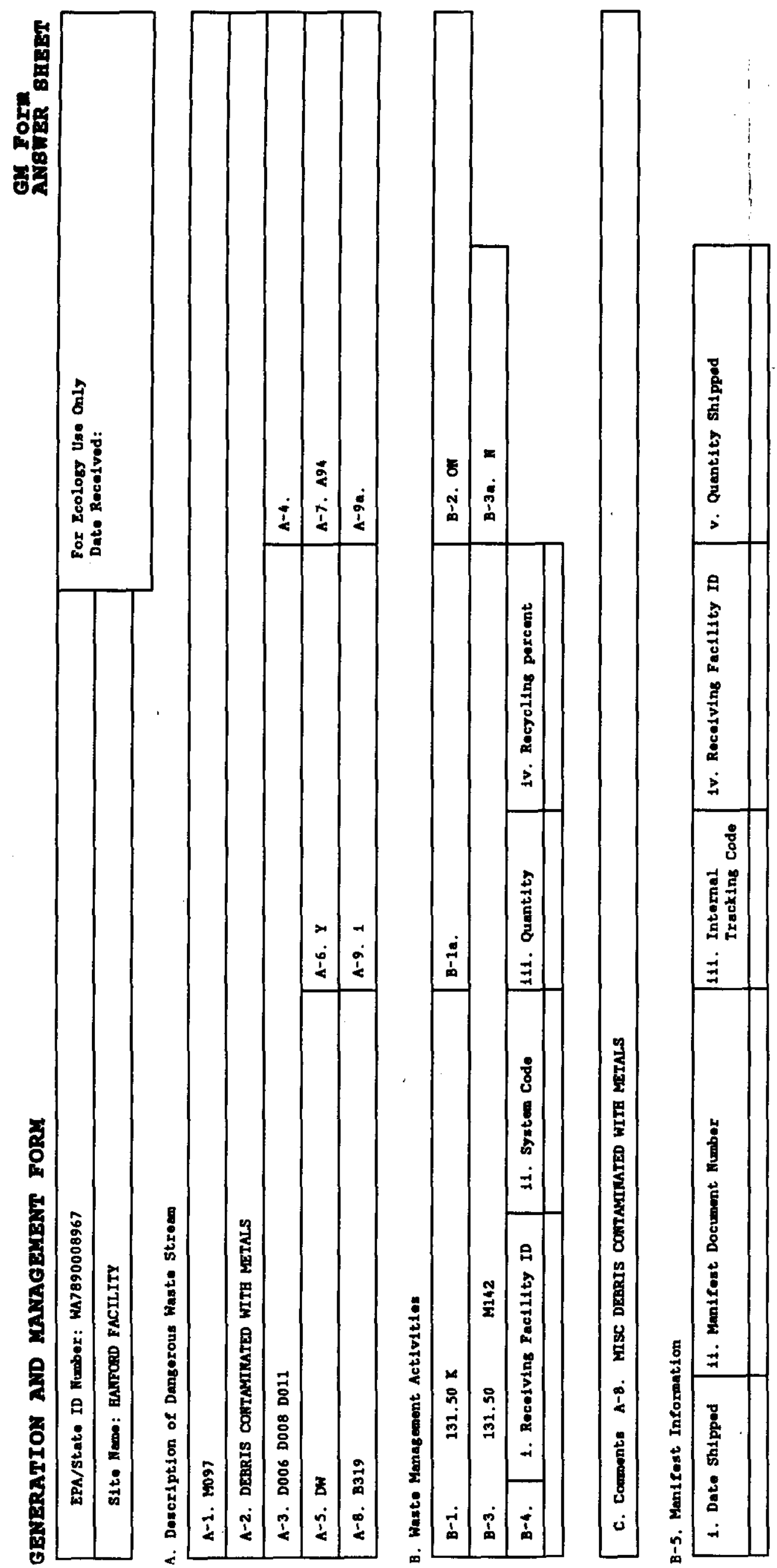




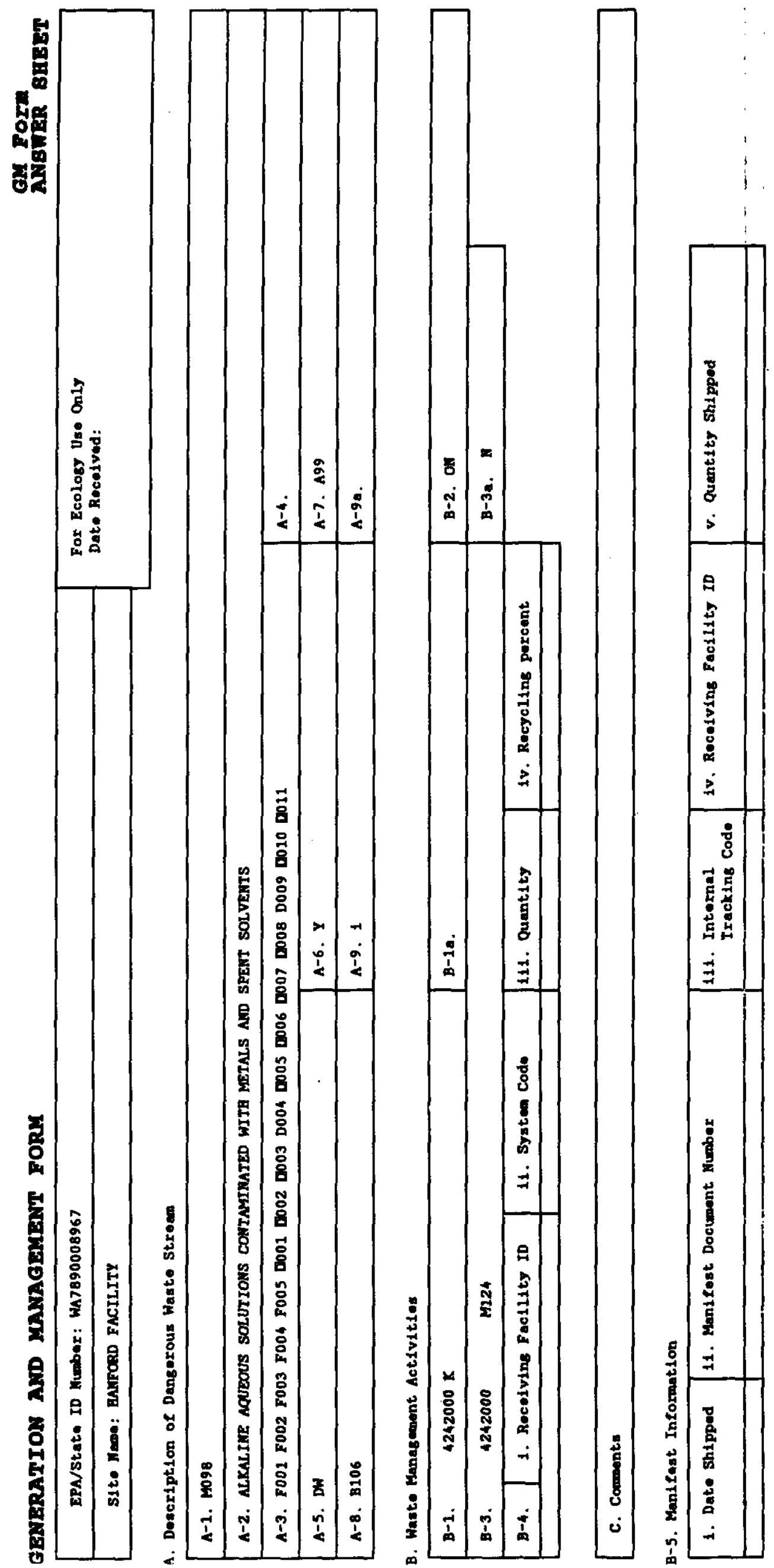




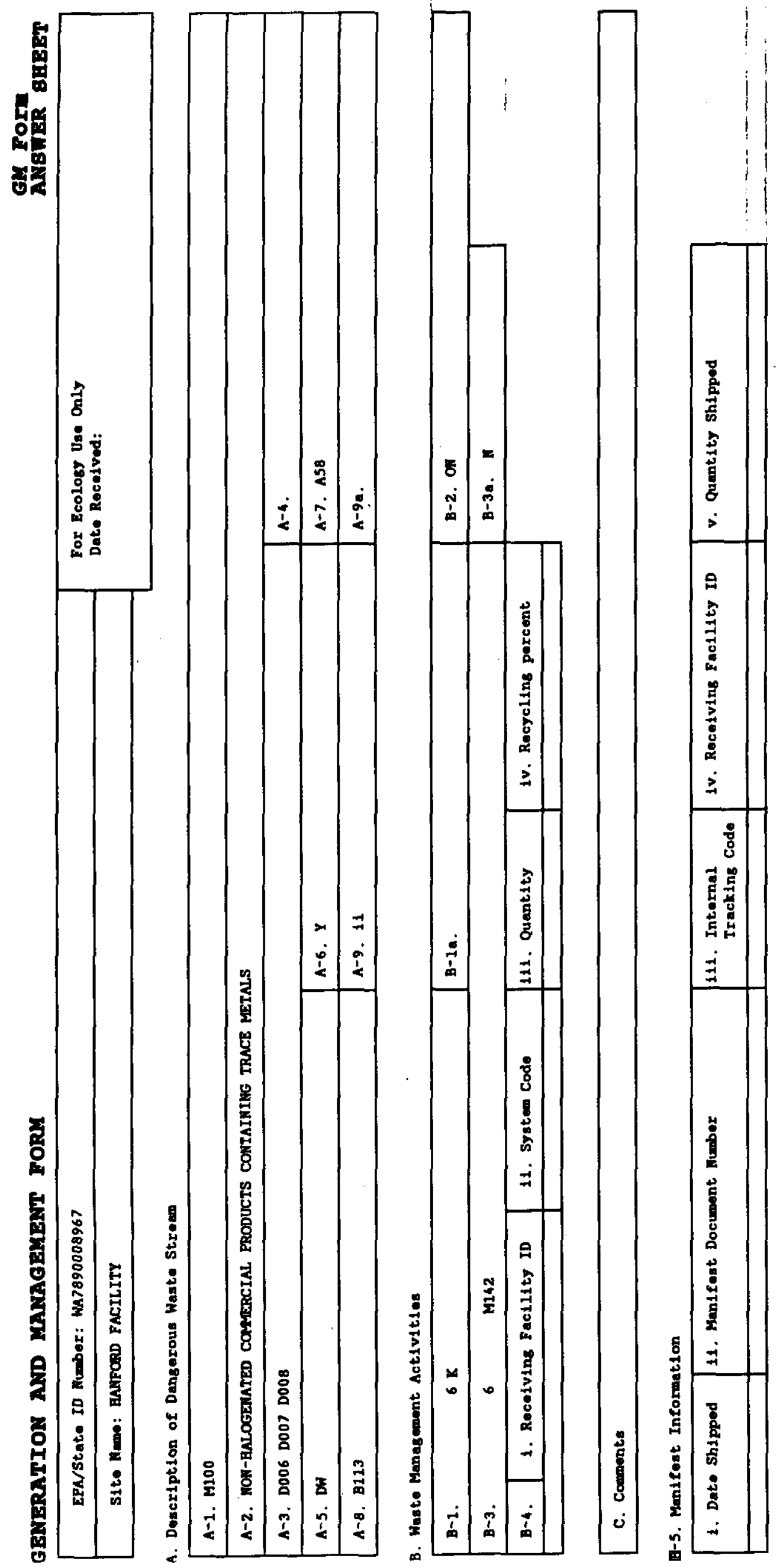




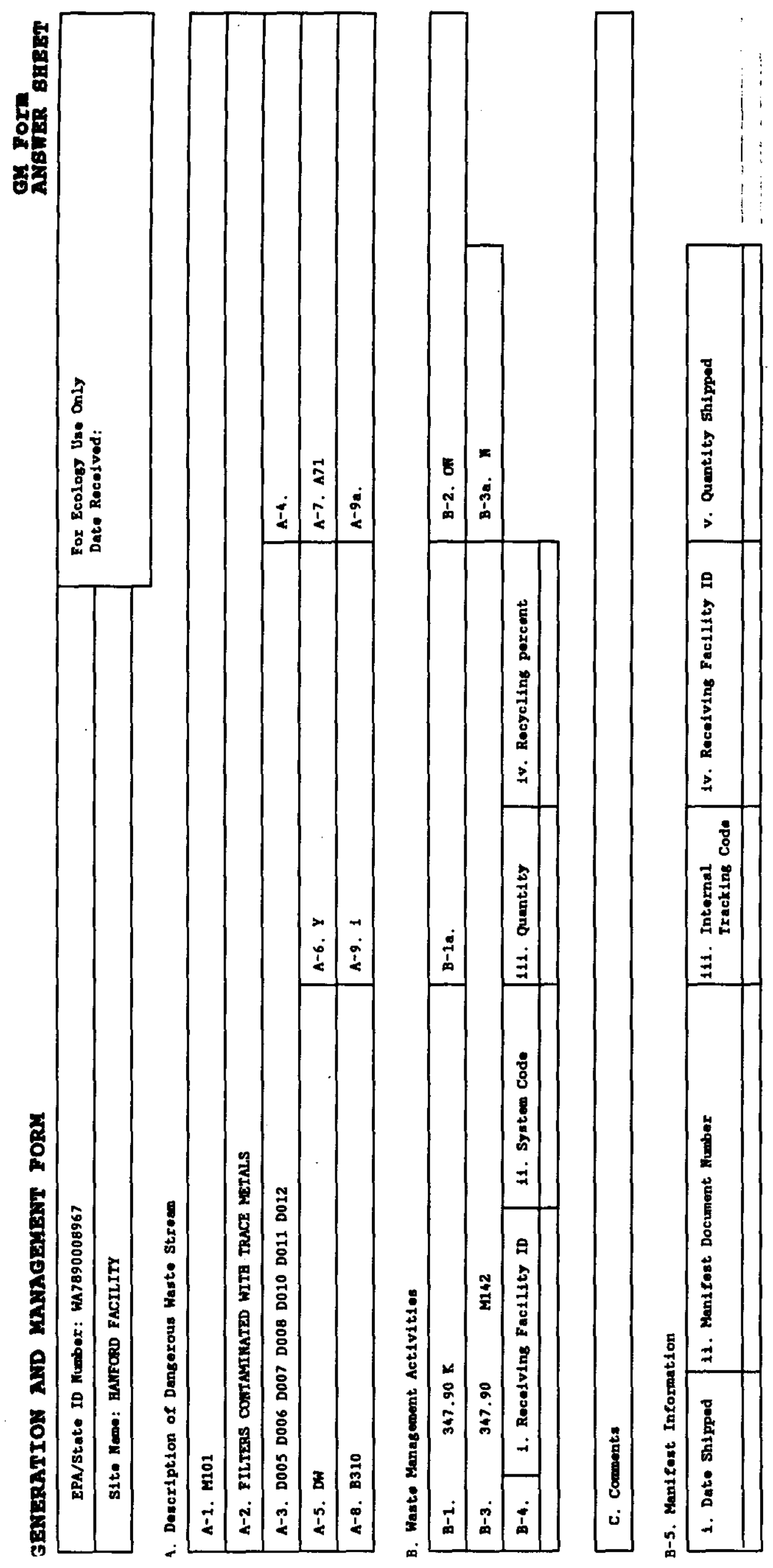




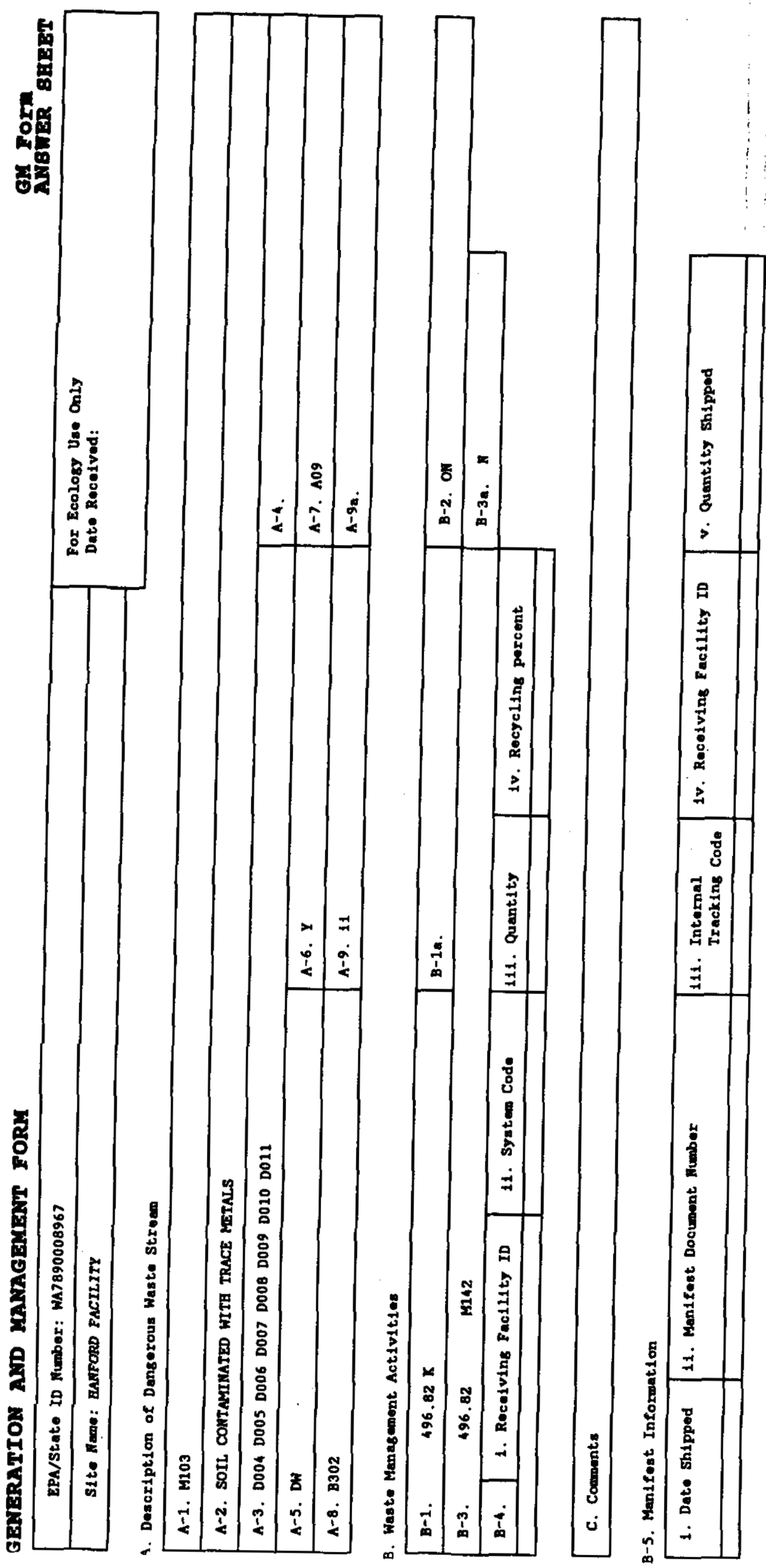




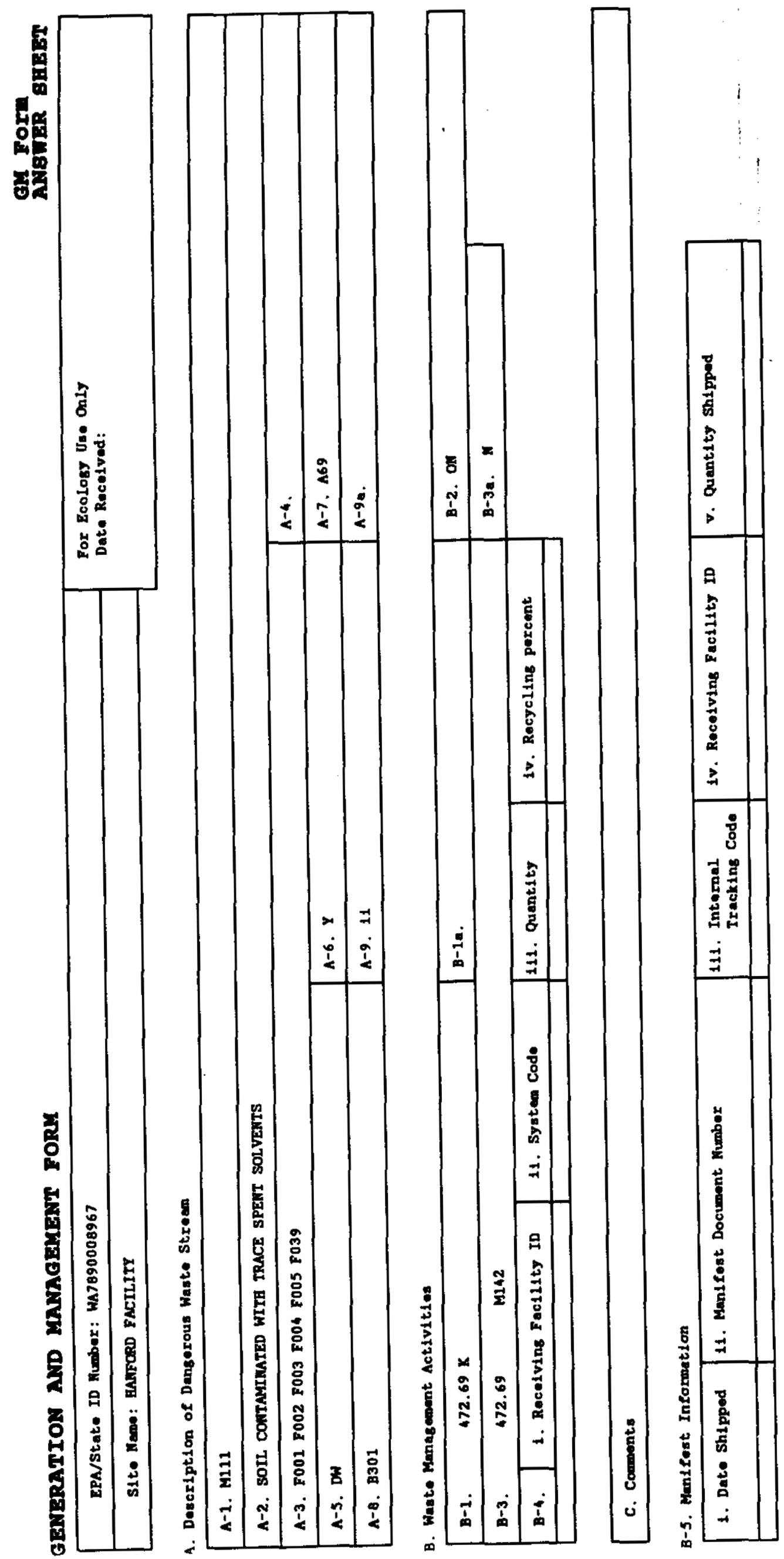




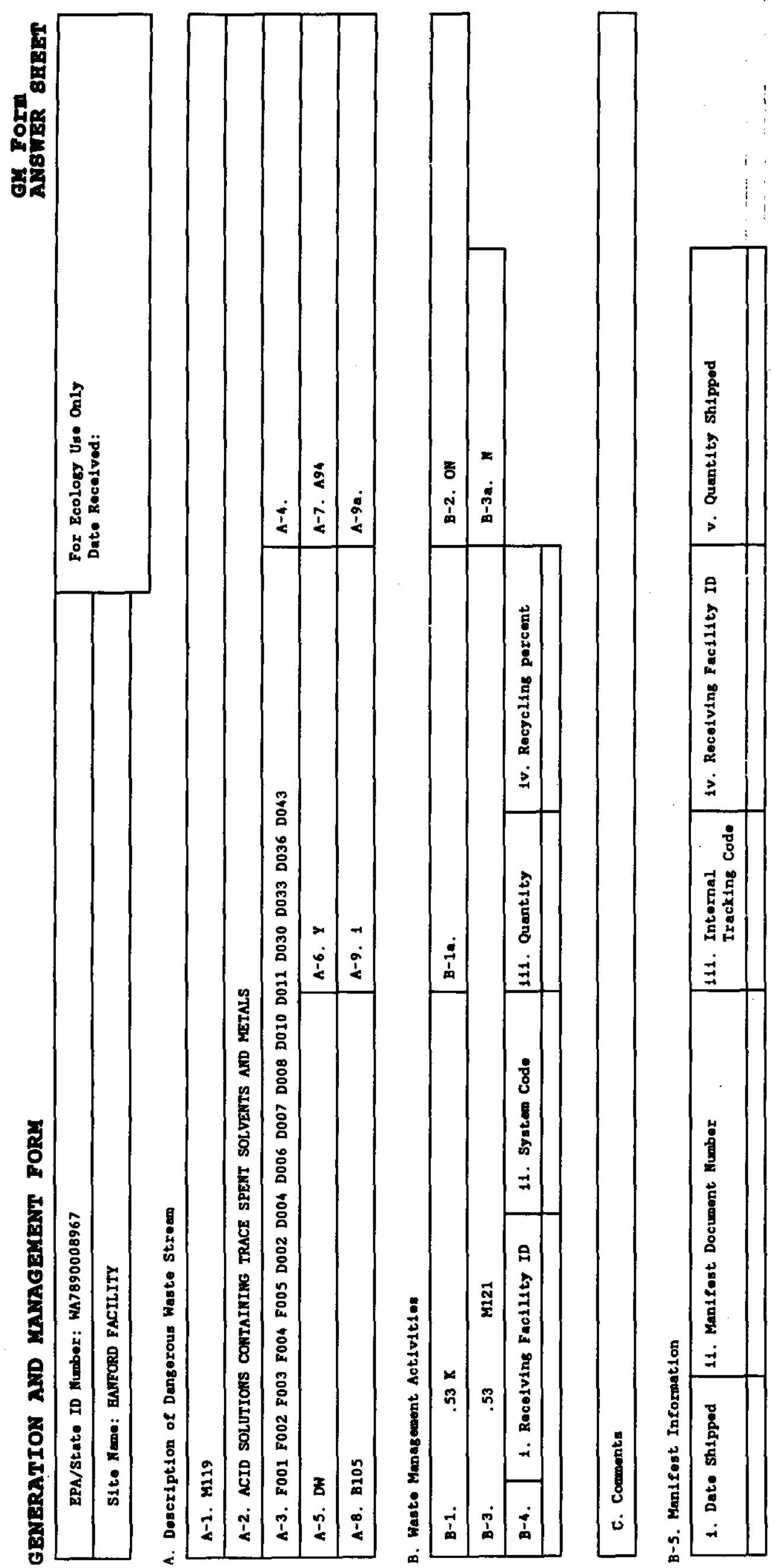




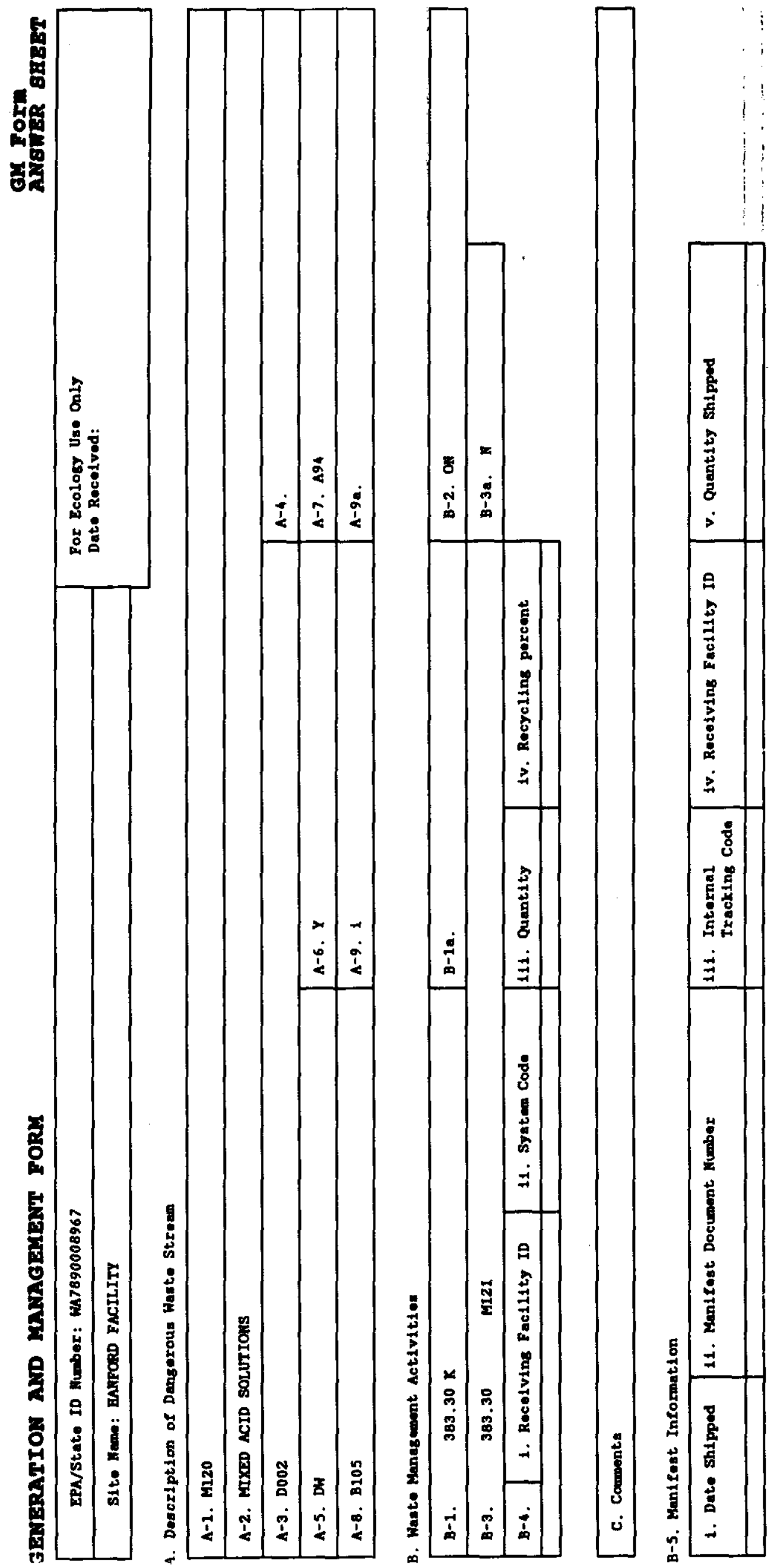




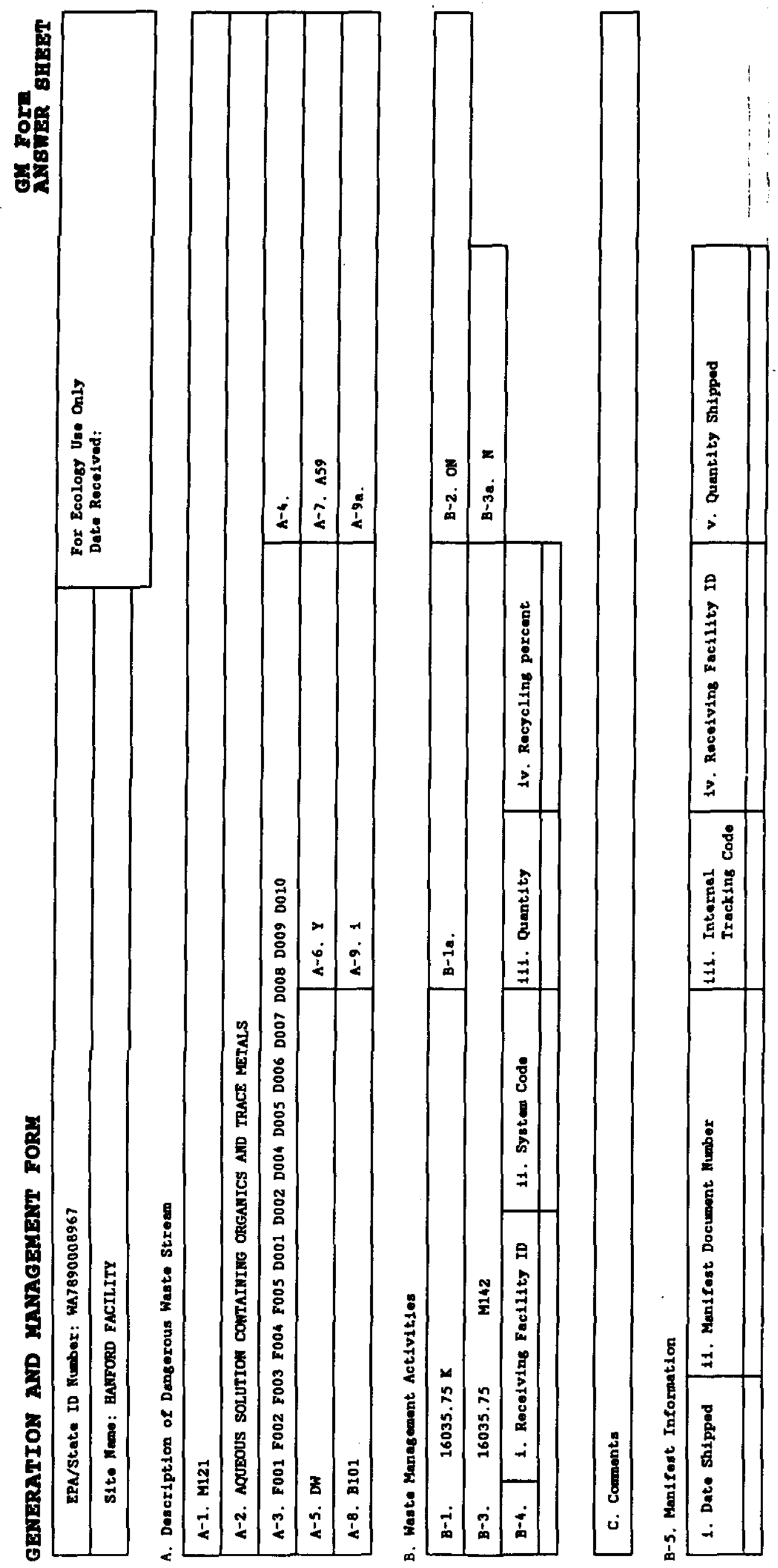



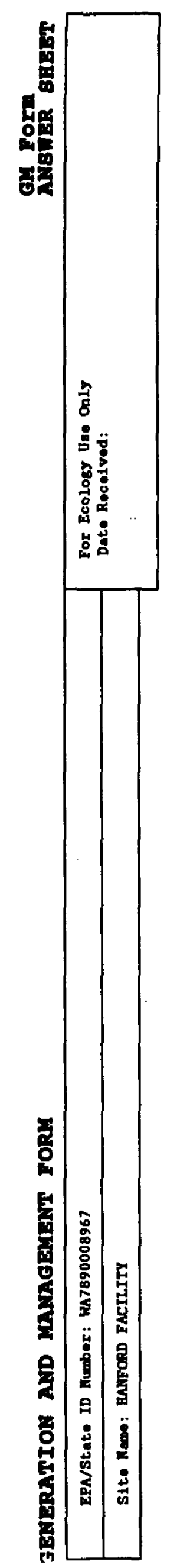
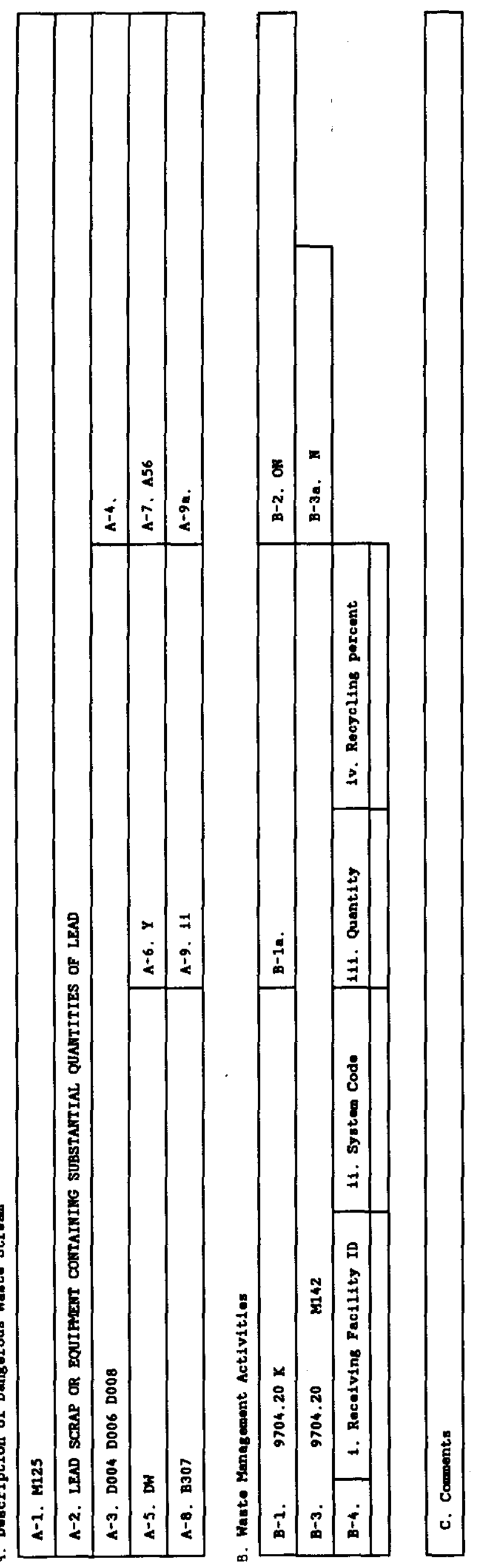
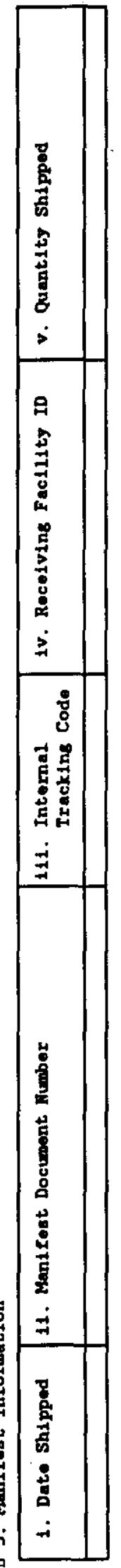


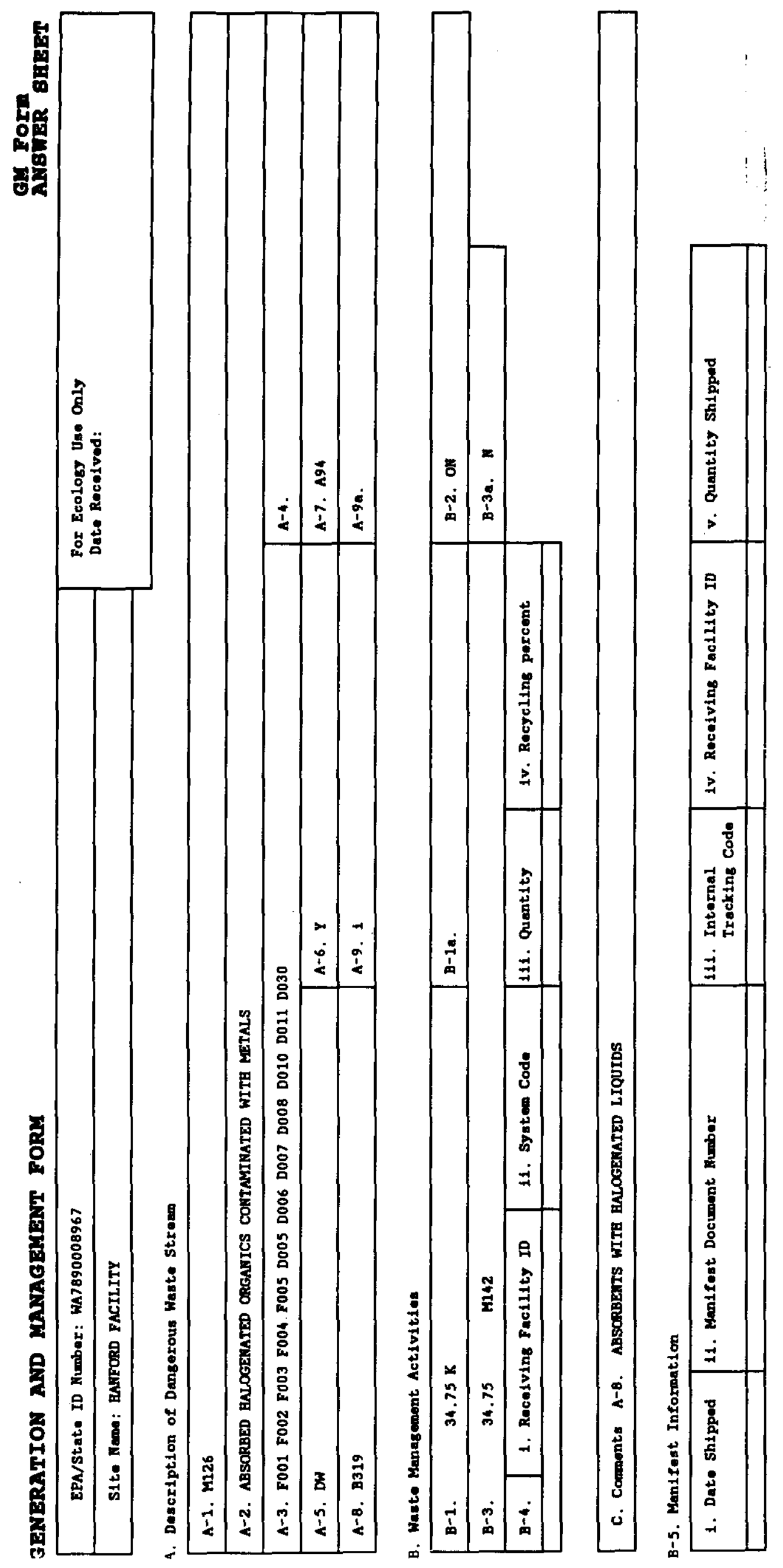




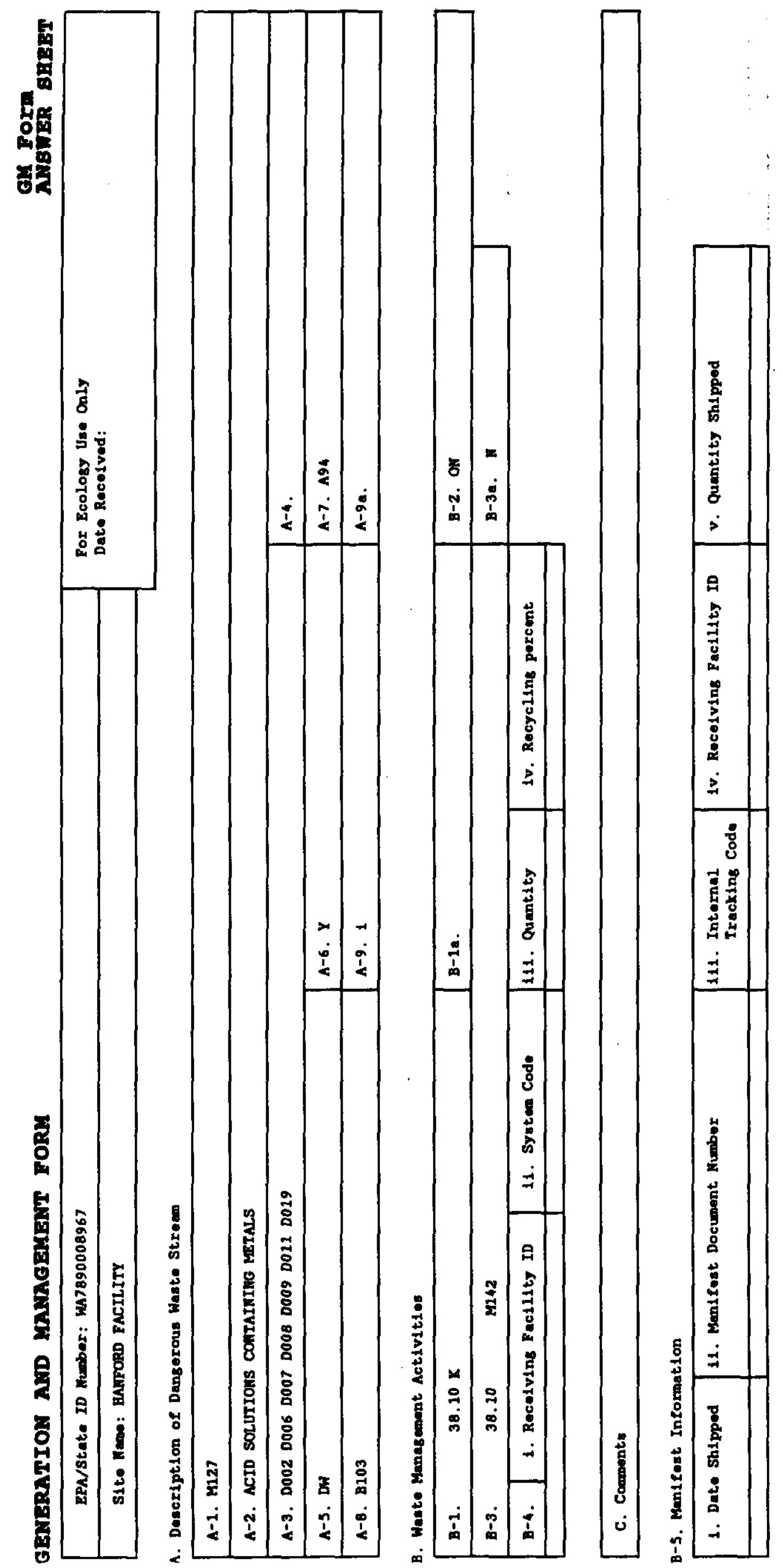




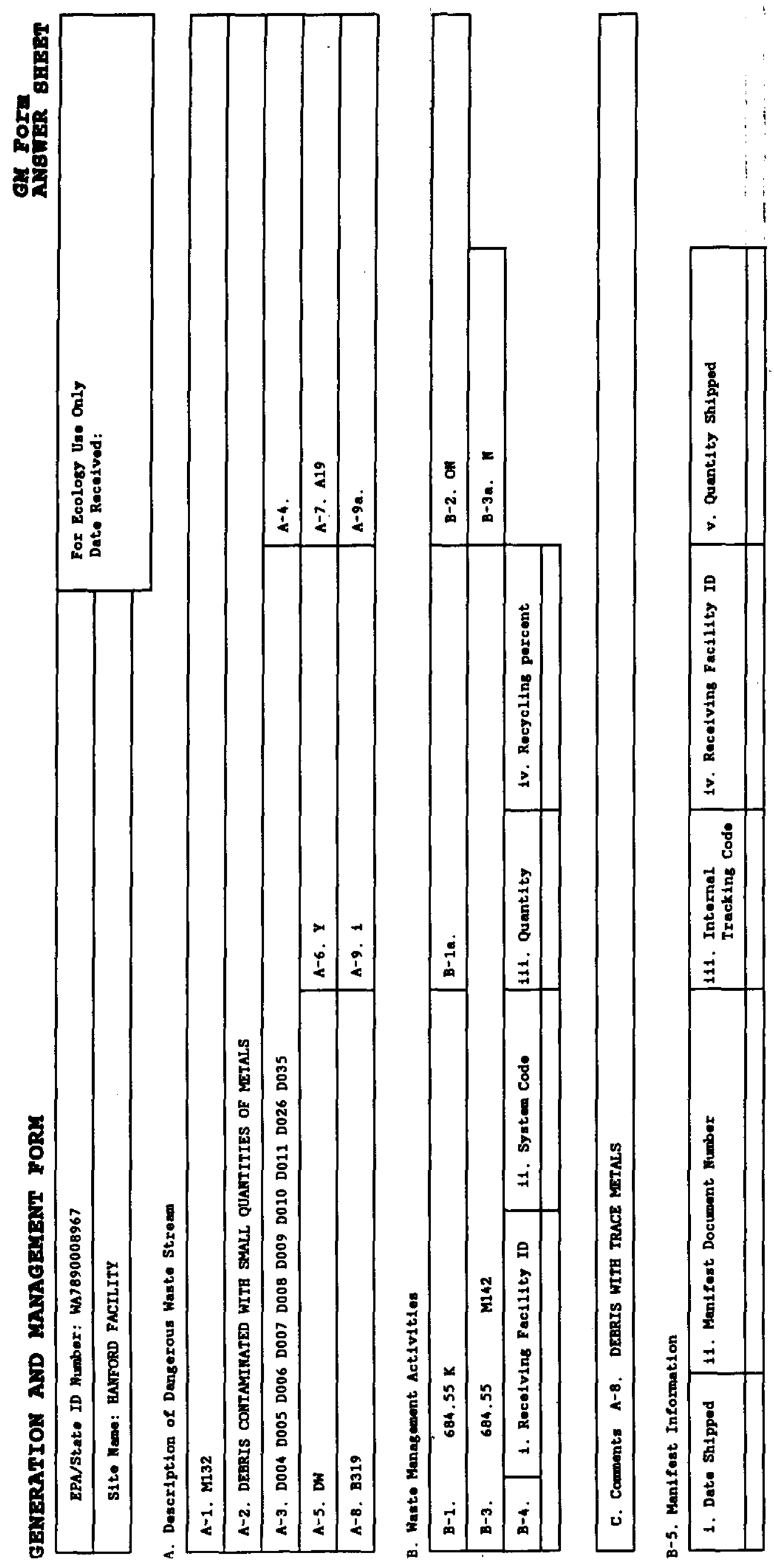




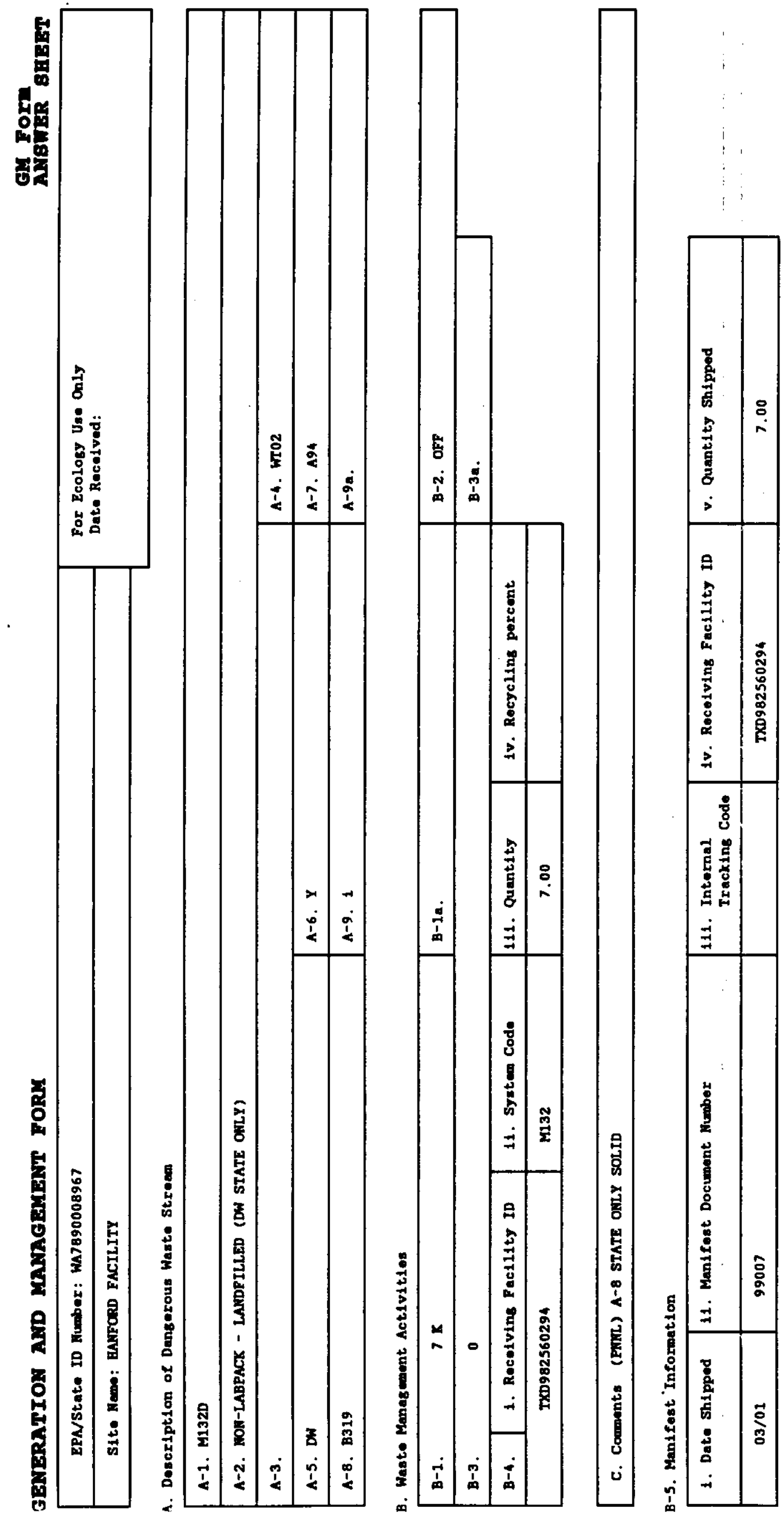




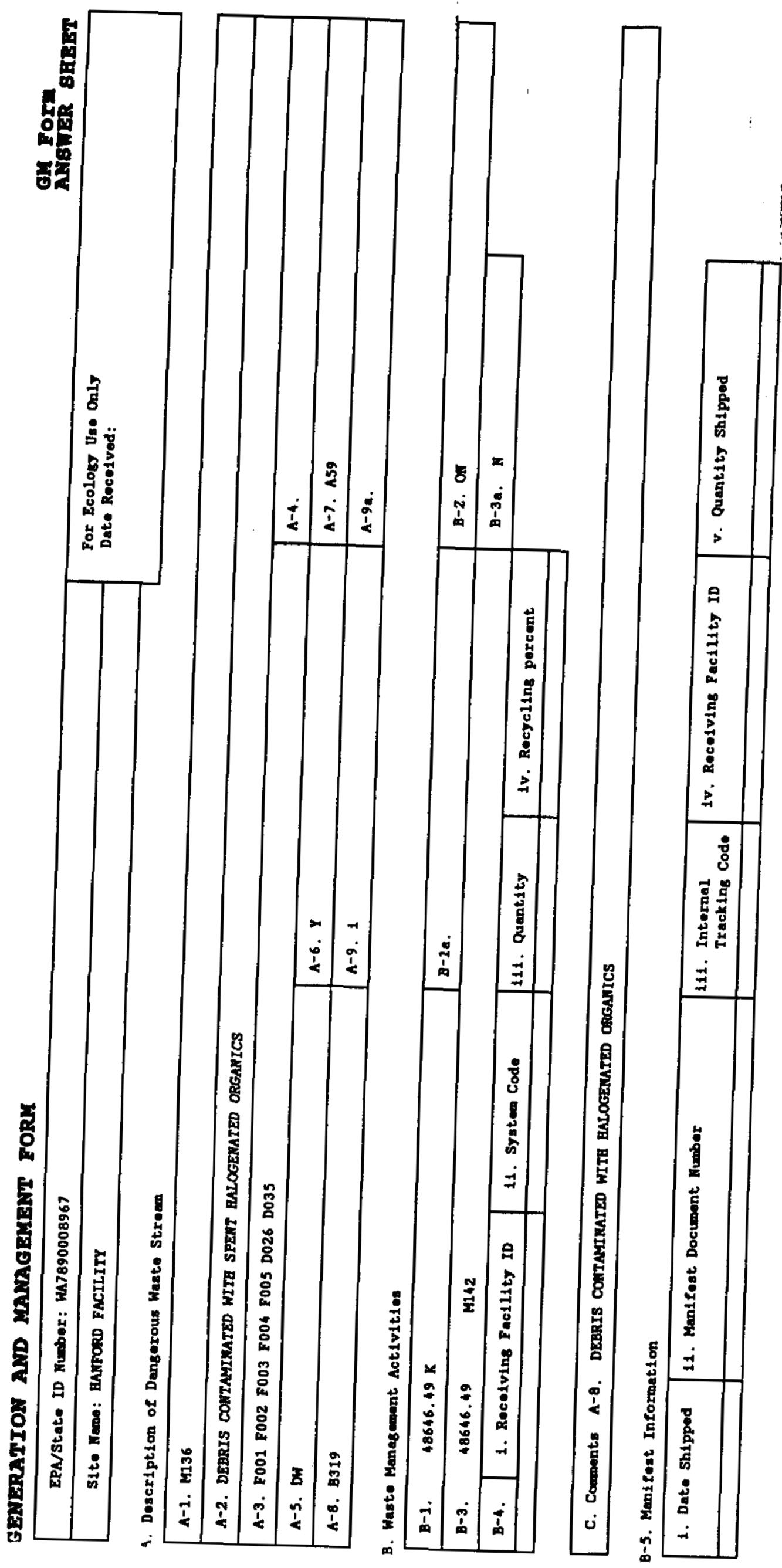

: 


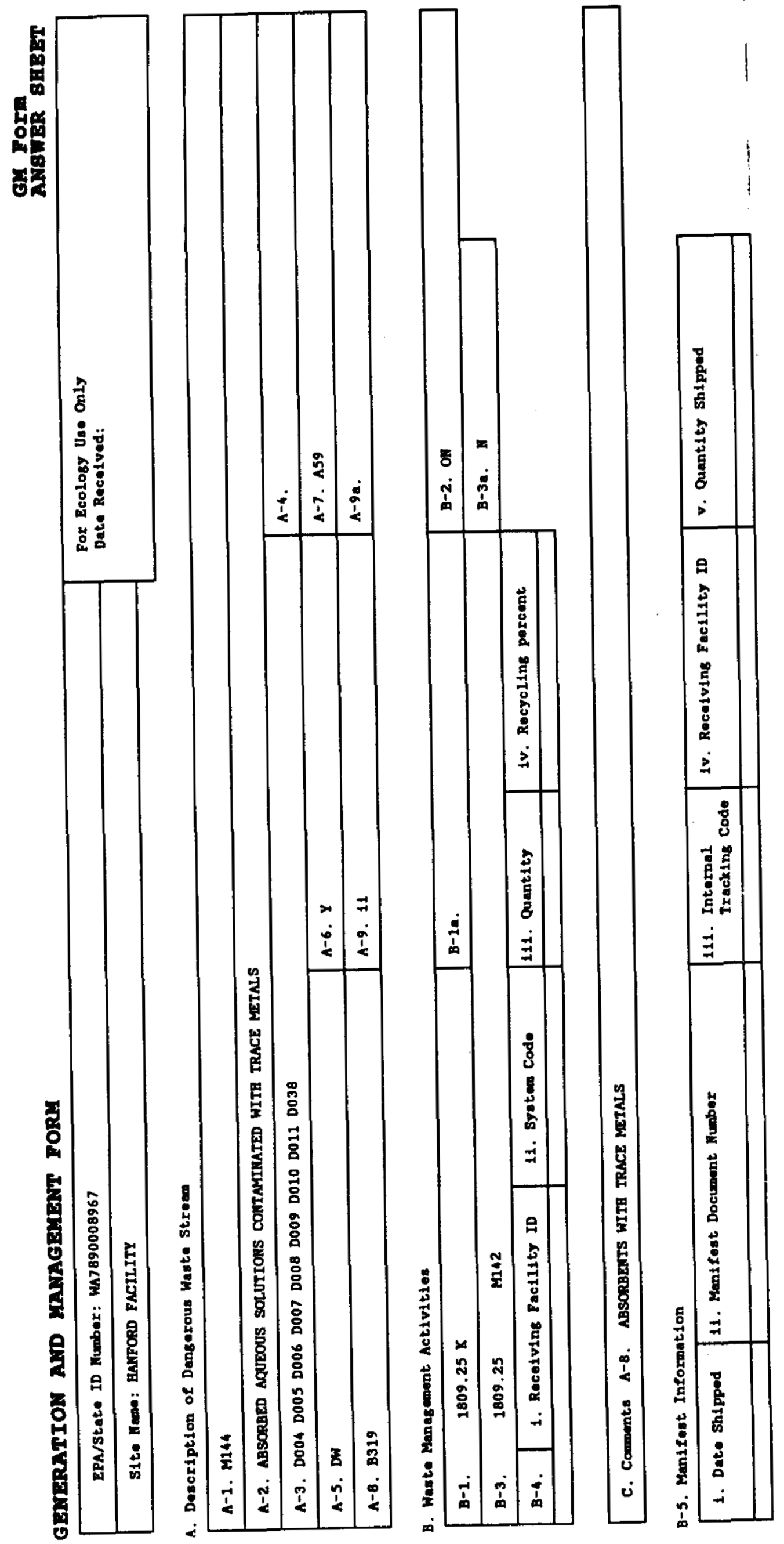



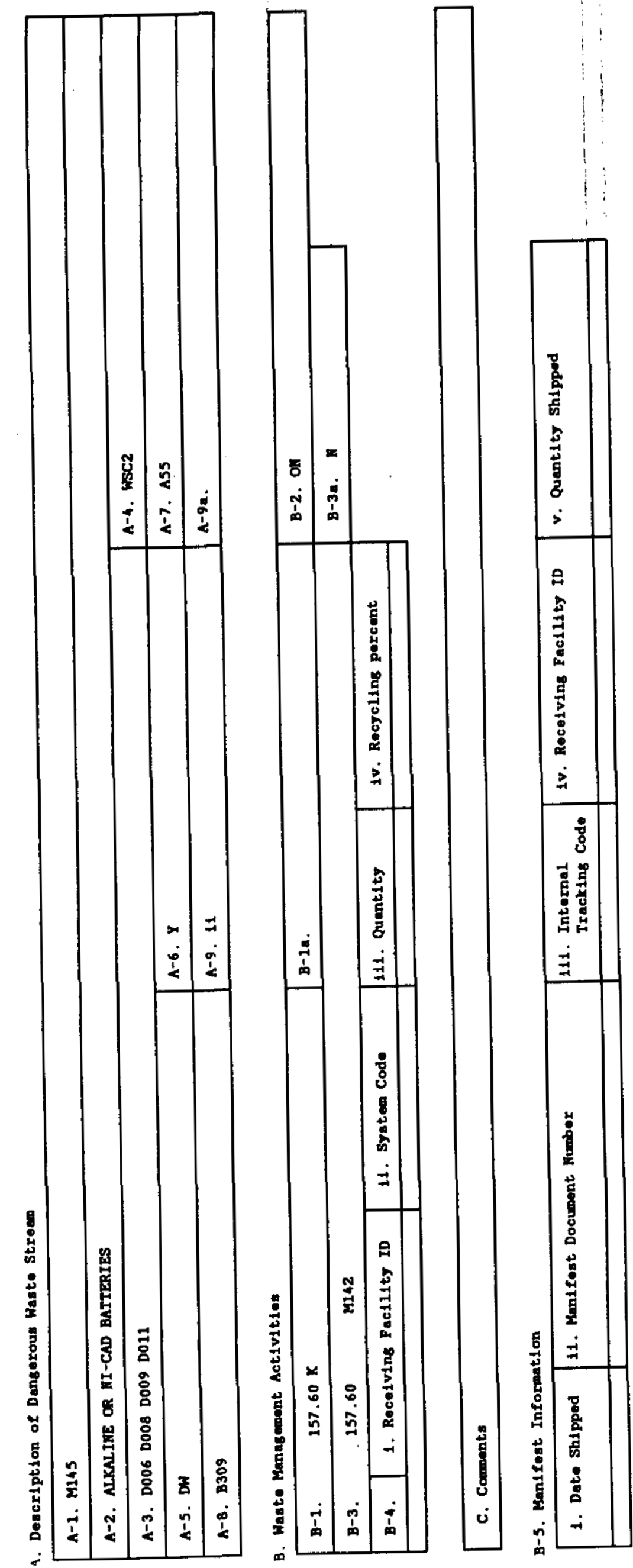

๙ั
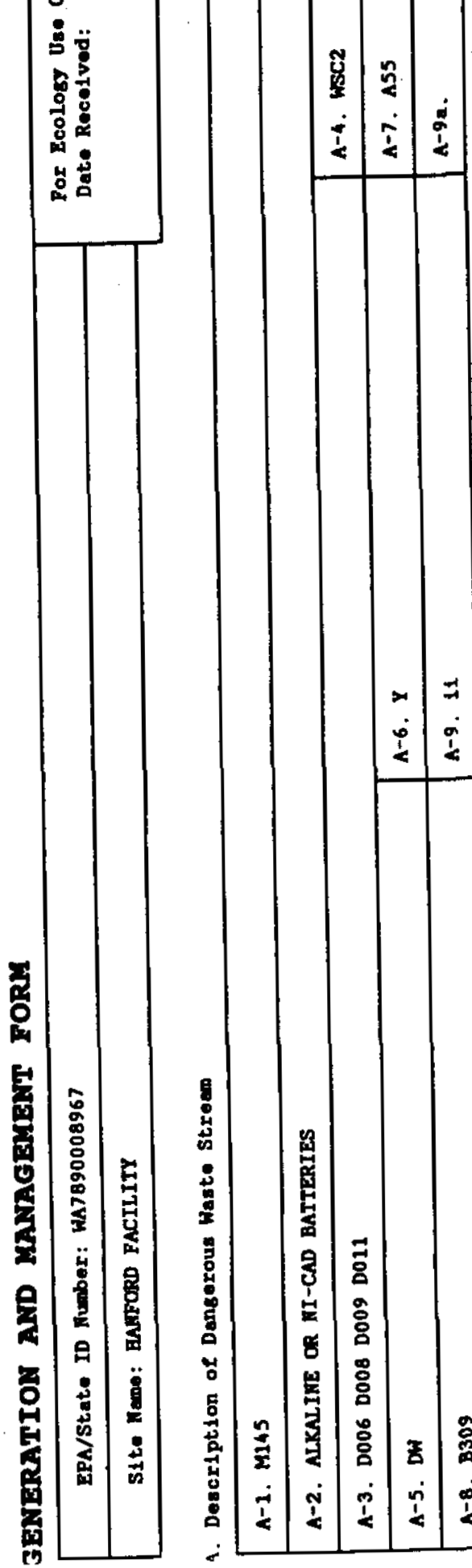

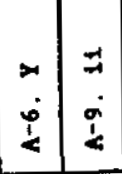

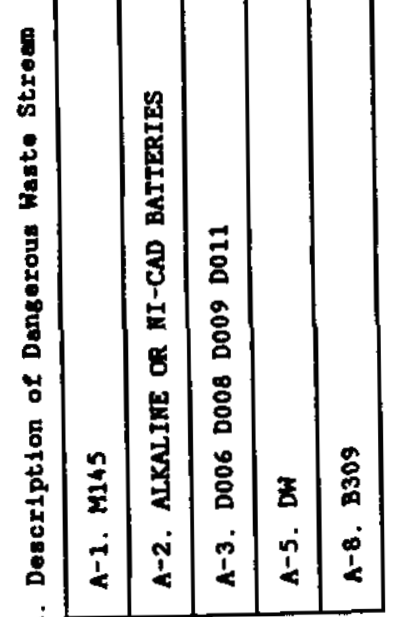




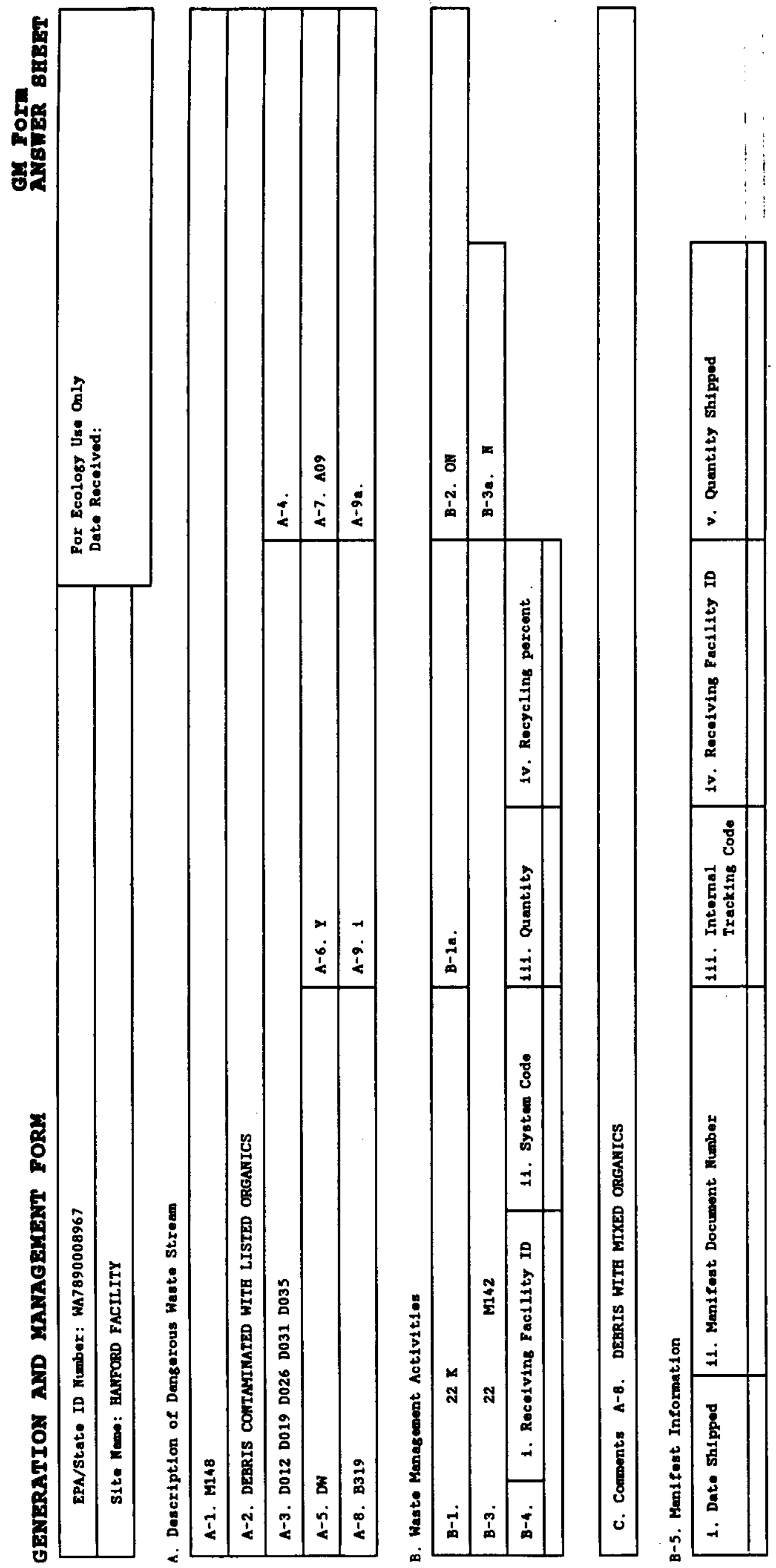




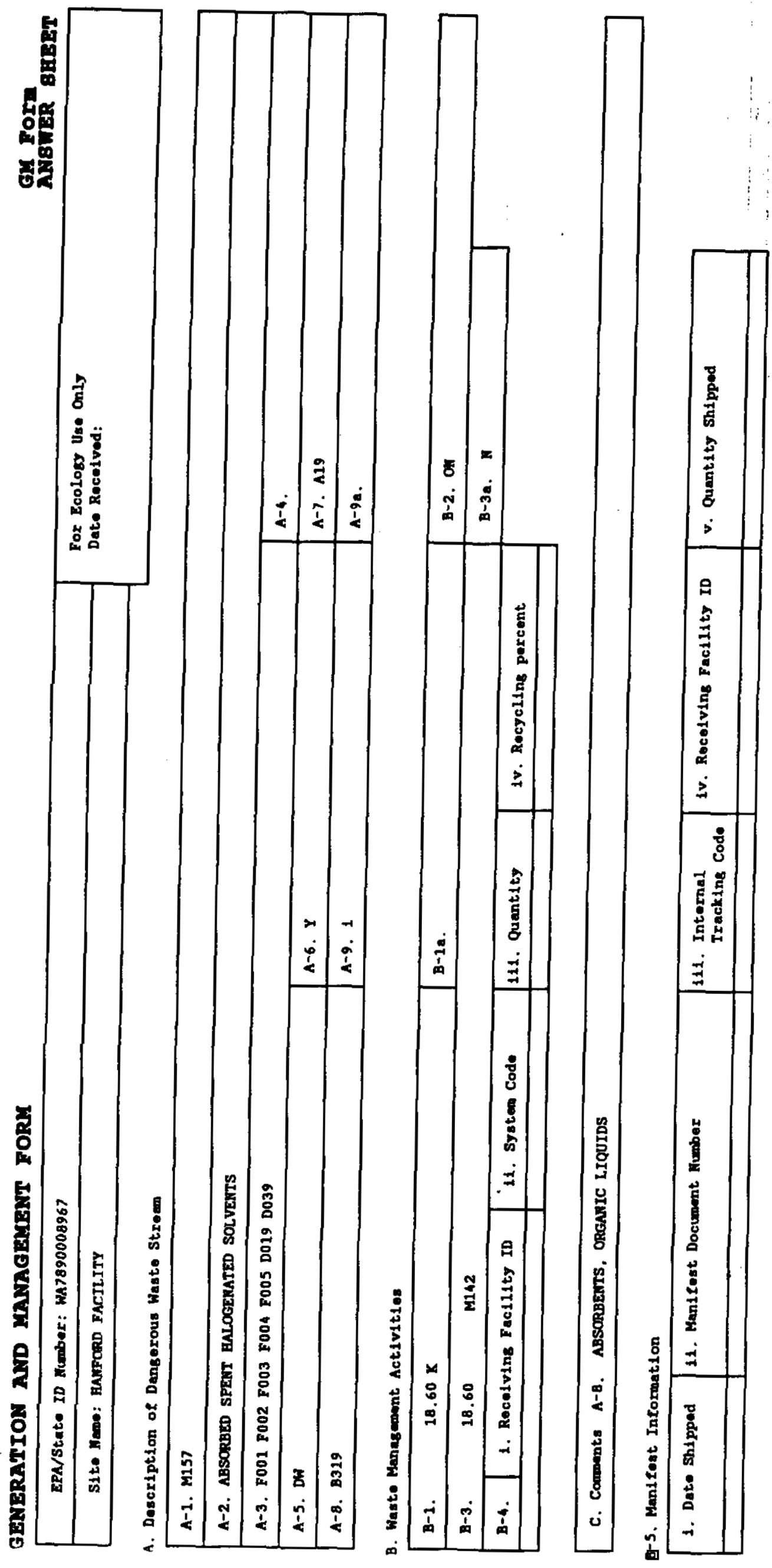




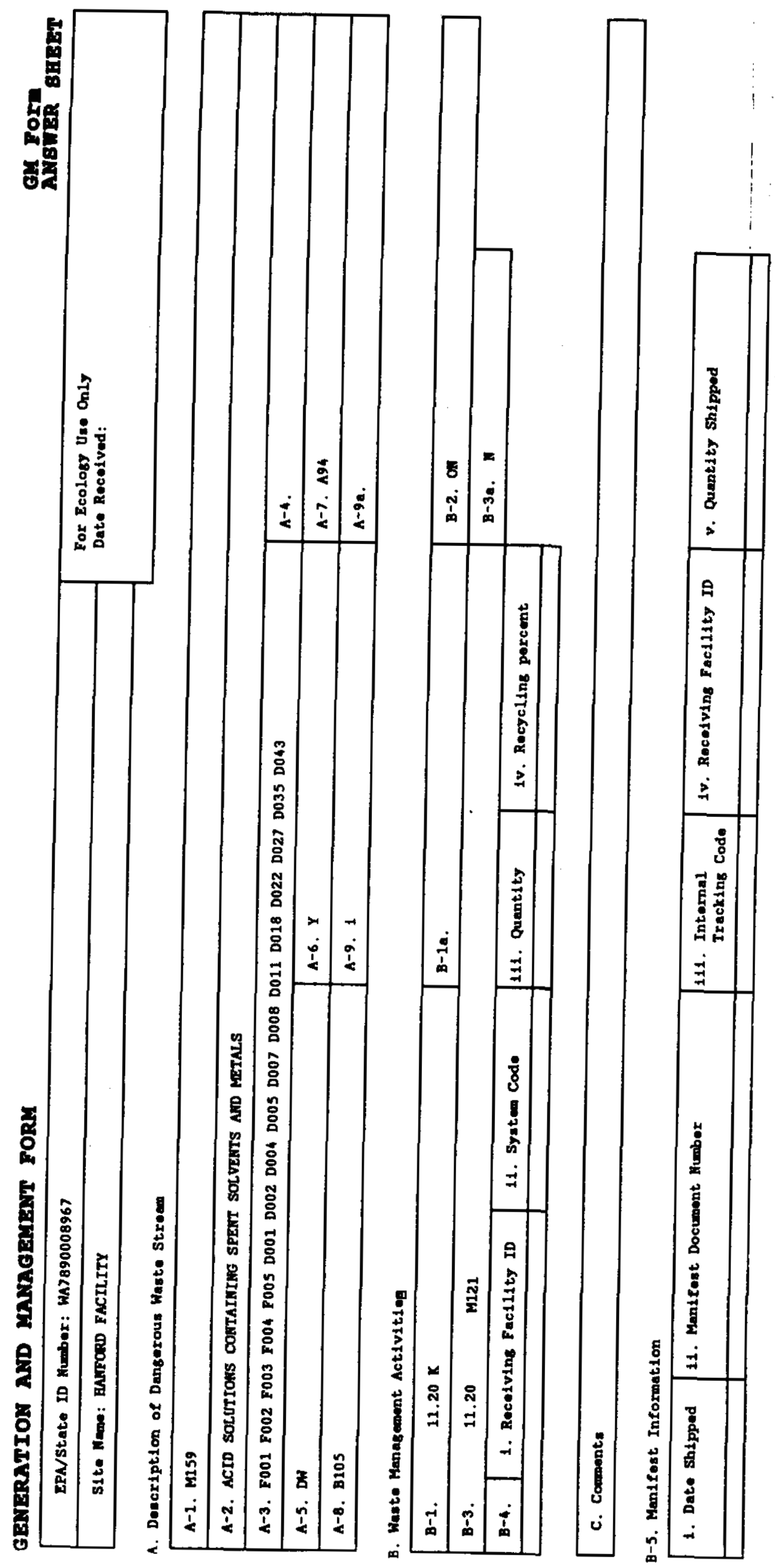




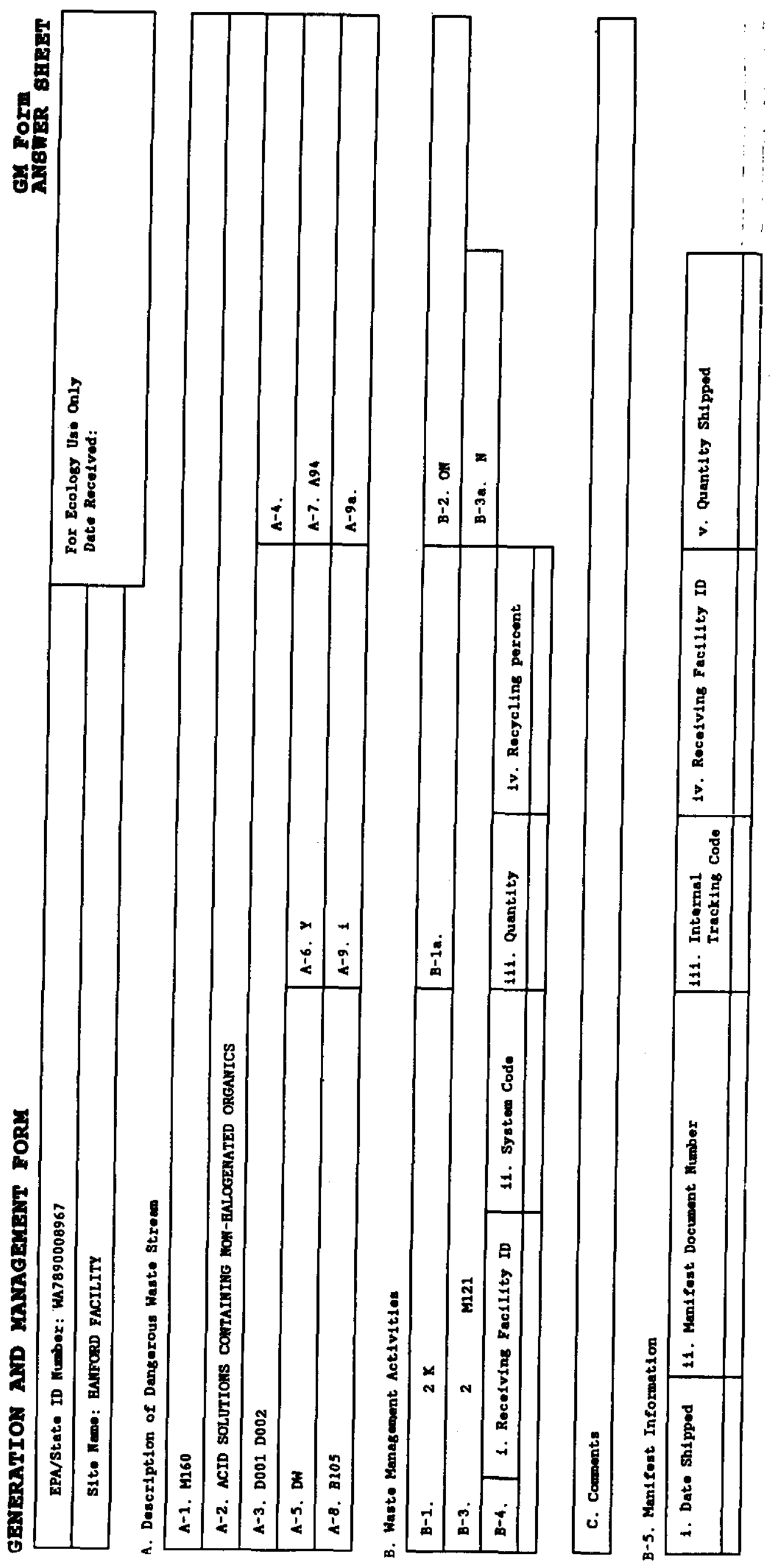




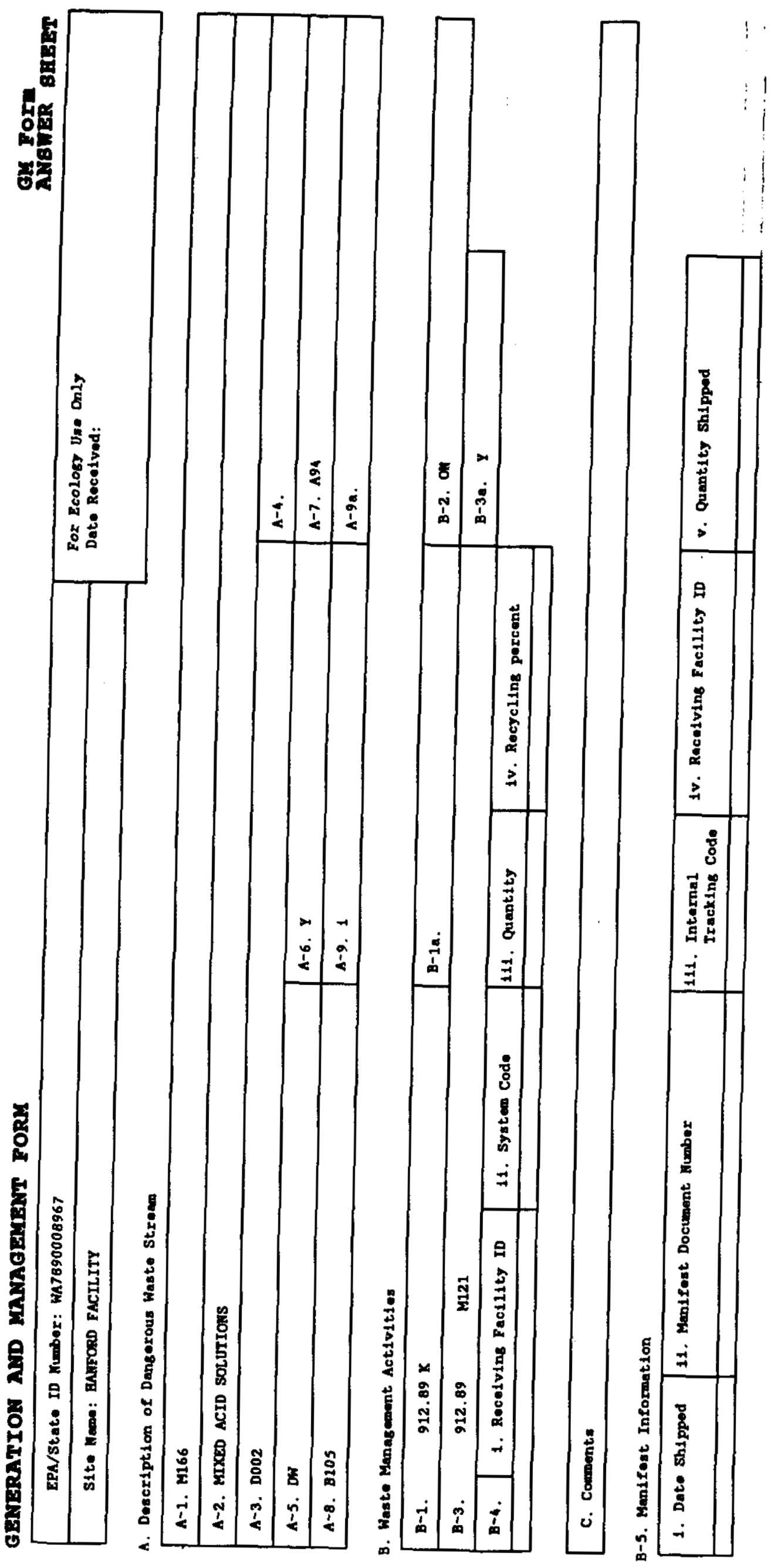




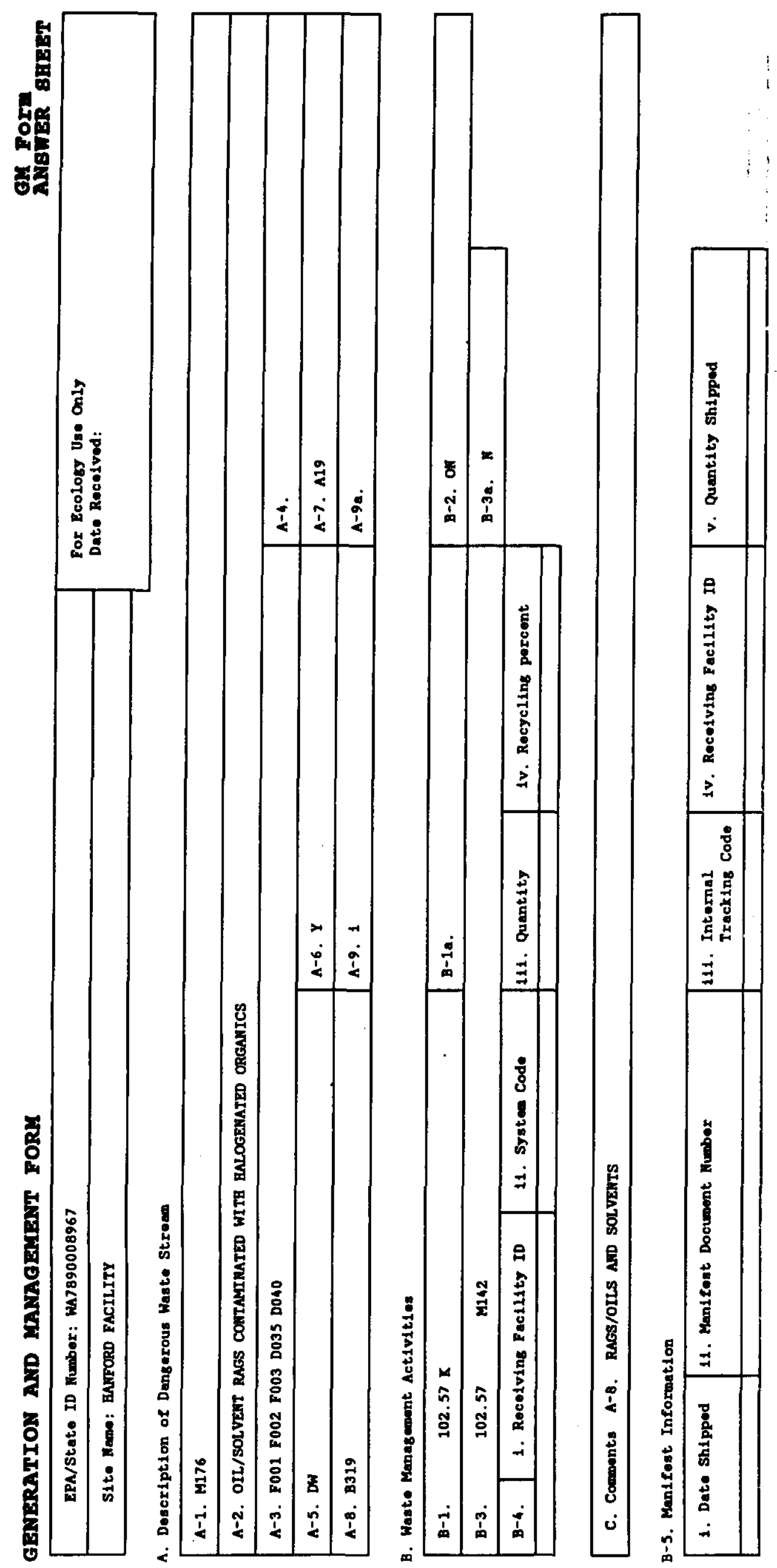




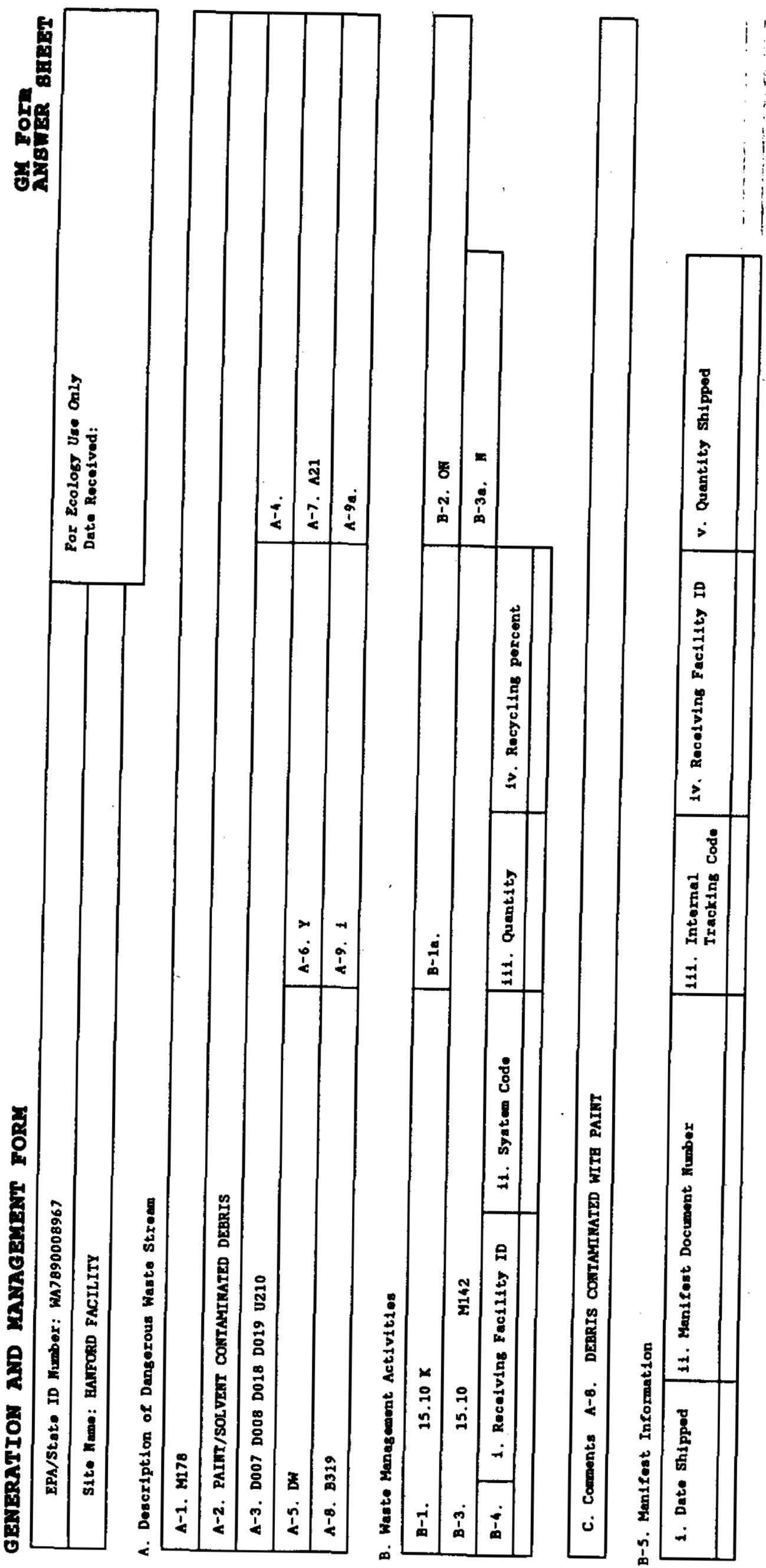




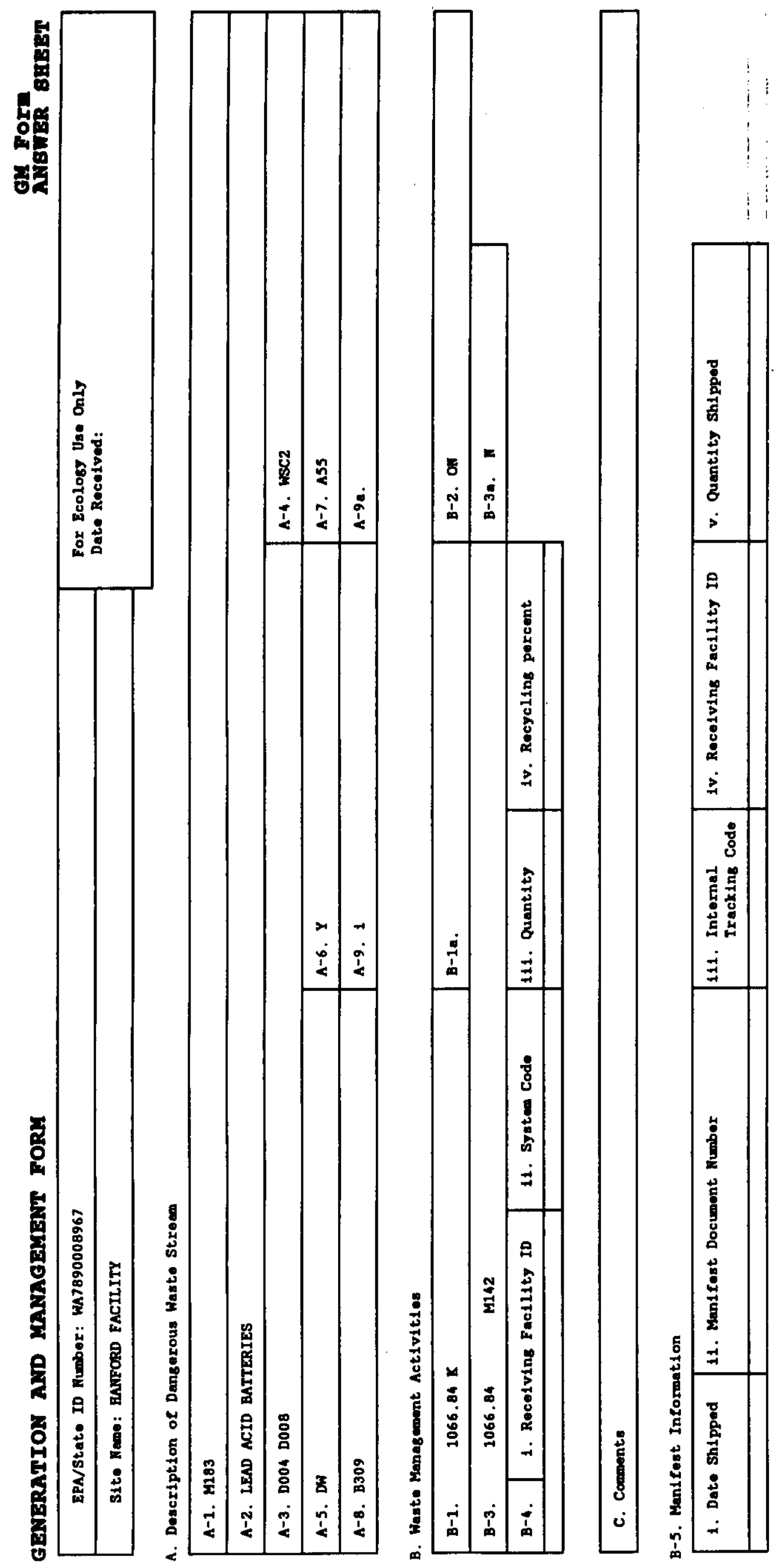



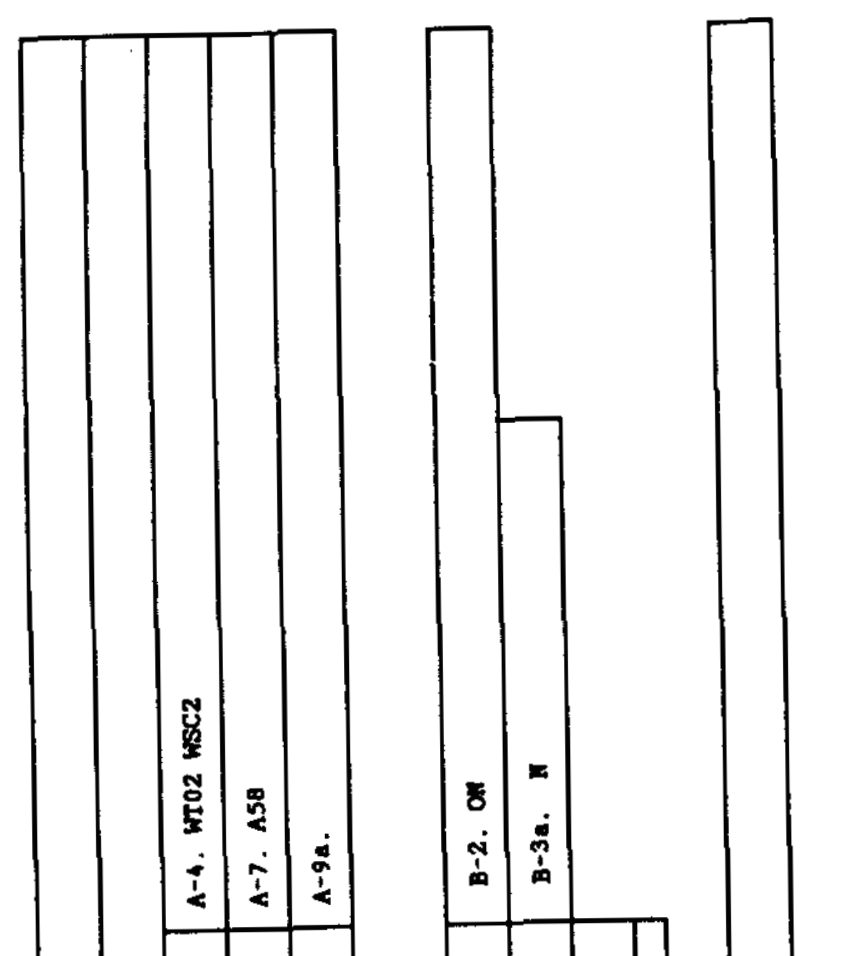

ป
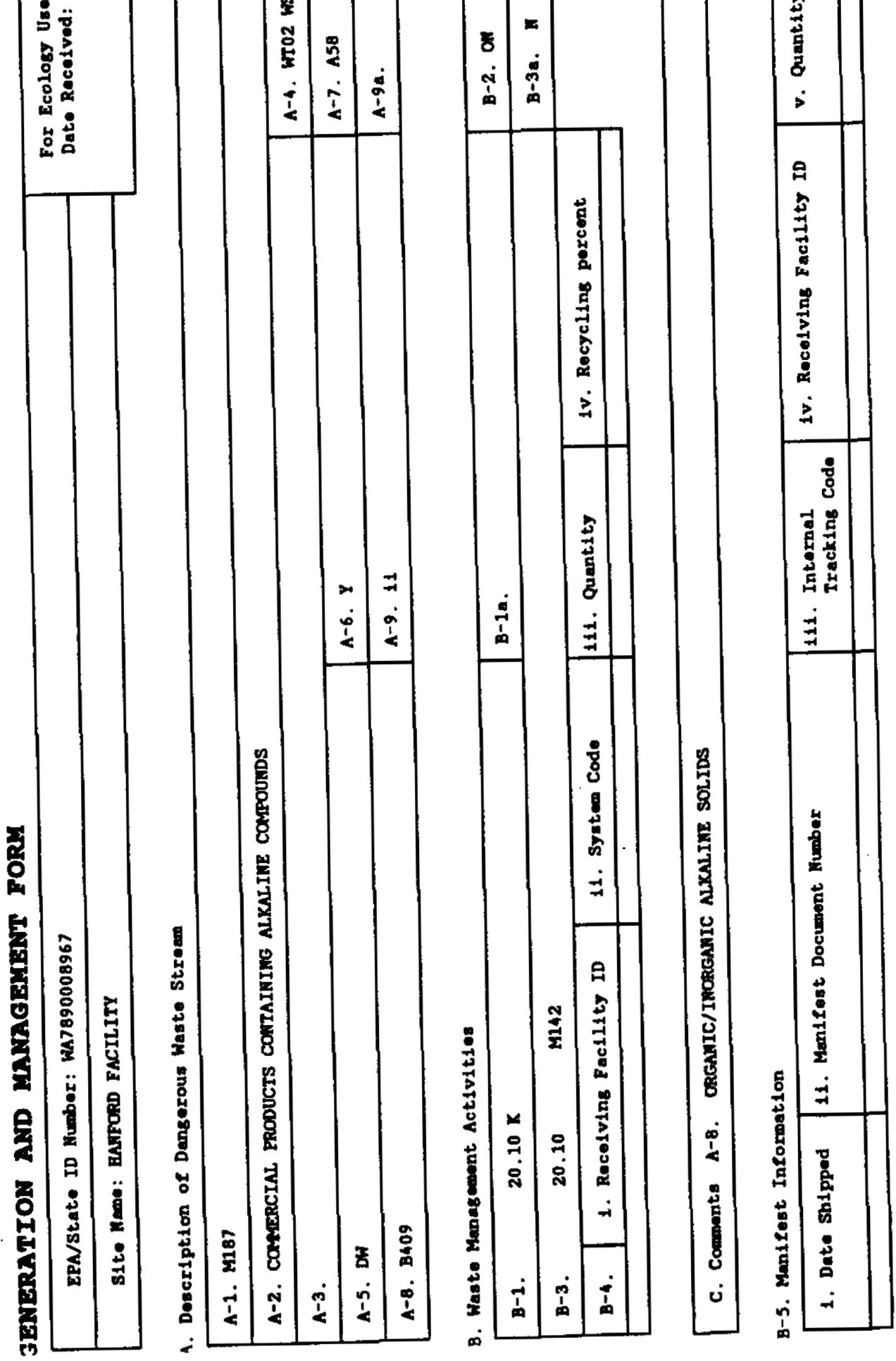


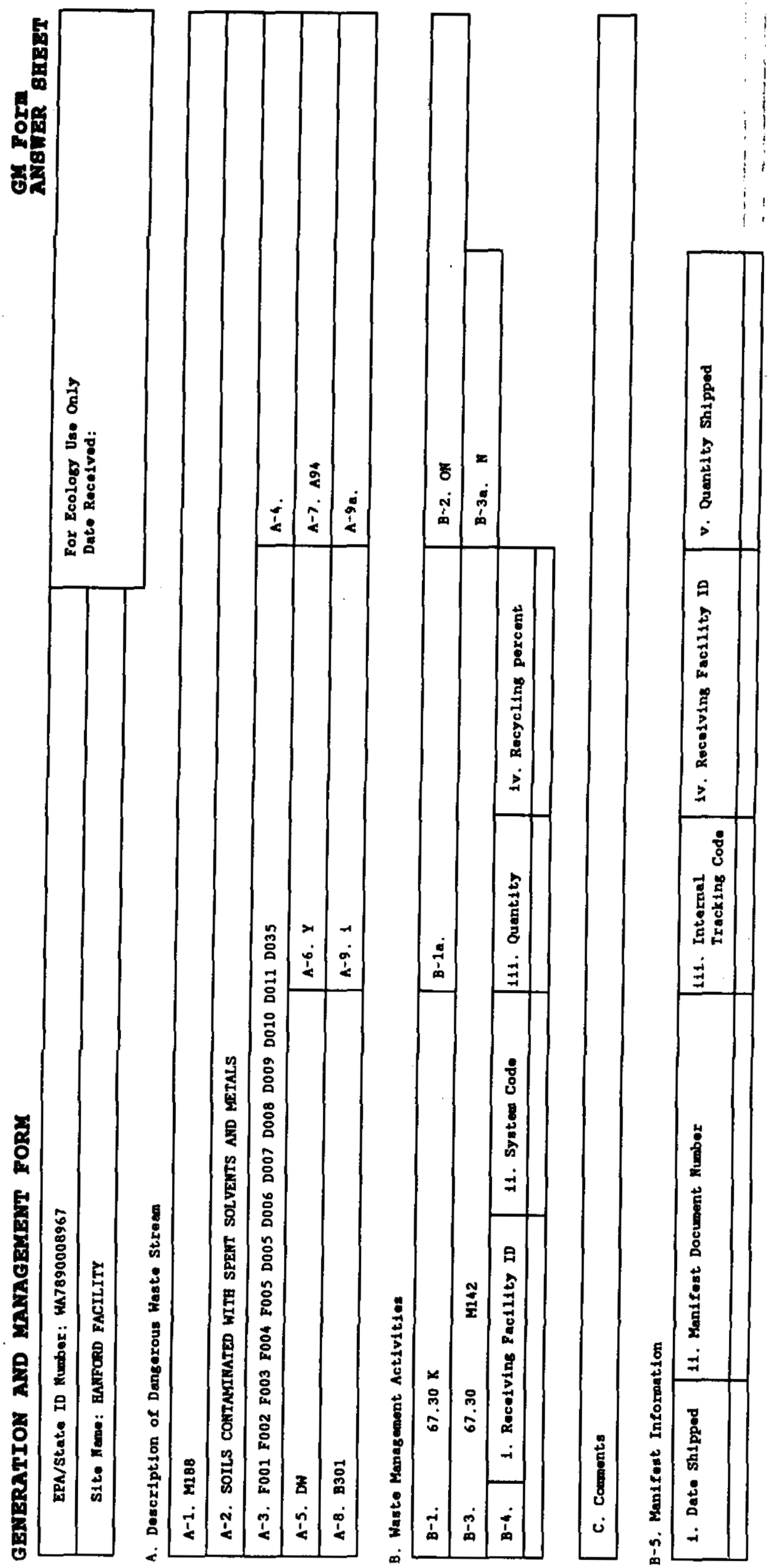




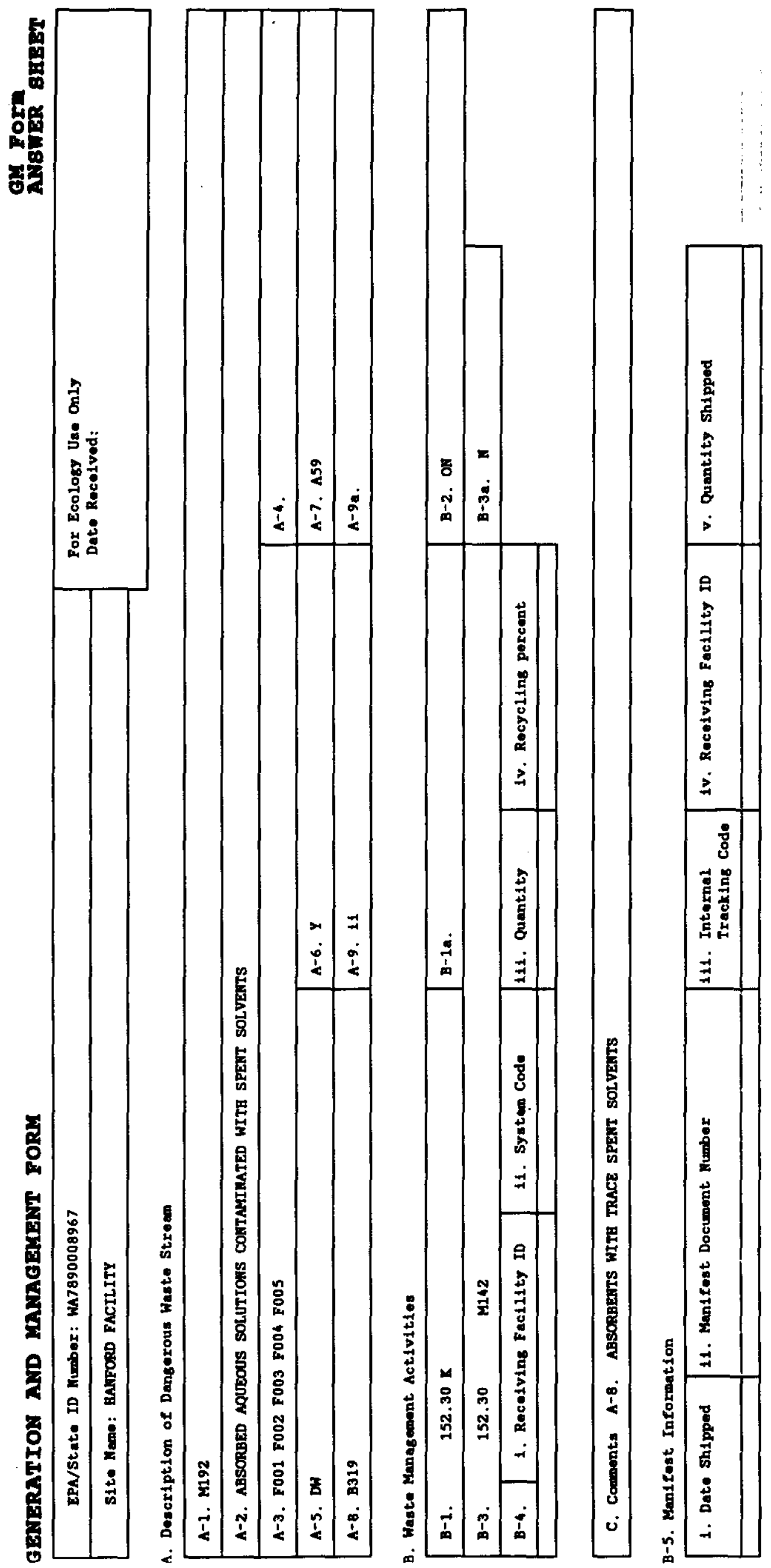




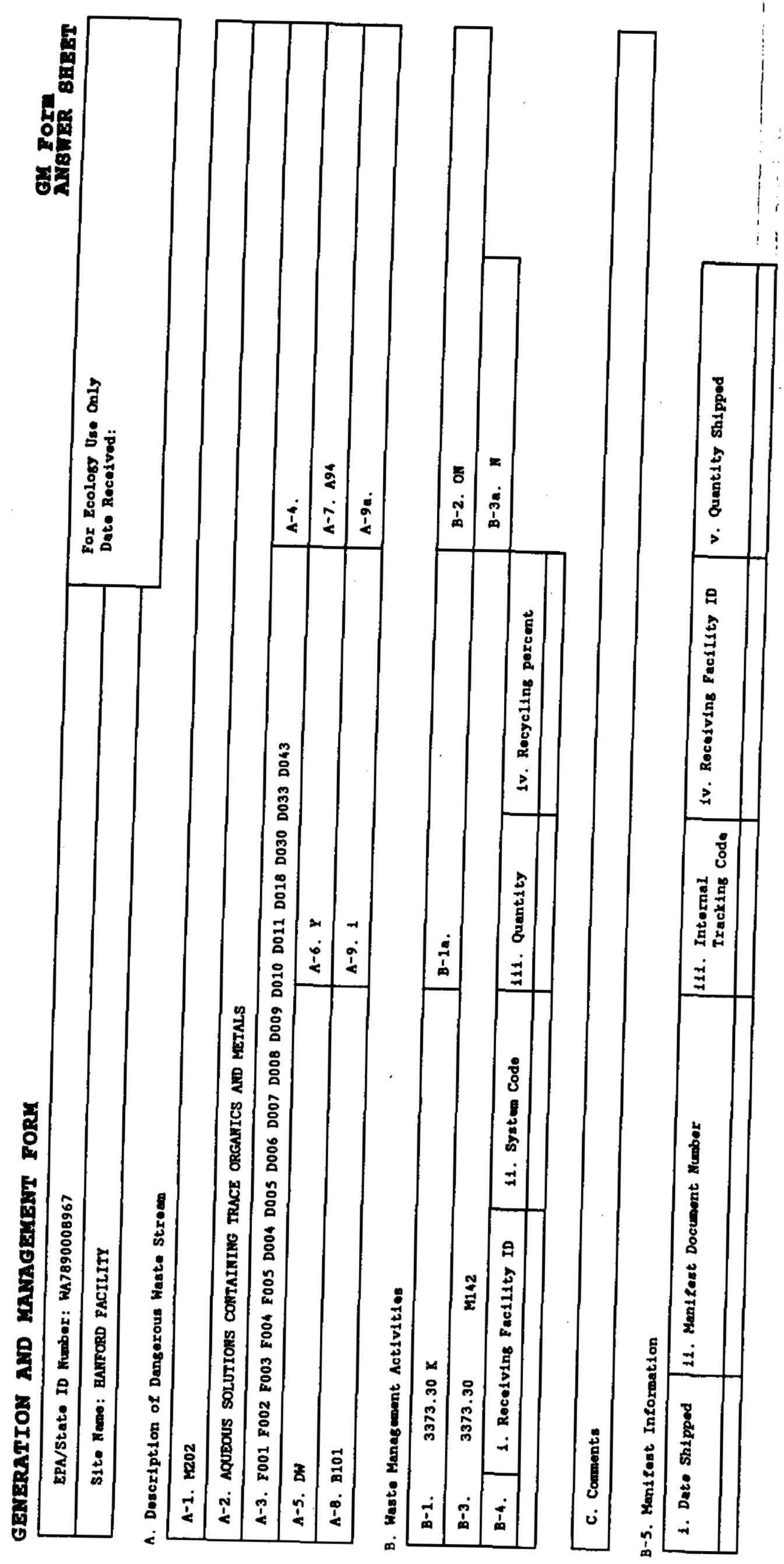



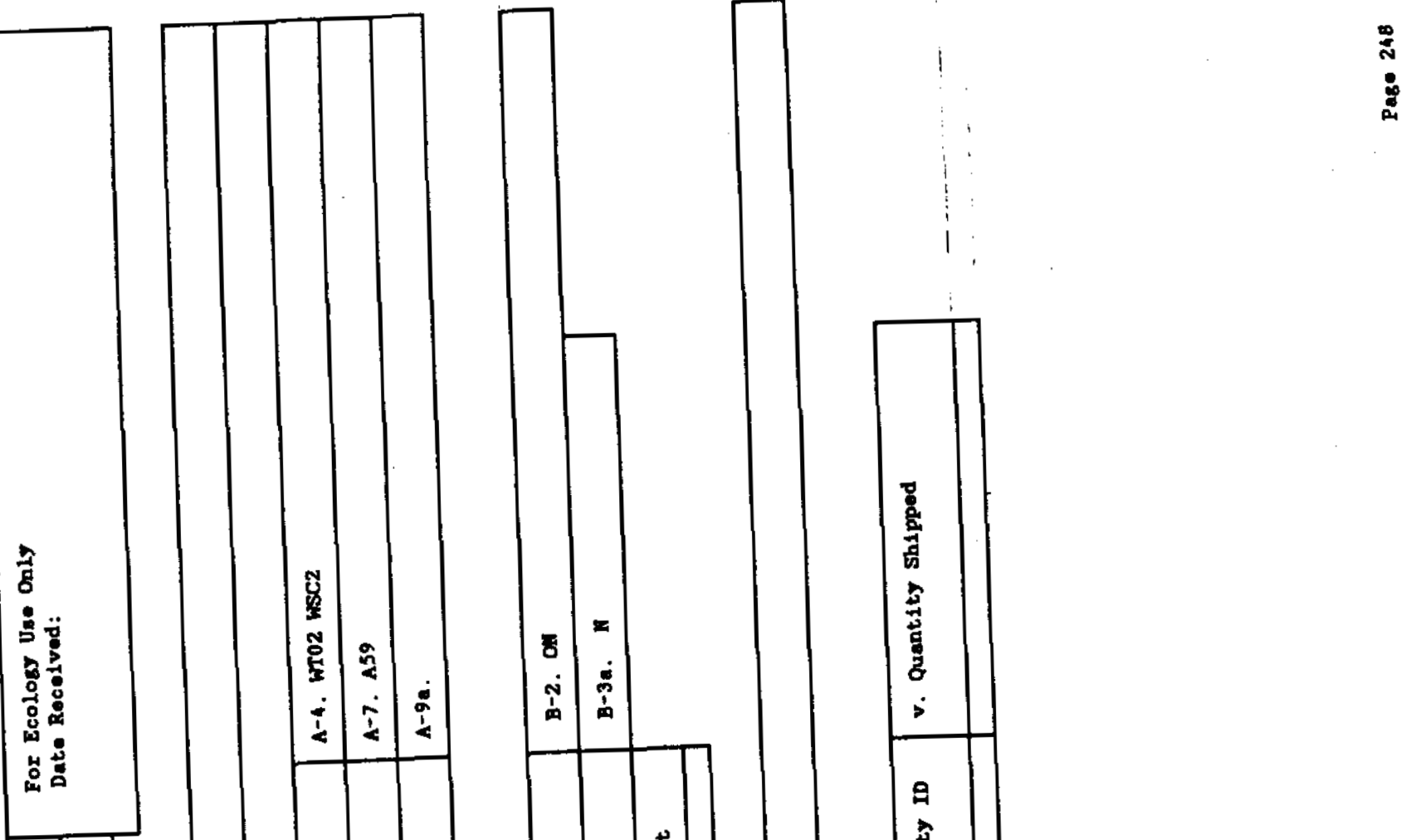

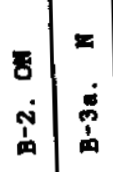

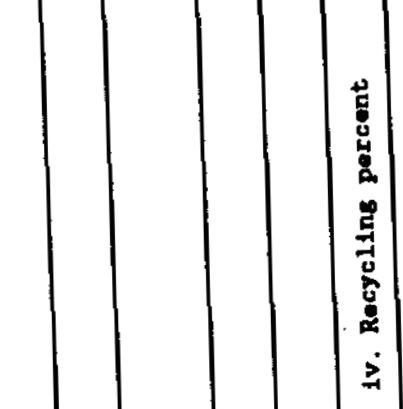

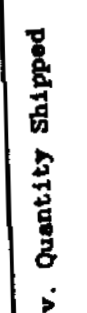
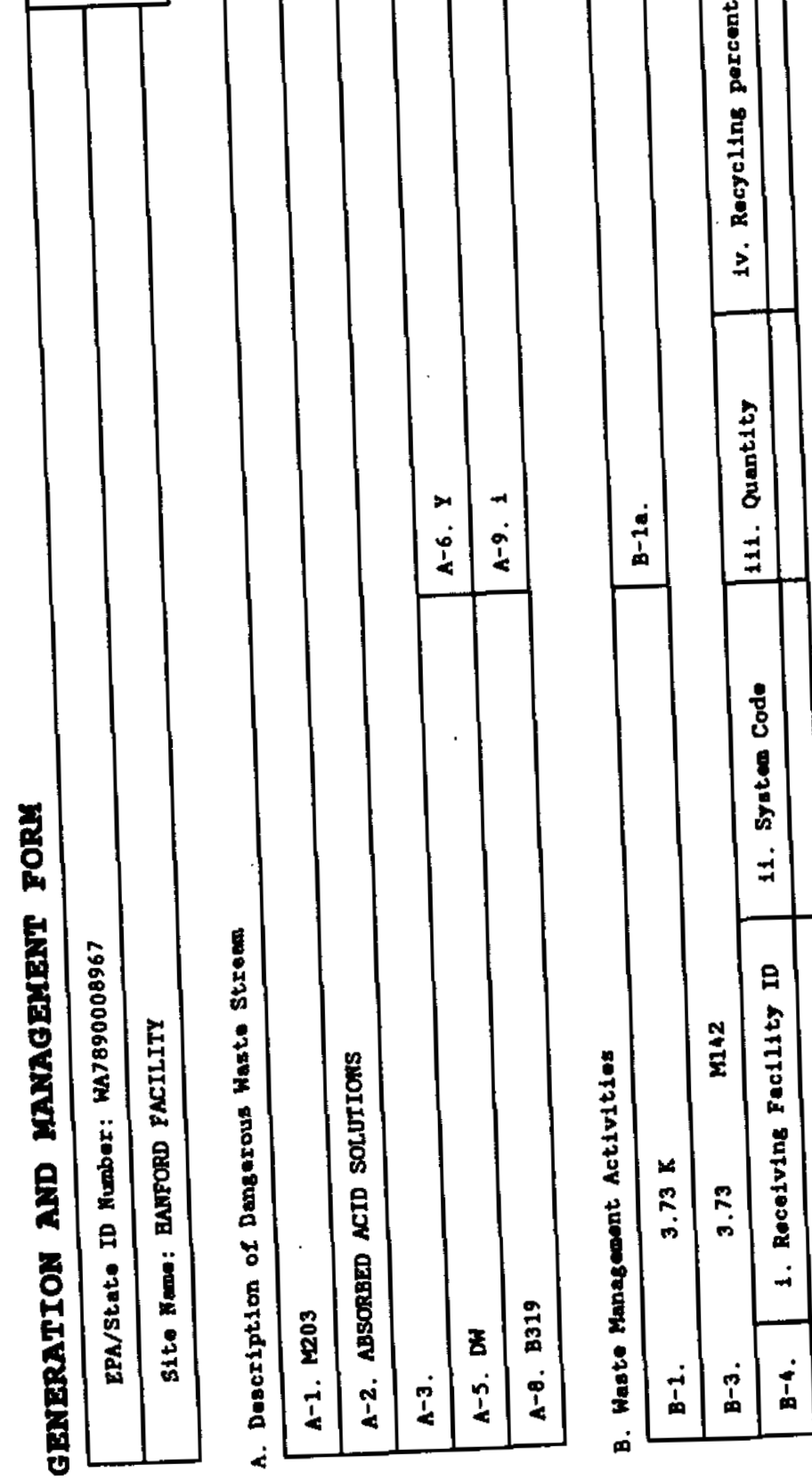

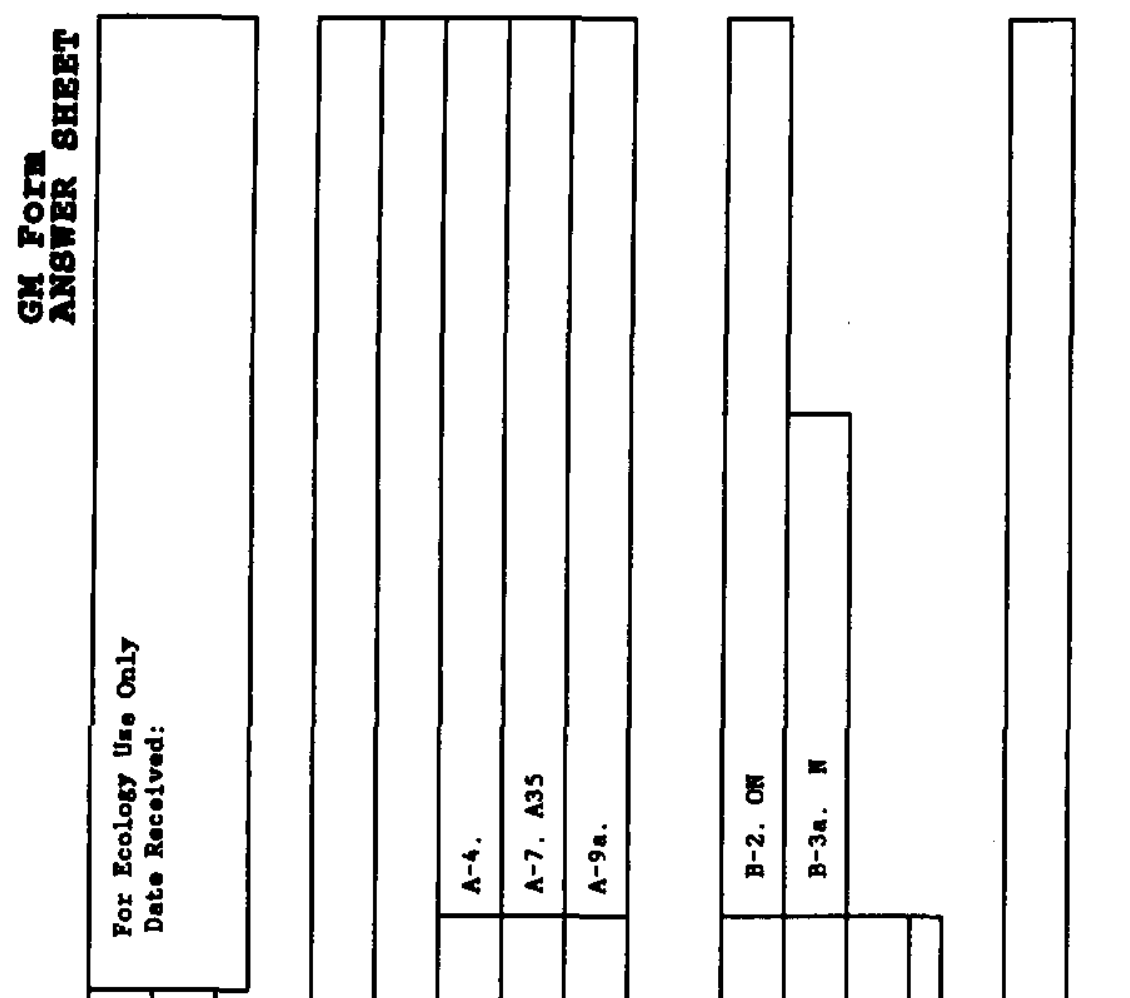

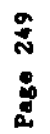
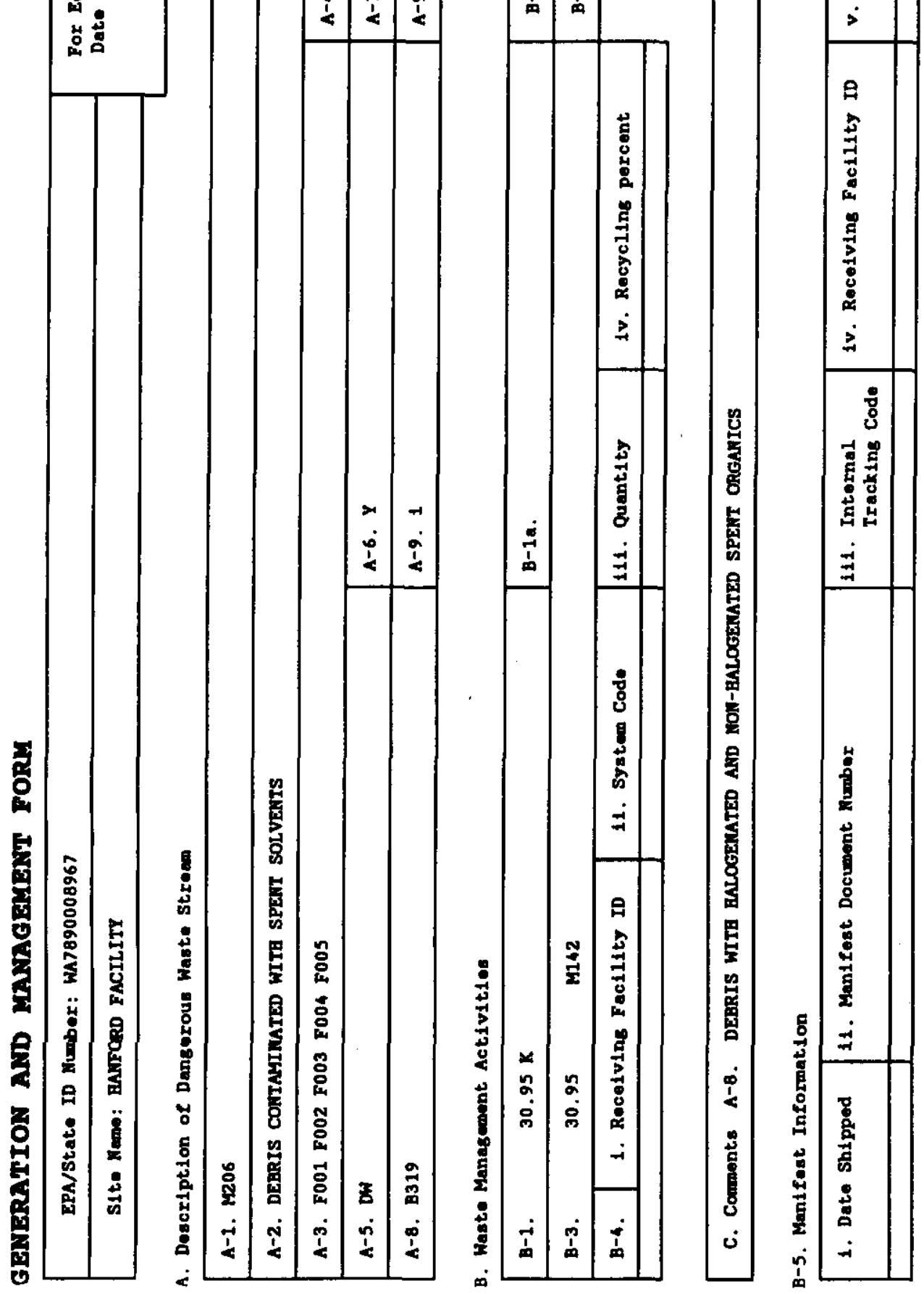


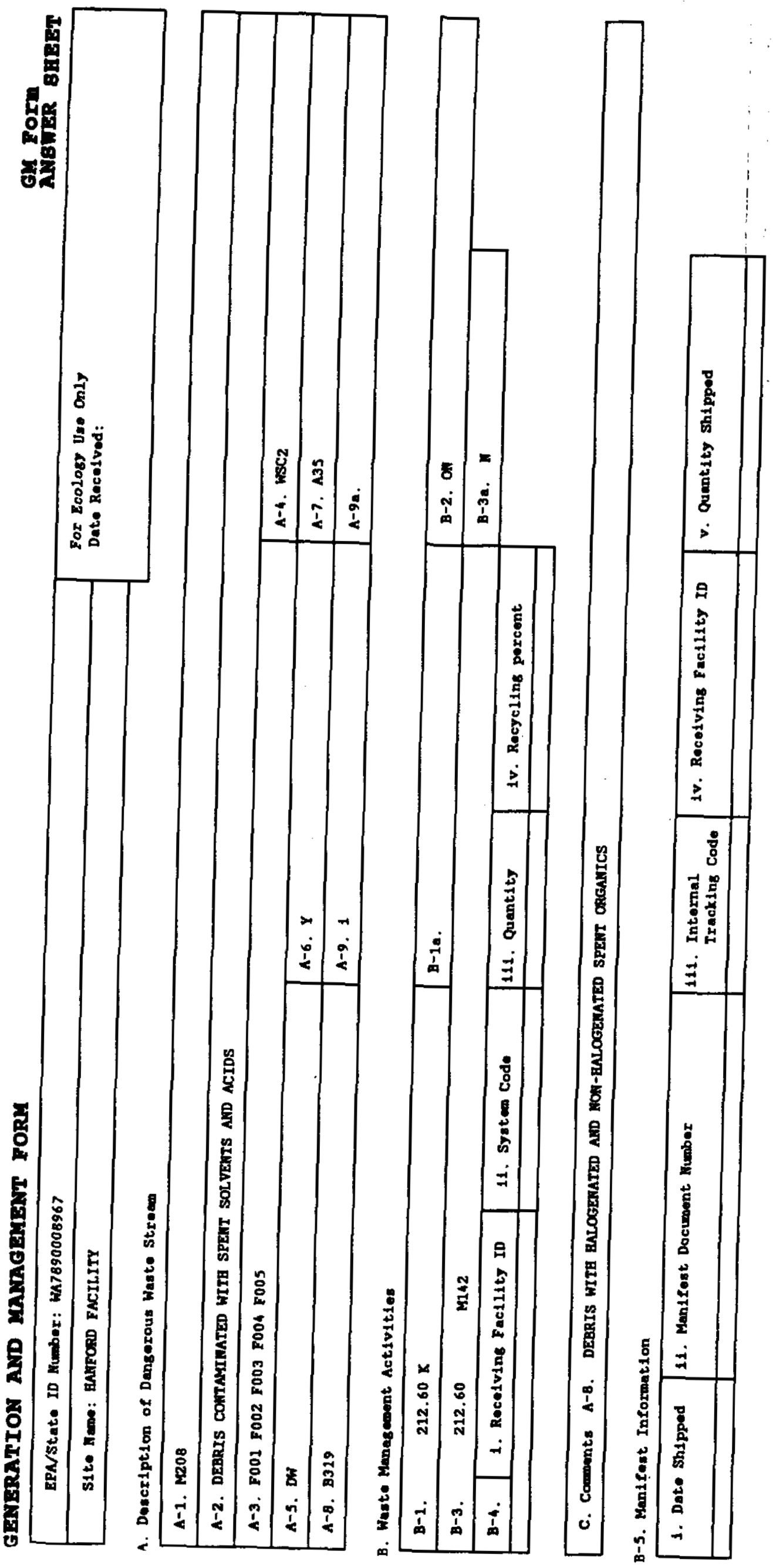




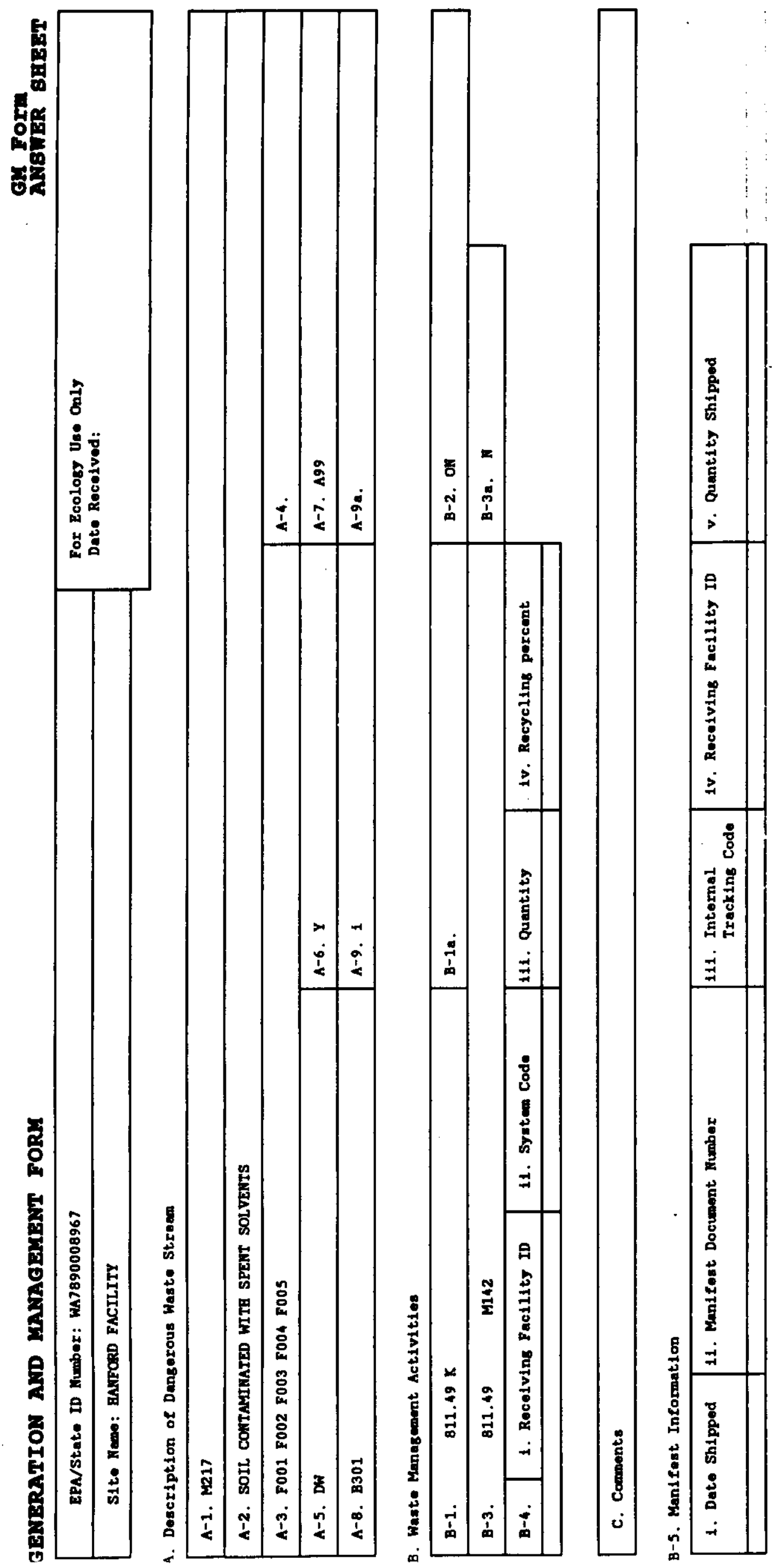




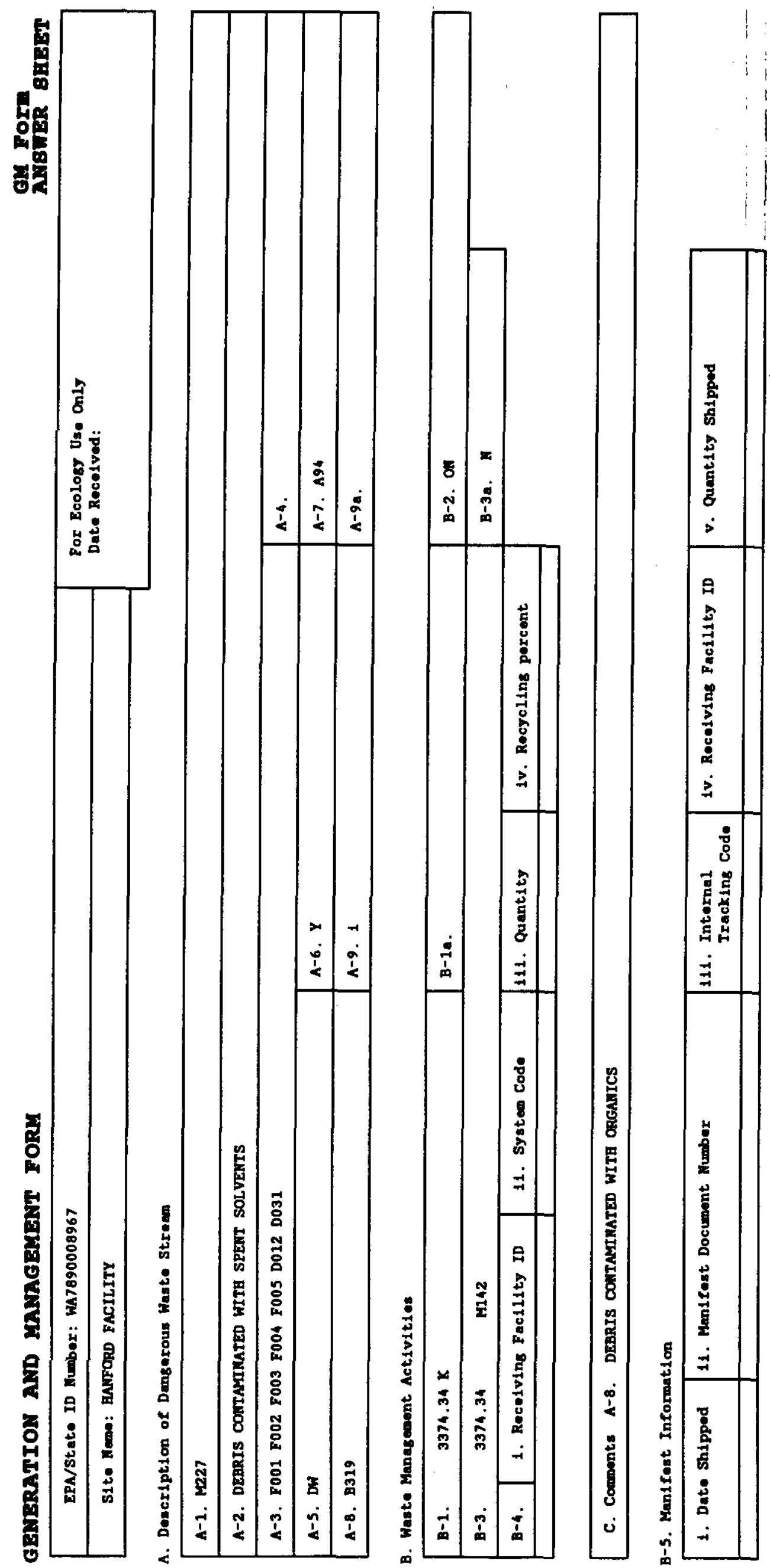




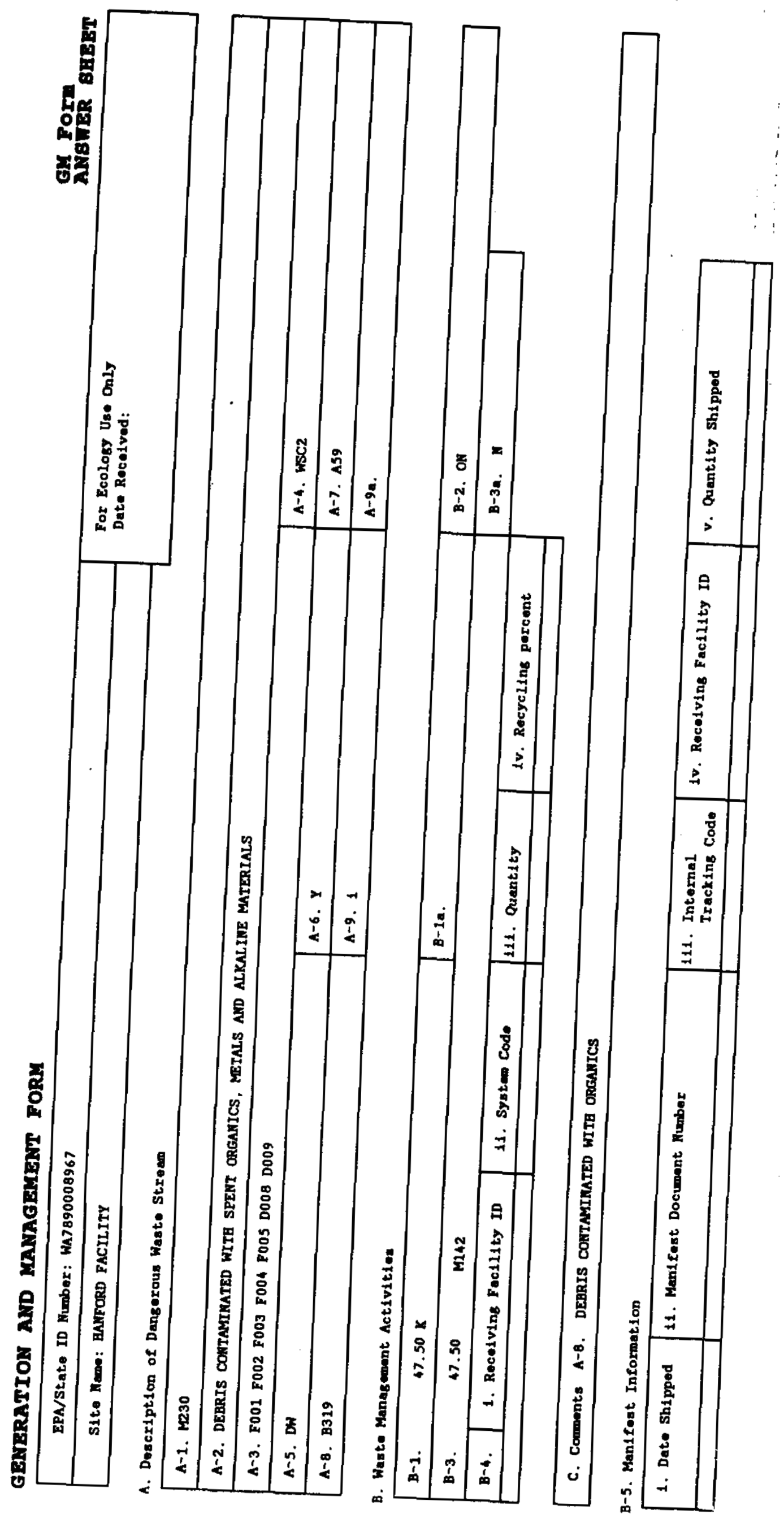




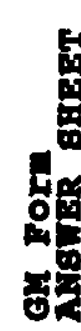
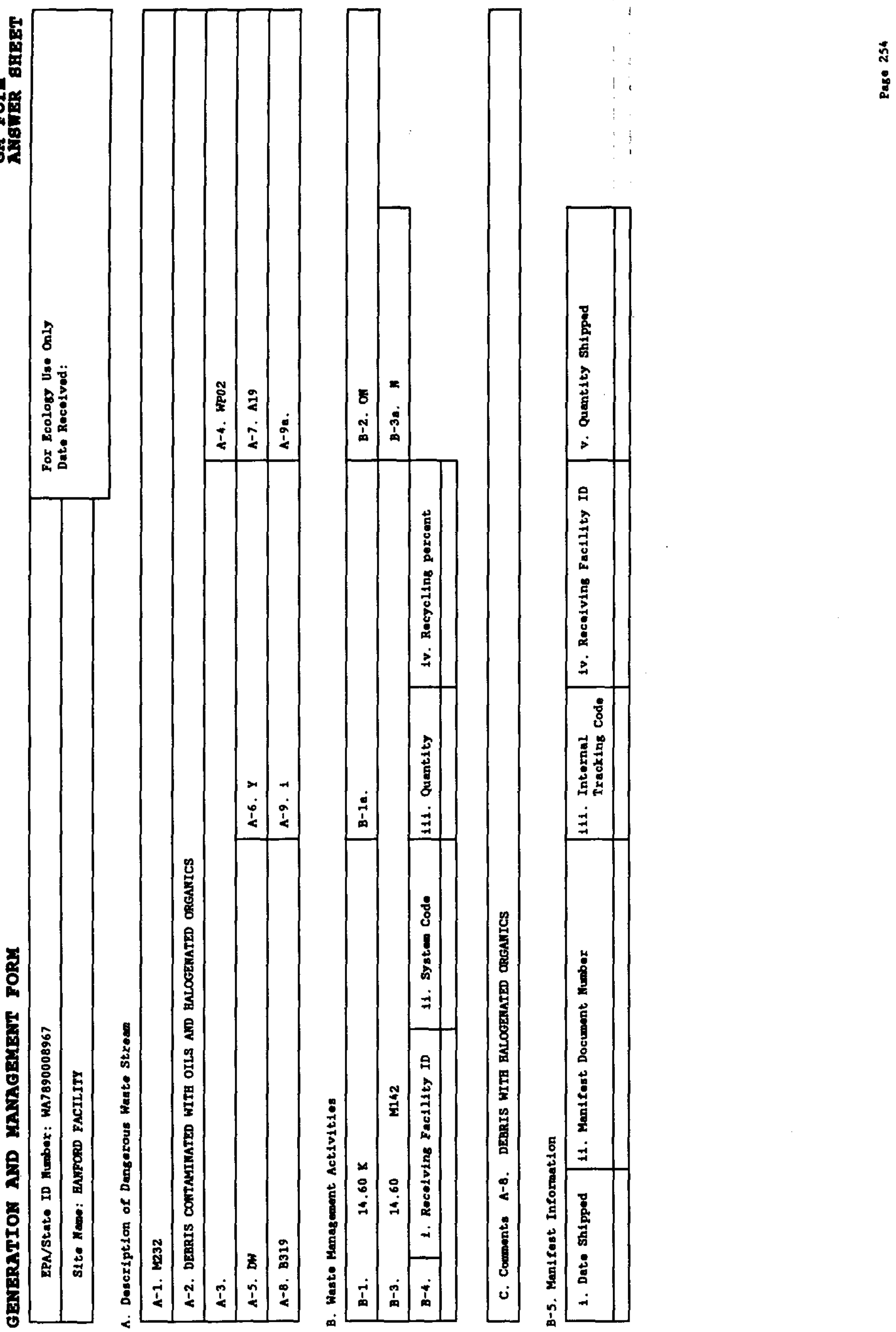


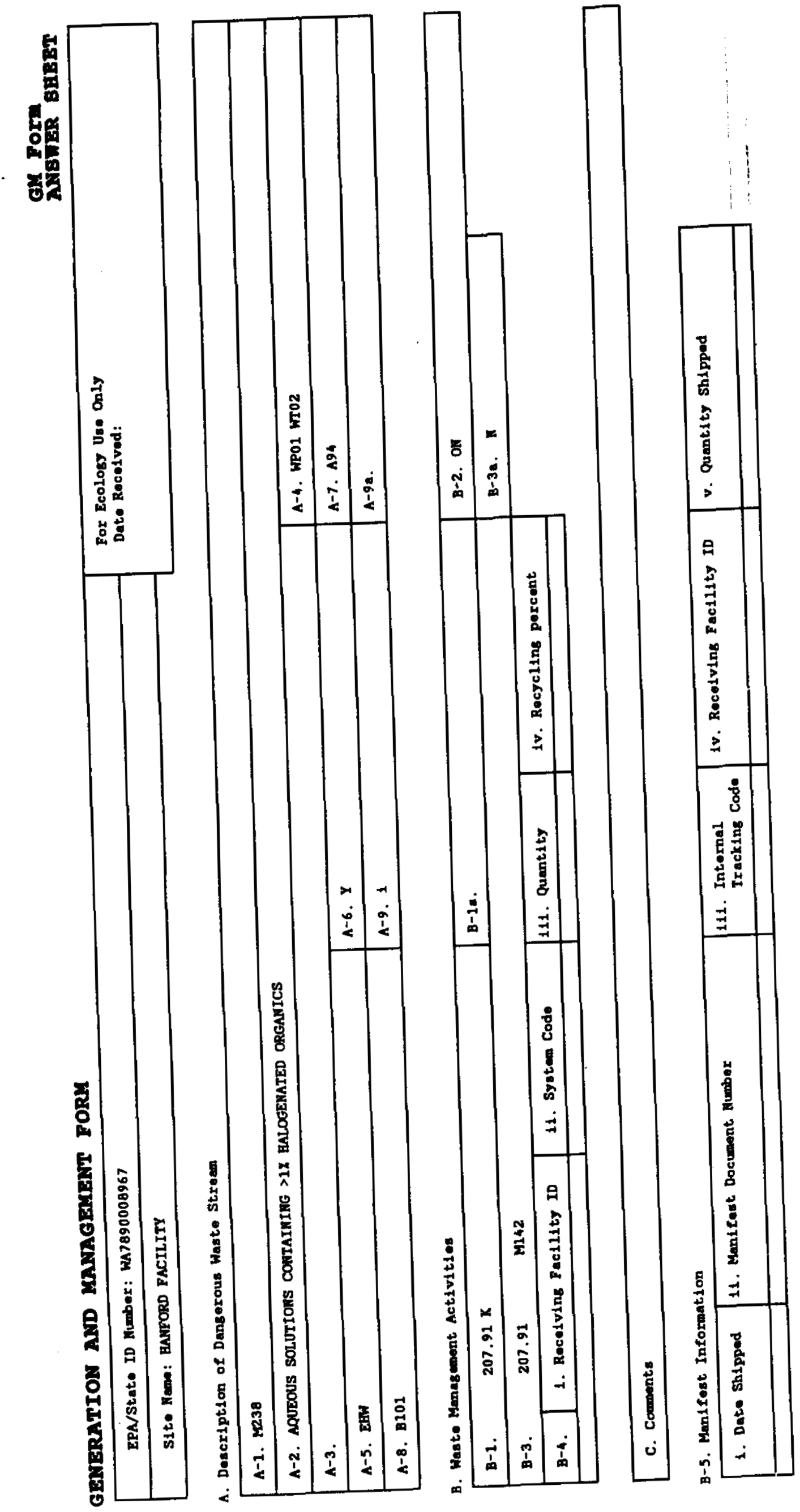




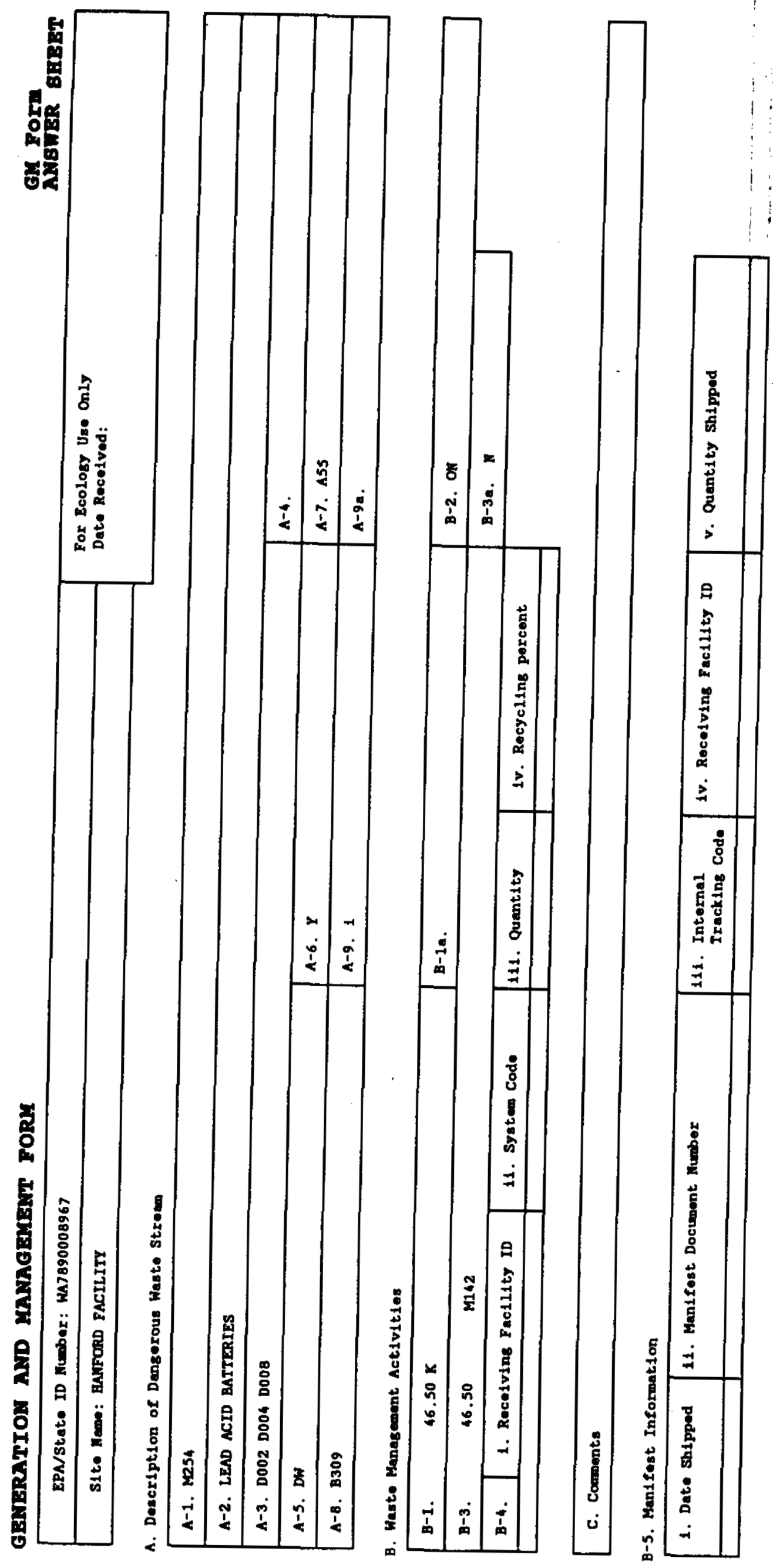




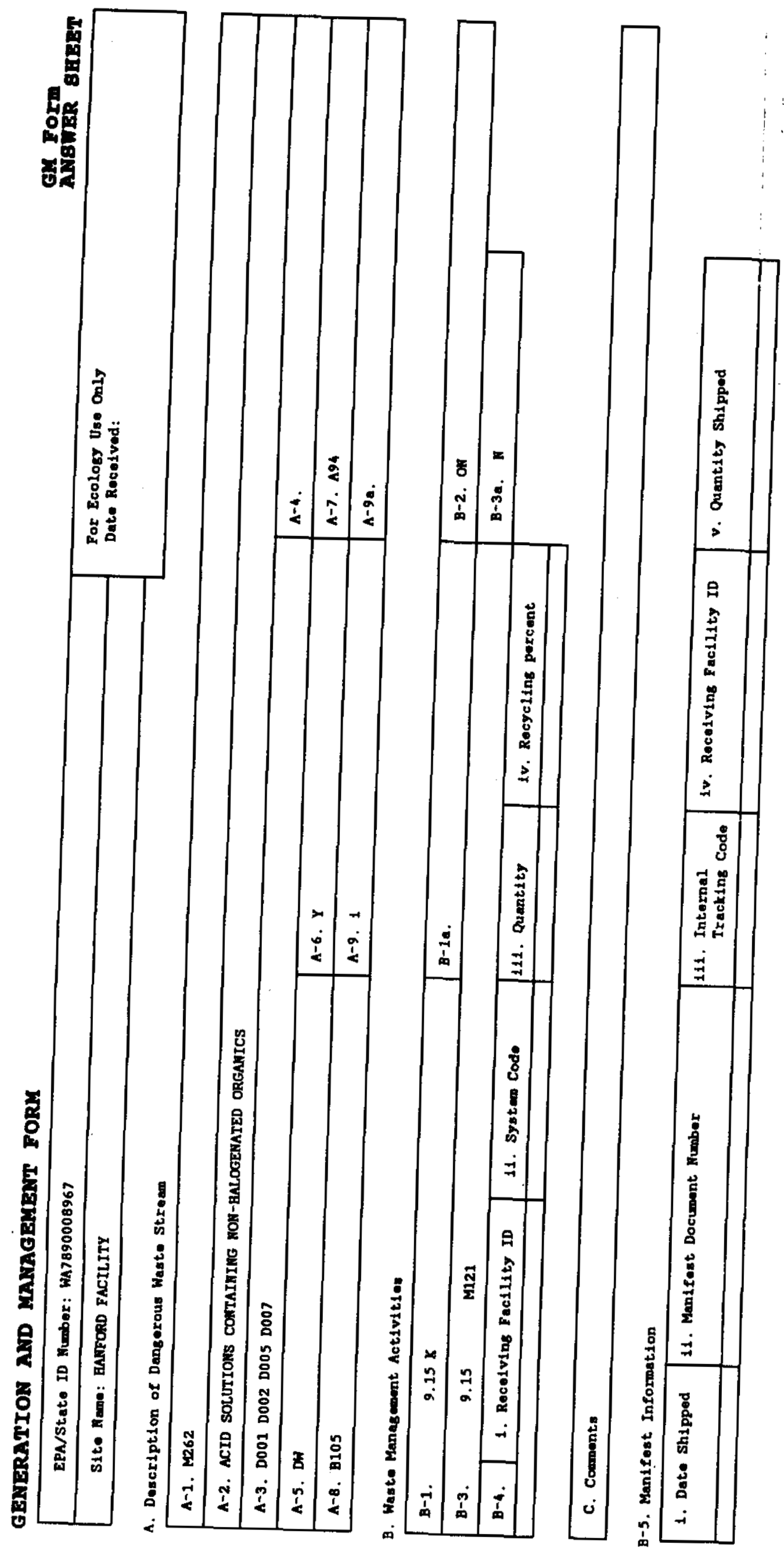

ฝิ 


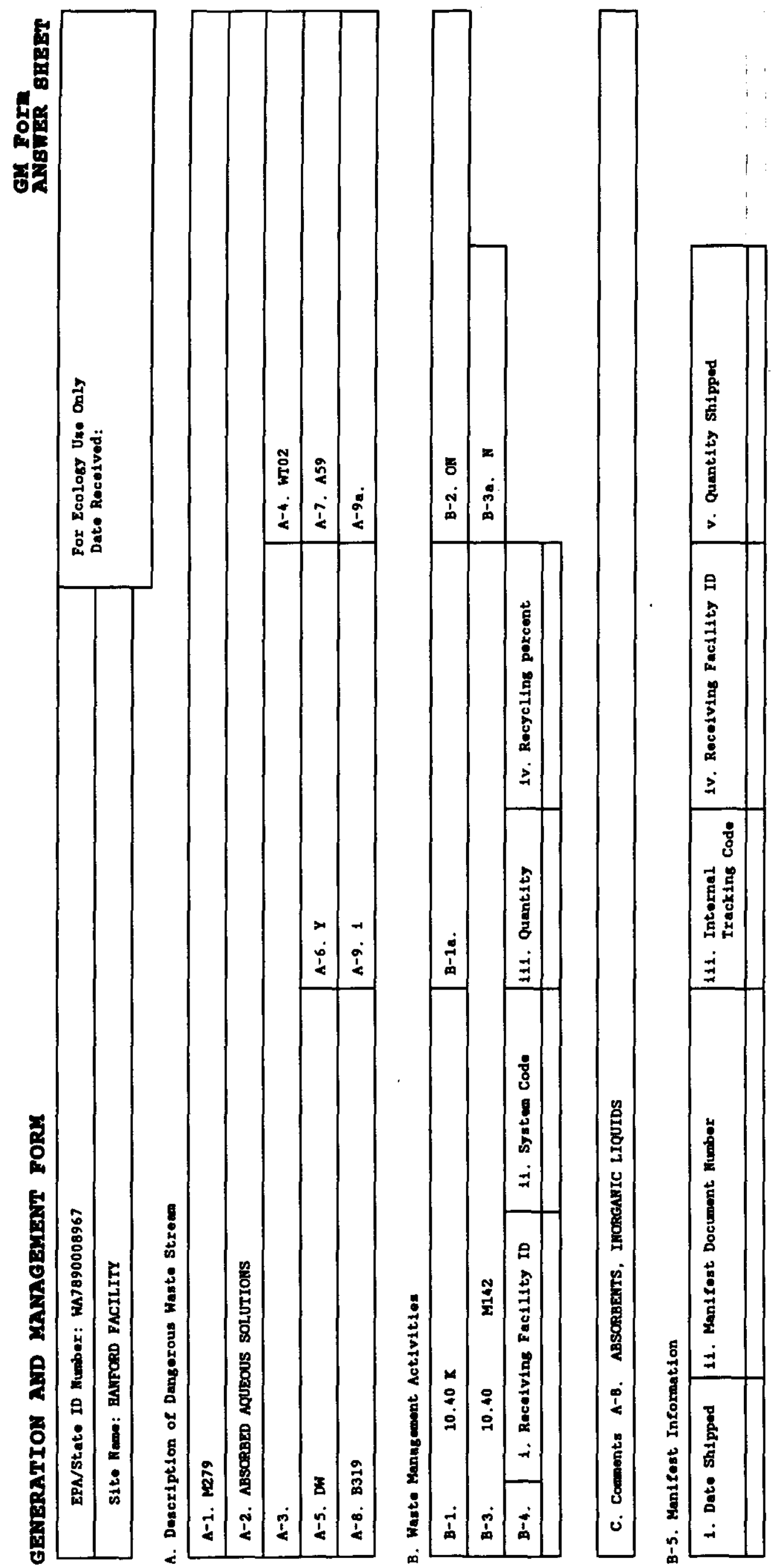




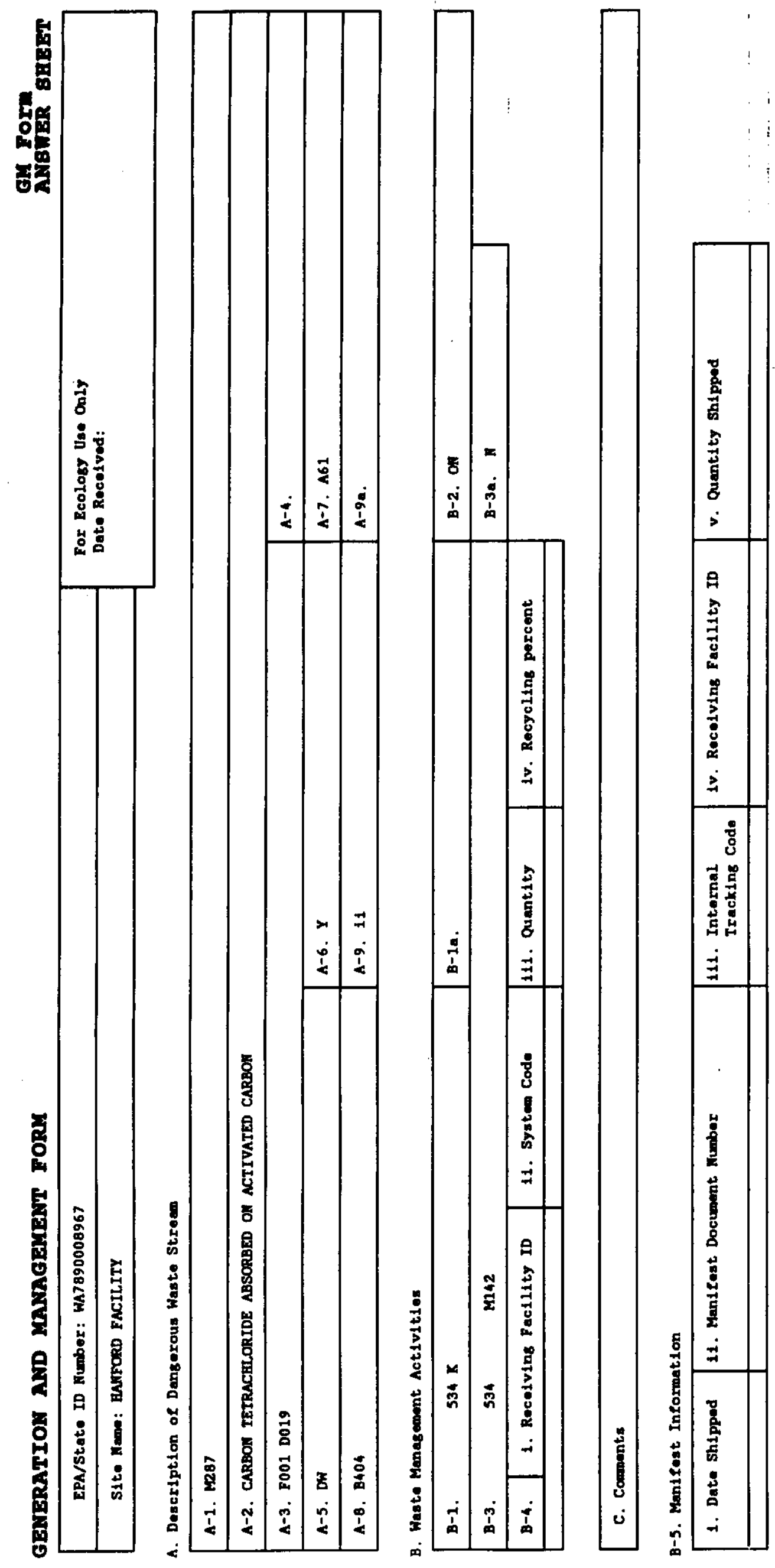




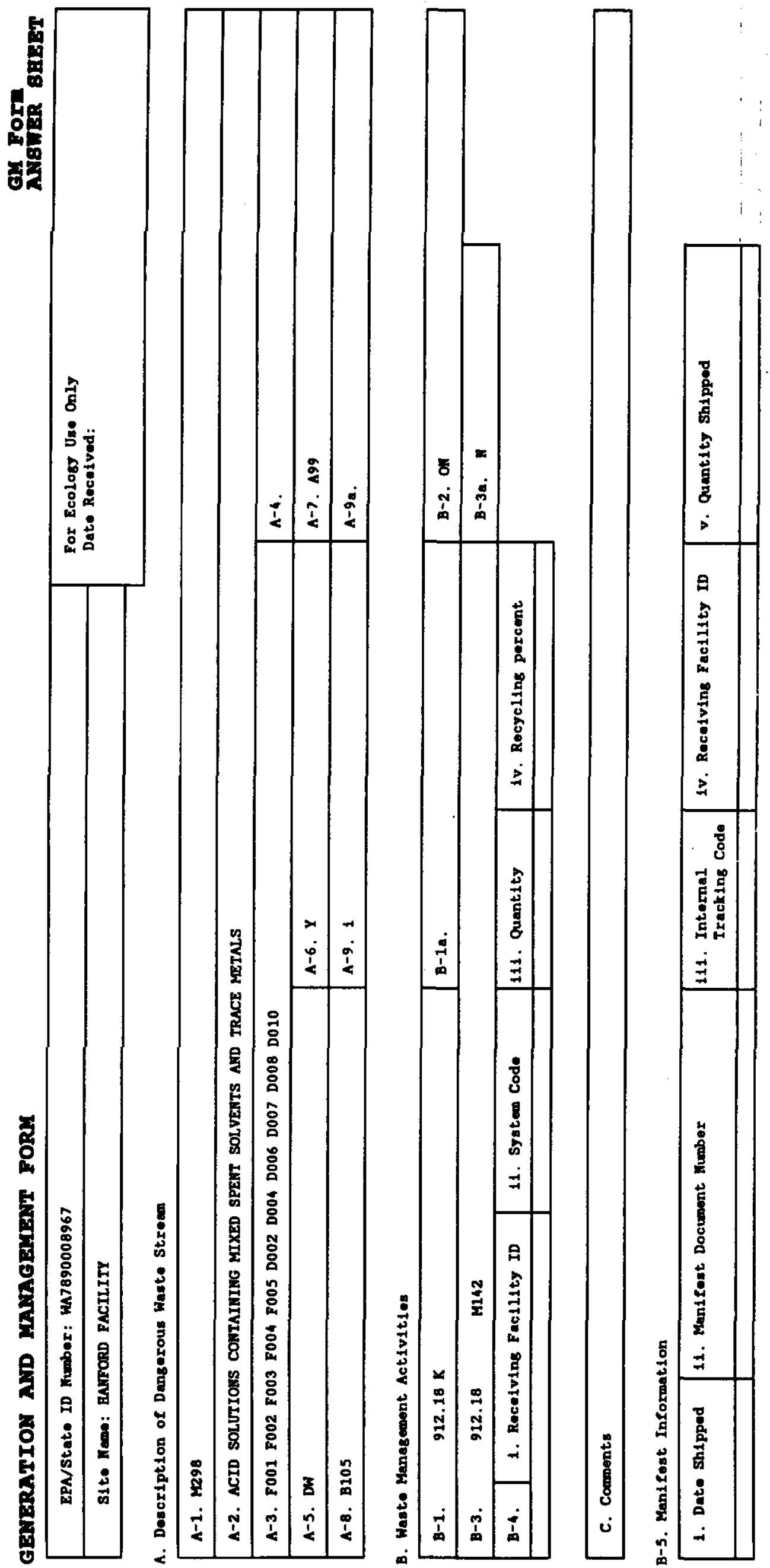




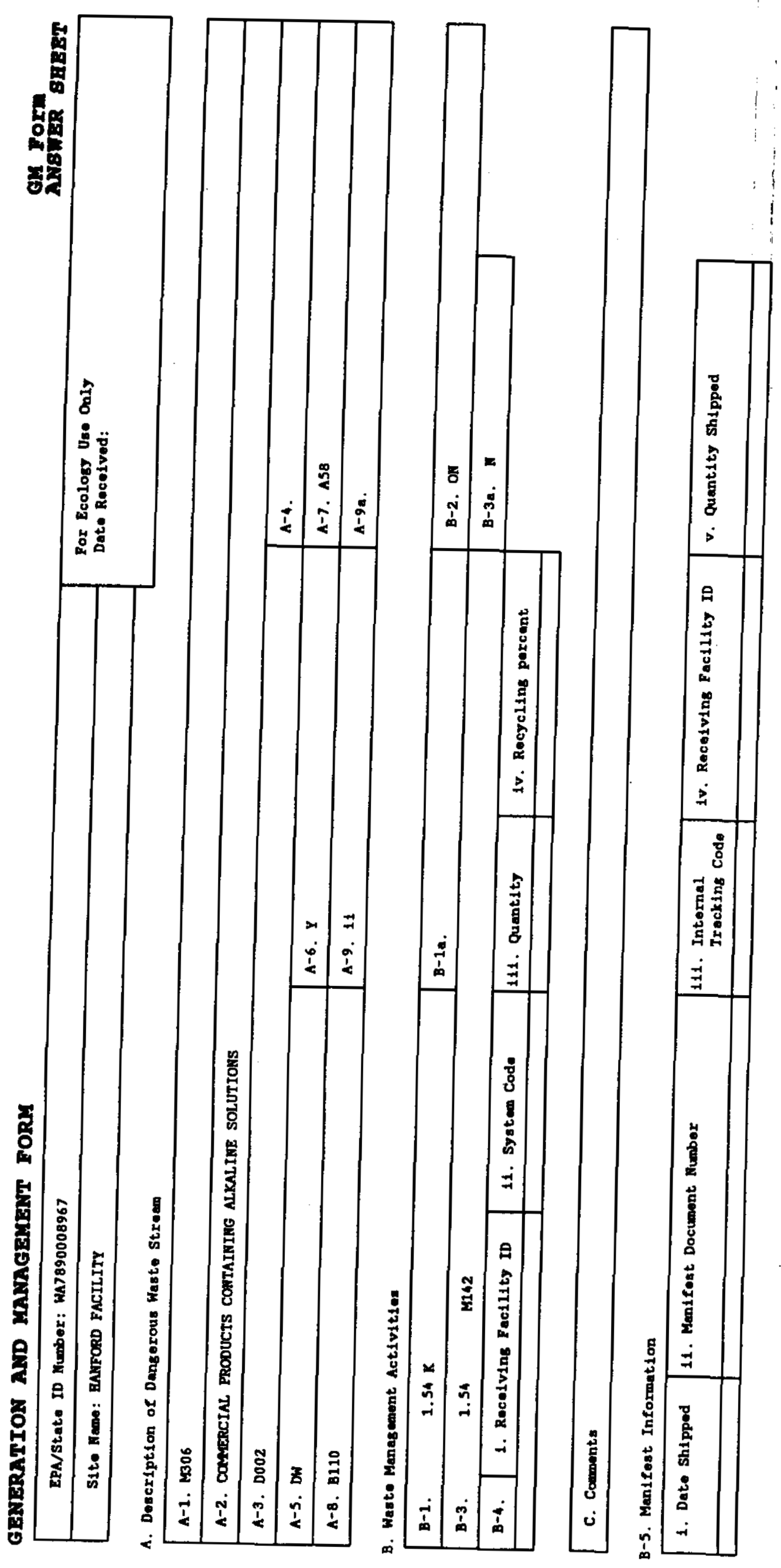




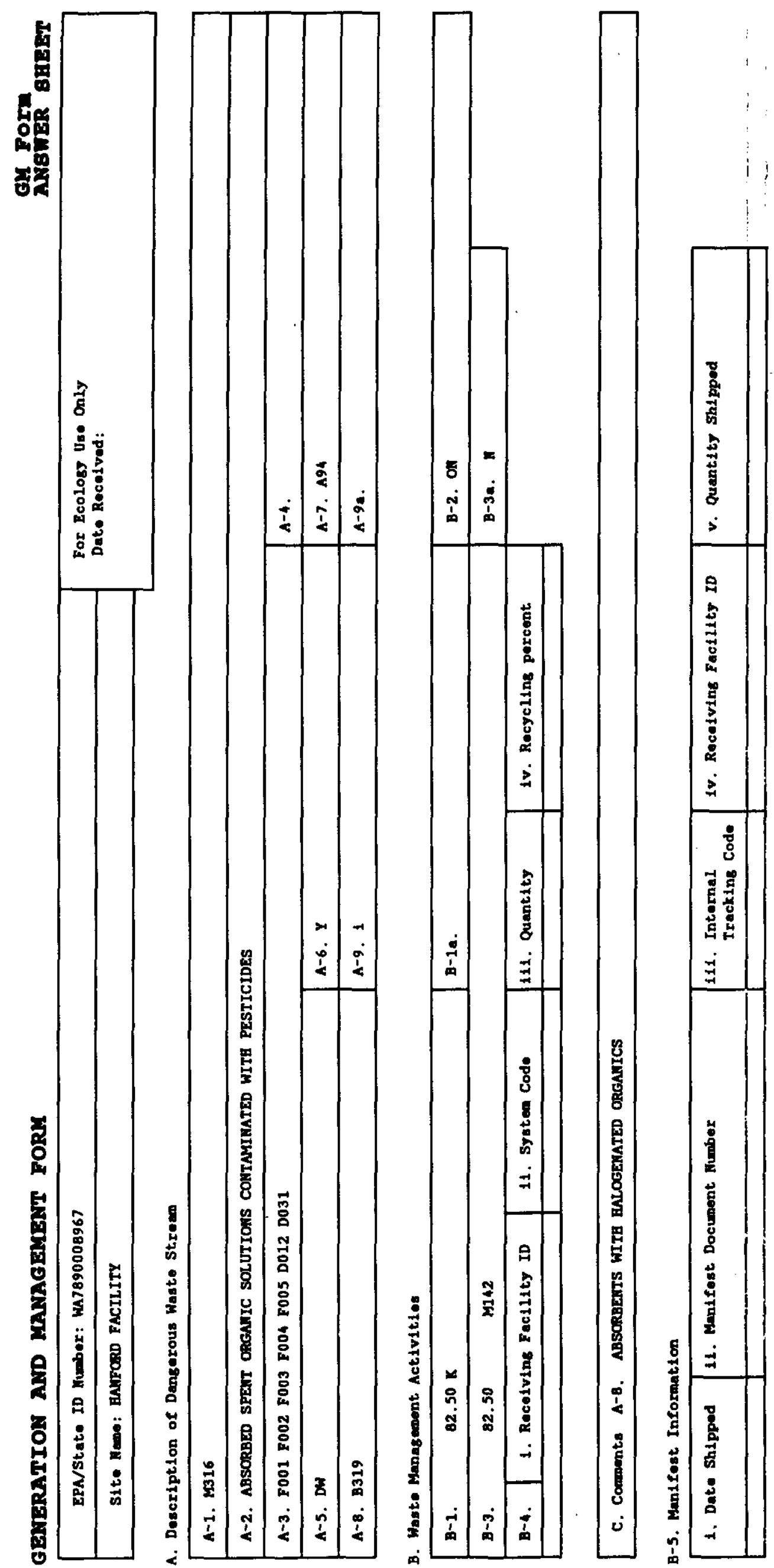




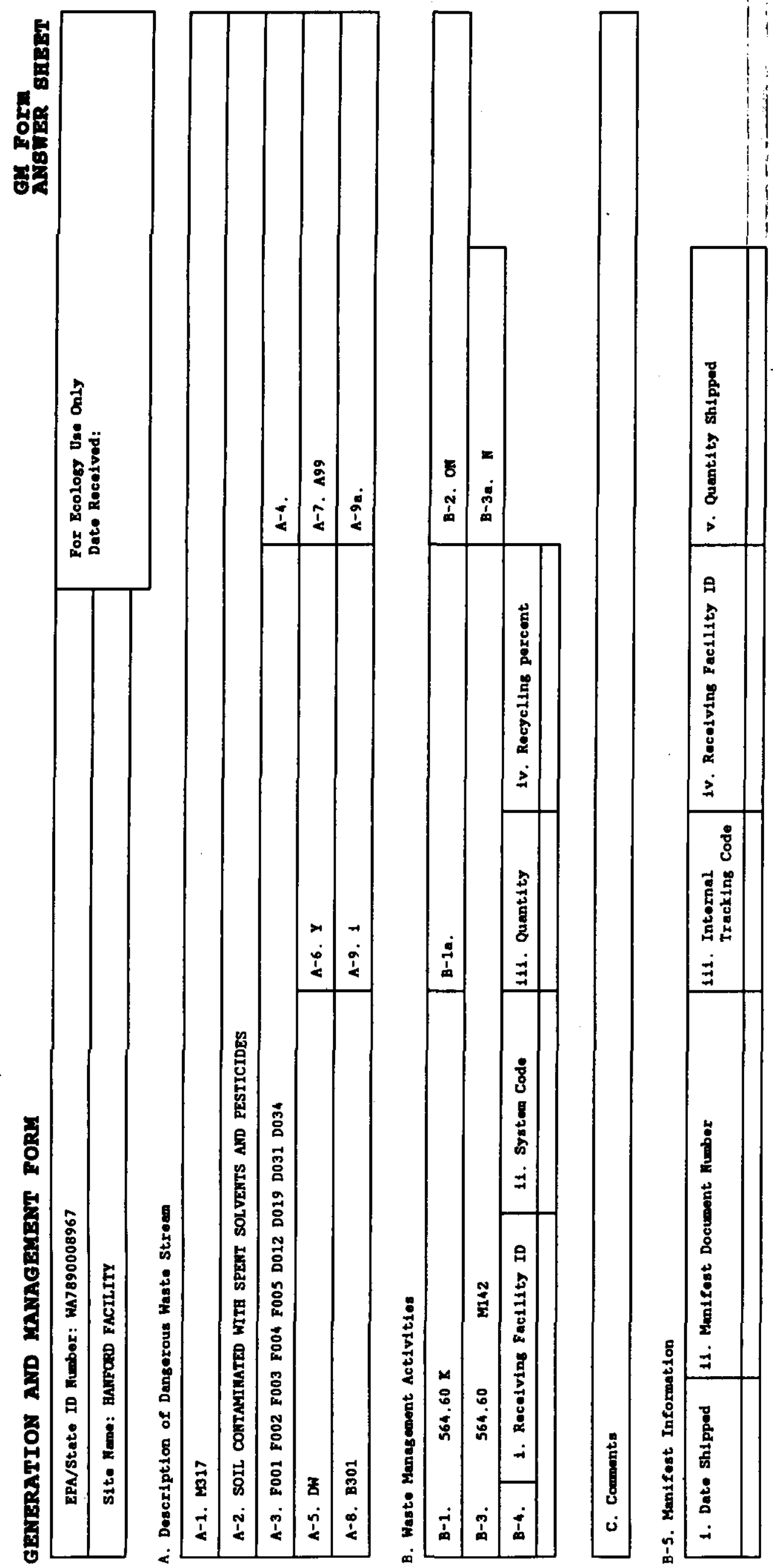




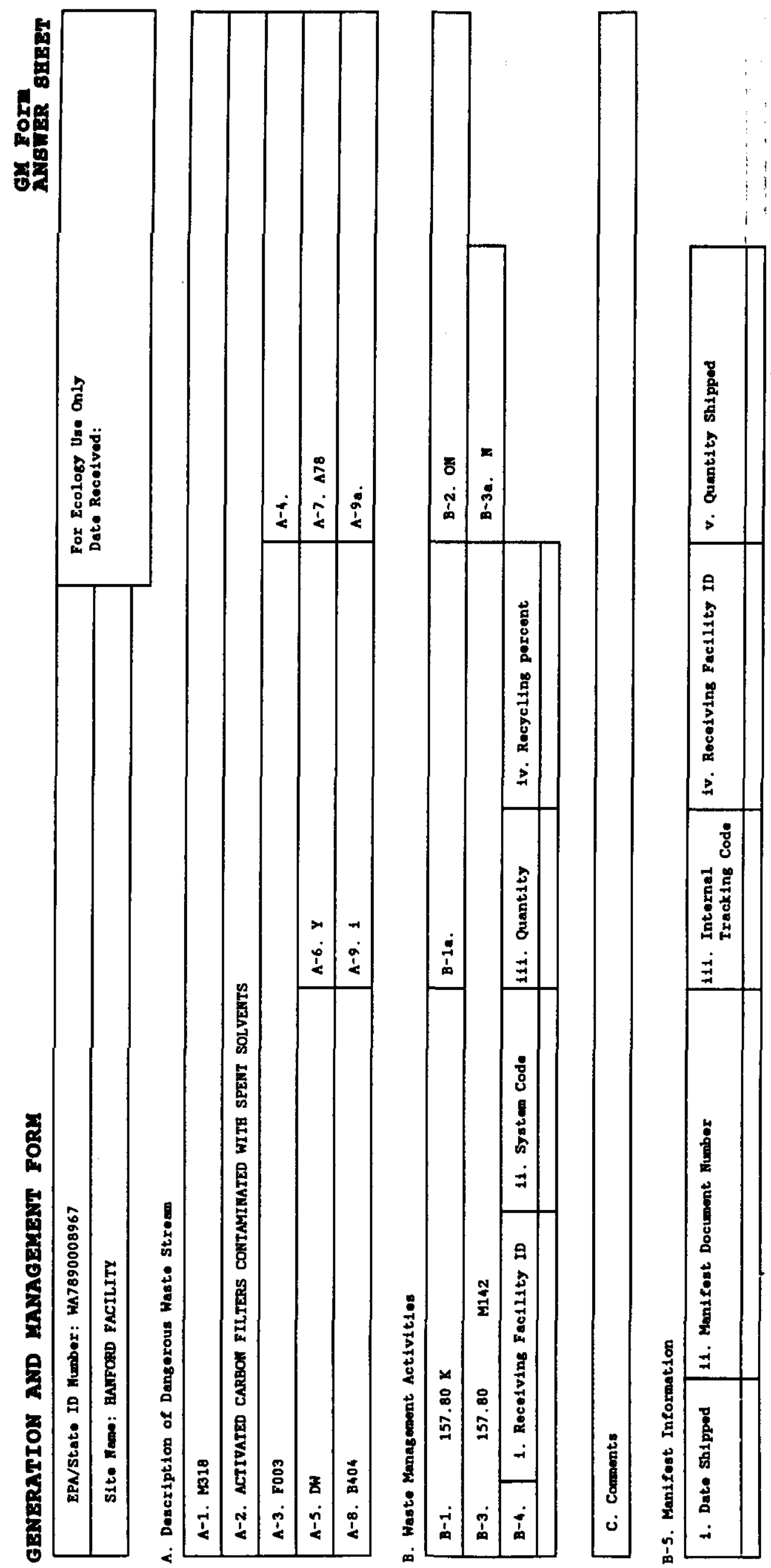




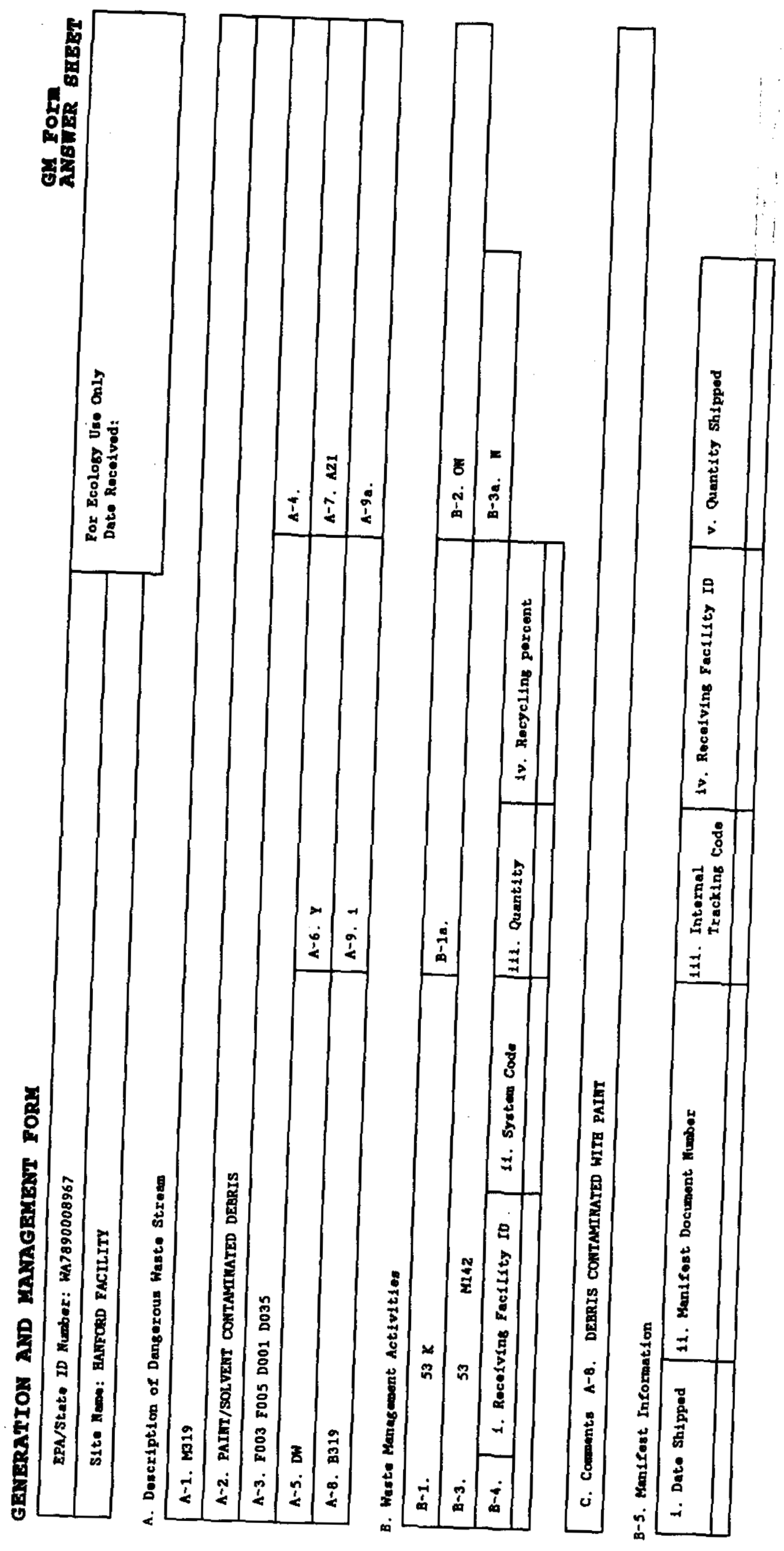

赵 


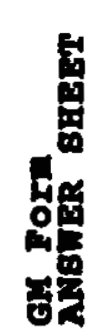
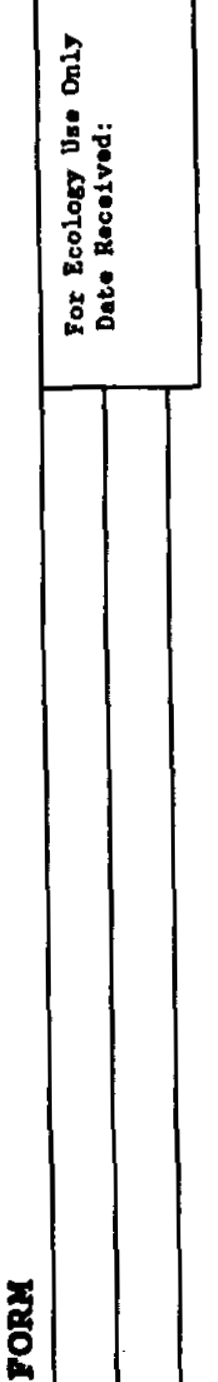

:

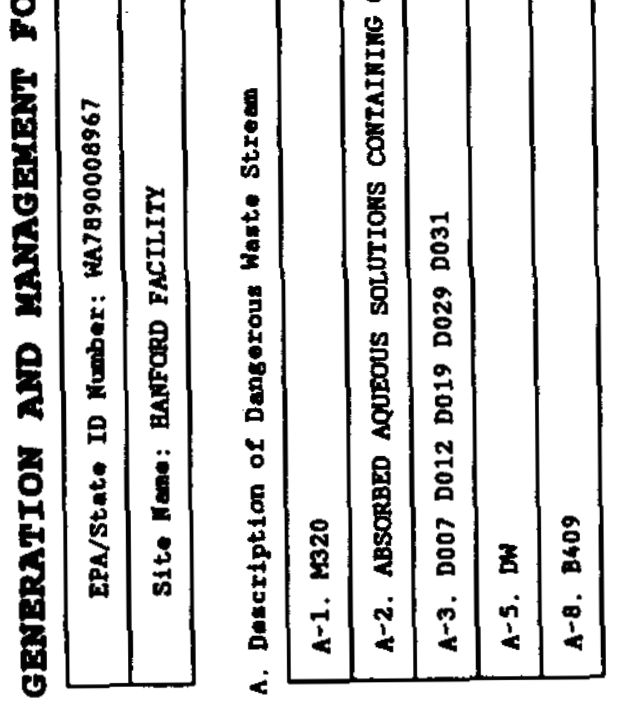

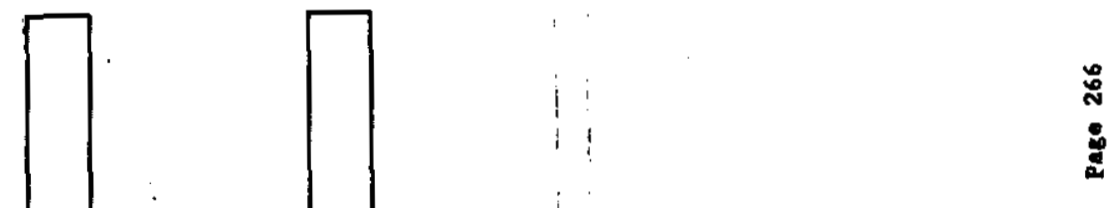

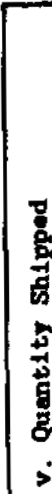

잉

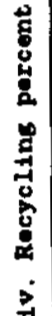

声

章

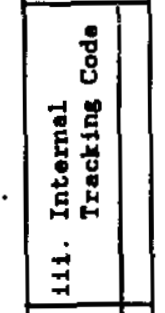

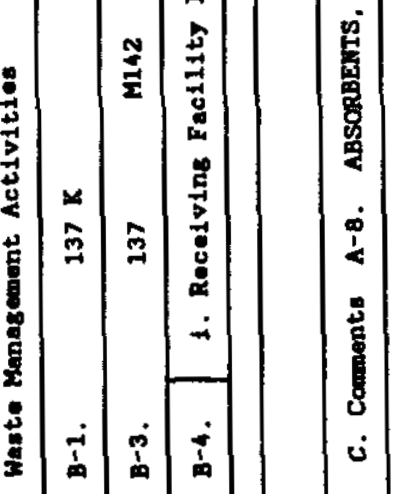

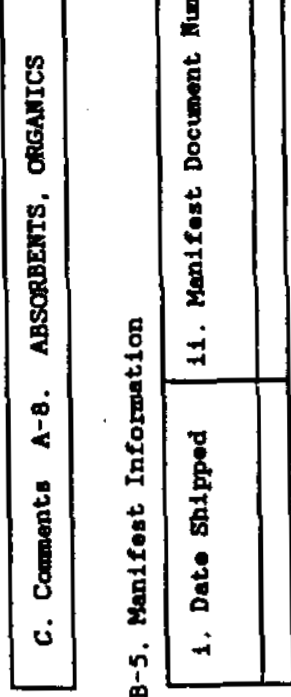




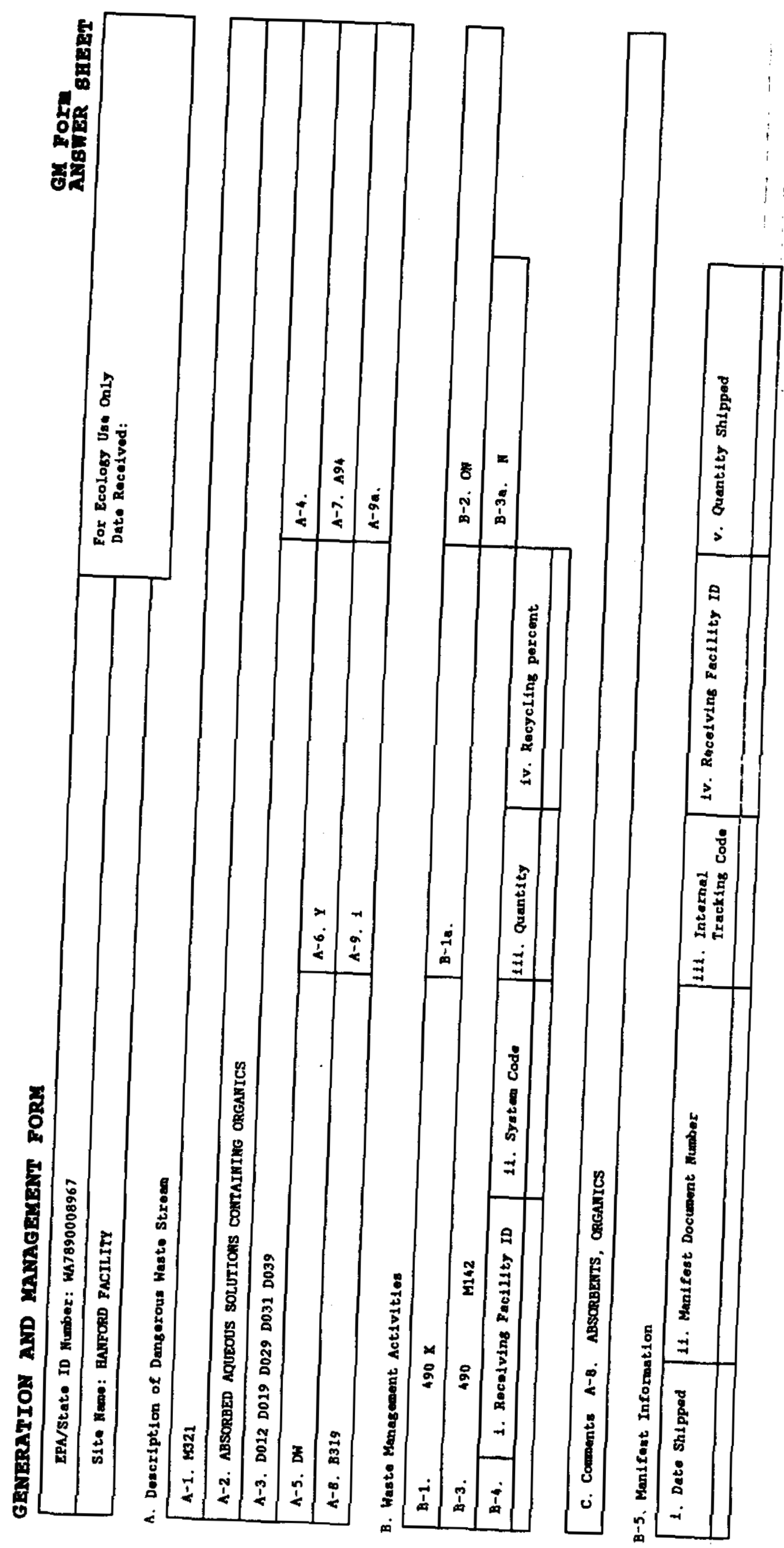




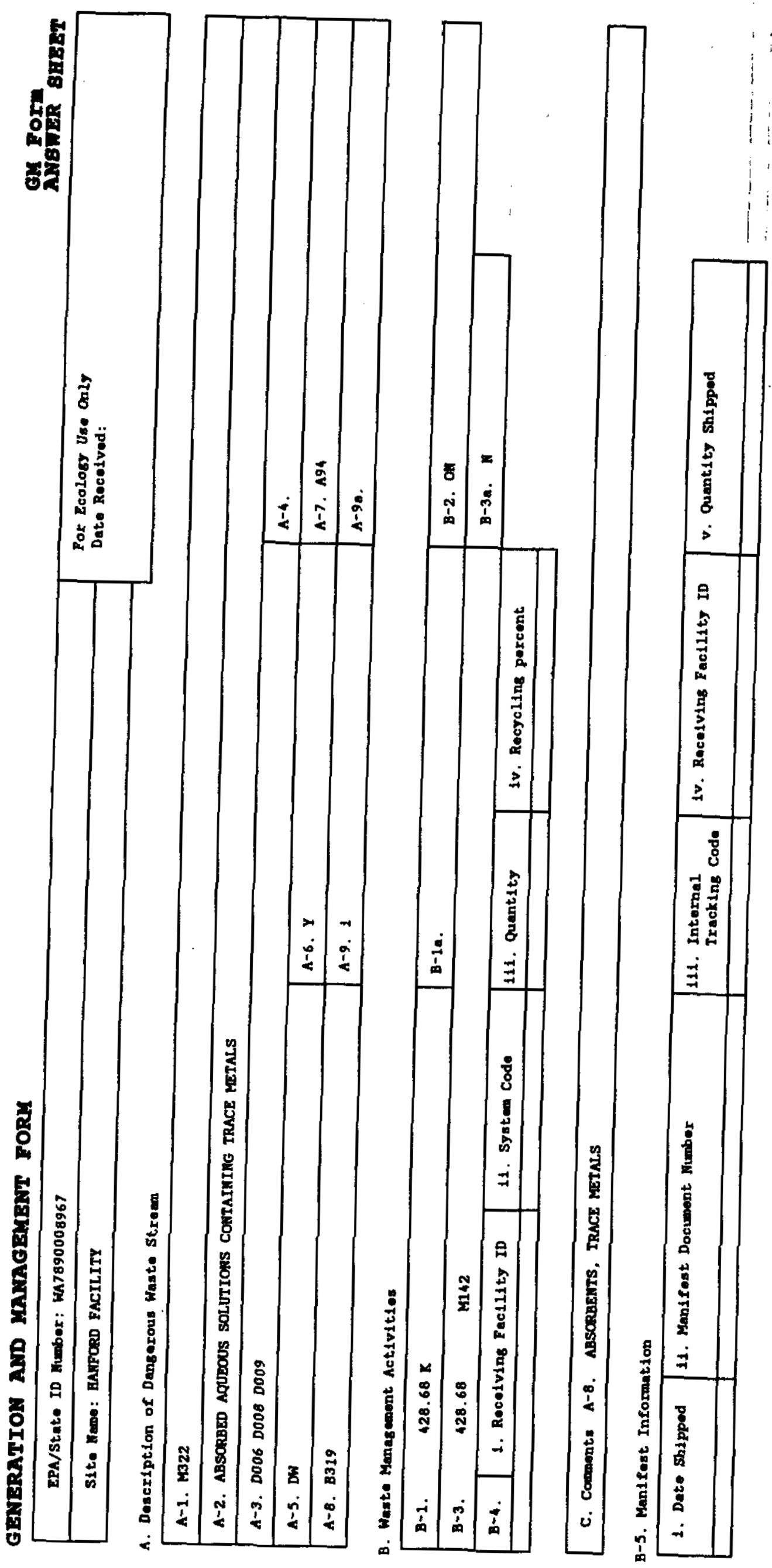




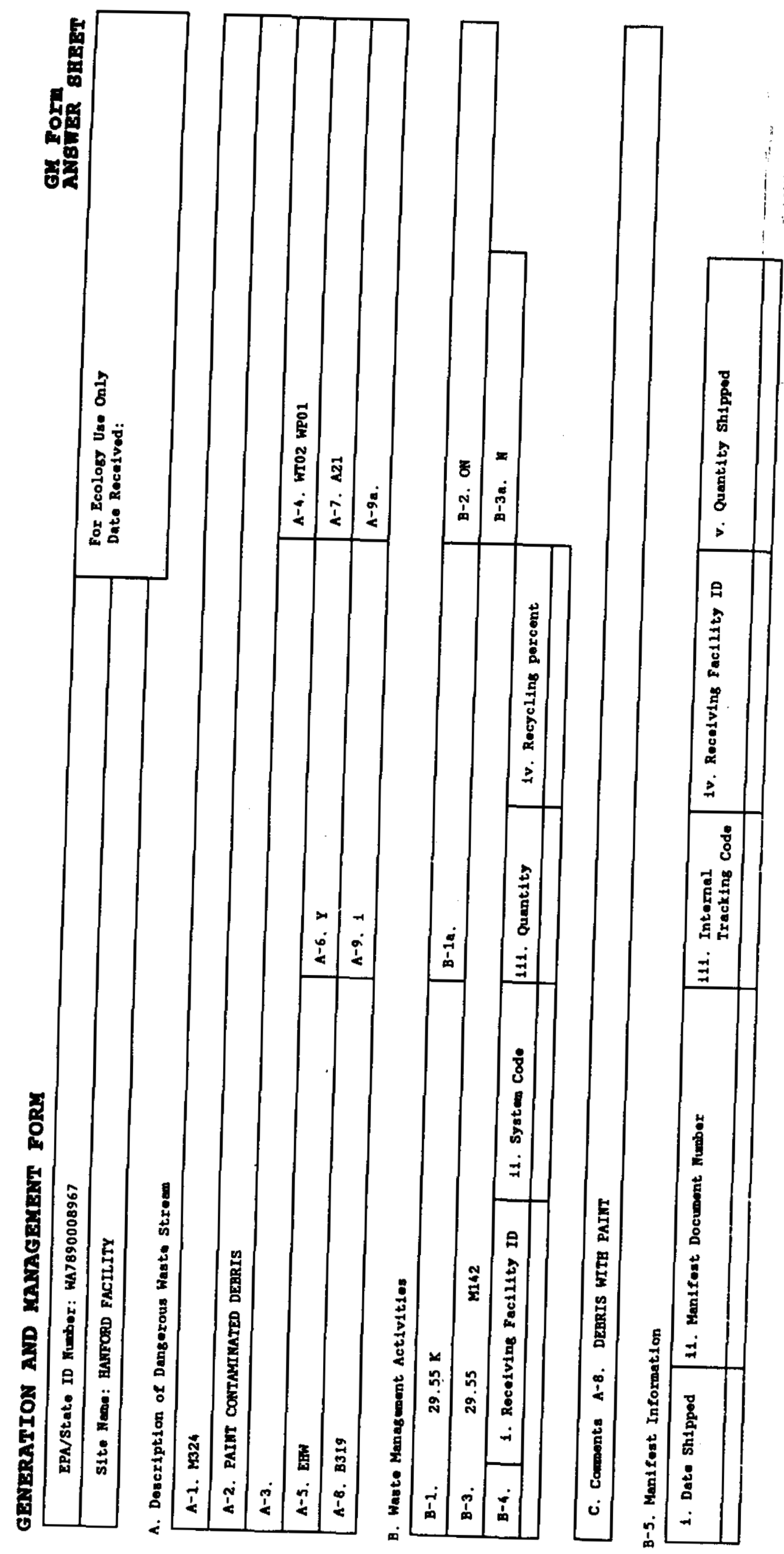




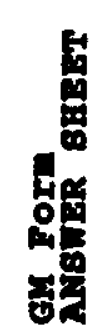
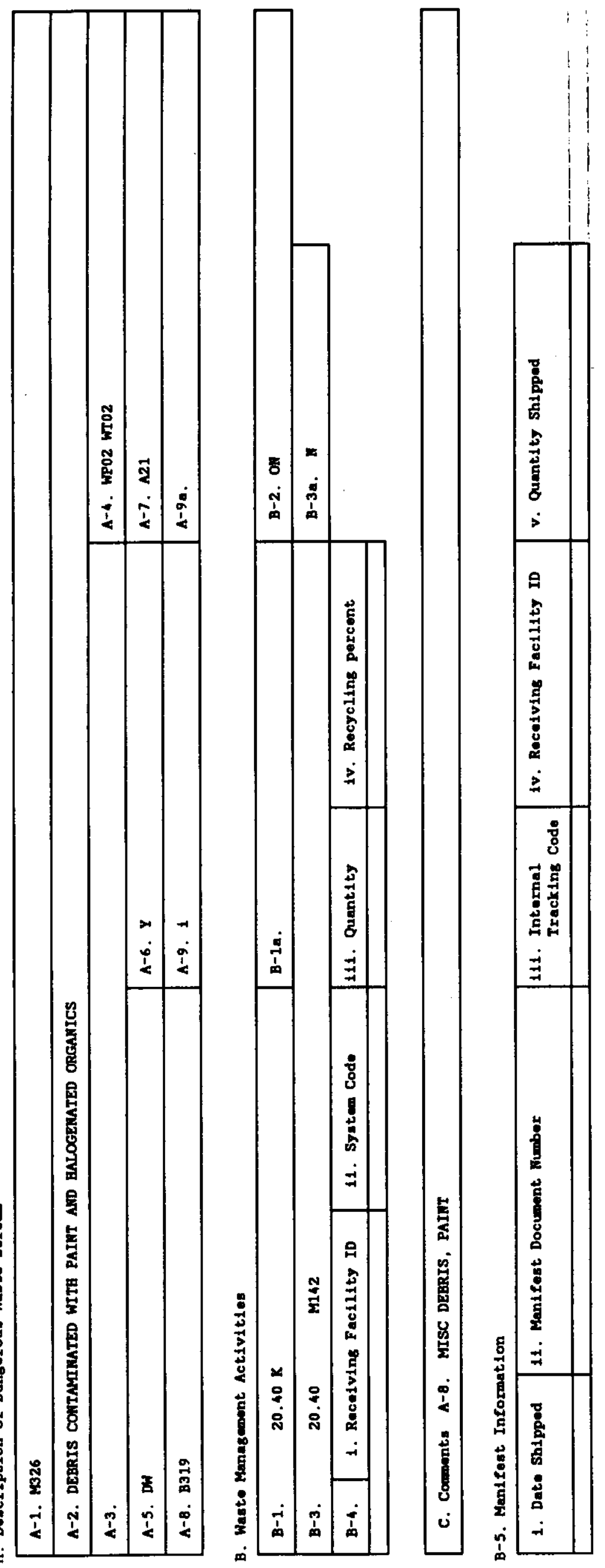

ฌุ
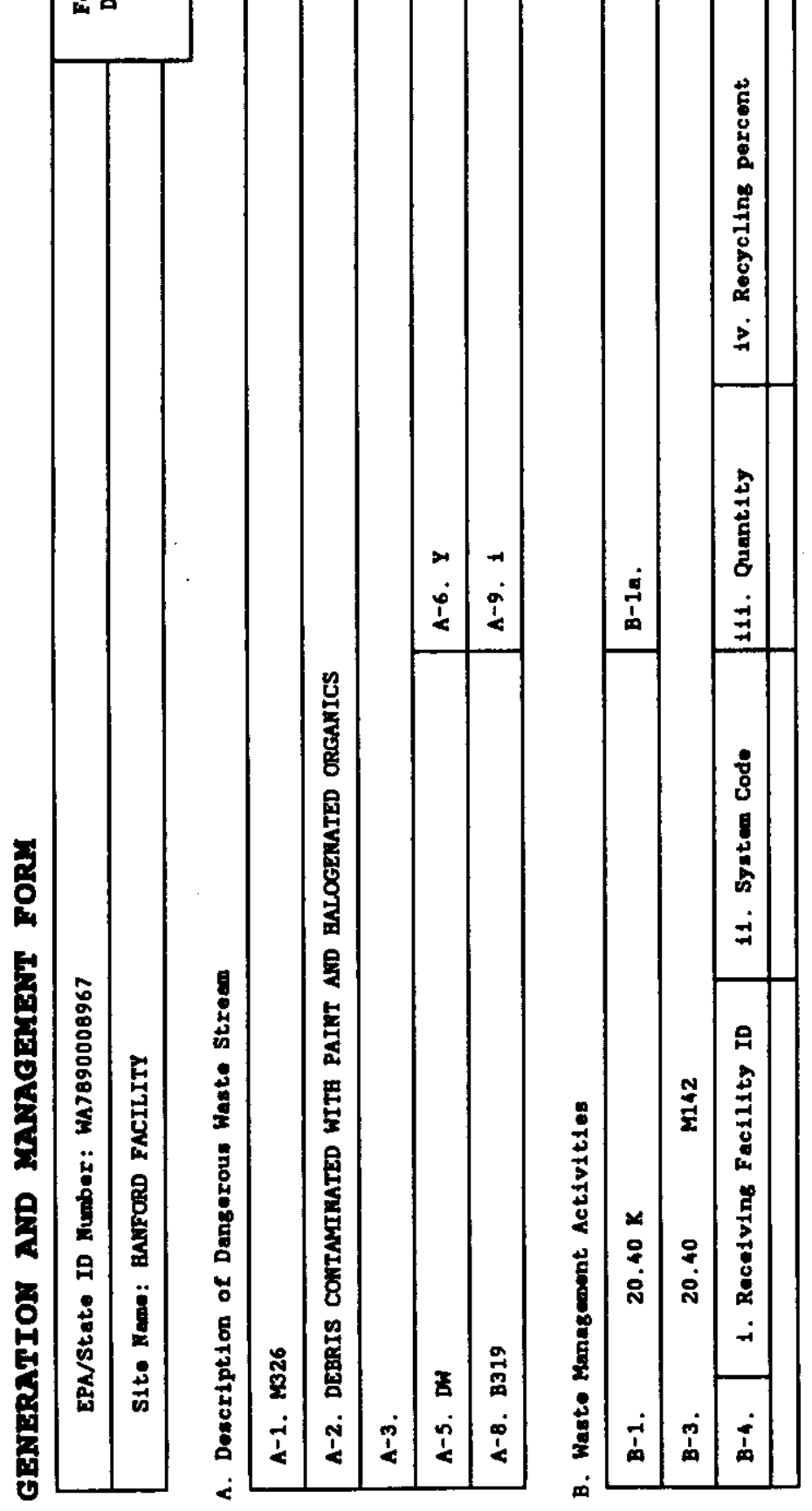


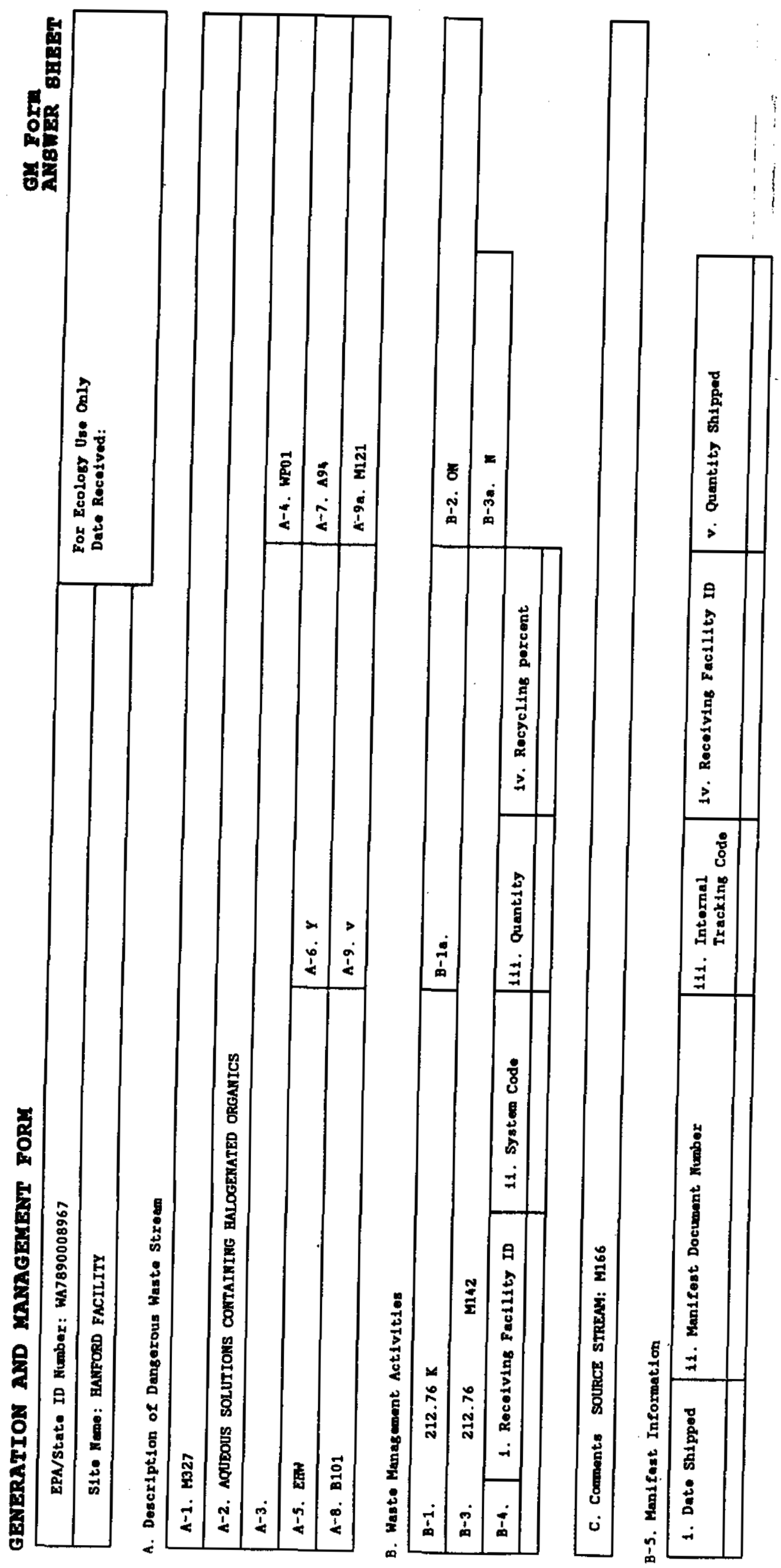




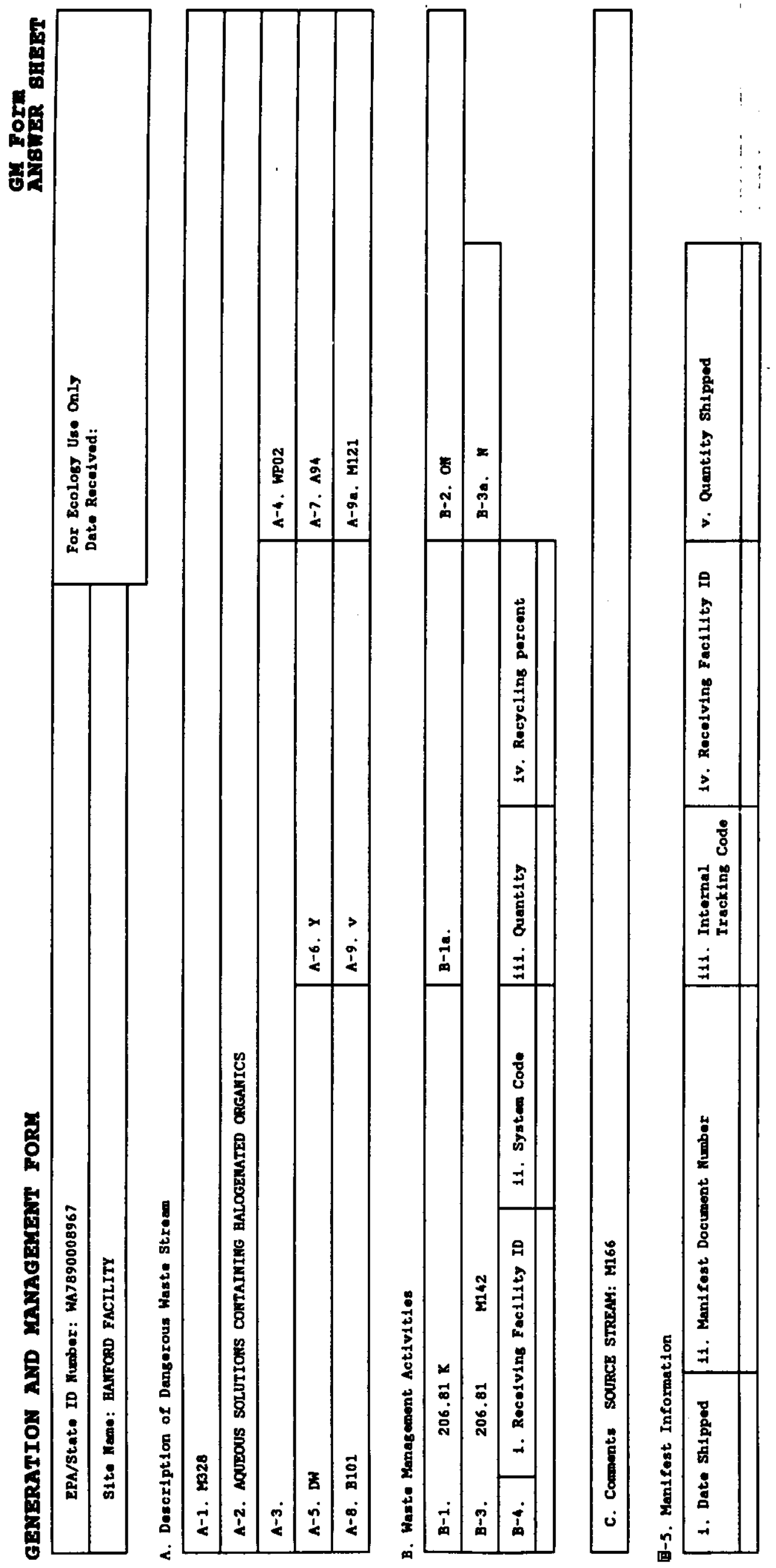




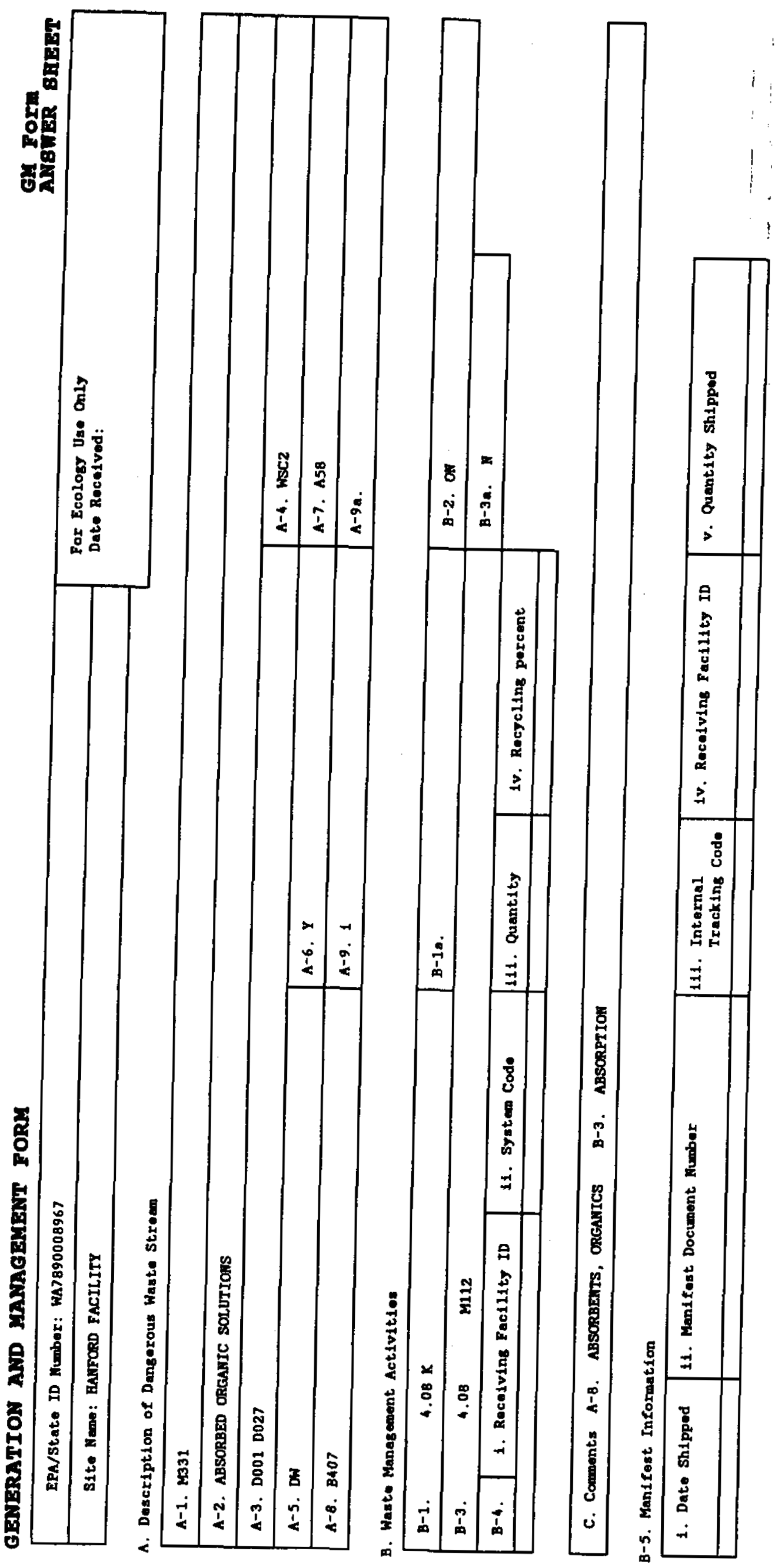




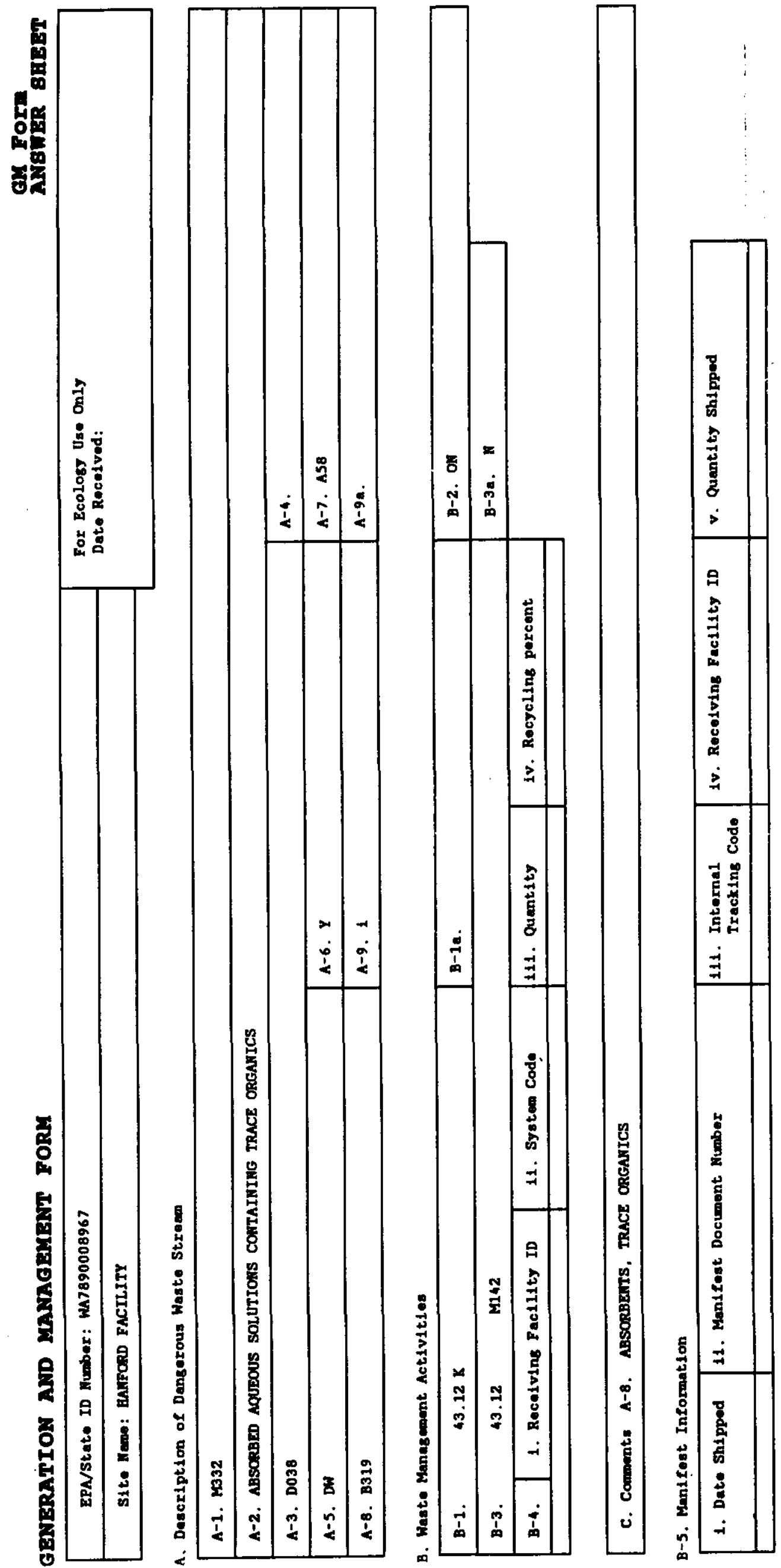




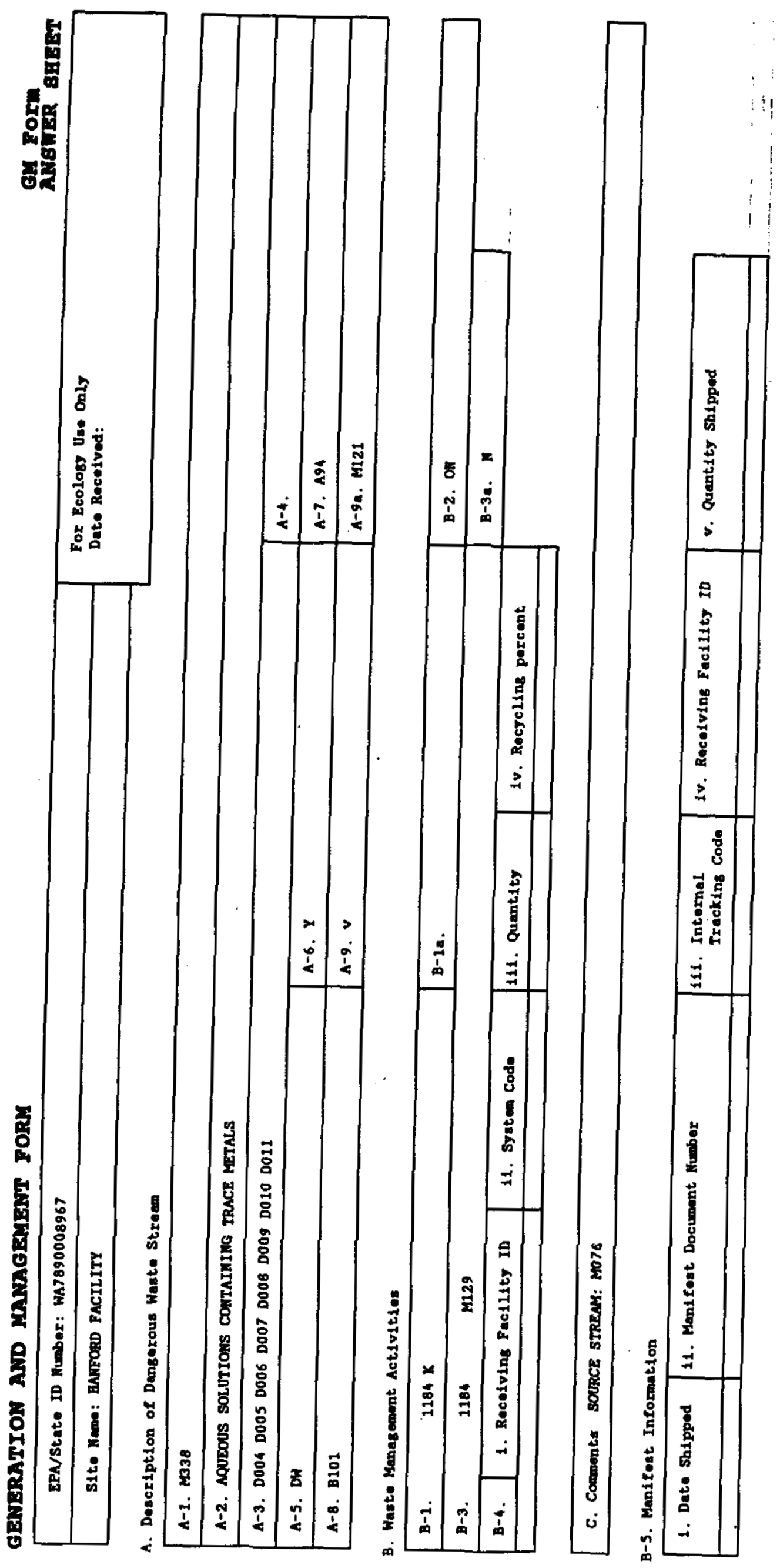




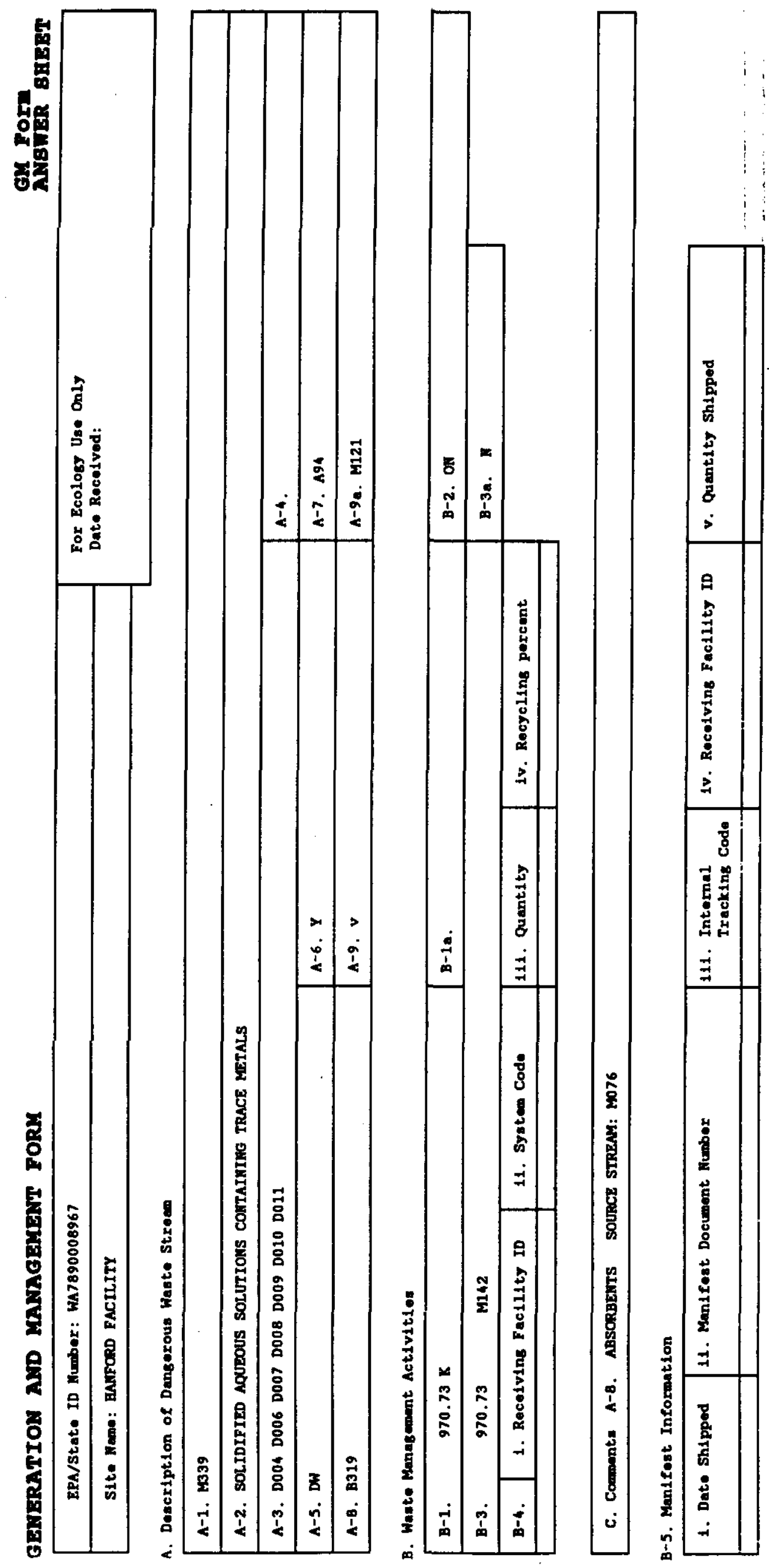




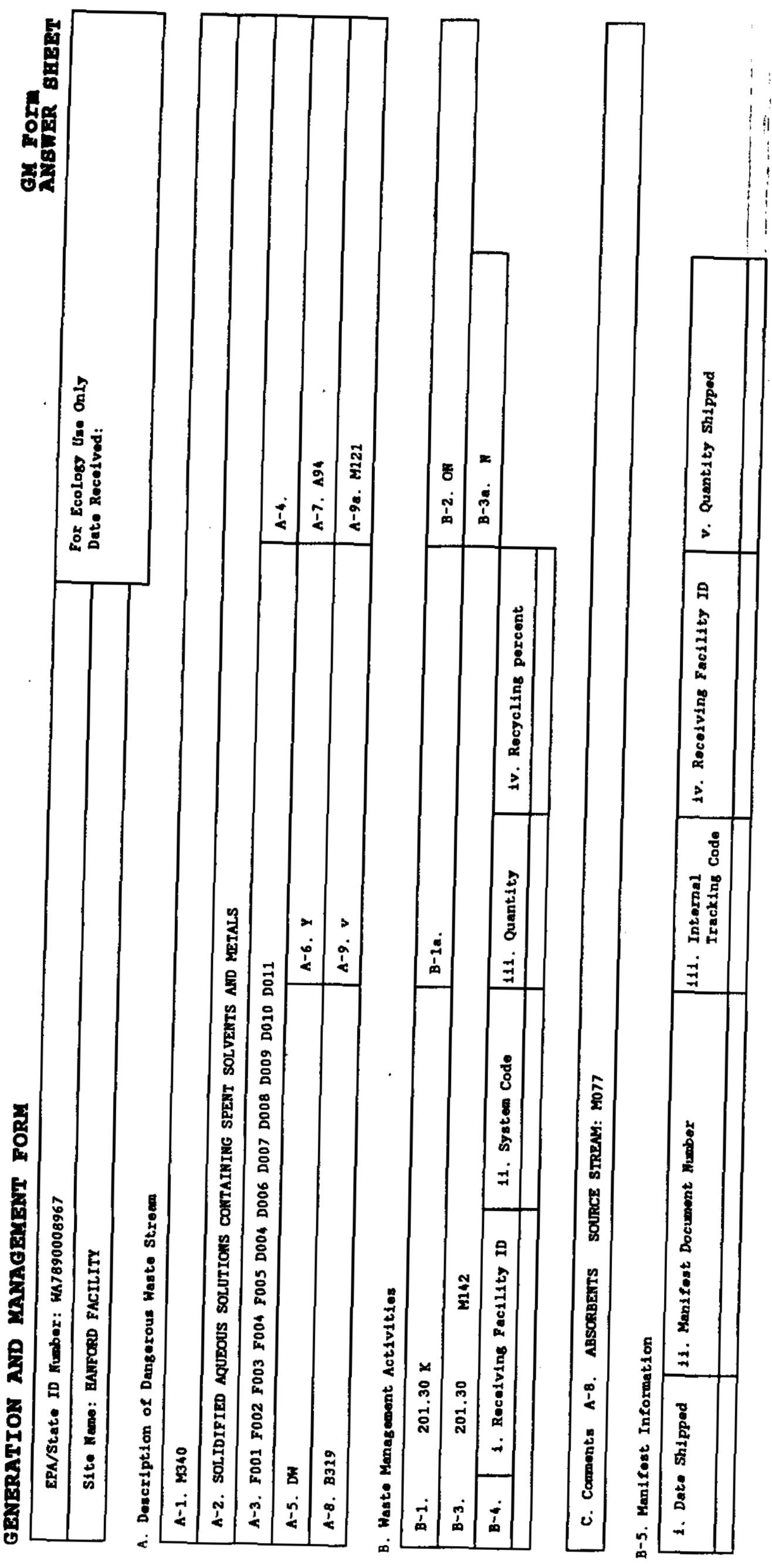




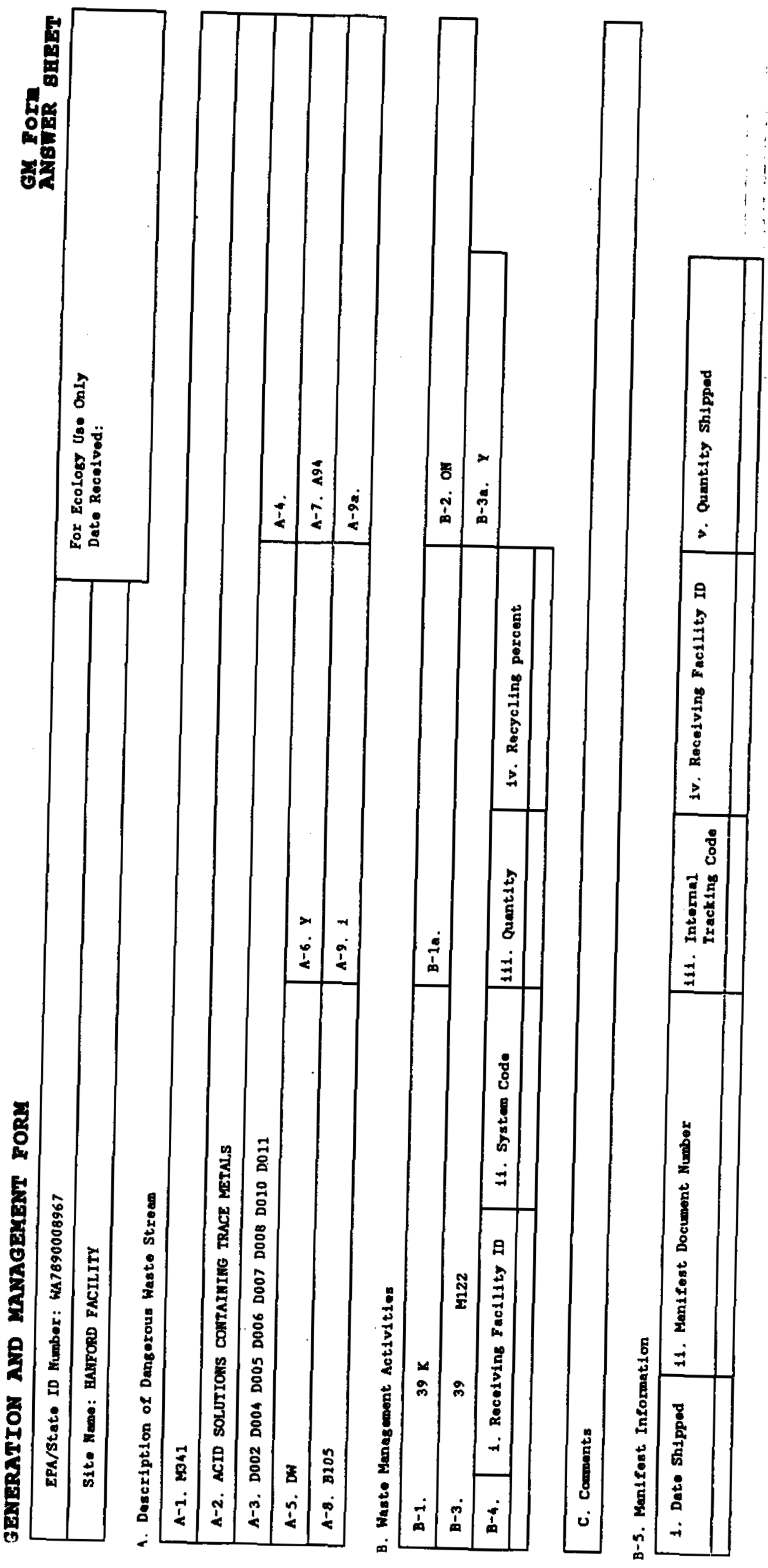




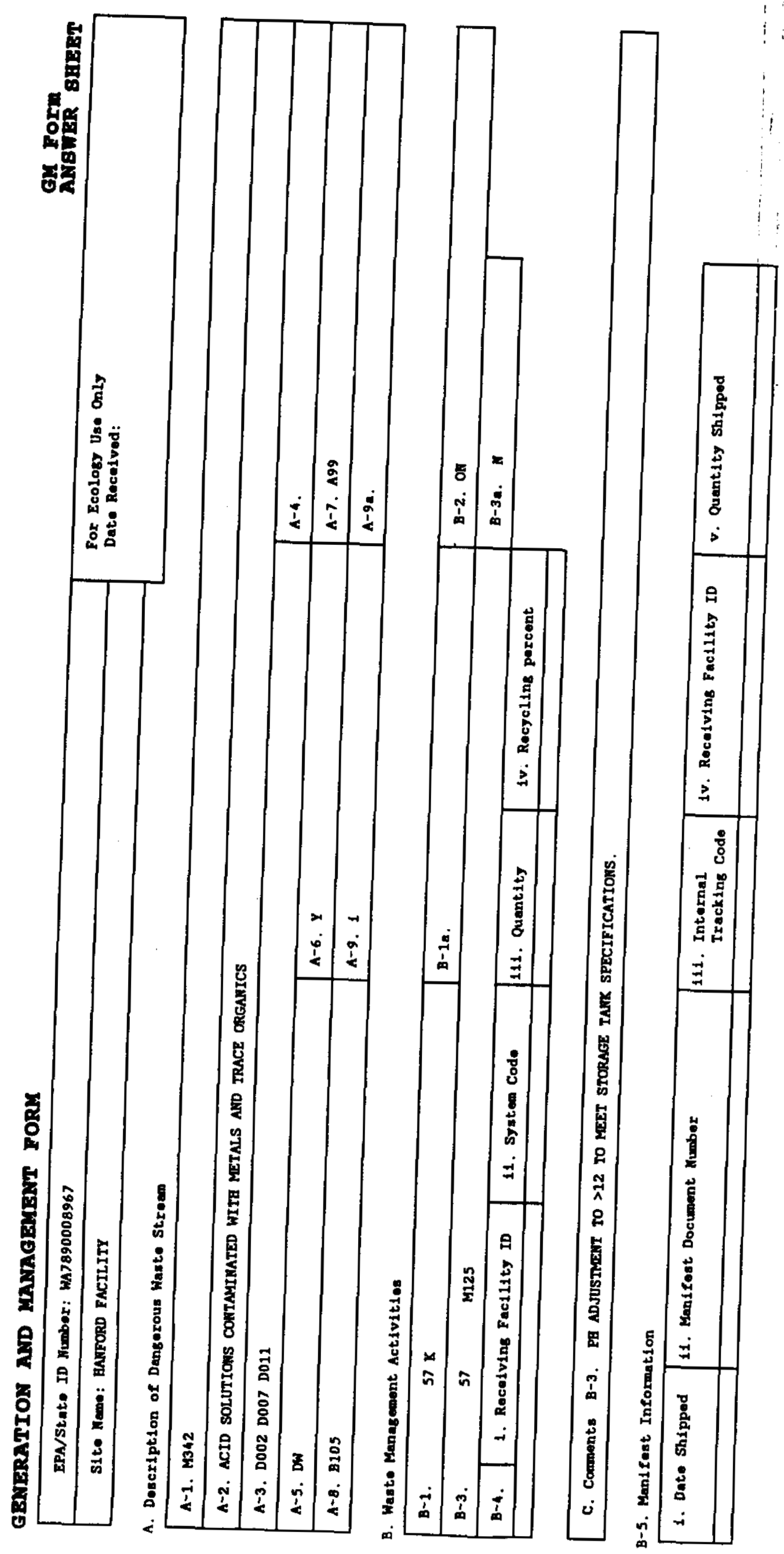




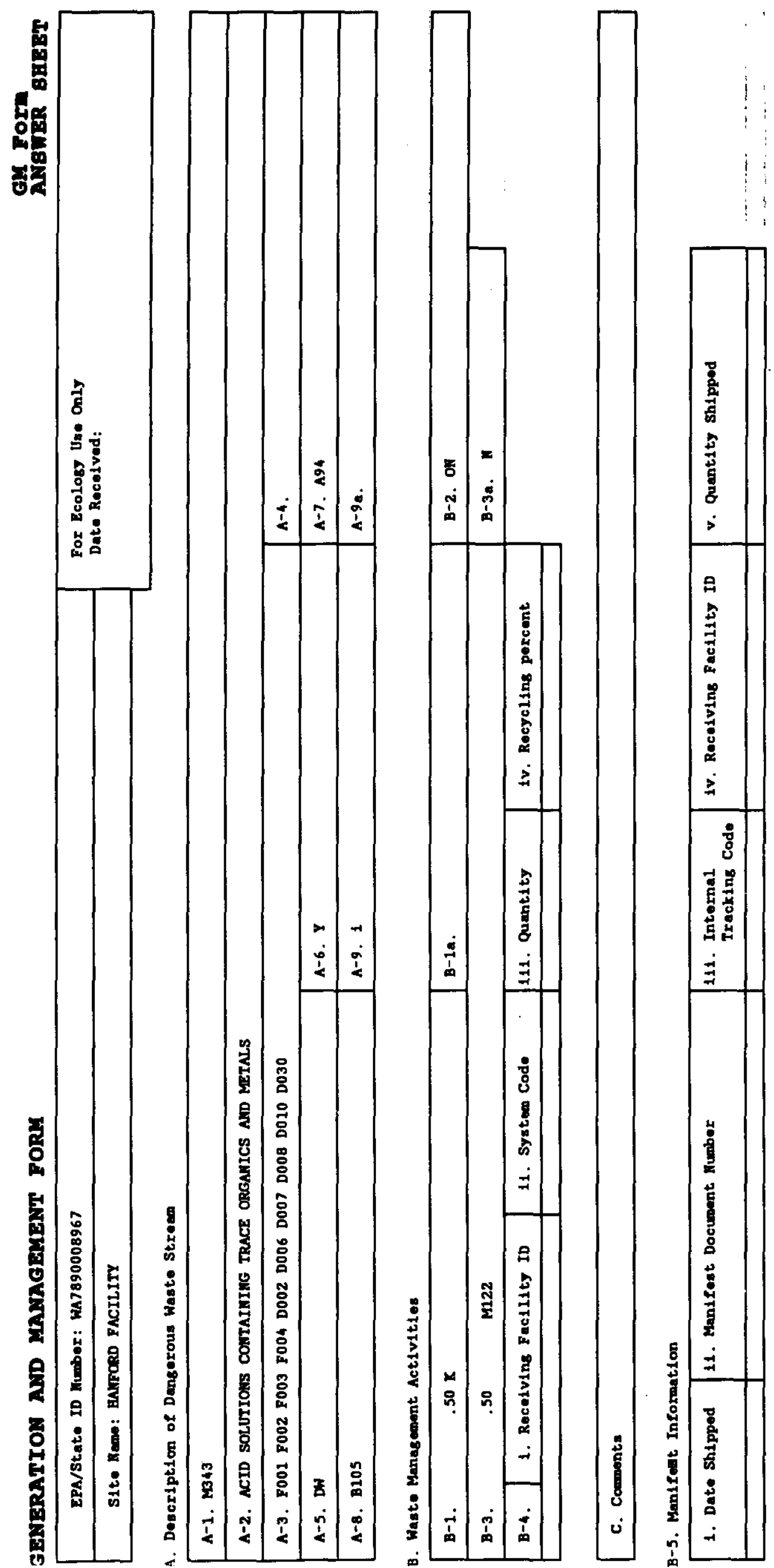




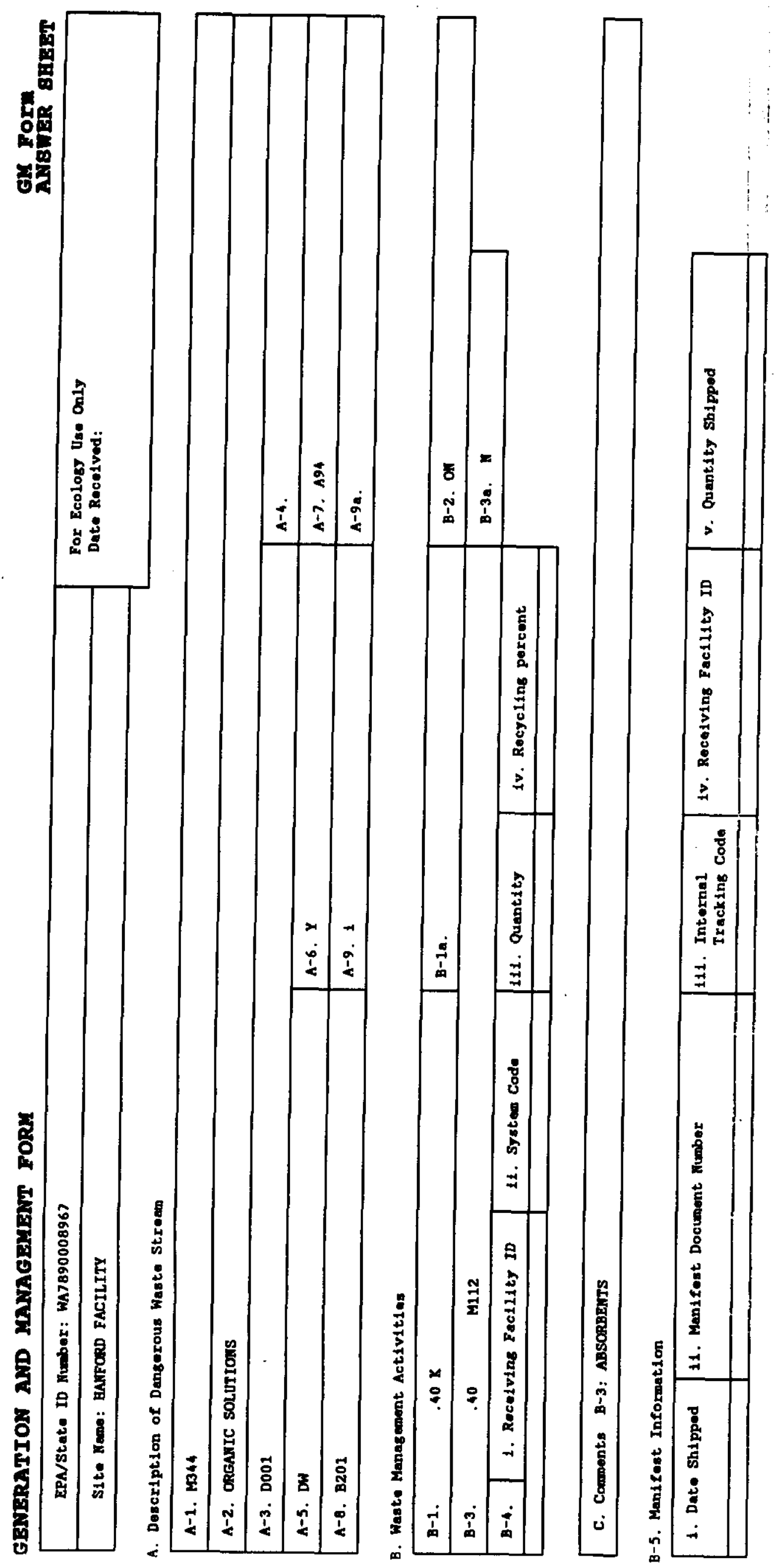




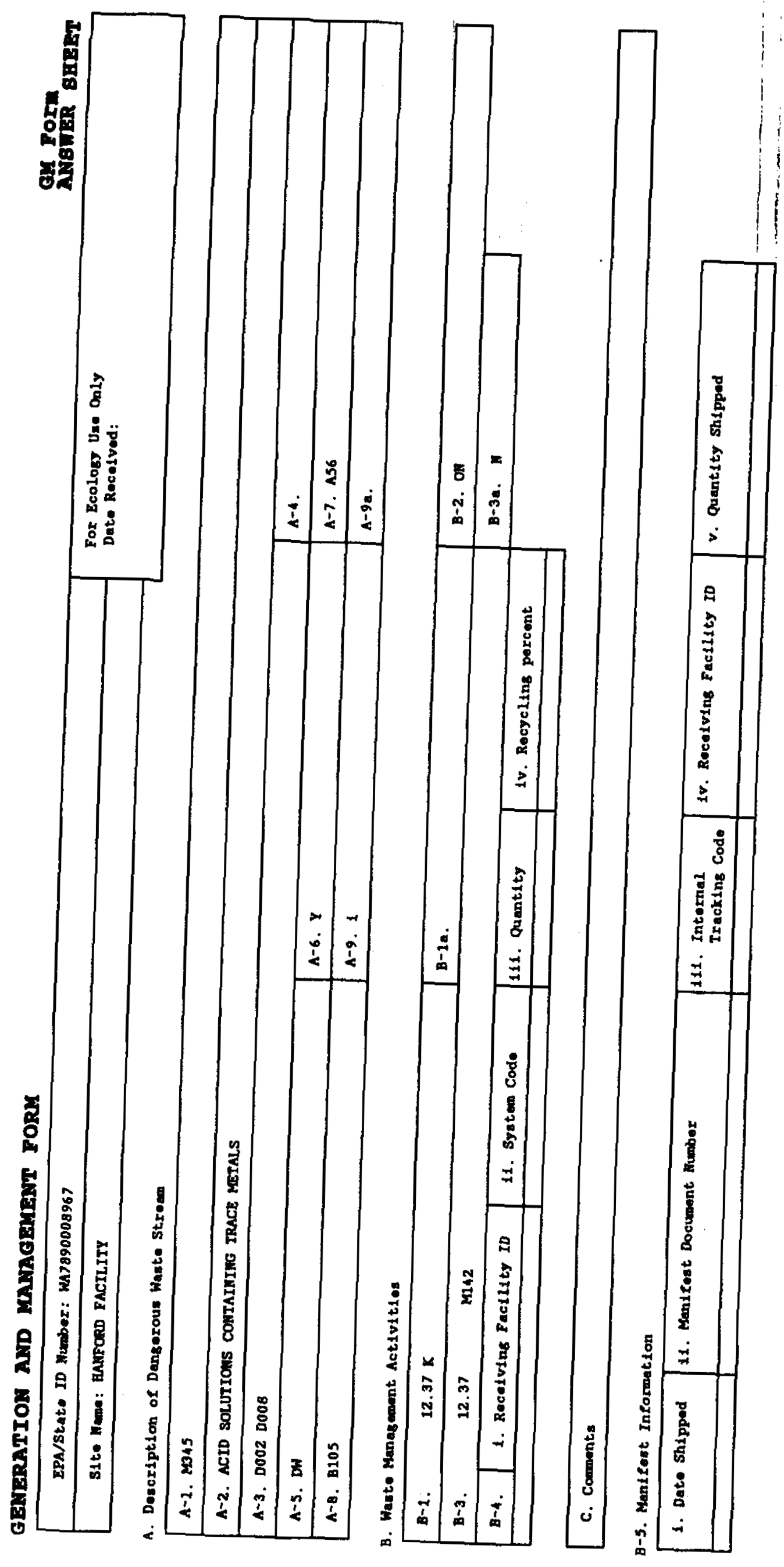




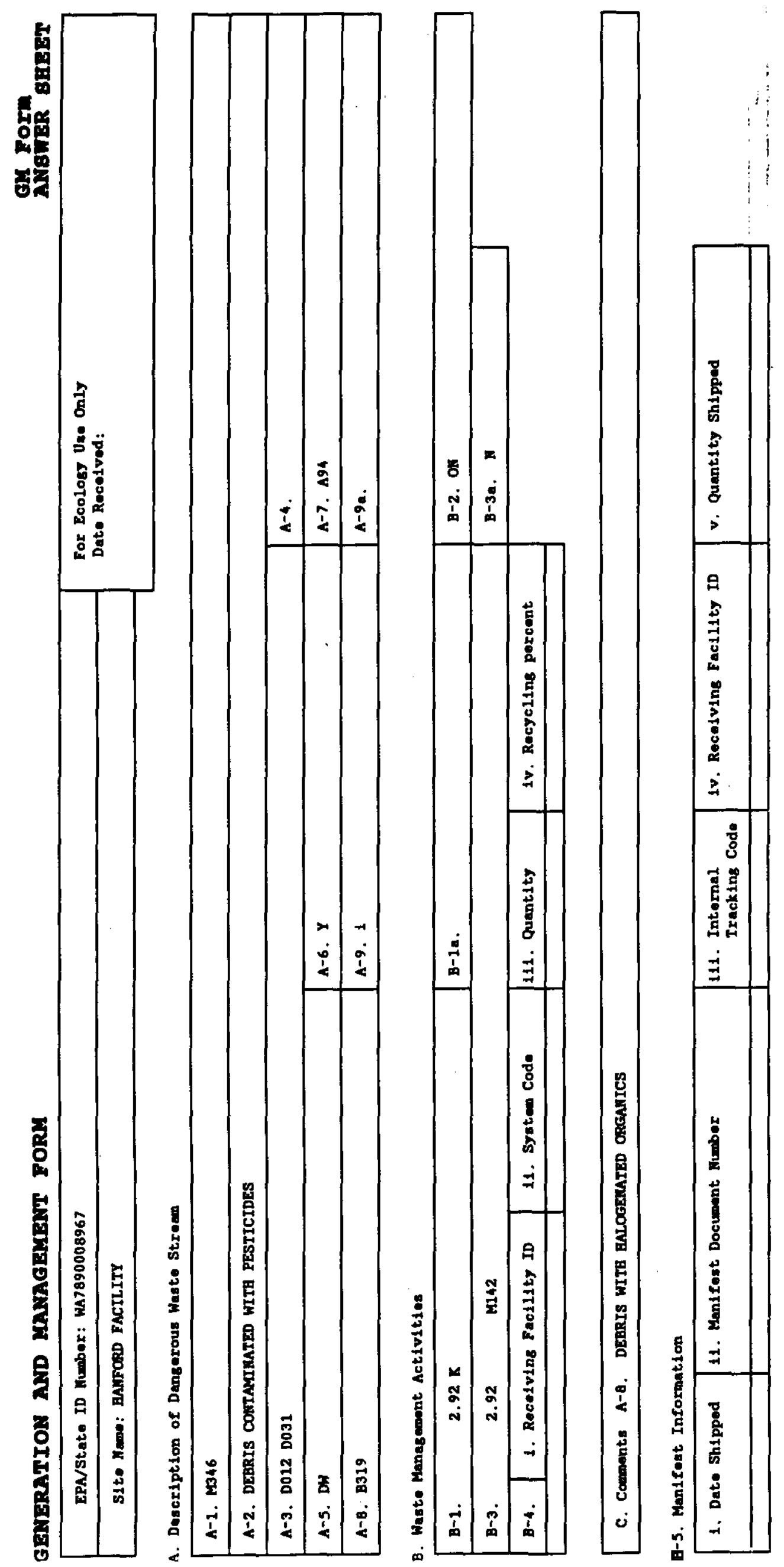




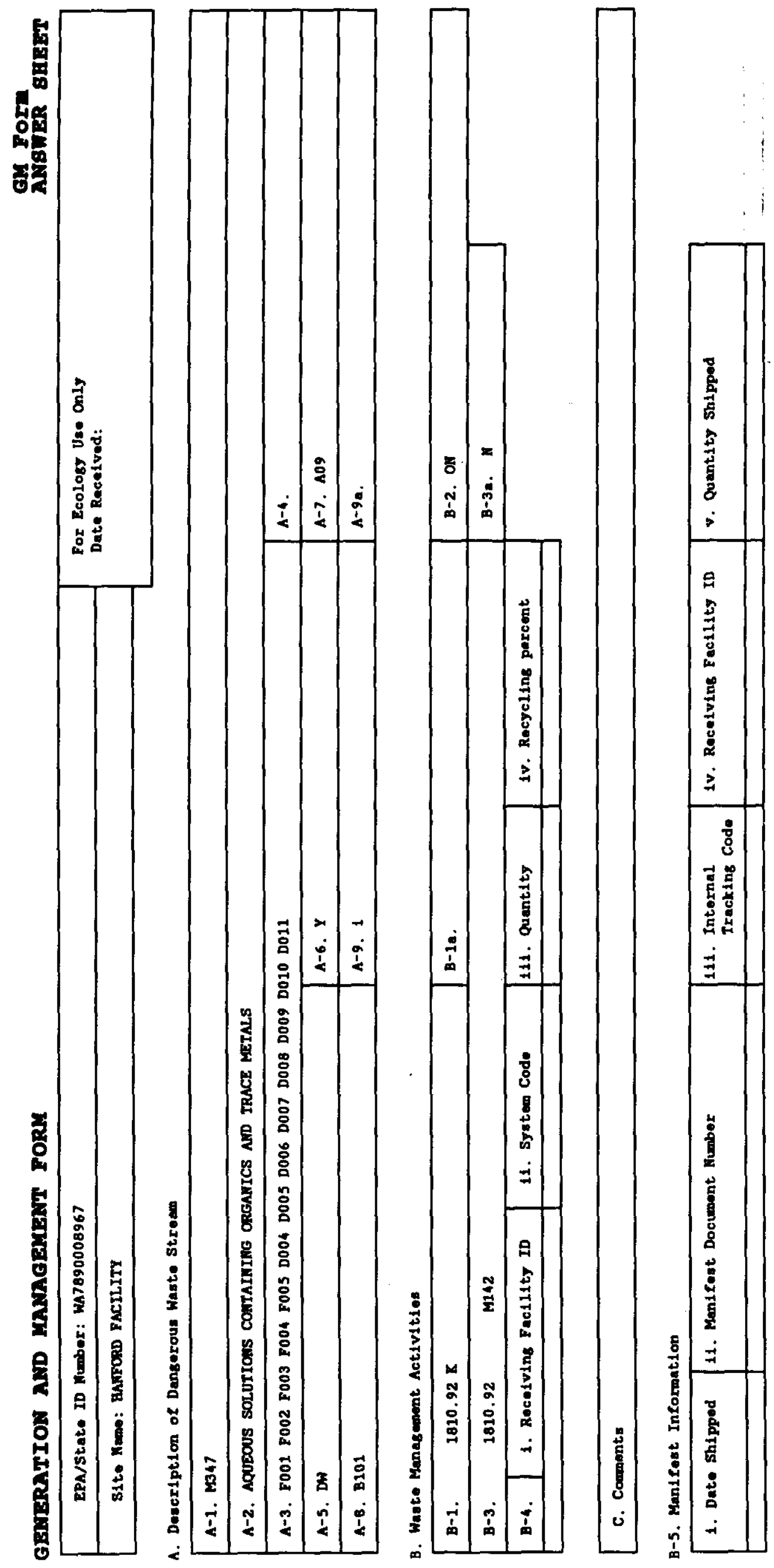




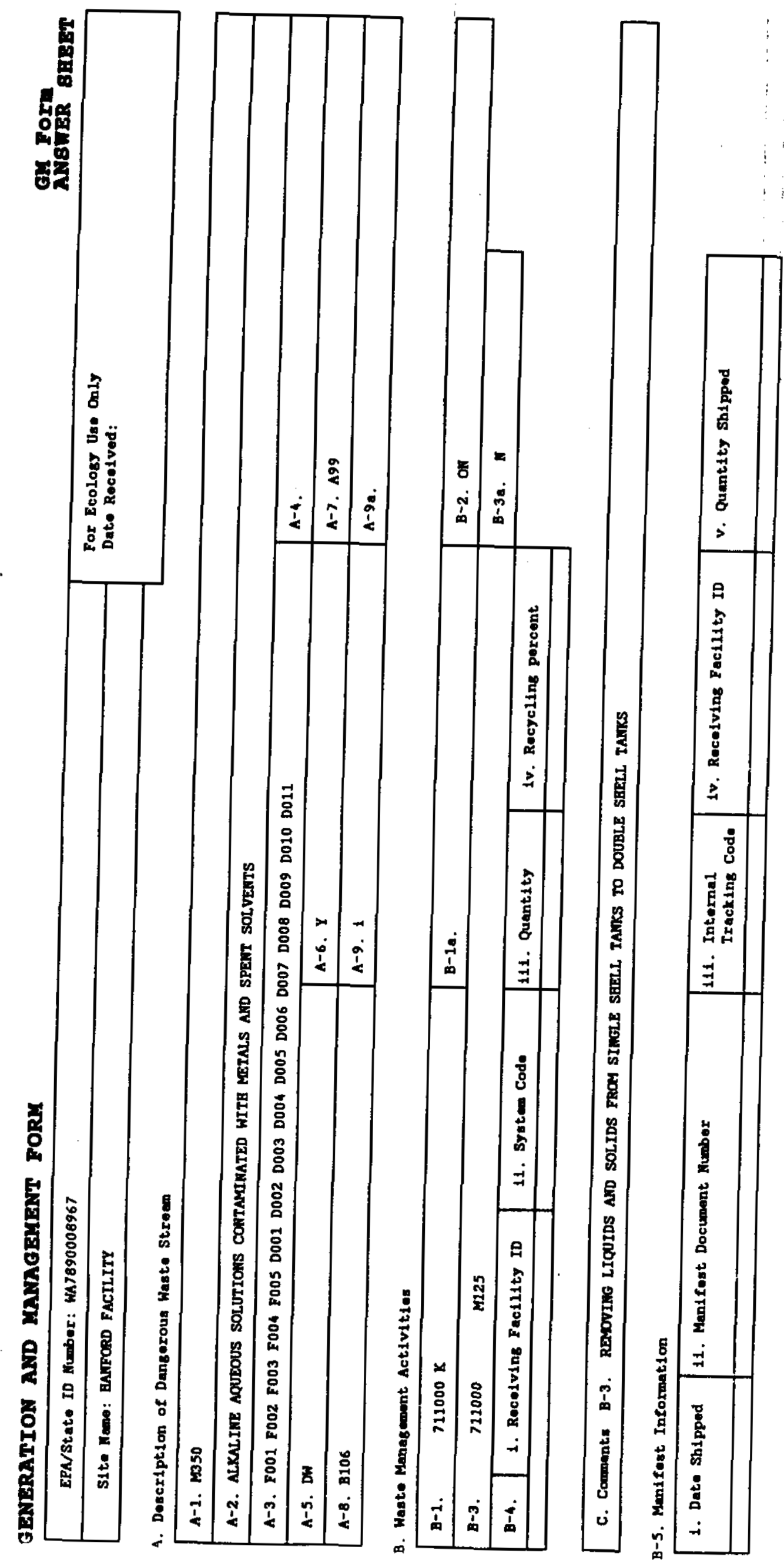




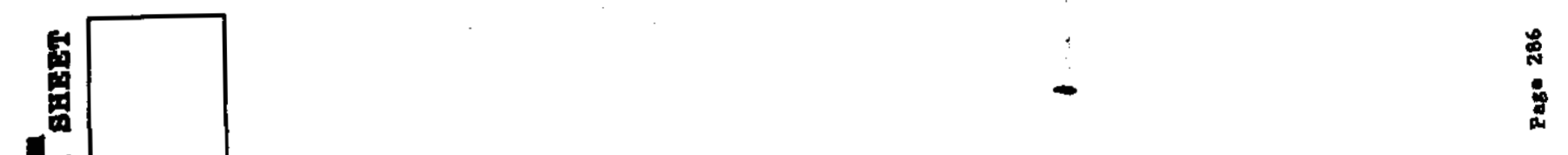




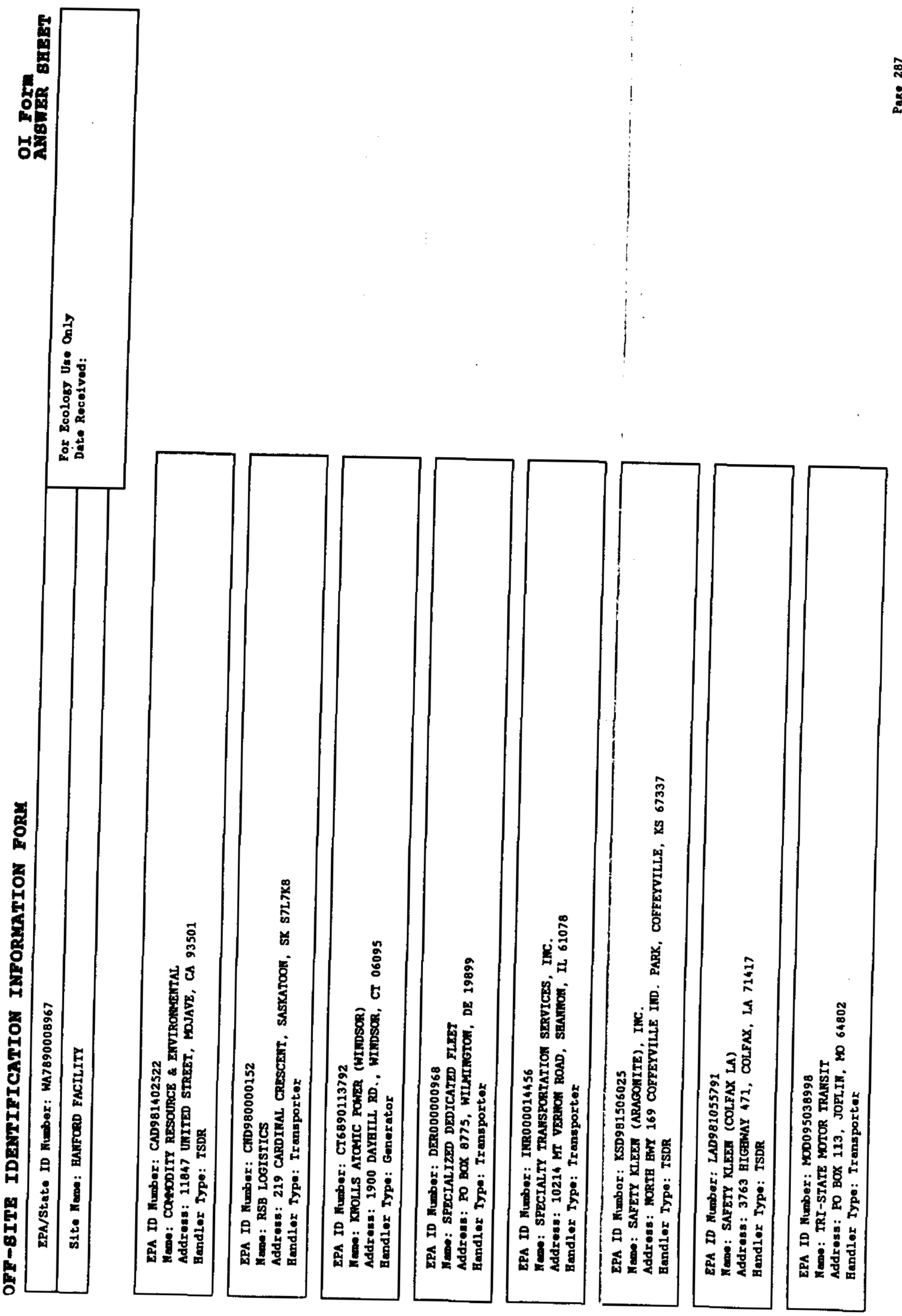



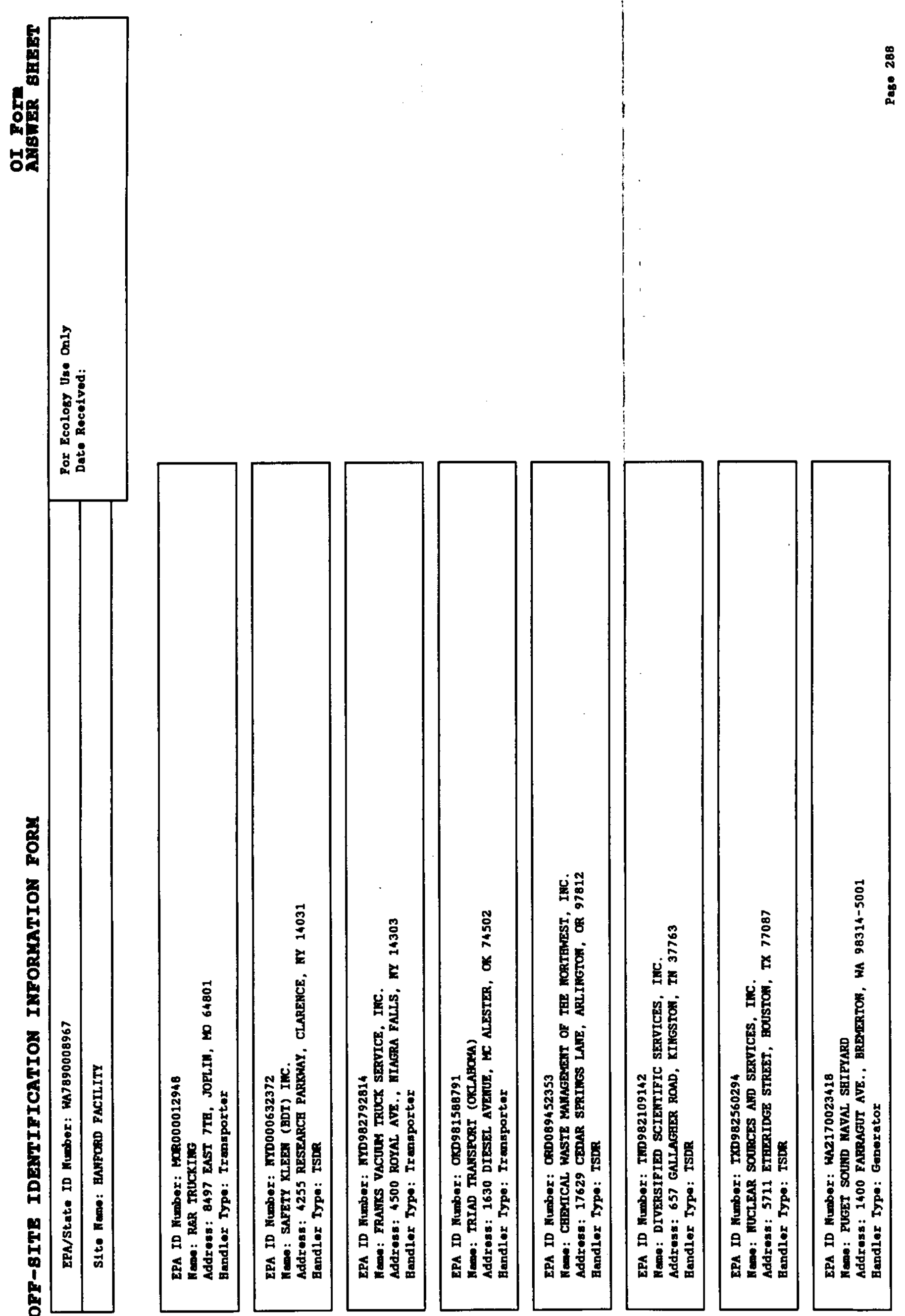


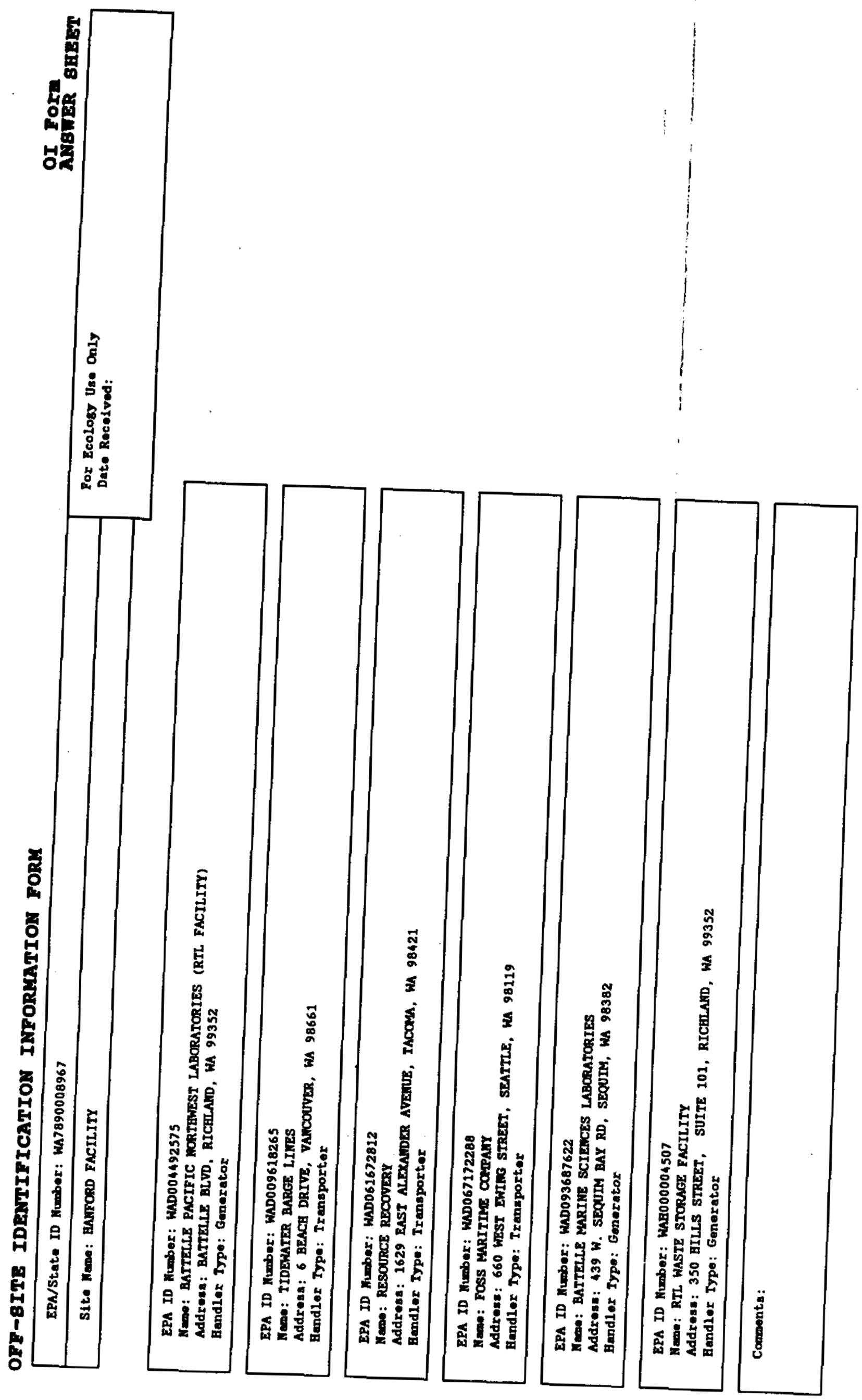




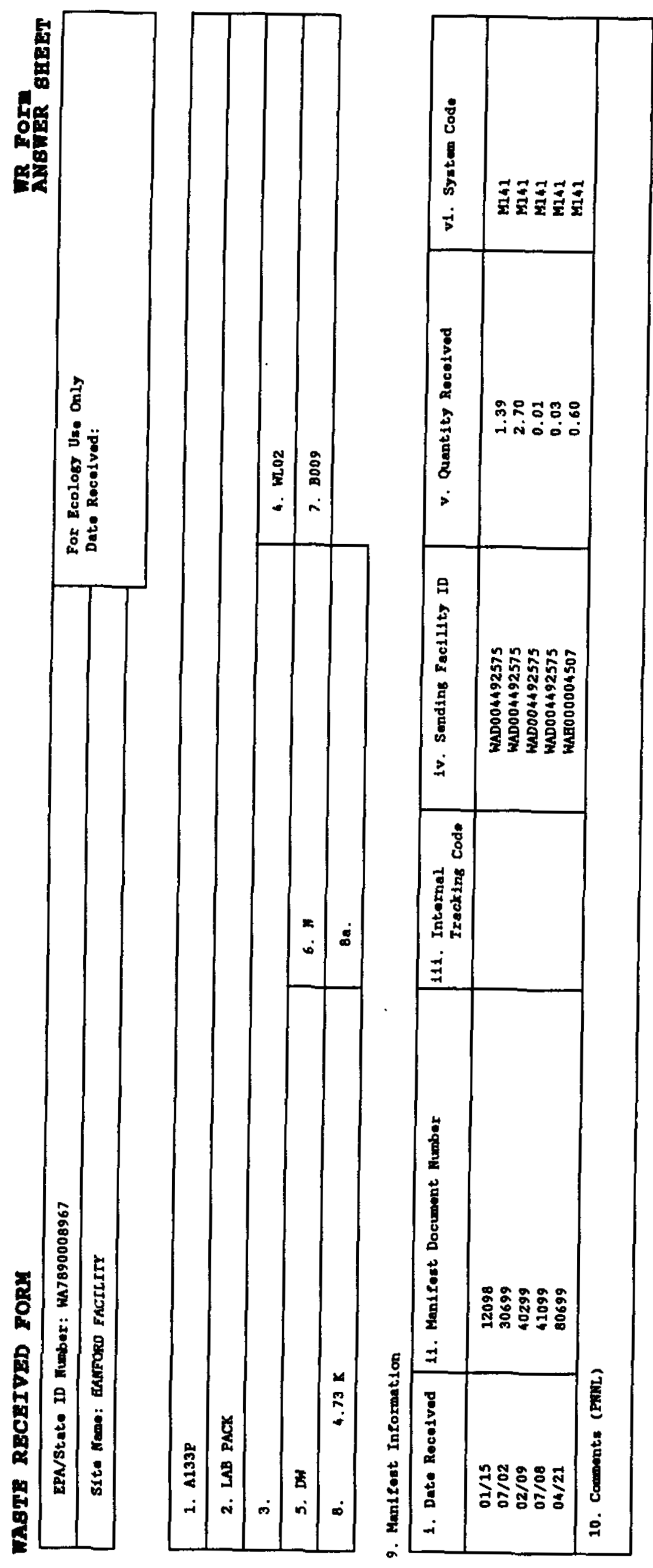

: 


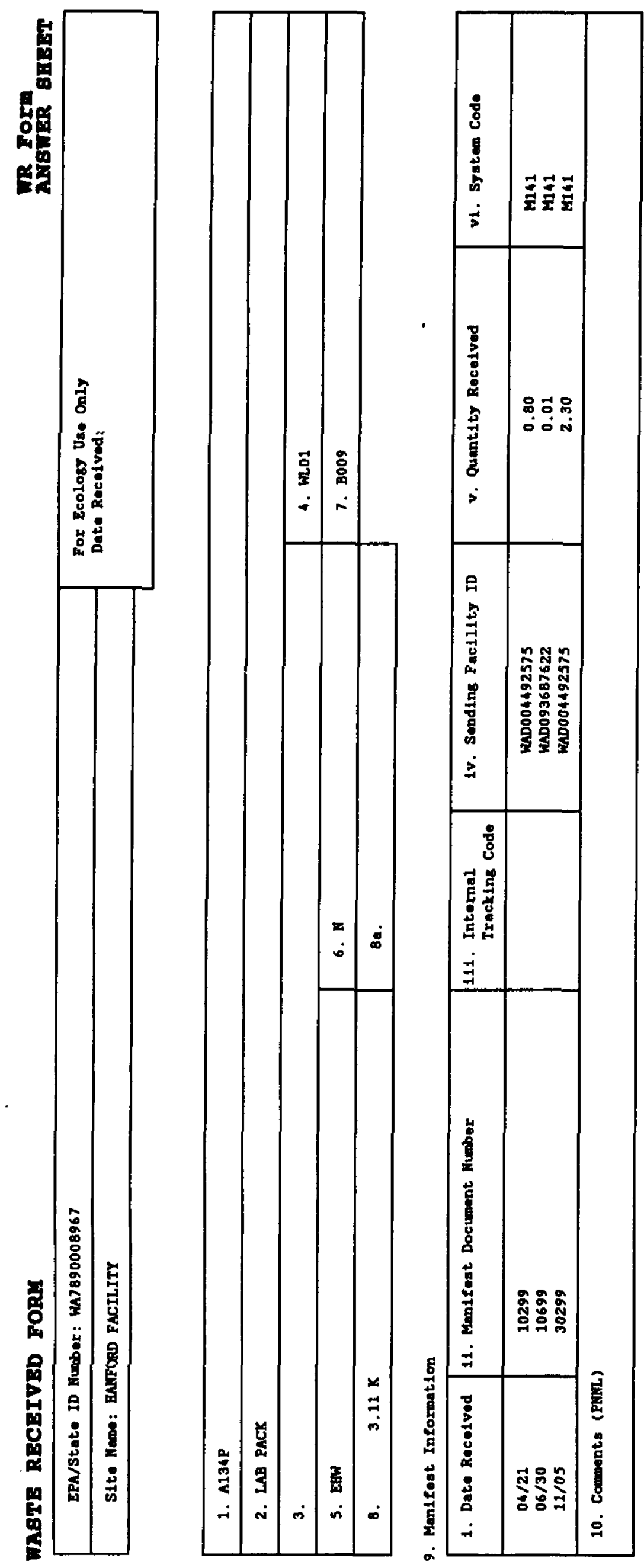

ลี 

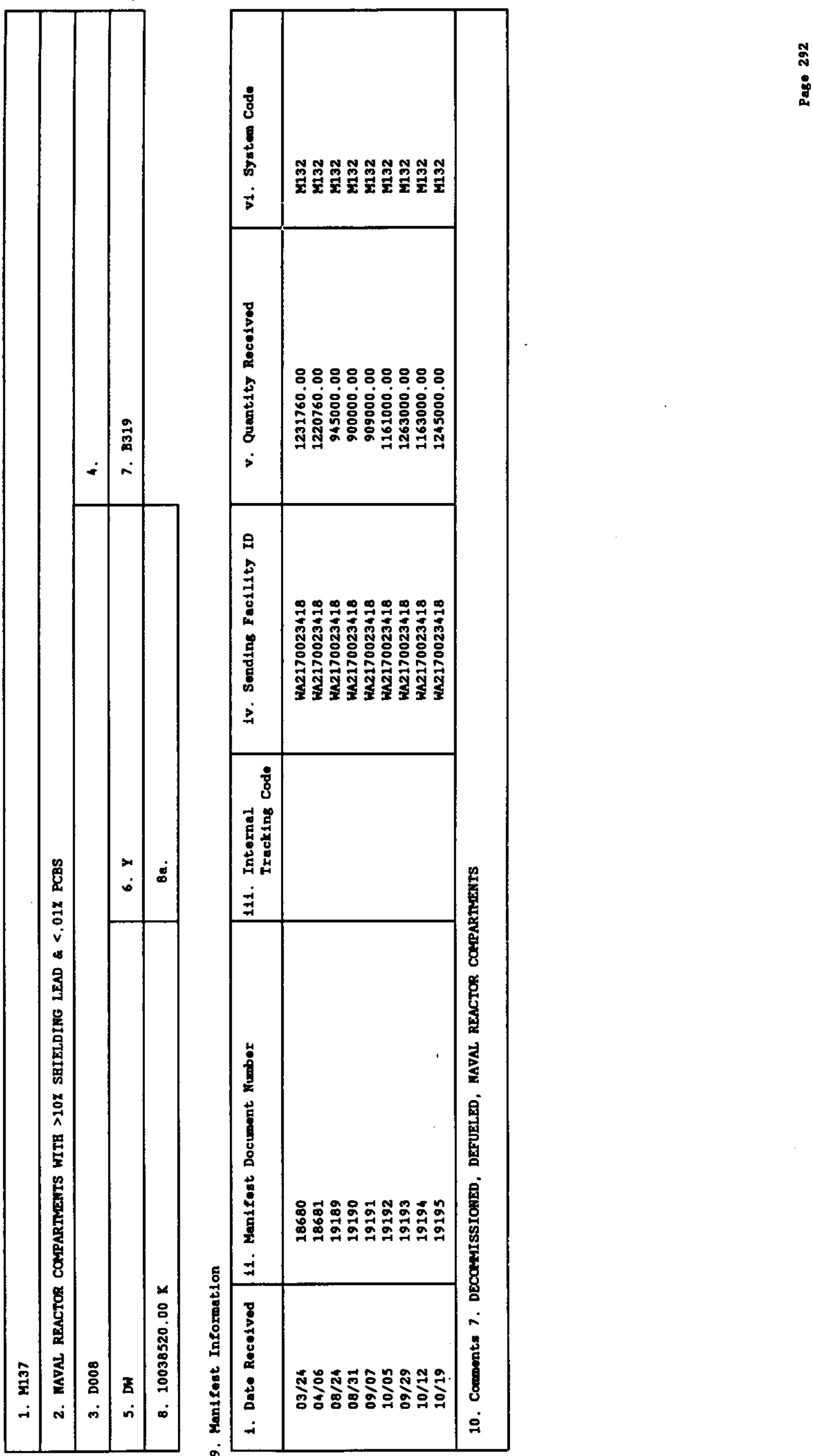

88888888

영ㅇㅇㅇ영

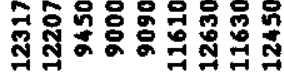

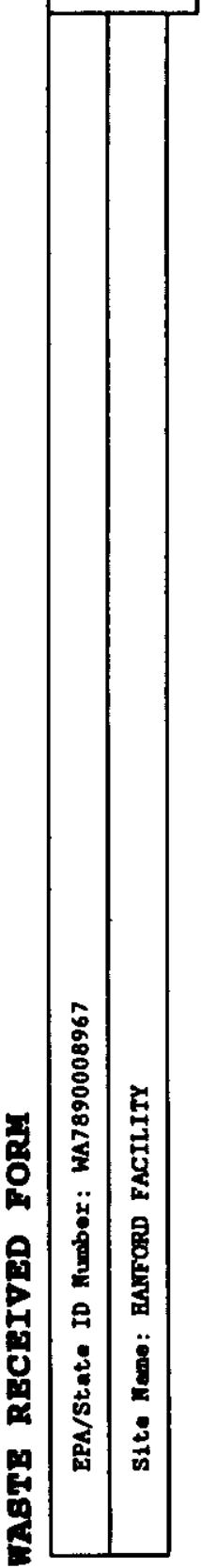

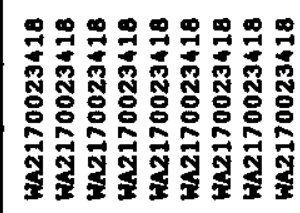
$\stackrel{5}{1}$

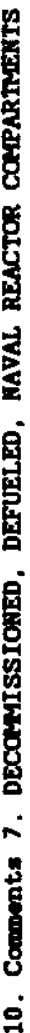




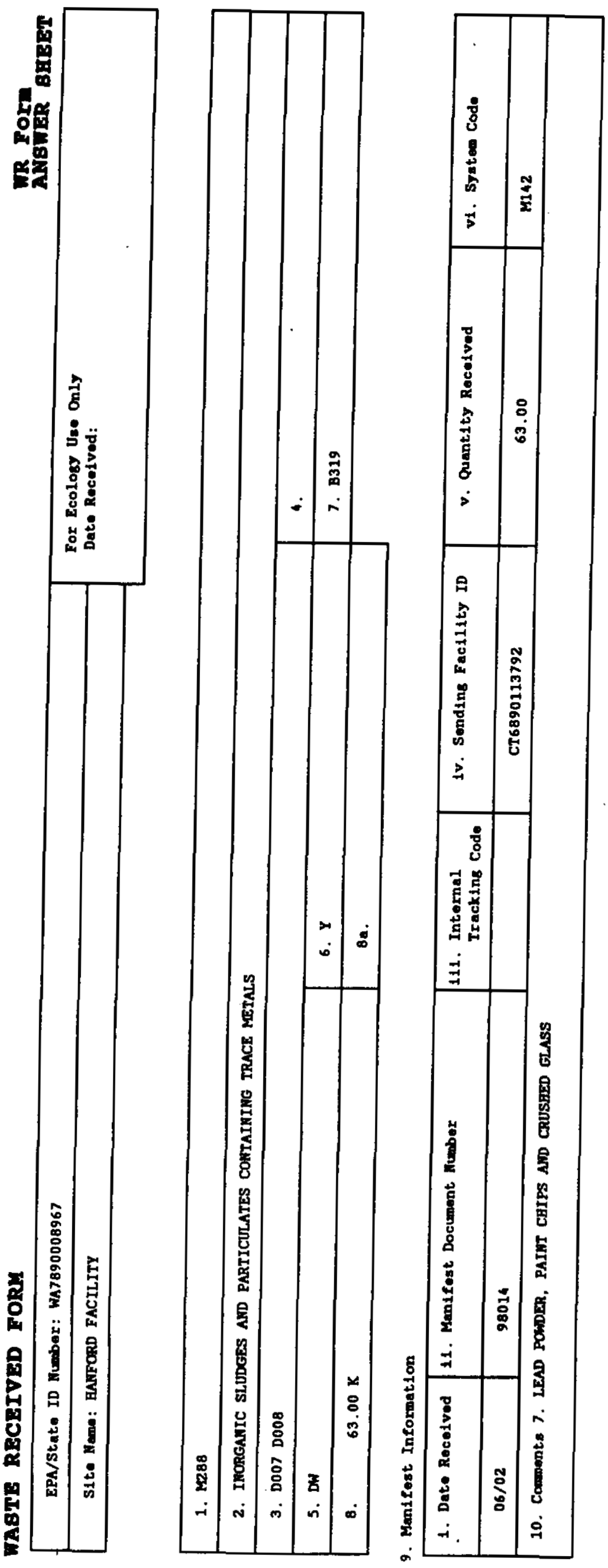

: 


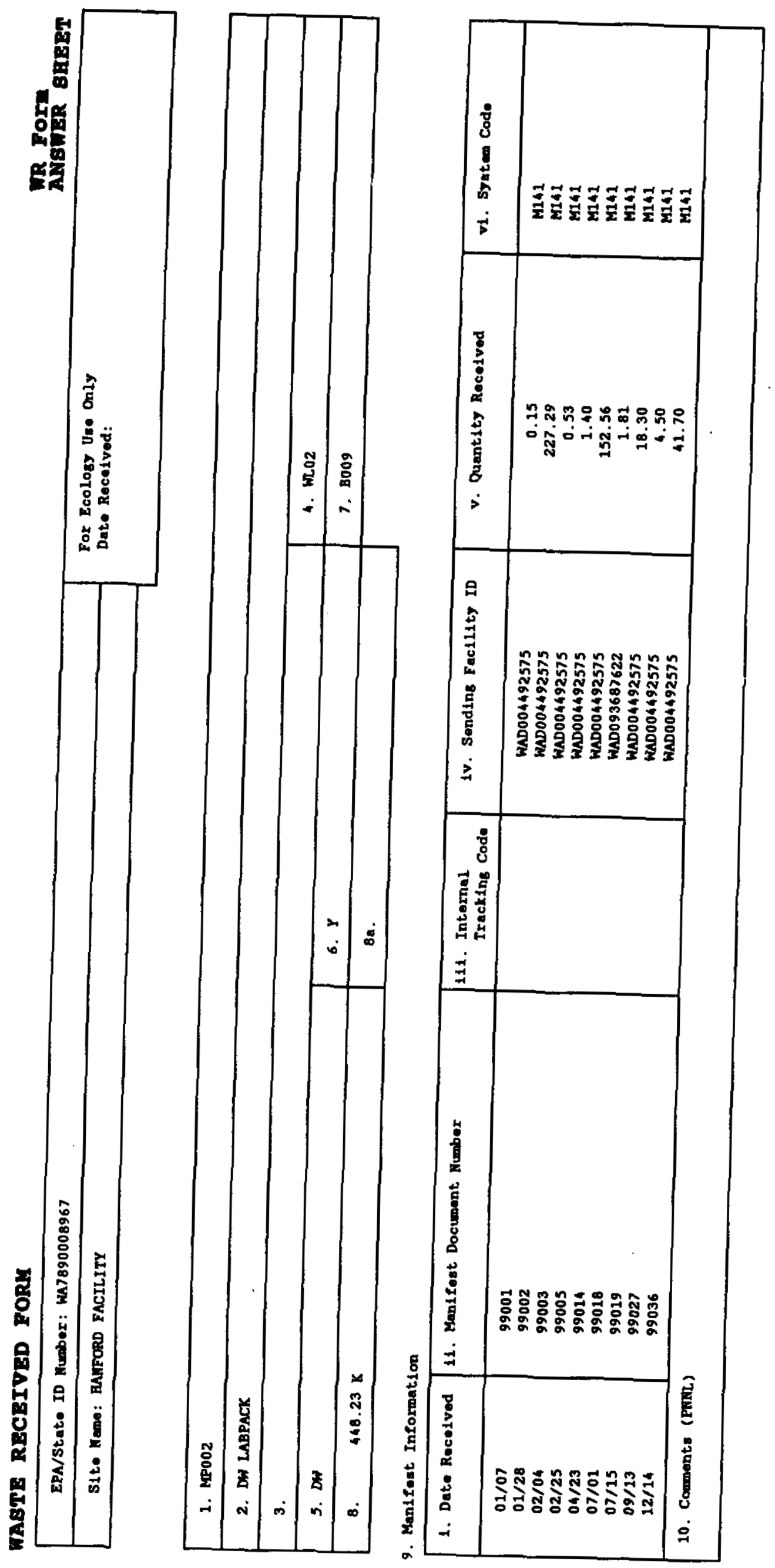



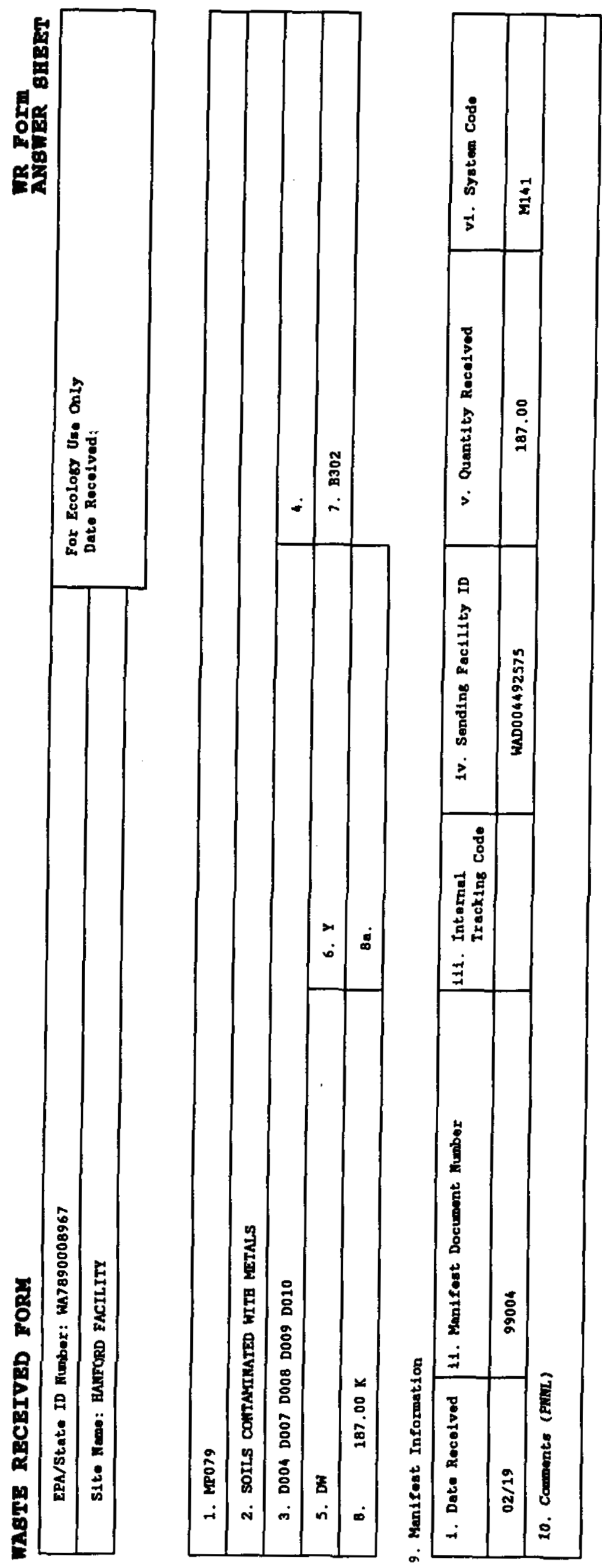

命

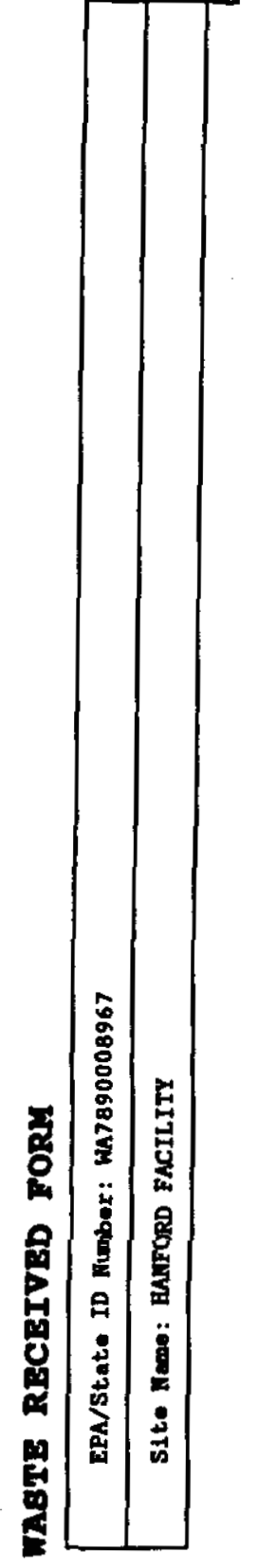



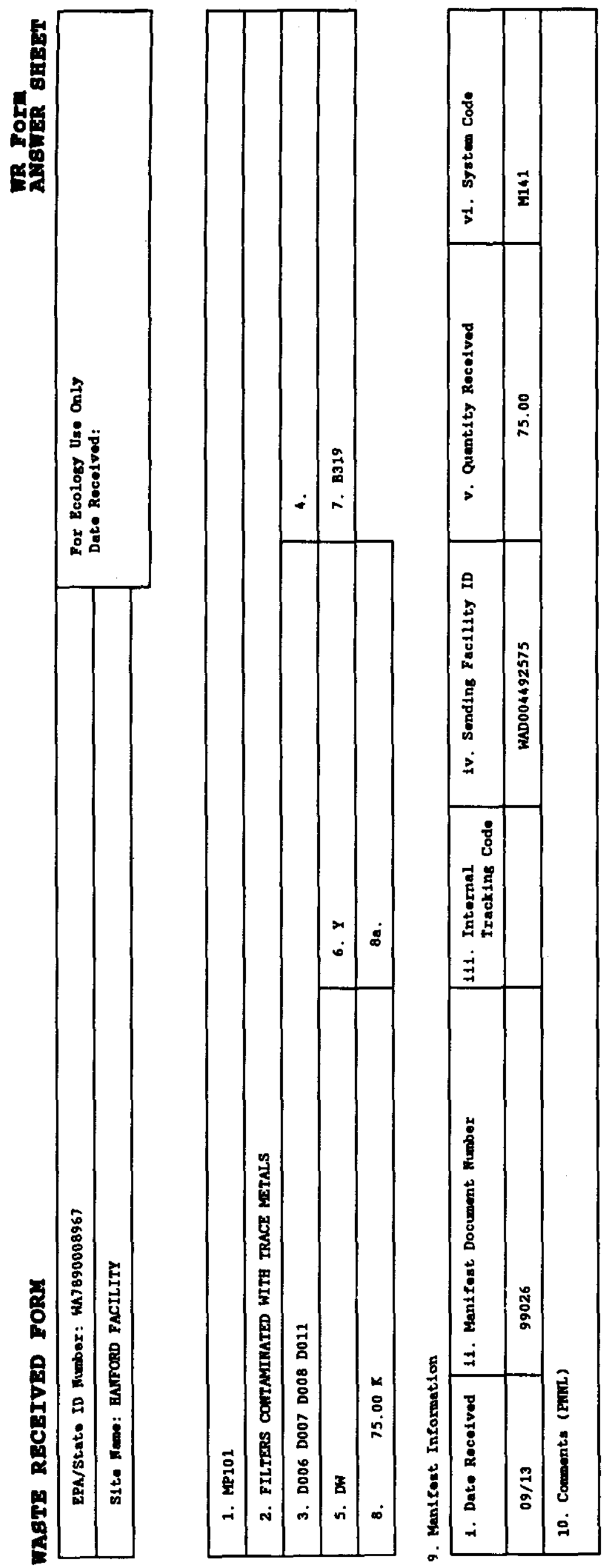

ฌั 

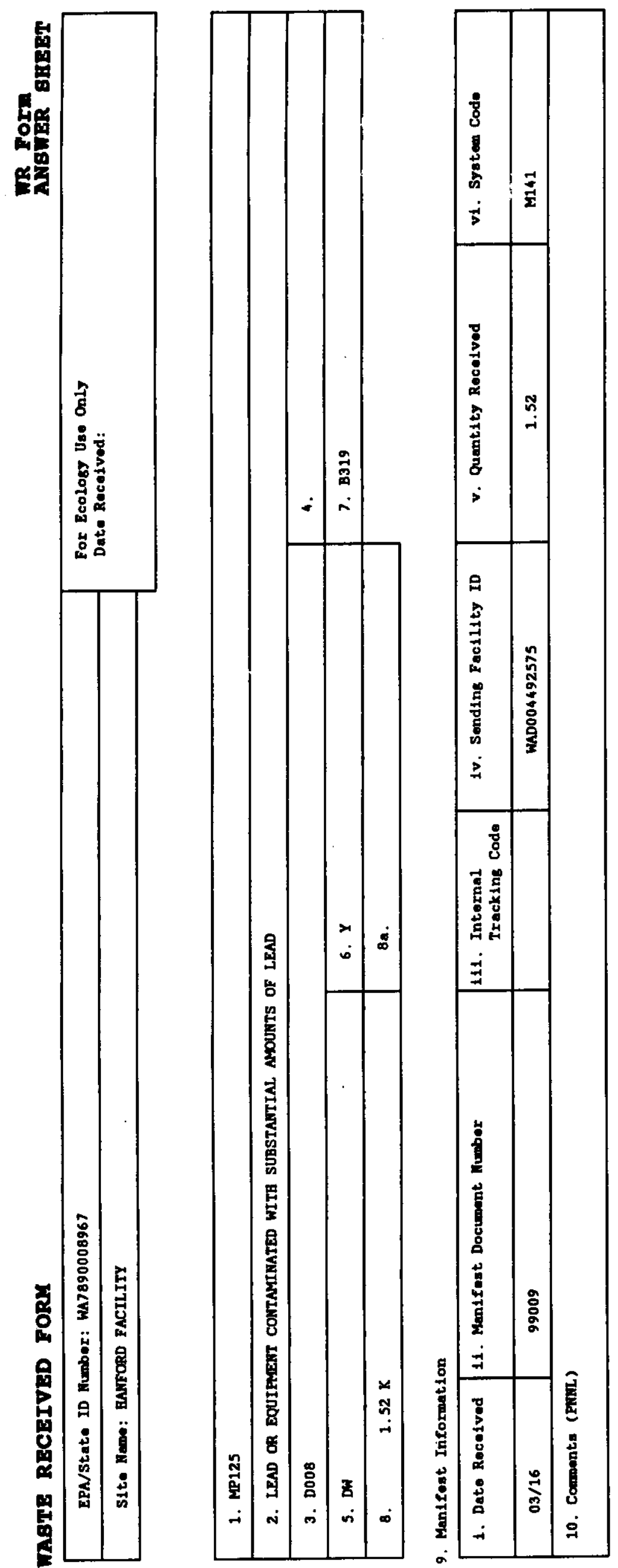

离

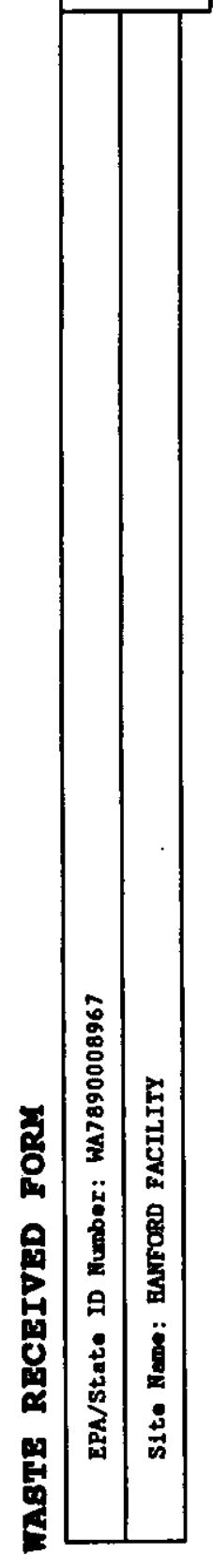




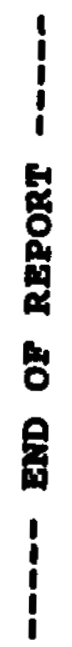


DISTRIBUTION

Number of Copies

OFFSITE

2

State of Washington, Department of Ecology

Laura E. Ruud

Hanford Facility RCRA Permit

1315 West Fourth Avenue

Kennewick, WA 99336

Jean Rushing

Solid and Hazardous Waste Program

PO Box 47658

Olympia, WA 98504-7658

1

U.S. Environmental Protection Agency

Douglas R. Sherwood

Hanford Project Manager

712 Swift Boulevard, Suite 5 MS B5-01

Richland, WA 99352

1

Yakama Nation

Mr. Russell Jim, Manager

Environmental Restoration and Waste Management Program

P. O. Box 151

Toppenish, WA 98948

1

Nez Perce Tribe

Mr. Patrick Sobotta, Mạnager

Environmental Restoration and Waste Management Program

PO Box 365

Lapwai, ID 83540

1

Confederated Tribes of the Umatilla Indian Reservation

Mr. James R. Wilkinson

Board of Trustees

PO Box 638

Pendleton, OR 97801

ONSITE

7

U.S. Department of Energy, Richland Operations Office

R. N. Krekel (6)

RL Public Reading Room

U.S. Department of Energy, Office of River Protection

R. R. McNulty

H6-60 
DISTRIBUTION, continued

ONSITE

2

Bechtel Hanford, Inc.

R. J. Landon

H0-02

J. F. Ollero

H9-01

2

CH2M HILL Hanford Group

D. J. Carrell

R1-51

P. A. Powell

R1-51

1

Fluor Federal Services, Inc.

R. L. Newell

B4-68

38

Fluor Hanford

B. M. Akers

G5-54

B. M. Barnes

T4-04

L. E. Borneman

G1-27

H. C. Boynton

T4-52

J. E. Bramson

T5-54

N. R. Dahl

N2-57

J. A. Dawson (7)

G1-27

L. P. Diediker (3)

G1-29

B. J. Dixon

G3-26

R. G. Gant

X3-79

C. K. Girres

T3-01

C. J. Grando

L6-04

E. M. Greager

G1-29

C. R. Haas

T3-28

D. L. Hagel (3)

T3-04

G. S. Hunacek, Jr.

X3-79

G. J. LeBaron

$54-49$

P. W. Martin

T3-04

J. K. Perry

L1-04

D. E. Rasmussen

L1-04

D. G. Saueressig

T4-04

F. M. Simmons

S6-81

J. O. Skolrud

G1-27

R.W. Szelmeczka

S6-72

J. E. Turnbaugh

X3-79

G. J. Warwick

S3-25

D. J. Watson

X3-79

J. A. Winterhalder

T6-16

Lockheed Martin Services, Inc. Central Files

B1-07

Document Processing Center

H6-08

EDMC (2)

H6-08 
DISTRIBUTION, continued

Hanford Facility Operating Record

H6-08

4

Pacific Northwest National Laboratories

E. L. Grohs (2)

P8-34

H.T. Tilden

P8-34

PNNL Technical Library

P8-55

Page 3 of 3 